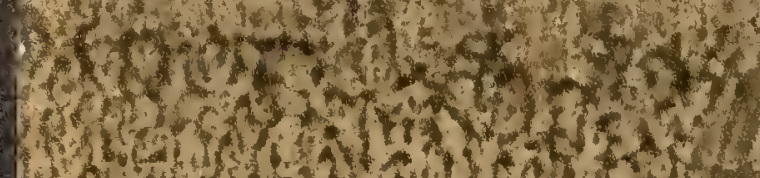

3 horathen

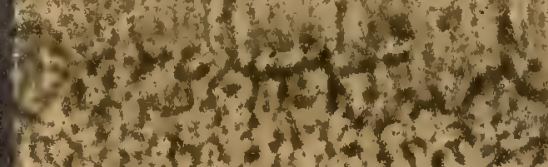

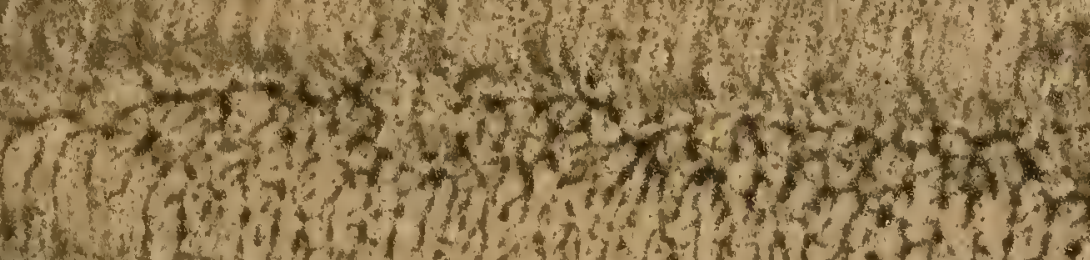

wintis

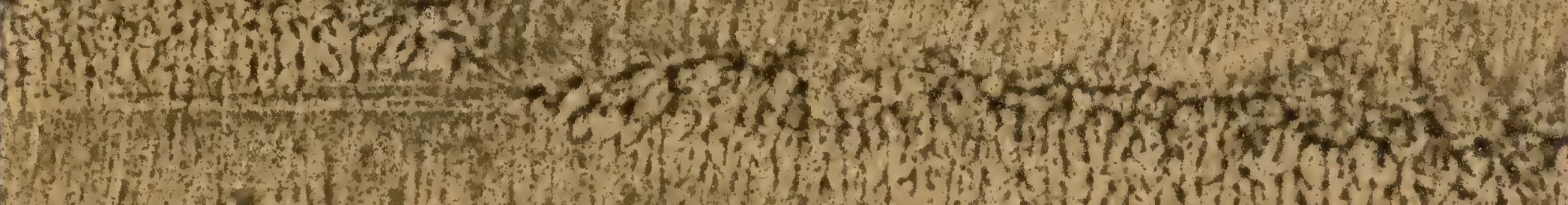

3ith

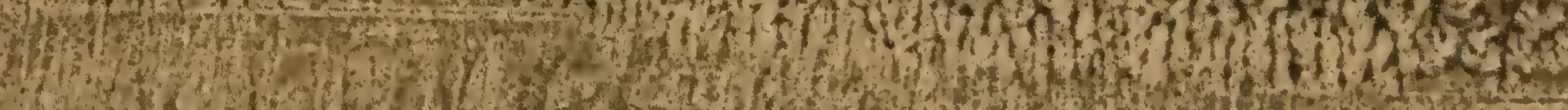

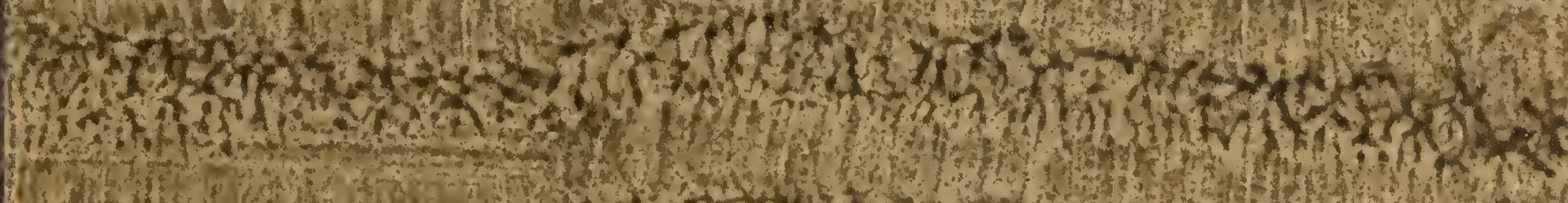

\subsection{3 (n)}

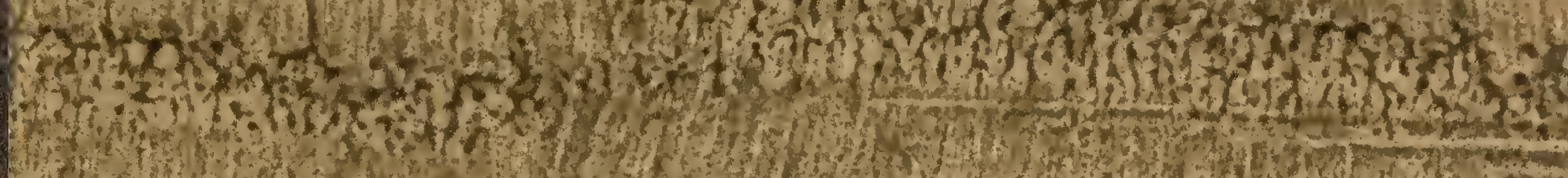

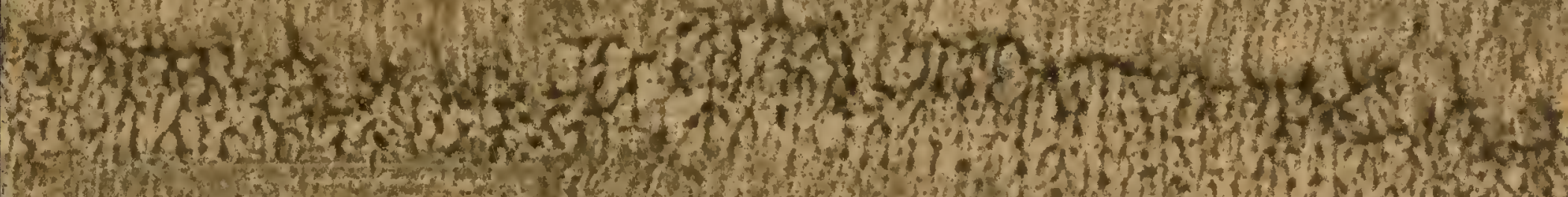

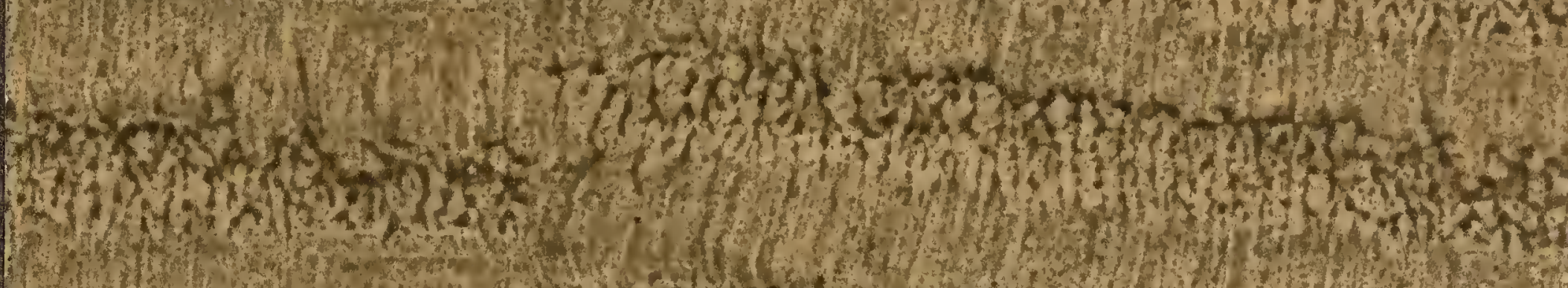

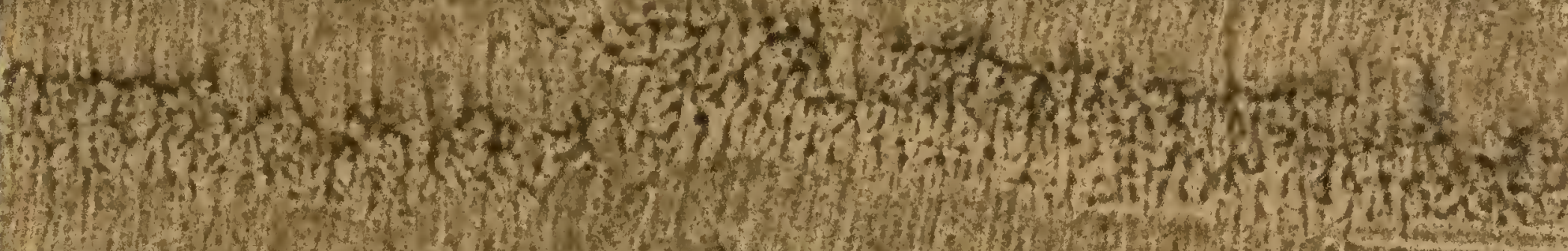

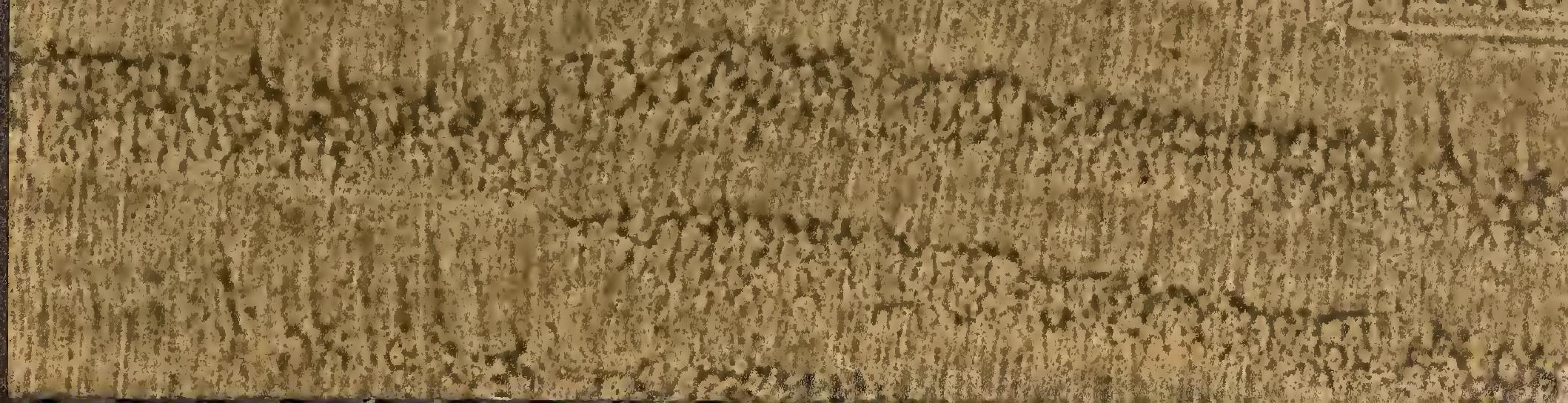




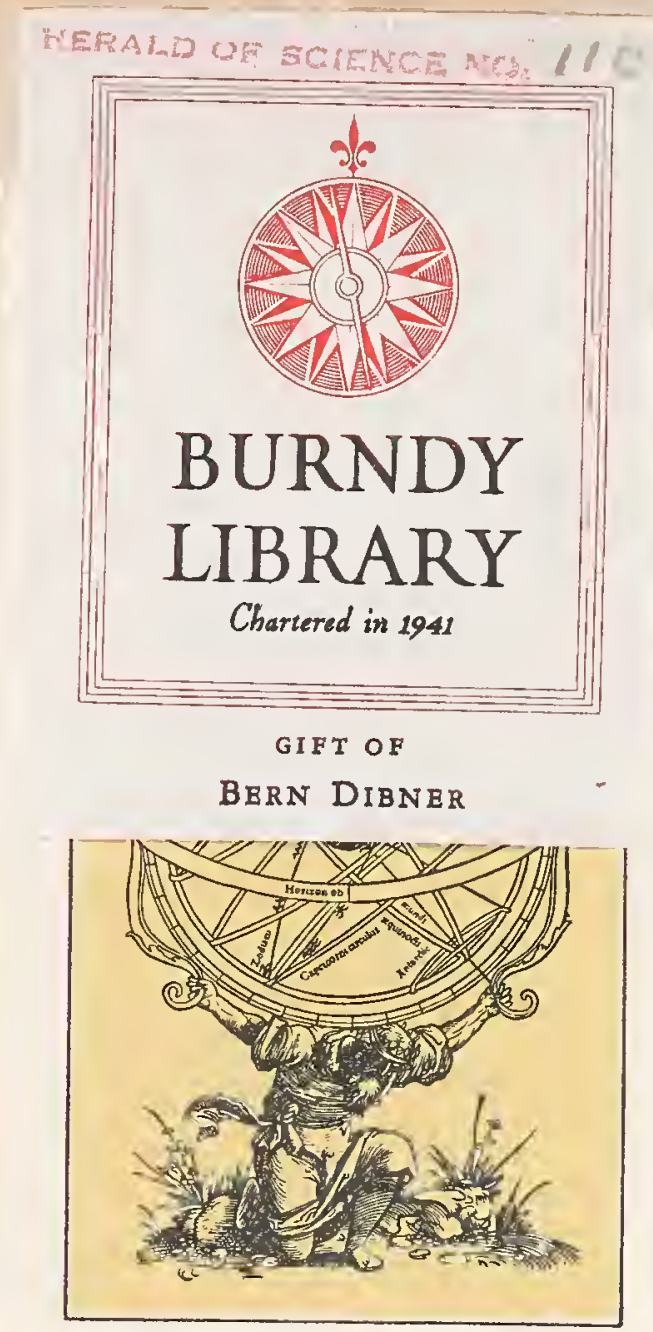




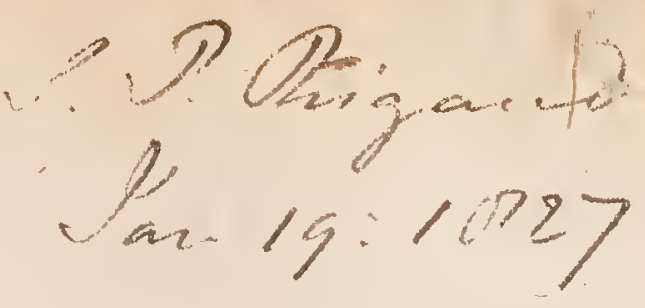







\section{JACOBI BERNOULLI,}

Profefl. Bafil. \& utriufque Societ. Reg. Scientiar. Gall. \& Pruff. Sodal.

Mathematici CeleberRimi,

ARS CONJECTANDI,

OPUS POSTHUMUM.

Accedit

T R A C T A T U S

DE SERIEBUS INFINITIS,

EtEristor Gallicé fcripta

D E L U D O P I L

R E T I C U L A R I S.

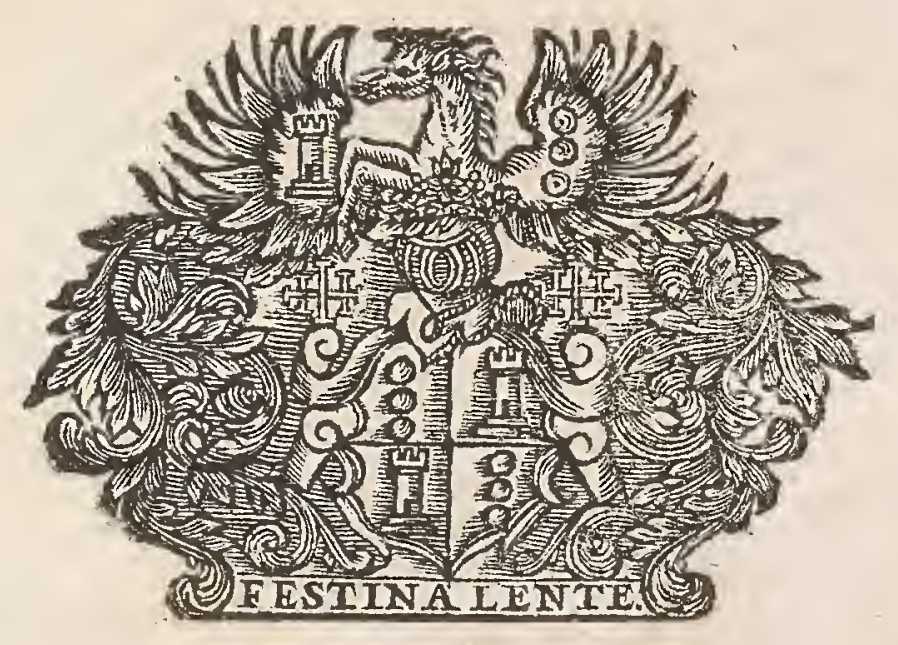

B A S I L E R,

Impenfis T H UR N I S I OR U M, Fratrum.

cIo Ioce XIII. 



\section{NICOLAUS BERNOULLI \\ L. S.}

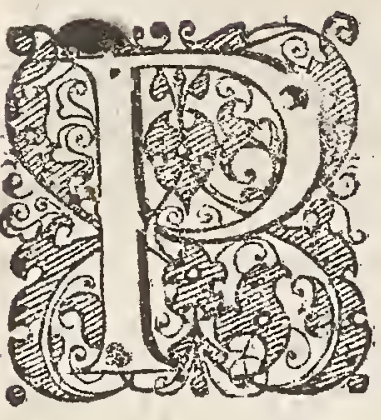

Rodit nunc tandem diu defideratus Patrui mei de Arte Conjectandi Tractatus pofthumus curâ Thurnifiorum Fratrum, qúi rem gratam publico facturi Manufcriptum Auctoris ab heredibus defuncti comparatum fuis fumtibus imprimi curaverunt. Propofitum fuic Auctori monftrare eximium ufum quem in vita civili habet ea Mathefeos pars, à paucis hactenus tractata, qua de probabilitatibus dimetiendis agit. Qua ratione \& quoufque Auctor hoc fuum propoftum executus fueritjam recenfitum eft in Commentariis Academia Regia Scientiarum Gallica Anni I705. \& in Ephemeridibus Eruditorum Parifienfibus Anni 1 706. Divifit Auctor Opus iftud in quatuor Partes, quarum Ima continet Illuftris Hugenii Diatribam de Ratiociniis in Alea Ludo cum Annotationibus, quam Tra. ctatui fuo tanquam prima Artis Gonjectandi elementa pramittendam effe judicavit. II ${ }^{\text {da }}$ Pars complectitur Doctrinam de Permutationibus \& Combinationibus ad dimetiendas probabilitates fuñopere neceffariam, cujus Ufum Parte $11 I^{\text {tia }}$ in variis Sortitionibus \& Ludis Alex explicuit. IVtram Partem qua ufum \& applicationem præcedentium ad res civiles, morales \& oeconomicas oftendere voluit, adverfa diu ufus valetudine tandemque ipfa morte præventus imperfectam reliquit. Optaffent quidem Editores, utDefuncti Frater, qui unice abfolvendo huic operi maxime idoneus fuiffet, defectum fuppleviflet; fedipfi plurimis aliis diftrieto negotis operæ hujus demandatione noluerunt effe molefti. Mihiquoque, quem olim Speciminaquadam hujus Artis ad Jus applicate in DiffertationeInaugurali dediffe noverant, id negotii deferre in animo habebant, quod vero abfens. \& in 
peregrinatione conftitutus fufcipere non poteram. Reverfus in Patriam denuoque rogatus operam hanc declinavi, cum juvenem melongoque rerum ufu \& experientia ad materiam hanc tractandam neceffaria haud infeructum negotio huic imparem fore fentirem, facileque judicarem, non tantum Lectori non fatisfactum, fed etiam reliquis pretium ademtum iri, fi vulgaria duntax at \& trita afferrem. Suafor itaque fui, ut Tractatus ifte qui maxima ex parte jam impreffus erat, in eodem quo eum Auctor reliquit ftatu cum publico communicaretur. Nevero res utiliffima,applicatio fcilicet calculi probabilitatum ad aconomica \& politica, plane negligatur, rogamus Nobiliff. D. Auctorem Libri Gallici EfJai d' Analyfe fur. les Jeuxx de Hazard; Clarif: item Moyvræum, quorum uterque egregia hujus Artis Specimina non ita pridem publicavit, utipfi negotium hoc in fe fufcipere, eximiaque fua inventa cum publico fuo tempore communicare dignentur. Speramus interim generalia illa, qua Auctor quinque poftremæ Partis capitibus tradit, Lectori induftrio in fpecialium quaftionum enodatione non contemnendo ufüi fore. Hæc de ipfo Tractatu præfanda effe cenfuimus. Adjunctæ funt ab Editoribus Pofitiones Auctoris de Seriebus Infinitis, quinque Difputationibus olim ab ipfo pertractatæ, quarum cum exemplaria multa hactenus fruftra apud Bibliopolas noftros quæfita fuerint, illas fimul impreffas Tractatui ifti fubjecerunt. Accedit quoque ob cognatam materiam Epiftola Auctoris Gallica cui titulus: Lertre à un Amy, \& c. Illud etiam monendum eft Typum variationum Verfus Bauhufiani, Tot tibi \&c. inter fchedas Auctoris repertum a Correctore in gratiam Curioforum. infertum fuiffe, adeoque poftrema verba pagina 78 . omittenda effe. Reliquos errores, paucos quidem, à Correctore non obfervatos in calce Libri notavimus, quos ut Lector benevolus corrigat, precamur. 


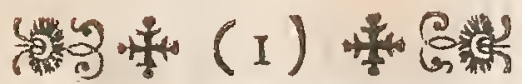

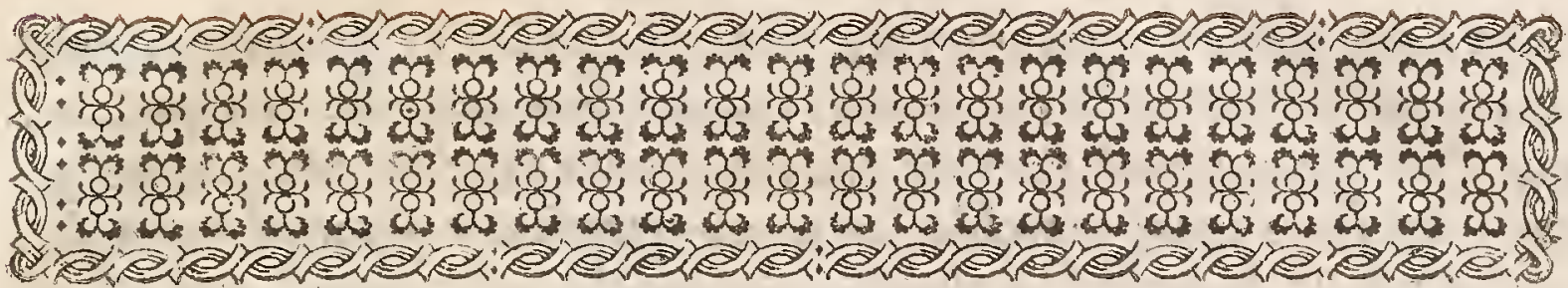

\section{E T T R E à un Amy. \\ fur}

les Parties du Feu de Taume.

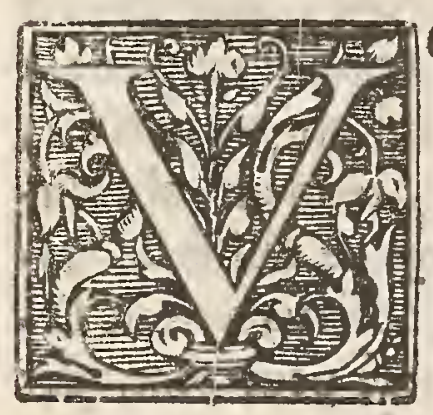

Ous me marquez, Monfieur, que vous avez vû une de mes Thefes, où j’avance quelques Propofitions nouvelles, touchant les Parties du Jeu de Paume; $8 z$ vous me demandez, si ces Propofitions renferment quelque realité qui puiffe étré démontrée, ou fi elles ne font fondées que far de pures conjectures faites en l'air, \& qui n'ont rien defolide; ne pouvant pas concevoir, à ce que vous dites, que l'on puiffe mefurer les forces des jouëurs par nombres, \& encore moins en tirer toutes les conclufions, que jen ay tirées. Ce qui moblige de mettre par écrit tout ce que jay medité fur cette matiere, $\&$ d'en faire le fujet de cette Lettre, que je vous écris en François, pour ne vous pas rebuter dans fa lecture par la traduction des termes qui font en ufage parmy les jouëurs, \& qui deviendroient peu intelligibles, fi on les mettoit en une autre Langue. 'Je ne m'arréte pas à vous y expliquer les Regles du Jeu, ni le principe de l'Art de conjecturer, qui doir fervir de fondement à nôtre recherche, fachantque l'un \& l'autre 


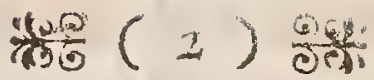

vous font parfaitement connus. Mais au refte jerrre dans le dé tarl de toutes les particularités de mon fujet, fans craindre le reproche, que l'on me pourroit faire de vous entretenir trop fur une bagatelle; car vous favez, que ce noble Jeu a toujours fait le divertiflement des perfonnes de la premiere qualité, \& bientôt vous verrez, que s'il eff utile pour l'exercice du corps, il eft tres-capable \& tres-digne auffi de fixer les meditations de l'efprit .

Je vous feray remarquer avant toutes chofes, que la raifon: pour laquelle dans les jeux de hazard on peut fupputer exactement les avantages \& les defavantages des Jouêurs, c'eft parce que le plus: fouvant l'on connoit au jufte le nombre des cas, qui leur font favo rables ou contraires : \& je dois vous dire, quill nen eft pas de mế me des jeux, qui dépendent uniquement, ou en partie, du genie, de linduftrie ou de l'adreffe des joueurs, tels que font les jeux de la paume, des échecs, \& la pluspart des jeux de cartes; étant bien viffio ble, que l'on ne fauroit déterminer par les caufes, ou à priori, comme l'on parle, de combien un homme eft plus favant, plus adroie ou plus habile qưun autre, fans avoir une parfaite connoiffance de la: nature de lame, \& de la difpofition des organes du corps humain laquelle mille caufes occultes, qui y concourent, rendent abfolus. ment impoffible. Mais cela n'empếche pas, qu'on ne puifle le fça voir prefque auffi certainernent, à pofferiori, par l'obfervation de l'événement plufreurs fois reiterée, etr faifant ce qui fe peut pratiquert dans les jeux même de pur hazard, lors qu'on ne fçait pas le nom. bre des cas, qui peuvent arriver. Pofons, quill y ait dans un fac quantité de billets en partie blancs \& en partie noirs, \& que je ne fache pas le nombre des uns ni des autres; que ferois -je pour le découvrir? je les tirerois l'un aprés l'autre, (en remettant chaque fois dans le fac le billet, que jen aurois tiré, avant que de prendire le fuivant, afin que le nombre des billets du fac ne diminuiât point) \& fij obfervois cent fois que jen tirâffe un noir, \& deux cent fois que j’en tirâffe un blanc, je ne héfiterois pas à conclure, que le nombre des blancs ne fút environ le double de celuy des noirs; car il eft tres-fur; que plus je ferois de ces obfervations en tirant, plus je pourrois efpérer d"approcher de la veritable raifon, qui fe trouve 


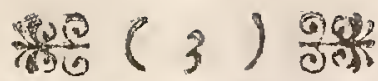

entre les nombres des ces deux fortes de billets; étant même un? chore démontrée, quion en peut tant faire, qu'il fera à la fin probable re toute probabilité donnée, \& par conféquent quil fera mom ralement cetain, que la raifon d'entre ces nombres, que l'on aura ainfi trcurée par expérience, difére de la veritable d'auffi peu que l'on voudra: qui eft tout ce qu'on peut fouhaiter, C'eft aufi de cette maniere, que dins les jeux d'art \& d'adrefle on peut connoirre de combien un jouëur eft plus fort que l'autre jouëur. Je vois par exemple deux hommes, qui jouënt d̀ la paume : je les obferve long temps, \& je remarque; que l'un d'eux gagne 200 ou 300 coups, pendant que lautre n'en gagne que cent: je juge par là, avec allez de certitude, que le premier eft deux ou trois fois meilleur jouëur que l'autre, ayant pour ainfi dire deux ou trois parties d'adreffe, comme autant de cas ou de caufes qui luy font gagner la bale, là où l'autre n'en a qu'une.

I. Cecy étant compris, mettons, pour entrer en matiere, deux jouëurs égaux A \& B (c’eft à dire, à qui nous ayons vû gagner \& perchre un pareil nombre de coups) qui foient prémiérement à deux ou trentains, ou quinzains, ou à but. Il eft évident, quils ont tous deux une égale efperance de faire les coups qui leur manquent, \& de gagner ainfí le jeu; ceft pourquoy le fort de chacun eft eftimé $\frac{x}{2}$ J ou $\frac{x}{2}$ Jeu. Mettons enfuite, qu'A ait $30 \& \mathrm{~B} 45$, ou (ce qui Ievient à un ) que celuy-cy ait l'avantage: vous voyez, qu'il eft bien autant probable, qu'A gagnera ou perdra le coup fuivant; mais s'il le gagne, ils redeviendront à deux $\&$ chacun aura, comme jay dit, 吾J; \& s'il le perd, il perdra auffi le jeu; c'eft ce qui luy vaut, par la Doctrine que vous $f_{\text {çavez }}, \frac{1 .^{1: 2}+1.0}{2} \infty \frac{r}{4}$. Mettons encore, que $\mathrm{A}$ ait is à $45 ; \hat{l}$ eft clair auff, qu'il luy eft également pofrible, de gagner 30 à 45,8 d'avoir ainsi le fort précédent $\frac{1}{4}$ J, ou de perdre le jeu (felon qu'il gagne ou perd le prémier coup) c'eft-ce qui rend maintenant fon fort $\frac{10^{1: 4}+10^{\circ}}{2} \infty \frac{1}{8} \mathrm{~J}$. Que si A avoit I 5 à 30 , un cas le rendroit trentain $8 x$ un autre is à 45, (dont celuy - là luy mene $\frac{x}{2} J, \&$ celuy - cy $\left.\frac{\pi}{8} J\right)$ ce qui luy vaudrait alors $\frac{I_{0}^{1: 2}+10: 8}{2}$ 
Table I.

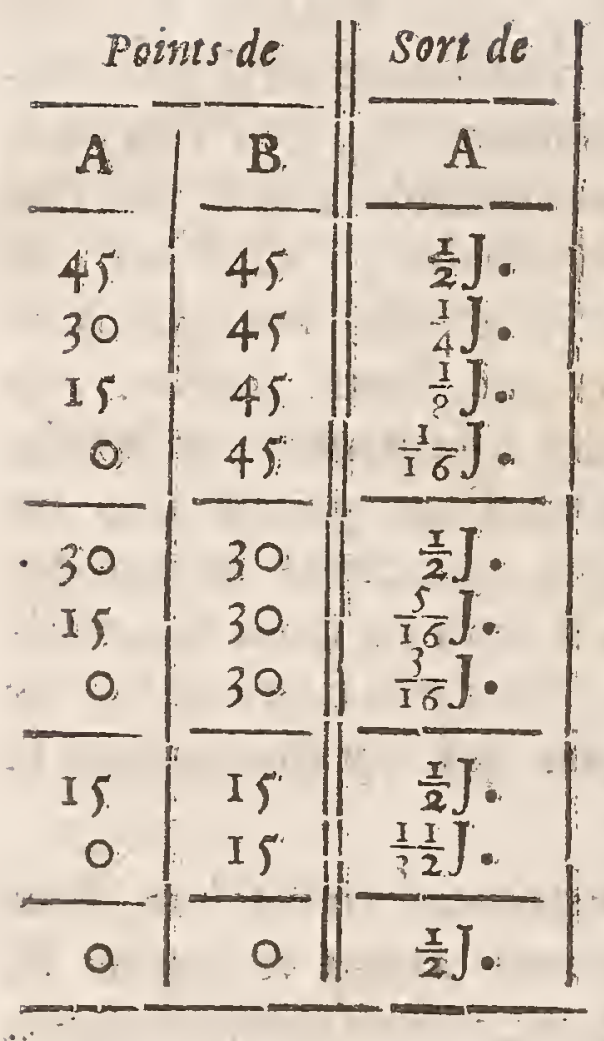

D $5_{1}^{5} \mathrm{~J}$. L'on trouvera tout de mếme les: forts d $\mathrm{A}$ pour les autres hipotêfes, com. me ils font marqués dans cette Table. Pour ceux de $\mathrm{B}$, ils fonr aisés à fuppléer, étant toûjours les reftes de ceux d'A à l'unité.

II. De même fi les deux jouëurs font à deux de jeu, il eft manifefte, que chacun d'eux peut également efpérer de gagner la Partie, en faifant deux jeux de fuite; \& que par conféquent le fort de chacun eft $\frac{x}{2} \mathbf{P}$ ou $\frac{x}{2}$ Partie. Mais fi (la Partie fe faifant par exemple à quatre jeux ) A en avoit gagné $2, \&$ B 3 , ou (ce qui eft le méme) si $B$ avoit l'avantage du jeu, if y auroit autant d'apparence, que le prémier jeu les rendit à deux de jeu; oú quil fit perdre la Partie à A ( felon que celuy-cy gagneroit ou perdroit ce jeu) ce

Trable II.

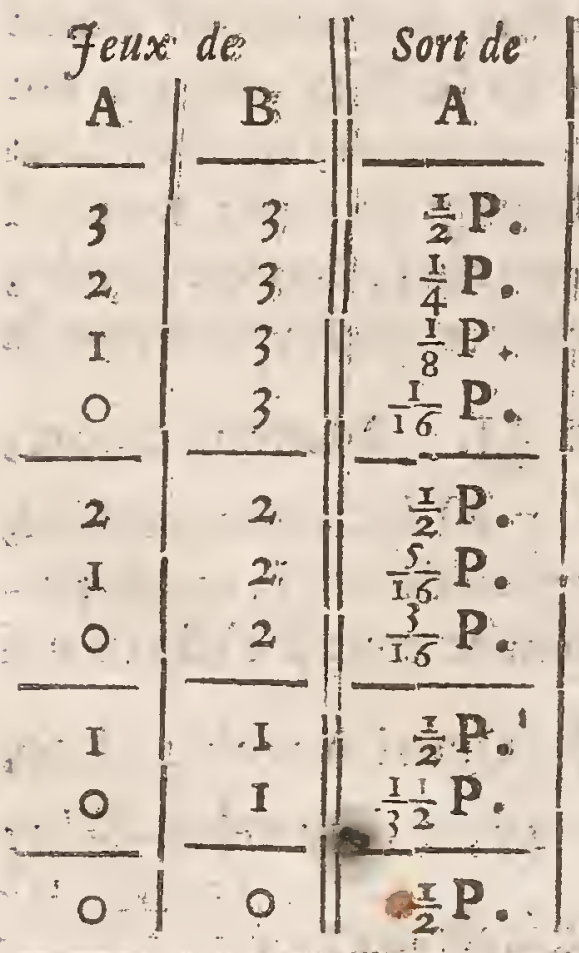
quil luy feroit avoir $\frac{\mathrm{r}^{\mathrm{I}: 2}+\mathrm{r}}{2} \infty \frac{\mathrm{x}}{4} \mathrm{P}$. Lion conclud de même, que fi $A$ avoit un jeu, \& $\mathrm{B}$ trois, le fort d'A feroit $\frac{1}{8} \mathrm{P}$. Et ainsi du refte, comme vous voyez dans: cetre autre Table, qui comprend les forts d'A par rapport à toute la Partie. Vous jugez, quelle doit étre la même que la prémiếre; car ce que les 4 coups d'un jeu font à liégard de ce jeu, les 4 jeux le font à l'égard de toute la Partie.

III. Confidérons encore les deux jouëurs, comme étant à deux de jeu, \& donnons en outre à $A 30 \&$ à $B$ 45: vous voyez que le prémier coup doit les mettre à deux, \& ainsi égaler leur fort, si A,ga: 


\section{秎昌 $(5)$ 的}

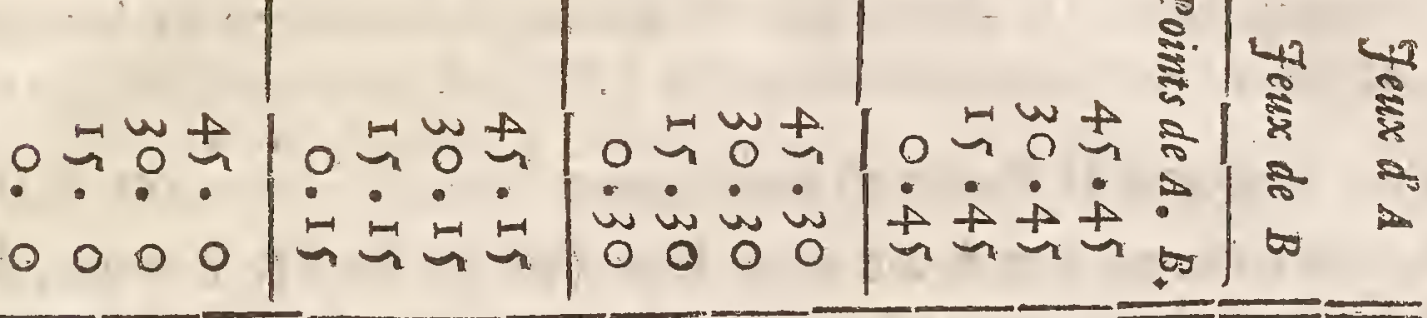

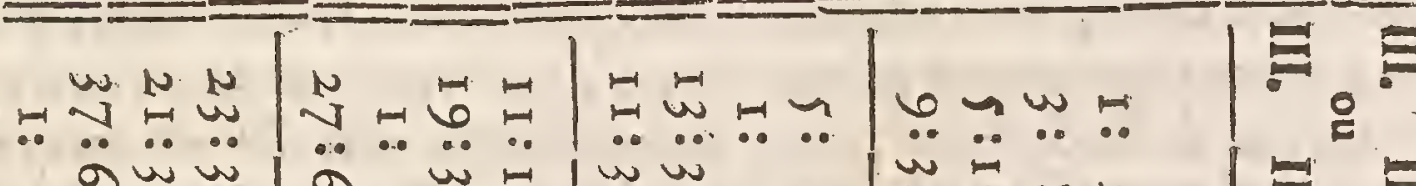

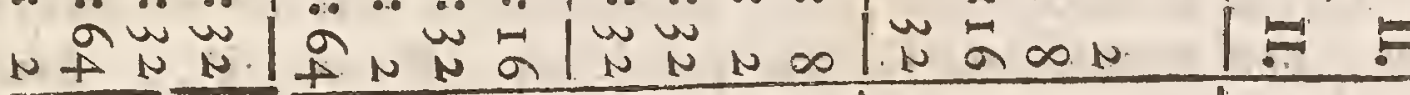

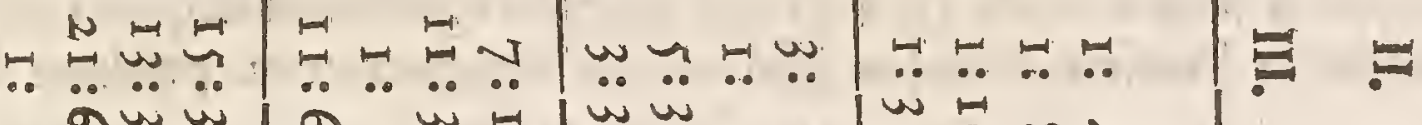

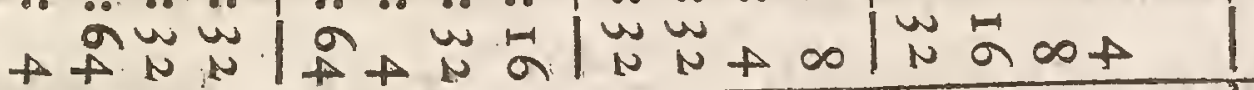

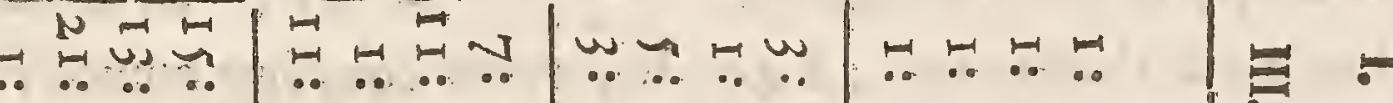

H 1 (1)

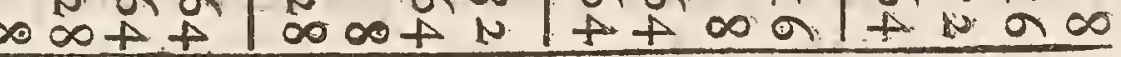

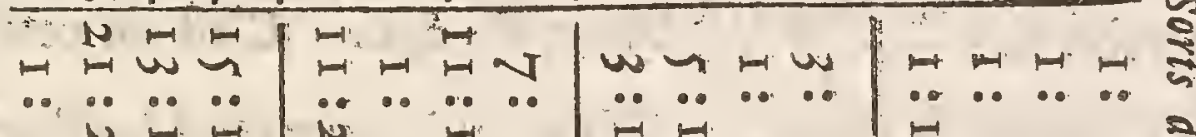

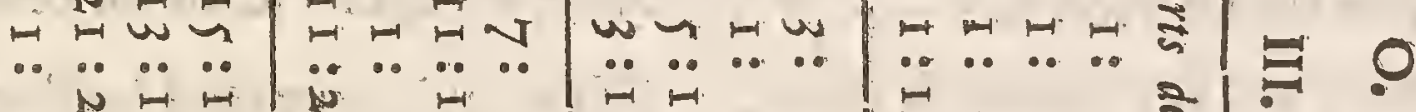

ज人

$6 \pi$ a 9 \& N w w

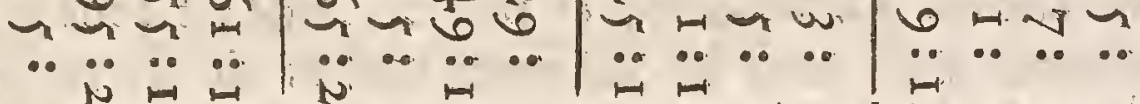

- F N N |

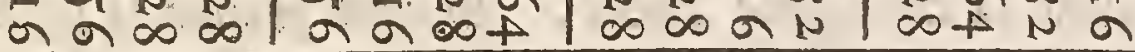

w

..

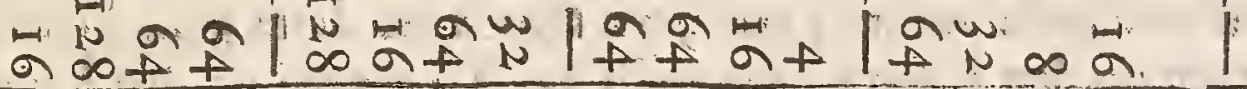

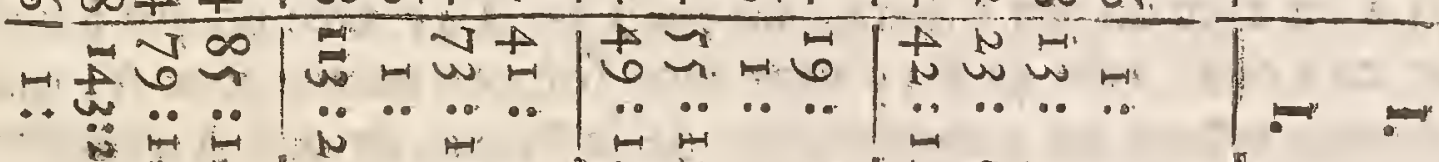

w

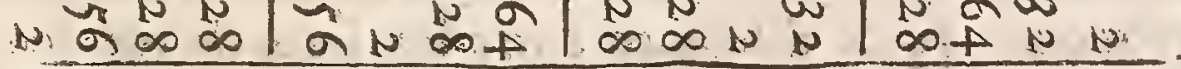

円

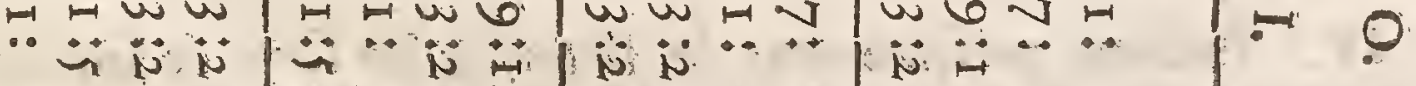

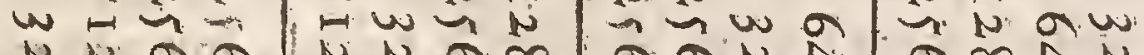

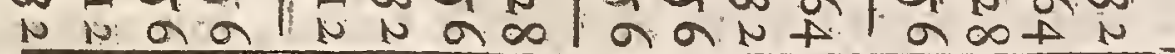

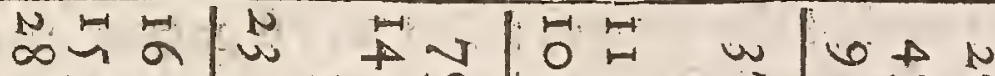

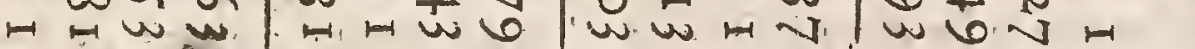

$\ldots \ldots \ldots \ldots \ldots \ldots \ldots+\ldots \ldots+\ldots$

$\because \mathrm{N} N \mathrm{~A} N \mathrm{~N} N$

N 


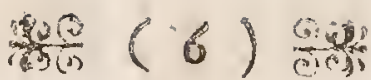

gne le coup; \&z s'il le perd, que B doit avoir l'avantage du jeu, art quel cas nous avons trouvé le fort d A ${ }_{4}^{1} \mathrm{P}$ : c'eft pourquoy l'efpérance quili a de gagner la Partie eft maintenant $\frac{10^{1: 2}+1{ }^{1: 4}}{2} \infty \frac{3}{8} \mathbf{P}$. Suppofons enfuite, que A ait deux jeux (ou un jeu) \& B trois, \& quils foient à deux, ou trentains, ou quinzains; if eft vilble, que chacun pouvant également gagner le jeu, c'eft tout con me sils n'avoient rien au de là de leurs jeux, de forte que le fort d'A eft encore, comme il a eté trouvé dans l'article précédent, ${ }_{4}^{1} \mathrm{P}($ ou $\mathrm{P})$. Mais si $\mathrm{A}$ avoit 2 jeux à $3, \& 30$ à 45 , il pourroit également acquerir 45 , ou perdre la Partie avec le jeu (fuivant qu'il gagneroit ou perdroit le prémier coup) ce quiluy vaudroir $\frac{1^{1: 4}+10^{\circ}}{2} \infty \frac{1}{8} \mathrm{P}$. Et si outre les 2 jeuxà 3 il n'avoit que 15 à 45 , le prémier coup luy pourroit également donner 30 à 45 , ou luy faire perdre le jeu \& la Partie; ce qui alors rendroit fon fort $\frac{1{ }^{1: 8}}{2}+1 . \infty \frac{\pi}{16}$ P.\&c. C'eft de cette maniére, que j'ay calculé la troifiéme Table, qui comprend les forts d'A pour tous les états polfibles des deux jouëurs, lors qu'outre les jeux entiers ils ont encore gagné quelques points. Elle eft donc générale, \& elle renferme aufi dans les derniers chifres de fes rangs perpendiculaires toute la deuxiéme Table. Si vous prenez la peine de l'examiner, vous y pourrez faire plufieurs reflexions dignes de remarque. Vous verrez par ex. que I 5 à 30 , les jouëurs étant à deux de jeu, valent tout jufte autant, que 30 à rien avec deux jeux à trois, ou 45 à 30 avec un jeu à deux, ou enfin 30 aे 45 avec un jeu à un: qu'un jeu à deux avec 45 à i 5 vaut tant foit peu mieux pour $A$, que s'ils étoient encore au com̌ncement de la Partie, \& que A n'eûtrien \& B I 5 , n'y ayant que $\frac{-1}{5} \frac{1}{2}$ de diférence entre les forts de ces deux hipotêfes . \& c.

IV. Tachons préfentement de découvrir les forts de jouëurs, quand ils font d'inégale force: Pour abreger le calcul, foit pris généralement "pour le nombre des coups, qu'on ait vû gagner au plus forr A, contre lesquels le plus foible B n'en ait gagnéqu'un; de for- 


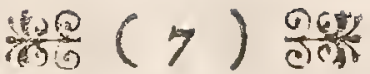

te que $n$ à I marque la raifon des forces des detux jouëurs; aprés quoy mettons, quils foient à deux, \& quil faille trouver leur fort. Si un feul coup fufifoit à chacun d'eux pour gagner le jeu, la queftion feroit déja ảecidée; puisque la raifon de $n$ à $I$, qui eft celle de leurs forces, feroit aufi celle de leurs efpérances pour ce jeu - là; mais parce que les loix du jeu en ont ordonné autrement, \& qu'elles demandent qu'on gagne deux coups de fuite pour gagner le jeu, la raifon qu'on cherche eft différente de celle - là, \& il faut un peu d'analyfe pour la trouver. Sachant done, quaprés le prémier coup l'un doit avoir l'avantage, \& qu'aprés le fecond coup le jeu fe peut remettre à deux, \& qu étant à deux il retourne le même fort inconnu, que nous voulons chercher, apellons le fort d'A en cet état $x, \&$ confidérons ce qui arriveroit, fi l'un ou l'autre gagnoit l'avantage. Or fi A le gagne, qui eft $n$ fois plus habile jouëur que l'autre, il y aura pour luy $n$ aparences de gagner le jeu, \& une aparence de fe remettre à deux (fuivant quili gagnera auffi ou perdra l'autre coup) ce qui luy vaut $\frac{n+10^{x}}{n+1} \infty \frac{n+x}{n+1}: \&$ si c'eft $B$ qui gagne l'avantage, il y aưra pour $\mathrm{A} n$ vrayfemblances de fe remettre à deux, \& une vrayfemblance de perdre le jeu; ce qui luy fait $\frac{n^{x}+x^{\circ}}{n+1} \infty$ $\frac{n x}{n+1}$. D'où il s'enfuit, que les jouëurs étant encore à deux, auquel cas il y a pour A par la même raifon $n$ fois plus de vrayfemblances de gagner l'avantage, que de le perdre, fon fort doit étre $\frac{n .^{n+x: n+1}+1 .^{n x: n+1}}{n+1} \infty \frac{n n+2 n x}{n n+2 n+1}$, \& parce que le méme eft apellé $x$, il y aura $x \infty \frac{n n+2 n x}{n n+2 n+1}$; ce qui nous donne $x$ $\infty \frac{n n}{n n+1}, \&$ refte pour le fort de fa Partie $\frac{1}{n n+1}$, tellement que leurs forts font entre eux en raifon de $n n$ à $I$, doublée de celle de leurs forces $n \grave{z} \mathbf{I}$. Cecy étant établi, l’on pourra continüer par ordre nôtre recherche pour touttes les autres hipotêfes, comme on a fait dans les articles precédens, pourvî qu'on fe fouvienne icy, qu'à chaque coup il eft $n$ fois plus probable, que A gagne ce coup, qu il n'eft probable, quill le perde: Posé donc par cxemple, qu'A ait 30 
Table IV.

\section{स्व}

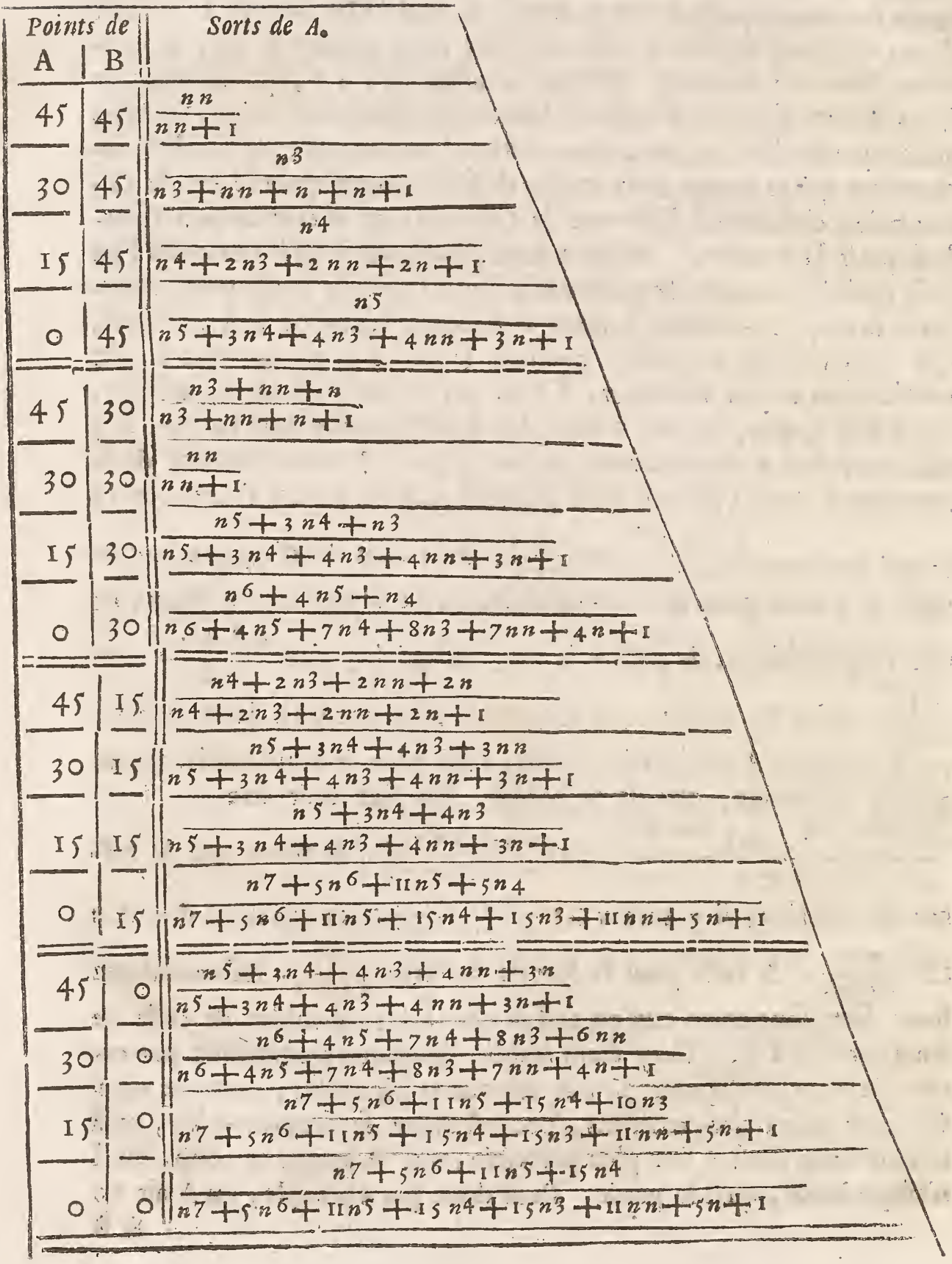




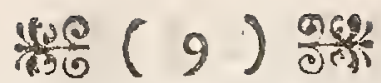

2. B 45 ; il y a $n$ cas qui mettent le jeu à deux, \& un cas qui le fair perdre à $A$; ce qui luy vaut $\frac{n n n n+1+1.0}{n+1} \infty \frac{n^{3}}{n 3+n n+n+1}$. Posé qu'A ait i 5 à 45 , il y a cas, qui luy font gagner 30 à 45 \& encore un cas qui luy fait perdre le jeu; ce qui luy fait naitre le fort $\frac{n .{ }^{n} 3: n 3+n n+n+1+1}{n+1} \infty \frac{n 4}{n 4+2 n 3+2 n n+2 n+1}$. On trous ve de la même maniére le fort d'A, quand il n'a rien \& $B$ 45. Lors qu'ils font trentains, ils ont le même fort qu'étant à deux, parce qu'il leur faut aufi gagner deux coups de fuite, pour faire le jeu. On trouvera de même leur fort, A ayant r 5 ou $0, \&$ B 30. Semblablement on cherche les forts, A ayant $45, \&$ B 30 , Is ou o; comme auffi $\mathrm{A}$ ayant $30, \& \mathrm{~B}$ I 5 ou 0 . Ainsi l'on ne peut ignorer les forts, quand ils font quinzains, ou $\mathrm{A}$ ayant 0 \& $\mathrm{BI} 5$, ou au contraire $\mathrm{A}$ I 5 \& $\mathrm{B}$ O, ou enfin quand ils font encore à but. C'eft ce qui produit la quatriéme Table, où eft contenuie la valeur des efpérances de A (par raport à chaque jeu) généralement pour toute forte de raifons, qu'on puiffe imaginer entre les forces des jouëurs:

V. Vous jugez bien, que si vous y prenez $n$ pour 1 , il en doit refulter la prémiére Table, faite pour des jouëurs d'égale force: \& fi vous faites valoir fucceffivement cette lettre pour $2,3,4.8 \mathrm{c}$. la Table fervira pour des jouëurs, dont l'un eft deux, trois, ou quatre fois plus fort que l'autre. Si par exemple $A$ eft deux fois plus fort que $B$, vous trouverez fon fort, étant à deux, $\frac{4}{5} \mathrm{~J} ; \&$ ayant 30 à $4 \dot{\zeta}$ voús le trouverez $\frac{8}{15}$ ]; de forte quill reftera pour celuy de $B, \frac{1}{5} \mathrm{~J} \& \frac{7}{\frac{1}{5}} \mathrm{~J}$; \& par conféquent les forts des deux jouëurs en ces cas feront entre eux en raifon de 4 à $1, "$ \& $x$ de 8 à $7, \&$ ainsi de tout le refte, comme il eft reprélenté dans la cinquiéme Table.

Vous vous fouviendrez pourtant de ce que jay dit, que ces $T$ ae bles ne fervent que pour chaque jeu féparément; car il en faudroit encore donner une femblable, qui comprit les forts des jouëurs par raport à toute la Partie; lors qu' ils jouënt à plufieurs jeux, dont ils ont déja gagné quelques uns, avec quelques points encore, fi vous voulez; comme jay fait la troifiéme Table pour des jouëurs égaux: mais parce que la continuation de cette recherche par lettres feroit 


\section{橉器 ( 10$)$ ) \\ Table V.}

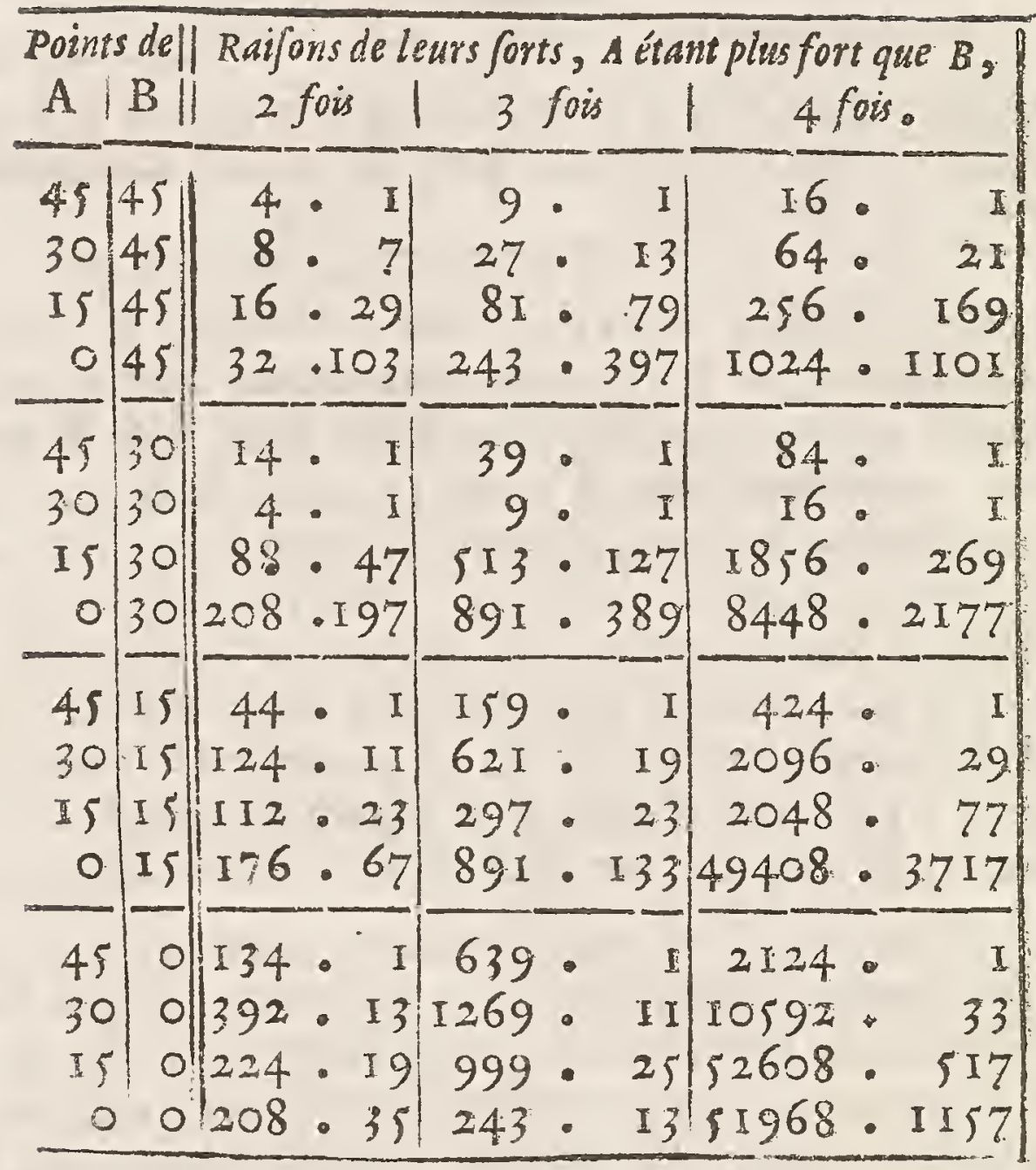

tres-pénible, \& demanderoir un calcul immenfe, je me contenteray de faire voir dans un exemple particulier, comment il $s^{3} y$ faudroit prendre, pour trouver en abregé ce qu'on cherche. Supófons, que la Partie fe face à 4 jeux: que $A$ ait un jeu \& outre cela I $5, B$ deux jeux avec 45,8 que $A$ foit deux fois plus fort que $B$; on veut $\llbracket$ çaim voir la valeur des efpérances qu ils ont de gagner la Partie. Remarquons avant toute, chole que les facilités, qu'ont ces jouëurs à ga gner chaque jeu étant encore à but, font entre elles par la cinquiéme Table en raifon de 208 à 35 , ou bien de $\frac{20}{35}$ à 1 ; \& que parconfequent celuy qui eft deux fois plus fort qu un autre, aura $\frac{208}{35}$ fois (c’eft près de fix fois ) plus de facilité pour gagner ce jew: encure de guoy confidérons, que le jeux, dont ils ons déja fait une Partie, étans 


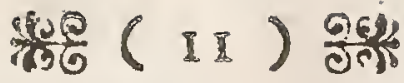

teant achevé, ils auront ou deux jeux à deux, ou un jeu à trois (fulvant que l'un ou l'autre l'aura gagné) en quelle fictation il leur man quera encore ou deux jeux à chacun, ou trois jeux à $\mathrm{A} \&$ un jeu à $\mathrm{B}$ 。 Or il eft bien clair, que ceft alors tout comme s'il leur manquoit feulement autant de coups, qu'il leur manque de jeux ( $c$ ' eft à dire comme s'ils eftoient trentains, ou is à 45 ) fuposé que la facilité, que le plus fort a de gagner un jeu entier, fût celle, qu $u^{3}$ il a de gagner un fimple coup, \& que nous avons nommée $n$. Mais cette facilité, comme je viens do dire, eft exprimée par $\frac{228}{35}$; si vous fubftituez donc cette fraction numerique à la place de $n$ dans les quantités $\frac{n n}{n n+8} \& \frac{n 4}{n 4+2 n 3+2 n n+2 n+1}$, qui marquent, par la $4^{\text {me }}$ Table, le fort de A quand il eft ttentain ou Is à 45 , vous aurez les forts, qui luy tombent quand il a deux jeux à deux, ou un jeu à

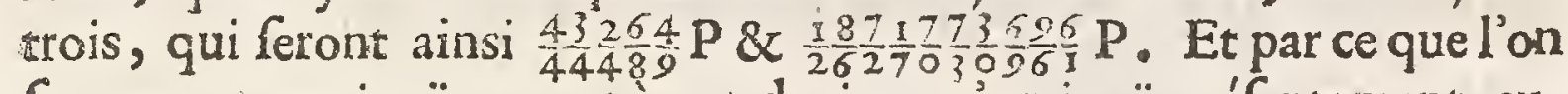
Cupose, que ce jouëur 215 a 45 du jeu qu' on jouë préfentement, auquel étar il a I 6 cas de gagner ce jeu, \& 29 cas de le perdre, par la cinquiéme Table; il s'enfuit, quil y a I 6 cas qui luy acquiérent deux jeux à deux, \& 29 cas, qui luy font avoirjun jeu à trois, ce qui rend Ha valeur de fon efpérance à gagner la Partie,

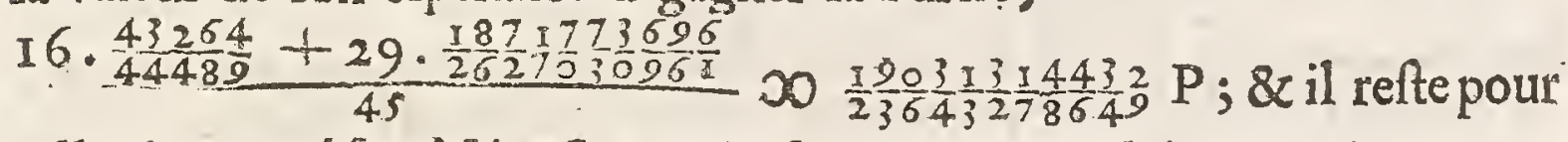

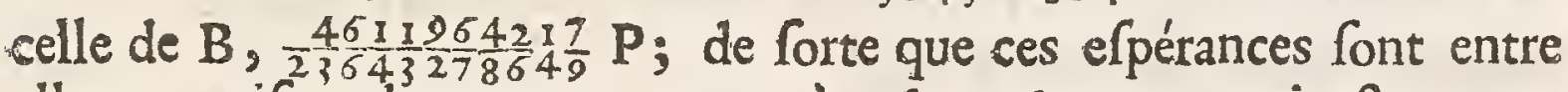
elles en raifon de I903I 3 I 4432 aे 46 II 6422 I7, qui eft un peu plus que quadruple. Mais paffons plus outre.

VI. Si le raport des forces de deux joueurs eft connu, l'on peut Cçavoir, combien l'un doit donner d'avantage à l'autre pour rendre le jeu égal. On n'a qu'à jetter les jeax fur la cinquiéme Table, pour voir ou les nombres, qui marquent le raport de leurs efpérances, s'aprochent le plus. C'eft ainsi que nous obfervons, que lorsque $\mathrm{A}$ eft deux fois plus fort que $\mathrm{B}$, leurs forts différent le moins, A n'ayant rien \& B 30 ; de forte que A peut donner à B $30, \&$ mêtme avec quelque petit avantage pour foy, fon efpéranceà gagner le jeu étant tant foit peu plus grande que celle de B. Si A eft trois fois plus fort que B, \& qu' il luy donne $4 r$, nous voyons, qu' il y a un avantage notable pour $B$, mais qu'il y a beaucoup plus d'avanta- 


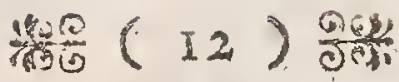

ge pout luy même, s'il ne luy donne que 30. Pour rendre done la Partie égale autant qu'il fe peut, il faudroit qu' il donnât à $B 45$. prenant pour luy 55 . Si A eft quatre fois plus fort, il peut donner B 45 , pourtant avec quelque petit avantage pour $B$; mais $s$ il étoit cinq fois plus fort que B, il pourroit luy donner $45, \&$ auroit encore un avantage afsés confidérable pour foy - même, puifque leurs forts fe trouveroient étre comme 3125 \& 249 I \& $c$.

VII. Si A donne à B I 5 , oul 30 , ou 45 , f̧avoir au contraire, de combien $A$ eft plus fort que $B$ ? Pour refoudre cette queftion il faut confidérer, que lors que pour égaler la Partie A donne à $B$ un avantage de quelques points, le fort de chacun doit étre $\frac{x}{2} ;$ ceft pourquoil' on prendra dans la Table IV les quantités, qui marquent le fort de A, lors qu'il n'a rien, \& B 45, ou 30 , ou $15, \&$ on les fera chacune $\bigcirc \frac{x}{2} ;$ ce qui nous fournit trois égalités:

$$
\begin{aligned}
& \frac{n^{5}}{n^{5}+3 n^{4}+4 n^{3}+4 n n+3 n+1} \infty \frac{x}{2} \\
& \frac{n^{6}+4 n^{5}+n^{4}}{n^{6}+4 n^{5}+7 n^{4}+8 n^{3}+7 n n+4 n+1} \infty \frac{n^{7}}{n^{7}+5 n^{6}+\operatorname{IIn} n^{5}+5 n^{4}} \\
& \& \frac{n^{7}+5 n^{6}+11 n^{5}+15 n^{4}+15 n^{3}+\operatorname{II} n+5 n+1}{2} \infty
\end{aligned}
$$

lesquelles étant reduites feront

$$
\begin{aligned}
& n^{5}-3 n^{4}-4 n^{3}-4 n-3 n-1000 \\
& n^{6}+4 n^{5}-5 n^{4}-8 n^{3}-7 n n-4 n-1000 \\
& n^{7}+5 n^{6}+11 n^{5}-5 n^{4}-15 n^{3}-11 n-5 n-1000
\end{aligned}
$$

Et parce que les racines de ces équations, qui marquent la valeur de l'inconnuë $n$, font fourdes, il s'enfuit que les forces des jouëurs, dont l'un donne à l'autre un avantage de quelques coups, font incommenfurables entre elles. La racine de la prémiére eft à peu prés 4.216 (ou environ $4 \frac{1}{5}$ ), de la feconde 1.946 ( ou $I_{1} \frac{2}{0}$ ), de le troifiéme I. 3 I 3 ( ou I $\frac{3}{1}$ ); ce qui fait voir, que celuy qui peut donner à l'autre quarante - cinq, doir étre $4 \frac{1}{8}$ fois plus fort: que celuy qui peut donner trente, doit étre $I_{\mathrm{I}} \frac{9}{0}$ fois; \& qui peut donner quinze, $I_{1} \frac{3}{0}$ fois plus fort que l'autre: c'eft à dire, que le prémier. doje 


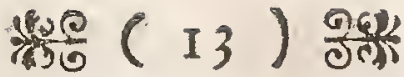

doit gagner 42, le fecond 19 , \& le troifiéme 33 coups; lorsque leurs Parties en gagnent 10 .

Or si $\mathrm{A}$ donne à $\mathrm{B}$ l'avantage, qui eft neceffaire pour rendre le jeu égal, ce fera toute la même chofe, de jouër à un jeu, ou à deux jeux, ou à trois, ou à tant qu'il vous plaira: car s'il eft également probable, que A gagne un jeu, ou qu' il le perde; il ef aufí également poffible, quil face deux jeux de fuite, ou qu'il les perde; quand la partie fe fait à deux jeux; ou bien qu'il gagne ou perde trois jeux, quand elle fe fait à trois jeux \&cc.

VIII. Si A donne à B demi- I 5 , ou demi-30, ou demi-45, f̧̧avoir de combien A eft plus fott que B? Mettons, qu' A donne à $B$ demi -45 , que la Partie fe jouë à deux jeux; que $B$ prenne au premier jeu $30, \&$ à l'autre 45 ; puis derechef 30 , si la Partie fe remet à deux de jeu, puis $45, \&$ ainsi alternativement; \& que toutes les fois quil prend 30, fon efpérance de gagner le jeu foit à celle de $A$ en raifon de $b$ à $a$, \& toutes les fois qu il prend 45 , en raifon de $d$ à $c$. Cela posé, faifons le fort $\mathrm{d}^{\prime} \mathrm{A}$ au commencement de la partie $\infty \mathrm{z}, \&$ confidérons ce qui arriveroit, si $B$ gagnoit le prémier jeu: Alors B prendroit 45, \& par l'hipotéfe A auroit $c$ vraifemblances de gagner le jeu fuivant, $\& d$ vraifemblances de le perdre. Or si A le gagne, la Partie fe remet à deux de jeu, \& il faut que B reprenne 30, tout de même qu'au cońnencement de la Partie: mais si A le perd, il perd enfemble la Partie: d'où il fuit, que le fort de $\mathrm{A}$ feroit en ce $\operatorname{cas}^{c} \frac{{ }^{2}+d 0^{\circ}}{c+d} \infty c z+d$. Que fi au contraire $A$ avoit gagné le prémier jeu, B prendroic auffi $45 \& A$ auroit aprés cela $c$ aparences de gagner enfemble le jeu \& la Partie; \& d aparences de remettre la Partie à deux de jeu, en perdant le jeu: ainsi fon fort feroit alors $\frac{a^{P}+d z}{c+d} \infty \frac{c P+d z}{c+d}$ Enfin confidérans les jouëurs comme au commencement de la Partie, où $B$ prend 30 , nous voyons qu'il y a pour A, a probabilités de gagner l'avantage du jeu, c'eft a dire de parvenir au fort précédent $\frac{c P+d z}{c+d}, \& b$ probabilités de perdre cetavantage \& d'acquerir ainsi le fort $\frac{c z}{c+d}$; ce qui luy vaut
b 3 $a a^{6 P}$ 


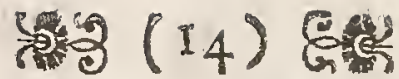

$\frac{a \cdot{ }^{c}+d z: c+d+b \cdot c z: c+d}{a+b} \infty \frac{a c \mathcal{P}+a d z+b c z}{a+b c+d}$. Mais nous fupofions le méme fort, qu'obtient $\mathrm{A}$ au commancement de la Partie so z; c'eft pourquoi il y a égalité entre $z \&$ la dite quantité $\frac{a c p+a d z+b c z}{a+b . c+d}$, laquelle étant reduite on trouvera $z \infty \frac{a c}{a c+b d} P$. Et parce que la Partie à demi-45 eft fuposée égale, dans laquelle avant le commencement du jeu le fort de chacun foit $\frac{x}{2} P$, il doit $y$ avoir encore égalité entre $\frac{5}{2} P, \&$ la valeur trouvée de $z$, d'où il refulte celle - cy $a c, \infty \quad b d$, qui nous donne l'analogie $a . b:: d . c$.

Cela fait voir, que la Partie fera égale, quand ces quatre quantités $a, b, d, c$, font proportionnelles; c'eft à dire, quand l'efpérance du plus fort à gagner le jeu eft à l'efpérance du plus foible (ayant 30 ) comme reciproquement l'efpérance du plus foible (ayant 45 ) eft à celle du plus fort: ou bien, quand il y a 2,3 ou 4 fois plus d' apa rence, que le foible perdele jeu, ayant 30 , \& qu' il y ait au contraire autant d'aparence, quill le gagne, ayant 45 , on luy peut donner. demi -45 .

Et il eft à remarquer, qu' il n'importe, foit que $B$ prenne aus prémier jeu $30 \&$ à l'autre 45 ; ou qu' au contraire il prenne d'abord $45, \&$ puis 30: car ayant fait nôtre calcul, pour cette derniere hipotêfe, nous trouverons $z \infty \frac{c^{a} P+b z: a+b+d \cdot a z: a+b}{c+d}-\infty$ $\frac{a c P+b c z+a d z}{a+b \cdot c+d}$, c'ett à dire encore $z \infty \frac{a c}{a c+b d} \mathrm{P}$, comme auparavant. Par conféquent ceux - là fe trompent, qui s'imaginent, qu' il y a de l' avantage à prendre au prémier jeu le moins, \& à l'autre le plus.

Or parce que le mểme raifonnement fubfifte toujours, quelque raifon que puiffent marquer les lettres $a, b \& d, c$; il s'enfuit, quil en fera de même de la Partie, qui fe jouë à demi- 30 , ou à demi - I 5 ; f̧̧avoir, qu' elle fera égale toutes les fois, que l'éfpérance de A par raport à chaque jeu furpaffe celle de B \& en eft furpaffée alsernativement en même raifon.

Pour faire l'aplication de ce que nous venons d'établir, il faut déter- 


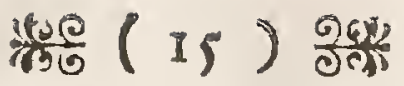

déterminer pour chaque hipotéfe la valeur des lettres $a, b, c, d$; ce qui fe fait fans peine. On n'a qu' à prendre dans la $4^{\mathrm{me}} \mathrm{T}$ able les forts de $A$, quand $B$ eft fuposé avoir 45 , ou 30 , ou I $\zeta_{2}$ olr 0 , से rien? lesquels étant par ordre $\frac{n 5}{n 5+3 n+4 n 3+4 n n+\frac{1}{6} n^{2}+x^{2}}$,

$\frac{n^{6}+4 n 5+n}{n^{6}+4 n^{5}+7 n 4+8 n^{3}+7 n n+4 n+1}$,

$\frac{n 7+5 n^{6}+11 n 5+\sin 4}{n^{7}+\operatorname{sn}^{6}+11 n 5+15 n+15 n+11 n n+5 n+19}$

$$
n^{7}+5 n^{6}+11 n^{5}+15 n^{4}
$$

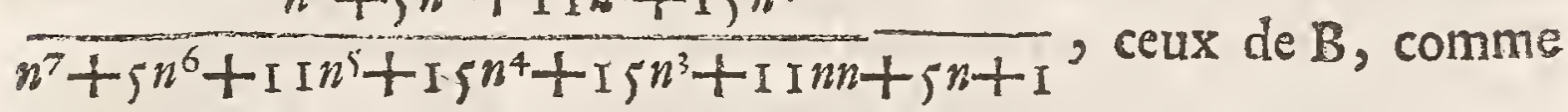
les reftes à l'unité, feront $\frac{3 n^{4}+4 n^{3}+4 n n+3 n+I}{n^{5}+3 n^{4}+4 n^{3}+4 n n+3 n+I}$,

$$
6 n^{4}+8 n^{3}+7 n n+4 n+1
$$

$n^{6}+4 n^{5}+7 n^{4}+8 n^{3}+7 n n+4 n+1$

$$
10 n^{4}+15 n^{3}+\operatorname{IIn} n+5 n+I
$$

$n^{7}+5 n^{6}+\operatorname{IIn} n^{5}+\operatorname{s5n} n^{4} \operatorname{I5} n^{3}+\operatorname{IIn} n+5 n+13$

$$
\text { I } n^{3}+\operatorname{IIn} n+5 n+I
$$

$n^{7}+5 n^{6}+11 n^{5}+\operatorname{I5} n^{4}+\operatorname{I5} n^{3}+\operatorname{Ir} n n+5 n+1$

\& par conféquent les efpérances d'A auront à celles de $\mathrm{B}$ les raifons

$$
\begin{aligned}
& \frac{n^{5}}{3 n^{4}+4 n^{3}+4 n n+3 n+5}, \frac{n^{6}+4 n^{5}+n^{4}}{6 n^{4}+8 n^{3}+8 n n+4 n+1} \\
& \frac{n^{7}+5 n^{6}+\operatorname{IIn} n^{5} 5 n^{4}}{\operatorname{In} n^{4}+15 n^{3}+\operatorname{IIn} n+5 n+1}, \frac{n^{7}+5 n^{6}+\operatorname{II} n^{5}+\operatorname{I5} n^{4}}{\operatorname{I5} n^{3}+\operatorname{IIn} n+5 n+\mathrm{I}}
\end{aligned}
$$

D'où il eft clair, que quand la Partie fe jouë à demi-45, l' on doir faire $\frac{a}{6} \infty \frac{n^{6}+4 n^{5}+n^{4}}{6 n^{4}+8 n^{3}+7 n n+4 n+1}, \quad \& \frac{c}{d} x$

$$
n^{5}
$$

$3 n^{4}+4 n^{3}+4 n n+3 n+5$

: quand elle fe joü̉ à demi-30; 


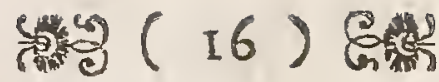

$\sum_{6} \infty \frac{n^{7}+5 n^{6}+\operatorname{II} n^{5}+5 n^{4}}{10 n^{4}+15 n^{3}+\operatorname{II} n+5 n+1}, \& \frac{6}{d} \infty$ $n^{6}+4 n^{4}+n^{4}$ : \& enfin quand on la jouẽ à demi$\overline{6 n^{4}+8 n^{3}+7 n n+4 n+1}$

I5, $\frac{a}{b} \infty \frac{n^{7}+5 n^{6}+11 n^{5}+15 n^{4}}{\operatorname{I5} n^{3}+\operatorname{IIn} n+5 n+1}, \& \frac{c}{d} \infty$

$\frac{n^{7}+5 n^{6}+\operatorname{II} n^{5}+5 n^{4}}{10 n^{4}+\operatorname{I5} n^{3}+\operatorname{IIn} n+5 n+1}$. Subltituans done ces rac
leurs, nous aurons à la place de ac $\infty$ bd, dans la prémiére hipotêfe,

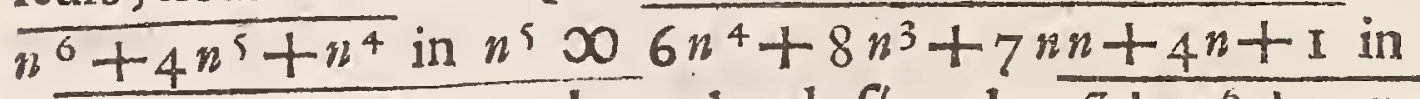
$3 n^{4}+4 n^{3}+4 n n+3 n+I$ : dansla féconde, $\overline{n^{7}+5 n^{6}+I I n 5+5 n^{4}}$ in $n^{6}+4 n^{5}+n^{4} \infty 0$ 10 $n^{4}+15 n^{3}+\operatorname{IIn} n+5 n+1$ in $\overline{6 n^{4}+8 n^{3}+7 n n+4 n+1}:$ \& dans la troifiéme,

$n^{7+5 n^{6}+11 n^{6}+15 n^{4}}$ in $n^{7}+5 n^{6}+11 n^{4}+5 n^{4} x$.

$\overline{15 n^{3}+\operatorname{II} n n+5 n+I}$ in $\overline{10 n^{4}+\operatorname{I5} n^{3}+\operatorname{II} n n+5 n+1}$; ceet à dire, que la multiplication faite, nous aurons les trois égalités: $n^{17}+4 n^{10}+n^{9} 5018 n^{8}+48 n^{7}+77 n^{6}+90 n^{5}+77 n^{4}$. $+49 n^{3}+23 n n+7 n+1$,

$n^{13}+9 n^{12}+32 n^{11}+54 n^{10}+31 n^{9}+5 n^{8} \infty 60 n^{8}+$ $170 n^{7}+256 n^{6}+263 n^{5}+193 n^{4}+102 n^{3}+38 n n+9 n+$ I $n^{14}+10 n^{13}+47 n^{12}+130 n^{11}+221 n^{10}+220 n^{9}+75 n^{8}$ $\infty$ I $50 n^{7}+335 n^{6}+380 n^{5}+281 n^{4}+140 n^{3}+47 n n+10 n+1$; lesquelles enfuite fe reduifent à celles - cy:

$$
n^{12}+4 n^{10}+n^{9}-18 n^{8}-48 n^{7}-77 n^{6}-90 n^{5}-77 n^{4}-
$$
$49 n^{3}-23 n n-7 n-1000$,

$n^{13}+9 n^{12}+32 n^{18}+54 n^{10}+31 n 9-55 n^{8}-170 n^{7}$ $-256 n^{6}-263 n^{5}-193 n^{4}-102 n^{3}-38 n n-9 n-1000$; $n^{14}+10 n^{33}+47 n^{12}+130 n^{12}+221 n^{10}+220 n^{2}+75 n^{8}$ $-150 n^{7}-335 n^{6}-380 n^{5}-281 n^{4}-140 n^{3}-47 n n-10 n-1000$ où $l^{1}$ inconnuë $n$ nous marque la raifon d'entre les forces des deux jouëurs. Celuy qui aura le loifir, pourra chercher les racines de ces équa- 


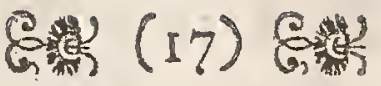

Squations; je conjequre, quelles font environ $2 \frac{7}{1}, I_{\frac{1}{1}} \frac{6}{0}, \& I_{1} \frac{\pi}{10}$ tellement que celuy qui peut donner demi -45 , doit gagner 27 : qui peur donner demi - 30, doit gagner I6: \& enfin qui peut donner demi - I 5 , doit gagner I coups contre dix coups de fa Partie.

Avant que de finir cet arcicle, je dois encore remarquer, que si l'avantage qu'on donne alternativement au joueur $B$, eft tel, comme je l'ai dit, $c$ eft à dire que les deux joueururs faffent par là à chaque jeu un échange continuel de leurs efpérances, la Partie fera toujours égale. non feulement quand on la jouë à un ou plufieurs couples de jeux, comme l'on pourroit s'imaginer, mais aufi à quel nombre de jeux, qu'on voudra la jouër. Car posé qu'on jouë à 3,4 ou 5 jeux, que A donne à $\mathrm{B}$ un avantage alternativement plus petit \& plus grand: favoir le plus petit, quand la fomme des jeux qui leur reftent eft un nombre pair, \& le plus grand quand cette fome eft un nombre impair; \& qu' au prémier cas il y ait deux fois plus d'aparence que A gagne le jeu, \& qu' à l'autre il y ait au contraire deux fois plus d'aparence que $B$ le gagne: on trouvera le fort de chacun à chaque jeu par ordre, coñe l'on voit ici.! (Tab.vI.) Les petits ronds vous marquent les jeux qui leur reftent à faire; \& il paroit, que quand le nombre de ces jeux eft égal de part \& d'autre, le fort de chaque jouëur eft toujours $\frac{x}{2} P$.

IX. A donne à $\mathrm{B}$ demi-30, \& à C 4 r; combien $\mathrm{B}$ peut - il donner à $C$ ? Ref . Parce que la force de B eft à celle d'A, comme io à I 6, par l'article précédent; \& celle d'A à celle de $\mathrm{C}$, comme 42 à IO, par l'art.7. on doit conclure ex equo perturbatè, que la force de $B$ eft à celle de $C$, comme 42 à 16 , ou à peu prés comme 26 à IO; de forte que $B$ pourra donner à $C$ demi-45, par l'art. précéd.

$\mathrm{X}$. A donne à $\mathrm{B}$ demi-30, \& $\mathrm{B}$ à $\mathrm{C}$ demi -45 ; que peut donc $\mathrm{A}$ donner à $\mathrm{C}$ ? Re $\beta$. la force d'A étant à celle de $\mathrm{B}$, comme $\mathrm{I} 6$ à $10: \&$ celle de $\mathrm{B}$ à celle de $\mathrm{C}$, comme 27 à 10 , par l'article 8 ; il s'enfuit par la compofition des raifons, que la force d'A eft à celle de C, comme 432 à I00, c'eft a dire que celui- là peut donner à celuicy quarante - cinq, par l'art. 7 .

XI. A eft deux fois plus fort que $B, \&$ cinq fois plus fort que C. Donc $\mathrm{B}$ eft $\frac{s}{2}$ fois plus fort que $\mathrm{C}, \&$ lui peut donner par conféguent prefque demi - 45 , par l'art. 8 . 


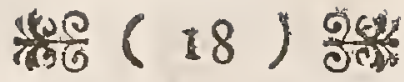

\section{Table VI.}

\begin{tabular}{|c|c|c|c|}
\hline \multicolumn{2}{|c|}{ Feux qui reftent } & \multirow{2}{*}{$\begin{array}{l}\text { Sornme de } \\
\text { ces jeux }\end{array}$} & \multirow[t]{2}{*}{ Sort de $A$} \\
\hline A & B & & \\
\hline 0 & 0 & Pair & $\underline{z}$ \\
\hline 0 & 0 & ran & 2 \\
\hline $\begin{array}{l}0 \\
0\end{array}$ & 0 & Impair & $\frac{1 .^{1: 2}+20^{0}}{2} \infty \frac{\pi}{6}$ \\
\hline 0 & 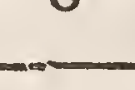 & & 3 \\
\hline 00 & 0 & $\mathbf{P}$ & $\frac{2 .^{1: \sigma}+r^{0}}{3} \infty \frac{1}{y}$ \\
\hline $\begin{array}{ll}0 & 0 \\
0 & 0\end{array}$ & 0 & $I$ & $\frac{10^{1: 9}+20^{0}}{3} \infty 0 \frac{1}{27}$ \\
\hline$\because 0$ & 0 & P & $\frac{2 .^{1: 27}+10^{0}}{3} \infty 0 \frac{2}{83}$ \\
\hline 0 & $\begin{array}{l}0 \\
0\end{array}$ & 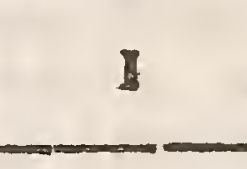 & $\frac{I_{0}^{12}+\frac{200^{1: 2}}{3}}{2} \infty \frac{2}{3}$ \\
\hline 0 & 00 & $\mathbf{P}$ & $\frac{20^{1}+10^{2: 3}}{3} 00 \frac{8}{9}$ \\
\hline 0 & $\begin{array}{ll}0 & 0 \\
0 & 0\end{array}$ & I & $\frac{1.82 .8: 9}{3} \infty 0 \frac{25}{27}$ \\
\hline$\circ$ & $\begin{array}{l}\circ 0 \\
0\end{array}$ & $\mathbf{P}$ & $\frac{x .^{1}+1 . .^{25: 27}}{3} 50 \frac{79}{81}$ \\
\hline $0_{0}^{\circ}$ & $\begin{array}{l}0 \\
0\end{array}$ & 1 & $\frac{10^{1: 20}+2 .^{1: 9}}{3} \infty 0 \frac{13}{54}$ \\
\hline $\begin{array}{ll}0 & 0 \\
0 & 0 \\
\end{array}$ & $\begin{array}{l}0 \\
0\end{array}$ & $\mathbf{P}$ & $\frac{2 .^{13: 54}+1 .^{1: 27}}{3} \infty 0 \frac{14}{81}$ \\
\hline $0_{0}^{0}$ & $\begin{array}{l}0 \\
0\end{array}$ & 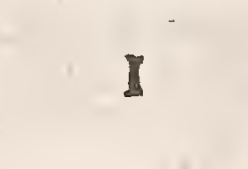 & $\frac{1.14: 81}{3}+2 .^{2: 81}-0 \frac{x}{27}$ \\
\hline
\end{tabular}




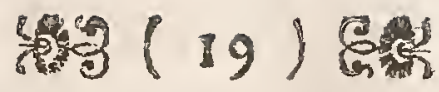

\begin{tabular}{|c|c|c|c|}
\hline \multicolumn{2}{|c|}{ Fenx qui refent } & $\begin{array}{l}\text { Somme de } \\
\text { ces jeux }\end{array}$ & Sert de $A$ : \\
\hline $\begin{array}{l}0 \\
0\end{array}$ & $\begin{array}{cc}0 & 0 \\
0\end{array}$ & I & $\frac{8: 9+2.8: 2}{3}>0 \frac{17}{27}$ \\
\hline 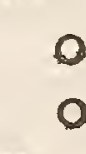 & $\begin{array}{ll}0 & 0 \\
0 & 0\end{array}$ & $\mathbf{P}$ & $\frac{2.25: 27+1 .{ }^{17}: 27}{3} \infty 0 \frac{67}{8}$ \\
\hline $\begin{array}{l}0 \\
0\end{array}$ & $\begin{array}{l}0 \\
0 \\
0\end{array}$ & I & $\frac{5.79: 81+2.67: 81}{3} \infty 0 \frac{7 \pi}{8}$ \\
\hline${ }^{\circ}$ & $\begin{array}{c}0 \\
0\end{array}$ & $\mathbf{P}$ & $2 \frac{.17: 27+1.13: 54}{3} \infty 0 \frac{\pi}{2}$ \\
\hline $\begin{array}{l}0 \\
0\end{array}$ & $\begin{array}{c}0 \\
0\end{array}$ & I & $\frac{1.1: 2+2.0^{14: 81}}{3} \infty 0 \frac{137}{486}$ \\
\hline $\begin{array}{l}0 \\
0^{\circ}\end{array}$ & 00 & $\mathbf{P}$ & $2 . \frac{137: 486+1.2: 27}{3} \infty 0 \frac{15}{72 \frac{5}{9}}$ \\
\hline 0 & $\begin{array}{ll}0 & 0 \\
0 & 0\end{array}$ & 1 & $\frac{8.67: 81+2 \cdot 1: 2}{3}-50 \frac{14}{24} \frac{8}{3}$ \\
\hline${ }^{\circ}$ & :० & $\mathbf{p}$ & $\frac{2.71: 81}{3}+x^{848: 243}-x \frac{574}{729}$ \\
\hline $\begin{array}{l}0 \\
0\end{array}$ & $\begin{array}{ll}0 & 0 \\
0 & 0\end{array}$ & $\mathbf{P}$ & 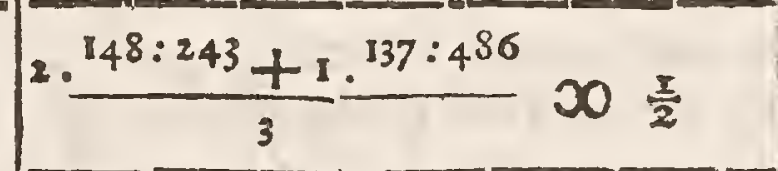 \\
\hline $0_{0}^{\circ}$ & $\begin{array}{lll}0 & 0 \\
0 & 0\end{array}$ & 1 & $\frac{1.1: 2+2.155: 729}{3}-\infty 0 \frac{1349}{4374}$ \\
\hline & \%० & I & $\frac{1.574: 729+2.0^{1: 2}}{3} \infty 0 \frac{13}{2} \frac{203}{87}$ \\
\hline & $\begin{array}{l}0 \\
0 \\
0\end{array}$ & p & $\frac{321303: 2187+1.1349: 4374}{3}$ \\
\hline
\end{tabular}




\section{$\cdot \frac{\pi}{400}(20) \frac{0}{20}$}

XII. A eft $\frac{3}{2}$ fois plus fort que $B, \& B \frac{5}{2}$ fois plus fort que $C$. Donc $A$ eft $\frac{15}{24}$ fois plus fort que $C, \&$ ainsi lui pourra donner plus de demi -45 , \& moins de 45 .

XIII. Connoiffant les raifons d'entre les forces de trois Jouëurs $A, B, C$, joüans un à un en tous fens, on connoîtra auffi le rapore de leurs forces, quand deux de ces jouëurs joiient de compagnie contre le troifiéme. Supolons, que les forces abfoluës des trois jou ẹurs foient marquées par les lettres $l, m, n$; que A jouë contre les deux autres, \& qu'il jouë indifféremment tantôt à $B$, tantôt à $C$ : Sil jouë à $B$, il a $l$ degrés de facilité de gagner le coup. \& m degrés de le perdre; ce qui luy vaut $\frac{l}{l+m}: \& s^{3}$ ill jouë à $C$, il a encore $l$ degrés d'aparence de gagner le coup, \& $n$ degrés de le perdre ; ce 'qui fait $\frac{l}{l+n}$. Donc s'il eft également pofrible, qu'il envoie $\mathrm{l}_{2}$ balle à $\mathrm{B}$ ou à $\mathrm{C}$, comme nous fupofons, il y a un cas, quiluy fait avoir $\frac{l}{l+m}$, \& un autre, qui luy fait acquerir $\frac{l}{l+n}$; ce qui luy donne par rapport à ce coup-là, $\frac{1 . l+m+1 l: l+n}{2} \infty \frac{l}{2 l+2 m^{3}}$ $+\frac{l}{2 l+2 n} \infty \frac{2 l+l m+l n}{2 l b+2 l m+2 l n+2 m n}$, tellement quil refte pourle fort des autres $B \& C, \frac{l m+l n+2 m n}{2 k+2 l m+2 l n+2 m n}$. Ainsi leurs forces étant par exemple en raifon de $3,2, \mathrm{I}$, le fort d'A eft $\frac{27}{4}$, , \& celuy des $\mathrm{B} \& \mathrm{C} \frac{13}{4}{ }^{\circ}$, c'eft à dire que A peut gagner 27 coups, lorsque les autres nen peuvent gagner que 13 ; de forte quil leur peut donner trente avec quelque avantage pour foi, comme il paroit par la cinquiéme Table. Que fi vous faites $\frac{2 l+l m+\ln }{2 l l+2 l m+2 \ln +2 m n} \infty$ $\frac{l m+l n+2 m n}{2 k+2 l m+2 l n+2 m n}$, vous aurez $l \infty 0 m n$; ce qui vous marque, que quand la force abfoluë de celui, qui jouë contre les deux autres, eft moienne proportionnelle entre les forces de ceux-cy, la Partie fe peut jouër à but.

Quand nous avançons, comme également probable, que le jouëur $A$ envoie la balle à $B$ ou à $C$, ce n' eft qu' une fupofition, \& la verité eft, que plus le jouëur eft habile, plus fouvent il envoiera la balle 
la balle au plus foible. Pour avoir égard à cela, fupolez que toutes les fois qu' il jouë $p$ balles au plus fort $B$, il en jouë un plus grand nombre $q$ au plus foible $C$ : donc il y a $p$ cas, qui luy font avoir $\frac{l}{\sqrt{-} \cdot m}, \& \&$ cas qui lay font obtenir $\frac{l}{l+n}$; ce quiluy vaut $\frac{p \cdot l: l+m+q \cdot \cdot^{l: l+n}}{p+q} \infty$ $\frac{p l}{p+q \cdot l+m}+\frac{q l}{p+q \cdot l+n} \infty \frac{p l l+q l l+q l m+p l n}{p l l+q l l+p l m+q l n+p l n+q l n+p m n+q m n}:$ où si vous interpretez les lettres $l, m, n, \operatorname{par} 3,2, \mathrm{I}$, comme auparavant, \& outre cela 8 par I, \& $q$ par 3 , vous trouverez le fort d'A à l'égard de chaque coup $\infty \frac{57}{8},{ }^{3}$ plus grand que $\frac{\overline{2} 7}{40}$ le fort qu'il a, lors qu'il envoie les balles indiféremment à chacun des autres; en forte qu'il leur peut maintenant donner presque demi-45. Si vous faites $\frac{p l l+q l l+q l m+p l n}{p l l+q^{l l}+p l m+q l m+p l n+q l n+p m n+q^{m} n} \infty \frac{x}{2}$, vous aurez $p l m-p l n+p m n-p l l \infty$ qlm - qln - $q m n+q l b$; ce qui marque, que la Partie à but fera égale, quand $p$ eft à $q$, comme $l m-l n$ $-m n+l l$ à $l m-l n+m n-l l ; \&$ il faut pour cet effet, que $m n$ Coit toujours plus grande que $\| l$.

Maîs l'on doit encore ici confidérer une chole, qui contrebalance en quelque maniére l'avantage, que tire le jouëur A de ce qu'il jouë le plus fouvant au plus foible. C'eft qu'étant feul contre deux, il fe fatigue auffi plus que chacun des autres, \& que cette fatigue femble diminuër confidérablement fa force \& fon fort: car trois perfonnes d'une égale force joilans enfemble, un contre deux, on voit bien, que felon ce calcul, la Partie devroit étre égale, au lieu qu'il eft plus probable, que les deux la gagneront contre le troifiéme, vû qu'ils ne fe laffent pas tant, \& qu'ils ne défendent chacun que la - moitié du Jeu de Paume. Pour avoir donc égard à cette diférence, il faudroit juger des forces abfoluës de nos jouëurs par le nombre des coups, qu'ils gagnent ou qu'ils perdent, non quand ils joìent chacun feul contre $A$, mais quand ils joüent conjointement contre luy: car ayant obfervé par exemple, que de tous les coups, qui fe joüint entre A \& B, le nombre de ceux que A gagne eft au nombre de ceux que gagne $B$, comme $l$ à $r ;$ \& que de tous les coups qui fe joüient 


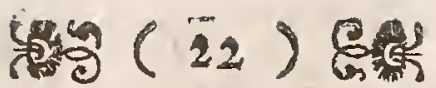

entre A \& $\mathrm{C}$, le nombre de ceux que $\mathrm{A}$ gagne eft au nombre de ceux que gagne $\mathrm{C}$, comme $l$ à $s$; il eft clair, que les forces abfollies des trois joüeurs $A, B, C$ feront alors en raifon de $l, r, s ; d^{2}$ oì leurs forts fe déduifent enfuite comme deffus, en forte qu' on n'a qu'à fubltituër fimplement les lettres $r \& s$ à la place de $m \& n$.

XIV. Connoiffant les raifons des forces de quatre jouèurs $A_{3}$ $B, C, D$, joüans un à un en tous fens, on connoîtra le raport de leurs. forces, quand ils joüent deux à deux, A \& B contre C \& D. Supofons que leurs forces abfoluës foient exprimées par $k, l, m, n ;$ il fe peut faire, que $A$ (de même que $B$ ) jouë à $C$ ou à $D$. Si $A$ jouể à $C$, il a $\frac{k}{k+m}$; \& s'il jouë à $D$, il a $\frac{k}{k+n}$ vraifemblances de ga gner le coup; ceft-ce quile fait parvenir au fort

$\frac{k: k+m+1}{2}-k: k+n=\frac{2 k k+k m+k n}{2 k k+2 k m+2 k n+2 m n}$. Par la même raifon si c'eft B qui jouë, fon fort eft $\frac{1 \cdot l: l+m}{2}+1^{l: l+n} \infty$ $\frac{2 l l+l m+l n}{2 \|+2 l m+2 l n+2 m n}$. Or il eft également polfible, que $A$ ou $B$ jouie: donc il y a un cas, quileur aporte $\frac{2 k k+k m+k n}{2 k k+2 k^{m}+2 k^{n}+2 m n}$, $\&$ un autre, qni leur donne $\frac{2 k+l m+l n}{2 u+2 l m+2 l n+2 m n}$; ce qui leur vaut $\frac{2 k k+k m+k n}{4 k k+4 k m+4 k n+4 m n}+\frac{2 l l+l m+l n}{4 k+4 m+4 l n+4 m n}$. Ainsi les for ces abfoluës des quatre jouëurs $A, B, C, D$, étant comme I, $I_{\text {a }}$ 2,3 , le fort d'A \& B par raport à chaque coup fera $\frac{32}{6} \frac{3}{2}, \&$ cee luy de C \& D $\frac{349}{67}$; fi bien que ceux - cy peuvent donner à ceux -là presque demi-quinze. Si dans les dénominateurs de ces fractions literales vous mettez $4 \mathrm{kl}$ au lieu de $4 \mathrm{~mm}$, vous aurez

$\frac{2 k k+k m+k n}{4 k k+4 k m+4 k n+4 k l}+\frac{2 l l+\ln +\ln }{4 l+4 m+4 \ln +4 k l} \infty \frac{2 k+m+n}{4 k+4 m+4 n+4 l}$ $+\frac{2 l+m+n}{4+4 n+4 n+4 k} \infty \frac{2 k+2 l+2 m+2 n}{4 k+4 l+4 n+4 n} \infty \frac{x}{2} ;$ ce qui montre, que si les forces des joitieurs d'un côté \& d'autre fe trouvent reciproquement proportionnelles, la Partie qu'ils joüent à but fera égale. Toutes fois il faut ici repeter l'avertiffement du précédent articlé, fçavoir 


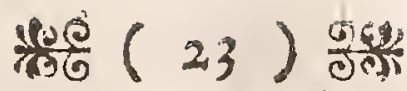

Içavoir que les habiles ioüeurs tâchent toujours d'envoier les balles au plus foible, à quoi il faut avoir égard, sil'on y veut aller bien jufte.

$X V$. Si de deux jouëurs $A \& B$ l'un peut donner à l'autre un avantage de quelques coups, \& qu' il aime mieux luy donner cet $\dot{a}$ vantage en jeux entiers qu' en points; on veut Ç̧avoir, combien de jeux il luy doit donner? Par exemple, si $\mathrm{A}$ peut donner à B 4.5, \& quil veüille joüer à but avec luy on demande, de combien de jeux il les luy peut donner tous à la referve d'un feul? Pour réfoudre cete te queftion, il faut confidérer, que I. A pouvant donner à $B$ 4i, la valeur de fa force, marquée par la lettre $n$, fera $\frac{4}{1} \frac{2}{2} \frac{1}{6} 6$ parl'art. $7^{\text {me }}$. 2. Quand il eft à but avec B, l'efpérance qu'il a de gagner le jeu eft par la $4^{\text {me Table, }} \frac{n 7+5 n^{6}+11 n 5+15 n^{4}}{n 7+5 n^{6}+11 n 5+15 n+15 n^{3}+n n n+5 n+1}$; par conféquent celle de $B$ eft

$\frac{15 n 3+11 n n+5 n+1}{n 7+5 n^{6}+11 n^{5}+15 n 4+15 n+11 n n+5 n+1} ;$ \& la raifon de leurs efpérances $\frac{n 7+5 n^{6}+11 n 5+15 n 4}{15 n^{3}+11 n n+5 n+1}$ 3. Pour expliquer cette raifon par nombres, en y fubitituant $\frac{42}{1} \frac{1}{0} 0 \frac{5}{0}$ a la place de $n$, on peut fe fervir des Logaritmes, par le moien desquels on la détermine fans peine a $7 \frac{1}{3} \frac{1}{3} \frac{5}{4} \frac{2}{6}$. Nommons cette raifon $m, \&$ cherchons fucceffivement, quel eft le fort de $\mathrm{A}$ par raport à la Partie, quand il luy manque $I, 2,3,4$ \&c.' jeux, pendant qu'à $B$ il n'en manque toujours qu'un; jufqu'à ce que nous voïons par la progreffion, quel doit étre ce fort, lors qu' il luy manque $x$ jeux. Or sil luy manque un jeu, de même qu'à $\mathrm{B}$, c'eft à dire si les deux jouieurs font à deux de jeux, il eft aisé de juger par ce que j'ay démontré dans l'art. 4 , que le fort de A eft $\frac{m m}{m m+I}$. S il luy manque deux jeüx, il eft clair quil y a $m$ cas, qui le pourront mettre à deux de jeu avec $B$ en luy faifant gagner le jeu, \& un cas qui luy fait perdre le jeu \& la Partie; ce qui luy vaut $\frac{m m: m+1+10^{0}}{m+1} \infty \frac{m 3}{m+1 \cdot m+1}$. S'il luy manque trois jeux, il $n^{2}$ eft pas moins clair, que $m$ cas luy en feront refter deux en luy faifant gagner le jeu, \& qu'un cas luy fera encore 


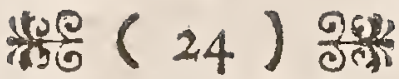

perdre la Partie; ce qui lúy produit $\frac{m .^{m}: m m+1 . m+1+10^{0}}{m+1} \infty$ mi 4

$\overline{m+1 \cdot \overline{m+1}{ }^{2}}$. Et sil luy en manque quatre, il y a $m$ cas qui luy. en feront refter trois, \& un cas qui luy fera perdre la Partie; ce qui luy aporte $\frac{m .^{m} 4: m+1 \cdot m^{2}+1^{2}}{m+1} \infty \frac{m 5}{m m+1 \cdot \overline{m+r^{3}}}$ En un mot, quel nombre de jeux qu' il luy manque, fon fort fe trouve toujours exprimé par une fraction, dans laquelle l'expofant de $m$ eft plus grand, \& celuy de $m+$ I plus petit d' une unité, que le nombre de ces jeux. D'où l' on infére, que s'il manque $x$ jeux à $A \&$ un jeus à $\mathrm{B}$, c'elt à dire s' ils joüent à $x$ jeux, dont $\mathrm{A}$ donne $x-\mathrm{I}$ d'avance à $\mathrm{B}$, le fort de A fera $\frac{m^{x+1}}{m m+1 \cdot \overline{m+1} x-1} ;$ \& parce qu' en cet état la Partie eft fuposée égale, il y.aura $\frac{m x+1}{m m+1.1}=\infty \frac{x}{2}$, c'eft a dire 2. $m^{x+1} \infty 0 m+1 . \overline{m+1}{ }^{x-1} ; \&$ en prenant les logaritmes, $L_{2}+x+1 L m \infty m m+I+\overline{x-1} L m+I$ ou par la tranfpofin tion $x L \overline{m+I}-x L m D L L+I+L m \pm L 2-L m m+I$; \& enfin par la divifion $x \infty \frac{L \overline{F_{1}}+L m+L_{2}-L m \bar{m}+1}{L m+1}$. Pour achever maintenant la folution on n'a qu' à y mettre $7 \frac{1}{1} \frac{1}{3} 4 \frac{52}{6} \frac{9}{6}$ au lieu de $m_{2}$ - '\& fon logaritme au lieu de $L m$ \&c. moiennant quoi l'on trouve que $x$ eft tant foit peu plus grand que 38 ; de forte que celuy qui peut donner à l'autre 45 pourra luy donner jufques à 37 jeux entiers dé 38 ; s'ils veulent joiier à but enfemble. D'où il paroit, qu'il y a bien de la diférence entre denner de 4 coups trois, \& donner de 4 jeux trois; vî que nous venons de voir, que celuy qui peut donner à l'autre 45 , c'eftà dire trois coups de quatre, peut bien luy donner d'avantage que trois jeux de quatre. En voici le calcul:
$m \infty \frac{7114529}{134167}$,
$m+1 \infty \frac{7348696}{124167}$
L7II 4529006.8521462 ,
L 7248696 006.8602599 .
L $134167005.1276457, \cdots \cdot . .5 .1276457$, 


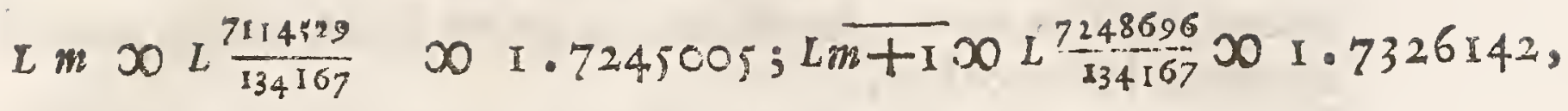
2 ,

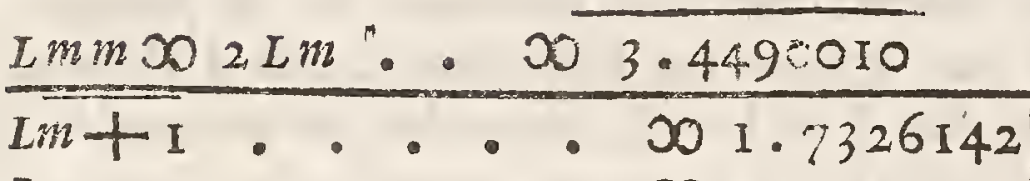

$L m$. ... .

$L_{2} \cdot \cdot \cdot \cdot .000 .3010300$

$L m+I+L m+L_{2} \cdot \infty 3 \cdot 7581447$

$L m+1$. - . . $003: 4491555$

$L m+1+L m+L 2-L m m+I 000.3089892$ $2 m m+I$ s 3.4491555 .

$L \overline{m+1}-L m$. . $\infty 00.008$ II37

$81137) 3089892(3800 x$ $\frac{243411}{655782}$ 649096 6686

XVI. Le Jotieur A pouvant donner à B 45 , l'on demande de combien de jeux illes luy peut donner tous à la referve d'un feul, si outre les jeux entiers qu' il luy donne, il luy veut encore donner I $_{5}$ ou 30 à chaque jeu? Pour fatisfaire à la queftion, vous n' avez qu'à mettre $\frac{n 7+5 n^{6}+11 n 5+5 n}{10 n 4+15 n 3+11 n n+5 n+1}$ \& puis $\frac{n 6+4 n 5+n 4}{6 n^{4}+8 n^{3}+7 n n+4 n+1}$ (raifons des efpérances, qu'on leur trouve par la $4^{\text {me }}$ Table, lorsque B a I 5 ou 30 à rien) à la place de $\frac{n 7+5 n^{6}+11 n 5+15 n^{4}}{15 n+11 n n+5 n+1}$ (raifon des efpérances qu'ils obtiennent quand ils joüent à but), en y interprétant encore $n$ par $4 \frac{215}{10} \frac{5}{0}$ : ce qui vous fera trouver $m \infty \frac{6798590}{4}, 8$ puis $m \infty \frac{1125963}{26} 3 \frac{63}{4}$; d'où le refte fe déduit comme deffus, \& il proviendra à peu prés $x x_{12}, \&$ enfuite $x x_{4}$; de forte que $A$ peut donner à B I I jeux de I 2 , \& encore 15 points en chaque jeu; ou' bien 3 jeux de $4 \&$ encore 30 points en chacun.

XVII. Si A peut donner à B 30, \& qu'on demande combien de jeux entiers il luy peut donner; il faut feulement changer la valeur de $n$, qui marque fa force, en $\frac{1}{2} \frac{4}{2} 50$ par l'art. $7^{m c}$, \& faire enfuite comme deflus, pour trouver celle de $x$. Le calcul nous aprend, qu'il peut luy donner environ de cing jeux quatre, \& joüer à but ; ou deux jeux de trois, \& encore Is points en chaque jeu. Si A ne peut don-

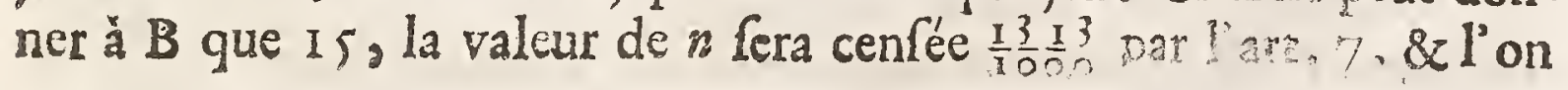




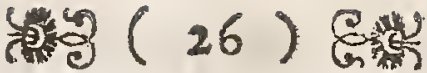

trourvera qu' il ne fauroit luy donner qu' un jeu de deux, s'il prétend de joïer à but avec luy.

XVIII. On peut former plufieurs queftions fur les Bifques, qui font des coups d'avance donnés par l'une des parties à l'autre, qui en profite quand bon luy femble; \& demander par exemple: si dans un cas donné il eft plus avantageux de prendre fa bifque, out de ne la pas prendre? si deux bifques en quatre jeux valent mieux que demi - quinze: ou quinze \& deux bifques mieux que demi-trente? \& autres femblables. Mais comme ces queftions nous meneroient trop loin, je ne veux pas les toutes entreprendre: je me contenterai feulement de m'arréter un peu fur la prémiére. Supofons, que les joueiirs ne jouënt qu'à un jeu: que la force de $\mathrm{A}$ foit à celle de $B$ en raifon d'égalité ou d'inégalité quelconque, $n$ à $I: \&$ que $B$ donne à $\mathrm{A}$ bifque ( car bien que cela ne fe pratique pas, quand on fçait que les joüeurs font égaux: il arrive fouvant, que $B$ ne connoit pas les forces d'A, celuy-cy ayant diffimulé auparavant fon jeu; ou que A la demande par opiniâtreté, ou parce qu'il a perdu le jeu précédent qu' il jouoit à but, quoy qu' on fache d'ailleurs qu' ils font égaux) puis fupofons, qu'ils foient à deux \& que $A$ n'ait pas encore pris fa bifque; l'on demande, quelle eft fon efperrnce de gagner le jeu? \& s'il fait mieux de prendre fa bifque, ou de la garder plus long temps? Sur quoi je fais ce raifonnement: $S^{3}$ il prend fa bifque, il gagne l'avantage, mais il n'aura plus de bifque: par conféquent fon fort fera par la Table IV $\frac{n^{3}+n n+n}{n^{3}+n n+n+1}$; s'il ne prend pas fa bifque, il fe psut faire qu' il gagne ou perde le coup prochain: s. il le gagne, il a gagné le jeu; car ayant l'avantage il ne manquera pas de prendre aprés fa bifque: mais s'il perd le coup, il aurabien encore fa bifque, mais B aura l'avantage; \& puisque le fort d" $\mathrm{A}$ en cette rencontre à caufe de la bifque $m^{\prime}$ eft encore inconnu, jel' apelley. Yayant donc par l'hipotêre $n$ cas qui luy font gagner le coup, \& un cas qui le luy fait perdre le fort qu'il obtient quand il ne prend pas la bifque fera $\frac{n^{1}+1 . y}{n+1} \infty \frac{n+y}{n+1}$. Or, par le privilége des bifques, A eft également en pouvøir de prendre fa bifque ou de ne la pas 


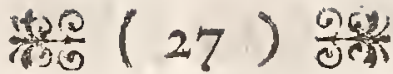

Ix pas prendre; $c$ eft à dire, il peut également acquerir $\frac{n 3+n n+n}{n^{3}+n n+n+1}$ ou $\frac{n+y}{t+1}$ : ceft pourquoi si le fort, qui luy convient pendant cette indifference, eft apellé $x$, il y aura $x \infty \frac{n^{3}+n n+n}{2 n^{3}+2 n n+2 n+2}+\frac{n+y}{2 n+2}$. Pour chercher le fort $y$, il faut faire un femblable raifonnement: Si A prend a bifque, il remet le jeu à deux, \& n'aura plus de bifque $;$ c'eft-ce quiluy donne parla Table IV $\frac{n n}{n n+1}$. S'il ne prend pas la bifque, \& qu'il gagne le coup, il gagne le fort $x$ (parce qu'il fera à deux, \& aura encore fa bifque); mais s'il le perd il perd enfemble le jeu; c'eft ce qui luy vaut alors $\frac{n^{x}+10^{0}}{n+1} \infty \frac{n x}{n+1}$. Or A eft également en droit de prendre $f_{a}$ bifque ou de ne la pas prendre, $c$ ' eft à dire d'acquerir $\frac{n n}{n n+1}$ ou ${ }_{n+1}^{n x} ; c^{3}$ eft pourquoi fon fort pendant cette indiférence, que nous apellons $y_{2}$ fera $\frac{n n}{2 n n+2}+\frac{n x}{2 n+2}$. Mettant donc cette valeur de $y$ dans l'équation $x x_{2 n} \frac{n 3+n n+n}{+n n+2 n+2}+\frac{n+y}{2 n+2}$, nous trouverons $x \rightarrow \frac{4 n^{4}+7 n 3+7 n n+4 n}{4 n^{4}+7 n^{3}+8 n n+7 n+4} \infty$ $\frac{n+1.4 n 3+3 n n+4 n}{n n+1.4 n+7 n+4}$; \& puis fubftituant reciproquement cellecy nous aurons $y\left(\frac{n n}{2 n n+2}+\frac{n x}{2 n+2}\right) \infty \frac{n n \cdot 4 n n+5 n+4}{n n+1.4 n+7 n+4}$. Ainsi le jeu étant à deux, il le préentent trois quantitez, $\frac{n 3+n n+n}{n 3+n+n+1}\left(\frac{n 3+n n+n}{n n+1 \cdot n+1}\right), \frac{n+y}{n+1} \& \frac{n+1.4 n 3+3 n n+4 n}{n n+1.4 n+7 n+4}$, qui marquent le fort de A dans trois differentes hipotêfes: l'une, quand il prend fa bifque: l'autre, quand il ne la prend pas: \& la troifiéme (qui doit étre moienne entre les deux autres), quand il eft encore dans l' indiférence de la prendie ou de ne la prendre pas. Et parce que la prémiére aprés la reduction à un ménie dénominateur fe trouve plus grande que la troifiéme, il s'enfuit qu' à plus forte rai- 


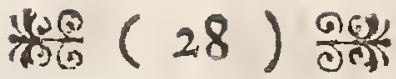

fon elle fera plus grande que la feconde, \& que par conféquent A fait mieux de prendre fa bifque, que de la garder pour une autre fois. Si l'on examine ces trois autres quantitez $\frac{n n}{n n+1}, \frac{n x}{n+1}, 8$ $\frac{n n \cdot 4 n n+3 n+4}{n n+1 \cdot 4 n n+7 n+4}$, que nous avons trouvées par la même opéra. tion, \& qui marquent le fort de A dans les dites hipotêfes, quand B a l'avantage, ou (ce qui eft autant) quand il a 45 à 30 , l'on peut remarquer, que la prémiére eft auffi plus grande que les deux autres; de forte qu' en cet état A fait encore mieux de prendre fa bifque.

Vous trouverez enfin avec ces raifonnemens les forts du jouëur $A$, pour toutes les autres conftitutions du jeu, lorsque $B$ a 45 à 15 , ou 45 aे rien, ou 30 à I 5 \& c. \& më̀me avec moins de peine, fi vous $y$ allez par ordre; car vous ne rencontrerez plus dans vôtre opération que des forts déja trouvés \& connus. Je me contente de vous les donner pour des joüeurs égaux dans les trois colonnes marquées 1. II. III. de la Table feptiéme : la prémiére confidéie le jout eur $A$, comme prenant fa bifque; la troifiéme, comme ne la prenant pas; \& celle du milieu, comme ne s'étant pas encore déterminé s'il la prendra ou non: \& l'on remarque par tout, que les fractions de la prémiére colonne font un peu plus grandes que celles des autres; d'où l'on peut généralement conclure, qu'il eft toujours plut avantageux pour $\mathbf{A}$ de prendre d'abord fa bifque, que de la garder plus long temps.

XIX. Le calcul du précédent article fupofe le joüieur $\mathrm{A}$ dans une parfaite indiférence au regard de $\mathrm{fa}$ bifque, qui luy donne toujours un panchant égal de la prendre ou de ne la prendre pas: cepenpendant il faut remarquer, que quoi qu il foit ég 1 lement en pouvoir de la prendre à chaque coup, il ñ eft pas toujours également probable qu'il la prenne; $y$ ayant des endroits, où il peut la faire mieux valoir qu' en d' autres; fi ce n' eft peut-étre quand on joile fans faire des chalfes, auquel cas je ne vois aucune raifon, pourquoi il faudroir diférer la bifque d'un feul coup: mais faifant des chaffes, il y a des rencontres, ou on la peut emploier si utilement, qu' elle fert prefque 


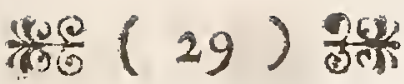 \\ Table VII.}

NB. A \& B font des joüieurs égaux:

A a une bifque à prendre.

\begin{tabular}{|c|c|c|c|c|c|c|c|c|c|c|c|}
\hline \multicolumn{2}{|c|}{ Points de } & \multicolumn{3}{|c|}{ Sorts de A } & \multirow{2}{*}{$\begin{array}{c}\text { col. } \\
\text { de } \\
\text { chalf. }\end{array}$} & \multicolumn{2}{|c|}{ Points de } & \multicolumn{3}{|c|}{ Sorts de $A$} & \multirow{2}{*}{$\begin{array}{c}\text { colo } \\
\text { des } \\
\text { chafs. }\end{array}$} \\
\hline A & B & I. & II. & III. & & A & B & I. & II. & | III. & \\
\hline \multirow{4}{*}{$\begin{array}{r}45 \\
30 \\
15 \\
0\end{array}$} & 45 & $\frac{3}{4}$ & $\frac{1}{7} \frac{1}{5}$ & $\frac{43}{65}$ & $\frac{11}{1} \frac{9}{2}$ & 30 & 15 & $\frac{1}{8}$ & $\frac{2}{3}=\frac{9}{4}$ & $\frac{1}{5}$ & $\frac{17}{5}$ \\
\hline & 45 & $\frac{i}{2}$ & $\frac{1}{30}$ & $\frac{1}{3} \frac{1}{0}$ & $\frac{\pi 5}{7}$ & 15 & IS & $\frac{1}{1} \frac{1}{6}$ & $\frac{21}{3} \frac{1}{20}$ & $\frac{1}{1} \frac{09}{6}$ & $\frac{47}{44}$ \\
\hline & 45 & $\frac{1}{4}$ & $\begin{array}{l}7 \\
35 \\
35\end{array}$ & $\frac{1}{6} \frac{3}{7}$ & 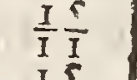 & 0 & Is & $\frac{x}{2}$ & $\frac{3}{64} \frac{3}{0}$ & $\frac{x y 9}{325}$ & $\frac{61}{5} \frac{1}{9}$ \\
\hline & 45 & 3 & $\frac{2}{240}$ & $5 \frac{1}{6}$ & $\frac{1}{1} \frac{2}{3}$ & \multirow{2}{*}{30} & \multirow[t]{2}{*}{0} & \multirow{2}{*}{$\begin{array}{l}\frac{15}{16} \\
13\end{array}$} & \multirow{2}{*}{$\begin{array}{l}\frac{899}{960} \\
779\end{array}$} & \multirow{3}{*}{$\begin{array}{l}449 \\
480 \\
3 \frac{89}{480} \\
503 \\
\end{array}$} & \multirow{3}{*}{$\begin{array}{l}\frac{16}{15} \\
\frac{1}{1} \frac{23}{1} \frac{3}{9} \\
\frac{30}{2} \frac{3}{98}\end{array}$} \\
\hline & 30 & $\frac{1}{4}$ & $\frac{1}{1} \frac{1}{5}$ & $\frac{43}{65}$ & $\frac{1}{1} \frac{9}{5}$ & & & & & & \\
\hline & $\begin{array}{l}30 \\
30\end{array}$ & $\frac{1}{2}$ & $\begin{array}{l}\frac{5}{2} \frac{2}{2} \\
-92\end{array}$ & $\begin{array}{r}29 \\
60 \\
-49 \\
-49\end{array}$ & $\begin{array}{r}\frac{8}{7} \\
4 \frac{5}{5}\end{array}$ & 0 & 0 & $\frac{21}{32}$ & $\frac{1007}{15} \frac{7}{6}$ & & \\
\hline
\end{tabular}

prefque de trente; car $\mathrm{y}$ ayant une chaffe dificile à gagner pour $\mathbf{A}$, elle eft autant que perduë pour luy; prenant donc fa bifque, il empéche non fulement fa Partie de gagner I 5 , mais il les gagne luymême, ce qui luy vaut 30. Comme donc la détermination dù forr des joiieurs, qui demande la confidération des bifques, dépend de la conftitution particuliére du jeu, de la diverfité des chafles, \& mêtme du caprice des joüeurs, qui $n^{3}$ obfervent point de regles, il eft dificile d'en former des conjectures bien fûres. Voici pourtant la maniére, dont je voudrois $\mathrm{m}^{3} \mathrm{y}$ prendre, $s^{3}$ il falloit encore avoir égard aux chaffes: Posé que les joutieurs foient trentains ou à deux, \& quil y ait une chaffe plus dificile à gagner à l' un qu'à l'autre (le nombre des fois, qưon en a vî gagner une femblable au joüeur $\mathbf{A}$, étant au nombre des fois, qu' on en a vî gagner à $B$, en raifon d' inégalïté quelconque de $m$ à I) bien que les deux jotieurs foient d'ailleurs égaux; je confidére, que si le joüeur A gagne la chaffe fans prendre fa bifque, il gagne le jeu, car il ne manquera pas dela prendre aprés: $\&$ s il perd la chaffe, B aura l'avantage, mais $\mathrm{A}$ retiendra fa bifque, qui luy vaut, par la IIme colonne de la VIIme Table, $\frac{13}{30}$. Parce donc que par $l^{\prime}$ hipotêfe ce joüeur a $m$ degrez de facilité de gagner la chafle contre un degré de la perdre, le fort, qu'il pofféde quand il 
ne prend pas fa bifque, fera $\frac{m{ }^{I}+1 .{ }^{13: 30}}{m+1} \infty \frac{30 m+13}{30 m+30}$. Mais si au contraire il prend cette bifque, la chaffe eft morte, \& fon fort fe srouve, par la I. colonne de la dite Table, $\frac{3}{4}$. Je n'ay donc qu'à chercher, laquelle des deux fractions, ou de $\frac{30 m+13}{3-m+30}$ où de $\frac{3}{4}$, furpafie l'autre; en faifant fur elles les mênes opérations, que $s^{\circ}$ il y a. voir égalité entre elles; jufqu'a ce que $m$ demeure feule d'un côté: moiennant quoi je trouve, que le joiieur A fait mieux tantôt de garder, tantôt de prendre $\Upsilon_{a}$ birque, fuivant que $m$ eft plus grande ou plus petite que $\frac{1}{1} \frac{2}{5} ; \&$ qu'il luy doit étre indiférent de la prendre ou de la garder, si $m$ eft au jufte $x \frac{12}{5}$. Posé de nouveau, que $\mathbf{A}$ ait 30 à 45 , ou que B ait l'avantage, \& qu'il y ait la même chaffe; il eft clair, que si A la gagne fans prendre $f a$ bifque, il fera à deux, par conséquent par la II. col. de la VIIme Table il aura $\frac{I}{1} \frac{1}{5}$ : mais que s'il perd la chaffe, il perdra le jeu. . Ayant donc in cas de lagagner $\&$ un cas de la perdre, il aura (quand il ne prend pas fa bifque) $\frac{m .^{11: 15}+10^{\circ}}{m+1} \infty \frac{11 m}{15 m+15^{\circ}}$. Si A veut au contraire prendre la bif que, le jeu fe met à deux, \& la chaffe étant morte le fort de chacun

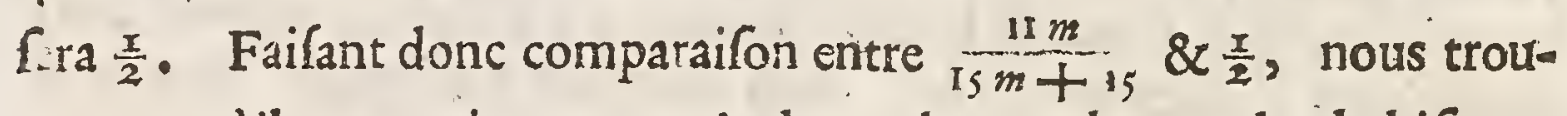
vons, qu' il vaut mieux pour $\mathrm{A}$ de garder ou de prendre la bifque, felon que $m$ eft plus grande ou plus petite que $\frac{15}{7}$. \& que l' un vaut autant que l'autre, si $m \infty \frac{15}{7}$. De ce que je viers de faire voir, nous pouvons encore conclure, que la facilité, qu'a le jotieur A de gagner une chaffe, étant exprimée par un nombre compris entre $\frac{12}{15} \&$ $\frac{15}{7}$, il fera mieux de garder fa bifque, si le jeu eft a deux; mais que si B a l'avantage, il feroit mieux de la prendre. Enfin c' eft de cette maniére, que j' ay determiné tous les autres nombres de la colonne des chaffes de la VIIme Table, qui nous peuvent marquer, quand le joüeur A doit prendre ou garder fa bifque: car s'il a plus de facilité de gagner quelque chaffe, qu'il n’eft porté par ces nombres, il fait mieux de grder la bifque; s'il en a moins, il fait mieux de la prendre; \& s il en a tout jufte autant, il peut faire fans préjudice ce qu'il veut. 


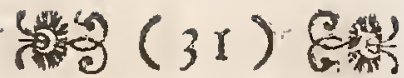

XX. Il me refte encore à parler des fervices, \& de l'avantage qu il y 2 de les donner. Vous fçavez, que le prémier coup de chaque bale, qu' on donne fur le toit, s'apelle fervice. Celuy quile donne femble avoir quelque avantage par deffus celuy qui le reçoit, pour deux raifons: l'une, parce que le coup de fervice eft un coup feur, qui fe donne la bale à la main; au lieu quie les coups qui fe joüent enfuite la bale en l'air font fujets d'étre manqués: l'autre, parce que quand celuy qui fert manque quelque bale, $c^{\prime}$ eft une chaffe, au lieu que quand lautre la manque, il perd toujours quinze (du moins si la bale entre dans le jeu; car pour les chaffes de vers le jeu, je n'en veux pas parler, de peur de me trop étendre, \& il me fufit de vous marquer en gros la route, qu il faut tenir dans cette recherche.) Pofons qu'il y ait deux jouieurs $\mathrm{A} \& \mathrm{~B}$, que $\mathrm{A}$ donne le fervice, que contre un coup qu'il a manqué, on air, obfervé quil ait fait $p$ bons coups; \& que contre un coup qu'a manqué $B$, on luy en ait vâ faire $q$ de bons: polons encore que dans le temps que c' eft à $\mathrm{A}$ de joüer, fon efpérance de gagner la bale foit $y$, mais que cette efpérance devienne $z$, quand l'autre B doit joïer; \& confidérons prémiérement ce qui feroir de ces elpérances, fil'on joïoit fans faire des chaffes, c'eft à dire fi la bale qu' on manque étoit toujours perduë pour celuy qui la devroit joüer. Or par ce que nous venons d'établir il eft aisé de voir, que fi A doit joiier, il y a un cas, qui luy fera perdre la bale, \&x cas qui luy faifant reiifir fon coup mettront $B$ dans la neceffité de joiier, \& changeront ainsi le fort $y$ da joüeur $\mathrm{A}$ en celuy de $z$. Si c'eft au contraire $B$ qui joüe à fon tour, il y a un cas qui fera gagner la bale à $A$ (en la faifant perdre à B ) \& $q$ cas qui remettront le joiieur $\mathrm{A}$ dans la neceflité de joüer, \& luy rameneront le fort $y$. Donc nous aurons d'un côté $y \infty \frac{\mathrm{I}^{\circ}+p .{ }^{2}}{1+p} \infty \frac{p z}{\mathrm{I}+p}$; de l'aưre $z$ $\infty \frac{\mathrm{r}^{1}+q^{y}}{1+q} \infty \frac{1+q y}{1+q}, c^{\prime}$ eft à dire, mettant à la place de $y$ fa váleur trouvée $\frac{p z}{1+p}, z \infty \frac{x+p+p q z}{1+p \cdot I+q} \infty \frac{1+p+p q z}{1+p+q+p q}$ d'où l'on tire $z \infty \frac{1+p}{1+p+q}$. Or parce que le joïeur $\mathrm{A}$ ne fauroit manquer 


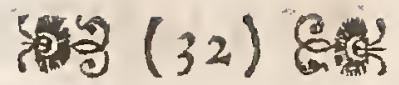

fon coup de fervice, il $s^{3}$ enfuit qu il ne faut pas conter ce coup, \& s'imaginer quand il le jouë, comme si c'étoit à $B$ de jouër : donc l'érpérance $q u{ }^{\prime}$ il a de gagner la bale fera censée alors $\frac{1+p}{1+p+q}$ par conféquent celle de $B \frac{q}{i+p+q}$, \& la raifon de ces efpérances $I+p$ à $q$. D'où il paroit, que fi les deux jouëurs font égaux, \& que chacun puiffe fraper par ex. dix bons coups contre un qui ne vaut rien, les lettres $p$ $\& q$ valant chacune $10, l^{2}$ avantage de celuy qui donne le fervice fur celuy qui le reçoit eft comme de II fur 10 ; mais que cet avantage augmente à mefure que les joüeurs font plus foibles, \& quil diminuë jufques à s'anéantir entiérement, à mefure qu' ils fe trouvent plus habiles.

XXI. Joignons y maintenant la confidération des chaffes, mais fans nous embaraffer de leur inégalité, en nous imaginant, comme si elles étoient toutes deffous la corde; c'elt à dire, comne si toutes les bales qui paffent la corde, pouvoient les gagner. Vous fçavez que quand il y a chaffe, les joiieurs font un échange de leurs places, \& pafflant chacun de l'autre côté du jeu, celuy qui a donné les fervices, eft obligé de les prendre aprés. Que ces quatre lettres $v$, $x, y, z$, marquent donc l'elpérance d'A en quatre diférens états; f̧̧avoir, les deux prémiéres $v \& x$, avant gu' il y ait chaffe; les autres $y \& z$ aprés la chaffe, quand les joüeurs ont pafsé: la prémiére $v \& z$ troifiéme $y$, quand c'eft à A de joiier; \& la feconde $x \& 4^{\mathrm{me}} z$, quand lautre B doit joüer. Cela posé, \& le raifonnement du précédent article compris, vous comprendrez auffi fans peine la raifon des quatre égalitez fuivantes, fans qu' il foir befoin d' alonger d'avantage ce

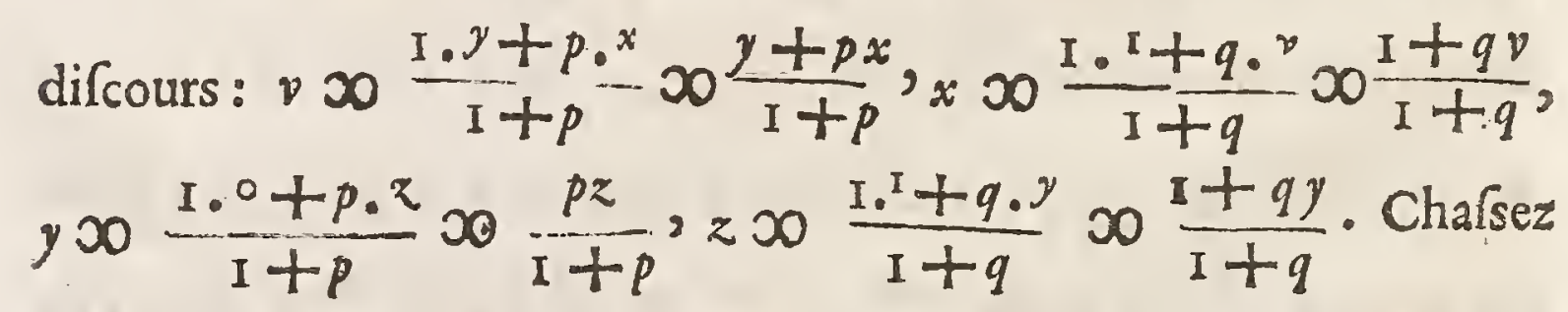
de l'égalité $x$ la lettre $v, \&$ de l'égalité $y$ la lettre $z$, vous aurez $x>0$ $\frac{1+p+q y+p q x}{\mathrm{I}+p \cdot \mathrm{I}+q}, c^{\prime}$ eft à dire $x>\frac{\mathrm{I}+p+q y}{\mathrm{I}+p+q} ; \& y \infty$ $\frac{p+p q y}{x+p \cdot x+q}$ 


\section{tos $(33) \frac{9 g}{20}$}

$\frac{p+p q y}{1+p .1+q}$, c'eftà dire y $x \frac{p}{1+p+q}$. Chaflés encore y de la nouvelle égalité $x$, vous trouverés enfin $x \infty \frac{1+2 p+q+p p+2 p q}{1+p+q^{2}}$ \& fon refé à l'unité $I-x \infty \frac{q+q q}{1+p+q^{2}}$. Doù il faut conclurre, que l'efpérance $d^{\prime} A$, dans le temps que $B$ doir recevoir de luy le coup de fervice, eft à celle de $B$ en raifon de $I+2 p+q+p p$ $+2 p q a ̈ q+q q$; ò vous pouvés remarquer, que $p \& q$ étant égales plus on augmente leur valeur, plus cette raifon approche de la triple, de forte que de deux jouëurs, qui jouënt également $\&$ parfaitement bien, celuy qui fert a environ trois fois plus d'efpérance de gagner la bale, que l'autre: mais fouvenés vous, que c'eft dans la fuppofition, quion ne faffe point de diftinction entre les chaffes, \& qu'on n'admette pas celles, qu'on apelle de vers le jeu; car autrement ce double regard diminâroit fon avantage de beaucoup.

XXII. Je ne dois pas finir ma Lettre, Monfieur, fans avoir prévenu certains faux raifonnemens, qui pourroient tomber dans l'efprit fur cette matiére, de peur qu'ils n'éblouiffent par leur éclat trompeur, \& ne faffent douter de la folidité des principes cy - deffus établis. Dans l'article feptiéme on a demandé, combien de fois le jouëur A devoit étre plus fort que $B$, pour luy pouvoir donner 45 ? Quelqu'un auroit pt̂ raifonner là-deflus ainfi: Si B joüioit contre un troifiéme jouëur $\mathrm{C}$ de pareille force que luy, \& quils fuffent 45 à $O$, leurs forts feroient par la I Table en raifon de IS à I, c'eft à dire que B pourroit gagner le jeu Is fois, lorsque $\mathrm{C}$ ne le feroit qu'une fois. Or A donnant 45 à B la Partie eft fuppofée égale, $c^{\prime}$ eft à dire telle, que quand $B$ gagne $I 5$ fois le jeu $A$ le peut auffi I 5 fois. Donc A \& C joüians enfemble à but, A le peut gagner Is fois, là où $C$ ne le peut gagner gu' une fois; \& par conséquent A doit étre 15 fois plus fort que $C$, ou (ce qui eft autant) que $B_{2}$ qui eft d'une même force: au lieu que par nôtre analy fe nous avons trouvé, qu'il ne devroit étre que $4 \frac{r}{5}$ fois plus fort que luy. A quoi je répond, que quand ce raifonnement feroit auffi evîdenc 


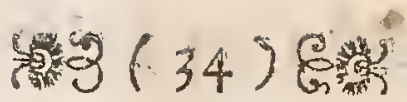

qu' il ne l'eft pas, il tire mal de la conclufion ce confectaire qui eft faux: Par conféquent A doit étre \&rc. A, qui peut domner 45 à $\mathrm{B}$, peut gagher Is jeux contre un, s'il jơuë à but avec liy, je l'accora de, car il en peut bien gagner $\frac{7114529}{134176} c^{3}$ eft à dire plus de 50 , par le $I_{5}^{\text {me }}$ art. mais il ne s'en furt pas de là, qu' il foir I 5 fois plus fort, fe pouvant faire qu'il gagne Is jeux, ou mếme 50 jeux, si vous voulés, contre un, fans quil ait gagné plus que 4 ou 5 fois plus de coups; à cauk que tous les coups, que gagne $\mathrm{B}$ durant chaque jeut qu'il perd, ne font contés pour rien, lesquels pourtant affemblés feroient peut - étre la quatriéme Partie des coups d’A. Remarquéz donc, qu'il vaut mieux, mefurer les forces des jouëurs par le nombre des coups que chacun gagne, que par celuy des jeux ou des Parties quils font, quand ils jouënt à but.

Dans l'arcicle treiziéme l'on à recherché, de combien $\mathrm{A}$ de voit étre censé plus fort, $s$ il joiloit contre deux autres B \& C, poe sé que leurs forces abfoluës fuffent en raifon de 3.2 . I ? Il y auroit bien des gens, qui pour répondre à cette queftion fe ferviroient de l'analogie tirée du mélunge des chofes: S'il y avoit par ex. trois fortes de vin, dont le prix fuffent en vaifon de $3 \cdot 2.1$, il eft certain, qu'ayant mélé les deux plus petits enfemble en égale quantité, le prix du mélé fera de $I \frac{x}{2}$, \& par conséquent le prix du meilleur à celuy de l' autre, comme 3 à I $\frac{x}{2}$, ou comme 2 à $\mathrm{I}$. Tout de même, dis-je, pourroientils penfer, que les deux jouëurs $B$ \& $\mathbb{C}$ qui jouent de compagnie contre le troifiéme $A$, ne paffant que pour un jouëur, leur jeu fe mélant quasi, \& qu'ainsi la force de A doit aufi étre double de celle des doux autres prix enfemble. D' autres raifonneroient peut-étre comme cela: Puis que par l' hipotêfe A gà gne trois coups, là où B n’en gagne que deux, \& qu' il en gagne encore trois, là où C n' en fait qu'un; il s'enfuit, qu'il doit gagnes, fix coups, lorsque les deux autres enfemble n'en font que $3+i$. Do $3 ;$ \& \& que par conséquent fa force doit encore furpaffer au double celle des autres, comme nous avons conclu par le prémier dif. cours: Or cela eft contraire au calcul du 13 me article, qui nous a Eair troumer le fort de A plus que le double de celuy des autres. Je 


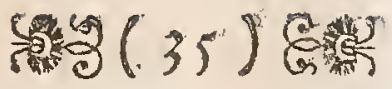

Fuis répondre êr peu de mots à ce deux raifonnemens: Pour lé prémier, vous fçavés, que les analogies ne prouvent rien; \& poutr l'autre, fon paralogifme paroit, en ce qu'on doit raifonablement fuppofer, que $\mathrm{A}$ jouë autant de fois ou plus fouvent au plus foible C qu'a B. \& que fuivant ce raifonnement il s' en fait tout le contraire; parce que A jouëroit a B cinq coups, dont il gagneroit trois; \& à il ne jouëroit que quatre coups, dont il gagneroit encore trois: au lieu que nôtre calcul remplic parfaitement cette condition; car mettéz que $\mathrm{A}$ jouë 20 coup̀s à $\mathrm{B}$, il en doir gagner $12: s^{\prime}$ il en jouê donc autant à $\mathrm{C}$, il en doit gagner 15 ; ce qui fair en tout $27, \& \mathrm{~B}$ \& $\mathrm{C}$ gagnent les autres $13:$ mais s'il jouë trois fois autant, $c^{\prime}$ eft à dire 60 coups, à $C$, il en doit gagner 45 , lef́quels joints au I 2 , quill gagne fur $B$, font 77 , 8 il refte pour $B$ \& $C$ les autres 2,3 ; ce quí eft. tout à fait conforme à ce que porte le calcul du $I 3^{\text {nte }}$ article.

Je finis, Monfieur, par cette reflexion: c'eft qu'il eft extrémement facile de fe méprendre dans toutes fes connoiffances, si l' on $\mathrm{n}^{3}$ y fait pas toujours une ferieufe attention: car les raifonnemens, qu'on fait communément dans le monde, ne font pas meilleurs, que ceux que je viens de rapporter, mais fouvant beaucoup pires: l'on voit tous le jours, que le plus fçavans raifonment fur de pures analogies; où s'ils s'imaginent de voir clair dans les chofes, ils prennent pour trés - évident ce qui ne l'eft pas. \& dont il n'y a que ceux à qui l'úage des Mathematiques a éclairé l'efprit, qui foient capar bles d'en découvrix l'impolture. Je fuis \&C.

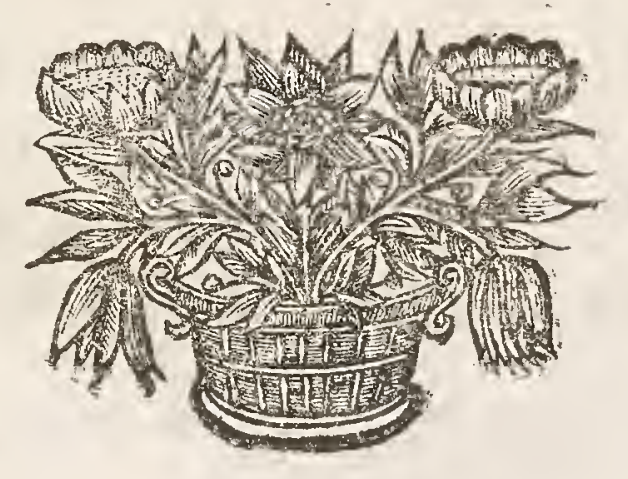




\section{E R R A $T$.}

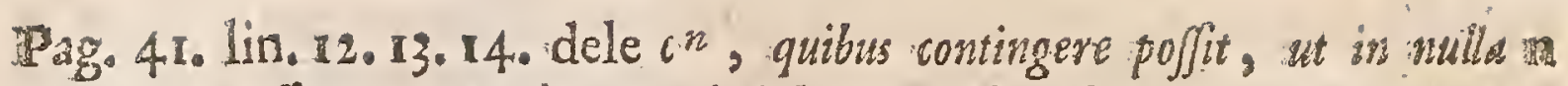
tefferarum prodeat quod fufceptume eft; os fimili modo colliginut cuffis effe

Pag. 70. lin. 24. in fin. pro in 1. $2 n_{0}$

Pag. 71. lin.9. pro $6 n \mathrm{~cm} 1.6 \mathrm{ncm}$

Pag. 84. lin. pen. pro erit $2^{n}$ I 1 e erit $2^{\text {s }}-1$.

Pag. 92. lin. 2. poft conflat adde Lemma propofitum.

Pag. 93. lin. 140 ab initio pro $\frac{b+a}{10} \frac{b+a}{r}$

\& in fin. pro ${ }^{n q-p-p-b-i-b--g}$ lege $\frac{n q}{r} \frac{-p-b-i-b-s}{r}$

Pag. 95. in fin. lin. 4. \& init. lin. 5. lege $\frac{n \cdot n-1 . n-2 . n-3}{1.2 .3 .4}$, fic ese tiam in fine lin. 1 . \& init. lin. I2.

$$
\text { lege } \frac{n-1 \cdot n-2 \cdot n-3 \cdot n-4 \ldots \ldots \cdot n-c+1}{n \cdot 2 \cdot 3 \cdot 4 \cdot \ldots \cdot c-1}
$$

Pag. 106. lin. 28. pro $\frac{n \cdot 2 \cdot n-3 \cdot n-4 \ldots n-c}{1.2 \cdot 3 \cdot 4 \cdots \cdot c-1}$

$$
\text { lege } \frac{n-2 \cdot n-3 \cdot n-4 \ldots n-c}{1 \cdot 2 \cdot 3 \cdot 4 \cdot \ldots \cdot c-3}
$$

Pag. 142. Iin. 27. pro $\frac{\mathrm{r.2} \cdot 4}{1.3 \cdot 5} 1 \frac{\mathrm{x.2} \cdot 4}{3.3 \cdot 5}$

Pag. 143. lin.6. pro $\frac{x \cdot 2 \cdot 4 \cdot 4 \cdot 16}{2 \cdot 3 \cdot 5 \cdot 9 \cdot 17} 1 . \frac{1.2 \cdot 4 \cdot 8 \cdot 16}{2 \cdot 3 \cdot 5 \cdot 9 \cdot 17}$

Pag. 150. lin. 21. pro extra hanc 1. extrahanto

Pag. 178. lin. x. pro $\frac{2}{969} 1 . \frac{20}{969}$.

Pag. 198. in medio pro $2 n-3^{t} 18.1 .2 n-3: 18$.

Pag. 203. lin. 5. pro $\frac{a}{b}-\frac{a}{b}-n \frac{c^{n}}{a^{n}} 1_{0} \frac{a}{b}-\frac{a}{b}-n \frac{c^{n}}{a^{n}}$

Ead. pag. lin. ult. pro $\frac{b^{m \cdot I}+c 0^{-1}}{a} 1 . \frac{b^{m-1}+c .-1}{a}$.

\section{Lettre fur les Parties du Feu de Paume.}

Pag. 8. lin. 4. pro $\frac{n 3}{n 3+n n+n+n+1}$ 1. $\frac{n 3}{n 3+n+n+1}$.

Pag. 24. lin. pen, pro $m+120 \frac{7348696}{124167} 1 . m+1 \infty \frac{7248696}{334167}$ 


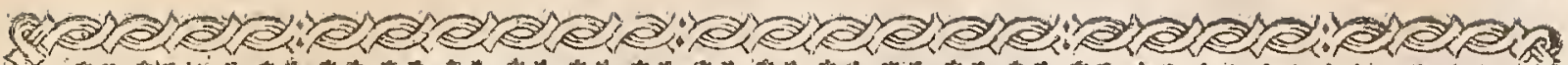

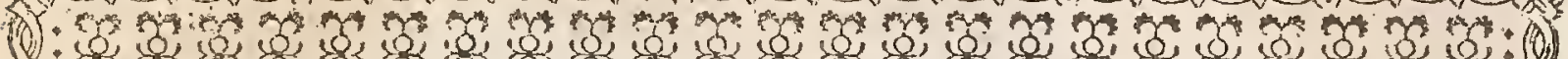
1.

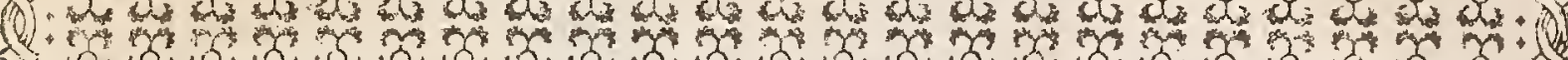

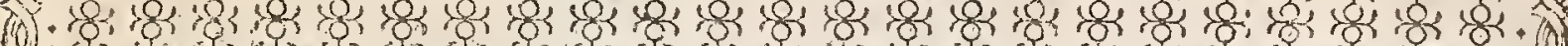

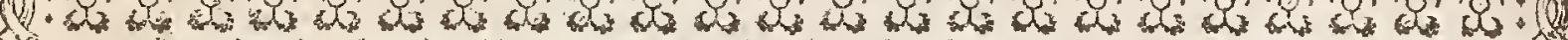

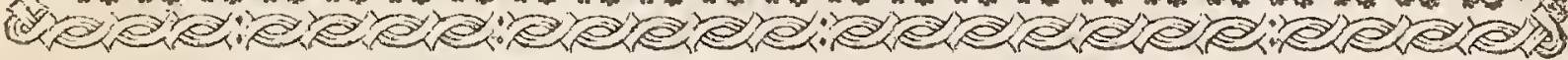

\section{ARTIS CONJECTANDI PARS PRIMA,}

Complectens

Tractatum Hugenii de Ratiociniis in Ludo Alex,

\section{Cum eAnnotationibus}

JACOBI BERNOULLJ.

\section{CHRIST.HUGENII $\mathrm{ad}$}

FRA N C,$S C H O O T E N I U M$ Prafatio.

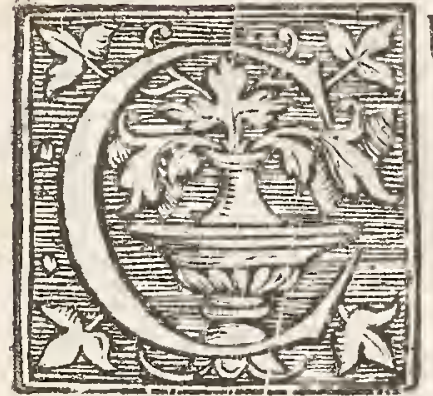

Um in editione elegantifimorum ingenii Tui monumentorum, quam præ manibus nunc habes, Vir Clarifime, id inter coetera Te fpeetare fciam, ut varietate rerum, quarum tractationem inftituift, oftendas quàm latè fe protendat divina Analytices fcientia, facilè intelligo etiam illa plurimùm propofito Tuo infervire poffe, quæ de Alex Ratiociniis 
conficripfimus; quantò enim minùs rationis terminis comprehendi poffe videbantur, qux fortuita funt atque incerta, tanto admirabilior ars cenfebitur, cui ifta quoque fubjacent. Quare cum in Tui gratiam primùn illa exponenda fufceperim, Tuque digna exiftimes, qux fimul cum fubtilifimis 'Tuis inventis in lucem exeant, adeò Tibi non refragabor, ut etiam è re meâ efre exiftimem hâc potifimùm ratione ipfa in manus hominum pervenire. Quippe cum in re levi ac frivolâ operam collocâle videri alioqui porrem, non tamen prorfùs utilitatis expers ac nullius pretii cenfebitur, quod Tu veluti inter Tua adoptaveris, nec fine multo labore vernaculâ linguâ noftrâ in Latinam converteris. Quan. quam, fi quis penitiùs ea qux tradimus examinare caperit, non dubito quin continuò repertürus fit, rem non, ut videtur, ludicram agi, fed pulchræ fubtilifimæque contemplationis fundamenta explicari. Et Problemata quidem qux in hoc genere proponuntur, nihilo minùs profundæ indaginis vifum iri confido, quàm quæ Diophanti libris continentur, voluptatis autem aliquantò plus habitura, cùm non, ficut illa, in nudâ numerorum confideratione terminentur. Sciendum verò, quòd jam pridem inter praftantifimos totâ Galliâ Geometras calculus hic agitatus fucrit, ne quis indebitam mihi prima inventionis gloriam hâc in re tribuat. Caterum illi, difficilimis quibusque quæfionibus fe invicem exercere folit, methodum fuam quisque occultam retinuêre, adeò ut à primis elementis univerfam hanc materiam evolvere mihi necene fuerit. Quanobrem igno. ro etiamnum an eodem mecum principio illi utantur; at in refolvendis Problematis pulchre nobis convenire fapenumerò cxpertus fum. Horum Problematum non. nulla 


$$
\text { PAS PRMA: }
$$

nulla in fine operis addidirfe me invenies, omifsâ tamen analyf, cum quòd prolixam nimis operam pofcebant, fi perfpicuè omnia exequi voluiffem, tum quòd relinquendum aliquid videbatur exercitationi noftrorum, if qui erunt, Lectorum. Vale.

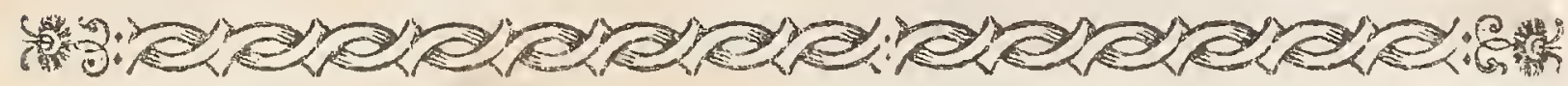

\section{DE RATIOCINIIS in Ludo Alex.}

Tfi lufionum, quas fola fors moderatur, incerti folent (1) 25 .ffe eventûs, attamen in his, quantò quis ad vincendum - 7 quàm perdendum propior fit, certam femper habet deI Lu terminationem. Ut fi quis primo jactu unâ tefferâ fe2. narium jacere contendat, incertum quidem an vincet; at quantò verifimilius fit eum perdere quàm vincere, reipsầ definitum eft, calculoq́ue fubducitur. Ita quoque, fi cum aliquo certem hâc ratione, ut ternis lufibus conftet victoria, atque ego jam unum lufum vicerim, incertum adhuc uter noftrûm prior tertii victor fit evafurus. Verùm quanti exfpectatio mea, \& contra quanti illius, æeftimari debeat, certiffimo ratiocinio confequi licet, atque hine definire, fi lttdum uti eft imperfectum linquere inter nos convenerit, quantò major portio ejus quod depofitum eft mihi quàm adverfario meo tribuenda effet: vel etiam $f 1$ quis in locum fortemq́ue mean fuccedere cupiat, quo pretio me eam ipfi vendere æquum fit. Atque hinc innumeræ quaftiones exoriri poflunt inter duos, tres, plurésve collufores. Cumq́ue minimè vulgaris fit hujusmodi fupputatio, \& fæpể utiliter adhibeatur, breviter hîc quâ ratione aut methodo expedienda fit exponam, ac deinde etiam, qua ad aleam five tefferas proprie pertinent, explicabo.

Hoc autem utrobique utar fundamento: nimirum, in alca lum do tanti aftimandam effe cujusque fortem feu expectationem ad aliquid obtinendum, quantum fi habeat, poffit denuò ad fumilem for 
tem five expectationem pervenire, aquâ conditione certans. Ü. exempli gratiâ, fi quis me infcio alterâ manu 3 folidos occultet, al terâ 7 Clidos, mihique optionem det ex utrâ manu folidos accipere mâlim; hoc tantundem mihi valere dico, ac fi 5 folidi mihi dentur. Quoniam quinque folidos habens, denuò eò pervenire poffum, ut aquam expectationem nancifcar ad 3 vel 7 folidos obtinendos: ida q́ue aquo lufu contendens.

\section{PROPOSITIO}

SI a vel $b$ expectem, quorum utrumvis æquè facilé $\checkmark$ mihi obtingere poffit, expectatio mea dicenda eft: valere $\frac{a+b}{2}$.

Ad hanc regulam non folùm demonftrandam, verüm etiam pri: mitùs eruendam pofito $x$ pro eo quod rquivalet expectationi mex. oportet me, quùm $x$ habeo, rurfus ad fimilem fortem pervenire pof fe, æquâ conditione certantem. Ponatur itaque lufus effe talis, ut cum altero certem hầc conditione, ut quisque deponat $x, \mathrm{ac}$ ut victor vieto traditurus fit $a$. Hic autem lufus juftus eft, \& patet me hấc ratione aquam habere fortem ad obtinendum $a$, fi lufum perdam ficilicet; aut $2 x-a$, fi vincam: tum enim obtineo $2 x$, id nempe quod depofitum eft, de quo alteri erogandum eft $a$. Quòd fi autem $2 x-\infty$ cantundern valeret atque $b$, æqua mihi fors obtingeret ad a quàm ad b. Pono itaque $2 x-a x b, \&$ fit $x \infty \frac{a+b}{2}$, pro valore mex expectationis. Cujus demonftratio facilis eft. Etenim habens $\frac{a+b}{2}$ polfum cum alio certare, qui etiam $\frac{a+b}{2}$ deponere volet, hâc conditione ut vincens viłto fit traditurus $a$. Quâ ratione fimilis expectatio mihi obtinget ad obtinendum $a$, fr perdam, aut ad obtinendum $b$, fi vincam; tum enim obtineo $a+b$, id nempe quod depofitum eft, alteriqque inde concedo $a$.

In numeris. Si ad 3 vel 7 rqua fors mihi obtingat, tum expetatio mea per lianc Propofitionem vallet $5 ; \&$ certum eit me 5 liabentem rurfus ad eandem expectationem pervenire poffe. Si enim 


$$
P A S P R I M A
$$

cum alio certans 5 deponam, atque ille fimiliter 5 deponat, hấc conditione, ut, qui vincit, alteri fit dacurus 3 : erit hic lufus omnino juftus, \& patet mihi æquam obtingere fortem ad obtinendum 3 , fi perdam; aut 7, fi vincam: quoniam tunc obtineo 10, de gुuo als teri concedo 30

\section{- Annotationes.}

A Uctor hujus Tractatûs in fine Procemii fui generaliter, in hâtc 1 verò \& duabus fequentibus Propofitionibus fpecialiùs totius Ari tis fundamentum exponit, quod clim plurimùm interfit ut recte inEelligatur, conabor illud alio magis populari \& ad cujusque captum accommodato ratiocinio demonftratum dare, hoc tantum pofito feut: axiomate feu definitione: quòd unusquisque tantundem expectet, vel expectare dicendus fit, quanrum infallebiliter obtinebit. Nimirum ad primam Propofitionem: Cogitemus, quendam alterầ manu occultâffe 3 folidos feu $a$, alterầ 7 follidos feu $b ;$ alterique mecum permittere, uc unus quod in unâ,, alter quod in alterầ manu eft, accipiamus: quâa ratione fiet, ut fimul ambo infallibiliter confecuturi fimus, ac proinde expectare debeamus, id quod in utrâque manu reconditum eft, nempe 10 folidos feu $a+b$. Sed concedendum quoque eft, utrumque noftrûm sequale jus habere in hoc quod expectamus; quare confeguitur, expectationem totalem in duas æquas portiones dividendans. effe, \& cuique tribuendum feorfim dimidium expectationis totalis, id eft, 5 feu $\frac{a+b}{2}$.

coroll. Patet hinc, fi in unầ manu occultaverit aliquid feu $a$, in alterâ nihil, fore cujusque expectationem feorfim illius alicujus; dimidium, feu $\frac{x}{2} a$.

Schol. Ex dictis colligi poteft, vocabulum Expeciationis non fumi híc fenfu vulgari, quo communiter expectare vel 'perare dicimur quod omnium optimum ef, licè nobis pejus accidere poffit; fed: quatenùs. fpes noftra impetrandi optimum temperata \& imminuta eft. metu confequendi pejus : adeò ut per valorern ejus femper fignificetur intermedii quidpiam inter optimum quod fperamus, \& peflimum quod metuimus: quod hîc \& in fequentibus ubique eft intelligendum,

$$
\text { 㮣 }
$$




\section{PROPOSITIO II.}

$1 a, b$, vel $c$ expectem, quorum unumquodque pari $\checkmark$ facilitate mihi obtingere pollit, expectatio mea ærimanda eft $\frac{a+b+c}{3}$.

Ad quod rurfus inveniendum, ponatur, ut ante, $x$ pro valore expectationis mex. Oportet ergò me, $\operatorname{cùm} x$ habeo, ad eandem expectationem pervenire poffe jufto lufu. Ponatur lufus effe talis, ut cum duobus aliis ludam hâc conditione, ut quisque noftrûm trium deponat $x, \&$ ut cum uno hoc pactum aggrediar, fi ipfe vietor ev:a dat, mihi fit daturus $b, \&$ ego ipfi traditurus fim $b$, fi idem mihi obtingat. Cum altero autem hanc ineam conditionem, ut ille ludum vincens mihi traditurus fit $c$, aut ego ipfi fim daturus $c$, fi ego vincam. Et patet hunc ludum juftum effe. Equam autem hâc rätione fortem habebo ad obtinendum $b$, fir nimirum primus vincat, aut $c$, ff fecundus vincat, aut etiam $3 x-b-c$, fi ego vincam: tunc enim obtineo $3 x$, quod depofitum eft, de quo uni concedo $b$, $\&$ alteri $c$. Quòd fi $3 x-b-c$ xquále fuerit ipfi $a$, eadem milni obtingeret expectatio ad obtinendum $a_{3}$ quæ ad $b$, aut ad $c$. Pono itaque $3 x-b-c: 0 a, \&$ fit $x>\frac{a+b+c}{3}$, pro valore meæ ex pectationis. Eodem modo invenitur, fi ad $a, b, c$, aut $d$ æqua fors mihi obtingat, id tanti valoris efle, quanti $\frac{a+b+c+d}{4}$. Atque ita porrò.

\section{Annotat.}

Aliter fic demonftrabitur: Fingamus, tres effe loculos, in quo: rum uno reconditum fit $a_{2}$ in altero $b$, in tertio $c$, mihiqque cum duobus aliis poteftatem fieri, ut quisque pro fe loculum accipiat, fervetque quod inibi repererit: fic fiet, ut omnes tres accipiamus omnes loculos, habeamusçue quicquid in is reconditum eft, fcil. $a+b+c$; unde, cùm dici nequeat, unum altero potiorem fpem vel expectationem habere, confequens eft uniuscujusque expectationem feorfim 2 quivalere tertire parti hujus aggregati, vid。 $\frac{a+b+c}{3}$. Eodem modo, il 


$$
P A R S P R I M A \text {. }
$$

$d o$, if 4 fint loculi, in quibus abfcondita fint $a, b, c \& d$, mihique unus corum in fortem cedere debeat, cenfebitur mea expectatio $x-$ quare $4^{\text {tam }}$ partem totius aggregati, five $\frac{a+b+c+d}{4}$. Sic fi. 5 fint loculi, erit mea expectatio $\frac{a+b+c+d+e}{s}, \& c$.

cor. Patet etiam, $f i$ in uno pluribusvé loculis nihil fit abfonditum, quòd tum fimiliter expectatio mea, ejus quod in reliquo vel reliquis continetur, futura fir pars tertia, fi loculi fint tres, vel quarta fi 4 , vel $5^{\text {ta }}$ fi $5, \& c$ 。

\section{PROPOSITIO III.}

SI numerus cafuum, quibus mihi eveniet $a$, fit $p$; Sumerus autem cafuum, quibus mihi eveniet $b$, fit $g$, fumendo omnes cafûs æquè in proclivi effe : expectatio mea valebit $\frac{p a+q b}{p+q}$.

Ad hanc regulam eruendam, ponatur rurfus $x$ pro valore expectationis mex: ergo oportet me, cùm $x$ habeo, ad eandem expectationem pervenire poffe, ut ante, jufto lufu. Ad hoc autem tot cols lufores fumam, ut unà mecum numerum ipfius $p+q$ efficiant, quorum deponat quisque $x$, ita ut depofitum fit $p x+q x, \&$ quisque fibi ludàt æquâ expectatione ad vincendum. Porrò cum tot ex hifce colluforibus, quot indicat numerus $q$, figillatim hoc pactum inibo, ut eorum qui vincat mihi fit daturus $b$, aut ego contra ipfi idem $b$, fi vincam. Similiter cum reliquis colluforibus, conftituentibus $p$ - I figillatim hanc conditionem aggrediar, ut eorum quisque, qui ludum vincit, mihi fit daturus a, \& ego tantundem ( $a$ filicet) ipfi, fi ego vincam. Er patet hunc lufum hâc conditione juftum effe, nemine videlicet injuriam patiente. Deinde patet me nunc $q$ expectationes habere ad $b, \& p-1$ expectationes ad $a, \& 1$ expectationem (me nempe vincente) ad $p x+q x-b q-a p+a$, tunc enim obtineo $p x+q x$, id quod depofitum eft, de quo tradere debeo $b$ unicuique $q$ luforum, \& anicuique $p-I$ luforum, quæ fimul conficiunt $b q+a p-a$. Si itaque $p x+q x-b q-a p+a$ xquale effet ipfi $a_{2}$ haberem expectationes ad $a$, (quandoguidem jam $p$ - I expectationes 
fiones ad id habebam) \& $q$ expectationes ad $b, \& 2$ fic ad priorem meam expectationem rurfus perveniffem. Quocircà pono $p x+q x$ $=b q-a p+a \infty a, \&$ fit $x \times \frac{a p+b q}{p+q}$, pro valore expectationis mex, omnino ut in initio politum fuit.

In numeris. Si 3 mihi expectationes forent ad 13, \& z expeetationes ad 8, haberem per hanc regulam tantundem ac ir. Et facile eft oftendere, me, fi II habeam, rurfus ad eandem expectatiom. nem pervenire poffe. Ludens enim contra 4 alios, \& guisque nofruím quinque deponens Ir, cum duobus ex illis figillatim pactün inibo, ut horum qui vincat mihi fit daturus 8 , aut ego ipfi idem 8 , fi vincam. "Similiter cum duobus reliquis, ut eorum quisque, qui ludum vincit, mihi frt daturus 13, aut ego ipfi tantundem, fi ego vincam. Qui quidem lufus juftus eft. Et patet me hoc modo duas habere expectationes ad 8 , nimirum fi alteruter eorum, qui mihi 8 promiferunt, vincat, \& 3 expectationes ad 13 , nimirum fi alteruter reliquorum duorum, qui mihi 13 tradere debent, vincat, aut fi iple Iudum vincam : ego enim ludum vincens obtineo depofitum, id eft, 55 , de quo unicuique duorum tradere debeo $13,8 x$ unicuique reliquos cum duorum 8 , ita ut $\&$ mihi relinquatur 13.

\section{Annotat.}

Aliter ita: Ponamus, tot unà mecum efle collufores, quor funt in univerfum cafûs, nimirum $p+q$, fingulisq́ue fingulos evenire çIth ; quod fit, fi totidem concipiantar loculi, \& in fingulis recondit tum intelligatur, quantum unoquoque cafu acquiritur, videl, in fin-. gulis $p$ loculorum $a$, \& in fingulis $q$ loculorum $b$; finguli jam collufores accipiant fingulos loculos, univerfi ergò accipient omnes, obsinebuntq̣́tie infallibiliter quicquid in loculis reconditum eft, id eft, $p a+q b$. Igitur cùm omnes expectent æqualiter, diftribuendum erits quod univerfi accipient, per numerum colluforum feu cafuum, fic ut fingulorum expectatio fiat $\frac{p a+q b}{p+q}$. Atque eâdem ratione oftendèsur, fi mihi $p$ cafibus eveniat $q, q$ cafibus $b, \& r$ cafibus $\sigma$, fortem meam fore $\frac{p a+q b+r c}{p+q+r}$.

Corolls. 


$$
\text { PARS PRIMA }
$$

Coroll. I. Conftat hine primò, fi $p$ cafibus mihi eveniat $a_{2}$ 2 q cafibus nihil, expectationem meam fore $\frac{p a}{p+q}$.

2. Conftat deinde, fi numeri cafuum recipiant communen diviforem, polfe valorem expectationis reduci ad minores terminos: ut, fr a obtingat mihi cafibus $m p, \& b$ cafibus $m q$, fiet expectatio mea juxta regulam $\frac{m p a+m q b}{m p+m q}$, quæ factâ divifione per $m$ æqui valet huic $\frac{p a+q b}{p+q}$.

3. Si habeam $p$ casûs ad obtinendum $a, q$ castis ad $b$, \& $r$ ad $c$, tantundem hoc mihi valet, ac fi $p \& q$ cafibus in unum conw Hatis, haberem $p+q$ castis ad $\frac{p a+q b}{p+q}, \& r$ casûs ad 6 ; qui utroque modo per regulam invenitur fors mea $\frac{p a+q b+r c}{p+q+r}$.

4. Si habeam $p$ casûs ad $a, q$ ad $b, \& r$ casûs ad permanendum in eoftatu, in quo fum, five ad retinendam priftinam meam fortem, erit fors ifta $\frac{p a+q b}{p+q}$, eadem planè quam haberem, fi nula lus $r$ cafuum adeffet. Nam pofito $x$ pro valore ejus, habeo per hyp. $p$ casûs ad $a, q$ ad $b, \& r$ ad $x$, quod forterm meam per regulam efficie $\frac{p a+q b+r x}{p+q+r}$; unde cùn hæc mea fors vocetur $x$, erie $x \infty \frac{p a+q b+r x}{p+q+r}$, hoc eft, factâ multiplicatione, $p x+q x+r x$ $\infty p a+q b+r x, \&$ deleto $r x, p x+q x \infty p a+q b$, feu denique $x \infty \frac{p a+q b}{p+q}$.

5. Si habeam $p$ castis ad obtinendum a (quidpiam cujus ego femiffem contuli), \& $q$ castus ad obtinendum nihil, expectatio $\frac{p a}{p+q}$, quæ per Cor. I. hujus invenitur, totum depofitum refpicit, \& partem fignificat qua mihi ex illo debetur, non quantitatem folius lucri vel damni : de hoc enim folo fi quaftio fit, confidero, quòd dum obtineo depofitum $a$, lucrifacio tantùm $\frac{x}{2} a ; \&$ dum obtineo nihil depofiti, perdo $\frac{\pi}{2} a$, hoc eft, acguiro - $\frac{\pi}{2} a$; unde fors mea hoc fenfu accepta fit $\frac{p^{d: 2}+q \cdot-a: 2}{p+q} \infty^{\frac{p-q^{a: 2}}{p+q}}$ \& \& ind nuit lucrum, fi $p$ fuperet $g$; damnum, fi hac fuperet illam. 
6. Si habeam $p$ casûs ad acquirendum $a, \& q$ casûs ad ob. tinendum $b$, quorum quidem ego nihil contulero, attamen jactus alea mihi redimendus fit pretio $n$, expectatio mea $\frac{p a+q b}{p+q}$ iterum non tota in lucro ponenda eft, fed priùs diminuenda valore $n$. Etenim cùm alteri do $n$, \& iple mihi viciffm reddit $a$ vel $b$, perinde eft, ac fil ego nihil darem, acciperem verò tantùm $a-n$, vel $b-n$; id quod efficit expectationem meam ita refrictam $\frac{p_{0}^{a-n}+q^{b-n}}{p+q}$ $\infty \frac{p a+q b}{p+q}-n$, quæ rurfus vel lucrum vel damnum fignificat, prout pars affirmata præpollet negatæ, aut hæc illi.

sibol. Perfpicuum eft ex calculi hujus confideratione, magnam illi intercedere affinitatem cum Regulâ Arithm. Alligationis dỉtâ, quâ res diverfi pretii in datâ quantitate mifcentur, \& quæritur pretium rei mixtæ; aut poriùs calculum utrinque planè eunden effe. Sicut enim fumma productorum ex quantitatibus fingularum mifcibilium in fua refpectivè pretia, divifa per aggregatum omnium mifcibilium, exhiber pretium quafitum, quod femper medium eft inter pretia extremorum : ita fumma productorum ex numeris cafuum in id quod quovis calu acquiritur, divifa per numerum om nium cafuum, oftendit valorem expectationis, qui proinde femper intermedius erit inter maximum \& minimum quod acquiri poteft. Unde fi iidem numeri affumantur, ibi pro quantitate mifcibilium, corumque pretiis; hîc pro cafibus, \&x eo quod quovis cafu obtinetur; idem quoque numerus denotabit ibi pretium rei mixtæ, \& hîc expectationem. Ex. gr. fi 3 canthari vini pretii 13 mifceantur cum 2 cantharis pretii 8 ; multiplicatis 3 per I3 \& 2 per 8 , exurgit pretium omnium cantharorum 55 , quo divifo per 5 numerum cantharorum, habetur il pretium unius canthari mixti: quanta quoque juxtà regulam expectatio cujuspiam aftimanda eft , qui 3 ha buerit casûs ad 1$\}, 82$ ad $\delta$. 


\section{$P A R S-P R I M A$. \\ PROPOSITIO IV.}

UUmpto itaque me cum aliquo certare, hoc påto: $\checkmark$ ut qui priùs ter vicerit, quod depofitum eft, lucretur, \& me jam bis viciffe, alterum verò femel. Scire cupio, fi lufum profequi non velimus, fed pecuniam, de quâ certamus, prout æquum eft, partiri, quantum ejus mihi obtingeret.

Ut igitur ad primò propofitam quæftionem veniamus, nimim xum, de faciendâ diftributione inter diverfos collufores, quando eorum fortes inæquales funt, opùs eft ut à facilioribus incipiamus.

Primò confiderare oportet lusûs, qui utrobique deficiunt. A Certum enim eft, fi inter nos convenerit, verbi gratia, ut quod depofitum eft lucretur is, qui priùs vigefies vicerit, \& ego decies $8 x$ novies vicero, at alter decies \& octies, tantò meliorem fore eo cafu fortem meam, quantò hîc melior eft, ubi à tribus lufibus binos confequutus fum, ille verò unum duntaxat: quia nimirum utrobique mihi unus tantummodò lufus fed ipfí duo deficiunt.

Porrò ad inveniendum quanta pars utrique debeatter', advertendum eft quid fieret, fit in lufu pergeremus. Certum enim eft, fi primum ludum vincerem, me præfcriptum numerum impleturum \& omne depofitum confecuturum, id quod vocetur $a$, Quòd $B$ fi autem alter primum ludum vinceret, tunc æquata utriusque fors foret, (quippe utrique uno adhuc deficiente ludo, ) adeoq́ue cederet cuique $\frac{x}{2} a$. Manifeftum autem eft, me æquam habere fortem ad primum ludum vincendum aut perdendum, ita ut mihi nunc sequa fit expectatio ad obtinendum $a$ aut $\frac{x}{2} a$ : quod ipfum per $1^{\mathrm{mam}}$ Propofitionem tantum eft ac fir utriusque fortis dimidium, id eft, $\frac{3}{4} a$, haberem; \& relinquitur alteri meo collufori $\frac{T}{4} a$, qua ipfius $\mathrm{C}$ portio ftatim ab initio eodem modo reperiri potuiffer. Unde pa- D tet, eum, qui ludum meum in fe recipere vellet, mihi $\frac{3}{4} a$ pro eo tradere debere, ac proinde femper tria contra unum deponere eum E poffe, qui unum ludum vincere contendat, priusçuàm alter duos vincat。 


\section{Annotat.}

A Primò confiderare oportet lusûs, qui utrobique deficiunt.] Adeoq́ue in computandis fortibus folummodo futurorum lufuum, nulla prateritorum habenda eft ratio; cùm pro unoquoque fequentium lufuum nulla major fit probabilitas, ut fortuna iisdem favere pergat, quibus favit anteà, quàm iis qui omnium fuêre infortunatiffimi: quod obfervandum contra ridiculam plurimorum opinionem, qui fortunam ut nefcio quem habitum confiderant, qui aliquandiu in homine permaneat, eique jus quafi tribuat fperandi in pofterum fimilem fortunam.

Id quod vocetur a.]

Per lit. a non folùm cum Austore intelligere poffumus depofitam pecuniam, qua inter collufores pro ratione fortium diftribui poteft; fed etiam in genere omne illud, quòd licet indivifum eft in $\mathrm{fe}$, concipi tamen poteft ut divifibile pro numero cafuum, quibus acquiri vel amitti, effici vel non effici poteft, ut in ultimâ libri parte fufrùs oftendetur: putà, præmium quodcunque, laureola, victoria, ftatus vel conditio peifonæ aut rei, munus quoddam publicum, opus quodcunque fufceptum, vita vel mors, \&cc. Ita fi duobus maleficis ex fpeciali gratiâ Principis æquầ forte de vitâ decertandum fit, utervis eorum habere cenfebitur per I. Prop. $\frac{x}{2}$ vitæ $\& \frac{I}{2}$ mortis, fic ut ejusmodi homo etiam in proprio fenfu femi-vivus vel femi-mortuus nuncupari poffit.

Et relinquitur alteri meo collufori $\frac{1}{4} a_{0}$ ] Hoc eft, refis duum totius depofiri $a$; quia fcil. finito certamine ambo fimul infallibiliter habituri fumus integrum $a$ : at fi feri quodam cafu pofo fit, ut ambo ludentes impetrent plus minúsve integro $a$, evidens eft, quòd tunc unius expectatio alterius expectationem nequeat complem re ad a. Ex, gr, Si duo laqueo digni ludere cogantur tefferầ eâs lege, ut qui pauciora puncta jecerit fufpendatur, altero manente vivo; fi verò eundem jaciant punctorum numerum, ut ambo vitât donentur; reperitur pro unius expectatione, ut fuo loco patebit, $\frac{7}{1}$ a feu $\frac{7}{1}$ vitæ; unde tamen non fequitur alterius expectationem fore tantìm $\frac{5}{12}$ vitæ: cùm enim hîc fortes manifefte fint æquales, expectabit \& ifte $\frac{7}{12}$ vita, proinde uterque fimul $\frac{7}{6}$ vitæ, hoc eft, plus 
plus integrẩ vitâ ; quod inde fit, quia nullus quidem cafus eft, quo non finitầ aleâ unus minimùm fuperftes maneat, poffunt tamen nonnullis cafibus ambo vivi fuperefle.

Que ipfius portio fation ab initio \&cc.] Nempe hầ D ratione : Si collufor meus proximum ludum vincat, æequata erit urriusque fors, proinde cedet cuique $\frac{\pi}{2} a$ : fin ego vincam, obtinca bit ille nihil. Cùm igitur pari facilitate obtinere poffit $\frac{x}{2} a$ vel ni= hil, expeetatio ejus per Coroll. r. Prop. III. dicenda eft $\frac{x}{4} a_{*}$

Ac proinde femper tris contra unum oc.] Oftenden. $E$ dum, quòd is qui tres haber casûs ad vincendum, \& unum ad perdendum, feu qui tres quartas partes depofiti expectat, tria poffit deponere contra unum. Hunc in finem folummodò fupponi dea bet, eum trium colluforum vicem fuftinere. Etenim fi fint 4 cols lufores, qui æequâ forte ludant, \& quorum finguli deponant 1 , expectabit unusquisque id jpfum quod depofuit, hoc eft, $4^{\text {tam }}$ partem totius depofiti, per Cor. 2. Prop. III. adeoque terni eorum quivis tres quartas partes depofiti, \& quartus non nifi $\frac{T}{4}$. Sed quia illi tres quoque tria depofuerunt, cùm quartus tantùm depofuerit unum, patet omnino juftum effe, ut is, qui cupit in fortem trium fuccedere, hoc eft, triplò plus expectare alio, triplò quoque plus deponas. Aliter ita: Qui tres habet casûs ad vincendum, \& unicum ad perdendum, is toties ter vincere potelt, quoties altêr femel tantum; proinde fi lufus juftus effe debet, oportet ut tribus ille vicibus tantundem lucri reportet, quantum alter unicâ vice; quod fieri nequit, nifi tria deponat contra unum. Et fic in genere oftendetur, quòd quantò quis altero potiorem ad vincendum expectationem habet, tantò etiam plus eum deponere juftum fit, fi æquâ forte contendere velinto

\section{PROPOSITIO V.}

POnamus unum mihi deficere ludum \& collufori 1 meo tres lufüs. Oportet hîc facere diftributionem. Advertamus itaque rurfus, in quo effemus ftatu; fr ego vel iple primum vinceret lufum. Si ego vincerem, obtinerem depofitum, id eft, a quòd fi autem ille primum ludum vincexes, deficerent ipfi 
duo lusủs \& mihi unus, ac proinde in eodem fatu effemus, qui in pracedenti Propofitione pofitus fuit, mihique obtingeret $\frac{3}{4} a$, ut ibi oftenfum eft. Iraque pari facilitate vel a mihi obtinget vel $\frac{3}{4} a$, id quod tantum eft, per 1 mam Propolitionem, ac $\frac{7}{8} a$. Et relinquitur $\frac{1}{2}$ a collufori meo; ita ut mea fors ad fortem illius fe habeat, ficut 7 ad I.

Quemadmodùm autem ad hunc calculum requifitus eft præcedens, ita rurfus hicce infervit fequenti: nimirum, fi ponamus

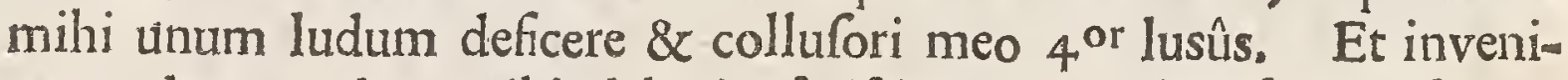
tur eodem modo, mihi deberi $\frac{15}{1} \frac{5}{6}$ ifius quod depolitum eft, \& ipli $\frac{1}{16}$.

\section{ennotat.}

Ex progreffione harum fractionum, $\frac{3}{4} a, \frac{7}{8} a, \frac{\pi}{1} \frac{5}{6} a$, qua per praced. \& hanc Propolitionem inventa funt, porrò infertur, fi collufori meo deficiant ludi 5 , fore fortem meam $\frac{3}{3} \frac{1}{2} a$ : fi $\mathrm{fex}_{2} \frac{63}{64} a$ : fi feptem, $\frac{1}{1} \frac{27}{28} a ; \&$ in genere, fi mihi deficiat unus lufus \& collufori meo ludi quotcunque, meam fortem fore ad fortem illius in eâ ratione, quam habet, demtâ unitate, productum binarii toties pofiti $8 x$ multiplicati in $\mathrm{fe}$, quoties indicat numerus lufuum alteri deficientium, ad, unitatem.

\section{PROPOSITIO VI.}

POnamus mihi deficere duos lufûs \& collufori meo
tres lufûs.

Fiet itaque primo lufu ; vel ut mihi unus lufus deficiat $\&$ ipfi tres (unde mihi per precedentem Propofitionem obtinget $\frac{7}{8} a$ ); vel ut cuique noftrûm adhuc duo lusûs deficiant, unde mili debebitur $\frac{x}{2} a$, quandoguidem fic utrique æequa fors futura eft. Eft mihi autem æqualis facilitas ad primum ludum vincendum aut perdendum; ita ut mihi æqua fit expectatio ad obtinendum $\frac{7}{8} a$ aut $\frac{x}{2} a$, id quod mihi valet $\frac{11}{1} \frac{1}{6} a$, per Imam Propofitionem. Et debentur mihi ur partes ejus quod depofitum eft, \& collufori meo 5 partes. 


\section{$P A R S P R I M A$. \\ PROPOSITIO VII.}

DOnamus mihi deficere duos lufús \& collufori meo quatuor.

Fiet itaque, ut , fi primum ludum vincam, unum ludum vineere debeam \& alter quatuor; vel, fi eundem perdam, duos \& alter tres. Ita ut æqua mihi fors obtingat ad $\frac{15}{15} a$ aut $\frac{11}{1} \frac{1}{6} a$, id quod tantum valet ac $\frac{13}{15} a$, per 1 mam Propofitionem. Unde patet, eum meliorem habere fortem, qui duos lusîs vincere debet dum alter quatuor, quàm eum, qui unum dum alter duos. In hoc enim pofteriori cafu, nimirum ipfius I ad 2 , portio mea, per $4^{\text {tam }}$ Propofitionem, eft $\frac{3}{4} a$, quæ minor eft quàm $\frac{13}{16} a_{0}$

\section{Annotat.}

Unde patet eum meliorem \&oc.] Sic adhuc meliorem $F$ fortem habet, qui tres lusûs vincere debet, dum alter fex; reperitur enim ejus portio $\frac{2}{2} \frac{1}{2} a$, , major quàm $\frac{13}{16} b_{\text {. Ita etiam, qui }}$ unum ludum vincere fufcipit dum alius quatuor, non parem fubit fortunam cum illo, qui duos vincere debet dum alter octo; fed cum illo, qui duos vincere tenetur dum alter fex. quanquam nemo fortafis eft, qui fibi non perfuaderet, eanderin inter fortes rationem obtinere debere, ubi numeri lufuum utrobique deficientium eandem quoque inter fe rationem fervant; nifi nos calculus aliud docuiffet. Quo ipfo proin monemur, ut cauti fimus in judicando, nec ratiocinia noftra fuper quâcunque ftatim analogiâ in rebus deprehensâ fundare fuefcamus; quod ipfum tamen etiam $\mathrm{ab}$ iis, qui vel maximè fapere videntur, nimis frequenter fieri folet.

Caeterùm lubet hîc Tabulam adjicere pro duobus colluforibus, qqualem infra in Propof, IX, pro tribus fubjungit Auctor: 
Tabella hæcce le. viffimo negotio quoufque opus fuerit continuabitur, in fupremâ quidem ferie transverfali per ea qua ad Propor, 5 annotata funt; in primâ ferie perpendiculari per continuam bifecionem dimidii; in locis intermediis per dimidiationem fummæ duarum areolam rum immediatè præcedentium in eâdem ferie perpendiculari \& transverfali; cujus conftructionis ratio ex dictis plus fatis perfpicua eft. Quomodo autem expeatationes duorum ludentium absque continuatione Tabella indefinite ad quotvis deficientes lusûs exhiberi polfint, infra in Appendice Cap.4. Part. II. oftendetur.

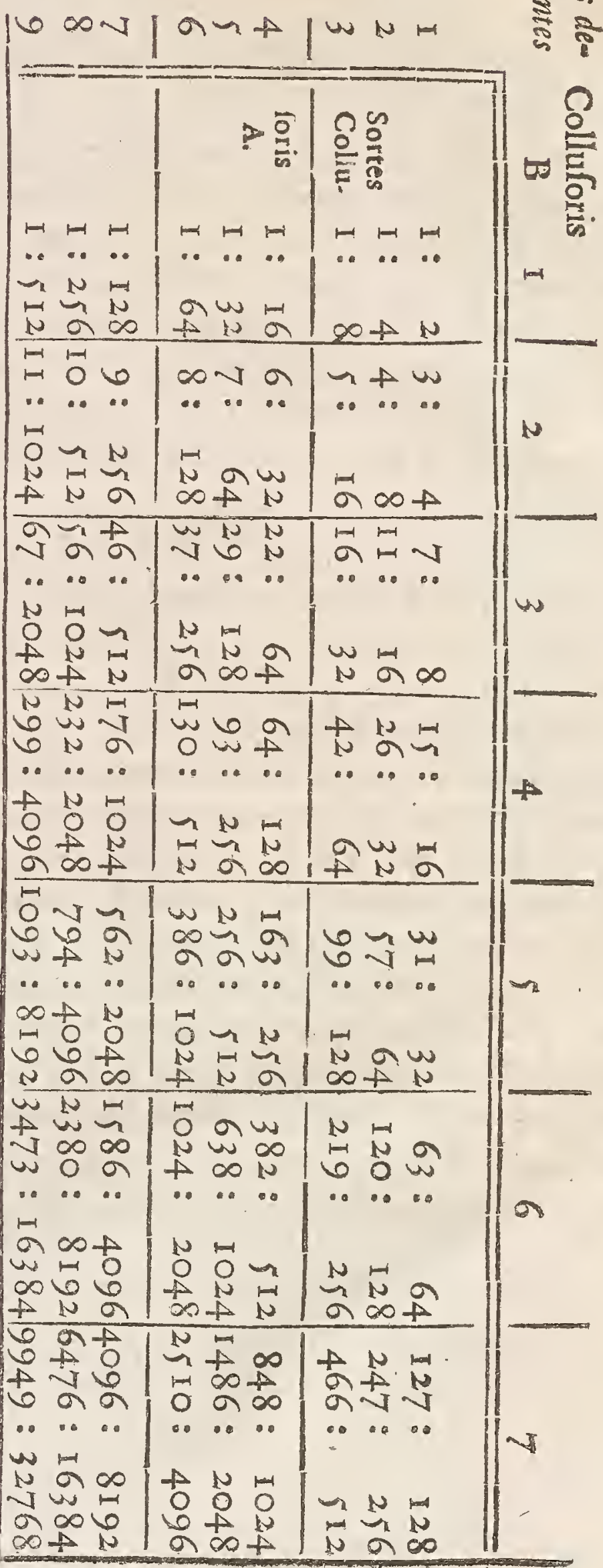




\section{$P A R S P R I M A$. \\ PROPOSITIO VIII.}

Uunc verò ponamus tres effe collufores, quorum 1 primo ut \& fecundo unus lufus deficiat, fed tertio duo lusûs.

Ut igitur inveniatur primi pars, rurfus advertendum eft, quid ipfi deberetur, fi vel ipfe vel alter reliquorum duorum primum lufum vinceret. Si ipfe vinceret, haberet depofitum, id quod fit $a_{\text {. }}$ Quòd fi fecundus vinceret, primus nihil haberet, quoniam fecundus fic lufui finem impofuiflet. At fi tertius vinceret, tunc cuique trium adhuc unus deficeret lufus, ideoque tam primo quàm utrique reliquorum deberetur $\frac{1}{3} a$. Et fit primo una expectatio ad $a$, una ad $0, \&$ una ad $\frac{1}{3} a$, (quandoquidem æquè facilè contingere poteft cuique trium ut primum ludum vincat, ) quod ipfi tantundem valet ac $\frac{4}{9} a$, per $2^{\text {dam }}$ Propofitionem. Et fit fimiliter fecundo $\frac{4}{9} a$, \& remanet tertio $\frac{1}{9} a$. Cujus pars feparatim etiam $C$ inveniri potuerat, atque inde reliquorum partes determinari.

\section{Annotat.}

Cujus pars feptratim etiam inveniri potuerat.] Nem- G pe hoc pacto: Si ipfe fequentem ludum vinceret, expectatio ejus foret $\frac{1}{3} a$; fed fi vel primus vel fecundus proximi ludi victor evaderet, tertius nihil haberet: quare unum cafum habet ad $\frac{1}{3} a, \&$ duos ad 0 ; id quod ipfi per Coroll. I. Prop. III. valet $\frac{3}{9} a_{0}$.

\section{PROPOSITIO I X.}

$\bigcup^{T}$ tot colluforum, quot quis voluerit, ex quibus uni plures \& alii pauciores lusûs deficiunt, cujusque pars inveniatur, confiderandum eft, quid illi, cujus partem invenire volumus, deberetur, fi vel ipfe, vel quilibet reliquorum primum fequentem ludum vinceret. Hæa autem partes fi in unam fummam colligantur, \& aggregatum per numerum colluforum dividatur, quotiens oftendet unius quafitam partem. 
Ponamus tres effe collufores $A, B, \& C, \&$ ipfi $A$ unum luw dum deficere, ipł B duos lusûs, \& ipfi C fimiliter duos lustis. Invenire oportet, quid ipfi $B$, ejus quod depolitum eft, debeatur. Id grod vocetur $q$.

Primò examinandum eft, quid ipfi $B$ deheretur, fi vel ipfe; vel $A$, vel $C$ primum fequentem ludum vinceret.

Si A vinceret, ludo finem impofuiffet, ac per confequens ipfi $B$ deberetur 0 . Si ipfe $B$ vinceret, deficeret illi adhuc unus lufus, \& ipfi A unus lufus, at ipfi $C$ duo lusûs. Quocirca ipfi $B$ hoc in cafu deberetur $\frac{4}{9} q$, per 8 vam Propofitionem.

Denique fi $\mathrm{C}$ primum fequentem ludum vinceret, tunc ipfis A \& C fingulis unus deficeret lufus, fed ipfî $B$ duo lusûs, ac per confequens ipfi B deberetur $\frac{I}{S} q$, per eandem Propofitionem $8^{\text {vam. }}$ Nunc autem in unam fummam colligendum eft, id quod in tribus hifce cafibus ipf $B$ deberetur: nimirum, $0, \frac{4}{3} q, \frac{1}{9} q$ : quorum fumma eft $\frac{5}{2} q$. Quod ipfum divifum per 3 , numerum colluforum, dat $\frac{5}{27} q$. Quæ ipfius B quafita pars eft. Demonftratio autem hujus patet ex 2 dâ Propolitione. Quoniam enim B æquam habet fortem ad obtinendun $0, \frac{4}{9} q$, vel $\frac{1}{9} q$, habet per 2 dam Propofitionem tantundem ac $0+\frac{4}{2} q+\frac{1}{9} q: 3$, id eft, $\frac{5}{27} q$. Et certum eft, hunc diviforem 3 effe numerum colluforum.

Ut autem inveniatur, quid cuipiam debeatur in quolibet cafus videlicet fi vel ipfe vel aliquis reliquorum primum fequentem ludum vincat: oportet fimpliciores casûs primó inveftigare, \& horum medio fequentes. Nam ficut hic ultimus cafus folvi non potuit, priusquàm ille octavæ Propofitionis calculo fubdustus effet, in quo deficientes lusûs erant I, I, 2, ita etiam cujusque pars fupputari nequit in tali cafu, ubi deficientes lusûs funt $I, 2,3$, quin primùm calculo fubductus fit cafus deficientium lufuum $1,2,2$, quemadmodùm jam fecimus, \& prætereà ille, in quo lufus deficientes funt I, I, 3; qui fimiliter per 8 vain Propofitionem fupputari potuifet. Atque hoc quidem pacto confequenter fupputare licet casûs omnés qui in fequenti tabulâ comprehenduntur, \& infinitos alios. 


$$
\text { ARS PRIMA. }
$$

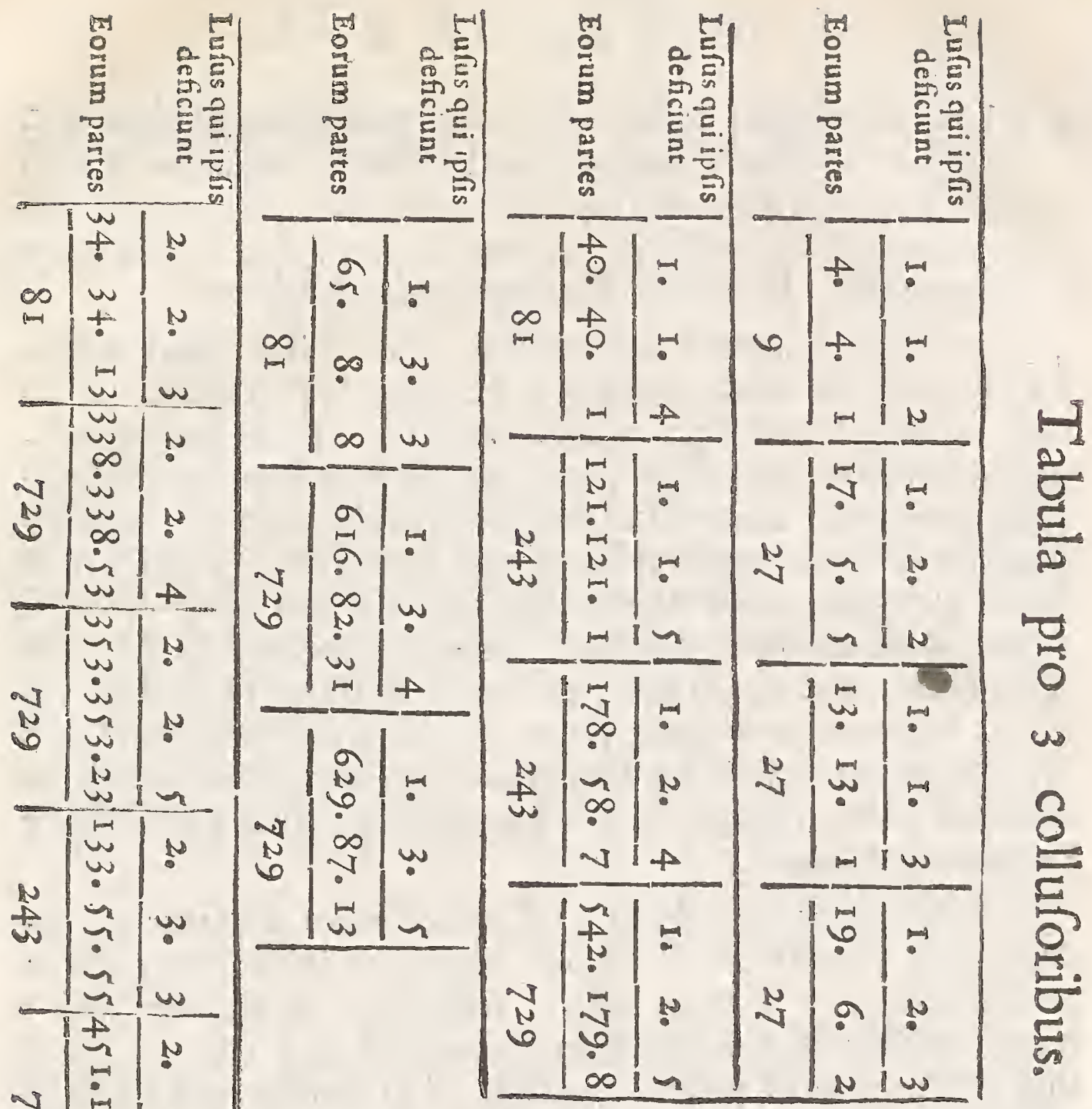




\section{E T E S S E R I .}

Uod ad Tefferas attinet, de iis hæ quaftiones proponi pof funt : videlicet, quotâ vice unâ tefferâ fenarium jacere perì clitandum fit, aut aliquod reliquorum punetorum. Item quotâ vice duos fenarios duabus tefferis, aut tres fenarios tribus tefferis jacere fit tentandum. Et plures aliæe hujusmodi quæftiones.

Ad quas folvendas advertendum eft. Primò unius tefferse fex effe jactûs diverfos, quorum quivis æquè facilè eveniat. Sumo enim tefferam habere figuram cubi perfectam. Porrò duarum teffe. rarum 36 effe diverfos jactûs, quorum fimiliter quivis aquè facile obtingere poteft. Nam ratione cujusque jactûs unius tefferæ potef unus fex jactuum alterius tefferæ fimul contingere. Et fexies 6 ef ficiunt 36 jactûs. Item trium tefferarum effe 216 jactûs diverfos: Nam ratione cujusque 36 jactuum duarum teflerarum poteft unus

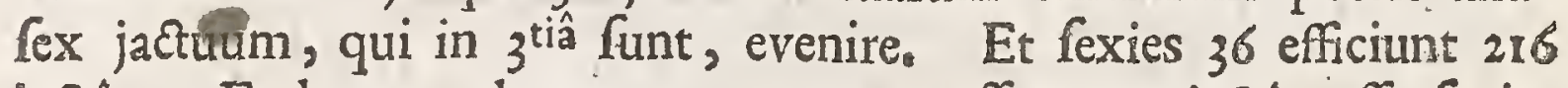
jactûs. Eodem modo patet, quatuor tefferarum jactûs effe fexies 216 , id eft, 1296; atque fic ulteriùs jactûs quotlibet tefferarung fupputari poffe, fumendo femper pro acceffione unius tefleræ fexies jactûs precedentis.

Porrò notandum, duarum teflerarum unum duntaxat effe jaci Etum, qui 2 aut 12 puncta efficiat, duos verò jactûs, qui 3 aut $\mathbf{~} 1$. puncta efficiant. Si enim tefferas vocemus $\mathbf{A} \& \mathbf{B}$, patet, ad 3 puncta jacienda in $A$ unum $\&$ in $B$ duo, vel in $B$ unum $\&$ in $A$ duo puncta reperiri poffe. Similiter ad II puncta jacienda in A quinque $\&$ in $B$ fex, vel in $A$ fex $\&$ in $B$ quinque puncta patêre poffe. Quatuor punctorum tres funt jactûs, videlicet, ipfius A I \& B 3 puncta, vel ipfius $A 3 \&$ B I punctum; vel ipfrus $A 2 \& B$ puncta.

Decem punctorum fimiliter tres funt jactûs.

Quinque vel novem punctorum $4^{\text {or funt jactús, }}$

Sex vel octo punctorum 5 que funt jactûs.

Septem punctorum 6 funt jactûs, 


$$
P A R S P R I M A^{\circ}
$$

In tribus tefleris reperiuntur $\left\{\begin{array}{r}3 \text { vel I } 8 \\ 4 \text { vel I } 7 \\ 5 \text { vel I } 6 \\ 6 \text { vel I } 5 \\ 7 \text { vel I } 4 \\ 8 \text { vel I } 3 \\ 9 \text { vel I } 2 \\ \text { IO vel I I }\end{array}\right\}$ punetorum $\left\{\begin{array}{r}I \\ 3 \\ 6 \\ \text { Io } \\ \text { I } 5 \\ 21 \\ 2,5 \\ 27\end{array}\right\}$ jactus.

\section{Annotat.}

Quod hic Auctor præftitit in duobus \& tribus tefferis, prefta. ril quoque poteft in quatuor quirique pluribúsve, in quibus numeri jactuum quotvis punctorum haud aliter invenientur. At quia facile feri poreft, præefertim ubi tefferæ multæ fuerint, ut quamplurimi jactûs prætereantur, nifi aliquem in is inquirendis ordinem obfer: ves, oftendam quâ quis methodo uti debeat, ut certus effe poffit, fe omnes adinveniffe nullo pretermiffo. Primò inquirendum, quot modis diverfis componi poffit propofitus punctorum numerus, ex tot partibus quot funt tefleræ, quarumq́ue p rrtium nulla fenarium fuperet: deinde explorandum, quot jactûs cuilibet horum modorum refpondeant; qua quidem omnia meliùs exemplis quàm regutlis addifci poffunt: Efto itaque indagandum, quot jactûs reperiantur 12 punctorum in 4 tefferis.

Hunc in finem incipio aे 4 unitatibus, fcribendo I. 1.1.1, deinde primam unitatem adaugeo continuâ additione unitatum, quoufque fenarium efficiant \& habeatur 6.I.I.I ; fed quia fumma horum numerorum nondum exæquat numerum propofitum i2, attollo etiam fecundam partem ad binarium, ad ternarium, fcribendo 2.2. I. I, deinde 3.3.1.1, fingulisq́ue vicibus primum numerum ad fenarium elevo, ut habeantur 6.2.1.I, \& 6.3.I.I, quorum fumma adhuc à propofito numero deficiunt: quare pergo fcribere 4.4.I.I, primoque quaternario ad fenarium elevato habebo tandem 6.4.1.I, quorum fumma aqualis 12 ; quare feorfim illos 2dnoto: pofteà fcribo 5.5.1.I, quos quia pariter I2 efficiunt, ites rum refervo, Jam quia 6.5.1.1, uti \& 6.6.1.1, excedunt 12 ; C 3 illis 
ill is neglectis tertiam quogue unitatem, qux hactenù intacta. manfit, ad binarium elevo, fribendo 2.2 .2 .1 , fed quia primo binario ad fenarium promoto numeri 6.2 .2 .1 , deficiunt adhuc à $\mathbf{1 2}$, transeo ad $3 \cdot 3.2 .1$, quorum primus pro more adaulctus exhibet numeros 6.3 .2 .1 , feorfim ponendos, quia complent $12:$ Deinde folummodò fecundam partem augeo, primam verò minuo unitate, \& habebo alios quatuor 5.4 .2 .1 feorfim adnotandos. Jam non pergo atrollęre fecundam partem ad 5 vel $\sigma^{a u m}$, quia ad complen-

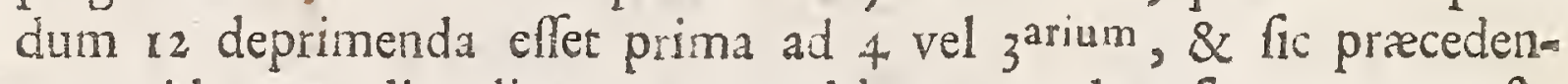
tes quidam modi redirent; nam ad hoc cavendum femper opus ef . ut nulla partium priorum minor conftituatur ullâ fequentium: quocirca ftatim propero ad $3 \cdot 3 \cdot 3 \cdot 1$, ubi mutato primo ternario in quinarium obtineo numeros $5 \cdot 3 \cdot 3 \cdot 1$ conftrtuentes fummam propolis tam. Mox verò fecundâ parte fublatâ \& primâ depreflâ ad quaternarium, habebo alios quatuor numeros quæfito fatisfacientes 4.4.3.I. Porrò quia manifeftum eft, neutram dua:um priorum partium, imò nec ipfam tertiam partem unitate poffe augeri, quin vel fumma omnium quatuor excedat 12, vel aliqua præcedentium partium minor frat aliquâ fubfe uentium, \& fic priftıni quidam modi redeant; idcircò poftremam etiam unitatem, quam hactenùs intactam reliqui, ad binarium promoveo fribendo 2.2 .2 .2 , primo que binario ad 6arium fublato, 6.2 .2 .2 , qui modus quæiito fatisfacit. Hinc fecundam partem augeo, primam minuo, tum unitas te, tum binario, \& habebo duos alios modos requifitos $5 \cdot 3 \cdot 2.2$, \& $4 \cdot 4 \cdot 2.2$. Ubi quia denuò apparet, neutram priorum partium poffe augeri, quin vel altera minuatur, \& fic priftini refultent modi ; vel fumma omnium fuperet 22 ; progredior ad $3 \cdot 3 \cdot 3 \cdot 2$, five aucto unitate primo ternario ad $4 \cdot 3 \cdot 3 \cdot 2$, qui novum modum fup peditant, quo componi potelt numerus propofitus. Tandem quo niam $\mathrm{ob}$ eandem rationem nullam trium priorum partium ampliùs augere licet, poftrema ad ternarium elevanda fcribendumq́ue $3 \cdot 3 \cdot 3 \cdot 3$, quorum fumma \& ipfa æquat 12 ; quo facto non fas eft ulteriùs progredi, quandoquidem poftremus terminus augeri nequit, quin aliquis priorum diminuatur, \& fic redire faciat unum præcedentium modorum. Quapropter conftat, nullos dari alios modos, quibus componi poffit numerus 2 ex quatuor aliis, quorum finguli. 
guli fenarium non fuperant; præter undecim hactenùs enumeratos, quios eo ordine quo fefe offerebant, adjuncto laterculo infertos con-

\begin{tabular}{|c|c|}
\hline Modi & 7 actus. \\
\hline 6. $4 . I_{0} I$ & 12 \\
\hline 5. 5. I. I & 6 \\
\hline 6. 3. 2. I & 24 \\
\hline I. 4. 2. I & 24 \\
\hline 5.3 .3 .1 & I 2 \\
\hline $4 \cdot 4 \cdot 3.1$ & I 2 \\
\hline $6.2=2.2$ & 4 \\
\hline 5.3 .2 .2 & 12 \\
\hline $4 \cdot 4 \cdot 2 \cdot 2$ & 6 \\
\hline $4 \cdot 3 \cdot 3 \cdot 2$ & 12 \\
\hline $3 \cdot 3 \cdot 3 \cdot 3$ & I \\
\hline $\begin{array}{l}\text { Summa } \\
\text { factusm }\end{array}$ & 125 \\
\hline
\end{tabular}

fpicis. Haud abfimili autem ratione recenm fere poterimus omnes modos pollibiles, quibus evenire poteft quilibet alius punctorum numerus in tot tefferis quot quis voluerit, dummodò advertamus, primæ tefferæ puncta continuâ adjectione unitatis elevanda effe ad fenarium, priusquàm puncta fecunda augeantur folâ unitate, \& puncta pariter fecunm dæ attollenda ad fenarium, priusquàm punEta tertia augeantur unitate, \& puncta tertix, priusquàm puncta $4^{\text {tax }}, \& 4^{\text {tx }}$ priusquàm $5^{\text {tax }}, \&$ ita deinceps.

Hoc peracto, aliud fupereft negotium in eo confiftens, ut exploretur numerus jactuum fingulorum modorum; nam fingulis horum modorum plures iterum refpondere poffunt jactûs, prout hic vel ille numerus in hâc illâvé teflerâ confpici poteft. Ita fi quatuor tefferæe vocentur $A, B, C$, $\& D$, patet ad primum modum efficiendum 6.4 .1 .1 , poffe vel in $A 6,8<$ in $B$ vel $C$ vel $D 4 ;$ vel in $B 6, \&$ in $A$ vel $C$ vel $D 4$, $\& c$. puncta reperiri: unde tot refultabunt jactûs, quoties ifti 4 numeri diverfo ordine locari poffunt; quod de reliquis modis pariter intelligendum. Poffunt verò numeri 6.4 .1 .1 , quorum duo funt diverfi, duo iidem, locum inter fe permutare duodecies: fequentes $5.5 .1 . I$, quorum duo priores, ut \& pofteriores duo funt iidem, non nifí fexies: fequentes verò 6.3 .2 .1 , qui omnes inter fe differunt, vicies quater; uti conftabit ex Doctrinâ de Permutationibus \& Combinationibus, quam parte fecundâ pertractandam fufcepi. Hi jactûs unà cum jactibus reliquorum modorum in unam fummam colleki efficiunt 125 , numerum indigitantem omnes quot-, quot dari poffunt jactû́s is punctorum in 4 tefferis. Quod ipfum indagandum erat.

Verùm enimverò quoniam hæc methodus fupputandi numerum jactum in pluribus tefferis, fupra modum tædiofa \& prolixa eft, 
eft, oftendam porrò, quâ arte idem confequi poffimus non tantuhmì pro certo punctorum numero, fed pro omnibus omninò punctis, beneficio appofita Tabulæ, quæ \& expeditè admodùm conftrui poteft, \& naturam progreffionemq́ue, quam numeri jactuum inter fe fervant, apertiùs ob oculos ponit. Conftructio talis eft: Scribantur ordine numeri omnium punctorum quotquot tefferæ recipere poffunt à minimo ad maximum, putà, $4 \cdot 5 \cdot 6.7$ \&c. ufque ad 24 pro tefferis quatuor; aut 5.6.7.8 \&c. ufque ad 30 pro tefferis quinque, \&cc. \& fub eorum fex primis collocentur fex unitates, quibus fubjungantur fex aliæ unitates, \& his iterum $\mathrm{ex}$ aliæ, idq́ue fiat fexies, promovendo fingulis vicibus earum primam uno gradu versùs dextram : quo facto addendæe quæ in eâdem ferie perpendiculari fibi invicem refpondent, ut fiant numeri $1.2 \cdot 3 \cdot 4$ \& 2 . Horum deinde numerorum fex quoque conftituendi funt ordines, ita ut fequentium quilibet præcedenti uno puncto anterior fiat; $\&$ tum addendi, ut prodeant numeri 1.3.6. 10 \& 2 . Hi iterum fexies gradatim ponendi \& addendi; idque tamdiu continuandum eft, donec tot ex ultimâ additione refultantes habeantur numeri, quot reperiuntur diverfa puncta in propofito tefferarum numero; fignificabuntq́ue numeri finguli punctorum fibi refpondentium ja¿tûs. Ita 4 tefferarum jactus unus eft, qui 4 aut 24 puncta prom ducit, quatuor jactûs, qui 5 aut 23 , decem qui 6 aut 22 , viginti qui 7 aut 2 I puncta efficiunt \&x. Racionem hujus conftructionis attendenti percipere haud difficile eft: Cùm enim fingulæ accedentes tefferæ jactûs præcedentium fextuplicent, manifeftum eft, cur numeri jactuum piæcedentium tefferarum fexies repetendi \&r addendi fint; \& quia numeri punctorum, qui fingulis ifts jactibus refpondent, augentur unitate, vel binario, vel ternario \&c. prout in accedente tefferâ vel unum, vel duo, vel tria \&cc. inveniuntur puncta, patet etiam, cur feries ifta jactuum fingulis vicibus uno gradu dextrorfum promovenda fit, nimirum ut hâc ratione cuili bet jactuum numero refpondeat numerus punctorum unitate major quàm eidem refpondebat in ferie præcedente.

Nota, non omnes punctorum numeros pro 5 \& $\mathrm{Cex}$ tefleris ob Epatii defectum apponi potuiffe; fed facile fupplentur, qui defunt, ex parallelis: nam bini puntorum numeri ab extremis æqualiter 


\begin{tabular}{|c|c|c|c|c|c|c|c|c|c|}
\hline I & I. & 2. & 3. & 4. & & & & & \\
\hline II & 2. & 3. & 4. & S. & & & & & \\
\hline III & 3. & 4. & 5. & 6. & & & & & 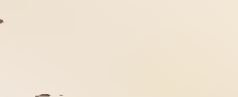 \\
\hline$\overline{I V}$ & 4. & 5 & 6. & 7. & 10. & 21. & 22. & 23. & 240 \\
\hline$V$ & 5 & 6. & 7. & 8. & I. & 22. & 23. & 24. & $25.8 \times c$ \\
\hline VI & 6. & 7. & 8. & 9. & 12. & 23. & 24. & 250 & 26. \& $2 c_{0}$ \\
\hline
\end{tabular}

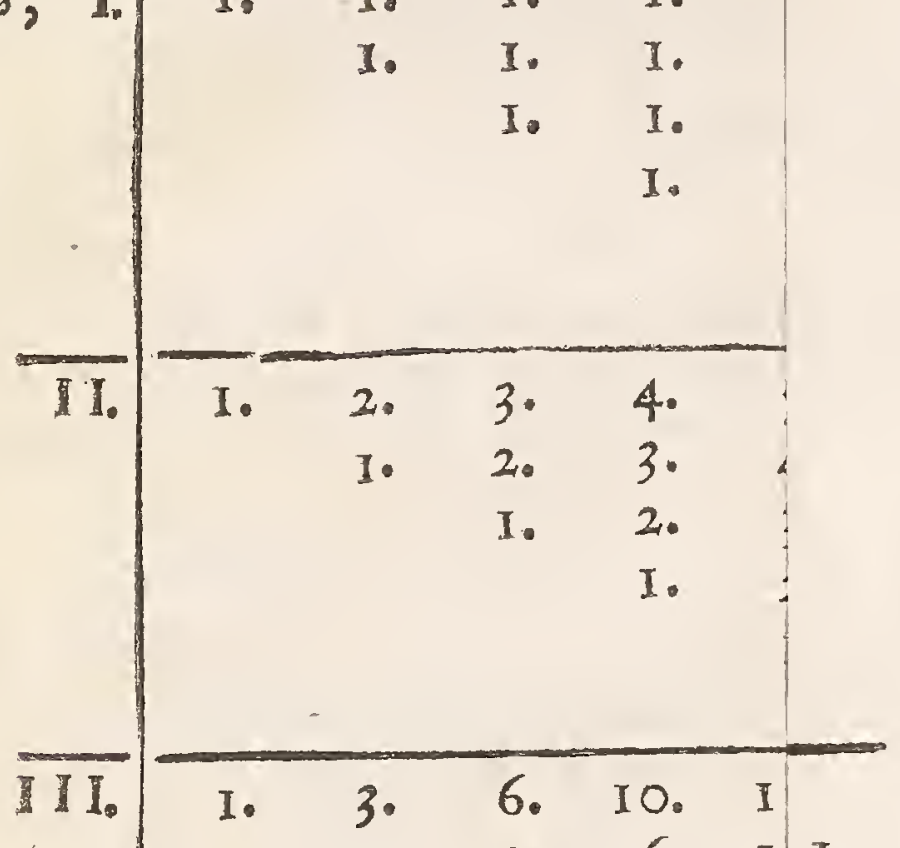





\section{Puncta:}

\begin{tabular}{|c|c|c|c|c|c|c|c|c|c|c|c|c|c|c|c|c|c|c|c|c|}
\hline 1 & I. & 2. & 3. & 4. & 5. & 6. & & & & & & & & & & & & & & \\
\hline II & 2. & 3. & 4. & 5 & 6. & 7. & 8. & 9. & 10. & II. & 120 & & & & & & & & & \\
\hline III & 3. & 4. & 5. & 6. & 7. & 8. & 9. & 10. & II. & 12. & 13. & 14. & I\%. & I6. & 17. & 18. & & & , & \\
\hline I V & 4. & 5. & 6. & 7. & 8. & 9. & 10. & II. & 120 & 13. & 14. & 15.0 & 16. & 17. & 18. & 19. & 21. & 22. & 23. & 24 \\
\hline$V$ & 50 & 6. & 7. & 8. & 90 & IO. & II. & 12. & 13. & I4. & 15. & 16. & 17. & I8. & 19. & 20. & 22. & 23. & 24. & $25.8 c_{0}$ \\
\hline $\mathrm{VI}$ & 6. & 7. & 8. & 9. & 10. & II. & 12. & I3. & 14. & 15 & 16. & 17. & 18. & 190 & 20. & $2 I_{0}$ & 23. & 24. & 25. & 26. \& $2 c_{0}$ \\
\hline
\end{tabular}

MStm. jadtisum tro Teforis, I

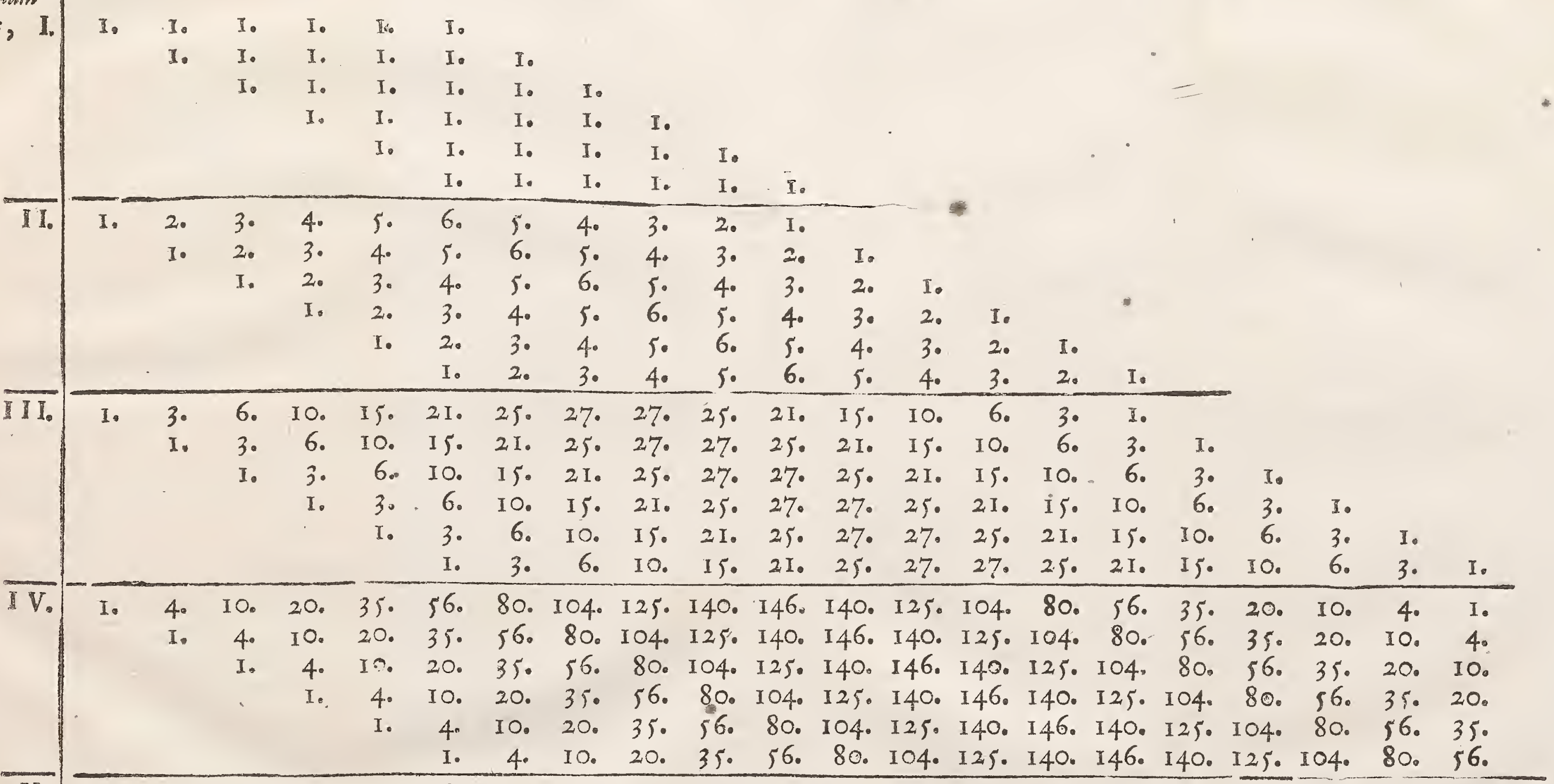

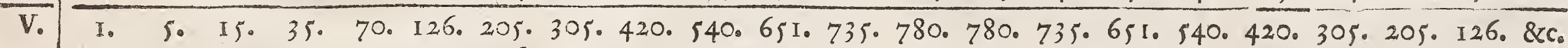

I. 5. I5. 35. 70. 126. 205. 305. 420.540.651.735.780.780.735.651.540.420.305.205.

I. 5. I5. 35. 70. I26. 205.305.420.540.651.735.780.780.735.651.540.420.305.

I. 5. Is. 35. 70. I26. 205. 305.420.540.65I.735.780.780.735. 65I. 540.420.

3. 5. $15.35 .70 .126 .205 \cdot 305 \cdot 420.540 .651 .735 \cdot 780.780 .735 .651 .540$.

I. 5. I5. 35. 70. I26. 205. 305. 420.540.65T.735.780.780.735. 65I.

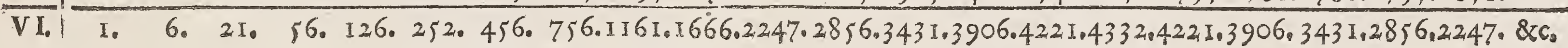



pemoti (quos parallelos voco) equali femper jactuum numero gaudent.

Non inopportunum erit hîc loci indigitare, cùm id fcire non: munquam interfit, quot jactibus effici poffint in tribus tefleris puncta triplicata vel duplicata, (Galli vocant rafles \& doublets) "hoc eft, quoties contingere queat, ut vel in omnibus tribus, vel faltem in duabus tefferis, reperiatur aqualis punctorum numerus: Liquet vero, unum tantum effe jactum, quo produci poffunt tres fenarii, item unum quo tres qumarii, unum quo tres quaternarii \&x. adeoque non nifi 6 punctorum triplicatorum jactûs exiftere poffe. Sed contra I5 funt jactûs, quibus duo ex. gr. fenarii contingere poffunt: etenim fi tellera vocentur $A, B, \& C$, fieri potelt, ut duo illi femarii reperiantur vel in tefferis $A \& B$, vel in $A \& C$, vel in $B \&$ $C$, quod tres castús efficit: ac deinde ratione cujusque horum cafuum jactus tertia tefleræ, in quâ diverfus punctorum numerus confpici debet, variari poteft quinquies; unde quinquies tres feu 5 exiftunt duorum fenariorum jactûs; quod cùm idem de duobus quinariis, quaternariis $\&$ reliquis intelligendum, fequitur punctorum duplicatorum effe fexies quindecim feu go jactûs: Proinde cùm trium tefferarum jactûs in univerfum exiftant 216 , erunt reli= qui 120 jactûs fimplices, quorum numerus etiam initio inveftigari potuiffet.

\section{PROPOSITIO X.}

TNenire, quot vicibus fufcipere quis poffit, ut unâ 1 tefferâ 6 puncta jaciat.

Si quis primâ vice fenarium jacere contendat, apparet unum effe cafum, quo vincat, habeatque id, quod pignoris loco depofitúm eft; quinque verò effe casûs, quibus perdat, \& nihil habeat. Sunt enim 5 jactîs contra ipfum, \& tantùm unus pro ipfo. Quod autem depofitum eft vocetur $a$. Eft itaque ipfi unica expectatio ad obtinendum $a$, fed quinque ad obtinendum $0 ;$ id quod per 2 dam Propolitionem tantundem valet ac $\frac{1}{6} a$. Et manet pro eo qui ipfi humic cafum offert $\frac{5}{6} a$. Ita ut tantummodo I contra 5 deponere poffiz; qui primâ vice fúcipere velit. 
Qui duabus vicibus femel fenarium jacere certet, fors ejus hoe påto computatur. Si primâ vice 6 jaciat, obtinet $a$. Si diverfum eveniat, unus ipfi reftat jactus, qui ex præcedenti tantum valet, quantum $\frac{1}{5} a$. Atqui ưt primâ vice 6 jaciat, unus tantừm cafús eft, \& quinque casîs, quibus diverfum eveniat. Itaque $a b$ initio unus calus eft, qui det ipfi $a ; \&$ quinque qui dent $\frac{1}{6} a$, id quod per 2 dam Propofitionem valet $\frac{x}{3} \frac{1}{6} a$. Unde contracertanti lufori cem dit reliquum $\frac{25}{36} a$; adeò ut fors utriusque five æfltimatio expectationis eam fervet rationem, quam II ad 25 ; id eft, minus quàm I ad 2.

Hinc eodem modo calculo fubducitur, quòd fors ejus, qui tribus vicibus femel fenarium jacere fufcipit, fit futura $\frac{2 \pi}{216} a ;$ ita ut 9 r contra 125 deponere poffit; id eft, paulò minus quàm 3 ad 4 is

H Qui quatuor vicibus idem fufcipit, fors ejus eft $\frac{671}{1296} a$; ita ut 671 contra 625 deponere poffit; id eft, plus quàm I ad 1 .

Qui quinque vicibus idem fufcipit, fors ejus eft $\frac{4551}{77} \frac{1}{6} a, \&$ poteft 465 I contra 3125 deponere; id eft, paulo minus quàm 3 ad 2 .

Qui fex vicibus idem fufcipit, fors ejus eft $\frac{31031}{46656} a, \& 2$ poteft 3103 I contra 15625 deponere; id eft, pauld minus quàm 2 ad I.

Atque ita confequenter quilibet jactuum numerus inveniri poteft. Sed licet majori compendio progredi, ut in fequenti Propofie tione oftendetur; fine quo calculus aliàs multò prolixior foret.

\section{ennotat.}

H 2ui quasuor vicibus idem fufcisit, orc.] Subiit alli quando cogitatio, poffe fortè quempiam calculum Au\&toris tali dif curfu fufpectum reddere : Si quis quatuor jactibus fenarium jacere contendens, æquam circiter ad vincendum ac perdendum expecta. tionem habeat, hoc eft, æque facilè vincat ac perdat, flet ut aliquan diu ludens toties vincat quoties perdit, fi $\&$. pari fortuna utatur $;$ adeoque ut è quaternis jactibus toties unus fenarius exiftat, quoties è quaternis aliis nullus : quare in octonis jactibus unus reperietur fenarius, ac proinde in fexcentis verb. gr. jactibus fenarii 75 . Sunto jam fex alii, qui eâ conditione ludant, ut primus vincat, fi unum punctum jaciatur, fecundus fi duo, tertius fi tria \& $x$, quo utique pacto 


\section{ARS PRIMA.}

pacto æquá forte certabunt; fed ludant etiam pari fortunâ, fic fet neceffariò, ut in fexcentis jactibus centum eveniant fenarii : idcircò cùm æquấ forte \& pari fortunâ luditur, in fexcentis jactibus fenarii prodibunt centum \& pauciores quàm centum, quod abfurdum. Huic fallaciæ ut fatisfiat, pono quidem, quòd ubi æquâ fortunâ ludituth, ibi in jactibus 600 evenire debent fenarii centum; fed nego quod fi quis quaternis jactibus femel fenarium jacere certaverit, proptereà quatuor jactibus ad vincendum opus habeat; poteft enim vel primus, vel fecundus, vel tertius jaktus fenarius exiftere, quo cafu reliqui jactûs fequenti quatemario annumerantur ; fic ut pauciores quàm octo ad femel vincendum ac perdendum fufficere poffint. Id verò quo pacto huc quadret, fic oftendo: Fingo, in omnibus jactuum quaternariis, qui me ludi viktorem reddunt, primum quemque jactum fenarium exiftere; fic centies vincendo non nif centum jactûs infumuntur, reliqui 500 per 4 divifi indigitant me \$2 $5^{\text {ies }}$ perditurum. Si verò illorum quaternorum jactuum poftremus quisque fenarius foret, vincendo centies 4,00 jactûs abfumeren tur, refiduis tantùm ducentis, qui oftenderent me quinquagies pera diturum. Quocircà cùm nonnullis cafibus frpiùs perderem quàme vincerem, aliis pluries vincerem quàm perderem, colligo fieri benè poofle, ut hâc conditione æquâ forte certetur. Contra verò, fi quis tribus vicibus femel fenarium jacere fufcipiat, is quidem aliquot cafibus toties vinceret quoties perderet, nempe fi tertius quivis jactus fenarius exifteret; aliis multò pluries perderet quàm vinceret, fl nim. primus quisque fenarius foret; fed nullo cafu frpiùs vinceret quàm perderet : unde conftare liquidò potef, neminem nifi cum detrimento tali conditione certare poffe. Qux quidem eum in fisnem hîc adduco, ut palàm fiat, quàm parùm fidendum fit ejusmodi ratiociniis, quæ corticem tantum attingunt, nec in ipfam rei naturam altiùs penetrant; tametfi in toto vitæ ufu etiam apud $f_{2}$. pientiffimos quosque nihil fit frequentius.

\section{PROPOSITIO XI.}

Tvenire, quot vicibus fufcipere quis poffit, ut dua1 bus tefferis 12 puncta jaciat. 
Si quis primâ vice duos fenarios jacere contendat; appareft unum effe cafum, quo vincat, id eft, ad obtinendum $a ; \& 35$ effe castis, quibus perdat five nihil habeat, quoniam 36 funt jactûs. Ita. que habet per $2^{\text {dam }}$ Propofitionem $\frac{3}{36} a$.

Qui duabus vicibus idem fufcipit, fí primâ vice duos fenarios jaciat, obtinebit $a$; ferò primâ vice diverfum eveniat, unus jpfi reftat jactus, id quod ipfi, per illud quod jam dictum eft, valet $\frac{\pi}{36} a$.

Atqui ut primâ vice duos fenarios jaciat, unus tantùm eft cafus, fed 35 casûs, quibus diverfum eveniat. Itaque ab initio unus: cafus eft, qui det ipfi $a, \& x 35$ qui dent $\frac{x}{35} a^{2}$; id quod per 2 dam Propofitionem valet $\frac{7}{12} \frac{1}{9}-a_{\text {e }}$ Et remanet contracertanti $\frac{1}{1} \frac{2}{2} \frac{25}{2} a_{\text {e }}$.

Ex his invenire licet, qualis fit ei fors aut pars, qui idem fufe cipit quaternis jastibus, prætereundo cafum eum, cùm quis illud: ternis jactibus fufcipit.

Etenim, qui $4^{\text {or }}$ vicibus duos fenarios jacere contendit, fi ild lud Imâ aut 2 dâ vice faciat, obtinet $a$; fin minùs, reftant ipfit duo. jactûs, qui per illud quod fuperiùs dictum eft, valent $\frac{7}{12} \frac{1}{9} 5 a$. Sed

I propter eandem rationem habet etiam $7 \mathrm{I}$ casûs, ut ex duobus primis jactibus femel duos fenarios jaciat, contra 1225 casûs, quibus. diverfum eveniat. Habet itaque $a b$ initio $7 \mathrm{I}$ casûs, qui ipfr dent $a_{2}$ $\& 21225$ casûs, qui dent ipfi $\frac{71}{1} \frac{1}{2} \sigma a$. Quod ipfí per 2 dam Propofitionem valet $\frac{17899 \frac{1}{16}}{16} a_{0} \mathrm{Et}$ remanet contracertanti $\frac{1500}{16} \frac{52}{6} \frac{25}{16} a_{0}$ Id quod oftendit eorum fortes effe ad fe invicem, ut 178991 ad 500625 .

$E^{\prime}$ quibus porrò eâdem ratione invenitur expectatio ejus, quì 8 vicibus femel duos fenarios jacere certat. Ac inde rurfus expecta tio ejus, qui idem fufcipit I6 vicibus. Atque ex hujus expectatione, ut etiam ex expectatione illius, qui iftud 8 vicibus fufcipit, ins venitur expectatio ejus, qui illud 24 vicibus in fe recipit. In quât operatione, quoniam pracipue quaritur in quo numero jacturum zqualis fors incipiat, inter eum qui id fufcipit \& eum qui offert, licebit à numeris, qui alioquin in immenfum excrefcerent, pofteR riores aliquot characteres auferre. Atque ita quidem reperio ei, qui illud 24. vicibus fufcipit, adhuc aliquid deficere; tumque demum eum potiorem conditionem inire, cùm 25 jactibus aggreditur, 


\section{Annotat.}

Sed propter eandem rationem habet etiam 7 I casits 6.6.] I Juvat hîc obfervare, quod Auctor fupponit, expectationem quamcunque fractione expreffam confiderari etiam poffe tanquam refulm tantem ex tot cafibus ad obtinendum depofitum $a_{2}$ quot indigitat numerator fractionis, \& tot cafibus ad nihilum, quot fignificat differentia inter illum \& denominatorem; tametfi fortâfîs aliter ad expectationem illam perventum fuerit: Sic quanquam ille, qui duabus vicibus duos fenarios jacere fufcipit, ad expectationem fuam $-\frac{71}{2} \frac{1}{96}$ perveniat per I cafum ad $a, \& 35$ casûs ad $\frac{1}{36} a$; nihilominuis cenferi etiam poterit eam fibi acquirere per $7 \mathrm{I}$ casûs ad $a, \&$ 1225 casûs ad o. Quoniam habens 71 casûs ad $a, \& 1225$ ad 0 , habet hanc expectationem $\frac{7}{12} \frac{1}{2} \sigma a ; \&$ qui plures casûs ad a haberet ac pauciores ad nihilum, aut vice versâ, ejus quoque expectatio contra hypoth. major minorvé foret, quàm $\frac{71}{12} \frac{1}{2} a_{2}$ per Coroll. $I_{0}$ Propofit, III.

Atque ita quidem reperio ei, qui illud 24 vicibus fufci- $K$ pit oc.] In præced. Propofo adftruxit Auctor, poffe quatuor jactibus cum lucro fufcipi, ut unâ tefferâ fenarius jaciatur; nune afferit, nondum illud 24 jactibus poffe, ut duabus tefferis duo jaciantur fenarii ; quae multis planè videbuntur ácísalos, cìm 24 ja¿tûs ad omnes 36 jactûs duarum tefferarum eandem præcisè rationem fervent, quam 4 jactûs ad omnes fex jactû́s unius tefferæ. Eấdem olim difficultate confrictus hefit, referente $\mathrm{Pafcalio}$ in literis ad Fermatium, quæ hujus operibus Tolofæ $\mathrm{A}^{\circ}$. 1679. impreffis pagin. 18I. infertæ leguntur, Anonymus quidam cæeterà fubacti judicii Vir, fed Geometrix expers. Hâc enim qui imbuti funt, ejusmodi zuavihoposysés minimè morantur, probè confcii dari innumera, quiæ admoto calculo aliter fe habere comperiuntur, quàm initio apparebant; ideoque fedulò cavent, juxtà ìd quod femel iterum gue monui, ne quicquam analogiis temerè tribuants. 


\section{Ad Propofitionem in genere:}

Sl pro numeris literas fubftituiffet Auctor, potuiffet hane \& pre:1 cedentem Propofitionem uno Problemate complecti, ejusque folutionem generalem pari facilitate inveftigare, hoc pacto: Pona: tur $a: D b+c$ pro numero omnium cafuum, qui reperiuntur in unâ phuribusvé tefferis, aut in quâvis aleâ, (cùm hæec non magis tefforis applicari debeant, quàm quibusvis fortitionibus aliquoties reiterandis, \& in quibus numerus cafuum perpetuò conftans idemque manet) $b$ verò fumatur pro numero cafuum, quibus præfcriptus punctorum numerus obtinetur, feu quibus obtinetur quod fufceptum eft; \& c pro numero cafuum, quibus illud non obtinetur. feu quibus non preftatur quod intenditur.

Jam fi quis primâ vice fufcipiat præftare aliquid, patet, eum habere $b$ feu $a-c$ castus ad illud preftandum, hoc eft, ad obtinendum depofitum, quod nunc fit $I, \& c$ casûs ad obtinendum 0 ; quare ejus fors per Cor. I. Prop.III. fit $\frac{a-c}{a}$ : Si quis duabus vie cibus illud fufcipiat, rurfus habet $a-c$ casûs ad I vel $\frac{a}{a}$, fed $c$ cas sûs quibus pertingit ad præcedentem expectationem $\frac{a-c}{a} ;$ id quod per III. Prop. valet $\frac{a a-c c}{a d}$ : Si quis tribus vicibus idem præftare contendat, habet denuò $a-c$ casûs ad I feu $\frac{a d}{d a}, 8 x c$ casûs ad for tem proximè inventam $\frac{a d-c c}{a d}$; quod ipfi tantundem valet, ac $\frac{a^{3}-c^{3}}{a^{3}}$ : Eodem modo, $\mathrm{fi}_{4}$ vicibus illud in fe recipiat, invenitur ejus expectatio $\frac{a^{4}-c^{4}}{a^{4}}$ : fi quinque, $\frac{a^{5}-c^{5}}{a^{5}} ; 2 x$ in genere fi $n$ vicibus, reperitür fors ejus $\frac{a^{n}-c^{n}}{a^{n}}$, fic ut remaneat contracertanti $\frac{c^{n}}{a^{n}}$ :

Prater hanc methodum, quæ Auctoris eft, duo alii fuppetunt modi haud inelegantes Problema folvendi, quorum unus hic eft: Quærantur ordine expectationes aleatoris pro fingulis jactibus feorfim, 


\section{$P A R S P R I M A$.}

fim, hoc eft, quæratur quæ fint illius fortes, fi primo, fecundo, tertio, quarto \&xc. demùm jastu, non alio, præeftare quid velit; quod enim ex omnium expectationum additione refultat, erit expectatio quafita, Qui primo jactu quid fufcipit, ejus fors oftenfa eft efle $\frac{a-c}{a} \infty \frac{b}{a}$. Qui fecundo jactu preftare vult, ille fi primo præftat, non præftat quod intendit, cùm folo fecundo præftare debuiflet; ideoǵue depofito fruftratur: fin autem primo non præftat, reftat illi unus jactus quo id præftare tenetur, qui ipfi valet, ut diatum $\frac{b}{a} ;$ fed numerus cafuum, quibus primo jactu id efficir, per hyp. eft $b, \&$ eorum quibus non efficit $c$; unde per I. Coroll. III. fors ejus fit $\frac{b c}{a a}$. Qui tertio demùm jactu praftare intendit, is fi primo preftat rurfus depofito excidit, quia intentum non affecutus eft, quod eò tendebat, ut folo tertio præftaret: fin primo jactu non præftet, fuperfunt ipfi duo jactûs, quorum folo pofteriori præftare tenetur, quo cafu oftenfum eft ipfi deberi $\frac{b c}{a d}$; fed prius illud $b_{2}$ hoe $c$ cafibus contingere poteft, quod proin fortem ejus per idem Coroll. efficit $\frac{b c c}{d^{3}}$. Qui folo $4^{\text {to }}$ jactu preftare aggreditur, is fi primo preftat, depofito identidem privatur : fi fecùs, per tres reefiduos jactûs ad præced. expectationem $\frac{b c c}{a^{3}}$ pertingit; quod illi nune fortem parit $\frac{b c 3}{a^{4}}$. Atque codem modo colligitur, quòd fors ejus, qui $5^{\text {to }}$ jactu in fe recepit, fit $\frac{b c 4}{a^{5}}$; qui fexto, $\frac{b c 5}{a^{6}}$; \& generaliter qui $n$ jactu, $\frac{b c^{n-1}}{a^{n}}$. Ergò cùm fors ejus, qui primo jaatu aggreflis eft, fit $\frac{b}{a} ;$ qui fecundo, $\frac{b c}{a a^{3}} ;$ qui tertio, $\frac{b c c}{a^{3}} ;$ qui ultimo, $\frac{b c^{n-1}}{a^{n}} ;$ atque expectatio ejus, qui illud indefinitè in aliquo primorum $n$ jactuum præftandum fufcepit, ex omnibus illis fmaul funtis confletur, fequitur hanc fore ejus expectationem 
$\frac{b}{a}+\frac{b c}{a d}+\frac{b c c}{a^{3}}+\frac{b c 3}{a^{4}} \ldots$ ufque ad $\frac{b c^{n-1}}{a^{n}}$, quæ feries eft quantitatum geometricè - proportionalium, quarum fumma invenitur $\frac{a^{n}-c^{n}}{a^{n}}$, ut fuprà。

Alter modus: Qui $n$ jactibus unius tefferæ præforiptum puncto rum numerum jacere fufcipit, perinde facit, ut ad feq. Prop. oftendetur, ac fi eundem unico jactu $n$ teflerarum in aliquâ minimùm tefferâ jaciendum fufciperet. Concipiantur itaque $n$ tefferæ, fingu= læ inftructæe $a$ hedris, quas inter fint $c$ ifto punctorum numero non fignatæ. Sic erit numerus omnium cafuum in univerfis $n$ tefferis, $a^{n}$; (ut fupra poft Prop. IX. evicit Auftor) \& per eandem rationem numerus eorum, quibus optata puncta in nullâ tefferarum emicant, $c^{n}$; quia nimirum ratione cujuslibet ex $c$ hedris unius tefferæ, quælibet fimilium hedrarum alterius tefferæ fimul cadere poreft. Neceffe igitur eft, ut reliquis $a^{n}-c^{n}$ cafibus hac puncta faltem in aliquâ tefferarum reperiantur. Quare qui tali conditione certat, habet $a^{n}-c^{n}$ casûs ad obtinendum depofitum $\mathbf{I}, \& c^{n}$ ca* sûs ad obtinendum o; quod rurfus ut anteà fortem illi paris $\frac{a^{n}-c^{n}}{a^{n}}$, fic ut contracertanti femper relinquatur $\frac{c^{n}}{a^{n}}$.

Exhibitâ fic generali Problematis folutione, fi nunc poîrò cưner Auctore fcire cupiamus, quo jactuum numero æqualis fors inter -contracertantes incipiat, æquandæ tantùm inter fe erunt eorum inventæ fortes, ut fiat $a^{n}-c^{n} \times c^{n}$, hoc eft, $a^{n} \infty 2 c^{n}$; quo indicatur nil aliud requiri, quàm ut numerus omnium cafuum, \& numerus eorum quibus non obtinetur quod fufceptum eft, continuo in fe ductu ad fimiles poteftates attollantur, quoufque produEtum prioris numeri fiat pofterioris duplum : tum enim index poteftatis, ad quam uterque elevatus eft, indigitabit quæfitum. Quix operatio illud infuper commodi præ Hugenianâ habet, quòd non fupponat ullius præcedentis casûs fortem cognitam effe : cætera enim compendia, quorum meminit Auctor, de abfcindendis à fine notis , \& eliciendis per faltum expectationibus, \& hîc loci obtinet 
quandoquidem dato cujuslibet numeri guadrato, ejus biquadratum inveniri poteft non reperto cubo, \& liquadrato-quadratum non repertis intermediis poteftribns, \&c. Vifum autem ef, exempli Auktoris, in quo a valet $36 \& 635$, totam operationem, hîc fubjungere:

$$
\begin{aligned}
& \text { jufto minor major } \| \text { c } \infty^{\text {mino }} 35^{\text {maj. }}
\end{aligned}
$$

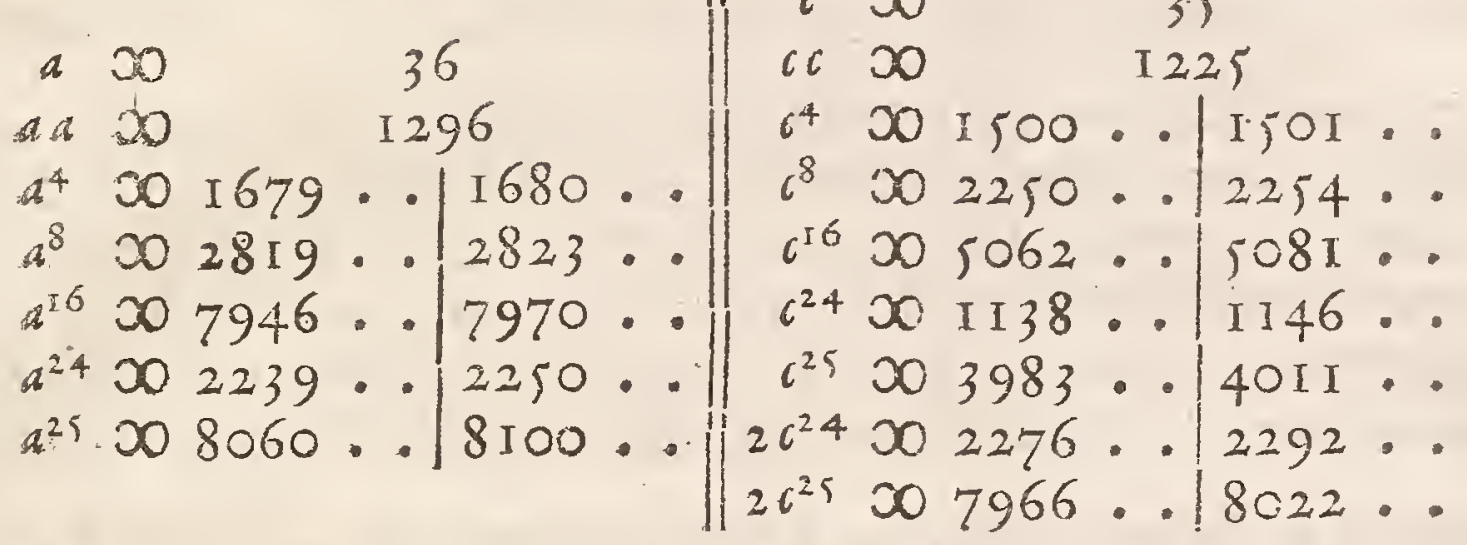

ubi liquet, $24^{\text {tam }}$ poteftatem numeri 36 (quæ cadit inter $2239 \ldots$ \& $225^{\circ} \ldots$ ) deficere à $24^{\text {tx }}$ poteftatis numeri 35 duplo (quod cadit inter $2276 \ldots$ \& $2292 \ldots$ ): fed $25^{\text {tam }}$ poteftatem illius numeri (cujus limites funt $8060 \ldots \& 8100 \ldots$ ) excedere vicifim duplum $25^{i x}$ hujus, (utpote quod terminis continetur $7966 \ldots$ \& $8022 \ldots)$.

Monendum tamen eft, totum hoc expediri poffe negotium comm pendio citra comparationem majori per logarithmos, ita: Quia habemus $a^{n} \mathrm{D}_{2} c^{n}$, \& xqualiumn numerorum æquales funt logarithmi, erit quoque $n l a \infty l_{2}+n l c$, five $n l a-n l 6 \infty l_{2}$, feu denique $n \infty \frac{l_{2}}{l a-l s}$; quo indicatur quxefitum numerum jactuum haberi, dividendo fimpliciter log-um binarii per differentiam inter $\log$-os numerorum a \& $c$. En operationem:

$$
\begin{aligned}
& \text { a } \infty \begin{array}{ll|llll} 
& 36 & \text { la } & \infty & \text { I. } 5563025
\end{array}
\end{aligned}
$$

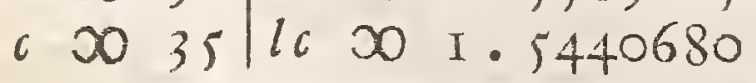

$$
\begin{aligned}
& \text { la-lc } 00 \text { 0.0122345) l2,000.3010300 (plus }
\end{aligned}
$$
quàm $24, \&$ minus quàm $25 ;$ quæe calculo Auctoris \& noftro plane funt confonà. 
Cæterum folutio noftra Propofitionis præfentis anfam nobis fuppeditavit inveftigandi praterea nonnulla alia huic affinia Problemata, quorum unum hoc eft: Si plures collufores jacere fufcipiant præfriptum punctorum namerum, iisque fingulis uni poft alterum nonnulli jactus, huic plures illi pauciores, continuò inftituendi concedantur, quxritur cujusque fors? Ante omnia liquet, quòd ille cujus fors quæritur haberet per ante oftenfa $\frac{a^{n}-c^{n}}{a^{n}}$, fi ipfe ludum. inciperet; fed quia alii præcedunt, qui victoriam illi præripere pof funt, fors ejus minoris aftimanda venit. Deinde patet, quòd expectationes omnium ipfum præcedentium fimul fumtæ æequari debeant expectationi unius folius, qui in locum eorum fuccedere velo let, \& cui tot jacturs concederentur quot omnibus illis fimul. Sed: per eandem rationem, if numerus horum jastuum dicatur $s$, expeatatio hæc foret $\frac{a^{s}-c^{s}}{a^{s}}$; unde per annotata hujus ad lit. I. ille curjus fors quæritur, tum, cùm primus ludere incipit, habere cenfetur $a^{s}-c^{s}$ cafus, quibus aliquis præcedentium vincat fibique depofitum præripiat; \& $c^{s}$ cafus, quibus ludendi vices ad fe devolvuntur ipfeque fortem antè dictam $\frac{a^{n}-c^{n}}{a^{n}}$ acquirit: id quod ipfi pere I. Coroll. III. valet $\frac{a^{n}-a^{n} \cdot c^{s}}{a^{n} \cdot a^{s}} \infty \frac{a^{n} c^{s}-c^{n}+s}{a^{n}+s}$. Idem etiam fic: evincitur: Quia univerfis colluforibus inclufo ultimo per hyp. conceff funt $s+n$ jactus, erit eorum expectario totalis $\frac{a^{s+n}-c^{s+n}}{x^{s}+n}$; غ̀ quâ proin fi expectationes omnium pracedentium poftremum, qua fimul furntæ conftituunt $\frac{a^{s}-c^{s}}{a^{s}}$, fubtrahas, relinquetur pre: expectatione folius ultimi $\frac{a^{5}+n-c^{3}+n}{a^{s}+n}-\frac{a^{3}+c^{3}}{a^{s}} \infty \frac{a^{n} c^{3}-c^{n}+s}{a^{n}+s}$. ut antea. Nota, infigniter hic abbreviari calculum, fi numeri caCuum a \& 6 compofiti fint, \& eorum loco per ${ }_{2}$ Cor, III, minimi 
in eâdem ratione termini accipiantur: Proponantur ex. gr. aliquot colluforibus jacienda duabus tefferis puncta feptem, \& eorum primo permittatur unus, fecundo 2 , tertio 3 , quarto 4 jactus cone:cutive inftituendi, velimque fcise expsctationem quarti. Quoniam hîc numerus jactuum quarti $n \times 0$, \& fumma eorum, qui præcedentribus tribus funt conceffi, $5 \infty 01+2+3006$; \& proin $\frac{a^{n} c^{s}-c^{n}+s}{a^{n} t^{s}} \infty 0 \frac{a^{4} c^{6}-c^{\mathrm{IO}}}{a^{\mathrm{IO}}} ;$ infuperque numeri $a \& c$ cafuum fil. tum omnium in duabus tefferis, tum eorum quibus non obtinetux prafcriptus punctorum feptenarius, funt $36 \& 230$, pro quibus pono tantùm $6.85 ;$ idcirco à producto ex $4^{\text {tâ }}$ poteftate fenarii in $6^{\text {tans }}$ quinarii aufero decimam quinarii, reliquumque divido per decimam fenarii, \& prodibit pro quæfitâ expectatione colluforis quarti $\frac{10484378}{00466176^{\circ}}$

Manifeftum eft in hocce Problemate, omnium colltiforum, quotquot etiam fuerint \& quotcunque jactus ipfis concedantur, expectaciones in unam fummam collectas neceffario $a b$ ano integro deficere debere; quandoquidem femper cafu quodam utcunque rariffimo accidere poteft, ut eorum nullus prefcriptum punctorum, numerum confequatur. Deinde etiam per fe clarum eft, quòd in pari jactuum numero unusquisque pofteriorum colluforum deteriorem fortem nancifci debeat unoquoque priorum, eoque magis quò plures unicuique jactus continuò inftituendi conceduntur; cùm utique tot concedi poflint, ut primi ludentis fpes in certitudinem ferè abeat, reliquis verò omnis vincendi fpes evanefcat. Quæ proin confideratio aliud nobis fuggeffit Problema, quod eò tendit, ut dato numero jactuum à primo confecutivè inftituendorum inveftigetur, quot jactus fecundo reliquisque concedendi fint, ut fortes omniuma fiant æquales: oportet autem, ut numerus jactuum primi non pariat ei fortem excedentem unum dimidium, fi collufores funt duo; äut tertiam partem integri, fi funt tres; aut $4^{\text {tam }}$ fi quatuor $\& c_{\text {. }}$ cìm fecis Problema impoffibile foret. Sint collufores $m$, numerus jactuum $a b$ univerfis inftituendorum vocetur $x, a b$ omnibus excepto slimo $y$, adeoque à folo ultimo $x-y$; numerus verò jactuum E 2

primi 
primi fit $n$ : erit ejus expectatio $\frac{a^{n}-c^{n}}{a^{n_{0}}}$, \& omnium $m$ colluforum expectationes conjunetim $\frac{a^{x}-c^{x}}{a^{x}}$; cumque fingulæe expectationi primi ponantur æquales, erit quoque eaxum fumma $\frac{m \cdot a^{n}-c^{n}}{a^{n}}$; quare $\frac{m \cdot a^{n}-c^{n}}{a^{n}} \infty \frac{a^{x}-c^{x}}{a^{x}}$, hoc eft $m-\frac{m c^{n}}{a^{n}} \infty \mathrm{I}-\frac{c^{x}}{a^{x}}$, fert factâ transpolitione, $\frac{c^{x}}{a^{x}} \infty \frac{m c^{n}}{a^{n}}+I-m \infty \frac{m c^{n}+\overline{1-m} a^{n}}{a^{n}}$, \& fumm tis logarithmis, $x l c-x l a \infty \overline{l m c^{n}+\overline{1-m} a^{n}}-n l a$, factâque divifione, $x \infty \frac{l_{m c^{n}+\overline{r-m} a^{n}}-n l a}{b c-b a}$, five (mutatis fignis ob $a>c$ ) $x \infty \frac{n l a-l \overline{m c^{n}+\overline{1-m}} a^{n}}{l_{q}-l c}$ Ob eandem rationem omnium colluforum præcedentium ultimum, hoc eft, primorum $m-I$ colluforum expectationes fimul fumtæ funt $\frac{m-1 \cdot a^{n}-c^{n}}{a^{n}} \infty \frac{a^{y}-e^{y}}{a^{y}} ;$ unde fimili modo elicitur $y \infty \frac{n b a-l \overline{m-1 c^{n}+\overline{2-m} a^{n}}}{l a-l c}$ : quare

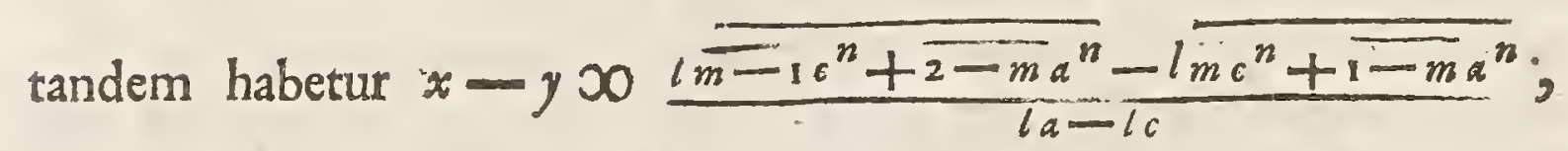
quod requirebatur. Ita fi fint tres collufores, \& eoram primo duo concedantur jactus, jacienda verò proponantur duabus tefferis punEta feptem (vel etiam unâ tefferâ puncta fex; quia utrobique ratio numeri $a$ ad numerum ( ea eft, quam habet 6 ad 5 ) quo cafu primi fors per fuprà oftenfa, propter $n D_{2}$, eft $\frac{a a-c c}{a d} \infty \frac{11}{36}$ pauld minor triente depofiti : facio primò $m x_{2}$, deinde $m x_{3}, \&$ hoc pacto reperio, quòd ad aquandas quàm proximè reliquorum fortes concedendi fint fecundo collufori tres, \& tertio octo jactus. 


\section{$P A R S P R I M A$. \\ PROPOSITIO XII.}

Nvenire, quot tefferis fufcipere quis poffit, ut primât I vice duos fenarios jaciat.

Hoc autem tantundem eft, ac fi quis fire velit, quoto jactu $L$ quispiam unâ tefferâ fufcipere poffit, ut bis fenarium jaciat. Quòd fi quis duobus jactibus fufciperet, obtingeret ei, per ea quæ ante $M$ oftenfa funt, $\frac{1}{35} a$. Qui illud tribus jactibus in fe reciperet, fi primus ejus jactus fenarius non foret, haberet adhuc duos jactus, quorum uterque fenarius effe deberet, id quod tantundem valere dictum eft ac $\frac{1}{35} a_{\text {. }}$. At verò primo ejus jactu exiftente fenario, opus eft, ut ex duobus jactibus non nifi femel fenarium jaciat. Quod per $X$. Propofitionem tantundem valet ac fi $\frac{11}{3} \frac{1}{5}$ haberet. Atqui certum eft ipfum unum habere cafum, quo primâ vice fenarium jaciat, \& quinque cafus quibus diverfum eveniat. Habet itaque $a b$ initio unum cafum ad $\frac{11}{3} \frac{1}{5} a, \& 5$ cafus ad $\frac{1}{36} a$, id quod per II. Propofitionem tantundem valet ac $\frac{16}{2}+\frac{6}{56}$ feu $\frac{2}{27} a$. Hoc pacto affumendo continuè unum jactum ampliùs, invenitur to jactibus unâ tefferâ, aut ro tefferis primo jaçu fufcipi poffe, ut duo fenarii jaciantur, idque cum lucro.

\section{Annotat.}

Hoc autem tantundem est \&.c.] Si cui decem ex. gr. L tefferis unus jactus concedatur, evidens utique eft nihil referre, five decem illas tefferas fimul \& femel feu fucceffivè unam poft alteram in alveum projiciat : \& fi fucceffivè id facit, perinde rurfus effe conftat, five tefferæ illæ decem quæ projiciuntur fint toridem diverfæe teflera, five una eademque decies ex alveo fublata \& projecta.

per ea que ance oftenfa fuxt oc.] Oftenfum eft in $M$ preced. Propof. $\frac{\mathrm{r}}{35}$ a effe partem ejus, qui uno jactu duabus tefferis duos fenarios jacere contendit, fed modò audivimus perinde effe, five quis unum jactum duabus tefferis, five duos jactus unâ tefferâ inftituat: quare \& illi, qui unâ tefferâ duobus jaetibus duos fenarios; hoc eft, bis fenarium jacere fufcipit, eadem debetur portio $\frac{1}{3} \sigma^{a}$. 


\section{ARTIS CONGECTANDI \\ Ad Propofitionem in genere:}

DRoblema hîc loci propofitum, non fecùs atque præcedens, fo1 lutionem quoque admittit per fymbola; \& generaliter conceptum huc redit, ut inveniatur expectatio ejus, qui certo jactuum numero fufcepit aliquid præftare bis, vel ter, vel quater pluriesve. Nam qui femel tantùm id præftare fufcipit, ejus fors in præced. jam Propoficione calculo fubducta habetur.

Qui duabus vicibus aliquid bis præftare fufcipit, ille fi primâ vice non præeftat nihil depofiti habebit, fed totum adverfario cedet: fin id primâ vice præftiterit, reliquo aleæ jactu adhuc femel præftare tenetur; quo cafu per annotata præeced. Propol. (pofitâ fignificatione literarum $a, b \& c$, ut ibi) ipfi debetur $\frac{a-c}{a}, \&$ adverfario ejus $\frac{c}{a}$; (præftat enim hujus fortem, ceu brevioribus terminis comprehenfam, inquirere.) Atqui funt $b$ cafus, quibus id primâ vice efficere poffit; \& $c$ cafus, quibus fecus eveniat: quocirca funt contracertanti $c$ cafus ad obtinendum depolitum i $\infty \frac{c+b}{a}, \& b$ cafus ad acquirendum $\frac{c}{a}$; id quod ipfi valet $\frac{c c+2 b c}{a b}$.

Qui tribus vicibus aliquid bis efficere contendit, ille fi primâ vice efficiat, quod femper $b$ cafibus evenit, duabus reliquis vicibus idem non nifí femel efficere obftrictus eft, fortemque adeò Antagoniftæ fui per Annotat. præc. Prop. facit $\frac{c c}{a a}$ : fin primâ vice id non efficiat, quod cafibus c contingit, tenebitur illud duabus reliquis vicibus bis præftare; quod valere modò diximus Adverfario ejus $\frac{c c+2 b c}{a d}$. Habet igitur ifte $c$ cafus ad $\frac{c c+2 b c}{a a^{-}}, \& b$ cafus ad $\frac{c c}{a a}$; id quod ei parit expectationem $\frac{c 3+3 b c c}{a^{3}}$.

Sic qui quatuor vicibus aliquid bis effectui dare tentat, is $b$ cafibus, quibus primus ei jactus ex voto fuccedere poteft, adver $a-$ rio fortern acquirit $\frac{c 3}{a^{3}} ; \& c$ cafibus, quibus contrarium accidit, 
eum ad præcedentem expectationem $\frac{c^{3}+3 b c c}{a^{3}}$ perducit; id qued huic fortem gignit $\frac{c 4+4 b c 3}{a^{4} \text {. }}$

Qui verò tribus vicibus ter præftare quippiam conatur, is fi primo jactu fcopo aberret, antagoniftam fuum depofici $1 \infty$ $\frac{c c+2 b c+b b}{a}$ victorem reddit: fin confequatur quod intendit, re= fiduos habet duos jactus, quorum etiam uterque ejus voto refpondere deberet; quo in ftatu adverfarii fortem oftendimus effe $\frac{c c+2 b c}{a c}$. Pofterius autem $b$, prius $c$ cafibus accidere diximus; unde contracertantis expectatio refultat $\frac{c^{3}+3 b c c+3 b b c}{a^{3}}$.

E' quibus porrò haud abfimili ratione inveniri poffunt expectationes ejus, qui alteri 4, 5, 6 \&c. aleæ jactibus aliquid bis, ter, quater, pluriesve præftandum offert : unde nata eft fequens Tabella, quam quis levi labore continuabit, quoufque opus fuerit; fi confideret, columnas transverfales tabellæa ordine complecti quantitates omnium poteftatum binomii $\frac{c+b}{a}$, fecundam nim. quadrati, tertiam cubi, quartam biquadrati \&c. ita quidem, ut prima columna verticalium folos primos, fecunda duos, tertia tres, quarta $4^{\text {or }}$ priores harum poteftatum terminos exhibeat. Hinc enim colligitur facile, illum qui indefinite $n$ jactibus aliquid bis præftandum offert, fortem habere $\frac{c^{n}+n b c^{n-1}}{a^{n}}$; qui ter, $c^{n}+n b c^{n} n-1+$ $\frac{n \cdot n-1}{2} b b c_{n-2}: a^{n}$; qui quater, $c^{n}+n b c^{n-1}+\frac{n \cdot n-1}{2} b b c n-2+$ $\frac{n \cdot n-1 \cdot n-2}{2 \cdot 3} 6 c^{n}-3: a^{n} ; \&$ generaliter denique, qui illud $m$ vicibus praftandum offert, huic fortem competere $c^{n}+n b c^{n-1}+$ $\frac{n \cdot n-1}{2} b 6 c^{n-2}+\frac{n \cdot n-1 \cdot n-2}{2 \cdot 3} b^{3} c^{n-3} \ldots \ldots$ ufque ad + $\frac{n \cdot n-1 \cdot n-2 \ldots n-m+2}{2 \cdot 3 \cdot 4 \cdots m-1} b_{m-1} \varepsilon^{n}-m+1: a^{n}$.

Eadem etiam formula aliter \& fcitè elici potê, in auxilium vocat combinationum doarinâ, hoc modo: Conftat ex fuprà Tabus 


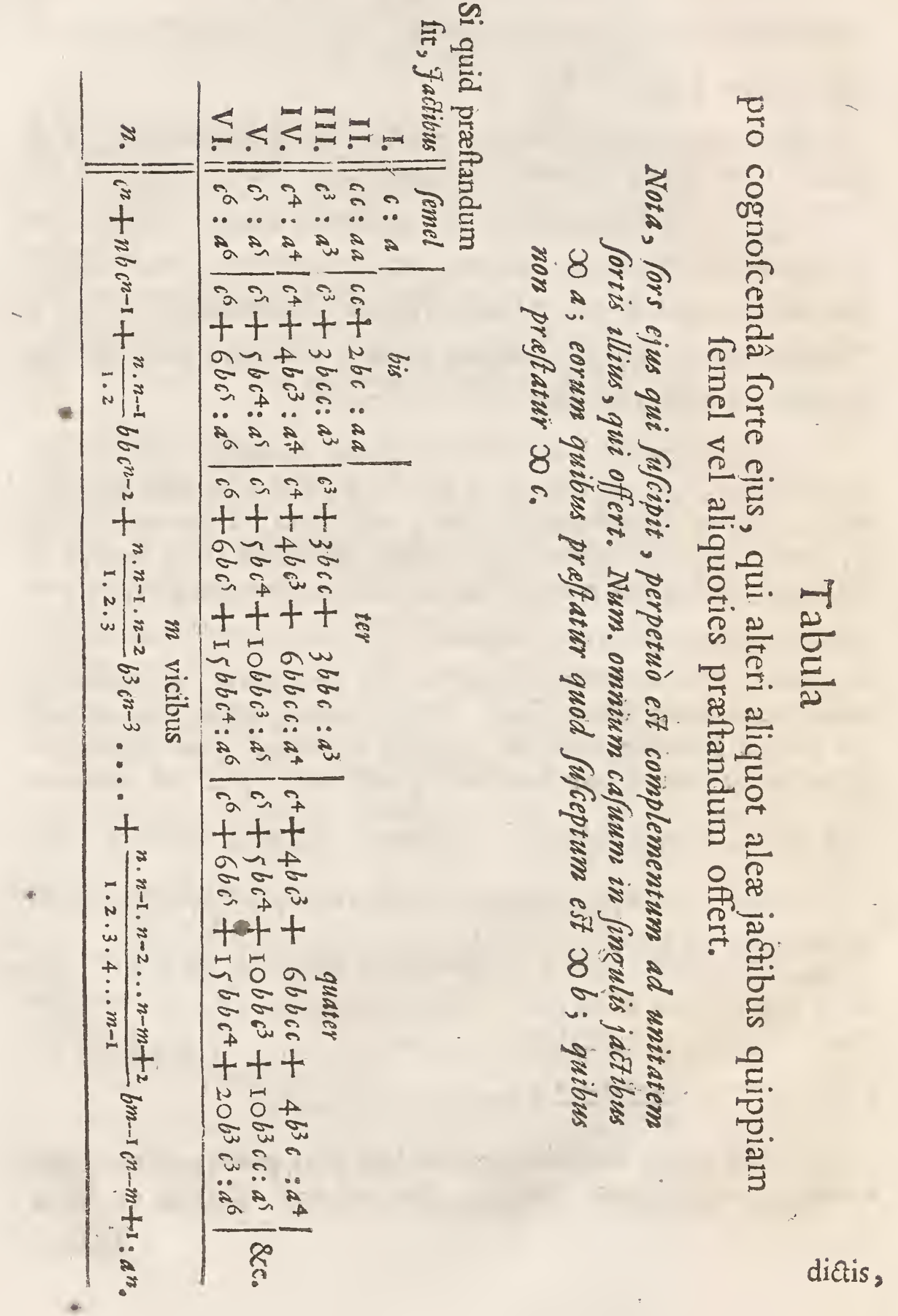


dictis, codem recidere, five quis $n$ jactibus unius tefferre aliquid $m$ vicibus præftandum fufcipiat, five id unico jastu $n$ tefferarum in m tefferis præfandum fibi ftmat: Sint igitur teferæ A, B, C, D \& c. quarum numerus fit $n$, fingulæ inftuctx $a$ hedris, quas inter $b$ voto fufcipientis refpondeant, reliquæ $c$ non refpondeant; \& quæraaur, quot cafibus accidere poffit, ut tum in nullâ tefferarum, tum in unâ tantùm teflerâ, tum in folis duabus, 3,4 \&c. tum denique in $m-1$ tantùm tefferis preftetur quod fufceptum eft : omnibus enim his cafibus fufcipiens voto fuo excidit, \& antagonifta ejus victoria potitur. Ofenfum autem fuit in annot. præc. Prop. cafus effe $c^{n}$, quibus contingere polfit ut in nullâ $n$ tefferarum prodeat quod fuf ceptum eft : \& fimili modo colligirur, cafus effe $c^{n}$, quibus contingere poflit ut in nullâ $n$ tefferarum prodeat quod fufceptum eft ; $\& z$ frmili modo colligitur cufus effe $b$ vel $b b$ vel $b^{3} \& c$. quibus una tefferarum. putà $A$, aut dur $A \& B$, aut tres $A, B \& C \& c$. Cúcipientis voto refpon-

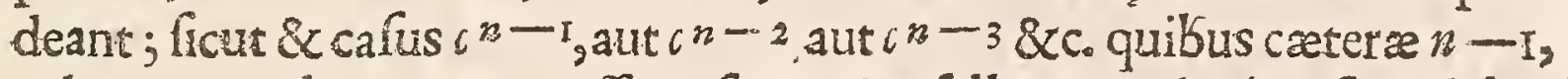
vel $n-2$, vel $n-3 \& \mathrm{rc}$. tefferæ fpem ejus fallans: unde cùm finguli hoIum cafuum cum unoquoque priorum conjungi poffint, ex ductu horum in illos nafcentur cafus $b c^{n-1}$, aut $b b c^{n-2}$, aut $b^{3} c^{n-3} \& c$. Et quia teffera illa vel illa, quæ favent fufcipienti, poteft effe vel $A$ vel $B$ vel $C \& c$, fi fit una: vel $A-\& B$, aut $A \& C$, aut $B \& C \& c$. fi fint dur: vel $A, B \& C$, aut $A, B \& D \& c$. fi fint tres, \& $\&$. hinc numeri cafuum rurfus toties multiplicabuntur, quoties ex univerfis $n$ tefferis fingulas, binas aut ternas \& $x$. accipere licet; fed licet hoc, per doctrinam combinationum fecundâ parte tradendam, $n$, vel $\frac{n . n-1}{I_{1} 2}$, vel $\frac{n . n-1 \cdot n-2}{1.2 .3} \&$ c. vicibus : quare factâ hâc alterâ multiplicatione cafus emergent $n b c^{n-1}$, aut $\frac{n \cdot n-1}{1.2} b b c^{n-2}$, aut $\frac{n \cdot n-1 \cdot n^{n-2}}{1 \cdot 2 \cdot 3} b^{3} c^{n-3} \& c_{0}$ quibus in unâ, duabus, aut tribus \& $2 c_{0}$ duntaxat tefleris, fed quomodolibet fumptis, eveniat quod fufceptum eft; \& confequienter etiam cafus $\frac{n \cdot n-1 \cdot n-2 \ldots n-m+2}{1 \cdot 2 \cdot 3 \cdot 4 \ldots m-1}$ $b^{m-3} c^{n-m+r}$, quibus id eveniat in $m-\mathrm{I}$ tefferis. Cùm itaque omnes hi recenfiti cafus antagoniftam fufcipientis, uti diaum, ludi vistorem reddant, pretereague in univerfis $n$ tefferis calus exiftante F $a^{n}$, fies 
$a^{n}$, fiet per 1. Coroll. 3. fors ejus $c^{n}+n b c n-1+\frac{n \cdot n-1}{1 \cdot 2} b b c n-2$ $+\frac{n \cdot n-1 \cdot n-2}{1.2 \cdot 3} b^{3} c n-3 \ldots+\frac{n \cdot n-1 \cdot n-2 \ldots n-m+2}{1 \cdot 2 \cdot 3 \cdot 4 \cdots m-1} b m-1$ $c^{n-m+1}: a^{n}$, ut fuprà. Quoniam autem in propofitâ quæetione, ficut in præcedente, præcipuè hoc intenditur, ut inveftigetur, quot aleæ jactibus expectationes luforis \& adverfaii incipiant æequari, five utrivis competere dimidium depofiti; idcircò nunc porrò æquationem inftituo inter repertam adverfarii fortem $\& \frac{x}{2}$, indeque valorem numeri $n$ quoad poffum determino. Ex. gr. Si cum Auctore fire defiderem, quo jactuum numero quid bis piæftandum fufcipi poffit, putà unâ tefferâ fenarius bis jaciendus, ut æequâ forte certetur; facio $\frac{c^{n}+n b c^{n}-1}{a^{n}} \infty \frac{x}{2}$, \& habebo $a^{n} \infty 2 c^{n}+2 n b c^{n-1}$

$\infty \overline{2 c+2 n b}, c^{n-1}$, quo indicatur, numerum $a$ ad eam poteftatem elevandum effe, qua proximè fit æqualis producto ex poteftate uno gradu depreffiore ipfius $c, \&$ duplo fummæ, quam numerus $c$ cum ipfo $b$ ducto in indicem poteftatis a conftituit. Hoc enim facto index poteftatis a denotabit numerum jactuum, quo quid bis præftandum. fufcipi poteft. Addo calculum pro Auktoris exemplo, in quo a num merus omnium cafuum unius tefferæe valet $\sigma, b$ numerus eorum quibus obtinetur fenarius $I, \& 6$ corum quibus non obtinetur 5 :

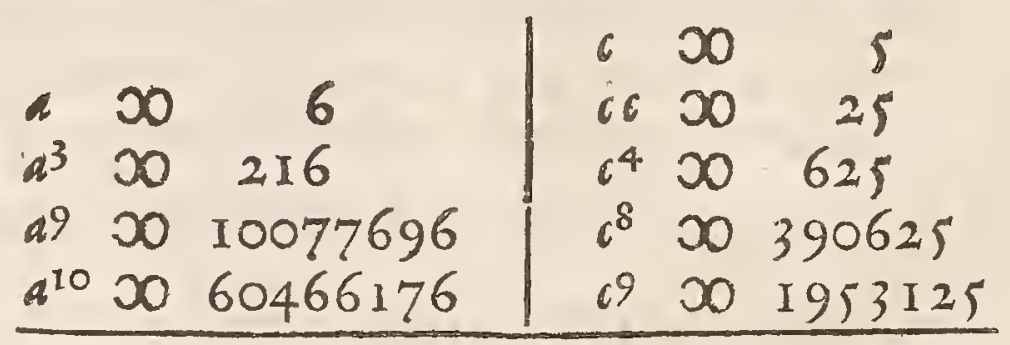

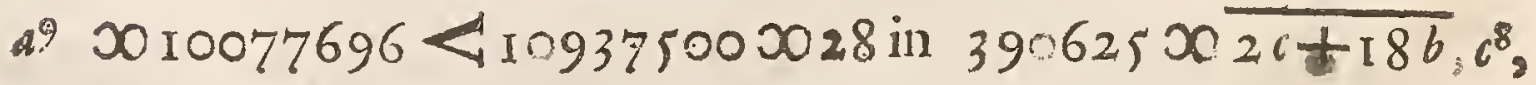
$a^{10} x 60466$ I $76>58593750 x 30$ in $1953125 x 2 c \overline{720 b}, c \%$. quare cùm nona poteftas ipfius $a$ adhuc deficiat, decima verò excedat poteftatem ipfius $c$ uno gradu inferiorem \& dictâ ratione multiplicatam, colligi debet, novem jactus nondum fufficere, at jactibus decem cum lucro fufcipi poffe, ut unâ tefferâ bis fenarius jacia. tour. 


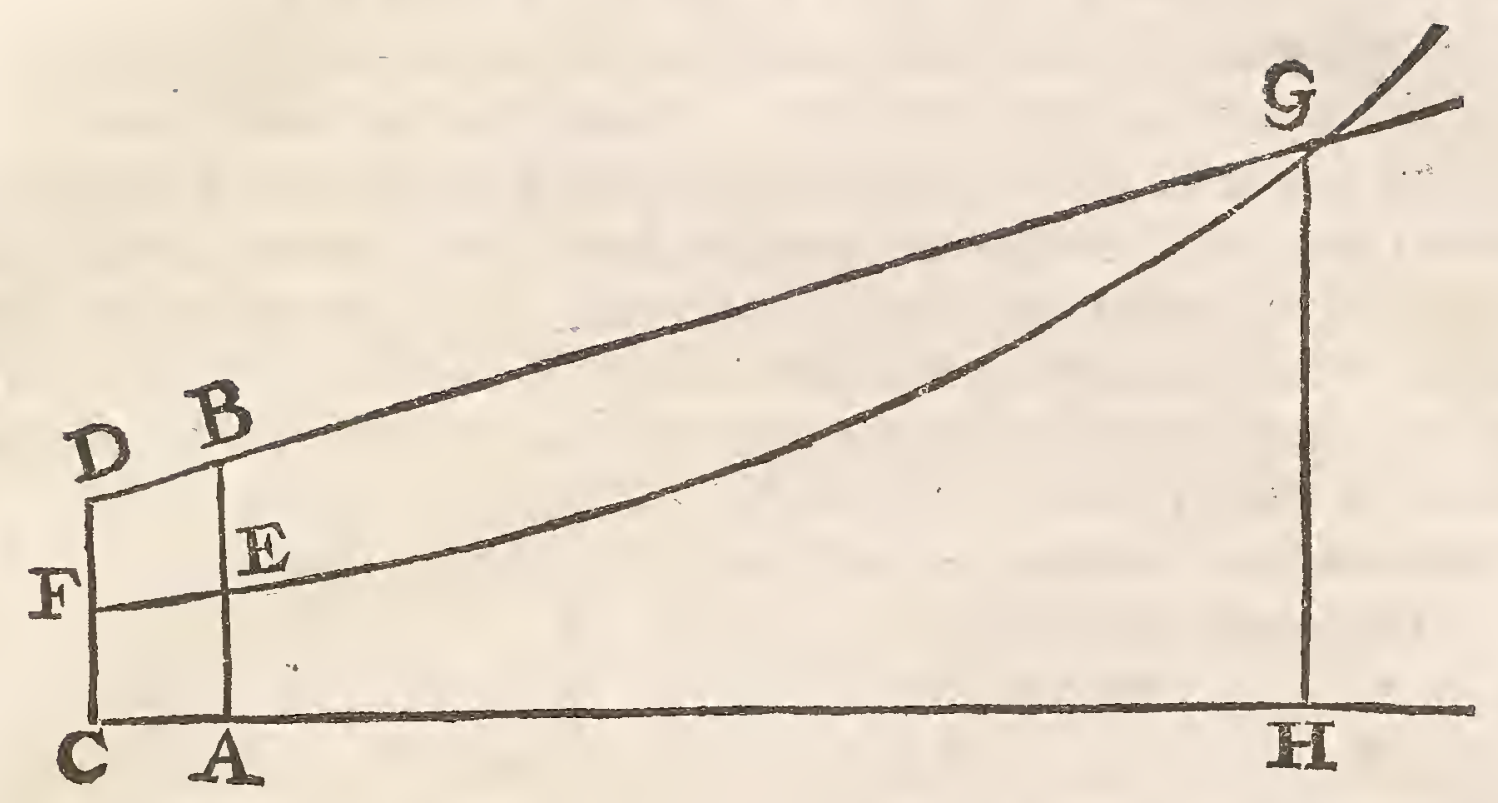

Idem etiam per conftruationem Geometricam non incencinnam obtinere licet, ope Curvæ quam vocant Logarithmicæ: Infiftat axi CH Logarithmica quævis $F E G$, cui applicentur rectæ $A E \& C F$, quæ fint in ratione $a$ ad $c$, producendæ ad duplam longitudinem in $B$ \& $D ; \&$ agatur recta $D B$, occurrens curvæ in $G$ : fumtâ pro unitate $\mathrm{CA}$, abfindet demiffa applicata $\mathrm{GH}$ in axe portionem. $\mathrm{CH}$, numero jactuum, quo aliquid bis præftandum fufcipi poteft. Et quemadmodum hoc confecuti fumus occurfu lineæ recta \& logarithmicæ: fic numerum jactuum, quo quid ter præeftandum poteft fuccipi, per interfectionem Parabolæ \& logarithmicæ; \& quo id quater frepiusve, ejusdem \& altioris gradatim curva algebraicæe ope definire licet.

Caterùm poffemus \& hic, uti fecimus in præced. Propol. ma teriam hanc profequi ulteriùs $\&$ inveftigare fortes plurium Aleatorum, qui finguli æequali an inæquali numero jactuum confecutivè inftituendorum fufciperent aliquid præftare aliquoties; aliasque plures ejusmodi quæftiones formare; nifi \& brevitati confulendum, \& Leetoris induftriæ quæedam relinquenda effe viderentur.

Unicum tamen, ne hactenùs dicta finiftrè acciperentur, monere adhuc operæ pretium duximus: nempe, Problemata hujus \& præcedentis Propofitionis, ubi quæritur expectatio ejus, qui aliquot aleæ jactibus quippiam femel vel aliquoties præftandum fufcipit, ita 
effe intelligenda, ut fenfus fit, etiam tum lucraturum qui fufcepre If frepius quam fufcepit praftiterit. Nam fi fenfus eflet, eum hoc cafu perditurum, aliud foret Problema, \& aliz nafcerentur expecta tiones, qua quia in fequentibus ufum habebunt, determinandx no= bis fuperfunt, priusquàm hinc difcedamus. Ut autem generalior fat folutio, ponamus non in omnibus aleis aguè-multos regnare cafus, ati hucufque fuppofuimus, fed numerum corum in diverfis jactibus stcunque variare, vocando in jactu Fr. Sec Tert Quart Quint. $_{\text {. }}$

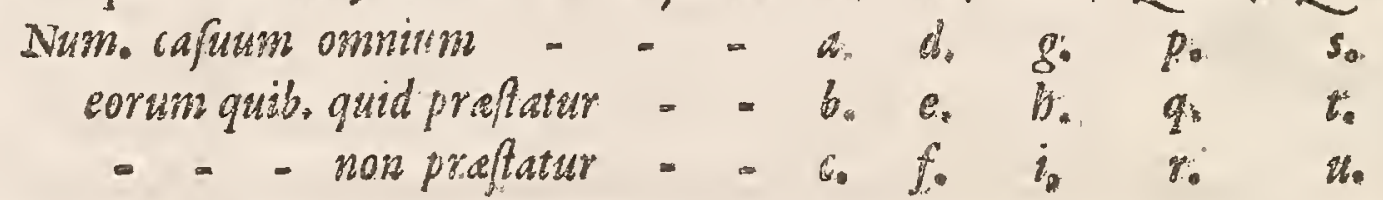
quo pofito, fi aliquot aleæ jactus, putà quinque fint inftituendir, $\&$ quæratur expectatio ad id præftandum in nonnullis horum jactuum ex. gr. in tribus primis, \& non praftandum in reliquis: confiderare oportet, quòd quilibet $b$ cafum primi jactûs conjungi poffit: cum quolibet $e$ cafuum fecundi, $\&$ inde refultantium cafuum $b e$ : quilibet rursùs cum quolibet $b$ cafuum tertii, quod facit $b$ e b cafus:: $\&$ pari modo, quòd quilibet $r$ cafuum quarti jactûs conjungi polfit: cum quolibet $u$ cafuum quinti, quod cafus fuppeditat $r u$; hinc cum: \& horum finguli cum quolibet prionum beh combinari queant, erit: numerus omnium cafuum quibus contingere potef, ut in primis: tribus jactibus præAtetur præftandum, in poftremis duobus non præ.. ftetur , $b$ e b.ru; \& quia ob fimilem rationem numerus omnium omninò. cafuum in univeris quinque jactibus eft adgps, fequitur expe.

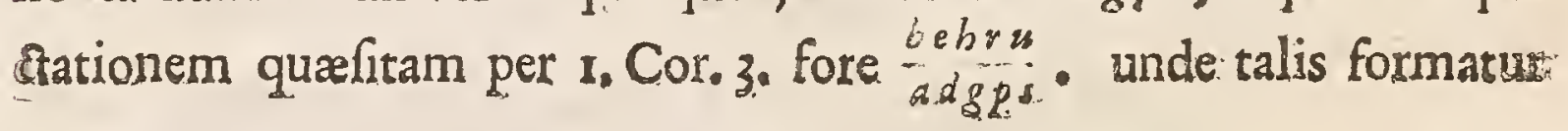

\section{Regula}

pro cognof́cendâ forte Aleatoris, cui plures alex jactus concefí \& qui precisè in certis quibusdam, non aliis jattibus quippiam preftare renetur.

PRoductum continum ex numeris cafum gubus quid praes. 1 Atarur in j.atibus, in quibus præftari debet, \& eorum quibus. gon preftatur, ubi non praftari debet, dividatur per productum conti- 


$$
P A R S \text { PRIMA. }
$$

continuum ex numeris omnium cafuum in jactibus tuniverfis; $\&$ quotiens exhibebit quæefitum.

Cornll. I. Si iidem numeri cafunm regnent in omnibus aleis, hoc eft, fi finguli $d, g, p, s \infty$; finguli $e, b, q, t \infty 0^{\circ} b$; \& finguli $f, i, r, u \infty 0 c$ : expectatio inventa $\frac{b_{e} \cdot b r u}{a d g p s}$ vertetur in hanc $\frac{b 3 c^{2}}{a^{5}} ; \&$ generaliùs in $\frac{b^{m} c^{n-m}}{a^{n}}$, fumto $n$ pro numero omnium jactuum, \&z $m$ pro numero eorim, in quibus præftandum præitari debet.

Cor.2. Si iidem numeri cafuum regnent in omnibus aleis, \& determinatus etiam fit numerus alearum feu jactuum, quibus quid præftari debet; ipfi verò jactus non fint definiti, fed quomodoliber accipiendi; putà, fi 5 jactus fint inftituendi, \& in tribus eorum quibuslibet quid præftandum fit, patet hinc quantitatem expectationis inventam toties adhuc multiplicari, quoties ex jactibus quinque diverfimodè terni, ho e. generaliter, ex $n$ rebus diverfa $m$ res accipi poffunt. Poteft autem hoc fieri, per Combinationum doctrinam feq. part. tradendam, $\frac{n \cdot n-1 \cdot n-2 \cdot n-3 \ldots \ldots n-m+1}{1 \cdot 2 \cdot 3 \cdot 4 \cdots m}$ five (quòd perinde) $\frac{n \cdot n-1 \cdot n-2 \cdot n-3 \ldots \cdot m+1}{n \cdot 2 \cdot 3 \cdot 4 \cdots n-m}$ vicibus: quare nunc expectatio fufcipientis valebit $\frac{n \cdot n-1 \cdot n-2 \cdot n-3 \cdots \cdots n-m+1}{1 \cdot 2 \cdot 3 \cdot 4 \cdots \cdots}, \frac{b^{m} c^{n}-m}{n}$, vel $\frac{n \cdot n-r \cdot n-2 \cdot n-3 \cdots \cdots+1}{1 \cdot 2 \cdot 3 \cdot 4 \cdot \cdots \cdot n-m}, \frac{6 m c^{n-m}}{a^{n}}$.

\section{PROPOSITIO XIII.}

I cum alio ludam duabus tefferis unum folummo. $\checkmark$ dò jactum, hâc conditione, ut, fi feptenarius eve. niat, ego vincam; at ille, fi denarius obtingat; fi verò quidquam aliud accidat, ut tum id quod depofitum eft aqualiter dividamus: Invenire qualis iftius pars cuique noftrúm debeatur. 
Quoniam 36 jactuum, qui duabus tefferis proveniunt, 6 jactus exiftunt feptem punctorum, \& 3 jactus decem punctorum, reftant adhuc 27 jactus, qui ludum rquare poffunt; id quod fi fiat, cui$\mathbb{N}$ que noftrîm debebitur $\frac{x}{2} a$. Verùm fi id non obtingat, habebo 6 cafus, quibus vincam, id eft, ut a habeam; \& 3 cafus, quibus diverfum eveniat, nihilque habeam: id quod per II. Propofitionem, tantundem eft ac fi tali cafu $\frac{2}{3} a$ haberem. Habeo itaque $a b$ initio 27 cafus ad $\frac{x}{2} a, \&$ \& cafus ad $\frac{2}{3} a$, id quod, per II. Propofitionem,

0 tantundem eft ac $\frac{13}{24} a$. Et remanet contracertanti $\frac{1 r}{24} a_{\text {。 }}$

\section{Arinotat.}

$\mathrm{N}$

Verum fi id non obtingat, habebo 6 cafus boc.] Arctor priùs quærit expectationem ejus, qui 6 habet cafus ad vincendum \& 3 ad perdendum, qua expectatio eft $\frac{2}{3} a$; eâque demum mediante infert quæfitum: fed poteft idem quoque non cognitâ illâ expectatione immediatè concludi; nam 27 cafus ad $\frac{x}{2} a, 6$ ca* fus ad $a, \& 3$ ad 0 , quos habeo fi propofitâ conditione ludo, etiam tantundem valent per 1. Coroll. 3 , ac $\frac{13}{4} a$; uti quoque 27 cafus ad. $\frac{x}{2} a, 3$ ad $a, \& 6$ ad 0 , quos habet collufor meus, ei per idem Cor. fortem pariunt $\frac{I I}{2} a$.

O Et remanet contracertanti $\frac{11}{24} a_{\text {. }}$.] Refiduum nempe totius depofiti. Quia enim ambo fimul finito lufu infallibiliter totum depofitum, nec plus nec minus, impetramus, hine etiam amborum fimul expectatio per Axioma noftrum integrum depofitum exhaurire debet, uti quoque in Propof. IV. ad literam C notavimuse Secùs foret, fi qui cafus darentur, quibus $\&$ alii de depofito participarent; veluti, fi poftrema conditio lufui annexa juberet, ut id quod depofitum eft in pauperes erogetur; tum enim propter 6 cam fus ad $a, \& 30$ ad 0 , non nifi haberem $\frac{1}{6} A ; \&$ collufor propter 3 cafus ad $a, \& 33$ ad 0 , tantùm haberet $\frac{1}{12} a$; refiduum vero depofiti $\frac{3}{4}$ a pauperibus deberetur, qui propterea $\&$ ipfi in rationem fortis venire cenfendi effent. 


\section{$P A R S P R I M A$. \\ PROPOSITIO XIV.}

SI ego \& alius duabus tefferis alternatim jaciamus, Shac conditione, ut ego vincam fimul atque feptenarium jaciam, ille verò quàm primùm fenarium jaciat; ita videlicet, ut ipfi primum jactum concedam: Invenire rationem mex ad ipfius fortem.

Ponatur, fortem meam valere $x, \&$ id quod depofitum eft vocari $a$; eritque fors alterius $50 a-x$. Et patet, quandocunque ipfius vices jaciendi revertuntur, fortem meam tum rurfus debere effe $50 x$. At quandocunque mex vices funt ut jaciam, fors mea pluris æeftimanda eft. Ponatur itaque pro ejus valore $y_{\text {* Jam }}$ quoniam ex 36 jactibus reperiuntur 5 in 2 eefferis, qui collufori meo fenarium dare lusîsque viktorem redd se poffunt; \& 3 I jąus, quibus diverfum eveniat, id eft, qui meas jaciendi vices promovent: habebo, priusquàm jacit, 5 cafus ad obtinendum $0, \& 31$ cafus ad obtinendum $y$. id quod per III, Propofitionem valet $\frac{31 y}{36}$. Pofuimus autem cafum meum à principio effe $\infty x$. Quiocirca erit ${ }_{36}^{31} y x$, adeoque $y>0 \frac{36 x}{31}$. Deinde pofitum fuit, vicibus meis venientibus, fortem meam valere $y$. Ego verò jacturus, habeo 6 cafus ad obtinendum $a$, quandoquidem 6 jactus reperiuntur 7 punetorum, qui me viftorem reddunt; habeoque 30 cafus, quibus vices colluforis mei revertuntur, id eft, ut mihi obtineam $x_{0}$ id quod per III. Propofitionem valet $\frac{6 a+30 x}{36}$. Hoc autem cùm fit $00 y$, erit, invento, ut ante, $\frac{36 x}{31} \infty 0 y,{ }_{36}^{30 x+6 a}-\infty \frac{36 x}{3 \mathrm{I}}$. Unde invenitur $x>0 \frac{31 a}{6 t_{1}}$, valor mex fortis. Et per confequens colluforis mei erit $\frac{30 a}{61}$; ita ut ratio fortis mex ad illius fortem fit, ut 3 II ad 30 .

\section{Annotat.}

Auctor in hoc Problemate primùm adhibere cogitur analy fin algebrạ̈: 
algebraicam, cùm in præcedentibus folâ fynthefi ufus fuiftet: cujus differentiæ ratio eft, quòd in illis omnibus expectatio ouæfita fluebat ex aliis expectationibus vel in totum cognitis \& datis, vel in. cognitis quidem, at naturâ prioribus ac fimplicioribus, \& qua ab hầc vicifim non dependebant; quapropter incipiendo $\mathrm{ab}$ onnium fimplicifimis earum ope gradatim pergere poterat ad enodandos alios cafus magis magisque compofitos absque analyfi ullâ. Secùs verò fe hîc res haber; nam expectationem meam, quam poffideo cùm colluforem ordo jaciendi tangit, Auctoris more æeftimare non polfum, nifi cognitam habuero fortem, quam acquiro ubi vices jaciendi ad me devolvuntur: fed \& hanc cognofcere nequeo, niff priorem illam compertam habeam, quæ tamen ea ipfa eft quam quærere intendo; unde cùm utraque fit incognita, \& altera ab alterâ vicifim dependeat, non poffunt Auctoris veftigiis infiftendo aliter quàm analyfeos ope ex fe mutuò elici : id quod operæ pretium eft obfrrvâffe, ut utriusque methodi difcrimen, \& quando hæc illave in ufum vertenda fit, perfpicuio aliquo exemplo pateret.

Dixi, Auctoris veftigiis infiftendo non poffe; datur enim adhuc alia peculiaris via, quâ quæfitum confequi poffum citra analyfin ullam, \& quam in fequentibus quoque utiliter adhibere licet. Fingamus loco duorum alternatim ludentium infinitos Collufores, quibus fingulis ordine uni poft alterum finguli tantùm concedantur jactus, eâ lege, ut cui colluforum in locis imparibus fenarius, aut cui in paribus feptenarius primùm evenerit, ille vincat atque depofitum auferat: quo pacto liquet, fecundum colluforem vincere non poffe, nifi duorum primorum jactuum folus pofterior præettet quod præftare debet; nec tertium vißtoriâ potiri polfe, nifi trium primorum jactuum folus tertius id præeftet; nec quartum, nifi quatuor primorum folus quartus, \& ita confequenter. Quare, fi pro $5 \&$ $3 \pi$, numeris cafuum quibus in tefleris duabus evenire poteft fenarius vel non evenire, ponamus $b \& c$; item pro $6 \& 30$ numeris cafuum, quibus feptenarius obtingere vel non obtingere poteft, $e \& f$; pro 36 verô numero omnium cafuum $b+c$, vell $e+f$, frim bamus $a$ : inveniemus per Regulam in fine annot. Prop. XII. tra. ditam fingulorum Colluforum expectationes, ut fequitur: 
colluf. I. II. III. IV. V. VI. VII. VIII. \& \&c.

Expect. $\frac{b}{a} \cdot \frac{c e}{a b} \cdot \frac{b c f}{a^{3}} \cdot \frac{c c e f}{a^{4}} \cdot \frac{b c c f f}{a 5} \cdot \frac{c 3 e f f}{a^{6}} \cdot \frac{b c 3 f^{3}}{a^{7}} \cdot \frac{c 4 c f 3}{a^{8}} \cdot \& c$.

Quòd fi nunc in primi, tertii, quinti \& reliquorum imparibus numeris defignatorum Colluforum locum unum folum mente fubftituam, meque ipfum in locum fecundi, quarti, fexti, \& cæeterorum, qui in pari graduum numero funt collocati, conttabit hune ipfum fore cafum præéntis quaftionis, atque infuper expectationes utriusque noftrûm æquari debere expectationibus fimul fumtis omnium illorum colluforum, in quorum locum fuffecti fumus. Sors itaque mea exprimetur per $\frac{c e}{a a}+\frac{c c e f}{a^{4}}+\frac{c 3 e f f}{a^{6}}+\frac{c 4 e f 3}{a^{8}} \& c_{0}$. $\&$ colluforis mei fors per $\frac{b}{a}+\frac{b c f}{a b}+\frac{b c c f f}{a 5}+\frac{b c 3 f 3}{a 7} \& c_{\text {。 }}$ feries fcil. infinitas quantitatum geometricè progredientium in ratione a a ad $c f, \&$ quarum prior fummam conficit $\frac{c e}{a a-c f}$, pofterior $\frac{a b}{a d-c f}$; fic ut fors mea ad fortem illius fe habeat, ut $c e$ ad $a b$, feu reftitutis valoribus $\operatorname{lit}_{0} a, b, c \& e$, ut 3 I ad 30 , planè ut fúprà。

\section{A P P E N D I X.}

Coronidis loco Auctor Tractatui fuo fubjunxit fequentia quinque Problemata, fed omifla analyfi vel demonftratione, quam Lectori eruendam reliquit. Hanc itaque nos partim hîc fupplere, partim in Librum fecundum rejicere coacti fumus.

\section{PROBLEMA I.}

A \& B unà ludunt duabus tefferis, hâc conditione, $A$ ut $A$ vincat, fi fenarium jaciat, at $B$ fi feptenarium jaciat. A primò unum jactum inftituat; deinde $\mathrm{B}$ duos jactus confequenter; tum rurfus $\mathrm{A}$ duos jactus, atque fic deinceps, donec hic vel ille viktor evadat. Quaritur ratio fortis ipfius $A$ ad fortem ipfius B? Refp. ut 10355 ad 12276. 
Solutio: Ponamus, fortem ipfus $A$ valere $t$, tum cum lude re incipit; at cùm ordo jaciendi colluforem $B$ tangit, $x$ : cùm $\mathrm{E}$ femel lufit, $y:$ cùm bis, hoc eft, cum ludendi vices ad ipfum redeunt, z. Quoniam enim omnes iftz fortes differentes funt \& incognitæ, earumque præcedens quælibet à fequente \& poftrema viciffim à primâ dependet, uti ex fubjunctâ operatione conftabit, non poterit Problema iftud Auctoris faltem methodo, per ea qua ad Propof. ult, annotata funt, aliter quàm mediante analyfi algebraicâ expediri. Primò itaque quia in 36 jactibus duarum tefleram rum reperiuntur 5 , qui ipfi A fenarium dare, eumque ludi victorem reddere poflunt; \& 31 jactus, qui ordinem jaciendi in collus forem B transferunt; habebit A, tum cum ludum inchoat, 5 cad fus ad obtinendum $a$ (id quod depofitum eft) \& 31 ad obtinendum $x$; id quod per frepius laudatam Propof. valet $\frac{5 a+31 x}{36}$ : cum autem eadem à principio fors vocata fuerit $t$, erit propterea $t, 0$ $\frac{5 a+31 x}{36}$. Deinde cùm ordo ludendi tangit colluforem $B$, habet A 6 cafus ad obtinendum nihil (quandoquiden 6 funt jactus 7 . punetorum, qui adverfario ejus favent) \& 30 cafus ad acquiren dum $y$, quod fortem ipfi parit $\frac{5}{6} y$. Eademmet vero fors fupras nobis dicta fuit $x$; quare $x \times \frac{5}{6} y$. Porrò cum collufor $\mathrm{B}$, abfoluto primo jactü alterum aggreffurus eft, habet $A$ ob eandem rationem 6 cafus ad $0, \& 30$ ad fortem fequentem $z$; \& fiquidem obtinere tum etiam fupponatur $y$, erit $y 3 \frac{5}{6} z$. Denique vicibus ludendi ad ipfum A revertentibus, quo cafu ejus expectationem $z$ vocamus, habet is 5 cafus ad a, fi nempe fenarium jaciat, \& 3 i calus ad obtinendam fortem prifinam $t$, fl fecus eveniat; quandoquidem tunc collufores in eo ftatu erunt, in quo fuerant a principio, dum ipfi A unus fuperelt jactus, quem excipere debent duo jactus à $\mathrm{B}$ inftituendi, $\&$ hos duo alii ab $\mathrm{A}$, atque ita deinceps, omnino frcut ab initio: conftat autem 5 cafus ad $a, \& 31$ ad $t$ valere $\frac{5 a+3 r t}{36}$; quocirca $z \infty \frac{5 a+3 r t}{36}$. Inventis hâc ratione tót xquationibus, quot fuppofitæ fuerunt literæ incognitæ, oportet poftremis ad primas retrogredi; fubfituendo valorem $z$ per ulti- 
mam repertum in proxime precedente, ut habeatur y $\infty \frac{25 a+15 \% t}{216}$; 8 hunc valorem in antepenultimâ, ut fiat $x \infty \frac{125 a+775 t}{1296} ;$ ac tandem valorem iftum in primâ; quâ ratione fors quæefita habetur $\$ \infty 0 \frac{10355 a}{22631}, \& x$ relinquetur pro forte colluforis $\mathrm{B} \frac{\mathrm{I2276a}}{22631}$. unde fors A ad fortem B erit, ut 10355 ad 12276 ; uti Auctor invenit.

Idem verò etiam aliquantò compendiofiùs inveftigari poteft; adhibitis tantìm tribus literis incognitis $t, x \& z$, prætereundo fortem $y$, quam acquirit $A$, poftquàm $B$ uno jactu defunctus eft. Ex Annot. Propor. XI. conftat, quòd fors ejus, qui duobus jątibus femel feptenarium jacere fufciperet, effet $\frac{11}{36}$ depofiti (quippe cùm a numerus omnium jactuum, ad c numerum eorum quibus non obtinetur feptenarins, eft in ratione 6 ad $5 ; \&$ propterea $\left.\frac{a a-c c}{a a} \infty \frac{11}{36}\right)$ unde, per ea quæ ibid. ad lit. I. monuimus, concludendum, in effe cafus, quibus collufor B ludendi vicibus ad fe devolutis alterutro fuorum jactuum feptenarium jaciat \& vincat, ipfeque A nihil acquirat; \& 25 alios, quibus id neutro jactuum præftet, ludendique ordo inde ad A reverfus huic fortem $z$ pariat; id quod ipfi $A$, qui eo ftatu poffidere fupponitur $x$, tantundem salet ac fi haberet $\frac{25 z}{36} ;$ adeò ut $x>\frac{25 z}{36}$. Cæteris enim pofitis ut priùs, fi valor ipfius $z$ fuprà inventus híc fubftituatur, invenie: tur ut ibi $x \infty 0 \frac{125 a+775 t}{1296}, \&$ confequenter $t \infty 0 \frac{10355}{22631} a_{0}$

Atque hinc perfpicitur methodus Auctoris, quam imitari cone venit in omnibus fimilibus fortitionibus \& ludis aleæ, in quibus plures continuò fortes incognitæ fe mutuò excipiunt, dummodò poft jactus aliquot priftina recurrat rerum facies, eædemque revertantur fortes incognitæ, quas aleatores ab initio ludi habuêre: Sed non tam facilè apparet, quo pacto illa Problemata traktanda fint, in quibus ludurn profequendo fortes nunquam in orbem redeunt, fed fubinde aliæ novæ prodeunt à prioribus diverfæ \& æquè ignotæ, idque in infinitum; cujusmodi quidem nulla in hoc Audtonis Tractatu habentur. Eorum aliqua propofui olim in Ephemer.

$$
\text { G } 2 \text { Erud. }
$$


Erud. Gall. 1685. art. 25, fpe fretus fore, ut nonnemo illorum folutionem aggredi dignaretur, quam cùm toto quinquennio nemo dediffet, ipfemet pofteà in Actis Erud. Lipf. m. Maj. 1690. communicavi, fecuto mox etiam fundamento folutionis ab ingeniofiffimo Leibnitio ibid. m. Jul. ejusdem anni occultiùs exhibito, quod ego nunc apertiùs exponam. Prius autem oftendam, quo pacto per illud prefens Auctoris Problema folvatur; nec enim differt hoc fundamentum ab eo, quo ad folutionem quogue præced. Propor. in annotat. fui ufus, eâdemque promifcue facilitate applicatur ad quæftiones, in quibus eædem perperuò expectationes in circulum redeunt, \& in quibus nulla tallis earum datur apocataftafis, hoc folo difcrimine, qudd in prioribus ad feries: infinitas unam pluresve, quarum fummæ unâ aliquâ quantitate exprimi poffunt; in pofterioribus verò ad alias. feries haud æquè fummabiles nos deducat.

Supponamus infinitos luffores, qui finguli ad fingulos fucceffivè jactus admittantur, \& quorum primus, quartus \& quintus, octavus \& nonus, \& fic porrò intermiffis duobus femper duo: fequentes, fenarii jąu: cæteri, fecundus \& tertius, fextus \& feptimus \&c. feptenarii jactu vincere polfint. Ac tum per Regulam annot. Prop. XII. annexam quarantur fingulorum expectationes, quæ fumto valore lit. $a_{2} b_{2}, c_{2}, \& f_{2}$ ut in annot. præc. Prop. ita habebunt :

coll.I.II.III. IV. V. VI. VII. VIII. IX. X. XI. XII, \&zc。 A. B. B A A B B A A B B A

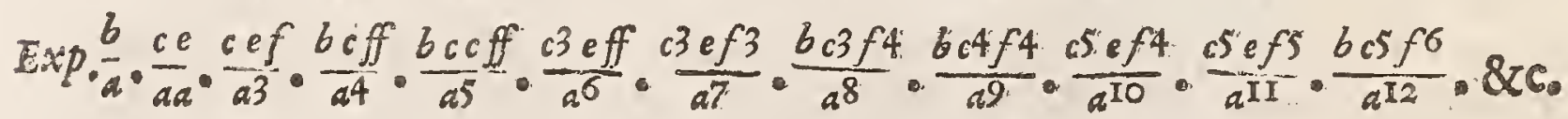
fubftitutis igitur in locum omnium eorum, qui fenario vincunt, uno folo collufore $A ;$; in locum eorum, qui feptenario vincunt, uno folo $\mathrm{B}$, habebimus cafum præfentis Problematis, indeque concludemus, fortem ipfius A fore $\frac{b}{a}+\frac{b c f f}{a^{4}}+\frac{b c c f f}{a 5}+\frac{b c 3 f_{4}}{a^{8}}+\frac{b c 4 f_{4}}{a^{9}}$ $+\frac{b c 5 f 6}{a^{12}} \& c_{0}$ \& fortem ipfius $B, \frac{c e}{a a}+\frac{c e f}{a^{3}}+\frac{c 3 e f f}{a^{6}}+\frac{c 3 e f 3}{a^{-}}+\frac{c 5 e f f^{5}}{a^{10}}$ \# $\frac{c 5 \text { efs }}{a^{I I}}$ \&ue. Et quia in utrâque hâc ferie termini locorum tum 


\section{$P A R S P R I M A$.}

parium tum imparium feparatim accepti Geometricas progreffiones conftituunt decrefcentes in ratione $\frac{c c f f}{a^{4}}$, liquet hinc etiam ambarum fnmmas in poteftate haberi. Reperitur autem fumma prioris feriei $\frac{a 3 b+b c f f}{a^{4}-c c f f}, \&$ pofterioris $\frac{a a c e+a c e f}{a^{4}-c c f f}$; fic ut ratio fortis $A$ ad fortem B fit, ut $a^{3} b+b c f f$ ad a ace $+a c e f$, hoc eft (factis $\left.a 0_{36}, 6005, c \infty 0_{31}, e 006, \& f 0_{30}\right)$ ut 372780 ad 44.1936 , feu ut 10355 ad 12276 , prorsùs ut fuprà.

Sequuntur nunc exempla talium quæltionum, ubi nulla datur fortium apocataftafis : Sint duo Collufores A \& B certatim ludentes duabus tefferis eâ lege, ut qui primus feptenarium jecerit vincat. Quaruntur eorum expectationes, fi ludere debeant hoc ordine

I. A femel, B femel, A bis, B femel, A ter, B femel, A quater, B femel \&c. II. A femel, B femel, A femel, B bis, A femel, B ter, A femel, B quater \& $\mathrm{cc}$. III. A femel; B femel, A bis, B bis, A ter, B ter, A quater, B quater \&tc. IV. A femel, B bis, A ter, B quater, A quinquies, B fexies, A fepties \&c,

Hîc methodus analytica Auctoris nil proficit, fed mea, eâdem quâ anteà facilitate quafitum determinat. Loco duorum alternis ludentium A \& B fingo rurfus lufores infinitos, quibus fingulis finguli tantùm concedantur jactus, \& quæro fingulorum expectationes. Repéritur autem per Coroll. 1. Regulæ ad Prop. XII. notatæ, ob numeros cafuum $a, b$ \& $c$ eosdem in omnibus aleis, expectatio cujusvis generaliter $\frac{b^{m} c^{n-m}}{a^{n}}$, ubi $m$ numerus jactuum, quibus feptenarius (unus $b$ cafuum) preftandus ent, perpetuò valet $x ; \& n$ numerus omnium ab initio jactuum fucceffivè valet $1,2,3,4$ \& $c_{0}$ his ergò fubftitutis fequens nafcetur laterculus

colloI. II. III. IV. V. VI. VII. VHI. IX. X. XI. XII. XIII, XIV. XV. \& $\begin{array}{llllllllllllllll}A & B & B & A & A & A & B & B & B & B & A & A & A & A & A\end{array}$ $\operatorname{Exp} \cdot \frac{b}{a} \cdot \frac{b c}{a^{2}} \cdot \frac{b c c}{a^{3}} \cdot \frac{b c^{3}}{a^{4}} \cdot \frac{b c^{4}}{a^{5}} \cdot \frac{b c^{5}}{a^{6}} \cdot \frac{b c^{6}}{a^{7}} \cdot \frac{b c 7}{a^{8}} \cdot \frac{b c^{8}}{a^{9}} \cdot \frac{b c^{9}}{a^{10}} \cdot \frac{b c^{10}}{a^{11}} \cdot \frac{b c^{I I}}{a^{12}} \cdot \frac{b c^{12}}{a^{13}} \cdot \frac{b c^{13}}{a^{14}} \cdot \frac{b c^{14}}{a^{15}} \cdot \& c_{3}$ tum loco horum colluforum repono duos $\mathbf{A} \& \mathbf{B}$, utrique ea afignando loca, qua juxta quaftionis tenorem illi competunt, tanC 3 demque 


\section{4}

demque expectationes omnes his locis refpondentes fummatim col: ligo, ad conftituendas expectationes totales utriusque. Sic quia juxtà conditionem exempli $4^{\text {ti }}$ ipfi A debetur jactus primus, deinde $4^{\text {tus }}, 5^{\text {tus }}, 6^{\text {tus }}$, porrò II $, 12,13,14,15^{\text {tus }}, \&$ fic deinceps; hinc expectationes colluforum his numeris defignatorum, primi, $4^{\text {ti }}, 5^{\text {ti }}, 6^{\text {ti }} \& x_{\text {c. }}$ in peculiarem feriem compingo; atque expectationes $2^{\mathrm{di}}, 3^{\mathrm{tii}}, 7^{\mathrm{mi}}, \&$ reliquorum, in quorum locum B fuccedit, in aliam feriem; quo pacto fiet fors ipfius $A \infty 0 \frac{b}{a}+\frac{b c 3}{a^{4}}+\frac{b c 4}{a 5}+$

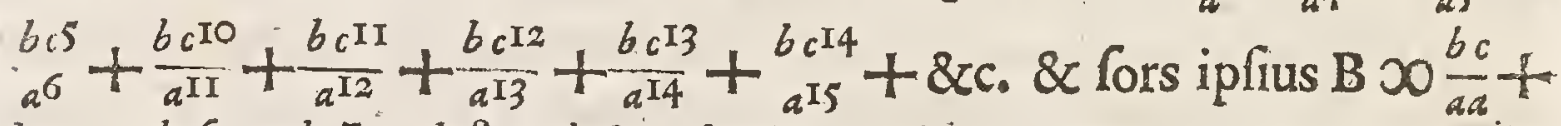
$\frac{b c 8}{a^{3}}+\frac{b c^{6}}{a^{7}}+\frac{b c 7}{a^{8}}+\frac{b c^{8}}{a^{9}}+\frac{b c^{9}}{a^{10}}+\frac{b c^{15}}{a^{16}}+\frac{b c^{16}}{a^{17}}+\frac{b c^{17}}{a^{18}}+\& c$. indeque por ro, eliminando $b$ ubique, \& ejus loco furrogando $a-c$, fors A $D_{1}$ - . $\frac{c}{a}+\frac{c^{3}}{a^{3}}-\frac{c^{6}}{a^{6}}+\frac{c^{10}}{a^{10}}-\frac{c^{15}}{a^{15}} \& c_{a}$ ut \& fors B $\infty \frac{c}{a}-\frac{c 3}{a^{3}}+\frac{c^{6}}{a^{6}}-\frac{c^{10}}{a^{10}}+\frac{c^{15}}{a^{15}} \& c_{6}$ prioris complementum ad unitatem.

Idem adhuc àliter ita elicio: Pono denuò loco duorum $\mathrm{A} \&$ $B$, infinitos lufores $A, B, C, D, E, F, G, \& C$. fed unicuique eorum tot jactus continue inftituendos tribuo, quot pro tenore qua. ftionis conceduntur alterutri $\mathrm{A}$ vel $\mathrm{B}$, quoties ludendi ordo de novo ipfum tangit. Verbi gratiâ, in exemplo antè allato quarto, pro eo quòd A ludere debet femel, $\mathrm{B}$ bis, hinc iterum A ter, $\mathrm{B}$ quater \&c. concipio A ludere debere femel, B bis, alium C ter alium $D$ quater \&c. tum feparatim uniuscujusque fortem inveftigo, attendendo ad numerum jactuum cùm ab ipfo inftituendorum, tum etiam $a b$ iis fimul omnibus, qui eum ludendo pracedere debent; quod nullo negotio fit, poftquàm jam fupra in annotatis Propor. XI. (politis illorum numero $n \&$ horum $s$ ) fortem hane generaliter oftendimus effe $\frac{a^{n} c^{s}-c^{n+s}}{a^{n}+s} \infty \frac{c^{s}}{a^{s}}-\frac{c^{n+s}}{a^{n+s}}$; fumtis enim in $4^{\text {to }}$ exemplo pro $n$ ordine numeris $\mathrm{I}, 2,3,4 \& \mathrm{c}$. \& pro $s$ numeris $0,1,3,6,10$ \& $c_{\text {c }}$ ceu fummis ipforum $1,2,3,4$ \& $c_{\text {. }}$ $a b$ initio collectis, emergent ftatim fingulorum fortes, ut fequitur collus A. B, C. D. E. F. G. \&

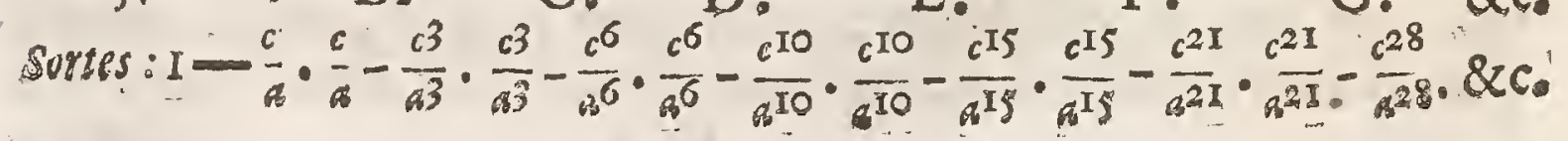


बुro facto nil fupereft aliud, quàm ut omnium luforum in locis im. paribus A, C, E, G \& cc. nec non omnium in paribus $B, D, F \& c$. expectationes in unam fummam colligantur ad producendas, quas antea, expectationes unius A \& unius B alternatim ludentium, utpote quas fummis illis æquari debere quivis per fe videt. Nec differret operatio, fi tres, quatuor pluresve collufores, in quaftione fupponerentur.

Utrovis autem horum modorum etiam cxteraram quaftionum exempla folvuntur. Solutiones omnium fic habent (fumto compendii gratiâ $m \infty \frac{c}{a}$ :

In qu. I. fors. A $001-m+m^{2}-m^{4}+m^{5}-m^{8}+m^{9}-m^{13}+m^{14}-m^{19}+8 x c_{0}$ $\mathrm{B} x+m-m^{2}+m^{4}-m^{5}+m^{8}-m^{9}+m^{13}-m^{14}+m^{19}-\& c_{0}$ I1 . A A $0 \mathrm{Or}-m+m^{2}-m^{3}+m^{5}-m^{6}+m^{9}-m^{10}+m^{14}-m^{14}+\& c_{0}$ $\mathrm{B} x \mathrm{O}+m-m^{2}+m^{3}-m^{4}+m^{6}-m^{9}+m^{10}-m^{14}+m^{15}-\& \mathrm{c}$ 。

III . A AOI $-m+m^{2}-m^{4}+m^{6}-m^{9}+m^{12}-m^{16}+m^{20}-m^{25}+\& \mathrm{cc}_{0}$ $\mathrm{B} x 0+m-m^{2}+m^{4}-m^{6}+m^{9}-m^{12}+m^{16}-m^{20}+m^{25}-\& \mathrm{c}_{0}$

IV. A A O $1-m+m^{3}-m^{6}+m^{10}-m^{15}+m^{21}-m^{28}+m^{36}-m^{45}+8 c_{0}$ $\mathrm{B} D 0+m-m^{3}+m^{6}-m^{10}+m^{15}-m^{21}+m^{28}-m^{36}+m^{45}-8 x c$

Singulæ hæ fortes exprimuntur, ut videre eft, per feriem aliquam infinitam, in quâ figna $+\&-$ perpetuò alternant, \& cujus termini ex ferie hâc continue proportionalium I. $m \cdot m^{2} \cdot m^{3} \cdot m^{4} \cdot m^{5}$ \&c. per faltus inæquales funt excerpti, quod impedit illius fum mationem abfolutam; Sed facilis eft approximatio in numeris quantumlibet exactis. Sic pofitis a $x_{3} 6$, numero omnium cafuum in tefferis duabus, \& $`{ }_{30} 3^{\circ}$ numero eorum quibus non obtinetur prafcriptus feptenarius, adeoque $\frac{\varepsilon}{a}$ feu $m \infty \frac{3}{3} \frac{0}{6} \infty \frac{5}{6}$, reperitur fors ipfius $A$ in primo exemplo $\frac{71931}{100000}$, in 2 do $\frac{40058}{100000}$, in $3^{\text {tio }} \frac{59679}{100000}$, in $4^{\text {to }} \frac{52392}{100000}$; ubique non unâ centies millefimâ parte major minorve, ac proinde ratio fortis A, ad fortem B in imo ut $7193 \mathrm{ad}$ 28069, in $2^{\text {do }}$ ut 40058 ad 59942 , in $3^{\text {tio }}$ ut 59679 ad 40321 , in to ut 52392 ad 47608 .

Cxterùm qui examinabit indices poteftatum quantitatis $m$, quase 
qux terminos harum ferierum conftituunt, deprehendet illorum differentias ubique coüncidere cum ipfis numeris jactuum, qui colluforibus A \& B juxtà quæetionis tenorem alternatim inftituendi funt : Ita in primâ ferie $1-m+m^{2}-m^{4}+m^{4}-m^{8}+m 9 \cdot \& c_{\text {. }}$ indices poteftatum ordine funt $0, x, 2,4,5,8,9$ \&c. \& indicum differentiæ I, I, $2, I, 3$, I \& c. præcisè refpondentes numeris jactuum, quos hypothefis primæ quæetionis requirit, quippe qua ipfi A I, B I, A 2 , B I, A 3, B I \& c. jactus ordine tribuit. Ope. ræ pretium autem eft obfervare, hoc adeò generale effe, ut etiam valeat in iis exemplis, in quibus duobus alternatim ludentibus numeri jactuum affignantur, quales fortuitò è calamo fcribentis fluere poffunt, nullâ certâ \& conftante ratione progredientes; cùm ifta confideratio regulam nobis fuppeditet amborum fortes momento exhibendi, quæ talis:

Regula pro cognofcendâ forte duorum certatim ludentium, donec alteruter corum vincat, quando utrique alternis vicibus aliquot ales jactus continue infituendi conceduntur fecundìm quosvis numeros datos E in infinitum continuatos.

(Pono autem cosdem regnare numeros cafurm feu eundern manere valorem quantitatis $\frac{c}{a}$ vel $m$ in omnibus aleis.)

Cribantur ordine primò dati numeri jactuum utrique conceffo. rum, dein fummæ corum $a b$ initio collectæ; tum fummæ hæ fiant indices totidem poteftatum quantitatis $m$, quibus per figna +8 - alternatim connexis habetur expectatio primi ludentis; omiffâ verò unitate quæ femper primus feriei terminus eft, fignis. que cæterorum inverfis habetur expectatio colluforis. Ex, gr. Si alternatim inftituere jubeantur, ipfe A jactus tres, B unum, A 4 , 


\section{$P A R S R R M A$}

绝 $I, A, B, B, \&$ fic deinceps in infinitum, putà fecundùm numeros .Cyclometricos Ludolfi, qui nullâ determinatâ lege progrediuntur, erunt ordine numeri jacturum - - 3 I $4, x+5 \quad 926$ horumque fumma ab initio collect $x, 0,3,4,8,9,54,2,25,3 \mathrm{t}, 36,2 \mathrm{kc}$. ac proinde fors ipfrus

A, $1-m^{3}+m^{4}-m^{8}+m 9-m^{14}+m^{23}-m^{25}+m^{3 r}-m^{36}+8 x c_{0}$

$\mathrm{B},+m^{3}-m^{4}+m^{8}-m^{9}+m^{14}-m^{23}+m^{2}-m^{31}+m^{36}-\& c_{0}$

Nota, fi numerus omnium jactuum fit limitatus, ultra quem etfi neuter adhuc vicerit ludere prohibeantur, eadem regula valebit, nifi' quòd ultimus terminus, cujus exponens ex omnium jactuum fummâ conflatur, in illâ ferie in quâ fignum + habet redundat, adeoque abjiciendus, quo fit, ut expectationes amborum fimul fumptæ eodem illo termino deficiant ab unitate. Sic in præced. exemplo fi poft ultimò adfcriptum quinarium, h. e. poft jactum . $3^{6^{\text {tum }}}$ effet fubfiltendum, fieret

fors $\mathrm{A}, \mathrm{I}-m^{3}+m^{4}-m^{8}+m^{9}-m^{14}+m^{23}-m^{25}+m^{3 x}-m^{36}$. fors $\mathrm{B}_{2}+m^{3}-m^{4}+m^{8}-m^{9}+m^{14}-m^{23}+m^{25}-m^{3 \mathrm{r}}$ 。 adeoque amborum fimul $1-m^{36}$.

\section{PROBLEMA II.}

TRes Collufores A, B \& C affumentes i 2 calcu1 los, quorum 4 albi \& 8 nigri exiftunt, ludunt hâc conditione: ut, qui primus ipforum velatis oculis album calculum elegerit, vincat; \& ut prima eleAtio fit penès $A$, fecunda penès $B, \&$ tertia penès $C$, $\&$ tum fequens rurfus penès $A$, atque fic deinceps alternatim. Quæritur, quænam futura fit ratio illorum fortium?

Senfus hujus Problematis ambiguus eft, unde variis quoque folutionibus locus. Vel enim fupponitur, electos calculos poft fingulas electiones in urnam recondendos effe, priusquàm fequens eligit, fic ut numerus eorum perpetud maneat idem; vel non effe recondendos, fic ut eorum numerus continuò decrefcat: deinde fuppo- 
fupponi poteft, vel à fingulis affumptos effe Iz calculos, vel ab univerfis in commune.

I. Si calculi poft fingulas electiones fint recondendi (quo quidem fenfu nil interef, five in commune feu à fingulis a calculi affumpti fuerint $\lambda$ quafita colluforum fortes hâc ratione inveltigantur:

I. Methodo Auctoris, Vocetur fors primi $x$, fecundi $y$, tertii $z$; Jam primus A cùm ludere incipit, 4 habet cafus ad vincendum feu obtinendum depofitum, ( $\mathrm{ob} 4$ calculos albos), \& 8 cafus ( ob 8 nigros), quibus perdit fuam precedentiam \& transfertur in ftatum tertii, adeoque acquirit fortem $z$; quod valet $\frac{4+8 z}{12}$ $\infty \frac{\mathrm{I}+2 z}{3}$; ac proinde fors primi $x x_{\frac{1+2 \pi}{3}}$. Ob eandem rae tionem habet fecundus $B$, cùm primus ludum inchoat, 4 cafus: ad obtinendum nihil, \& 8 cafus ad acquirendam pracedentiam, quâ transfertur in ftatum primi acquiritque fortem $x ;$ quod valet: $\frac{8}{2} x \infty \frac{2}{3} x$, quare fecundi fors $y \infty \frac{2}{3} x$. Pariter quoque tertius C a principio habet 4 cafus ad nihilum, \& 8 ad obtinendum fecun dum eligendi locum five fecundi fortem $y$; quod tantundem eft ac $\frac{2}{3} y ;$ quocircà tertii fors $z \infty \frac{2}{3} y$, hoc ef, $y \infty \frac{3}{2} z ;$ \& quia $y$ etiam reperta fuit: $\infty \frac{2}{3} x$, habetur $\frac{3}{2} z \infty \frac{2}{3} x$, hoc eft, $z \infty \frac{4}{9} x$, qui valor ipfius $z$ in primâ æquatione $x \infty \frac{1+2 \pi}{3}$ fubftitutus exhibet $x \infty \frac{1}{3}+\frac{8}{27} x$, hoc eft, $x \infty \frac{9}{19}$ : unde porrò invenitur $y\left(\frac{2}{3} x\right)$. $\infty \frac{6}{19} ; \& z\left(\frac{2}{3} y\right) \infty \frac{4}{19} ;$ ac proptereà ratio fortium $x, y \& z$, ut 9. 6. 4 .

2. Methodo noftá. Pofito generaliter calculorum omnium nutemero a.g alborum $b$, nigrorum $c$, concipiantur, ut jam fæpiùs fa¿tum, infiniti collufores, qui præécriptâ conditione ludant, unusque poft alterom calculum educat \& reponat; erunt rurfus per Cor. I. Reg. ad Prop. XII. exhibita propter invariatum manentem in omnibus eleationibus alborum \& nigrorum numerum, expecta: siones fingulorum colluforum fequentes: 
Coll. II. III. IV.V. VI. VII. VII. IX. X. XI. XII. XIII. XIV.XV. \&ce。

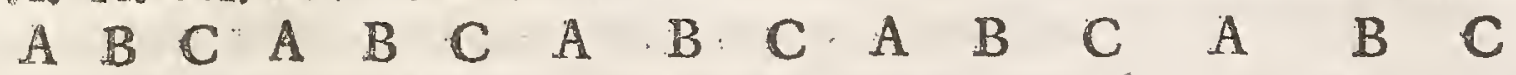

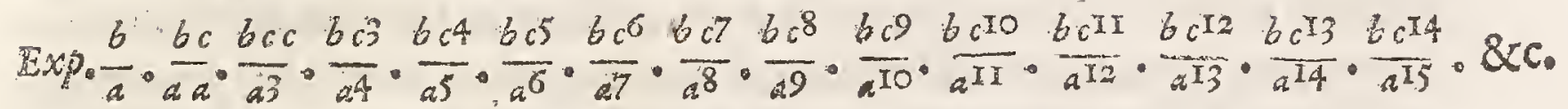
unde cùm per hypoth. prima, $\phi^{\mathrm{ta}}, 7^{\mathrm{ma}}$, roma $\& c$. electiones fint

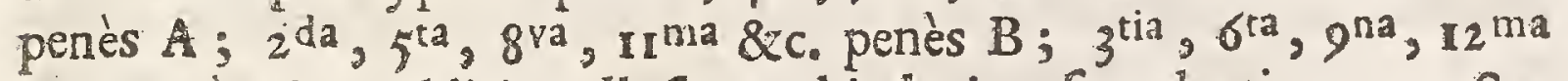
\&x. penès $C$; additis colluforum his locis refpondentium expectztionibus in unam fummam, habetur expectatio unius

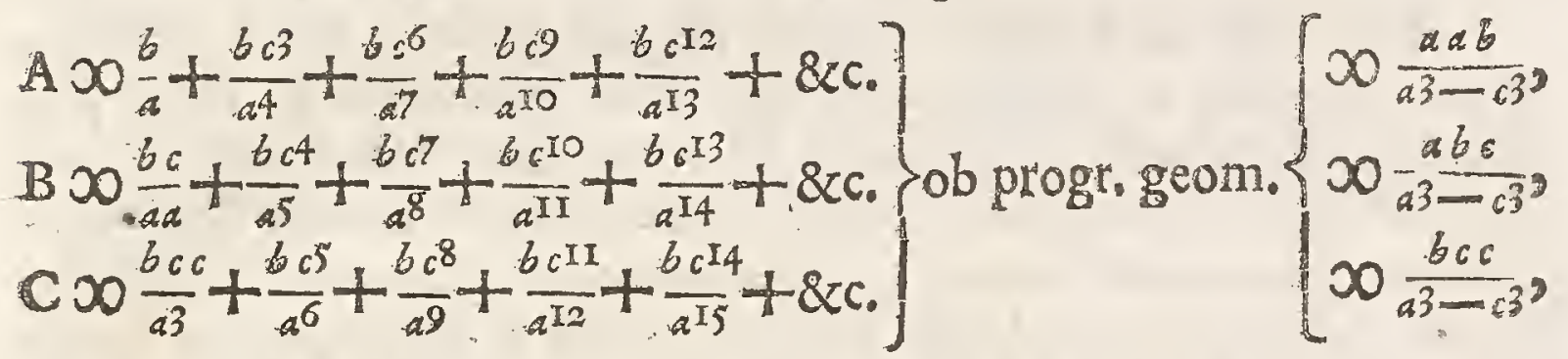
adeoque ratio fortium, vit $a a_{0} a c, c c$, id eft, hîc (ob $a, c:: r_{a}$ $8:: 3.2)$ ut 9.6 .4 ut anteà. Nota, fi qualtio proponeretur in collaforibus quatuor, fortes eorum eodem pacto repertum ini fe habere, ut $a^{3} \cdot a a c . a c c . c^{3} ; \& c$ fi generaliter in colluforibus $n$, ut $a^{n-1} \cdot a^{n-2} c \cdot a^{n-3} c c . \& c$. pergendo femper in ratione continuâ $a$ ad 6 o

11. Si porrò fenfus Problematis lit, ut affumpti in commine calculi I2 non reponantur, poftquàm ex urnâ exempti fuerint; obfervandum eft, quòd per continuam eduktionem calculorum nigrorum, primus quidem collufor transeat in locum rertii, tertius in locum 2 di, fecundus in locum primi, non idcircò tamen pariter fortes, quas $a b$ initio ludi habuêtre, invicem permutent, ut factum fuit in prec. hyp. fed quod fubinde alias novas \& à prioribus diverfas ob mutatum calculorum numerum acquirant, easque tamen fimpliciores quò plures calculi nigri educti fuerint, atque ita comparatas, ut tandem definant in fortes omnino coginitas. Quapropter incipiendo confuetâ Autoris methodo ab omnium fimplicifimis, \& pergendo retrò per omnes intermedias, perveniemus ultimò folâ fynthefi utendo ad cafum in quatione propofitum.

Hunc in finem fupponamus, eductos jam effe 7 calculos nigros, adeoque proximum eligendi locum ipfi B deberi, Sic pri$\mathrm{H}_{2}$ mats 
mus A nihil ampliùs expectabit ; quandoquidem reliquorum alterurer $B$ vel $C$ ob refidum nigrum unicum neceffario album educet \& vincet. Secundus verò $\mathrm{B}$ ob 4 albos 4 habebit cafus ad vincendum, unumque ob refiduum nigrum ad perdendum; quandoquidem fis hanc eduxerit, tertius $C$ infallibiliter vincet. Sed ob. eandem rationem tertius $\mathrm{C}_{4}$ habebit cafus ad perdendum \& unum ad vincendum. Unde colligimus; fortes trium $\mathrm{A}, \mathrm{B}, \mathrm{C}_{2}$ eо ç. in fore $0, \frac{4}{5}, \frac{x}{5}$.

Supponamus deinde, eductor efe nigros fex. Sic habebunt, primus quidem $\mathbb{A}$, quem proximus tunc ludendi ordo tangit, 4 cafus ad vincendum, totidemque ad perdendum duo reliqui: omnes verò tres ob refiduos duos nigros duos cafus ad obtinendum precedentes. fuas expectationes, qaandoquidem altero horum edweto unicus reftat niger, ordogue ludendi ipfum $B$ polcit, qui cafus eft preced. hypothefis. Unde fortes ipforum nunc funt $\frac{2}{3}, \frac{4}{15}, \frac{x}{15}$.

Fingamus porrò, eductos effe nigros quinque. Sic habebit tertius $C$, quem tangerent eligendi vices, ad vincendum; reliquique duo ad perdendum 4 cafus: ob refiduos autem tres nigros, quivis illorum etiam 3 habet cafus ad expectationem fuam modò inventam. Unde jam fortes ipforum fiunt $, \frac{2}{7}, \frac{4}{35}, \frac{3}{5}$.

Rurfus fi educti concipiantar nigri quatuor, fic ut aqualis alborum \& nigrorum numerus fuperfit, erit una medietas cafuun pro $B$, utpote penès quem tunc proxima foret electio, eademque contra A \& C ; altera velò medietas omnes tres ad præcedentes expectationes promovebit. Unde nafcuntur fortes $\frac{1}{7}, \frac{3}{7} \frac{2}{0}, \frac{3}{10}$. $\frac{13}{42}, \frac{1}{6}$ :

Eâdem ratione fi edußti fint nigri tres, inveniuntur fortes ${ }_{2}^{1} \frac{1}{1}$ a

Si nigri duo, $\frac{x I}{35}, \frac{13}{7}, \frac{x}{2}$. Si niger uinus, $\frac{3}{5}, \frac{5}{1} \frac{7}{10}, \frac{7}{2}$.

Si denique nullus adhuc calculus eductus fuerit, quem folum cafum primò intendimus., \& propter quem pracedentes omnes ex. pedire prius oportuit, fortes colluforum $A, B, C$, fimili modo rèperiuntur $\frac{7}{15}, \frac{53}{165}, \frac{7}{3} \frac{7}{3}$, five ad idem nomen reduct $\frac{77}{16.5}=\frac{53}{165}$ ? $\frac{35}{165}$; fic ut optata ratio fortium fit, ut $77.253,35$.

Methodus porro nobis familiaris etiam in prafente hypothef locum 


\section{$P A R S P R I M A$}

locum habet; neque enim hanc magis refpuunt ex quaftiones, qua communiter folâ fynthefí folvuntur, quàm qua analyfí opưs. habent. Quoniam osto funt calculi nigri non reponendi, poftquam educti fuerint, fingo novem effe collufores, qui finguli ordine fingulas electiones inftituant; quo fiet ut unus eorum neceffariò tandem album educar ac vincat. Nullus autem fpem vincendi habere poteft, nifi omnes ipfum præcedentes continuò nigros eduxerint; quocircà fuppono horum numerum (cui cafuum numerus proportionatur) gradatim minui, atque poft primam electionem fupereffe calculos nigros feptem, poft $2^{\text {dam }} \mathrm{fex}$, poft $3^{\text {tiam }}$ quinque, \& fic deinceps; indeque fingulorum colluforum fortes per Regulam Prop. XII, annexam elicio, juxta fequentem laterculum:

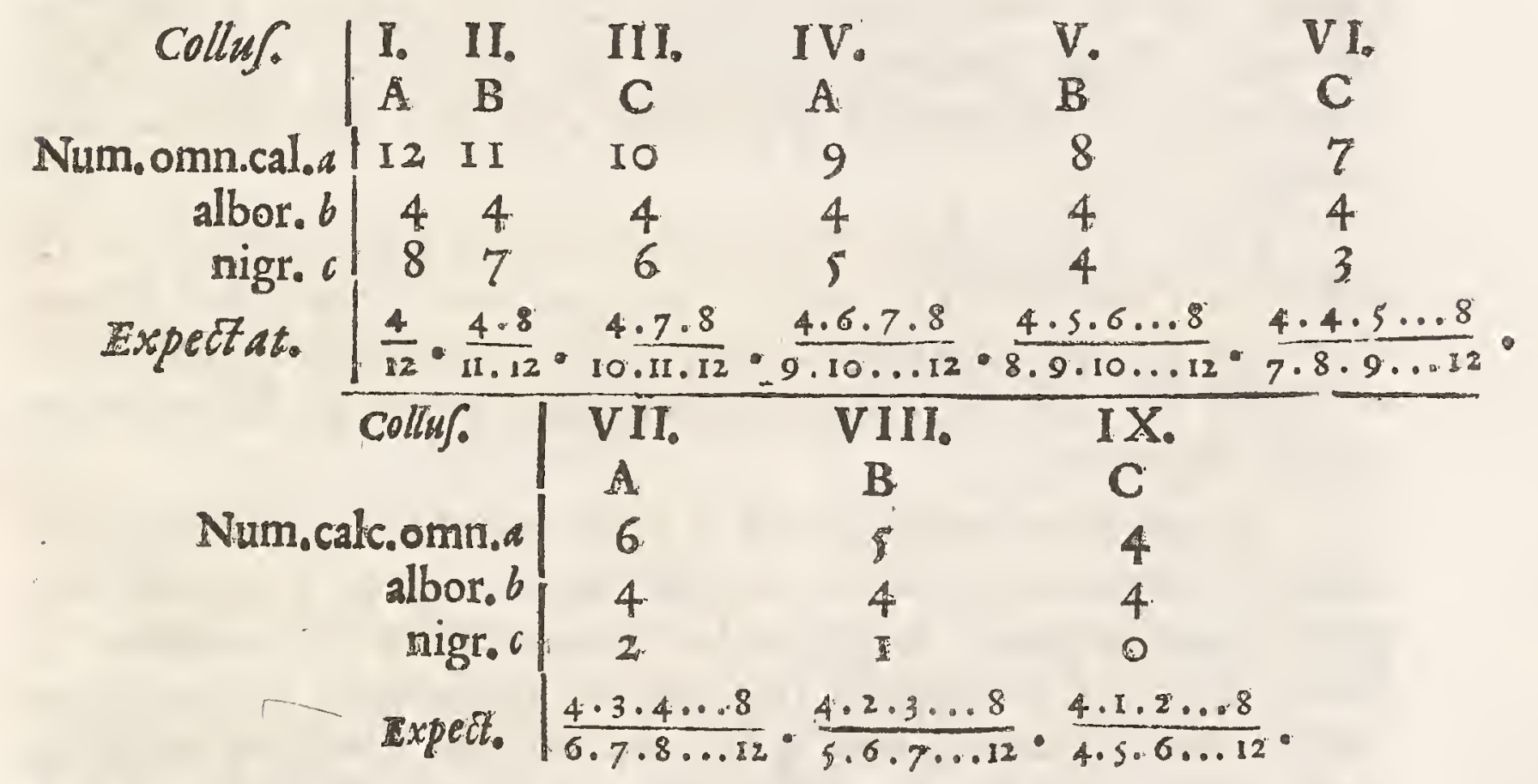

cum, quia prima, $4^{\text {ta }} \& 7^{\text {ma }}$ electiones debentur ipfi $A ; 2^{\text {da }}, 5^{\text {ta }}$ \& $8^{\text {va }}$ ipfi $B ; 3^{\text {tia }}, 6^{\text {ta }} \& 9^{\text {na }}$ ipfi $C$; expectationes colluforum his numeris defignatorum collectivè accipio, \& habebo pro expestatione ipfius $A, \frac{4}{12}+\frac{4 \cdot 0 \cdot 7.8}{9.10 \cdot 11.12}+\frac{4 \cdot 3 \cdot 4 \cdot 5 \cdot 6 \cdot 7.8}{6.7 \cdot 8 \cdot 9 \cdot 10.11 .12} ; B, \frac{4.8}{11.18}$ $+\frac{4 \cdot 5 \cdot 6 \cdot 7.8}{8 \cdot 9 \cdot 10.11 .12}+\frac{4 \cdot 3 \cdot 3 \cdot 4 \cdot 5 \cdot 6 \cdot 7 \cdot 8}{5 \cdot 6 \cdot 7 \cdot 8 \cdot 9 \cdot 10 \cdot 11.12} ; C, \frac{4 \cdot 7 \cdot 8}{10.11 .12}+\frac{4 \cdot 4 \cdot 5 \cdot 6 \cdot 7 \cdot 8}{7 \cdot 8 \cdot 9 \cdot 10.11 .12}$ $+\frac{4.1 .2 \cdot 3 \cdot 4 \cdot 5 \cdot 6 \cdot 7 \cdot 8}{4 \cdot 3 \cdot 6 \cdot 7 \cdot 8 \cdot 9 \cdot 10 \cdot 11.13} ;$ qua fradiones omnes ad nomen commu$\mathrm{H}_{3}$ ne 5. 
ne 5.6 .7 .8 .9 .10$. II. I2, reducte numeratores nancifcuntur fe quentes: $4.5 \cdot 6.7 .8 .9 .10 .11+4.5 .6 .7 .8 .6 .7 .8$ $+4.5 .3 .4 \cdot 5.6 .7 .8004 .5 .6 .7 .8$ in $\overline{3.4 .5}+\overline{6.7 .8}$

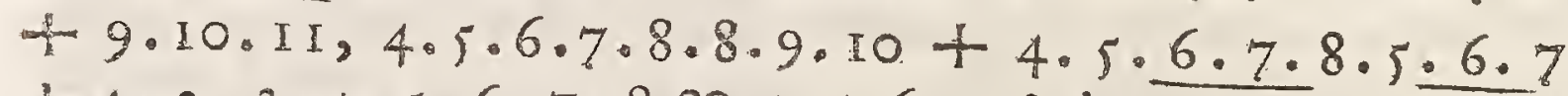
$+4.2 .3 .4 \cdot 5 \cdot 6.7 .8004 .5 \cdot 6.7 .8$ in $2.3 .4+5.6 .7$ $+8.9 .10,4.5 .6 .7 .8 .9 .7 .8+4.5 .6 .4 .5 .6 .7 .8$ $+1.2 .3 .4 \cdot 5.6 .7 .8 x 04.5 \cdot 6.7 .8$ in $1.2 .3+\overline{4.5 .6}$ $+7.8 \cdot 9$, unde elío communi factore $4.5 \cdot 6.7 .8$, ratio forrium exurgit, ut $3.4 .5+6.7 .8+9$. IO. II, 2.3 .4 $+5.6 .7+8.9 .10,1.2 .3+4.5 .6+7.8 .9$, feu divid: per 6 , ut $10+56+16500231,4+35+12000159$ ? I $+20+84,00$ 105, rurfusque divid. per 3 , ut $77,53,35$, uti fuprà. Et quia in numeris iftis certam progreflionis legem obfervamus, facile poffemus regulam dare generalem pro numero colluforum \& calculorum quocunque, fi tanti referret his im. morari.

III. Tertio fenfu acceptum Problema (cùm finguli trium colluforum affumunt 12 calculos, aliusque polt alium è fuis unum depromit \& non recondit) parùm differt à præcedente hypothefi, nifí quòd ob auctum calculorum numerum multò prolixiorem a peram deporcit。

Supponamus primò, ipfis A \& B nullum ampliùs fupereffe calculum nigrum, ipfi $C$ verò adhuc unum, quem proptereà eligendi vices tangent. Is propter 4 calculos albos \& I nigrum, 4 habet cafus ad vincendum \& unum ad perdendum; quandoquidem fi hunc eduxerit, ipfe $A$ cui non nifi albi fuperfunt infallibiliter vincet: fed $\&$ ob eandem rationem primus A vicifim 4 ha bet cafus ad perdendum \& unicum ad vincendum; fecundo vero $B$ nihil omninò relinquitur, è̀ quòd alterutri reliquorum neceffariò cedet victoria. Unde colligitur, fortes ipforum $A, B, C$, fore $\frac{1}{5}, 0, \frac{4}{5}$.

Supponamus deinde, ipfi A reftare nullum, \& fingulis reliquorum trium nigrum. Sic ipfe $\mathrm{B}$, quem eligendi ordo tangit. 6. ancendum calus habet, totidemque ad perdendum reliqui ; 


$$
\text { ARS PRIA }
$$

unus verò calus eft, qui unicuique illorum præcedentis cafus expectationem affert; id quod ipfis $A, B, C$, fortem parit $\frac{1}{25}$, $\frac{4}{5}, \frac{4}{25}$.

Supponamus tertiò, fongulis $A, B$ \& $C$, reftare unum calcuIum nigrum. Sic A quem penès proxima electio eft, 4 habebit $\mathrm{ad}$ vincendum, reliquique ad perdendum cafus; unum verò, quo perducuntur omnes tres ad precedentes fuas expectationes. Unde nafcuntur ipfis fortes $\frac{10}{1} \frac{1}{2}, \frac{4}{2}, \frac{4}{1} \frac{5}{5}$; quas inter ratio eft, ut 101 , 20,4 .

Eodem modo ulteriùs inveftigandum effet, quid deberetur colluforibus $A, B \& C$, cùm iplis reftant calculi nigri, $1.1,2, x, 2.2$, $2.2 .2,2.2 .3,2 \cdot 3 \cdot 3,3 \cdot 3 \cdot 3, \& c_{0}$ quoufque perveniretur ad cafum propofitum, qui fingulis colluforibus 8 nigros calculos attrim buit. Sed quia hæc figillatim perfequi fupra modum tædiofum foret, idcirco oftendam, qua pacto quæfitum per faltum obtineri queat, inveniendo folummodò fortes illorum ftatuum, in quibus unicuique colluforum æqualis nigrorum calculorum numerus fupereft; quem numerum femper vocemus $c_{2}$ ficuti alborum $b_{2} \& 0$ mnium $a \infty b+c$.

Oportet primò confiderare omnes variationes, quæe accidere poflunt cùm unusquisque colluforum unum calculum è fuis depromit; perfpicuum autem eft fieri poffe, ut vel omnes tres educant album calculum, vel duo tantùm, vel unus, vel nullus. Deinde attendendum, quot cafus fingulis harum variationum refpondeant; quorum quidem numerus hoc modo initur: Si quis certaret fore, ut omnes tres educant album, ejus fors foret $\frac{b 3}{a 3}:$ fi futurum contenderet, ut duo A \& B, vel duo A \& $\mathrm{C}$, vel B \& , album eligant $\&$ tertius nigram, fortem haberet $\frac{b b c}{a^{3}}$ : fi propugnaret fore, ut folus $A$ vel $B$ vel $C$ album eximat, reliqui nigrum, fortem porfideret $\frac{b c c}{a^{3}}$ : fi denique nulli album concedere vellet, fortem obti. neret $\frac{c 3}{a 3^{3}}$ ( (quæ omnia ex Cor. I. Regulæ Prop. XII. fubjundte patefcunt, cum tantundem hæc valeant, acfi ipfe in æquali numero cafuum tribus jactibus quippiam præcisè ter, aut bis, aut femel, 
præftandum aut planè non præftandum fufciperet:) quamobrem; per ea quæ ad lit. I. Prop. XI. annotavimus, rejecto fractionum harum communi denominatore fignificabunt numeratores numeros cafuum, quibus unusquisque horum eventukm contingere poteft.

Terciò denique obfervandum, quòd juxta tenorem Problematis primus A victoriâ potiri debeat, quotiescunque five folus five cum alterutro reliquorum five cum utroque album calculum ele gerit; fecundus autem B, five folus five junctim cum $C$ id præfiterit; \& tertius $C$, non nifi cum folus id effecerit: quoriescunque verò evenerit, ut nullus trium album educat, quòd tunc finm guli perveniant ad fortes, quas habere inventi funt, cùm nigri uno pauciores ipfis fupereffe ponebantur, Quapropter additis in unum. cafibus, qui cuique tum favent tum adverfantur, invenimus primum A habere $b^{3}+2 b b c+b c c$ cafus ad vincendum feu obtinendum depofitum $I, \& b b c+2 b c c$ cafus ad perdendum; fecundum B $b b c+b c c$ ad vincendum $\& b^{3}+2 b b c+2 b c c$ ad perdendum; 8 tertium $C b c c$ ad vincendum $\& b^{3}+3 b b c+2 b c c$ ad perdendum: omnes verò tres habere $c^{3}$ cafus, qui iplos ad fortes jam anteà inveftigatas perducunt; qux fortes fi dicantur $\frac{p}{p+s+t} \cdot \frac{s}{p+s+t}$. $\frac{t}{b+s+t}$; fiet per Prop. III. expectatio ipfius
A $\infty$
$\frac{b \overline{b+2 b b c+b c c} \text { in } 1+\overline{b b c+2 b c c} \text { in } 0+c 3 \text { in } p: \overline{p+s+t}}{a^{3}}$
$\mathrm{B} \infty \frac{\overline{b b c+b c c} \text { in } 1+b \overline{3+2 b b c+2 b c c} \text { in } 0+c^{3} \text { in } s: p+s+t}{a^{3}}$.
C $\infty \frac{b c c}{\text { in } x+\overline{b^{3}+3 b b c+2 b c c} \text { in } 0+c 3 \text { in } t: \overline{p+s+\varepsilon}}$.

hoc eft, elifo communi nomine \& factâ multiplicatione per $\frac{p+s+\varepsilon}{c^{3}}$, erit ratio fortium ipforum $A, B, C$, ut

$$
\left.\begin{array}{r}
b^{3+2 b b c+b c c} \\
b b c+b c c \\
b c c
\end{array}\right\} \text { in } \frac{p+s+t}{c^{3}}\left\{\begin{array}{l}
+p \\
+s \\
t i
\end{array}\right.
$$




\section{$P A R S$ PRIMA.}

Quibus ita præmiffis, ut ad folutionem noftri Problematis reverzamur, fupponendum porrò eft, fingulis colluforum reftare duos calculos nigros: Sic lit, $6 \& c$ valebunt $4 \& 2$ (pro quibus fubflitui poffunt minimi in eâdem ratione termini $2 \& 1$ ); \& quia ratio fortium in cafu precedenti cùm fingulis unus reftabat calculus niger, quam literis $p, s, t$ indigitamus, expreffa fuit per numeros 101, 20, 4, quorum fumma $p+s+i 20125$; hinc juxte præmiffam formulam expeditè inveniuntur numeri $235 \pi, 770,254$. exprimentes rationem fortium, quas collufores in cafu prefenti poffident.

Eodem pacto, fi fingulis tres nigri fupereffe fupponuntur: quo cafu lit, $b \& c$ valent $4 \& 3$, ipfæque $p, s, t$ numeros modd inventos $235 \mathrm{I}, 770,254$; ratio fortium reperitur defignari per numeros $2685 \mathrm{I}, 11270,4754$.

Si refidui fint fingulis 4 nigri, fic ut valor lit. $b \& c$ fit $4 \& 4$ (hoc eft, in minimis terminis I \& I) inveniuntur fortes fe habere in ratione $19835 \mathrm{I}, 97020,47629$.

Si reftent fingulis nigri 5 , hoc eft, fi lit. $6 \& c$ valeant $4 \& 5$; habetur ratio fortium in numeris $10874.07,590940,322029$; fel dividendo per 9, in $120823,65660,35781$.

Si fingulis fuperfint nigri 6 , adeogue valor lit. $6 \& 6$ fit $4 . \&$ 6 , feu $2 \& 3$; exprimetur ratio lortium per $5324,23,312620,183957$.

Si fingulis adhuc remaneant nigri 7 , fic ut lit. $6 \& c$ fignificent 4 \& $\%$, prodibir ratio fortium in numeris 1984423,1236620 , 771957.

Si denique nullo adhue calculo educto omnes 8 nigri fingulis fuperfint, literæque $b \& c$ valeant $4 \& 8$, hoc eft, $1 \& 2$, qui quidem cafus is eft, quem nobis enodandum propofuimus, $\&$ cujus gratiâ pracedentes omnes expedire priùs neceffum habuimus, invenimus, quodd optata ratio fortium colluforum $A, B, C$, defignesur per numeros $6476548,4231370,2768457$.

Applicationem methodi nobis ufitatæ ad hane hypothefin Leator iple li vult inftituet. Nos illam brevitatis gratiâ praterimus. 


\section{PROBLEMA III.}

A Certat cum B quòd ipfe ex 40 chartis luforiis; A id eft, to cujusque fpeciei, 4 chartas extrafturus fit; ita ut ex unaquaque fpecie habeat unam. Et invenitur ratio fortis $\mathrm{A}$ ad fortem $\mathrm{B}$ ut $1000 \mathrm{ad}$ 8 r39.

Solutio : Pone primò, jam tres diverfarum fpecierum chartas extractas effe; quo facto ex unaquâque harum fuecierum adhuc remanebunt 9, hoc eft, ex omnibus tribus fpeciebus 27 folia, \& ex quartâ fpecie io. Unde conftat, quòd quartum folium extracturus habeat 27 cafus ad perdendum, \& I0 ad vincendum; id quod ipfi valet $\frac{10}{37}$ depofiti.

Pone deinde, duas differentium fpecierum chartas extractas effe; quâ ratione ex iỉsdem fpeciebus adhuc reftant folia 18 , ficur ex reliquis duabus folia 20. Quapropter tertium folium exempturus 18 cafus habet ad perdendum, \& 20 ad obtinendum tres chartas diverfarum fpecierum, hoc eft, ad obtinendum pracedentem expectationem $\frac{10}{37}$; id quod ei fortem parit $\frac{1000}{7} \frac{0}{3}$.

Pone tertiò, extractam effe unam chartam; fic ex eâdem hấc fpecie, cujus eft extracta, fuperfunt charta 9 , ex reliquis verò tribus fpeciebus chartæ 30. Idcircò fecundum folium accepturus 9 habet cafus ad perdendum, \& 30 ad acquirendum diverfe fpeciei folium, hoc eft, ad impetrandam fortem modò inventam $\frac{1}{7} \frac{0}{3}$ id quod tantundem eft ac fi haberet $\frac{1}{9} \frac{0}{3} \frac{0}{3} 9$.

Si nulla adhuc charta extracta fit, fors extrahentis eadern eft cum pracedente, manetque $\frac{1000}{9} \frac{0}{1} ;$ quoniam omnes $40 \mathrm{cafus}$ ipfum neceffario in eum ftatum conjiciunt, qui in paragrapho præced. fuppofitus fuit. Quare tum etiam fors contracertantis erit $\frac{21}{9} \frac{1}{3} \frac{9}{2} ; \&$ ratio fortium, ut 1000 ad 8139 , quemadmodìm habet Auctor.

Ejusdem Problematis folutio etiam aliter per Combinationum doctrinam confici poteft, uti parte tertiâ polt hujus doctrinæ explicationem oftendemus. 


\section{$P A R S P R I M A$ \\ PROBLEMA I V.}

A Sumptis, ut ante, 12 calculis, 4 albis \& 8 ni. A gris, certat A cum B, quòd velatis oculis 7 calculos ex iis exempturus fit, inter quos 3 albi erunt, Quxritur ratio fortis ipfius $A$ ad fortem ipfius $B$.

Etiam iftud Problema in tertiam libri partem rejicere cogim mur, quoniam ad ejus folutionem artis combinasoriæ notitia pra** requiri videtur。

\section{PROBLEMA V.}

A \& B affumentes finguli 12 nummos ludunt triA bus tefferis hac conditione: ut, fi I I punda jaciantur, A tradat nummum ipfi $B$; at fi it puncta jaciantur, $B$ tradat nummum ipf $A$; \& ut ille ludum victurus fit, qui primùm omnes habuerit nummos. Et invenitur ratio fortis ipfius $A$ ad fortem ipfius $B$, ut $244 \mathrm{I} 40625$ ad $28242953648 \mathrm{I}$.

Solutio: Confiderandum primò, in tribus tefferis contineri 216 jactus diverfos, \& inter hos dari 15 jactus punctorum quatuordecim, \& 27 jactus punctorum undecim; adeoque 15 cafus effe in quolibet jactu, quibus efficitur ut aleator A à collufore B nummum accipiat, \& 27 cafus quibus contingit ut hic absillo nummum confequatur; alios verò 174 cafus, quibus uterque eundem nummorum numerum priftinamque proin fortem retinet.

Deinde attendendum, quòd illi 174 cafus irriti, quibus colIuforum fortes invariatæ manent, per 4 Coroll. 3 . diffimulari pof fint ac fi prorsùs abeffent, inque tefferis tribus folumm dò 42 reperirentur jactus, quorum is ipfum A nummo potiri faciant, \& 27 ipfum $B$.

Tertiò \& illud confiderandum, quòd pro numeris cafuin 4. 2, if \& 27 , utpote compofitis inter fe fubltitui poffint per $z$ 
Cor. 3 , minimi in eâdem ratione termini $14,582, ;$ in quorum tamen rurfus locum, ut generalior fiat folutio, nos literas $a, b$ \& c furrogamus.

Quibus animadverfis in enodatione propofitæ quæftionis ita ảeinceps progredior, ut inquiram ordine, quænam futuræ fuiffent colluforum fortes, fi finguli aflum pliffent nummum unum, deinde fi duos, pofteà fi tres, quatuor \&cc. quoufque per inductionem pateat, quænam iis fortes nunc competant, ubi finguli affumferunt nummos 12 .

Si finguli affumant nummum unum, perfpicaum eft, fortes corum fore in ratione ipforum numerorum $b \& c$.

Si finguli accipiant nummos duos, primus jactus efficiet, ut collufor $\mathrm{A}$ vel 3 poffideat nummos, vel ut unus tantùm ei fuperfit. Si tres poffidet, habet $b$ cafus ad acquirendum omnes quatuor, hoc $e f$, ad vincendum feu obtinendum depofitum $1 ; \& c$ cafus, nuibus ei relinquuntur nummi duo, hoc eft, quibus revertitur ad fortem initio pofitam, quam vocare lubet $z$; quod proin valet $\frac{b+c z}{a}$. Si unicus illi nummus fupereft, habet $b$ cafus ad recuperandum duos, hoc eft, fortem $z ; \& c$ cafus ad perdendum ludum; id quod efficit $\frac{b z}{a}$. Atqui ut poft primum jactum tres nummos numeret, rurfus $b$ funt cafus; $c$ verd cafus quibus ipfi unus tantùm relinquitur. Itaque $a b$ initio $b$ cafus extant qui ei dent $\frac{b+c z}{a}, \&$ c qui dent $\frac{b z}{a} ;$ id quod fortem gignit $\frac{b b+2 b c z}{a b}$ : quare $z \infty 0$ $\frac{b b+2 b c z}{a a}$, five $z \infty \frac{b b}{a a-2 b c} \infty \frac{b b}{b b+c c}$, \& relinquitur collufori B $\frac{c c}{b b+c c} ;$ adeò ut fortes ipforum fint in ratione $b b$ ad $c c$.

Si finguli affumant nummos tres, primo jactu continget, ut collufor $\mathrm{A}$ vel 4 nummorum compotem fe videat, vel ut duorum tantùm; in quibus ftatibus expertiones ejus appellentur $x \& y$. Si quaruor nummorum compos eft, u'terius vel ipfe primus ab altero duos nummos impetrabit ac vincet, vel ab ipfo duos.confe- 
Gquetur alter, fie ut ei relinquantur adhuc nummi duo: fed ut ipfe primus duos proximos nummos confequatur, $b \bar{b}$ cafus præfto funt, $\&$ \& c cafus quibus idem alteri obtingit (uti ex eo quod modd oftenfum eft collato cum annot. Propor. XI. ad lit. I colligitur) quapropter $b 6$ cafus habet ad I, \& $c c$ cafus ad fortem $y$, quod ei valet $\frac{b b+c c y}{b b+c c}$; cumque id ipfum etiam appellemes $x$, erit $x \infty$ $\frac{b b+c c y}{b b+c c}$, feu $y \infty 0 \frac{b b x+c c x-b b}{c c}$. Similiter cùm duo tantum ipfr reftane nummi, 66 cafus habet ad recuperandum adhuc duos alios, hoc eft, ad impetrandam fortem $x$, \& c c cafus ad perdendum fuos \& cum iis omne depofitum; quod tantundem eft ac fi haberet $\frac{b b x}{b b+c c}$; cumque tum etiam habere fupponatur y, fiet y $00 \frac{b b x}{b b+c c}$; fed fuprà inventa quoque y $x 0 \frac{b b x+c c x-b b}{c c}$; quare $\frac{b b x+c c x-b b}{c c}$ $\infty \frac{b b x}{b b+c c} ;$ atque hinc $x \infty \frac{b 4+b b c c}{b 4+b b c c+c 4}$; nec non $y\left(\infty \frac{b b x}{b b+c c}\right)$ ${\frac{b}{64}+b b_{c}+c 4^{\circ}}^{\circ}$ Quo facto demừm accedendum ad fatum inirid pofitum, cogitandumque quòd ubi finguli tres nummos affumunt, $b$ cafibus contingere poffit, ut collufor $A$ poft primum jaw ctum 4 nummos poffideat, hoc eft, ut fortem $x$ feu $\frac{b 4+b b c c}{b 4+b b c c+c^{4}}$ acquirat ; \& $c$ cafibus, ut duos refiduos habeat nummos, id eft, ut fortem $y$ five $\frac{b_{4}}{b^{4}+b b_{c}+c^{4}}$ confequatur. Unde tunc ejus expectas tio fiet $\frac{b 5+64 c+b 3 c c}{b 5+b 4 c+63 c c+b b c 3+b c 4+c 5} \infty$ (infitutâ per $b 6+b c+c c$ divifione) $\frac{b 3}{b^{3}+c^{3}}, \& 2$ relinquetur collufori $B \frac{c^{3}}{b 3+c^{3}} ;$ fic ut fortes corum nunc fint in ratione $b^{3}$ ad $c^{3}$.

Quandoquidem igitur fortes colluforum A \& B inveniuntur fe habere in ratione fimplici numerorum $b \& c$, cùm à fingulis unus nummus affumitur; $\&$ in ratione duplicatâ horum numerorum, cùm à fingulis affumuntur duo; $\&$ in triplicatâ, cùm tres: factâ inductione coll gimus, quòd acceptis etiam quotlibet nummis fortes iftæe perpetuò fưu ære fint in ratione toties multiplic tâ nu. merorum $6 \& c$, quot nummi à fingulis fuerint affumpti; \& quod 
per confequens in propofito Auctoris exemplo, ubi $a b$ unoqüoque ez aflumpti fupponuntur, fortes hæ fe habeant, ut $b^{12} \& b^{12}$, hoc eft, reftituendo $5 \& 9$, pro $b 2 x c$, ut $244140625 \& 28242953648 \mathrm{r}$; quemadnodum habet Außtor, Quod ipfum etiam vel absque calm culo utcunque fic inferri poteft: A habens omnes nummos præter unum habet 6 cafus ad vincendum, \& B habens omnes præter unum, habet $c$ cafus ad vincendum; dein $A$ habens omnes nummos prater duos habet $b$ cafus ad obsinendum omnes præter unum, id eft, ad $b$ cafus pracedentes, ideoque $b$ vicibus $b$ cafus feub $b \mathrm{ca}$ fus habet ad vincendum; \& $B$ habens omnes præter duos ob fimilem rationem habet $c c$ cafus ad vincendum: atque ita pro fingulis nummis qui colluforibus ad vincendum defunt, præeto funt ipfi $A b, \&$ ipfi $B c$ cafus, quibus ipfis acceflus fic ad cafus præcedentes; quare cum $a b$ initio ludi uterque habeat nummos $12, \&$ proinde utrique totidem ad vincendum deficiant, numeri $b \& 6$ duo. decies pofiti ac in fe ducti exhibebunt rationem fortium, ut anteà.

Quòd fi quis tamen ratiocinium iftud non fat evidentix has here exiftimet, neque etiam inductioni fatis fidat, is deinceps fimili compendio, quo Auctor in Propof. XI. ufus fuit, progredi poterit, nempe transeundo ftatim ad nummos fex, \& hinc ad duo decim, omintis omnibus intermediis cafibus. Quanquam ne fic quis dem ulteriori calculo indigemus; idem enim qui fupra fubduatus habetur in hypothefi duorum affumtorum nummorum, etiam valet, fi loco unius nummi quotlibet $n$ nummos, \& loco duorum in nummos affumtos intelligamus, dummodò pro numeris cafuum $b$ \& $c$ quibus alterutri colluforum unus nummus acquiritur vel de. perditur fubftituamus quoque numeros cafuum, quibus ille $n$ nummos acquirere vel amittere poteft; adeò ut hinc legitimè inferamus, rationem fortium quas habent collufores cum finguli 2 . nummos affumunt perpetuo duplicatam effe debere ejus quæ obtinet cùm fingulis tantùm $n$ nummi affumpti funt. Quare cùm fuprà in cafu trium affumtorum nummorum ratio fortium reperta fit ut $b$ ad $c$, erit illa in cafu nummorum 6 , ut $b^{6}$ ad $c^{6}$, indeque porrò in cafu nummorum 12 ut $b^{12}$ ad $c^{12}$, quemalmodum indul $=$ aione collegeramus. 


$$
P A R S P R I M A
$$

Et fic quidem liquet de fortibus colluforum, cum ambo æeque multos nummos acceperunt; fed nondum contat de fortibus quas acquirunt in quolibet ftatu, in quem luảum profequendo pervenire poffunt, quando uni plures, alii pauciores nummi contigére. Interim etiam pro iftis regula generalis datur ; pofito namque $m$ pro numero nummorum quos habet $A, \& 2 n$ pro numero eorum quos habet $B$, reperio quòd ratio fortis $\mathrm{A}$ ad fortem $\mathrm{B}$ femper fit futura, fi $b$ \& $c$ æquantur, ut $m$ ad $n$; fin $c$ excedit $b$, ut $6 n c m-b m+n$ ad $c^{m}+n-$ bncm; quorum demonfratio, cum operofiorem calculum depofcat,

Lecori enodanda relinquitar. Nos verò absque ulteriore morâ ad alteram propofiti noftri partem transimuss.

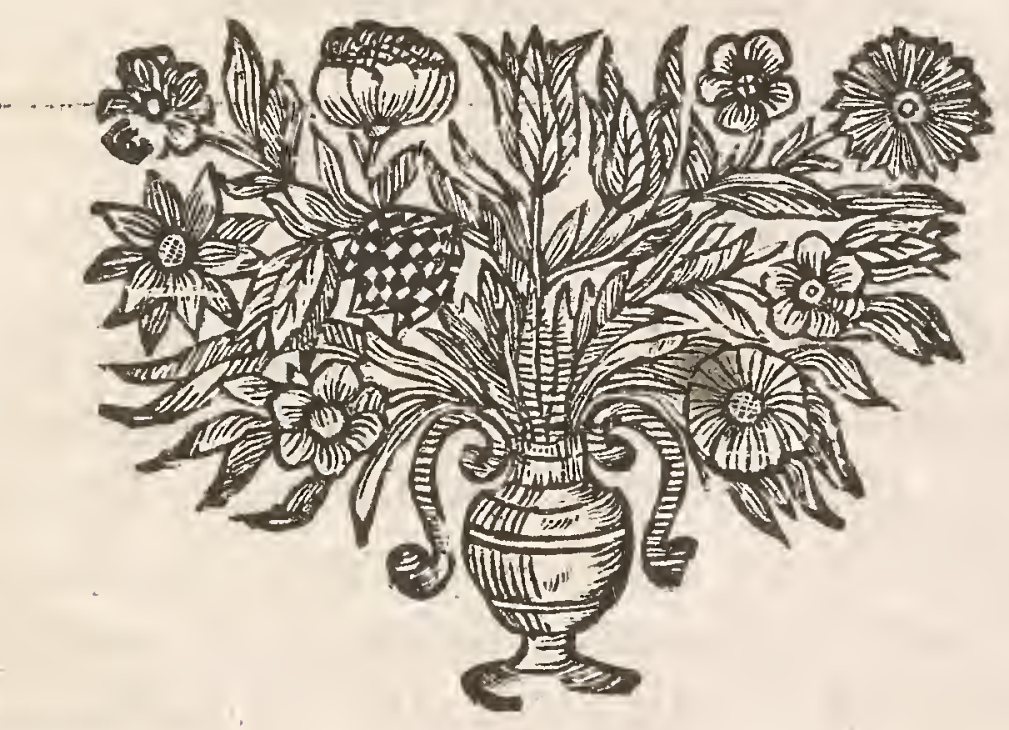




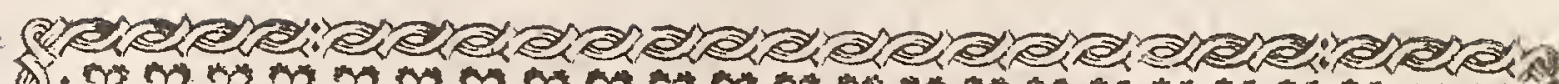

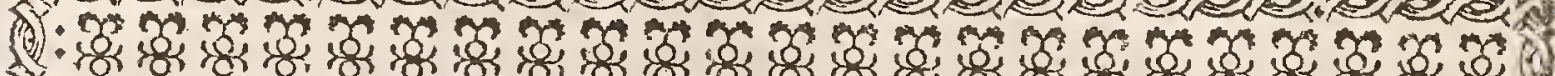

- .

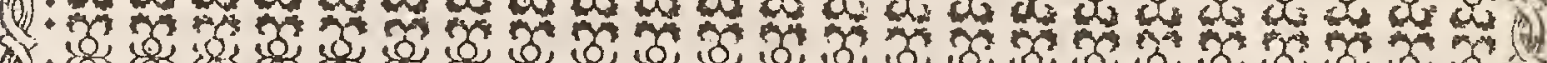

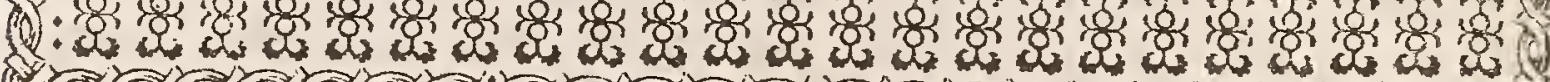

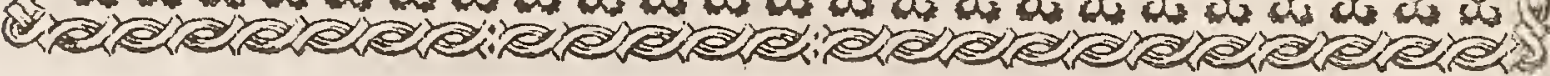

\section{ARTIS CONJECTANDI PARS SECUNDA,}

\section{continens}

Doctrinam de Permutationibus $\&$ Combinationibus.

\section{Procemium.}

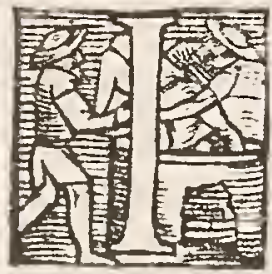

Nfinitam varietatem, quæ cùm in naturæ operibus, tùm in actionibus mortalium elucet, quæque præcipuam hujus Univerfi pulcritudinem conftituit, non aliunde quàm ex diverfimodâ compofitione, mixturâ \& transpofitione partium ejus inter fe originem ducere palàm eft. Sed quia multitudo rerum ad effectum aliquem producendum concurrentium fapenumerò tanta eft tamque varia, ut difficillimum fit recenfere vias omnes, quibus earundem compofitio vel mixtura fieri vel non fieri poteft, hinc fit ut nullum fit vitium, in quod homines etiam maximè prudentes \& circumfpecti frequentiùs incidant illo, quod Logici communiter appellant inrufficientem exsumerationem partium; adeò quidem ut non 
verear dicere, hanc unicam ferè fcaturiginem effe infinitorum eorumque gravifimorum errorum, quos in ratiociniis noftris circa res tum cognofcendas tum agendas quotidie committimus, Quare merito fuo utilifima cenfenda eft Ars, Combisatoria dicta, qux huic mentis noftræ defectui medetur, docetque fic enumerare modos omnes poffibiles, fecundùm quos res plures permifceri, transponi vel conjungi invicem poffunt, ut certi fimus, nos nullum eorum prætermififfe, qui inftituto noftro conducere valent. Quanquam enim hoc negotii eatenù fit confiderationis Mathematicæ, quatenùs in fubducendo calculo terminatur; fi tamen ufum \& necefitatem fpeetes, univerfale prorfus eft \& ita comparatum, ut fine illo nec fapientia Philofophi, nec Hiftorici exactitudo, nec Medici dexteritas, aut Politici prudentia confiftere queat. Argumento fit hoc unicum, quòd omnis horum labor in conjectando, \& omnis conjectura in trutinandis caufarum complexionibus aut combinationibus verfatur. Unde quoque nonnulli eximii Viri, ac nominatim Schootenius, Leibnitius, Wallifius, Preftetus, materiam hanc fibi tractandam fumplêre, ne quis exiftimet nova effe hic omnia quæ prolaturi fumus; tametfi quadam non contemnenda de noftro adjecimus, inprimis demonftrationem generalem \& facilem proprietatis numerorum figuratorum, cui cætera pleraque innituntur, \& quam nemo quod fciam ante nos dedit eruitve. Cum itaque nondum plenum Artis fyftema habeamus, tum verò ne illa qua habemus aliunde petere fit opus, vifum eft totam Doctrinam ab ovo ordiri ac ne quid indemonftratum relinquatur ex primis fundamentis eruere; quod tamen breviter fiet $\&$ K 
fuccinctè, nec nifi in quantum inftituti noftri ratio exigere videtur. Totam Tractationem ad duo fumma. capita referimus, quorum unum Permutationum, alterum Combinationum doctrinam perfequitur; cui accedit tertium, quod utrasque mixtim contemplatur.

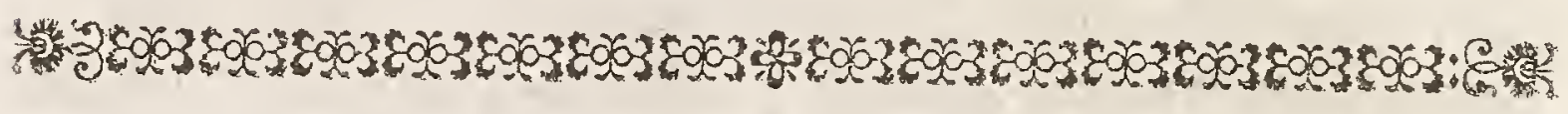

\section{A P U T I. \\ De Permutationibus.}

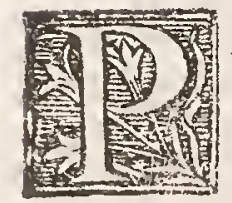

Ermutationes rerum voco Variationes, juxta quas fervati: eâdem rerum multitudine ordo fitusque inter ipfas diverfimodè permutatur.

Itaque fi quæratux, quoties nonnullix res transponi vel perw mifceri invicem poffint, fic ut femper accipiantur omnes folo ordine fituve mutato, dicentur quxeri omnes. Permutationes rerum: illarum.

Res autem permutandæ vel omnes poffunt effe diverfæ, vel alliquot earum eædem; quæ quidem per totidem Alphabeti literas five diverfas five easdem commodè defignabuntur.

\section{Si res omses permutanda funt diverfe:}

Cùm numerus permutationum in rebus pluribus iniri nequeat. nifi idem prits in omnibus aliis numero paucioribus comperzus habeatur, liquet in hâc inquifitione utendum viâ fyntheticầ, h. e. ordiendum nobis effe ab hypothefibus omnium primis \& fim plicifimis :

Unius rei vel literæ $a$, una tantùm fumtio vel pofitio eft.

Duarum rerum aut literarum $a \& b$, vel $a$ praecedit $\& b$ fequitur, vel præcedente $b$ fequitur $a$; unde duo ipfarum funt ordines $a b \& b a$.

Tres porrò literse $a, b, c$, ita collocari poffunt, ut primus locus vel ipfi a vel $b$ vel $c$ concedatux: fi a primum tenet locum, reliqua 


$$
P A R S S E C U N D A_{0}
$$

reliqua dure duobus, ut diximus, modis difponi queunt: fit $b$ in primum locum transferatur, reliquarum duarum duplex itidem poterit effe politio; quod \& intelligendum, ubi tertia s primam fidem orcupaverit. Unde trium literarum in univerfum ter duae fca 6 exiftunt permutationes $a b c, a c b: b a c, b c a: c a b, c b a$.

Similiter fi 4 extent literæ $a, b, c, d$, earum unaquæque prim mum obtinere locum potef, interea dum tres reliqua, ut nunc oftenfum, ter bis feu fexies ordinem variabunt: quare cùn earum, quze primo loco poni poflunt, fint quatuor, fequitur omnes quatroor quater ter bis, feu quater fexies, hoc eft, vicies quater fitum inter fe permutare poffe.

$\mathrm{Ob}$ eandem rationem accedente $5^{\text {tâ }}$ literâ $e$ inftitui poffunt quinquies tot variationes, quot in cafu præcedenti, hoc eft, quinquies 24, feũ 120. Et generaliter, datis quotcunque literis, numerus permutationum, quas fubire poflunt omnes, toties excedit numerum permutationum, quas recipiunt literæ unâ pauciores, quot funt unitates in dato literarum numero. Unde fponte manat fequens

$$
\text { Regula }
$$

pro inveniendis omsibus permutationibus verum quoto cunque datarum.

Mnes numeri ab unitate fe confequentes naturaclufive ducantur in fe invicem, productum manifeftabit quæfitum.

Putà, fi datus rerum numerus fit $n$, numerus permutationum erit $1.2 \cdot 3 \cdot 4 \cdot 5 \cdot 8 \mathrm{rc}$. ufque ad $n$; vel etiam (quia unitas non multiplicat ) $2 \cdot 3 \cdot 4 \cdot 5 \ldots \ldots n$. Nota, punctula numeris interjêta hîc \& ubique in fimili materiâ continuum numerorum in fe duetum fignificant. Ex. gr. feptem rerum permutationes funt $2 \cdot 3 \cdot 4 \cdot 5 \cdot 6 \cdot 7 x$ 5040. Ratio patet ex dictis, operatio ex adjunctâ Tabellâ: 
96

\section{Rerum, Nermutationum,}

$$
\begin{aligned}
& \text { I }-\infty \text { I } \\
& 2 \\
& 2-=\frac{2}{2} \\
& 3-.-6 \\
& 4 \\
& 4--24 \\
& 5-. \frac{5}{120} \\
& 6--\overline{720} \\
& 7 \\
& 7=-5040 \\
& 8-\overline{40320^{\circ}} \\
& 9 \\
& 9 \text { - } 362880
\end{aligned}
$$

10

$10-\overline{3628800}$ 3628800

II - 3991,6800 7983360

$12 \div 479001600$

\section{CONFECTANDI}

\section{Si rerum permutandarum nonnulle fint exdem:}

Quod fi literæ una pluresve recurrant frepiùs, hoc eft, fi in dato rerum nume. ro aliqua res fimiles fint five eædem; ut, fi datæ fint a a abcd, ubi litera a ter repetitur, numerus permutationum multo minor evadit: ad quem inveniendum cogitandum eft, quod, $f i$ omnes effent diverfæe, putà, fi loco a a fcriberetur $a \propto a$, poffent hæ tres literæ etiam nullâ cæeterarum loco motâ inter fe fexies transponi, per præced. Regul. unde totidem diverfe nafcerentur pe: mutationes; at nunc cum funt eadem, fex iftæe permutationes literarum a a a nullam univerfarum difpoficioni variationem inducunt, ac proinde pro unâ eâdemque habendæe funt: quod cùm de quâcunque difpofitione liserarum pariter fie intelligendum, indicium præbet, numerum permutationum rerum datarum fexies,

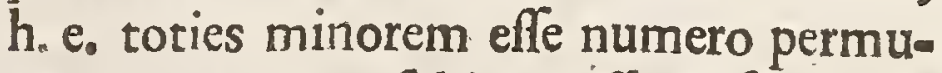
tationum, quas fubire poffent fi omnes effent diverfæ, quoties inter fe permutari queunt res fimiles: fed fi omnes $6 \mathrm{li}$ teræ diverfæ exifterent, permutari poffent juxta praced. 720. vicibus. Ergo nunc ubi tres ipfarum conveniunt, permutari duntaxat poterunt vicibus 120.

Tterum fi datæ fint 6 literæ $a a b b c$, ubi præter literam a quæ ter recurrit, etiam litera $b$ bis repetitur; manifeftum eft, numerum permutationum adhuc bis minorem evadere, quàm in præcedenti cafu fuerat, adeogue foliun ad 60 fe extendere: quandoguidem binæ qualibet permu 


$$
\text { PARS SECUNDA. }
$$

permutationes, qua ex folâ transpofitione duplici literarum $b b$, fi diverfx effent, nafcerentur, nunc coïncidunt. Eodem pacto colligendum, fi plures literæ repeterentur fæpiùs, pro fingulis earum numerum permutationum minui toties, quoties feorfim inter fe permutari poffunt eædem literæ. Unde ratio habetur fequents Regulæ:

\section{Regula}

pro inveniendis rerum permutationibus, cum earum nonvulle fisnt exdem:

JUmerus permutationum, quas admitterent datæe 1 res $f 1$ omnes differentes effent, dividatur per numerum permutationum, quas fubire poteft res fimilis fecundùm multitudinem fuam, fi una fit qua fæpiùs repetatur : aut per productum ex numeris permutationum, quas feorfim recipere poffunt finguIæ res fimiles fecundùm multitudinem fuam, fi plures fint quæ fæeiùs recurrant; \& quotiens exhibebit quafitumi.

Ufus Doctrinæ Permutationum infignis eft in definiendo numero Anagrammatum alicujus vocis: Ex. gr. Transpofitiones omines poffibiles literarum in voce Roma funt $1.2 \cdot 3 \cdot 4, x 24$, ob 4. differentes literas, per $1 \mathrm{Reg}$. in voce Leopoldus $\frac{362880}{2.2004} \times 90720$ : in voce Studiofus $\frac{362880}{2.65012}>30240$, ob 9 utrobique literas, interque illas ibi geminum $l \&$ geminum 0 , hîc geminum $u \&$ tri plex s, per 2 Rég.

Huc pertinent verfus nonnulli ob variationum multitudinem Protei dian?, quos inter celebrantur Lanfii, Scaligeri, Bauhufí. Thomæ Lanfio hoc diftichon debemus:

Lex, Rex, Grex, Res, spes, Fus, Thus, sal, sol, (bona) Lux. Likiss: Adaxs, Mors, Sors, Lis, Vis, Styx, Pus, Nox, Fexi, (mala) Crux, Frats. $\mathrm{K} 3$

cajpas 
cujus finguli verfus per Reg. pr. ob Ir monofyllaba (diffyllabis

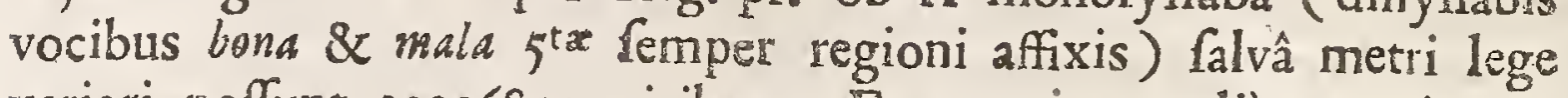
variari poffunt 39916800 vicibus. Et quanquam aliàs contingat, ut pleræque variationes in metri leges arietent, nec non ut pleriw que Anagrammatismi fint non-fignificantes \& barbari; levi taw men plerunque induftriâ opus eft ad fecernendum utiles $a b$ inutilibus, illorumque numerum feorfim ineundum, fi aliquem in is inquirendis ordinem obferves. Quemadmodum cernere eft in hew xametro à Bernh. Bauhufio Jefuitề Lovanienfi in laudem Virginis Deipara conftructo:

Tot Tibi funt dotes, Firgo, quot fidera colo;

quem dignum peculiari operâ duxerunt plures Viri celebres. E. rycius Puteanus in libello, quem Thaumata Pietatis inferipfit, variationes ejus utiles integris 48 paginis enumerat, easque num mero ftellarum, quarum vulgò 1022 recenfentur, accommodat omiffis fcrupulofitis illis, quæ dicere videntur, tot fidera cœlo effe, quot Mariæ dotes; nam Mariæ dotes effe multo plures Eundem numerum 1022 ex Puteano repetit Gerh. Voffius cap. 7. de Scient. Mathemat. Preftetus Gallus in primâ editione Element. Mathemat. pag. 348. Proteo huic 2196 variationes attribuit, fed factâ revifione in alterâ edit. tom. pr. pag. 133. numerum earum dimidio fere auctum ad 3276 extendit. Induftrii Actorum Lipf. Collectores m. Jun. 1686, in recenfione Tractatûs Wallifiani de Algebrâ, numerum in quæetione (quem Auctor ipfe definire non fuit aufus) ad 2580 determinant. Et ipfe poftmodùm Wallifius in edit. latinâ operis fui Oxon. anno 1693. impreffầ pagin. 494 , eundem ad 3096 profert. Sed omnes adhuc à vero deficientes, ut delufam tot Virorum poft adhibitas quoque fecundas curas in re levi perf́icaciam merito mireris. Facto enim examine deprehendo, fæetum hunc Bauhufianum exclufis etiam fpondaìcis, admiffis verò iis qui cæefurâ deftituti funt, falvâ metri lege omnino ter millies tercenties ac duodecies variabilem effe. At prolixiùs de his agere tanti non intereft, nec inftitutum noftrun patitur. 


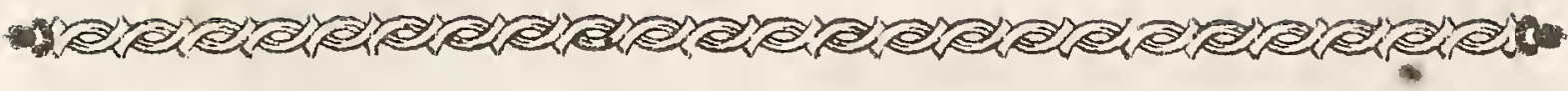

\section{Typus Variationum Versûs Bauhufiani:}

Tot Tibi fust dotes, Virgo, quot fidera calo.

\section{Quintam Regionem Hexametri occupat}

\section{vel}

Sidera, quam vocem excipit aut rox

I Diffllaba una, nempe vel

I celo, ac tum vox Tibi inter fex reliquas occupat locum vel

I I Secundum, præcedente voce nunc

$$
\text { I Monofyllabâ, eâque vel }
$$

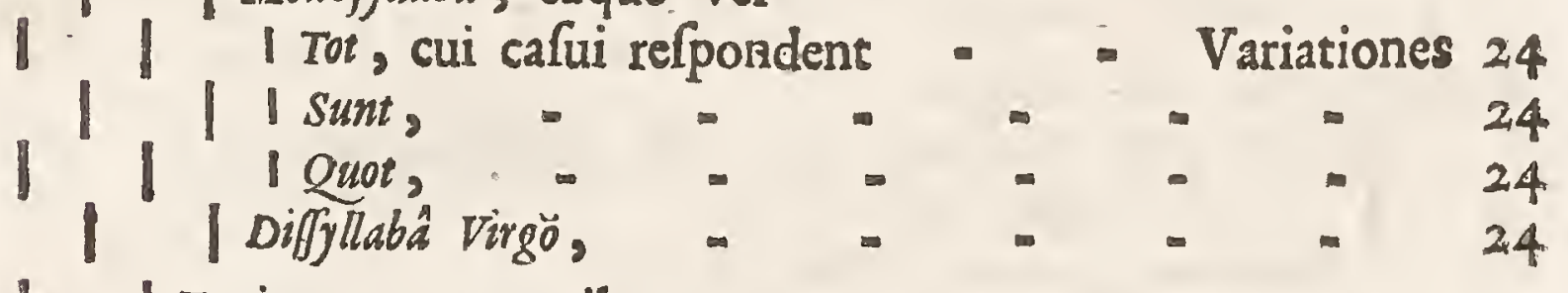

I | Tertium, præeuntibus

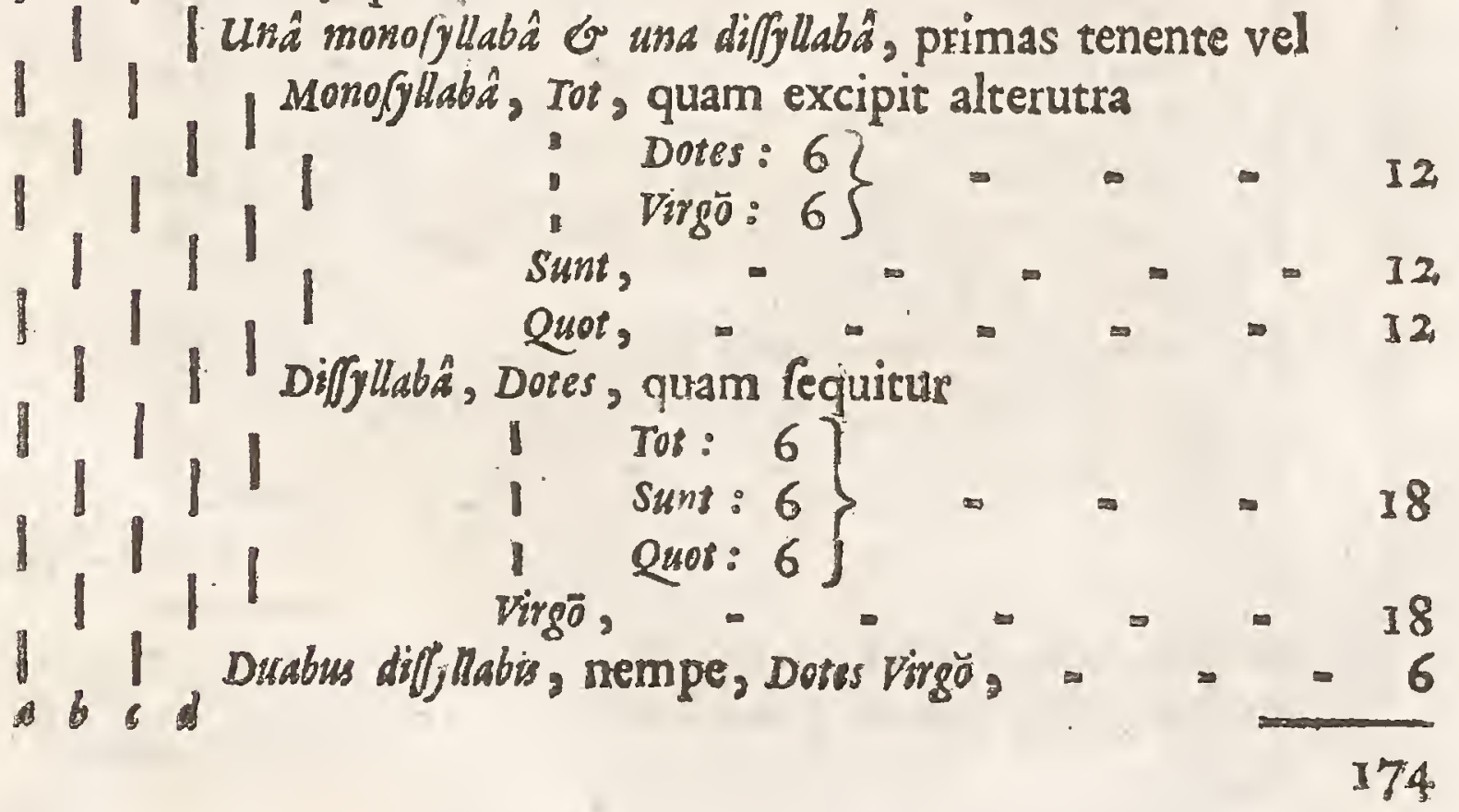


80 URTIS CONJECIANDI

$a b c d$

I Quartum; præcedentibus

I I Tribus monofpllabis, - - - - I2.

1 Duabus monofyllabis curs difjullabâ Virgŏ, - I 2

I Unấ monofyllabâ bo duabus diffyllabis? $\quad 36$

1 Quintum, præmiffis

1 Tribus monofyllabis cum unâ diffyllabâ, - - 48

1. I Duabus monofyllabis cum totidem diffyllabis, qua-

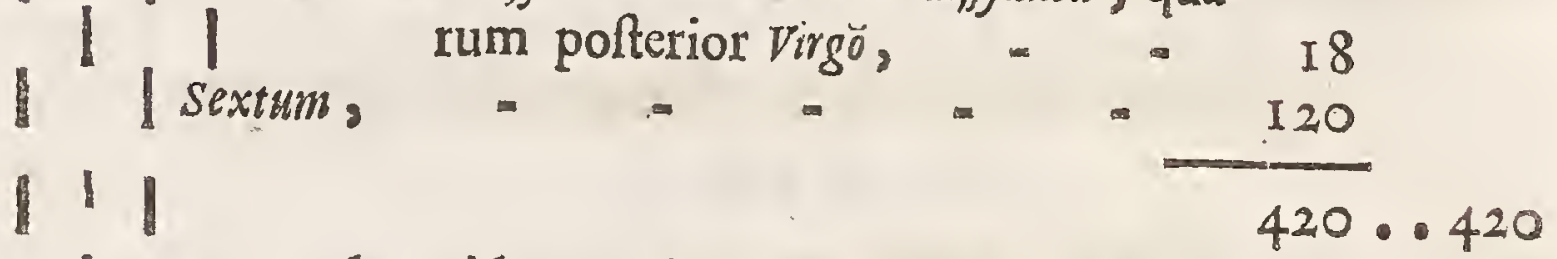

I Dotes, unde totidem variationes, quot in Calo, nempe $=420$

Virgo, unde rurfus totidem, quot in colo, exceptis fo-

I Iùm illis 60 variationibus, ubi poftrema fyllaba

1 in Virgo correpta eft; quibus proin demtis ex

1420 remanent

I Monofyllabe due, exque

Quot funt, vel Sunt quot; voce Tibi occupante low

$1 \mathrm{l}$ cum vel

secundum, primo relicto voci

1
- Monofyllabe, Tot:

- Diffyllabe, virgo:

| Tertium, præcedentibus

i Monofyllabâ cum Diffjllabấ,

1

1

Duabus Diffllabis, quarum polt. Virgŏ, $\quad \begin{array}{r}24 \\ \hline\end{array}$ Quartum, praeuntibus

1 1:Monofyllabâ cum duabus Diffyllabis, - . 36 1. Tribus Diffyllabis, quarum ultima Virgö, : 4

1 Quintum,

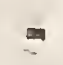

$=$

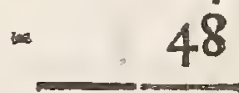

1 1

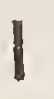

Tot funt, vel , sunt tot, totiden

Tot quot, aut, Quiot-tot; totidem Tibi, \& 8 。 


$$
P A R S \text { SECULDD }
$$

Tribi. quam vocem fequitur vox

Diffyllaba una, eaque vel

I Call, voce Sidera occupante locum aut

| Primum,

Sicundum,

| Tertium, præmiffis vel

1 Duabus Monofyllabis, - . 36

1 Duabus Diffyllabis, - - 12

Quartum, præeuntibus Duabus Monof. \& unâ Diff. 72

Quintum.spræc. duabus:Monof, totidemq; Diffyll. 72

11

$360 \cdot 366$

Dotes, totidem quot in Caila - - - - 360

Virgo, totidem - - - - - $=360$ Monofyllabe due, eæque

I Quot funt, vel, sunt quot: voce sidera tenente locum

TPrimism: - - - - - 48

secundum, poft Diffyllabam vocem, - $\quad 36$

| Teriium, poft duas Diffyllabas, - 24

$11^{\text {Quartum, poft tres Diffyllabas, }}=\frac{-12}{120-120}$

Tot funt, vel, sunt tot, totidem - - I - I20

I Tot quot, vel, Quot tot, totidem - - = I20 Monofyllabâ unâ, (quo cafu ante Tibi femper habetur'Virgö,) nempevel Sunt, voce sidera locum poffidente aut

| Primum:

Secundum: - - - -24

Tertium, præced, duabus Moniofyllabis, = - $=\begin{array}{r} \\ \mathrm{I} 2 \\ 4\end{array}$

1 guartum, - drabus Difgllabis, - - -4

Quintum, $=-12$

Tot, totidem quot in sunt, .

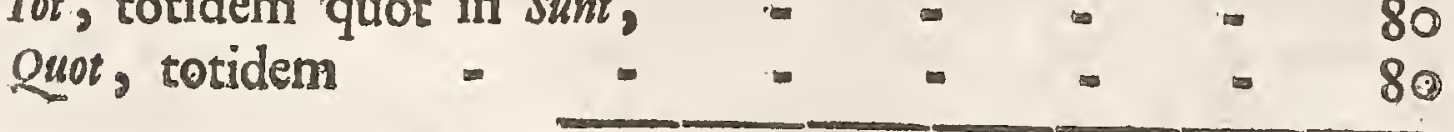

Summa omnium Variationum utilium $33 \mathrm{I} 2$ $\mathbf{L}$

CAP, 


\section{A P. II.}

De Combinationibus, iisque primo o cons deratis fimpliciter.

Tombinationes rerum funt Conjunctiones, juxta quas ex dato rerum multitudine nomullæ eximuntur, interque fe conjunguntur nullo ordinis fitusve ipfarum refpecu habito.

Idcircò cùm quæritur, quoties ex dato rerum numero vel bi næ, vel ternæ, vel quaternæ \& $\mathrm{c}_{\text {. }}$ accipi poffint, fic ut nunquam omnes exdem res fumantur frepiùs quàm femel, dicentur quæri omnes Combinationes diverfæ rerum datarum.

Numerus, fecundùm quem res datæ conjunguntur, dicitur Exponens Combinationis; ita fir res binæ fumuntur, Exponens erit 2 ; fi ternæ, 3 ; fi quaterni, 4 . Res verò fecundùm hos exponentes juncta dicuntur Binarii, Ternarii, Quaternarii \&c. vel Biniones, Terniones, Quaterniones \&.c. \& confonanter etiam uniones vel unitates quando res fumuntur fingtlæ, \& Nulliones cùm nulla planè fumitur.

Conjunctiones ipfas nonnulli vocant combinationes, con 3 nation= nes, Conunationes \&c. quas omnes vulgò unâ voce combinationum complecti folent, tametfi hre vox ftrictiori fignificatu propriè non nifi illas conjunctiones indigitare videatur, quibus res bin:e invi cem junguntur. Quamobrem alii generaliori voce Complicationum vel Complexionum uti malunt: alii magis appofite Electiones vocant, ut \& illæ fubintelligi poffint rerum acceptiones, quibus res fingu$\mathbb{l}$ feorfim fumuntur, aut quibus etiam nulla planè fumitur.

Res autem inter fe combinandæ vel omnes poffunt effe dia verfe, vel aliquot ipfarum exdem; exque vel ita combinari dea bent, ut in nullâ combinatione res eadem frepiùs contineatur, quàrm ipfa reperitur in toto rerum numero: vel fic, ut in eâdem combinatione res eadem etiam freì̀s recurrere, ho e. ut fecum ipsâ quoque combinari polfit. Iterumque quæri poteft numerus combinam tionum 


$$
\text { P ARS SECUNDA. }
$$

tionum vel fecundùm omnes exponentes conjunctim, vel fecuindùm fingulos feorfim. Atque infuper circa unumquemque horum combinandi modorum plures formari pofiunt quæftiones \& problemata, è quibus illa tantùn delibabimus, qua in fequentibus alicus ufui fore judicamus.

I. Si res omnes combinande funt diverfa, ingue nulld combinatione eadem res bis occurrere debet, invenire omnes Combinationes fimpliciter five fecundium omnes exponentes conjunctim:

CUnto combinandæ modis omnibus literæ $a, b, c, d, e \& c$. Fiant tot feries iquot literæ, hoc modo: In primâ ferie ponatur fola litera $a$.

In fecundâ ponatur $b$, nunc feorfim, nunc junctim cum $a$ ut habeatur $a b$ vel $b a$. Eadem enim conjunctio eft, qua $b$ cum $a, \&$ a cum $b$ jungit, cùm ordo non attendi fupponatur.

In tertiâ collocetur $c$, eaque primò fola, dein juncta, partim cum $a \& b$, ut fiant biniones $a c, b c$; parcim cum ipfo binione s $b$, ut flat ternio abco

$$
\frac{\frac{a_{0}}{b_{0} a b_{0}}}{c_{0} a c_{0} b c_{0} a b c_{0}} \frac{}{d_{0} a d_{0} b d_{0} c d_{0} a b d_{0} a c d_{0} b c d_{0} a b c d_{0}}
$$

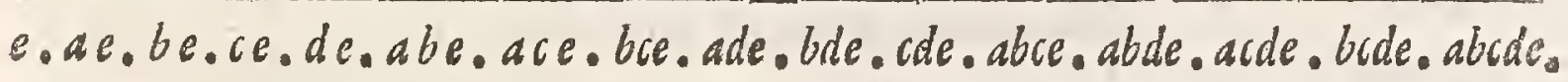

In quartâ ponatur $d$, primò fola, deinde juncta cum fingulis prrecedentium literarum $a_{2}, b, c$, fingulisque earun tum binariis $a b, a c, b c$, tum ternario $a b c$; ut fiant novi biniones $a d, b d, c d$, terniones $a b d, a c d, b c d, \&$ quaternio $a b c d$.

Similiter quintæ feriei agmen ducat litera $e$, quam primò ingrediatur fola, dein juncta cum omnibus præcedentium ferierum electionibus. Eademque methodo procedendum, fi plures effent 
datæ literæ. Quầ ratione fatis manifeftum eft, datas literas in iftis: feriebus omntifariàm inter fe junctas effe, nullamque earum fieri: poffe electionem, qua non: in unâ liarum ferierum reperiatur, fed' \& nullam effe qua alicubi bis occurrat; adeoque omnes una feries: fuppeditaturas omnes electiones peffibiles, quæ circa: datas. literas: inftitui queunt.

Harum igitur numerus initur facile, fi attendatur quòd in quâlibet femper ferie una ampliùs inveniri debear electio, quàm in antecedentibus omnibus: feriebus fimul; quoniam litera, qua illius: feriei caput eft, ibidem femel ponitur fola, 2 \& præterea: unà aflumit fecum omnes electiones præcedentium ferierum. Hinc enim: fequitur, quia in primâ ferie eft electio unica, fore in fecundầ ele. tiones duas, in tertiâ 4 , in quartâ 8, \& fic deinceps in progreffion geometricâ duplâ : quandoquidem progreffionis duplæa $a b$. unitate hanc: quoque naturam effe: conftat, ut funma terminorum: quotlibet unitate aucta fequentem: terminum exhibeat. Quocirca: fumma electionum, in feriebus omnibus æqualis eft fummæ terminorum totidem progreffionis dupla: $a b$ unitate; lioc eft; per modì: memoratam proprietatem, ipfi termino fubfequenti ejusdem progreffionis unitate multato; qui quidem terminus: fubfequens idem eft cum producto binarii toties pofiti $\&$ in fe ducti, quot ipfum in progreffione termini præcedint, hoc eft, quot funt feries, quarum: dectiones quæruntur. Unde talis exurgit:

\section{Regula:}

pro inveniendis omnibus electionibus rerum datarum: fecundim omnes exponentes:

A "producto binarii toties pofiti \& multiplicati in -1 fe, quot funt datæ res, auferatur unitas, reliquum indicabit quxiftum.

Hoc eft, pofito rerum datarum numero $n$, numerus omnium electionum fimpliciter, putà, omnium unionum, binionum, ternionum \&c. erit ${ }_{2}^{n}$ I. Hinc fi nullionem feu electionem, quâ: ex rebus datis nalla fumitur, quaque in quâvis rerum multitudine: 


\section{$P A R S S E C U N D A$.}

una femper eft \& unica, fimul comprehendas, fiet numerus ille $2 n$ : fin cum nullione ipfos quoque uniones refeces, quorum numerus ipfi rerum numero perpetuò æquatur, erit numerus binionum, ternio num, cæterarumque complexionum $2^{n}-n-1_{0}$. Ex. gr. Septem: Planetarum: conjunctiones vel complicationes: omnes diverfa funt $2^{7}$ - r $D$ 2.2.2.2.2.2.2- r $\infty$ r2.8- 100 r27; unde fi demas electiones 7, quibus finguli Planetæe feorfim accipiuntur, quæeque propriè non conjunctiones Fed disjundiones Planetarum funt, relinquetur numerus omnium conjunctionum ftrictè dictarum; quibus Planetæ vel bini vel terni \& $c$. vel denique fepteni junguntur, $2^{7}-7-1$ \$ r20. Sic etiam duodecim, uti vocant, Regiftra feu fiftularum ordines in organo pneumatico, quibus fonus mox fibilans mox tremebundus efficitur, aut aliter modificatur, variari poflunt $2^{12}-1$ $\infty$ 4.095 vicibus.

Nota:: Si quis examinet feries combinationum fupra in typo expofitas, obfervabit, in quâlibet ferie (folâ primâ exceptâ, quæe unicum unionem a complectitur) numerum electionum fecundùm exponentes pares æquari numero electionum fecundùm impares; faltem cum id in aliquot $a b$ initio feriebus verum deprehenderit, idemque quoque in ferie proximè fequente locum habere concludet: nam litera, quæ illius feriei caput eft, juncta precedentiüm ferierum electionibus is; quæ impares exponentes habent, parium; \& iis viciflim quæ pares habent juncta, imparium exponentium complexiones efficit; adfcilcens verò primæ feriei unionem $a$, paris, \& ipfa per fe fola accepta imparis exponentis electionem conftituit; unde \& in hâc ferie numerum harum numero illarum æquari confat. In omnibus igitur feriebus fimul fumtis numerus electionum fecundùm impares exponentes numerum electionum fecundùm pares unitate fuperabit; aut fis his infuper nullionem accenfeas, æquabit. Quocirca cùm numerus omnium electionum fimpliciter inclufo nullione oftenfus fit $2^{n}$, erit ejus femiffis five poteftas binarii proximè minor $2^{n-1}$ numerus electionum fecundùm folos impares; \& , demto rurfum nullione, $2:^{n-1}$ - I numerus electionum fecundùm folos: pares exponentes. Idem quoque demonfrabitur infrà in Córoll. $\sigma_{\circ}$ Cap. 40. 


\section{A P. I I I.}

De Combinationitus fecundim fingulos exponentes feorfm; ubi de Numeris Figuratis, corimque proprietatibus agitur.

FX typo Combinationum precedentis capitis manifentum fit, liteEram qua cujuslibet feriei caput eft, adjunctam unionibus ferierum pracedentium efficere fur feriei biniones, adjunctam binionibus efficere terniones. ternionibus $4^{\text {ones }}$ \& fic porrò : adeoque numerum binionum in quàvis ferie æquari fummæ unionum in omnibus feriebus antecedentibus, numerum ternionum fummæ biniow num, numerum quaternionum fummæ ternionum \& generaliter num merum combinationum fecundùm datum quemcunque exponentem in ferie quâcunque æquari fummæ combinationum omnium præcedentium ferierum fecundùm exponentem unitate minorem $\mathrm{d} z=$ to. Sequitur hinc, quòd

Uniones, quia in fingulis feriebus reperiuntur finguli; omnes inter fe conftituunt feriem I. I. I. I. I. \& 2 . feu, feriem unitatum.

Biniones in primâ ferie nulli funt, in fecundâ $\mathbf{r}$, in tertiâ $\mathbf{r}+\mathbf{I}$ $\infty_{2}$, in $4^{\text {tâ }} \mathbf{r}+\mathbf{r}+\mathbf{r} 0_{3}$, in $5^{\text {ta }} \mathbf{r}+\mathbf{r}+\mathbf{r}+\mathbf{r} 00_{4} \&$ \&c. proinde omnes biniones inter fe confituunt feriem $0.1 \cdot 2 \cdot 3 \cdot 4 \cdot 5 \cdot 8$. . hoc eft, feriem numerorum Arithmetice progreflionalium five iLatera* lium.

Terniones in primâ \& fecundâ ferie nulli funt, in $3^{\text {tia }} \mathbf{1}$, in $4^{\text {tâ }}$ $1+2003$, in $5^{\text {ta }} \mathbf{I}+2+3006$, in $6^{\text {tâ }} \mathrm{r}+2+3+400 \mathrm{ro} .8 \mathrm{kc}$ 。 omnes itaque ordine accepti feriem conficiunt $0.0 .1 \cdot 3 \cdot 6 \cdot 10.15$. $\& c$. hoc eft, feriem numerorum, ut vocant, Trigonalium.

Quaterniones in tribus primis feriebus nulli funt, in $4^{\text {ta }} \mathbf{I}$, in $5^{\text {tâ }} \mathrm{x}+3004$, in $6^{\text {tâ }} \mathrm{x}+3+60010$, in $7^{\mathrm{ma}} \mathbf{x}+3+6+100020$. $\& c$. qui omnes ordine affumti feriem efficiunt $0,0,0,1 \cdot 4 \cdot 10,20$. \& $x_{0}$, feriem videl, Pyramidalium. 


$$
\text { PARS SECULNDA. }
$$

Pari ratione Quiniones omnes feriem confituunt Trianguli-pyramidalium $0.0 \cdot 0 \cdot 0 \cdot 1 \cdot 5 \cdot 15 \cdot 35 . \& x c_{0}$ Seniones feriem Pyramidipyramidalium $0 \cdot 0 \cdot 0 \cdot 0 \cdot 0 \cdot \pi \cdot 6 \cdot 2 \pi$. \& $x$ c alixque combinationẹs fecundum altiores exponentes efficiunt alias atque alias feries Figuratorum alsioris generis in infinitum.

Et fic occafione Dodtrinæ Combinationum in fpeculationem infperatam Numerorum Figuratorum incidimus, quấ appellatione vulgò infigniuntur numeri, qui ex continuâ Arithmetice proportionâlium indeque ortorum numerorum additione vel collectione generantur.

Ut verò hæ figuratorum numerorum feries fub unum afpectum caderent, eoq́ue faciliùs comprehenderentur quæ de illis dicenda füperfunt, fequentem appofui Tabellam, quam quis nullo negotio quouf-

\section{Tabula}

Combinationum, feu Numerorum Figuratoram. Exponentes Combinationum.

III.|II. | III. | IV.| V. | VI. |VII. | VIII.|IX.|X. |XI. | XII. I.ll ol of ol of ol ol ol.ol ol ol 2.\|IIII of ol of ol of ol ol ol ol 0 3.|lI|2|I of of of ol of ol ol ol 0 4.||I|3|3|I| of of of of 0 of ol 010 $5 . \mid\{I|4| 6 \mid 4 !+1$ ol of 010101010 6.11 IIflioliol 5l Il of ol ol ol 01.0

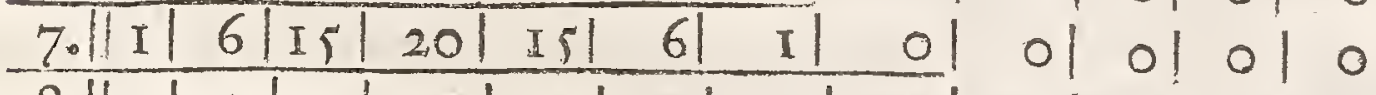
$8 .||$ I $|7| 21|35| 35|21| 7 \mid$ in of of 01.0

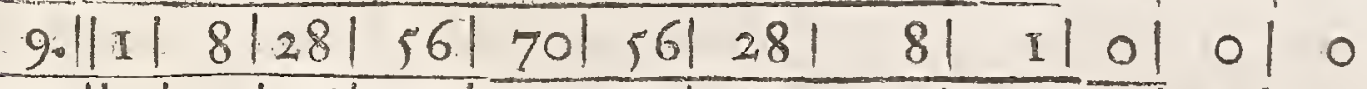

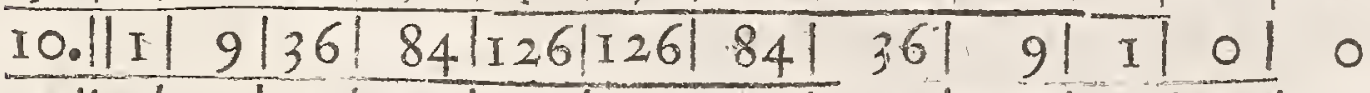

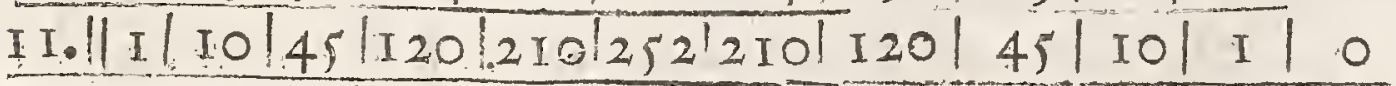
I2.|| I|II|55|I65|330|462/462/330|I65|55|II| I 
quoufque voluerit tum deorfum tum dextrorfum continuabit. Numeri barbari in finiftro Tabula margine adfcripti numerant columnas tranfverfas, \& fimul rerum combinandarum multitudinem: numeri verò Romani in fupremo margine confpicui numerant colutmnas verticales \& unà exponentes combinationum innuunt. CoIumnarum verticalium prima eft feries Monadum feu unitatum, fecunda feries numerorum naturalium feu lateralium ab unâ cyphrâ incipiens, tertia feries Trigonalium incipiens à cyphris duabus, $4^{\text {ta }}$ Pyramidalium incipiens à tribus, $5^{\text {ta }}$ Trianguli-pyramidalium incipiens à 4 cyphris; $;$ \& fic deinceps.

Habet hæc Tabula proprietates 'planè eximias \& admirandas; præterquàm enim quòd Combinationum myfterium in illâ latere jam oftendimus, notum eft interioris Geometria peritis, pracipua etiam totius reliquæ Mathefeos arcana inibi delitefcere. Nos proprietatum aliquas hîc delibabimus, \& quidem delibabimus tantùm, nullius nifi primariæillius, quæ propofito noftro infervit demonftrationem accuratiorem allaturi, cùm cæeteræ vel ex hâc oftendi polfint, vel ex ipsâ Tabellæ conftructione \& numerorum figuratorum genefi fatis pase tefcanto

\section{Mirifice proprietates Tabula Combinationum:}

r. Columnarum vercicalium fecunda incipit ab unâ cyphrầ, tertia à cyphris duabus, $4^{\text {ta }}$ à $3^{\text {bus }} ; \&$ generaliter columna 6 à cyphris $c-1$.

2. Columnarum verticalium termini primi fignificativi à finiftrâ dextrorfum oblique defcendendo ordine fumti reddunt ipfos terminos primæ columnæ verticalis, fecundi fecundæ, tertii tertiæ, \&

- ita deinceps: putà, primi conftituunt feriem monadum, fecundi lateralium, tertii trigonalium \& $x$.

3. Secundus ab unitate terminus columnæ verticalis cujuslibet æquatur ipfius columnæ numero.

4. Terminus quivis Tabellæe æquatur fummæ omnium fuperiorum præcedentis columnæ verticalis.

5. Quilibet terminus æquatur duobus aliis immediate fupra re poo 


$$
P A R S S E C U N D A \text {. }
$$

fe pofitis, quorum unus eft in eâdem verticali columnád, alter in prææ* cedente.

6. Columnæe cujufvis tranfverfe termini ab unitate aliquouf que crefcunt, deinde per eofdem gradus rurfum decrefcunt. Idens intellige de fummis columnarum verticalium æeque-altarum, cets terminis fequentis columnæ tranfverfæ, per 4 propr.

7. Columnarum verticalium æque-altarum bafes, five termini columnæ tranfverfæ cujuslibet, primus quidem \& ultimus fignificativus perpetuò inter fe æequantur, ut \& fecundus \& penultimus, tertius \& antepenultimus, atque ita porrò, fi columna pluribus terminis fignificativis conftet.

8. Quin \& fumtis ab initio columnis verticalibus quotcung; cum totidem tranfverfis, collectisque in unam fummam qui in eấdem verticali fibi refpondent terminis, erit fumma prima æequalis. penultimæ, fecunda antepenultimæ, tertia proantepenultimæ, \& fic deinceps. Exhibent enim hæ fummæ ipfos columnæ transverfæ fe quentis terminos primo excepto. Conf. propr. $48 \%$ Ex. $\mathrm{gr}_{\sigma}$ Quinque primæ columnæ tum verticales tum transverfæ funt:

I. 0.0 .0 .0$.
I. I. 0.0 .0$.
I. 2.0 I. 0.0.
I. 3.3 .1 .0$.
I. 4.6 .4 .1$.

5. I0. I0. 5. I. Termini fextæ columnæ transverfæ primo excepto.

9. Columnæ transverfæ ordine exhibent coëfficientes omnium poteftatum à radice aliquâ binomiâ genitarum; nempe fecunda coëfficientes radicis I.I. tertia quadrati 1.2.I. quarta cubi I $3 \cdot 3 \cdot 1$. quinta biquadrati $1.4 \cdot 6 \cdot 4 \cdot 1$. \& fic porrò.

10. Summæe ferierum transverfarum progrediuntur in continuâ ratione duplâ: fummarum verò fummæa ab initio collectæ tê minos conftituunt progreffionis duplæ unitate multatos; putà 


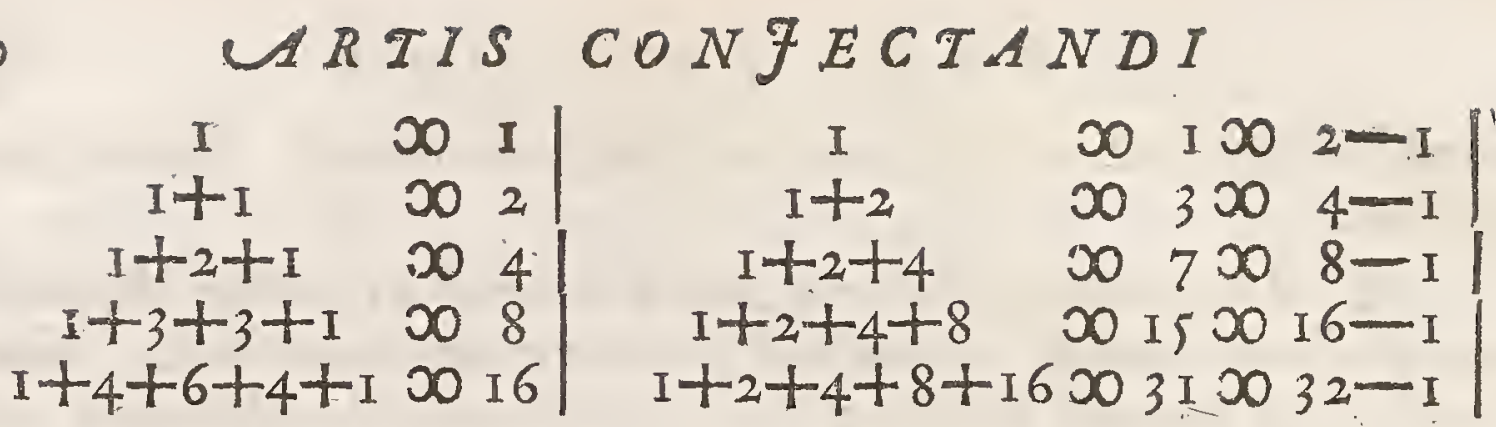

Fluit ex iis, quæ in præced. cap. de Combinationibus fimpliciter fpectatis dicta funt.

II. Termini feriei verticalis cujuslibet ordine divifi per terminos collaterales feriei precedentis (initio vel ab unitate vel à fuis refpeativè cyphris fagto) exhibent quotos Arithmeticè proportionales, quorum communis differentia eft fractio, cujus numerator eft unitas, \& denominator ipfe numerus five fecundus ab unitate terminus feriei dividentis. Ex. gr.

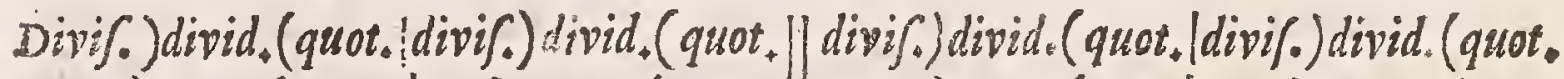
I) $1(2: 2$
I) $0(0: 2$
I) I $(3: 3$
I) $0(0: 3$
2) $3(3: 2$
2) $I(I: 2$
3) $6(4: 2$
3) $3(2: 2:$
3) 4
$(4: 3$
3) $I(I: 3$
4) $10(5: 2$
4) $6(3: 2$
6) $10 \quad(5: 3$
6) $4 \cdot(2: 3$
5) $15(6: 2$
5) $10(4: 2,1$
I0) $20 \quad(6: 3)$
10) $10(3: 3$
I5) $35(7: 3$ I 5 ) 20 ( $4: 3$

Non difficulter hæc proprietas, fi opus foret, deduci poffet ex fequente.

12. Summa terminorum quotcunque feriei verticalis cujuslibet à fuis refpectivè cyphris incipientis ad fummam terminorum tótidem ultimo æqualium eam habet rationem, quam habet unitas ad illius feriei numerum; hoc eft, Aggregatum numerorum quotcung; lateralium $a b$ unâ cyphrâ feriem aufpicantium eft ad aggregatum numerorum totidem maximo eorum ceu ultimo æqualium, ut I ad. 2; trigonalitim à cyphris duabus, ut I ad 3, pyramidalium à tribus, ut 1 ad 4. \&c. Idem quoque valet de ratione, quam habet fumma terminorum feriei cujuslibet $\mathrm{ab}$ unitate incipientis ad fummam totidem maximum fequenti termino æqualium, Ex. gr. 

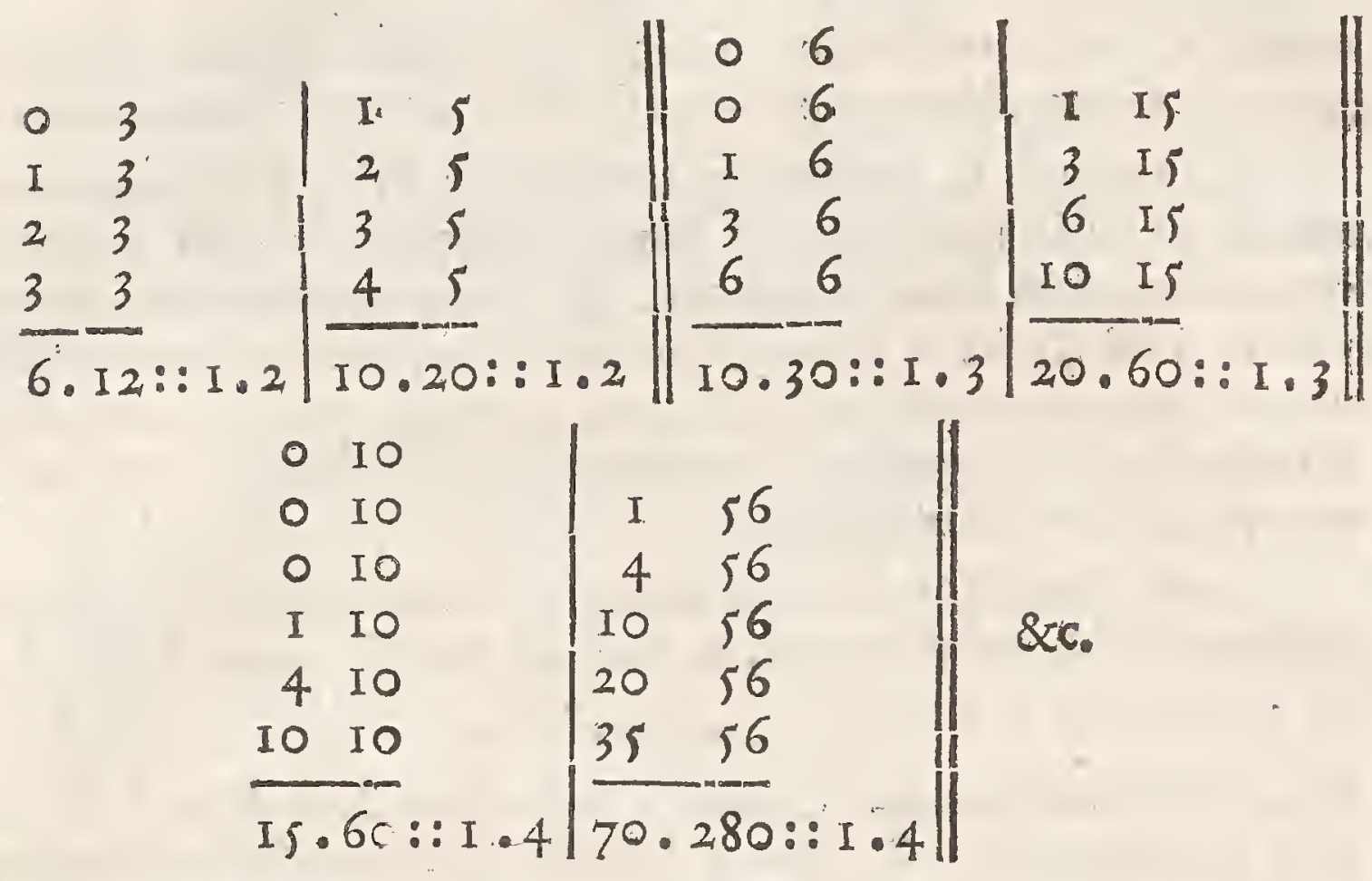

Cùm inter affection: $s$ numerorum figuratorum hæc præcipua.fit, eademque fcopo noftro primariò inferviat, vifum hîc eft exponere methodum, quâ talem proprietatic $\lambda^{\prime} \pi \delta^{\prime} \varepsilon \xi_{\xi} v$ exhibeo, quæ fimul \& $\mathrm{fcien}-$ tifica fit, \& propofitum univerfaliter concludat, Quem in finem fe: quentia præftruo lemmata:

1. Lemma: Summa terminorum quotlibet prima ferieiad fummam totidem terminorum ultimo æqualium rátionem habet æqualitatis, flive ut I ad.

Dem ${ }_{+}$Cùm enim feries meris conftet unitatibus, erit fumma terminorum quotlibet, fumma tot unitatum, $h_{0} e_{0}$ tot terminorum ullimo æqualium, quot funt termini.

2. Lemma : In qualibet ferie à fuis refpeetivè cyphris incipiente, fi quota eft ipfa inter feries, tot ab initio fumantur termini, erit fumma terminorum omnium ad fummam totidem ultimo æqualium, ut $\mathbf{r}$ ad feriei numerum.

Dem. Numerus enim cyphrarum quamcunque feriem aufpicantium unitate minor eft feriei numero, per propr. I . his igitur fi accedat fequens terminus, numerus terminorum feriei numero æquabitur: fed terminus, qui proximè cyphras fequitur, eft unitas, per M 2 propte 
propr. 2. unde terminorum aggregatum xquatur unitati, \& aggre gatum totidem ultimo æqualium ipfi feriei numero; quare conftat.

3. Lemma: In quâcunque numerorum ferie, fi fumma terminorum ab initio fumtorum ad fummam totidem ultimo æqualium perpetuò eandem habear rationem, quotcunque accipiantur termini, putà ut I ad $\mathrm{R}$, ita ut fumma terminorum æquetur fummæ totidem ultimo æqualium divifæ per $\mathbf{R}$; erit numerus terminorum affumtorum ablato $\mathrm{R}$ ad eundem numerum unitate multatum, ut fumto. rum penultimus ad ultimum.

Dem. Sumti fint ab initio termini quotlibet A. B. C. D. quorum numerus fit $N$, penultimus $C$, \& ultimus $D$. Eft utique $A+B+C$ $\infty \mathrm{A}+\mathrm{B}+\mathrm{C}+\mathrm{D}-\mathrm{D}$, hoc eft, per hypoth. $\frac{\mathrm{C} \text { in } N-\mathrm{I}}{\mathrm{R}} \infty \frac{\mathrm{D} \text { in N }}{\mathrm{R}}-\mathrm{D}$ $\&$ rque-multiplicando, $C$ in $N-I \infty D$ in $N-D$ in $R \infty D$ in $\mathrm{N}-\mathrm{R}$, adeoq; $\mathrm{N}-\mathrm{R} . \mathrm{N}-\mathrm{r}:: \mathrm{C} .{ }_{\mathrm{r}} \mathrm{D}$. Quod erat demonfrandum.

4. Lemma: In Tabulâ numerorum figuratorum fi duæ finccolumnæ verticales contiguæ, in quarum priore quotlibet ab initio termini ad totidem ultimo eorum æquales habeant conftantem rationem ut $t$ ad $r$; habeant verò in pofteriore termini aliquot $a b$ initio fumti ad totidem fumtorum ultimo æquales rationem ut $\mathbf{a d} r+\mathrm{I}$ : habebit quoque addito fequenti termino, fumma omnium terminorum unà cum adjecto ad tot terminos adjecto æquales, quot funt cum adjecto termini, rationem ut 1 ad $r+1$.

Dem. Samti Gint in pofteriore columnâ termini $E . F . G . H$, quos proximè fequatur I; atque fumantur in columnâ immediatè præcedente termini totidem A.B.C. D; fumtorum verò utrinque numerus fit $n$. Erit $r \mathrm{H} O$ ( ex num. figurat. geneli per propr.4) $r$ in $A+B+C x$ (per hyp.) $n-1$ in $\mathrm{C} x$ (perlemma 3$) n-r$ in $D$; quare $n-r . H:: r . D::$ (hypoth.) $n . A+B+C+D::$ (exnum. fig. genefi per propr. 4) n.I. Unde $n-r$ in $1 \infty 0 \mathrm{H} \infty$ (hypoth.) $r+\mathrm{Iin} \mathrm{E}+\mathrm{F}+\mathrm{G}+\mathrm{H}$; adeoque $n-r_{0} r+\mathrm{r}:: \mathrm{E}+\mathrm{F}+\mathrm{G}+\mathrm{H}$. $1, \&$ componendo $n+\mathrm{r} \cdot r+\mathrm{I}: \mathrm{E}+\mathrm{F}+\mathrm{G}+\mathrm{H}+\mathrm{I} .1$, hoc ent $\mathrm{E}+\mathrm{F}+\mathrm{G}+\mathrm{H}+\mathrm{I} . n+\mathrm{I}$ in I:: I.r+I. Q.E.D.

Cum olim horum Fratri copiam feciffem, animadvertit ille poffe demons 
demonfrationem eleganter abbreviari, poftremis tribus lemmatibus in unum conflatis, hoc modo:

Lemma: In Tab. num. fig. fi fumma terminorum ab initio feriei verticalis cujufvis ad fummam totidem maximo æqualium ubique rationem habeat ut I adr, habebit fumma terminorum feriei proximè Cequentis ad fummam totidem maximo æqualium rationem ut I ad $r+1$.

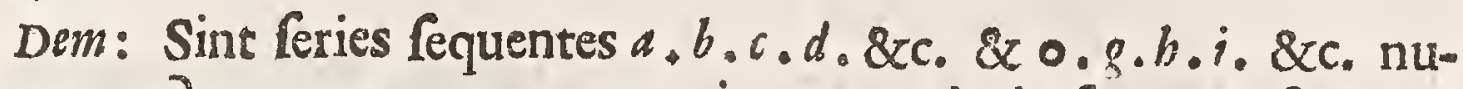
$n\left\{\begin{array}{r}a--0 \\ b--g \\ c=-b \\ d=-i \\ c=-l \\ f=-p \\ q\end{array}\right\} n+8$. merus terminorum prioris fit $n$, pofterioris $n+\mathrm{r}$. Eft primò $q+p+l+i+b+g$ tos (ex hyp. \& genefi num. fig. per propr. 4) $\frac{n f}{r}+\frac{n-r_{. e}}{r}+\frac{n-2 . d}{r}+\frac{n-3 . c}{r}$ $+\frac{n-4 \cdot b}{r}+\frac{n-5 . a}{r} \infty \frac{\overline{n \cdot f+e+d+c+}}{r}$

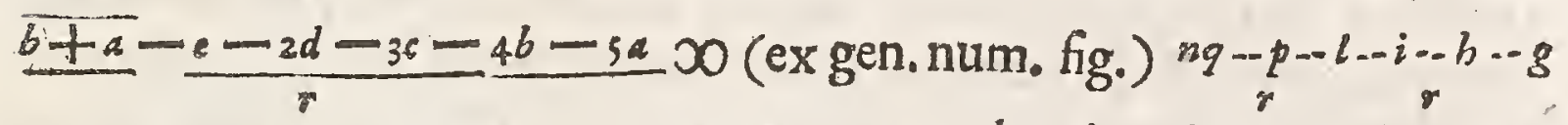
Ergò $r q+r . \overline{p+l+i+b+g} x n q-p-l-i-b-g ;$ factâqué

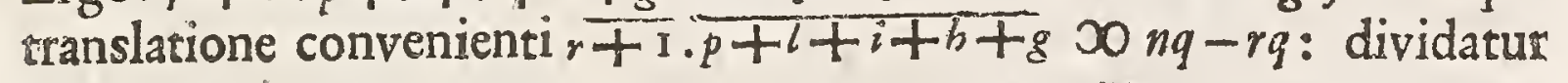
utring; per $r+1$, erit $p+l+i+b+g \infty \frac{n q-r q}{r+1}$; additoque $q$ ha bebitur $q+p+l+i+b+g \infty \frac{n q-r q}{r+i}+q \infty \frac{n+1 \cdot q}{r+1}$, hoc ef, $g+b+i+l+p+q . n+$ I. $q::$ I. $r+$ I. Q.E.D. Se-

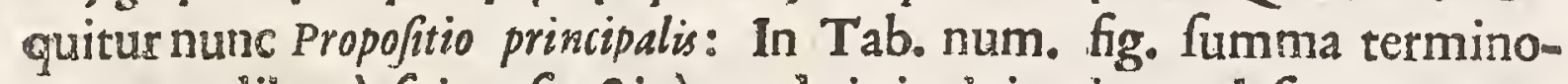
rum quotlibet à fuis refpectivè cyphris incipientium ad fummam totidem ultimo æqualium; item fumma terninorum quotvis incipientium ab unitate ad fummam totidern ultimum fequenti æcqualium, in ferie primâ feu monadum eft ut I ad I, in ferie fecundâ feu lateralium ut I ad 2 ; in tertiâ feu trigonalium ìt $\mathrm{I}$ ad 3 , in $4^{\text {th }}$ feu pyram midaliurm ut I ad 4 , \& generaliter in ferie quâcuinque ut 1 ad illius feriei numerum.

Den. I. De primâ ferie conftat ex primo lemmate: de fecundâ, tertiâ, $4^{\text {tâ }} \& c_{\text {co }}$ è reliquis. Nam quia fumma terminorum quot libet ad fummam totidem ultimo aequalium in primâ ferie eft ut I ad 1 , erit vi horum lemmatum in $2^{\text {dâ }}$ ut 1 ad $1+1202 ;$ \& quia in $\mathrm{M}_{3}$ ${ }_{2} d^{d}$ 


\section{4}

2 dâ eft ut 1 ad 2 , e rit in $3^{\text {tiâ }}$ ut 1 ad $2+1 \infty 03 ; \&$ propteréa etiam in 4 tâ ut I ad 3 + I $\infty_{4}$; in $5^{\text {tâ }}$ ut 1 ad $4+1 \infty_{5 ;} \&$ generaliter in ferie $c$ ut $\mathrm{I}$ ad $c$.

II. Quia rationem $\mathrm{I}$ ad $r+1$ memoratam in ultimo lemmate hic interpretamut per rationem 1 ad $c$, erit $r \infty c-1 \infty$ (per propr. I.) numero cyphrarum, à quibus columna $c$ incipit. Quare cum in $\mathrm{d}^{\mathrm{i}}$ co lemmate repertum fit $g+b+i+l+p \infty \frac{n-r \cdot q}{r+1} \infty \frac{n-r \cdot q}{c}$, fequitur quòd $g+b+i+l+p$ (fumma terminorum quorum numerus eft $n$ ) fe habet ad $q$ in $n-r$ (numerum terminorum minus numero cyphrarum ) ficut $\mathrm{r}$ ad $c$; hoc eft, fumma terminorum quotlibet ab unitate incipientium ad totidem terminos fequenti ultimum aquales, ut $1 \mathrm{ad} c$.

Confectarium: Ex hâc oftensâ proprietate facilè nunc eft, invem nire tum terminum optatum, tum fummam terminorum feriei cujuslibet: Sumti intelligantur termini æque-multi ex pluribus continuè columnis, \& fit numerus fumtorum ab initio cujusque columnæe $n$, adeoque numerus terminorum ab unitate (exclufis cyphris initialibus) in fecundâ columnâ $n=1$, in tertiâ $n-2$, in $4^{\text {tâ }} n-3 \cdot$ \& c . per 1 propr. quo pofito quæfitum ita colligo: Summa terminorum $n$ primæ columna, nempe, $n$ unitates feu $\frac{n}{1}$ xquatur termino $n+1$, hoc elt, termino fequenti ultimum fecundæ columnæ, per 4 propr. ex tabulæ genefi. Quare termini hujus in $n=1$ (numerum terminorum ab unitcte $2^{\mathrm{d} x}$ columnæ) ducti fubduplum, feu $\frac{n \cdot n-1}{1 \cdot 2}$, per 12 propr. xguale eft aggregato terminorum $2^{\text {dr }}$ columnæ, \& fimul iper 4 propr. ipfi termino fequenti ultimum tertia col. Unde fimiliter hujus termini in $n-2$ (num. termin. ab unitate $3^{\text {tix }}$ col.) ducti fubtriplum, nempe $\frac{n \cdot n \cdot 1 \cdot n-2}{1 \cdot 2 \cdot 3}$, xquatur per I2 propt. aggregato terminorum $3^{\text {tix }}$ columnæ, infimulque per 4 propr. ipfi termino fequenti ultimum $4^{\text {ta. }}$ Quocirca \& hujus termini in $n-3$ (num. term. ab unit. $4^{\text {ta }}$ col.) ducti fubquadruplum, putà $\frac{n \cdot n-1 \cdot n-2 \cdot n-3}{1 \cdot 2 \cdot 3 \cdot 4}$, exhibet fummam terminorum stre columna, unâque terminum qui fequitur ultimum $5^{\text {tæ }}$; $8 x$ rurfus ifius termini in $n-4$ duat fubquintuplum 
plum $\frac{n \cdot n-1 \cdot n-2 \cdot n-3 \cdot n-4}{1 \cdot 2 \cdot 3 \cdot 4 \cdot 5}$ producit fummam terminorum col. $5^{\text {tre }}, \&$ fimul terminum qui excipit ultimum $6^{\text {tx }} ;$ atque ita confequenter. E quibus igitur infertur, quòd fumma terminorum ns primæ columnæ fit $\frac{n}{\mathrm{I}}, 2 \mathrm{dx} \frac{n \cdot n-1}{1 \cdot 2}, 3^{\mathrm{tix}} \frac{n \cdot n-1 \cdot n-2}{\mathrm{I} \cdot 2 \cdot 3}, 4^{\mathrm{tx}} \frac{n \cdot n-1 \cdot n-2}{1 \cdot 2 \cdot 3 \cdot 4}$ $\stackrel{n-3}{ }, 5^{\text {tax }} \frac{n \cdot n-1 \cdot n-2 \cdot n-3 \cdot n-4}{1 \cdot 2}, \frac{3 \cdot 4 \cdot 5}{1}$ generaliter columnac $\iota$, $\frac{3 \cdot n-1 \cdot n-2 \cdot n-3 \cdot n-4 \cdots n-c+1}{1 \cdot 2 \cdot 3 \cdot 4 \cdot 5 \cdot 5}$. Et quia qualibet harum quantitatum etiam exprimit terminum $n+1$ fequentis columnæ, fequitur quòd ipfe illius terminus optatus feu ultimus $n$ habeatur mutato folummodò ubique $n$ in $n-1$; adeoque quòd terminus optatus, fecundæ columnæe fit $\frac{n-1}{1}$, tertix $\frac{n-1 \cdot n-2}{1 \cdot 2}, 4$ tx $\frac{n-1 \cdot n-2 \cdot n-3}{1 \cdot 2 \cdot 3}$, $5^{\operatorname{tx}} \frac{n-1 \cdot n-2 \cdot n-3 \cdot n-4}{1 \cdot 2 \cdot 3 \cdot 4}, \&$ generaliter columnx $c, n-1 \cdot n-$ $\frac{2 \cdot n-3 n-4 \cdots n-c+r}{1 \cdot 2 \cdot 3 \cdot 4 \cdots c-I}$

scholium: Multi, ut hoc in tranfite notemus, numerorum figuratorum contemplationibus vacârunt (quos inter Faulhaberus \& Remmelini Ulmenfes, Wallifius, Mercator in Logarithmotechniâ, Preftetus, aliique) fed qui proprietatis hujus demonftrationem univerfalem dederit \& f cientificam, novi neminem. Wallifius in Arithm. Infinitorum fundamentụm fuæ methodi jacturus., rationes: quas habent feries Quadratorum, Cuborum aliarumque poteftatum numerorum naturalium ad feriem totidem maximo aqualium, induatione inveftigat; indeque prop. 176 ad contemplationem Trigonalium, Pyramidalium, reliquorumque figuratorum tranfit: fed fatius fuiffet forteque naturæ rei convenientius, fi vice versâ tractationem numerorum figutatorum, eamque univerfali " $\&$ accuratâ demonitratione munitam præmififfet, ac tum demum ad poteftatum fummas inveftigandas perrexiffet. Præterquam enim quod modus demonfrandi per induktionem parum fcientificus eft, infuperque pro qualibet ferie peculiarem operan depofcit; illa utique omnium judicio præcedere debent, quæ cæeteris naturâ funt priora \& fimpliciora, quales videntur effe numeri figurati præ poteftatibus, tưm. quod. 
guod illi additione, hæ multiplicatione generantur, tum \& præ:cipuè quod feries figuratorum à fuis refpectivè cyphris incipientes ad feries æqualium rationem habent exacte fubmultiplicem, qualem non habere poffunt feries poteftatum (faltem in terminis numero finitis) absque aliquo exceffu vel defeetu quicunque cyphrarum numerus ipfis præfigatur. De cætero namque ex cognitis figuratorum fummis nihilo difficilius inveltigari poterunt poteftatum fumma, atque ex his priores collegit auktor; quod quomodo frat, paucis oftendam.

Proponatur feries numerorum naturalium ab unitate $1,2.3$. 4.5. \&x. ufque ad $n$, \& quærantur omnium ipforum, item omnium quadratorum, cuborum \&c. ex ipfis fummæ: Quoniam in tab. combinat. terminus fecundæ columnæ indefinite eft $n-1, \&$ fumma omnium terminorum, hoc eft, fumma omnium $n$ - I feu $\sqrt{\frac{\sqrt{n-1}}{-1}}$ per confeet. præcedens inventa $\frac{n \cdot n-1}{1 \cdot 2} \infty \frac{n n-n}{2}$, erit $\overline{j n-1}$ fis ve $\int n-\int 1 \infty \frac{n n-n}{2}, \& \int \sqrt{1} \infty \frac{n n-n}{2}+\int 1$ red $\int 1$ (fumma omniun unitatum) elt $n$; quare fumma omnium $n$ feu $/ n \infty \frac{n n-n}{2}+n \infty$ $\frac{1}{2} n n+\frac{\pi}{2} n$

Porrò cum terminus tertize columnæe indefinitè acceptus per idem confect. fit $\frac{n-1 \cdot n-2}{1 \cdot 2} \infty \frac{n n-3 n+2}{2}$, \& fumma omnium terminorum (hoc eft, omnium $\left.\frac{3 n-3 n+2}{2}\right) \frac{n \cdot n-1 \cdot n-2}{1 \cdot 2 \cdot 3} \infty$ $\frac{n 3-3 n n+2 n}{6}$; erit $\overline{\frac{n n-3 n+2}{2}}$ live $\int \frac{x}{2} n n-\int \frac{3}{2} n+\int 1 \infty \frac{n_{3}-3 n n+2 n}{6}$, \& $\int \frac{\pi}{2} n n \infty \frac{n 3-3 n n+2 n}{6}+\int \frac{3}{2} n-11 ;$ fed $\int \frac{3}{2} n \infty \frac{3}{2} \int n \infty$ Cper mo do oftenfa) $\frac{3}{4} n n+\frac{3}{4} n, \&$ i $\infty n$ : unde his fubftitutis fit $\int \frac{1}{2} n n \infty$ $\frac{n-3 n n+2 n}{6}+\frac{3 n n+3 n}{4}-n \infty \frac{1}{6} n^{3}+\frac{1}{4} n n+\frac{1}{12} n$ ejwsq; duplum fnn (fumma quadratorum ex omnibus $n$ ) $\infty \frac{1}{3} n^{3}+\frac{x}{2} n n+\frac{1}{6} n$.

Rurfus quia terminus $n 4^{\text {tæ }}$ columax eft $\frac{n-1 \cdot n-2 \cdot n-3}{1 \cdot 2 \cdot 3} \infty$ $\frac{m 3-6 n n+11 n-6}{6}$, \& fumma omnium terminorum $\frac{n \cdot n-1 \cdot n-2 \cdot n-3}{1 \cdot 2 \cdot 3 \cdot 4}$ 
$\infty \frac{n^{4}-6 n 3+1 \mathrm{Inn}-6 n}{24}$, erit utique $\sqrt{\frac{n^{3}-6 n n+11 n-6}{6}}$; hoc eft, $\int \frac{1}{6} n^{3}-\int n n+\int_{\frac{1}{6}} n-\int 1 \infty \frac{n 4-6 n^{3}+\operatorname{IInn-6n}}{24}$, indeque $\int \frac{1}{6} n^{3} \infty$ $\frac{n 4-6 n 3+11 n n-6 n}{24}+\int m-\int \frac{1}{6} n+\int 1$. Et quoniam per modo inventa $\int n n \infty \frac{\pi}{3} n n^{3}+\frac{x}{2} n n+\frac{\pi}{6} n$; nec non $\int \frac{\pi}{6} n$ five $\frac{\pi}{6} \int n \infty \frac{x}{1} \frac{1}{2} n n+\frac{1}{1} \frac{1}{2} n$ $\& \int \mathrm{I} \infty \mathrm{x} ;$ hinc factâ horum fubftitutione emerget $\int \frac{1}{6} z^{3} \infty$ $\frac{n^{4}-6 n^{3}+11 n n-6 n}{24}+\frac{1}{3} n^{3}+\frac{\pi}{2} n n+\frac{1}{6} n-\frac{1}{12} n n-\frac{11}{12} n+n \infty$ $\frac{1}{2} n^{4}+{ }_{12}^{1} n^{3}+\frac{1}{2} n n$, ejusque proin fextuplum $n^{3}$ (fumma cuborum ) $\infty \frac{1}{4} n^{4}+\frac{I}{2} n^{3}+\frac{I}{4} n n$. Atque fic porrò ad altiores gradatim poteftates pergere, levique negotio fequentem adornare laterculum licet:

\section{Summe Poteftatum.}

fn $\infty \frac{x}{2} n n+\frac{x}{2} n$.

$\int n n \infty \frac{\pi}{3} n^{3}+\frac{x}{2} n n+\frac{1}{6} n$.

$\int n^{3} \infty \frac{1}{4} n^{4}+\frac{x}{2} n^{3}+\frac{1}{4} n n$.

$\int n^{4} \infty \frac{1}{5} n^{5}+\frac{2}{2} n^{4}+\frac{1}{3} n^{3} *-\frac{8}{30} n$.

$f^{5} \infty \frac{1}{6} n^{6}+\frac{\pi}{2} n^{5}+\frac{5}{1} n^{4} *-\frac{1}{1} n n$.

$f n^{6} \infty x^{\frac{1}{7}} n^{7}+\frac{\pi}{2} n^{6}+\frac{1}{2} n^{5} *-\frac{1}{6} n^{3} *+\frac{1}{4} 2^{2}$

$n^{7} \infty \frac{1}{3} n^{8}+\frac{x}{2} n^{7}+\frac{7}{12} n^{6} *-\frac{7}{24} n^{4} *+\frac{1}{12} n n$.

$f n^{8} \infty \frac{1}{9} n+\frac{\pi}{2} n^{8}+\frac{2}{3} n^{7} *-\frac{7}{15} n^{5} *+\frac{2}{9} n^{3} *-\frac{1}{30} n 。$

f $n 9 \infty 0 \frac{1}{10} n^{10}+\frac{\pi}{2} n^{9}+\frac{3}{4} n^{8} *-\frac{7}{10} n^{6} *+\frac{1}{2} n^{4} *-\frac{1}{12} n n$. $\int n^{10} \infty 0 \frac{1}{1} n^{11}+\frac{\pi}{2} n^{10}+\frac{5}{6} n 9 *-\mathrm{I} n^{7} *+\frac{1}{1} n^{5} *-\frac{1}{2} n^{3} *+\frac{3}{66} n_{0}$

Quin imò qui legem progreffionis inibi attentius infpexerit, eundem etiam continuare poterit abfq; his ratiociniorum ambagibus: Sumtâ enim c pro poteftatis cujuslibet exponente, fit fumma omnium $n c$ feu $\int n^{c} \infty \frac{\mathrm{I}}{c+1} n^{c}+1+\frac{1}{2} n^{c}+\frac{c}{2} \mathrm{~A} n^{c-1}+\frac{c \cdot c-1 \cdot c-2}{2 \cdot 3 \cdot 4} \mathrm{~B}^{c-3}+$ $\frac{c \cdot c-1 \cdot c-2 \cdot c-3 \cdot c-4}{2 \cdot 3 \cdot 4 \cdot 5 \cdot 6} \mathrm{Cm}^{c-5}+\frac{c \cdot c-1 \cdot c-2 \cdot c-3 \cdot c-4 \cdot c-5 \cdot c-6}{2 \cdot 3 \cdot 4 \cdot 5 \cdot 6 \cdot 7 \cdot 8}$ Dnc-7 . . \& ita deinceps, exponentem poteftatis ipfius $n$ continue minuendo binario, quoufque perveniatur ad $n$ vel $n n$. Litere capitales $A, B, C, D$ \& c ordine denotant coëfficientes ultimorum terminorum pro $f m n, f n^{4}, \int n^{6}, f^{8} \& c_{+}$nempe $A \infty \frac{1}{6}, \mathbf{B}$ N $\quad \infty=\frac{1}{30}$ 
$x-\frac{1}{3}, C D \frac{T}{4}, 2, D=-\frac{1}{30}$. Sunt autem hi coëfficientes ita coms parati, ut finguli cum cæeteris fui ordinis coëfficientibus complere debeant unitatem; fic $D$ valere diximus $-\frac{1}{5}$, quia $\frac{1}{5}+\frac{1}{2}+\frac{2}{2}-\cdots \frac{7}{1}$ $+\frac{2}{3}(+D)-\frac{1}{3} D$ I. Huius laterculi beneficio intra femi-quadrantem horæ reperi, quòd poteftates decimæ five quadrato-furfolida mille primorum numerorum $a b$ unitate in fumman colleeta efficiunit

$$
\text { 91, } 409,924241,424243,424241924242500 .
$$

E quibus apparet, quàm inutilis cenfenda fit opera Ifmaëlis Bullialdi, quam confcribendo tam fpiffo volumini Arithmeticæ fuæ Infinitorum impendit, ubi nihil preftitit alıud, quàm ut primarum tantum fex poteftatum fummas (partem ejus quod unicâ nos confecuti fumus paginâ) immenfo labore demonftratas exhiberet.

Antequam caput hoc finiamus, paucis adhuc indicare lubet; quomodo fuppofitis iis, quæ de feriebus figuratis oftenfa funt, pof fint quævis etiam aliæ feries figuratarum analogæ (quæ fcil. differentias fuas primas, fecundas, tertias \& cc. æquales habent, adeoque ex continua additione terminorum alicujus feriei æqualium generantur ) ad homologas figuratas reduci, ac proinde fummari, vel poAtremi ipfarum termini inveniri: Sit leries quævis æqualium $D$, ex cujus additione nafcatur feries $\mathrm{C}$, \& ex hujus additione feries $\mathrm{B}, \&$ ex hujus tandem collectione feries $A$, fumtis ad arbitrium primis ferierum terminis $d, c, b, a$. Vocabitur feries A figuratarum analoga, cujus differentiæ primæ conftituunt feriem $B$, fecundæ feriem $C_{2}$

\begin{tabular}{l|l|l|l} 
D. C & B & A. \\
\hline$d$ & $c$ & $b$ & $a$ \\
$d$ & $c+d$ & $b+c$ & $a+b$ \\
$d$ & $c+2 d$ & $b+2 c+d$ & $a+2 b+c$ \\
$d$ & $c+3 d$ & $b+3 c+3 d$ & $a+3 b+3 c+d$ \\
$d$ & $c+4 d$ & $b+46+6 d$ & $a+4 b+6 c+4 d$ \\
$d$ & $c+5 d$ & $b+5 c+10 d$ & $a+5 b+10 c+10 d$
\end{tabular}
tertia feriem $D_{2}$ \&re. Et quo niam apparet, $\mathrm{fe}$ riem A compori ex feriebus unitatum $\mathbb{I}, \mathbb{I}, \mathbf{I}, \mathbf{I}$ 8cc. lateralium $\mathrm{x}, 2,3,4.8 \mathrm{x}$. trigonalium $1,3,6,10,8 x c$. pyramidalium $\mathrm{r}, 4,10,20 . \& c_{0}$ in primos differentiarum terminos $a, b, c, d$, feorfim ductis, quarumque mnium poftremi termini \& fumma per ante dicta habentur, ipfius quoqugé 
बุioque hinc feriei $A$ poftremum terminum \& funmam termino= rum obtineri poffe conftat; nimirum fi numerus terminorum vocerur' $n$, erit ultimus terminus feriei $\mathrm{A} \infty a+n-1 . b+$ $\frac{n-1 \cdot n-2}{2} c+\frac{n-1 \cdot n-2 \cdot n-3}{2.3} d ;$ \& fumma omnium termino rum $20 n a+\frac{n \cdot n-1}{2} b+\frac{n \cdot n-1 \cdot n-2}{2 \cdot 3} c+\frac{n \cdot n-1 \cdot n-2 \cdot n-3}{2 \cdot 3 \cdot 4} d$.

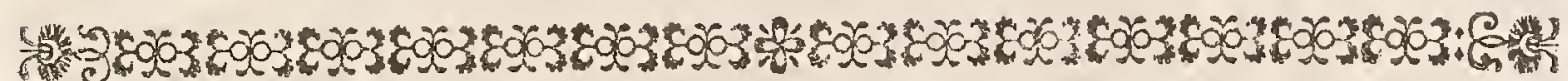

$$
\text { C A p U T IV. }
$$

Invenire numerum Combinationum fecundìm fingulos exponentes feorfim; ubi fimul ofenditur, in quot combinationibus una pluresvé res prefcripte conjunition vel divifise reperiantur.

FX cap. prac. conftat, numerum combinationum fecundùm quemcunque exponentem æquari aggregato refpectivæ feriei numerorum figuratorum, ad tot terminos continuatæ, quot fuerint combinandæ res. Quare cùm ibidem fit oftenfum, pofito numero terminorum $n$ fummam feriei cujusvis $c$ effe $\frac{n \cdot n-1 \cdot n-2 \cdot n-3 \cdots \cdots n-c+1}{1 \cdot 2 \cdot 3 \cdot 4 \cdots \cdots c}$, fequitur, eandem hanc quan:titatem exprimere quoque numerum combinationum, fumtis $n$ pro multitudine rerum combinandarum, \&c pro exponente combinationis.

Patet autem, quantitatem iftam defignari per geminam progreflionem arithmeticam, unam à numero rerum defcendentem, afcendentem ab unitate alteram, quarum communis exceffus eft $u$ nitas, \& utraque tot terminorum, quot unitates habet combinationis exponens c: quippe cùm in utrâque differentia primi \& ullo simi termini fit $c-I$. Unde talis emergit 


\section{Regula}

pro inveniendis Combinationibus fecundium datum exponentem:

Flant duæ Progreffiones Arithmeticæ, una defcenI dens à numero rerum combinandarum, altera afcendens ab unitate, quarum communis differentia fit unitas, \& utraque tot terminorum, quot unitates ha-. bet combinationis exponens: tum factum ex ductu terminorum prioris progreffionis dividatur per factum ex ductu terminorum pofterioris. Quotiens erit quxfita combinationum, qux fecundùm datum exponen. tem inftitui poffunt, multitudo.

Ita ex, gr. ex ro diverfis rebus fumi poffunt quaternarii

$$
\frac{10.9 \cdot 8 \cdot 7}{1.2 \cdot 3 \cdot 4} \infty \frac{5040}{24} \infty 250 \text {. }
$$

Nota: Si plufculæ res ad combinandum fint propolitæ, præ= fertim fecundum exponentem itidem majufculum; ut fi propofitum fit inquirere, quoties extrebus centum vicenæ poffint accipi, fupputatio fecundum regulam inftituenda perquàm prolixa \& tædiofa e= vaderet, excrefcente producto multiplicationis ad 40 ufque notas. Quare tum, ut quafitum compendio confequamur, poterimus terminos progreffionum ante multiplicationem per communes divifores tollere, hấc ratione:

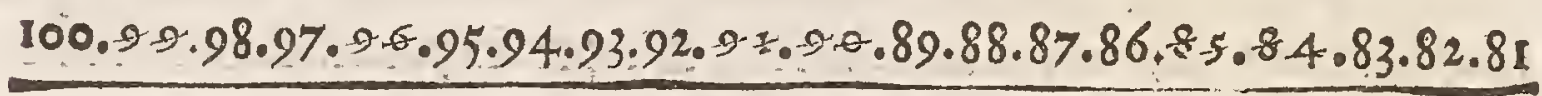

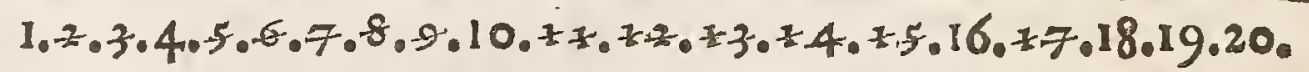

Divido utrumq; fractionis terminum per 9. ir 5099 , per 8.120096 , per 7.130091 , per 6.1400 .84 , per 5.170085 , \& per 2.3 .1500 90 , delendo numeros alteros ex numeratore, ex denominatore alteros, ut fractio ad minores terminos reducta fit hac :

$$
\frac{100 \cdot 98 \cdot 97 \cdot 95 \cdot 94 \cdot 93 \cdot 92 \cdot 89 \cdot 88 \cdot 87 \cdot 86 \cdot 83 \cdot 82.81}{I \cdot 4 \cdot 10 \cdot 16 \cdot 18 \cdot 19 \cdot 20}
$$


Deinde divido utrinque per 100 , delendo fuperiùs $100, \&$ fribendo inferius 2 loco 10.2000200 ; irerum divido per 8 , fcribendo fuperius II loco 88, inferius delendo modò afcripta 2. 4,08 : porrò quia 5.195095 , deleo infra 19, fupra loco 95 fcribo 5 : divido utrinque per 9, fcribendo fuperius 9 loco 81, \& inferius 2 loco 18 : divido per 4 , ponendo fuperius 23 loco 92 , inferius 4 loco 16 : tandem divido ter per 2 , fubftituendo fuperius $4,43 \& 47$ loco 82 , $86 \& 94$, inferius delendo omnia. Sic erit reducta feries ad hos terminos, $98,97 \cdot 93 \cdot 89 \cdot 87 \cdot 83 \cdot 47 \cdot 43 \cdot 41 \cdot 23 \cdot 11.9 \cdot 5$; qui in fe ducti continuè exhibent 535983370403809682970 numerum vicenariorum in rebus centum.

Quòd fi quis in numeris tam prolixis, ubi exacta præcifio neceffaria non eft, eâ quæ ad ufum fufficit acquiefcere velit, is utiliter \& magno cum compendio Logarithmos adhibebit. Nam fi fummam Logarithmorum $\mathrm{ab}$ I ad 20 (quæe reperitur 18.3861244 ) fubtrahat à fummâ $\log$ - orum ab 81 ad 100 (quae eft 39.1152756 ,) vel etiam ipforum tantùm numerorum 98.97.93. \&c. (qui polt inftitutam progreffionum reductionem remanferunt) Logarithmos addat, ftatim obtinebit 20.7291512 Log-um numeri combinationum quafiti, qui numerus propter characterifticam fui $\log -i 20$ conftare debet notis 2I. Harum priores quatuor in Canone reperiuntur 5359 , fequentes tres è comparatis proximorum Log-orum differentiis eliciuntur 833 , cætera 14 loca cyphris fuppleri poffunt, fic ut quæefitus

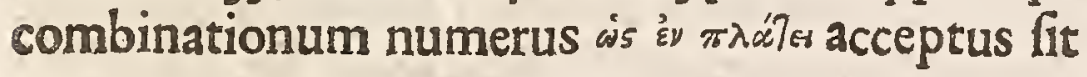

535983300000000000000 .

Porrò ex allatâ Regulâ, quam pro inveniendis combinationibus fecundum fingulos exponentes adduximus, fequentia manant corollaria:

Cor. I. In dato quovis rerum numero, crefente exponente combinationis quoufque medium numeri rerum attigerit, crefcit ipfa combinationum multitudo; crefcente verò ulterius exponente, hæe iterum decrefcit: Ita in rebus octo plures continentur biniones quàm uniones, terniones quàm biniones, quaterniones quam terniones; fed fi pergas ulterius, pauciores invenies quinarios quàm quaternarios, fenarios quàm quinarios \& $c_{\text {. }}$ Conf. propr. 6 Tab. num. fig. Etenim 8 vel $\frac{8}{1}$ numerus unionum in rebus octo coontinùe ductus in $\frac{7}{2} \cdot \frac{6}{3} \cdot \frac{5}{4}$. N3 
$\frac{4}{5} \cdot \frac{3}{6}$ \& \&c. Cuccefrivè producit $\frac{8.7}{1.2}, \frac{8.7 .6}{1.2 .3}, \frac{8.7 .6 .5}{1.2 .3 .4}, \frac{8.7 .6 .5 .4}{1.2 .3 .4 .5}$, $\frac{8 \cdot 7 \cdot 6 \cdot 5 \cdot 4 \cdot 3}{1.2 \cdot 3 \cdot 4 \cdot 5 \cdot 6 .} \&$ c. qui juxta regulam funt numeri binionum, ternionum, quaternionum, quinionum, fenionum \&xc. Unde cùm prio= rum factorum $\frac{7}{2}: \frac{6}{3} \cdot \frac{5}{4}$ finguli fint majores unitate, reliqui $\frac{4}{5} \cdot \frac{3}{6}$ \&c. unicate minores, fequitur, fucceffiva producta ex iftis factoribus, hoc ef, numeros combinationum aliquoufque continuè crefcere, \& poftmodùm iterum decrefcere debere. Quòd verò crefcant, donec exponens combinationis dimidium rerum numerum attingit, inde liquet, quòd fractionum iftarum $\frac{8}{1} \cdot \frac{7}{2} \cdot \frac{6}{3} \cdot \frac{5}{4} \cdot 8 \mathrm{cc}$. (ex quarum continuo ductu numeri combinationum refultant, quarumque primus numerator perpetuò rerum numerum, denominator primus unitatem requat) termini fuperiores $\&$ inferiores pro unoquoque fequentium exponentium binario fibi propiores fiunt (illis unitatis decrementum, his incrementum paffis ) proindeque fe mutuò affequuntur in tot terminis, quot indicat femiffis primi numeratoris five di= midius rerum datarum numerus; polt quos terminos ipfidenominatores fuis viciffim numeratoribus majores fiunt, $\&$ ab iis majori fubinde intervallo recedunt.

Cor. 2. Duo exponentes, qui frmul componunt ipfum rerum numerum (quos parallelos vocabimus) combinationes habent aque multas. Sic in rebus octo tot habentur feptenarii quot unitates, tot fenarii quot binarii, \& tot quinarii quot ternarii, propter $8007 \mathrm{I}$ $006+2005+3$. Huc refer propr. $6 \& 7 \mathrm{Tab}$. num. fig. Ratio e= videns : Quoties enim ex rebus octo ex. gr. binæ accipiuntur toties utique aliæ fenæe relinquuntur: ergò toties quoque è converfo fenæ poffunt accipi, fumtis nimirum is quae relinquebantur antea \& reli= ctis quæ fumebantur. Idem ex præf cripto regulæ fic evincitur: Juxtæ Illam numerus binariorum in rebus octo eft $\frac{8 \cdot 7}{\mathrm{I} \cdot 2}$; adjiciantur numeratori \& denominatori factores progreffivi æque-multi, quoad adjectorum ultimus in denominatore primo adjectorum in numeratore equetur, fil. $\frac{6 \cdot 5 \cdot 4 \cdot 3}{3 \cdot 4 \cdot 5 \cdot 6}$; fic factum ex adjectis aquatur unitati, numeratoribus $\& x$ denominatoribus inverfo ordine fe mutuò deftuentibus; ipfumque adeo productum integrum $\frac{8 \cdot 7 \cdot 6 \cdot 5 \cdot 4 \cdot 3}{1 \cdot 2 \cdot 3 \cdot 4 \cdot 5 \cdot 6}$ non dif- 
fert à numero binariorum $\frac{8 \cdot 7}{\mathrm{r} \cdot 2}$ : patet autem facilè, producum illud indigitare numerum fenariorum, feu combinationum quarum exponens unà cum binario datum rerum numerum complet; quandoquidem primus adjectorum in numeratore (qui per hyp. pofremo adjectorum inidenominatore, h. e.ipficombinationis exponenti aquatur) à primo omnium feu ipfo rerum numero tot unitatibus differt, quot ipfum alii præcedunt, hoc eft, quot unitates habet exponens combinationum, quarum numerum præcedentes factores $\frac{8.7}{1.2}$ infmuabant.

$\mathrm{Cor}_{+}$3. Exponens æqualis femiffi numeri rerum, fis datus rerum numerus eft par; aut duo exponentes contigui quorum fumma conftituit rerum numerum, fi hic eft impar, fuppeditant maximum numerum combinationum. Fluit ex præcedd Corollariis. Nan ex. gr. in rebus octo numeri feptenariorum \& unitatum, fenarioram \& binariorum, quinariorum \& ternariorum æquantur . per 2. Coroll. Cùm ergò plures dentur quaternarii, quàm ternarii, binarii vel unitates per 1 . Cor. etiam plures erunt quaternarii, quàm combinationes fecundùm ullum alium exponentem. Similiter in rebus novem. numeri octonariorum \& unitatum, feptenariorum \& binariorum, femariorum \& ternariorum, quinariorum \& quaternariorum æquantur per 2. Cor. Cùm igitur quinarii \& quaternarii quoad fuos exponentes fint medio numeri rerum proximi, patet eorundem numeros omnium reliquorum maximos effe, per I. Cor.

Cor 4 . Numerus combinationum rerum quotcunque fecundùm exponentem quemlibet ejusve parallelum æquatur numero permutarionum rerum totidem, quæ duîm tantùm fint generum talesque ut res ejusdem generis numero conveniant cum exponentibus parallelis combinationum; putà, tot funt, ternarii vel quaternarii, in rebus \%, quot permutationes rerum totidem, fi tres ipfarum funt eædem, \& reliquæ quatuor eædem. Nam numerus ternariorum juxta regulam $\infty \frac{7.6 .5}{1.2 \cdot 3} \infty \frac{1.2 \cdot 3 \cdot 4 \cdot 5 \cdot 6 \cdot 7}{1.2 \cdot 3 \cdot 4 \text { in } 1.2 .3} \infty$ numero permutationum dictarum per Reg. 2. Cap. I hujus .

Cor. 5. In quolibet rerum numero, multitudo combinationum fecundùm datum exponentem æquatur fummæ combinationum fecun: 


\section{IO4 LATIS CONFECTANDI}

fecundùm exponentem antecedentem $\&$ datum in numero rerum pre. cedenti; ex gr. tot funt quaterniones in rebus decem, quot terniones \& quaterniones fimul in rebus novem. Namque per regulan. numerus quaternionum in rebus decem $\infty \frac{10.9 .87}{1.2 .3 .4} \infty \frac{2.8 .7 \text { in } 6+4}{1.2 .3 .4}$ $\infty \frac{9.8 \cdot 7.6}{1.2 .3 \cdot 4}+\frac{9.8 \cdot 7.4}{1.3 .3 .4} \infty \frac{9.8 \cdot 7.6}{1.2 .3 .4}+\frac{9.87}{1.2 .3} \infty$ numero quaternionum plus numero ternionum in rebus novem. Aliter ita: Una decem rerum datarum vocetur $A$; manifeftum, tot dari præcisè quam ternarios in quibus $\mathrm{A}$ non reperitur, quot quaternarii ex reliquis novem poffunt accipi; tot verò effe alios in quibus reperitur $A$, quot terniones comprehenduntur in novem cæeteris, fiquidem fingulis iftis ternionibus adjectum ipfum $\mathrm{A}$ totidem quaterniones efficit, quos omnes $\mathrm{A}$ ingreditur ex conftruct. Quare cùm quaterniones illi in quibus reperitur $A, \&$ in quibus non reperitur, exhauriant omnes quaterniones pofibiles ex datis rebus accipiendos, conftat propolitum. Confo propr. $48.5 \mathrm{Tab}$. num, fig.

Cor. 6. Numerus combinationum fecundùm omnes exponentes pares (inclufo nullione) æequatur numero combinationum fecundùm omnes impares, proinde utervis femiffis eft numeri omnium combinationum fimpliciter (inclufo quoque nullione) h. e. cùm ifte in rebus $n$ fit $2^{n}$ per Reg. cap. 2 . utervis illorum erit $2^{n-1}$. Demonftratum habetur ibidem ad calcem dicti capitis, fed idem quoque ex præced. Coroll. fic deducitur: In rebus ex. gr. novem eft unus novenarius, ficut in rebus decem unus denarius, deinde utrobique eft unus nullio, ac præterea tot funt unitates $\&$ binarii fimul in rebus novem, quot foli binarii in rebus decem; tot ibi ternarii \& quaternarii fimul, quot hic foli quaternarii ; tot quinarii \& fenarii ibi, quothîc fenarii; tot denique feptenarii \& octonarii ibi, quot foli oftonarii hîc, per præced Coroll.5. quare numerus omnium fimpli= citer combinationum rerum novem æquaturnumero combinationum rerum decem fecundùm exponentes pares. Rurfus, per idem Coroll. tot habentur in rebus novem nulliones \& unitates frmul, quot unitates tantùm in rebus decem; tot ibi binarii \& ternarii frmul, tot quaternarii \& quinarii, tot fenarii \& feptenarii, tot denique oftonarii \& novenarii, quot hầ feorfim ternarii, quot quinanii, quot $\mathrm{fe}_{\text {. }}$ 


$$
P A R S \text { S E UNDA. }
$$

Ceptenarii \& quot novenarii: quocirca numerus omnium fimpliciter combinationum rerum novem æquatur etiam numeto combinationum rerum decem fecundum exponentes impares. Ergo numeri combinationum rerum decem fecundum exponentes pares \& fecundum impares inter fe aquantur. Ecce rem in fynopfi:

\section{Exponesites Combinat.}

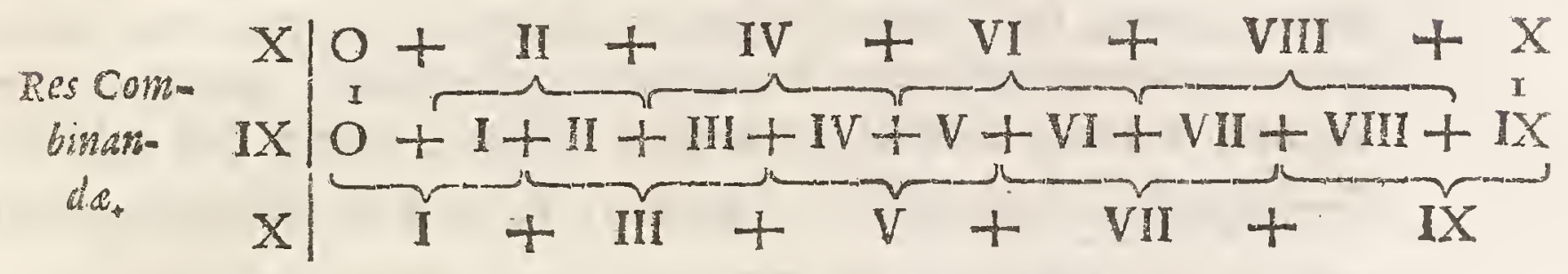

Superfunt nobis hîc loci nonnullæ quæftiones enodandæ, quæ circa combinationum materiam formari poffunt, fuumque aliquando ufum habent; ut, cùm indagandum proponitur, in quot combinationibus una pluresve res imperatæ five conjunctim five divifim reperiantur. Ejufmodi quiaftiones cùm in infinitum multiplicari poffine, omnes ad unum genus Problematis reducere conabimur, quod univerfaliter fic enunciamus: Dato numero rerum combinandarum \& exponente combinationis inveniendum fit, in quot combinationibus ex aliquot defignatis rebus nonnullæ, qua \& ipfa præf criptæ \& determinatæ fint, exclufis cæteris reperiantur; putà, fi ex numero rerum omnium $n$, combinatarum fecum invicem fecundùm exponentem $c$, defignentur aliquæe $\mathrm{A}, \mathrm{B}, \mathrm{C}, \mathrm{D}, \mathrm{E}$, quarum numerus fit $m$, five major five minor exponente $c$, \& quæratur in quot combinationibus defignatarum nonnullie $A, B, C$, quarum numerus fit $b$, unà junctæ reperiantur exclufis cæeteris $D$ \& E. Dico, Problematis generaliter fic concepti folutionem non minus promptam effe, ac fpecialis cujusvis cafus; \& numerum combinationum quas recipiunt res $n-m$ fecundùm exponentem $c-b$ (quique numerus per Regulam invenitur

$$
\left.\frac{n-m \cdot n-m-1 . n-m-2 \cdot n-m-3 \ldots n-m-c+b+r}{n \cdot 2 \cdot 3 \cdot 4 \cdot 5 \cdots \cdots c}\right) \text { ipfi confe- }
$$

ftim quæfito fatisfacere. Nam quia numerts rertum combinataruni eft $n, \&$ defignatarum ex illis $m$, erit exemptis defignatis reliquarum numerus $n-m$, quas fi combines inter fe fecundùn exponen. 
tem $c-b$, habebis novas combinationes, in quibus nulla defignam tarum reperitur; quare fi illarum fingulis adjungas præfcriptas $\mathrm{A}_{\text {, }}$ $B, C$, quarum numerus ponitur $b$, fiet tum utique combinationum exponens $c$, ipfæ verò combinationes fingulæ comprehendent ex defignatis folas A, B, C, feclufis reliquis, quod imperatum fuit. Quòd fi numerus $b$, carum ex defignatis, qua combinationes optatas ingredi debent, fir quidem determinatus, ipfre verò res non fint determinatz, fed quomodolibet ex delgnatis accipiendæ; patet, numerum combinationum hinc toties multiplicari, quoties ex defignatis $m$ rebus diverfa $b$ res eligi poffunt, nempe per regulam $\frac{m \cdot m-1 \cdot m-2 \ldots m-b+1}{1 \cdot 2 \cdot 3 \ldots b}$ vicibus; fic ut tum numerus combim nationum quafitus fit $\frac{m \cdot m-1 \cdot m-2 \cdot \ldots m-b+1}{1 \cdot 2 \cdot 3 \cdot \cdot \cdot b}$ in $\frac{n-m \cdot n-m-1 \cdot n-m-2 \cdots n-m-c+b+1}{1 \cdot 2 \cdot 3 \cdot 4 \cdot 6 \cdot b \cdot c}$

Nota, fi $n-m<c-b$, nulla inftitui potef combinatio, quae præfriptam conditionem habeat. Sed hæc ad nonnullos fpe. ciales cafus applicabimus:

Quæritur primò, in quot combinationibus reperiatur data quae. libet res? Quia hic defignatur res unica, erit $m \& 6.0$ I, adeoque $\frac{n-m \cdot n-m-1 \cdot n-m-2 \ldots n-m-c+b+1}{1 \cdot 2 \cdot 3 \cdot 4 \cdots \cdot c-b} \infty \frac{n-1 \cdot n-2 \cdot n-3 \cdots n-c+1}{1 \cdot 2 \cdot 3 \cdot 4 \cdot \cdots \cdot c-1}$ Do numero combinationum quafito, qui quidem ad numerum omnit combinationum $\frac{n-n-1 \cdot n-2 \cdot n-3 \ldots n-c+1}{1 \cdot 2 \cdot 3 \cdot 4 \cdot \ldots c}$ fe haber ut $c$ ad $n_{2}$ exponens fil. combinationis ad numerum rerum combinatarum. uti confat, fi utraque fractio dividatur per

$n-1 . n-2 . n-3 \ldots . . n-6+1, \&$ multiplicetur per $1.2 \cdot 3 \cdot 4 \cdot \ldots+c$

2. Sunto jam defignatæ res duæ $A \& B, \&$ definiendus fit combinationum numerus, in quibus reperitur $A$ abfque $B$. Quia hic $m \infty 2, \& b \infty \mathrm{I}$, erit numerus quæefitus $\frac{n \cdot 2 \cdot n-3 \cdot n-4 \cdots \cdots n-c}{1 \cdot 2 \cdot 3 \cdot 4 \cdots c-1}$, cujus proinde duplum, numerum combinationum denotabit, in quid bus alterutra ipfarum A \& B abfque alterâ reperitur.

3. Porro fi quaratur, in quot combinationibus reperiantuir ambre 


$$
P A R S S E C U N D A \text {. }
$$

ambæ A \& B; fet, propter $\& 6 x_{2}$, optatus numerus $\frac{n-2 \cdot n-3 \cdot n-4 \cdot \ldots n-c+n}{1 \cdot 2 \cdot 3 \cdot 4 \cdot \cdots \cdot c^{2}}$

4. Sin quaratur, in quot combinationibus neutra defignatarum reperiatur, invenitur, ob $m x_{2} \& b x_{0}$, quafra combinationum multitudo $n-2 \cdot n-3 \cdot n-4 \ldots n-c-1$.

5. Ita etiam fi rerum defignatarum tres fint, \& quaeftio fit quot combinationes ingrediantur duæ $\mathrm{A} \& \mathrm{~B}$ abfque tertiâ $\mathrm{C}$; quo cafu $m$ valet $3 \& 62$; quæfitus combinationum numerus invenitur $\frac{n-3 \cdot n-4 \cdot n-5 \ldots \ldots n-c}{1 \cdot 2 \cdot 3 \cdot 4 \cdots \cdots}$. Et quia ex tribus ter bine poffunt accipi, triplum illius numerum combinationum exhibebit, quas dua defignatarum quæcunque exclusâ tertiâ ingrediuntur. Atque ita porrò in aliis.

Appendix: Explicatâ numerorum figuratorum naturâ, ufuqựe quem in combinationibus præftant, inftituti noftri filum tantifper deferemus, promifin in fine Propof. 7 Part. 1 facti memores, donec porrò hîc oftenderimus, quomodo expectationes duorum colluforum indefinitè ad quotvis deficientes lufus in fymbolis exhiberi poffint, quod olim quoque $\mathrm{Pafcalium}$ occupavit; Duo autem præftò funt modi, quibus id confequi licet: unus reconditior, ex conftructione Tabellæ ibidem infertæ \& confideratione progreffionis, quam numeri illius inter fe fervant, petitus; quem nonquam fe affequi potuiffe fcribit Pafcalius in epiftolâ ad Fermatium, ut legere eft in hujus operibus Tolof impreffis A. 1679, p. 180: alter magis planus \& obvius, ex combinationum doctrinâ immediatè dimanans, quo AluEtor ille in fuâ Problematis folutione videtur ufus.

1. Mod. Sint duo collufores A \& B, quorum illi $n$, huic $m$ ludi ad vincendum defint, \& quærenda fit utriufque expectatio, h. e. quærendus fit in distâ Tabellâ numerus areolæ $n$ columnæ verticalis $m$. Adjecti intelligantur in columnarum capitellis tot termini progreflionis duplæa ab unitate; quota eft unaqueque inter columnas; inus primæ, duo fecundæ, tres tertiæ columnæ \&c, hoc pacto: 


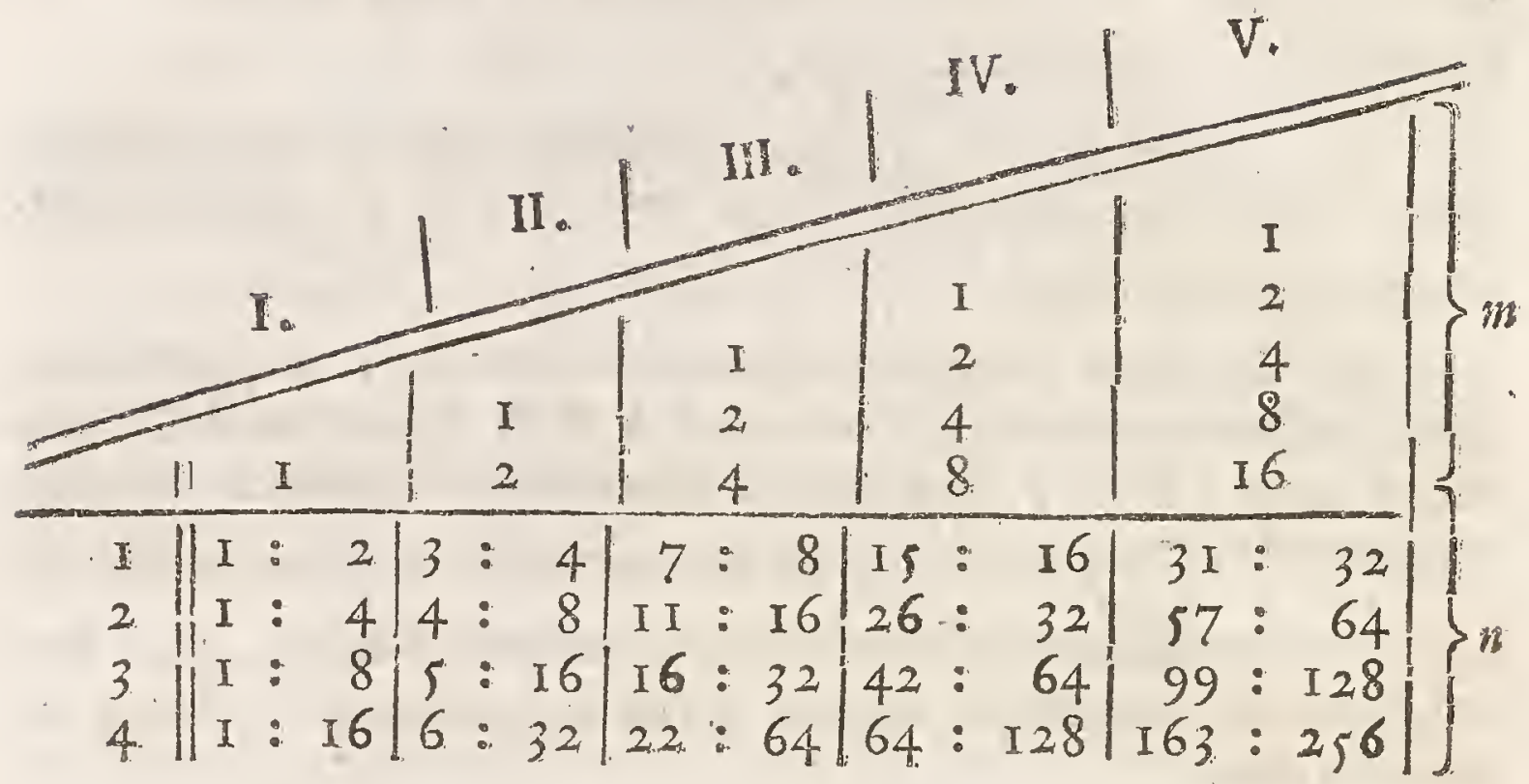

Et apparebit prino intuitu, progreffiones has duplas ordine continuari per denominatores fractionum in columnis, adeò ut denominator areolæ $n$ columnæ cujuslibet $m$ fit terminus $n+n$ progreffionis dupla ab unitate, i. e. poteftas binarii, cujus exponens $m+n-\mathbf{I}$, five, $2^{m}+n-1$. Ad numeratores verò fractionum quod attinet, perpendi debet quòd unusquifa; corum ex confructione Tabellæ loc. cit. infinuatâ æequetur duobus aliis, quorum unus illi immediatè fupra, alter ad finiftram pofitus eft; hinc enim inferri poteft, numeratorem areolæ $n$ columnæ: cujuslibet æquari quoque fummæ omnium $n$ numeratorum columnæ præcedentis unà cum terminis ipfi in vertice adjectis ac præterea unitáti; indeque porrò haud difficilius colligitur, quòd feries numeratorum fecundæ columnæ (unà cum terminis ipfi præfixis ) difcerpi poffit in duas alias feries, tertiæ in tres, quartæ in quatuor, \& generaliter columnæ cujuslibet $m$ in alias $m$ feries, \&c. quarum primæ femper fint feries monadum, fecundæ feries latera. lium cum unâ in vertice cyphrâ, tertiæ feries trigonalium cum cyphris duabus, quartæ pyramidalium cum cyphris tribus, \& ita dein ceps, hâc ratione: 


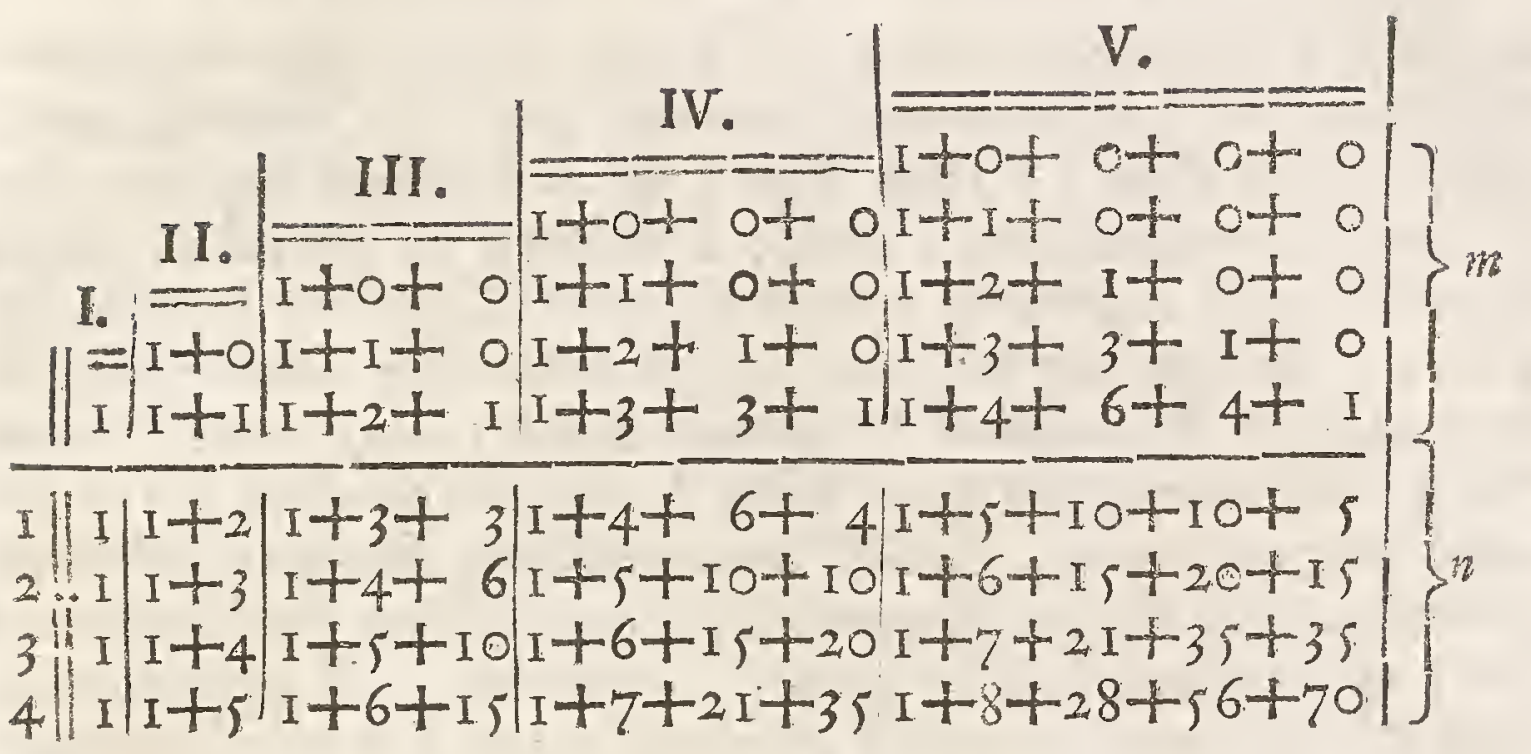

Unde củm terminus $m+n$, per confeat. Cap. 3 hujus, in ferie monadum fit $\mathrm{x}$, in ferie lateralium $\frac{m+n-1}{1}$, trigonalium $\frac{m+n-1 \cdot m+n-2}{1 \cdot 2}$, pyramidalium $\frac{m+n-1 \cdot m+n-2 \cdot m+n-3}{2 \cdot 3} \& x$. \& generaliter in $m$ ferie $\frac{m+n-\mathrm{I} \cdot m+n-2 \cdot m+n-3 \ldots m+n-m+\mathrm{I}(n+1)}{\mathrm{I} \cdot 2 \cdot 3 \cdot 4 \cdots \cdot m-1}$; erit numerator areolæ $n$ columnæ cujuslibet $m, I+\frac{m+n-I}{1}+$ $\frac{m+n-1 \cdot m+n-2}{1 \cdot 2}+\frac{m+n-1 \cdot m+n-2 \cdot m+n-3}{1 \cdot 3}+\ldots$ uf que ad $+\frac{m+n-1 \cdot m+n-2 \cdot m+n-3 \ldots m+1}{\mathrm{I} \cdot 2 \cdot 3 \cdot 4 \cdots \cdots}$. Er quia per Cap. 4. iisdem hujus quantitatis membris etiam multitudo denotatur nullionum, unionum, binionum, ternionum \&c. in rebus $m+n-1$ comprehenforum, fequitur dictum numeratorem conflari ex aggregato omnium nullionum, unionum, binionum, cæterarumque ordine combinationum rerun $m+n-$ I ufque ad illas inclufivè combinationes, quarum exponens fit $m-I$ : idemque proin aggregatum divifum per $2^{m+n-I}$ exhibiturum totam fractionem datæ areolæ, h。e. per hyp. optatam expectationem colluforis $A$, feu partem depofiti I, qua collufori debetur, cui $v$ ludi deficiunt, dum alteri lidi $m$. Nota: fi $m x n+1$, hoc eft, fi collufori $B$ unus tantùm lufus deficiat amplius quàm ipfi $A$, portio depofiti बुนæ huic debetur æequalis cenfebitur aggregato combinationum re- 
rum $2 n$, à nullione ad illas inclufivè quæ habent $n$ pro exponene. divifo per $22 n$ (qui numerus ef omnium fimpliciter combinationum rerum $2 n$ per Cap. 2) Finc ergò fi demas femiffem omnium fim plicicer Combinationum (nempe à nullione ad dimidium earum numerum qux exponente $n$ gaudent, uti colligitur ex Coroll. $2 \&$ 3 hujus ) divifum per integram fummam omnium abfolutè combia nationum, h.e. fi demas $\frac{1}{2}$ (partem depofiti quam contulit collu= for $A)$ relinquetur pro lucro ipfius $A$. five pro eo quod ipfi ex pecuniâ alterius debetur, femifis combinationum fecundùm folum exponentem $n$ divifus per fummam omnium abfolute combinationum $2^{2 n}$; qui quidem femillis cùm fe habeat ad $\frac{1}{2}$ (id quod depofuit alter $B$ ) ut integer numerus combinationum fecundùm exponentem $n$ dictâ ratione divifus (hoc eft, per Reg. cap. hujus, ut $\frac{2 n .2 n-1.2 n-2.2 n-3 \ldots n+I}{I \cdot 2 \cdot 3 \cdot 4 \cdots \cdots}$ divifus per $\left.22 n\right)$ ad I, manifeftum facit, partem quæ debetur collufori $A$ ex eo quod depofuit alter $B$, exprimi per $\frac{2 n .2 n-1.2 n-2.2 n-3 \ldots n+1}{1 \cdot 2 \cdot 3 \cdot 4 \cdots \cdot n}$ div. per $22 n$. Ex. gr。 fil $n$ ) 8 \& $m \infty$, h. e. fi collufori A deficiant 8 lufus, iplique B g, debebitur illi ex pecuniâ hujus portio, $\frac{16.15 \cdot 14 \cdot 13 \cdot 12 \cdot 11 \cdot 10}{\mathrm{I} \cdot 2 \cdot 3 \cdot 4 \cdot 5 \cdot 6 \cdot 7.8} \mathrm{EC}$. div . per $2^{16}$, quæ portio factoribus paribus numeratoris reâpfe octies per 2 divifis, \& fingulis factoribus denominatoris per 2 multiplicatis reducitur ad fradtionem $\frac{1 \cdot 3 \cdot 5 \cdot 7 \cdot 9 \cdot \text { II } \cdot 13 \cdot 15}{2 \cdot 4 \cdot 6 \cdot 8 \cdot 10 \cdot 12 \cdot 14 \cdot 16}$ oriundam ex divifione producti octo primorum imparium per productum totidem primo rum parium numerorum. Ipfa folutio Pafcaliana, quæ Auctori fuo tantopere arrifit.

II. Mod. Alter modus folvendi Problema, qui ex confideratione combinationum immediate fluit, fic habet: Difquiro, quot ludi inftituendi fint, ut unus colluforum (nec nifi unus) numerum fuorum lufuum neceffario compleat ac vincat; videoque requiri $m+n-1$ ludos: etenim abfolutis $m+n-2$ ludis, quorum unus evicerit $m-$ I, alter $n-$ I fic ut utriq; unicus defit proximus lufus alterutrum colluforum infallibiliter victorem reddet . Fingo itaque inftitui ab ipfis $m+n-1$ ludos non quòd paucioribus ludis alterutri contare victoria non polfit quâ femel obtentâ finita eft alea, fed quia ré 


$$
P A R S S E C U N D A \text {. }
$$

fidui ad $m+n-1$ ludi, fi maximè inftituerentur, complendo quoque alterius numero non fufficiunt, eoque victori nequicquam prejudicare poffunt) fingo inquam inftitui à colluforibus $m+n-1$ ludos, \& confidero quod ipfe $\mathrm{A}$ depofito potiatur, quoties accidi: ut alter $B$ aut nullum, aut unum, aut duos, aut tres, \&cc. aut denique $m$ - I horum ludorum, nec plures, evincat; id verò tot cafibus contingere poffe liquet, quot nulliones, uniones, biniones, terniones, $\& x$. ac deniq; combinationes fecundum exponentem $m-1$ in ludis $m+n=I$ continentur . Quare cùm totidem casus habeat $\mathrm{A}$ ad obtinendum depofitum 1 , \& reliquos ad perdendum, fitq; numerus omnium cafuum $2^{m+n-1}$ ceu omnium fimpliciter combinationum; erit ipfus fors per!. Cor. 3. Prop. I. part . æqualis aggregato diftarum combinationum (à nullione ad illas inclufivè, quœe exponente $m-$ I gaudent) divifo per $2^{m+n-1}$, ut fupra. Nota: fi numeri deficientium lufuum $m \& n$ exiguo differant, fatius eft quærere per 5. Coroll. cit. Prop. quantitatem folius lucri, feu quantitatem expeEtationis colluforis A non refpectu totius depofiti fed refpectu folius pecunix alterius. Ex. gr. fit $m \infty n+1$, adeoque $m+n-$ I $\infty 2 n$; denotabitur numerus cafuum, quos habet $\mathrm{A}$ ad obtinendam pecuniam alterius (quæ nunc fit $\mathrm{I}$ ) per numerum combinationum in ludis $2 n$ ab exponente o ufque ad exponentem $n$; \& numerus cafuum, quos habet ad perdendum tantundem, h. e. ad obtinendum - $r$, per numerum reliquarum combinationum fecundùm exponentes fuperiores: quare cùm bini exponentes paralleli, inferior \& fuperior, per Cor. 2 hujus combinationes habeant æque-multas, eoq; fe mutuò deftruant, relinquentur pro exceffu, quo numerus illarum combinationum harum numerum fuperat, folæ combinationes fecundùm exponentem $n$ femiffem ipfius $2 n$, quarum numerus eft $\frac{2 n .2 n-1.2 n-2 \ldots \ldots n+1}{x_{0} \cdot 3 \cdot 4 \cdots n}$, fic ut inde per diatum Coroll. 5. lucrum colluforis A refpectu pecunix alterius emergat $\frac{2 n .2 n-1.2 n-2 \ldots n+1}{1 \cdot 2 \cdot 3 \cdot 4 \cdots n}$ div. per $2^{2 n}$, itidem ut fupra. Neque abfimili modo definietur hoc lucrum in cafu $m \infty n+2$, aut $m \infty n+38 x c$. Reperio autem, quòd dato numero $n$, lucrum ipfius $A$ in cafu $m \infty n+1$, fit ad lucrum illius in cafu $m \infty n+2$, 
in ratione $n+1$ ad $2 n+1 ; \&$ lucrum in cafu $m \infty n+2$, ad lucrum in calu $m \infty 0 n+3$, in ratione $2 n+4$ ad $3 n+4$. \& 2 .

In gratiam eorum, qui fpeculationibus numerorum delectantur, obiter adhuc addo duas proprietates Tabella Prop. 7. Part. I fubnexæ è quarum utrâvis idem quæfitum exfculpi potuiffet. Una eft, quòd numeratores columnæ verticalis tertia int Trigonales $3,6,10,15,21$. \&c . aucti numeratoribus columnx 2 dx $4,5,6$, $7,8,8 x$. quòd numeratores col. quartæ fint Pyramidales 4,10 ,

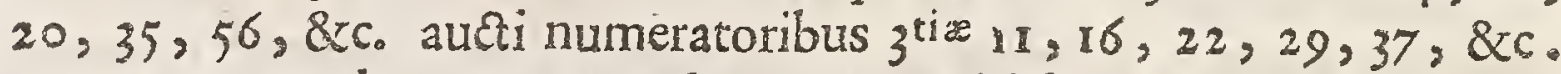
numeratores columnee $5^{\text {ta }}$ Triang. Pyramidales $5,15,35,70,126$, \&x. aucti numeratoribus $4^{\text {tx }} 26,42,64,93,130$, 8xc. incipiendo perpetuò à fecundis terminis. Altera, quòd numeratores col. $3^{\text {tix }}$ fint Trigonales $6,10,15,2$ I, \& c . aucti numeratoribus primæ $\mathrm{I}, \mathrm{I}$, I, I, \& $\&$. numeratores $4^{\text {tx }}$ Pyramidales 10, 20, 35, 56, \& $\mathrm{cc}$. aucti numeratoribus $2^{\mathrm{d}} 5,6,7,8$, \&c. numeratores $5^{\mathrm{i}}$ Triang. Pyramidales $15,35,70,126,8 \mathrm{C}$. aukti numeratoribus $3^{\text {tix }} 16,22$, 29, 37, \&c. initio femper facto â tertiis; atque fic porrò.

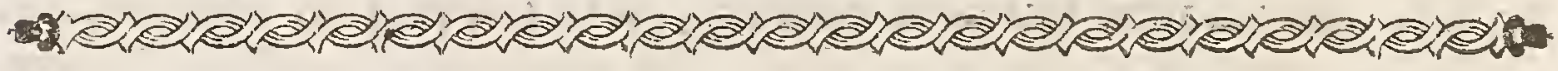

$$
\text { C A P. V. }
$$

Invenire numerum combinationum, cism quelibet rerum combinandarum à cateris quidem diverfa exiftit, attamen Sapius in eâdem combinatione recurrere potest.

TN Combinationibus pracedd, capitum nullam rem fecum ipsâ - jungi, neque adeò plus femel in eâdem combinatione accipi poffe fuppofuimus; nunc verò hane infuper conditionem adjiciemus, ut unaquæque res etiam fecum ipsâ jungi, adeoque in eâdem combinatione ræpiùs redire queat.

Sunto igitur combinandæe hâc ratione literæa $a, b, c, d, 8 x c$. 
Fiant tot feries quot literæ, \& fingularum capita occupent fingul literæ, ceu totidem uniones, ut factum cap. 2 .

Pro binionibus cujusque feriei inveniendis, litera, quæ ejus caput eft; non tantum cum omnibus præcedentibus literis, ut ibi faetum fuit, fed \& fecum ipsâ combinari debet: fic habebitur in primâ ferîe unus binarius $a d$; in fecundâ duo binarii $a b, b b$; in ter. ciâ tres $a c, b c, c c$; in quartâ quatuor $a d, b d, c d, d d$. $8 x c$.

Sic etiam pro formandis ternariis unaquæque litera non modd omnium præcedentium ferierum, fed \& fuæmet feriei binariis adjungenda: ut habeantur, in primâ ferie ternarius unus $a a a$; in $\mathrm{fe}-$ cundâ ternarii tres $a a b, a b b, b b b$; in tertiâ fex $a a c, a b c, b b c, a c c$, $b c c, c c c ;$ \& fic deinceps.

Atque hoc ipfum quoque in combinationibus omnium aliorum exponentium obfervandum; quâ ratione nullam electionum, quæe circa datas res inftitui queunt, præteriri poffe liquidè conftat. En Schema:

$$
\frac{a_{0} a a_{0} a a a_{0}}{b \cdot a b \cdot b b_{0} a a_{0} a b b \cdot b b b}
$$

$c_{0} a c_{+} b c_{0} c c_{0} a a c_{0} a b c . b b c_{0} a c c, b c c, c c c c_{0}$

$d_{0} a d_{0} b d_{0} c d_{0} d d_{0} a d_{0} a b d_{0} b b d_{0} a c d_{0} b c d_{0} c c d_{0} a d d_{0} b d d_{0} c d d_{0} d d d_{0}$

Hinc verò haud difficulter colligimus, uniones omnium ferien rum rurfus efficere feriem monadum, biniones feriem lateralium, terniones trigonalium, cæterasque combinationes majorum exponentium itidem conftituere feries aliorum figuratorum altioris generis, prorfus ut combinationes præcedd. capitum, hoc folo cum difcrimine, quòd ibi feries à cyphris, hîc ab ipfis fratim unitatibus incipi= ant; unde ff in Tabulam redigantur, hanc difpofitionem pra fe ferent; 
Numeri Rerum Combinandarum.

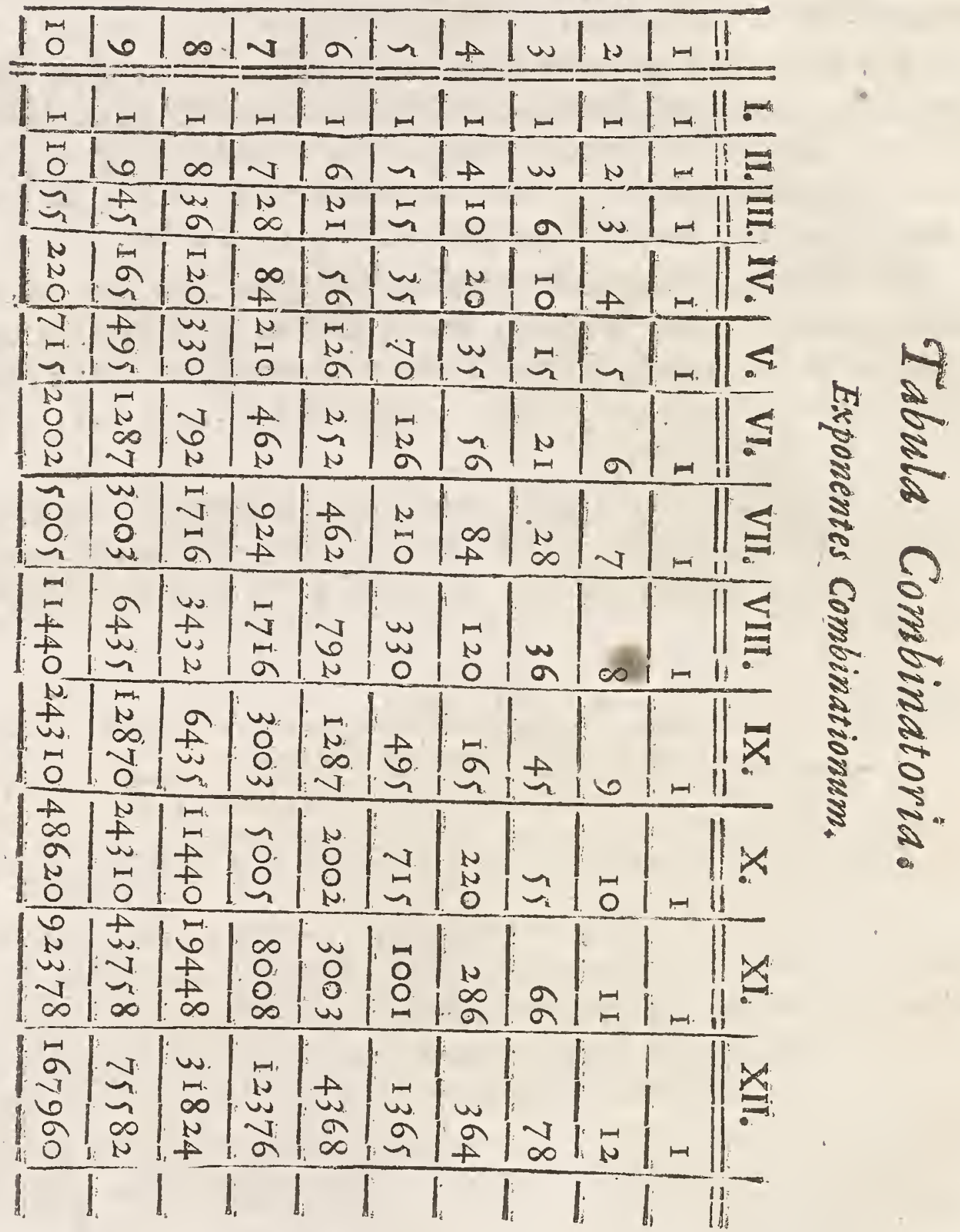

Tabulæ autem ita difpofitæ duas pracipuè proprietates notare aenvenit: 1. Quod columnæ transverfa congruunt verticalibus, prima primæ, fecunda lecundæ, tertia tertiæ, \&c. 2. Quòd imtis duabus columnis contiguis, five verticalibus five transverfis. 


\section{$P A R S$ SECUNDA.}

terminorum numero æqualium, fumma terminorum columnæ pra cedentis æquatur poftremo sermino columnæe fequentis.

E quibus facile eft, invenire fummam terminorum feriei cut jusvis, adeoque $\&$ numerum combinationum fecundùm exponen tem quemcunque. Nam fi numerus terminorum, hoc eft, rerum combinandatum dicatur $n$, crit fumma unionum feu terminorum feriei primæ, hoc eft, ultimus terminus feriei fecundæ, itidem $n$. Intelligatur feriei fecundæ præfixa cyphra, ut numerus terminorum fiat $n+1 ;$ per cujus dimidium fi multiplicetur terminus ultimus $n$, erit productum $\frac{n \cdot n+1}{1 \cdot 2}$ fumma binionum feù terminorum fecundæ feriei, per 12 propr. cap. 3 ; adeoque \& poftremus terminus tertiæ, per 2 propr. hujus.

Intelligantur feriei tertiæ præfixæ duæ cyphræ, fietque nume. rus terminorum $n+2$; in cujus trientem fi ducatur terminus ultimus modd inventus $\frac{n \cdot n+1}{1 \cdot 2}$ exurget $\frac{n \cdot n+1 \cdot n+2}{I_{1} \cdot 2 \cdot 3}$. fumma ternionum feu terminorum feriei tertiæ, \& fimul etiam poftremus 4 tæ per easdem.

Eâdem ratione fumma terminorum quartæ feriei feu quaternionum invenitur $\frac{n \cdot n+1 \cdot n+2 \cdot n+3}{1 \cdot 2 \cdot 3 \cdot 4}$, quintæ ferici feu quinionum $\frac{n \cdot n+1 \cdot n+2 \cdot n+3 \cdot n+4}{1 \cdot 2 \cdot 3 \cdot 4 \cdot 5} ; \&$ in genere fumma terminorum feriei $c, \dot{f}_{\text {feu }}$ combinationum fecundùm expónentem $c$, reperitur $\frac{n \cdot n+1 \cdot n+2 \cdot n+3 \cdots \cdots n+c-1}{1 \cdot 2 \cdot 3 \cdot 4 ! \cdots c}$. Ubi notandum, quòd exiftente $c>n$ factores fractionis poffunt abbreviari dividendo numeratorem $\&$ denominatorem per $n . n+1 . n+2 \ldots . c$, ut habeatur $\frac{c+1 \cdot c+2 \cdot c+3 \ldots \cdot c \pm n-1}{1 \cdot 2 \cdot 3 \cdot 4 \cdots \cdots n-1} ;$ \& quia hæc fractio ad formulam ex= acta fimul indicare debet fummam $c+1$ terminorum feriei $n-1$, fequitur quòd aggregatum $n$ terminorum in ferie $c$ femper æquetur aggregato $c+1$ terminorum in ferie $n-1$; qua alia non inelegans hujus Tabella proprietas eft. Inde verò refultat fequens

$$
\text { P } 2
$$

Regula. 
pro inveniendis combinationibus fecmoin datum expo nentem, cum eadem res candem combinationem cepius ingredi potest.

Flant dux Progreflones "Arithmetica afcendentes I altera à numero rerum combinandarum, ab unita. te altera, quarum communis exceffus fit unitas, \& u. traque tot terminorum, quot unitates habet combinationis exponens: tum factum ex ductu terminorum prioris progreflionis dividatur per factum ex duetu terminorum pofterioris; eritque quotiens quxfita combinationum fecundùm datum exponentem multitudo. Hoc fenfu numerus quaternionum in 10 diverfis rebus contentorum eft $\frac{10 \cdot 11 \cdot 12.13}{1.2 \cdot 3 \cdot 4} \infty \frac{17160}{24} \infty 715$.

Nota : Si combinationis exponens fit major rerum numero (guod utique fieri poffe in prafente hypothefi liquet) compendiofius erit, inchoari priorem progreffionem $a b$ hoc exponente unitate aucto, \& utramque fieri terminorum uno pauciorum, quàm fune datæres. Ita numerus combinationum fecundùm, exponentem 10 in:

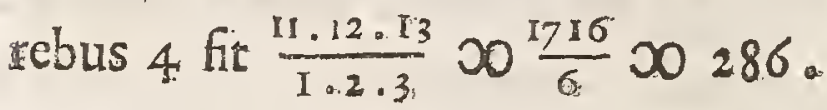

Sed \& numerum combinationum fecundum plures exponentes: ab unitate fe aliquoufque confequentes, hoc eft, fummam ferierum: quotcunque verticalium, nihilo difficiliùs venari licet: Cùm enim ex. gr. Io primi termini 4 primarum columnarum verticalium iidem fint qui 4 primi termini 10 primarum transverfarum atque infuper fumma hoium terminorum æquentur undecim terminis $4^{\text {tæ }}$ columnæ verticalis demto folo primo feu unitate (fingulæ fcil. fummæ fingulis terminis, utex propr. 2 dâ Tabellæ liquet) manifefum eft, etiam o primos terminos 4 primarum columnarum verticalium, h. e. fum 解am omnium unionum, binionum, ternionum \& quaternionuni fumencorum ex rebus 10 , unitate deficere ab undecim primis termi- 
nis columne $4^{\text {tx }}$, hoc eft, à numero quaternionum fumendorum ex rebus 11 , hoc eft, à numero combinationum fumendaram ex rebus unà pluribus fecundùn datorarm exponentium maximum. Quod idem etiam fic ofendo: Singulos quaterniones fumendos ex rebus undecim res undecima vel non ingreditur planè, vel ingreditur femel, vel bis, vel ter, vel quater; fed manifeftum ef, quaterniones, quos res undecima non ingreditur, effe illos ipfos quos decem reliquæ inter fe formare poffunt; nec minus perficicuum, quòd numerus illorum quos femel tantum dicta res undecima ingreditur, equari debeat numero ternionurn fumendorum ex Io reliquis; ficur etiam numerus illorum "quos bis ingreditur, numero binionum; \& quos ter ingreditur, numero unionum: quandoguidem ternionibus femel, binionibus bis, \& unionibus ter adjuncta quaterniones efficit: prætereaque conftar, quòd unus fit quaternio, quem res undecima quater repetita conftituit. Unde concluditur, numerum quaternionum comprehenforum in rebus $\mathrm{I}$, hoc eft, unâ pluribus quàm funt datæ res, unitate excedere omnes fimul uniones, biniones, terniones \& quaterniones rerum datarum decem; nifi his quoque nulliom nem accenfere velimus, quo cafu ipfis æquabirur.

Quapropter, cùm exiftente numero rerum datarum n, $8 x$ exponentium maximo $c$, numerus combinationum hujus exponentis in rebus $n+1$ per $R$ eg. cap. 4. inveniatur

$\frac{n+1 n+2 \cdot n+3 \cdot n+4 \ldots n+c}{1 \cdot 2 \cdot 3 \cdot 4 \ldots \ldots c}$, fiet numerus combinationum res rum $n$ fecundum omnes exponentes $\mathrm{ab}$ I ufque ad $c$ (utpote unitate ab illo deficiens) $\frac{n+1 . s+2 \cdot n+3 \cdot n+4 \ldots \ldots n+c}{1 \cdot 2 \cdot 3 \cdot 4 \ldots c}-1$. Quòd fic majus lit ipfon, hoc eft, exponentium maximus major rexum num mero, poterunt fractionis termini eo calu dividi per $n+1+n+2 . n+3 \cdot .+. \cdot c$, ac proinde quantitas compendiofiùs exprim $\mathrm{mi}_{2}$ ita $\frac{\epsilon+1 \cdot c+2 \cdot c+3 \ldots c t+n}{\mathrm{I}_{0} \cdot 3 \cdot 4 \cdot \ldots n}-\mathrm{I}$. Hinc talis emergit 


\section{Regula.}

pro invenienais Combinationibus fecundium plures expomentes ab unitate fe confequentes:

Conftituantur duæ Progreffiones Arithmetica afcendentes, altera à numero rerum combinandarum unitate aucto, ab ipsâ unitate altera, quarum communis exceffus fit unitas, \& utraque tot terminorum, quot unitatibus conftat exponentium maximus. (Quòd fi tamen exponentium maximus major fit rerum numero, fatiùs eft, priorem inchoari ab hoc exponente unitate aucto, \& utramque fieri tot terminorum, quot funt data res.) Tum factum ex ductu terminorum prioris progreffionis dividatur perfactum ex ductu terminorum pofterioris; eritque quotiens quæfita combinationum muititudo, fi fill. ipfum nullionem unà comprehenfum velis; fin velis exclufum, quotiens unitate multatus quafitum indicabit. Ita numerus omnium cum nullione unionum, binionum, ternïonum \& quaternionum in rebus ro eft $\frac{11.12 \cdot 13 \cdot 14}{1.2 \cdot 3 \cdot 4} \infty \frac{24024}{24} \infty \mathrm{roor}$, in rebus tantum tribus $\frac{5.6 .7}{\mathrm{I} .2 .3} \infty \frac{210}{6} \infty 35$; at nullione exclufo numerùs combinationum eft ibi 1000, hîc 34 .

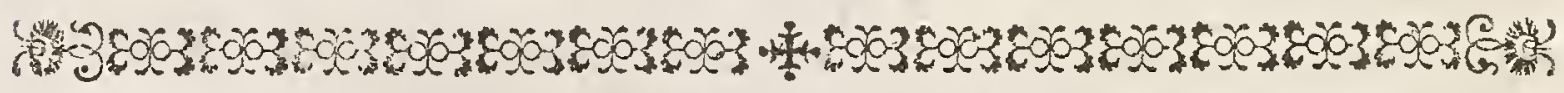

$$
\text { G A PU T VI. }
$$

Invenire numerum combinationum, cumnonnulle rerum combinandarum junt exdem, nulla verò Sapius in combinatione repeti debet, quàm ipla reperitur in toto rerum numero. 


\section{$P A R S S E C U N D A$.}

$T$ præced, capite licitum erat, quamlibet datarum diverfarum 1 rerum fecum ipsâ conjungere toties in combinatione, quot unitates habet ejus exponens; quo pacto dari poteft combinatio fecundùm lexponentem guemlibet, quæe ex unấ folâ re frepiùs repetitâ confret. Alia quæeftio eft, cùm determinatus eft numerus vicium, quibus unaquæque rerum datarum fecum ipsâ jungi poteft : ut cùm combinandæe veniunt literæe $a, b, c, d$, eâ lege, ut in nullầ combinatione litera a freiùs quàm quinquies, $b$ quàm quater, $c$ quàm ter, \& $d$ quàm bis repetatur; ubi manifeftum eft, nullam earum, combinationum, quarum exponens quinarium fuperat, ex unâ folấ literâ conflari poffe.

Tantundem autem eft, fi quatuor iftæ literæ dißâ lege inter $f e$ combinandæ funt, acfi datæ forent literæ quatuordecim, interque illas quinque $a$, quatuor $b$, tria $c \&$ duo $d$, modis omnibus inter fe combinandæe, fed eâ condirione, ut nulla fxpiùs in combinatione occurrat, quàm ipfa reperitur in toto rerum numero; hoc eft, acfi data foret quantitas algebraica a a a a ab666cocdd five $a^{5} b^{4} c^{3} d^{2}$, cujus omnes divifores quærerentur; quandoquidem divifores alicujus quantitatis aliter non exprimuntur; nifi per totiden combinationes factorum ejus: adeò ut doctrina hujus capitis præcipuè pro inveniendo numero diviforum datre alicujus quantitatis infervire: queat.

Liquet primò, unius literæe a tot clectiones aut divifores dari poffe, quoties ipfa in rerum numero occurrit, feu quot ipfi in quantitate tribuuntur dimenfiones; adeoque fi nullionem electionibus vell unitatem diviforibus accenfere quoque velis, unam dari electionem: aut diviforem ampliùs, putà fex: $1, a, a d, a^{3}, a^{4}, a^{5}$.

Deinde, filitera $b$ accedat, conftat illam in fingulas fex precedentium electionum aut diviforum duci poffe; unde totidem aliæ nafcuntur electiones; $b, a b, a a b, a^{3} b, a^{4} b, a^{5} b$. Quibus fi alterum $b$ adjungas, fex novas electiones habebis; $b b, a b b, a a b b$, $a^{3} b b, \& c$. Et his fi tertium $b$ applicetur, fex alize electiones emergent, iterumque fex aliæ, fi his applicetur quartum: adeò ut liteta $b$ toties fe $z$ novas electiones fuppeditet, quoties ip $f$ in dato rerum wumero occurrit, feu quot ipfa in propofita quantitate dimenfones: 
obtinet; nimirum quater fex electiones; quas omnes $b$ ingreditur ex confruatione. Unde fi his fex primas electiones, quas 6 non ingreditur, annnumeres, habebis in univerfum quinquies fex five $30 \mathrm{e}$. lectiones.

In fingulas porrò harum 30 electionum feu diviforum fi tertia litera $c$ ducatur, prodibunt 30 novæ electiones; $\&$ fi prodituris eadem litera adjungatur denuó, prodibunt 30 aliæ; iterumque 30 aliæ, fi applicetur tertium: unde ter 30 electiones exurgunt, in quibus $0=$ mnibus lit. $c$ reperitur. Quibus proin fi addas præcedentes 30 , in quibus illa non reperitur, numerabis in totum quater 30 five I20 eleationes.

Tandem fi fingulas harum 120 electionum vel diviforum eâdem ratione per quartam literam $d$ ob duas ejus dimenfiones bis multiplices, pioduces bis 120 novas electiones, qux omnes literam $d$ continent; adeoque (computatis unà prioribus 120 quæ eandem non continent) omnino ter 120 five 360 eleftiones. Er tantus quoque in univerfum diviforum numerus exiftit propolite quantitatis a b $^{4} 4$ $c^{3} d^{2}$, dummodò, quòd hîc femper fubintelligendum eft, literæ $a, b, c$ \& $d$ totidem primos ab unitate $\&$ à fe invicem diverfos numeros indigitent. Patet autem, acceflione cujufque literæ numerum omnium precedentium eledionum vel diviforum toties multiplicari, \&. femel ampliùs, quot literæ accedentis fuerint dimenfiones. Quo obfervato ratio percipi poreft fequentis Regula:

$$
\text { Regula }
$$

pro inveftigando numero diviforum alicujus quantitatis date, five numero combinationum rerum plu-

rissm, quarum nonnulle funt exdem:

Jumeros dimenfionum, quibus conftant fingula 1 diverfa literæ quantitatem propofitam conftituentes, unitate auge, ficque auctos in fe invicem ducito: erit productum eorum continuum numerus omnium divifo- 
diviforum datæ quantitatis, feu omnium combination um, quarum litera illam conftituentes funt capaces. Ubi tamen unitatem demere memineris, fi nullionem è combinationibus aut unitatem è diviforibus expunigam velis. Ex. gro In quantitate propofitâ $a^{5} b^{4} c^{3} d^{2}$ literze $a, b, c, d$ dimenfiones habent $5,4,3,2$, qui numeri unitate figillatim aucti efficiunt $6,5,4,3$, hi verò in fe ducti 360 numerum osnnium cum nullione combinationum, feu omnitum cum unitate diviforum quantitatis datæ.

Nota: Si numerus diverfarum literarum $a, b, c, d$ datam quanEitatem conftituentium fit $n$, omnesque literæ æqquali dimenfionum numero gaudeant, qui fit $p$; fiet per regulam numerus combinationum vel diviforum $\overline{p+1} n$. Et fpecialiùs fi $p \infty \mathrm{I}$, hoc eft, fi datæ guantitatis fingulæ literæ unam tantim dimenfionem habent, aut fi datæ res combinandæ omnes funt diverfæ, numerus diviforum vel combinationum determinatur ad $2^{n}$, reditque hypothefis capitis fecundi; cujus proinde folutio cum iftâ conferri poterit, ut utriusque convenientia appareat.

Qui autem ad difcurfum prefentis capitis vel leviter attenderit; facile porro fi opus determinabit, in quot electionibus vel diviforibus quælibet res aut litera reperiatur. Nam fi quæratur ex . gr . quiot divifores propofitæ quantitatis $a^{5} b^{4} c^{3} d^{2}$ ingrediatur litera $a$, indagandum folummodò eft, quot divifores inclusâ unitate admittat reliqua quantitas $b^{4} c^{3} d^{2}$; his enim (cim in iis a non reperiatur) filiteram iftam adjungas femel, habebis omnes divifores, in quibus \& reperitur unius dimenfionis: \& fi adjungas bis, habebis omnes eos in quibus eft duarum dimenfionum: $8 \mathrm{r}$. fi ter, illos in quibus trium \&c. unde concluditur, tot effe divifores, in quibus litera quælibet fecundùm eundem dimenfionum numerum reperitur, quot reliqua litera in univerfum divifores admittunt : cum igitur quantitas $b^{4} c^{3} d^{2}$ per regulam præced. recipiat 5.4.3 00 60 divifores (connumerando illis unitatem) complectetur etiam quantitas $a^{5} b^{4} c^{3} d^{2}$ divifores totidem, in quibus a unam obtinet dimenfionem, totidemque in quibus duas, tres \&c. dimenfiones; adeoque ob quinque dimenfiones ipfius a quinquies 60 five 300 divifores obtinebit, in 
quibus ifta litera utcunque fecundùm aliquem dimenfonum numeàrum occurrit: Neque diffcilius definitur numerus electionum aut diviforum, in quibus reperiantur ex. gr. dua litere, a cum dua bus $\&$ cum tribus dimenfonibus; nam fingulis diviforibus re. lique quantitatis $c^{3} d^{2}$ (quorum numerus per regulam invenirus $4 \cdot 30012)$ adjungas $a^{2} b^{3}$, palam ef oriri tocidem divifores opta tae conditionis, nec dari plures 2 : \& fic in aliis.

Plus diffcultatis babere forfan videbitur quaftio, qux numerum inire iubet diviform omnium ex xqu-multis dimenfonibus: confantium, hoc eft, combinationum fecundum fingulos expom nentes feorfin. Adid perquirendum methodum adhibeo, fimilem. illi, quâ fupra in part. I, polt prop. 9 ad numeros jactuum in teffe. ris inveftigandos fui ufus: Scribo ordine omnes exponentes comm. binationum feu omnes dimenfionum numeros, quarum propofica quantitas capax eft, nempe aे o uqque ad 14 pro quantitate $a^{5} b^{4} c^{3} d^{2}$. Sub horum primis eolloco fex unitates, unâ vid. plures quàm ef numerus dimenfionum primæ literæ, quibus fubjungo fex alias um nitates, \& his rurfum fex alias \&c. donec habeam feries unitatum: łnâ plures quàm eft numerus dimenfionum fecundæ literæ, fed fin gulas feries uno gradu dextrorfum promoveo, atque tum addo qua perpendiculariter in eodem gradu fibi refpondent unitates, ut fiant numeri $1,2,3,4,8 \mathrm{c}$. Horum deinde numerorum iterum fe. ries unâ plures contituo quàm eft numerus dimenfonum tertiz lïteræ, illas fimiliter gradatim ad dextram promovendo, \& poltmo. dùm addendo, ut prodeant numeri I. $3,6,10,14.8 \mathrm{c}$. quorum numerorum mox rurfus ordines uno plures, quàm eft numerus di. menfionum quartre, gradatim pono $\&$ addo, continuaturus eoden tenore ulterius, fi plures litera adeffento. En Tabulan: 


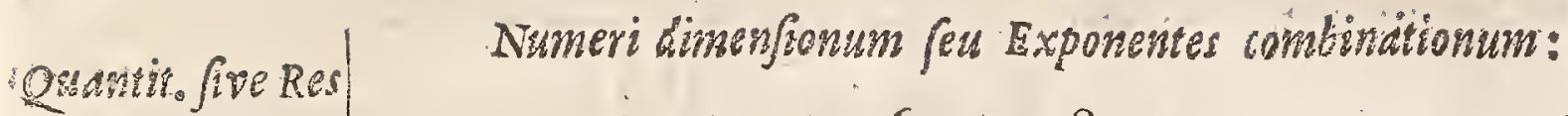

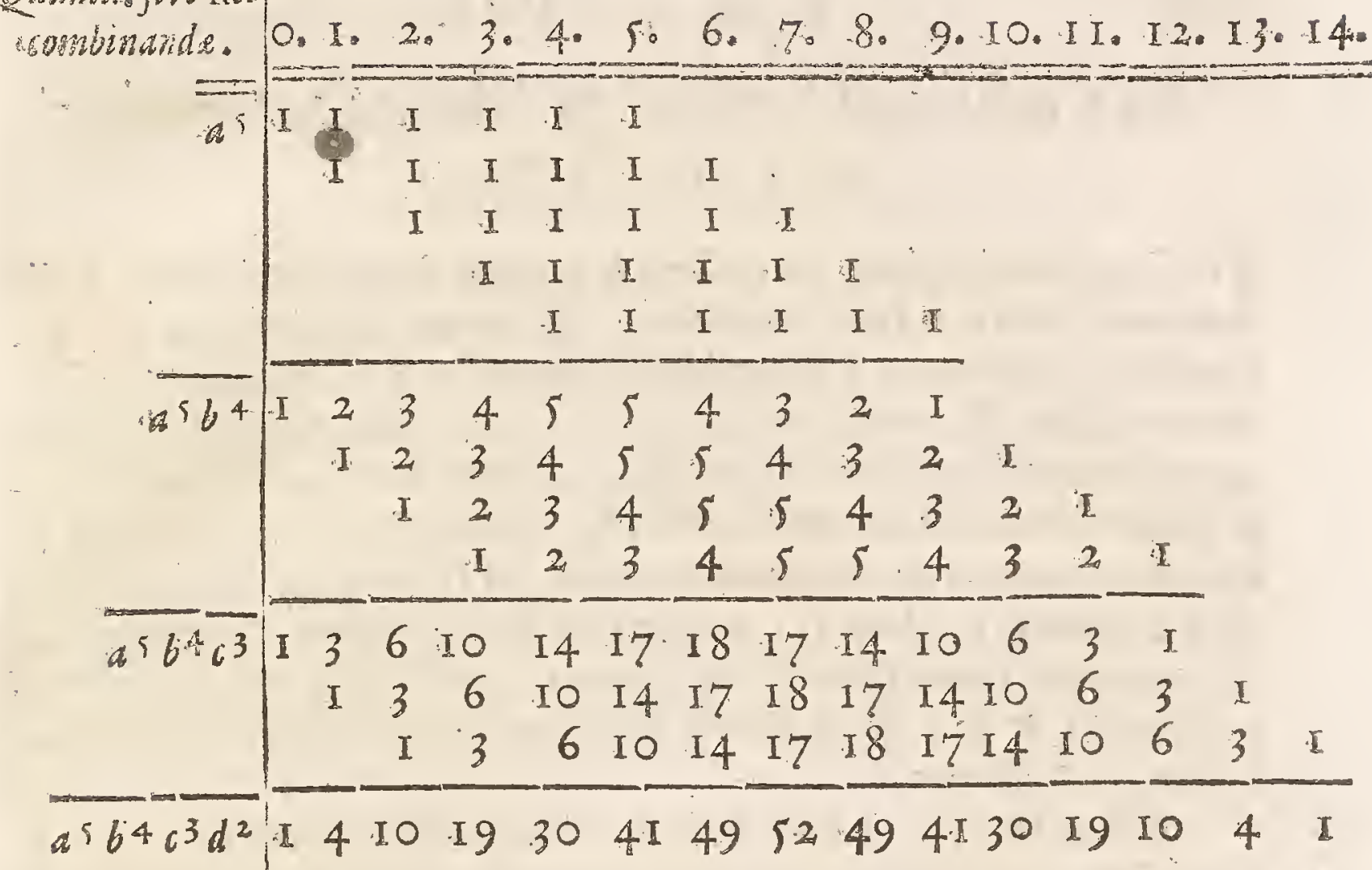

uo fåso qui ex additione ultimâ refultant numeri finguli, denotabunt multitudinem diviforum vel combinationum fecundùm finguhos dimenfronum numeros feu exponentes fupra fcriptos. Sic indicante Tabellâ reperio, quòd quantitas propofita habeat unum diviforem nullius, 4 divifores unius, 10 duarum, 19 trium $\& c$. dimenfonum, five, quod habeat unum nullionem, 4 uniones, to biniomes, 19 terniones, \& fic porrò; qui omnes collective fumti fumman conficiunt 360, ut oportebat. Qui rationem fimilis operationis pro tefferis intellexerit, rationem hujus quoque non difficulter capiet.

Plura de his, diviforibus prafertim (at nimium $a b$ infticuto aliena) legere eft in 5 prioribus fectionibus mifrellaneis Exercit. Math. Fr. Schoorenii, nec non cap. $3 \& 4$ Differt. Joh. Wallifii de combinationibus Tractatui ejus de Algebrâ fubnexæ. Quos Auctotres adeat qui volet. Nos properamus ad alia.

$$
\text { Q } 2 \text { CAP. }
$$




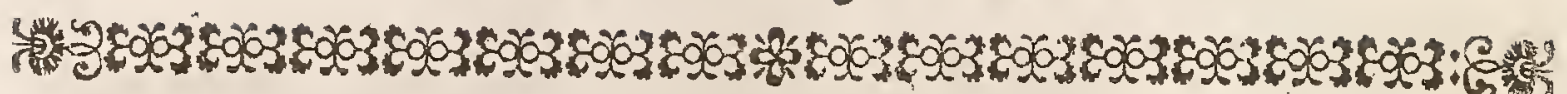

$$
\text { C A P. VII. }
$$

\section{De Combinationibus Ef Permutationibus mixtim pectatis.}

N Combinationibus, de quibus hucufque fermo nobis fuit, nulla Lordinis frtûsque ratio habebatur, \& unum eundemque ex. $\mathrm{gr}$ 。 ternarium conftituere intelligebantur literæ $a, b, c$, quocunq; friberentur ordine, feu $a b c$, feu $a c b$, feu $b a c \& c$. Sed quandoque præter complexionum varietatem ipfa quoq; ordinis \& difpofitionis variatio in rebus combinandis atteridenda eft; quemadmodum fieri folet in vocibus \& numeris: Alia enim vox eft vel fyllaba $a b, \&$ alia $b a ; \&$ alius numerus 12 , alius 21 ; quanquam eædem literæ eædemque notæ numerales concurrant ad formandas tum fyllabas $a b \& b a$, tum numeros 12 \& 2I; fic ut totum difcrimen à diversâ earundem difpofitione proficifcatur.

Reftat itaque. ut hoc \& fequentibus capitibus combinationum \& permutationú doetrinam mixtim contemplemur, indagando, quàm. variè plures diverfær res, aut quarum nonnullæ funt eædem, \& comm binari fecum invicem, \& combinatæ inter fe transponi poffint, idq nunc fecundùm unum exponentem, nunc fecundùm plures " \& modò. fic, ut nulla rerum datarum fecum ipfa combinari debeat, modo fic ut qualibet etiam fecum ipfa combinari, pluriesque adeò in eâdem combinatione repeti queat.

1. Invenire numerum ele fionsus plurium diverfarum re. rum, quarum nulla fecum ipla combinari debes, Jecundium unum exponentem.

Solutio quæftionis ex præcedentibus promta eft \& facilis: Si multitudo rerum combinandarum dicitur $n$, atquie exponens combinationis $c$, numerus combinationum neglectâ confideratione ordinis inter res combinatas eft $\frac{n \cdot n-1 \cdot n-2 \cdot n-3 \ldots \cdots n-c+I}{I \cdot 2 \cdot 3 \cdot 4 \ldots \ldots c}$ per cap. 4. Et quia fingula hæ combinationes ex hypoth, conftant re 


$$
P A H S \text { SECUNDA. }
$$

bus diverfis 6 , quæ per cap. $I$. ordinem inter fe variare poffunt 1. $2.3 .4 \ldots . .6$ vicibus, fequitur, fi $\&$ ordinis in combinationibus habeatur ratio, earum numerum totidem quoque vicibus majorem fore quàm ubi hæc confideratio negligitur, ac proinde æequari $\frac{n . n-1 \cdot n-2 \cdot n-3 \cdot \ldots n-c+1}{1 \cdot 2 \cdot 3 \cdot 4 \cdot \cdots \cdot c}$ in $1.2 \cdot 3 \cdot 4 \ldots \ldots c \infty$ $n+n-1 \cdot n-2 \cdot n-3 \ldots \ldots n-6+1 ;$ id quod fequentem Regulam fuggerit:

\section{Regula}

pro inveniendo numero combinationum fecundium datum exponentem:

COnftituatur Progreffio Arithmetica, cujus communis differentia fit $\mathrm{I}$, incipiens à numero rerum combinandarum, \& defcendens per tot terminos, quot unitates habet combinationis exponens; eritque factum ex ductu terminorum ejus quafita combinationum multitudo. Ex. gr. Quaterniones omnes in rebus 10, iique modis omnibus transpofiti funt 10.9.8.7 00 5040.

Confectaris: I. Si combinationis exponens ipfr rerum numero æquatur, tantundem eft, acfi fimplices permutationes rerum datarum quærerentur; quippe cùm omnes femper frmul accipiendæ, quæ hypothefis eft capitis 1 : eritque tum

$n \cdot n-\mathrm{I} . n-2 \cdot n-3 \ldots . . n-6+\mathbb{I} \infty 0 n \cdot n-\mathbb{I} \cdot n-2 \cdot n-3 \ldots . . \mathrm{I}$ $\infty 1.2 \cdot 3 \cdot 4 \ldots n$, quod convenit cum regulâ cap. 1 .

2. Omnes res fimul acceptæ, hoc eft, combinatæ fecundùm exponentem æequalem rerum multitudini, tot recipiunt permutationes ordinis, quot recipiunt earundem combinationes omnes fecundùm exponentem unitate minorem: Ita res 5 toties difponi poffunt diverímodè quinæa, quoties quaternæ; nam permutationes omnes quinque rerum funt $1.2 .3,4.5$ Ceu $5 \cdot 4 \cdot 3 \cdot 2$. I per regulam huju $\&$ primi capitis; \& permatationes quaternionum omnium fun $_{\mathfrak{t}}$ 
5. $4 \cdot 3 \cdot 2$ per eandem hanc regulam: eft verò $5 \cdot 4 \cdot 3 \cdot 220$ $5.4 \cdot 3 \cdot 2 \cdot x$. whde liquet \&Cc.

3. Summanionum \& binionum in rebus quotlibet $x$ quatur gudraco numeri rerum: pofro namque rerum numero $n$, wnionum mumerus juxta regulam eft $n$, \& binionum $n . n-1 x n n-n$. quorum fumma $n+n n-n \infty n n$. Sic ex. gr. colligere poffum mas, 9 notas numerales fignificativas acceptas fingulas \& binas mo dis omabus conftuere novies 9 feu 81 diverfos numeros; rotidem 6. ab a ad 100 reâple invenimus non plures, fi refecemus illos, quos vel cyphra ingreditur, vel idem geminatus charatter confituit.

4. Numerus combinationum fecundùm exponentem quem Ibet aquatur numero permutationum rerum totidem, quarum to frat eadem, quot unitates habet exponentis parallelus, reliquarum verò fingulie à fingulis divenfa. Sic tot funt ternarii in rebus 8. quot permutationes rerum 8 , quarum funt eadem, nempe 8.7 .6

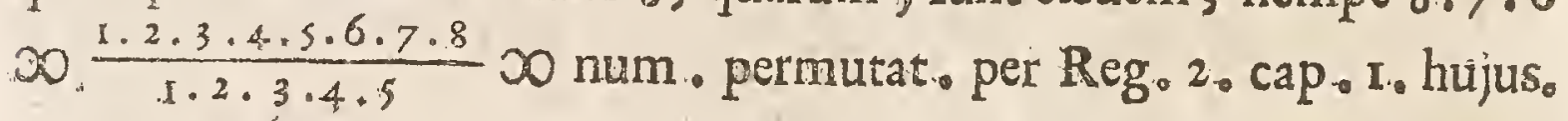

2. Invenire numerum electionum plurium diverfarum re= rum. quarum nulla fecum ip a combinanda eft. abm - Colutè feu fecundum omnes exponentes.

Si addantur numeri combinationum per praced regulam fecundùm fingulos exponentes feorfim quafiti obtinebitur numeris omnium combinationum abfolutè. Idem tamen paulò expeditiùs inveniri potef, fi attendatur ad proprietatem aliquam non contem= wendam, quæ ex collatis duobus ejusmodi numeris elicitur.

Sint primò combinanda res quatuor: /Conftat per praced. reg. numerum unionum effe 4 , binionum 4.3 , ternionum $4 \cdot 3 \cdot 2$, quaternionum denique $4 \cdot 3 \cdot 2.1$; \& propterea numerum omnium combinationum ab folute $4+4 \cdot 3+4 \cdot 3 \cdot 2+4 \cdot 3 \cdot 2 \cdot 1$.

Sint dein combinanda res guinque; ubi fmili modo colligiru, fummam unionum, binionum, ternionum, quaternionum $\&$ grinionum, fer numerum omnium abfolute combinationum effe $5+5 \cdot 4+5 \cdot 4 \cdot 3+5 \cdot 4 \cdot 3 \cdot 2+5 \cdot 4 \cdot 3 \cdot 2+1$. ER verò $5+5 \cdot 4$ t. 
$\overline{1+4+4 \cdot 3+4 \cdot 3 \cdot 2+4 \cdot 3 \cdot 2 \cdot 1}$, hoc eft, numerus combinationum rerum 5 quinquies major numero combinationum rerum 4 unitate aucto. Unde difcimus, numerum combinationum in rebus quotw cunque datis toties excedere numerum combinationum in rebus unat paucioribus unitate auctum, quot funt datæ res. (Intellige, non: computato utroque nullione.)

Quocirca cùm unius rei unica fit electio, addito I ad' I fummâque 2 multiplicatâ per 2 , erit prodůtum 4 numerus omnium combinationum in rebus duabus.

Rurfus addito I ad 4, fummâque 5 multiplicatâ per 3 , fignifio cabit productum 5 numerum combinationum in rebus tribus.

Similiter addito 1 ad 15 , fummâque 16 ductâ in 4 , exurgite 64. numerus combinationum in rebus quatuor .

Hunc unitate auctum fi ducas in 5 , habebis omnes combina tiones rerum quinque; atque ita porro in infinitum, ut ex fequenti lăterculo apparet.

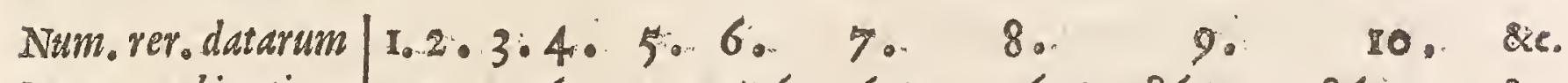

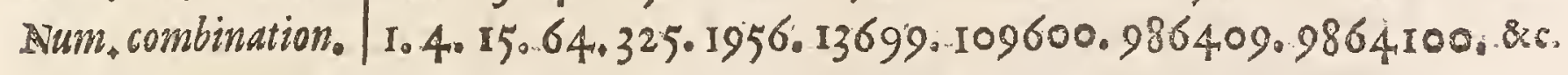

Hâc ratione colligimus, 9 notas numerales, fi fumantur fingulæ; binæ, ternæ, \&xc. \& tandem novenæ; ac transponantur modis omnibns, recipere 986409 mutationes, totidemque proin diverfos numeros formari poffe, in grorum nullo character aliquis plis unầ vice occurrat;

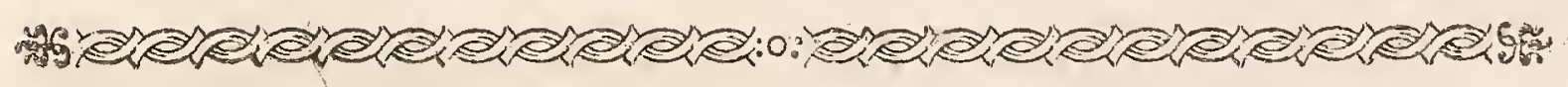

$$
\text { C. A. P. U T VIII. }
$$

3. Invenire numerum electionum plurium: diverfarum rerum, cum qualibet earum etiam fecum ipja combinari poteft, Jecundium unum exponentem. 
$N$ cap. praced, quafutus fuit combinationum numerus, quando 悬 nulla res plus femel in eâdem combinatione repeti poterat. Nunc fupponemus, rem quamlibet etiam fecum ipsâ jungi, adeoque bis: ter, quater pluriesvé in eâdem combinatione repeti poffe; inveltigabimusque, quis hoc fenfu futurus fit combinationum numerus, fi in illis etiam, ut anteà, attendatur ordinis varietas .

Sunto datæ res aut literæ quotlibet $a, b, c, d, \& c$. quarum numerus fit $m$, patet illarum tot uniones poffe accipi, quot funt $d z=$ tae res, putà $m$.

Applicetur is prima litera $a$, præponendo illam fingulis, ita: $a a, a b, a c, a d \& c$. \& habentur biniones, qui omnes incipiunt $a b a$. quorumque numerus æquari debet ipfi rerum numero $m$.

Deinde applicetur iisdem fecunda $b$, præfigendo illam fingulis. ut fiant $b a, b b, b c, b d \& c$. qui omnes funt biniones à $b$ incipientes, quorum proinde numerus itidem ipfi $m$ æequatur.

Simili ratione tertia $c, \&$ quarta $d$, cæteræque fi plures fuerint, fingulis datarum rerum femel præfigantur, \& exurgent novi biniones, quorum nonnulli incipiunt à literâ $c$, alii à $d$, alii à cæeterarum aliquấ; corum verò numerus, qui ab eâdem literâ incipiunt, perpetuò ipfi m aquabitur. Quo pacto manifeftum omnes in univerfum biniones repertos effe, eosque modis omnibus inter fe transpofitos; quorum proinde numerus toties fuperabit ipfum rerum numerum, quot funt datæ res: quarum cum hic fit $m$, binionum omnium numerus erit $m m$.

His verò binionibus $f 1$ denuò applicare pergas datas res, unicuique illorum fingulas has præponendo, formabis omnes ternionum ordines $a a a, a b b, a b c, a d d, a b a, a b b, \& c$. quorum qui ab eâdem literâ incipiunt femper tot exiftunt, quot funt inventi biniones; $0=$ mniumque proin numerus binionum numerum toties excedet quo fuerint datæ res, ac confequenter erit $\mathrm{m}^{3}$.

Similiter fr cunctis ternionibus identidem præfigi intelliganture ingulæ literæ, elicientur omnes quaterniones poffibiles, quorum per confequens numerus ternionum numerum rurfus $m$ yicibus fuperabit, eritque $m^{4}$. Atque 


$$
\text { \$RS SECUNDA. }
$$

Atq; ita apparet, combinationum numerum fectndìm quemcunque exponentem perpetuò $m$ vicibus fuperandum effe à numero combinationum fecundum exponentem proxime fequentem: fcilicet cùn numerus quaternionum fit $m^{4}$, erit quinionum numerus $m^{5}$, fenionum $m^{6}$, \& generaliter fi exponens dicatur $n$, numerus combinationum fecundum hunc exponentem erit $m n$. Unde expedita habetur

$$
\text { Regula }
$$

pro inveniendo numero combinationum modis onsibus permutatarum fecundum datum exponentem, cium qualibet res etiam fecum ip a combinati
potef.

Atus rerum numerus elevetur ad eam poteftatem, cujus index eft datus combinationis exponens; \& habetur quafitum. Ex. gr. Onnes novem notarum numeralium quaternarii fumti \& difpofiti modis omnibus exhibent $9^{4} \infty 0$

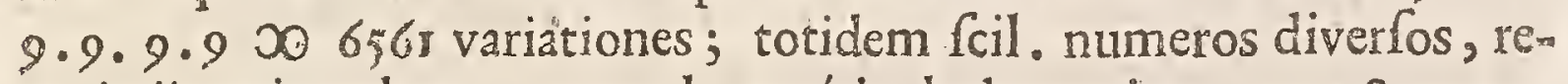
ectis iis qui cyphram unam pluresvé includunt, inter 1000810000 (limites eorum qui 4 characteribus fcribuntur) interiici neceffe eft. Sic 4 vocales A.E.I.O, quibus quadruplex differentia propofitionum fecundùm quantitatem \& qualitatem in Logicis innuitur, admittunt terniones $4^{3} \times 64 ;$ unde totidem oriuntur modi fyllogifni categorici boni malivé, non 36 tantùm ut voluit Ariftoteles cum Interpretibus. Quòd fi indefinitæ \& fingulares propofitiones $a b$ univerfalibus \& particularibus diftinguerentur, unde octuplex earum nafceretur difcrimen, numerus modorum omninò ad $5^{12}, 2_{:}^{:} \mathrm{Cu}-1$ bum nim. octonarii, affurgeret.

\section{Invenire numerum combinationum ejusmodi fecundim plures exponentes}

Quoniam ex iis quæe modò dicta funt apparet, numerum uniom num in datis rebus $m$ effe $m$, binionum $m$, ternionum $m^{3}$, qua $\mathrm{R}$ terniow 
ternionum $m+8 x$. conftat, numerum combinationum fecundùm exponentes plures ab unitate naturali ordine fe confequentes, quow num ultimus fit $n$, fore $m+m m+m^{3}+m^{4} \ldots+m^{n}$, fummam fcil. progreffionis alicujus geometricæ fecundùm rationem ad $m$, cujus primus terminus eft $m, \&$ ultimus $m^{n}$; quæque fumma vulgò notâ methodo compendiofiùs exprimitur $\&$ unâ quantitate fic effer tur: $\frac{m^{n}-I \text { in } m}{m-1}$, ita ut inflitutâ proportione $m-1$ frt ad $m$, ut $m^{n}-I$ ad quafitum: unde fequens mana

\section{Regula}

pro inveniendo sumero combinationum fecundìn plures exponentes, quorum maximus eft datus.

Clat, ut rerum datarum numerus unitate truncatus I ad eundem integrum; fic illius poteftas, quamindicat exponentium maximus, unitate truncata ad numerum quartum, qui optatam combinationum multitudinem exhibebit。 Ex. gr. ad ir,dagandum, quot diverfis modis inter fe transponi poffint to notz numerales, fi accipiantur tum fingulæ, tum binæ, ternæ, quaternæ, quinæ \& fenæ: vel addi poffunt fex primi termini progreffionis geometricæ 10. 200. 1000 . \& $x$. vel, fi videatur commodius, faciendum, ut 9 numerus notarum unitate minutus ad 10 eundem integrum, fic 999999 . ejufdem poteftas fexta five quadrato - cubica unitate truncata ad quaefitum: utroque enim modo obtinetur 1 IIIMO quæfita difpofitionum multitudo.

Notandum verò, non omnes iftas difpofitiones efficere peculiares numeros; quotquot enim numeri à cy phris unâ pluribusvé incipiunt, non differunt $a b$ iis, quos foli characteres reliqui neglectis cyphris conftituerent: quocirca ut fecernantur utiles à fuperfluis, confderandum, quòd ex decem notis folitariis unica eft inutilis, ipfa fcil. cyphra : ex numeris, qui duabus conftant notis, redundant ro; quandoquidem $\circ$ fingulis decem notis femel præponi poteft: ex iis qui fcribuntur notis tribus, fuperflui funt 100 ; ipfa enim o aut ter 


$$
P A R S \text { SECUNDA. }
$$

pofita eft fola, aut bis prafixa fingulis novem primis numeris, auk femel fingulis inter 9 \& 100 interceptis. Ita ex is qui quatuor charafteribus exprimuntur, fupervacanei funt 1000 ; fingulis namque numeris, qui paucioribus notis Icribuntur, quorumque fi cyphram, unà complectaris funt manifento mille, prafigi poteft una alteravé cyphra, ut notarum quaternarius compleatur. Ob frmilem rationem ex is, qui fcribuntur notis quinque, eliminandi $10000, \&$ I 00000 ex iis qui conftant notis fex: adeò ut, fi à numero I I I I I Io $\infty 10+100+1000+10000+100000+1000000$, feu fumma fex terminorum progreffionis decuplæe incipientis à IO, auferas II I I I 00 I $+10+100+1000+10000+100000$ fummana totidem terminorum ejusdem progreffionis incipientis ab unitate (quod compendio fit, auferendo folummodò primum terminum hujus $a b$ ultimo illius, cùm reliqui omnes fe mutuo deftruant) refiduun 999999 indicet numerum omnium differentium ordinum, qui tri * bui poffunt io notis numeralibus non ultra fenas acceptis, ad exprimendum per illos totidem numeros diverfos. Prout fanè evidens admodùm eft, quòd $a b$ unitate numerando ad üfque 1000000 , prijmum \& minimum eorum numerorum qui feptem? notis confant, inveniuntur præcisè 999999 differentes numeri; cùm numerus 999999, eorum qui fex fcribuntur notis maximus $\&$ ultimus, immediate excim piatur à 1000000 , ab eoque folầ unitate differat.

Non fecus iniri poteft numerus omnium combinationum ac permutationum 24 literarum Alphabeti, fi fiat, ut 23 ad 24 , fic vigeIrma quarta poteftas numeri 24 (neglectâ unitatis ablatione, quâ in tam vafto numero non opus eft) ad numerum quæefitum; qui per Logarithmos expedite invenitur conftare debere 34 notis, \& fuperare 1391 quinti-milliones. Tantus vid. eft numerus omnium vocum utilium \& inutilium, qua ex 24 Alphabeti literis modis omnibus formari poffunt, faltem fi illas non ultra vicenas quaternas combinari pofie intelligas.

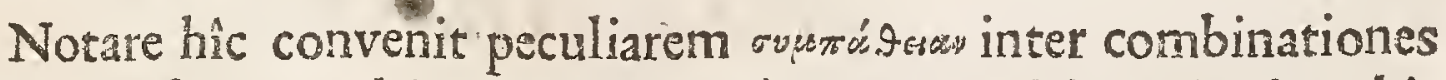
iftas $\& x$ poteltates multinomiorum: Cum enim ad inveniendum bim aiones omnes literarum $a, b, c, d$, fingulæ cunctis fint præfigendæ, $\&$ ad inveniendum terniones omnes, cunctis binionibus fingula lite$\mathbf{R} 2$ İe do 
xæ denuó applicandie, \& fic porrò, ut initio hujus capitis dictum: idemque etiam fieri foleat, ubi quantitas literalis $a+b+c+d$ duw cenda eft in fe quadratè, cubicè 8cc. fequicur, easdem literas, fípe ctentur ut partes radicis alicujus multinomia, binionibus fuis exhi bere omnia membra quadrati illius, ternionibus cubi, quatemionim bus biquadrati \&c. adeò ut membra potelatis cujusvis alirer non exprimantur nifi per coacervationem combinationum partium radicis, factarum fccundùm exponentem aqualem poteftatis indici: hoc tan tum cum difrimine quòd omnia illa membra, quæ iisdem conftant literis variè tantùm transpofitis, cùm candem quantitatem defignent, brevitatis fudio in unum terminum conflari foleant, præfixo illi membrorum æquivalentium numero, qui coëfficiens termini vom cari confuevit. Unde difcere proclive eft, quòd coëfficiens termin cujusvis exprimat numerum permutationum literarum illum terminum conftituentium, ipfa verò terminorum multitudo in quâvis poteftate áquetur numero combinationum, quæ inter partes radicis neglecto earum ordine fecundùm indicem poteftatis datæ inftitui pof funt, quarumque numerus per cap. $5^{\text {tum invenitur. }}$

Quod obfervaffe operæe pretium aliquando non exiguum erit, cùm exinde promtè definiri poffit tum multitudo terminorum, tum termini cujusvis coëfficiens in quâcunque poteftate. Ita, ex. gŕ。 decima poteftas trinomii $a+b+c$, per reg. cap. $5^{\text {ti }}$ conftabit ter minis $\frac{11.12}{1.2} \infty 066$, quorum $a^{5} b^{3}$ cc per reg. 2 cap. I mi coëfficientem habebit $\frac{1 \cdot 2 \cdot 3 \cdot 4 \cdot 5 \cdot 6 \cdot 7 \cdot 8 \cdot 9 \cdot 10}{r_{0} 2 \cdot 3 \cdot 4 \cdot 5 \text { in } 1.2 \cdot 3 \text { in } 1.2} \infty 2520$. Pariter cubus radicis quadrimembris $a+b+c+d$ continebitur terminis $\frac{4 \cdot 5 \cdot 6}{x_{0} \cdot 3}$ \0 20 , ejusq termini $a b a x a b c$ pro fuis coëfficientibus acquirent numeros $3 \& 6$.

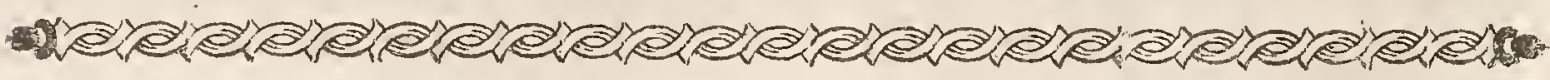

$$
\text { C A P. IX。 }
$$

Invenire numerum electionum rerum plurium, quarum nonnwlla funt eadem, nulla. 


$$
P A R S S E C U N D A_{0}
$$

yeró fopius in electione afpumi debet, quam ip a reperitur in toto revam numero.

TYpothefis hæc eft capitis Cexti, nifi quòd ibi omnes diverfi or11 dines unius combinationis pro unâ eâdemque electione, hîc pro rotidem diverfis electionibus habendi funt. De Problemate hoc fene fu accepto nihil definitum invenio apud Auctores; ego quafitum fequenti modo exploro: Sunto ex. gr. combinandæe \& permutaridæe modis omnibus literæ $a, b, c$, eâ lege, ut in nullâ combinatione $a$ frepiùs quàm quater, $b$ quam ter, $\& c c$ quàm bis occurrat, hoc eft, ut aliter enunciem, fint combinandæ \& permutandæ omnifariam literæ a a a abbbcc feu $a^{4} b^{3} c^{2}$, quarum 4 funt eadem, item tres alia, \& rurfum duæ aliæ eædem, fitque determinandus numerus harum combinationum, tam fecundùm fingulos quàm fecundùm omnes exponentes. Conftat, ante omnia electiones folius $a^{4}$, inclufo nullione quem unitatis notâ defignamus, effe has quinque: $x, a_{2} a a_{2} a^{3}, a^{4}$. Singulis harum applicetur litera $b$, primò femel, dein bis, tertio ter, ut fiant novæe electiones: $b, a b, a a b, a^{3} b, a^{4} b:$ nec non, $b b, a b b$, $a a b b ; a^{3} b b, a^{4} b b$ : ut $\& b^{3}, a b^{3}, a a^{3}, a^{3} b^{3}, a^{4} b^{3}$, planè ut factum cap. 6 . Sed harum electionum illæ, quas $b$ femel ingreditur, per reg. 2 , cap. I ordine infuper recipiunt permutationes $I, 2$, $3,4,5$; prima vid. unam $b$, fecunda duas $a b \& b a$, tertia tres $a a b, a b a, b a a \& c$. Illæ verò, quas $b$ ingreditur bis, ordine permutariones admittunt $1,3,6,10,15$, juxta numeros fcillo trigonales; prima nempe unam $b b$; fecunda tres, $a b b, b a b, b b a$; tertia fex, $a a b b, a b a b, a b b a, b a a b, b a b a, b b a a$. \& $c$. Et ill $x$, in quibus $b$ ter occurrit, permutationes ordine capiunt $1,4,10,20,35$, juxta numeros pyramidales: quemadmodùm etiam illæe, fi quæ darentur electiones, in quibus $b$ repiùs adhuc recurrit, permutationes admitterent juxta alios \& alios figuratos gradatim altiores in infinitum. Hoc peracto, fingulis præcedentium electionum permutationibus 1 ; $a, b ; a a, a b, b a, b b ; a^{3}, a a b, a b a, b a a, a b b, b a b, b b a, b^{3} ; \& c$. tertia porro litera $c$ nunc femelnunc bis adjungi intelligatur; ita nova prodibunt electiones, $c ; a c, b c ; a a c, a b i c, b a c, b b c ; a^{3} c \& c$ a 
nec non, $c c ; a c c, b c c ; a a c c, a b c c, b ; c c, b b c c ; a^{3} c c$ \& $c c$. quarum priores, qua literam $c$ femel tantum includunt, refpectu hujufce literæ, ordine reliquarum non immutato, fubeunt permutationes $\pi$, $2,3,4,8 x c$. juxta numeros naturales; nempe unio $c$ unam, finguli binionum $a c, b c$ duas; finguli ternionum $a a c, a b c, b a c, b b c$, tres, $\&$ ita porrò: polteriores verò, qua lit. $c$ bis continent, permutationes ordine patiuntur $1,3,6$, ro \& $\mathrm{c}$. fecundùm trigonales; binio nempe $c c$ unam, temionum $a c c, b c c$ finguli 'tres; quaternionum $a a c c, a b c c, b a c c, b b c c$ finguli $r e x, \&$ ita confequenter. Dico, or dine reliquarum præter $c$ literarum non immutato; aliàs enim ex. gr. abcc non 6 , fed 12 permutationes admittit, at quarum dimidis pars redundat, utpote Cequenti quatemioni b acc attribuenda. Quòd If jam quarta adeffet litera, ea fimiliter omnibus precedentibus permutationibus fecundum fingulas fuas dimenfiones foret applicanda. ad formandum novas electiones, qux denuò permutationes reciperent fecundim numeros vel laterales, vel trigonales, vel pyramidales, \&c. prout accedens litera vel femel, vel bis; vel ter is adjuncta effet. Quo paito nulla optatarum combinationum nos fugiet, neque etiant ulla bis computabitur. Ex dictis verò facilè perfpicitur ratio confructionis fequentis Tabellæe, quâ numerum talium combinationum fecundùm exponentes tam fingulos quàm univerfos expeditè definio. Scribo ordine omnes exponentes combinationum, quas propofita res $a^{4} b^{3} \cdot c^{2}$ fulcipere poftunt, à o ufque ad 9 ; \& fub eorum primis colloco tot unitates, quot prima litera habet dimenfiones, \& unam amplius, nempe quinque; quibus ftatim fubjungo quinque numeros laterales $I, 2,3,4,5 ;$ \& his totidem trigonales $I, 3,6,10$, I , totidemque pyramidales $I, 4,10,20,35$; donec præter feriem unitatum tot habeam feries, quot altera litera 6 habet dimenfiones, easq; gradatim dextrorfum promoveo, ut factum cap.6. Tum addo terminos, qui in eodem fibi gradu, perpendiculariter refpondent, ut fiant numeri $\mathrm{I}, 2,4,8$, I 5 \& $\mathrm{C}$. Hos confeftim duco in totidem la-

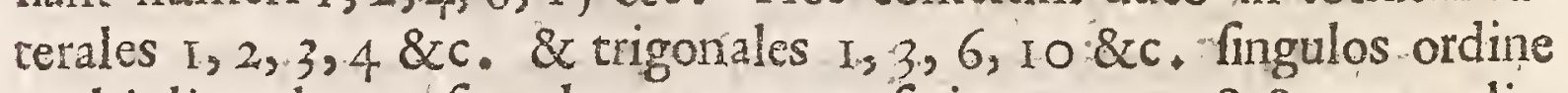
multiplicando per fingulos, ut præter feriem $1,2,4,8.8 \mathrm{c}$. tot aliæ prodeant numerorum feries, I., $4, \mathrm{I}, 2,32.8 \mathrm{CC}$. \& $\mathrm{C}, 6,6,24,80$ \& $\mathrm{x}$. quot tertia litera $c$ obtinet dimenfiones, quas rurfus gradatim difpono $\&$ addo, continuaturus eodem tẹnore últeriùs, fi plures literæ fu- 


$$
P A R S \text { SECUNDA. }
$$

pereflent. Sic tandem ex ultimâ additione prodibunt numeri, qui multitudinem combinationum fecundùm exponentes quifque fuos indicant, adeoque fimul collecti numerum omnium fimpliciter combinationum produnt:

$$
\begin{aligned}
& \text { Res Combio Exponentes Combinationum. }
\end{aligned}
$$

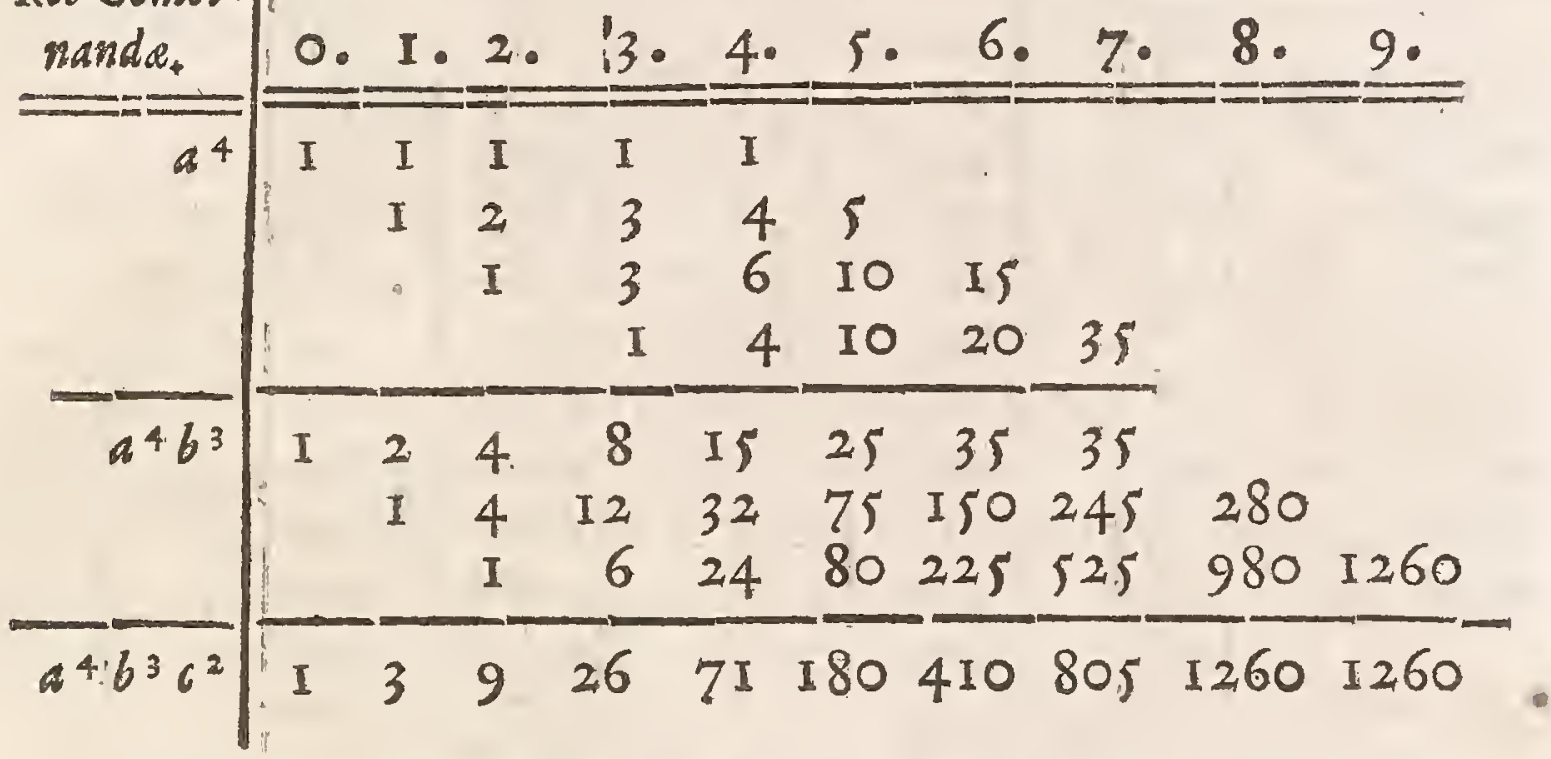

Difcimùs ex hâc Tabellâ, quòd res propofitæe. $a^{4} \cdot b^{3} c^{\prime 2}$ contineant unum nullionem, tres uniones, 9 binarios, 26 ternarios, \& 8 . tandemque 1260 novenarios, \& quòd fumma omnium abfolutè combinationum fit 4025. Methodo huic ex abundanti fidem conciliabit fequens laterculus, in quo primò adfcriptas vides omnes 60 rerum datarum electiones juxta hypothefin capitis $6^{\mathrm{ti}}$, \& $\mathrm{c}$ dein ad lam tus notatos numeros permutationum fingulis competentes per reguw lam 2, capitis primi: 


\begin{tabular}{|c|c|c|c|c|c|c|}
\hline $\begin{array}{c}\text { Elect. } \\
0\end{array}$ & $\begin{array}{l}\text { Eermut. } \\
\mathrm{I}-\mathrm{I}\end{array}$ & $\begin{array}{l}\text { Eled. } \\
a^{4}\end{array}$ & $\begin{array}{l}\text { Permut } \\
\text { I? }\end{array}$ & $\begin{array}{l}\text { Eled. } \\
a^{4} b b\end{array}$ & $\begin{array}{l}\text { Perm } \\
\text { I } 57\end{array}$ & \\
\hline a & $\mathrm{T} 7$ & $a^{3} b$ & 4 & $a^{4} b c$ & 301 & \\
\hline$b$ & 1 & $a^{3} c$ & 4 & $B^{4} C C$ & I5 & \\
\hline$c$ & $1 \int^{3}$ & $a a b b$ & 6 & $a^{3} b^{3}$ & 20 & $1 \mathrm{IO}$ \\
\hline$a a$ & I] & adcc & 6 & $a^{3} b c c$ & 60 & 410 \\
\hline$a .6$ & 2 & $a b^{3}$ & $7 x$ & $a \cdot b^{3} c$ & 60 & \\
\hline$a c$ & 2 & $a b b c$ & 12 & aabbcc & 90 & - \\
\hline 66 & $1\} 9$ & $a b c c$ & 12 & $a b^{3} c c$ & $60 j$ & \\
\hline$b c$ & 2 & $b b c c$ & 4 & $a^{4} b 3$ & 357 & \\
\hline $6 c$ & I J & over & 6] & $a^{4} b b c$ & 105 & \\
\hline$a^{3}$ & I? & $a^{4} b$ & 5 & $a^{4} b c c$ & 105 & Q \\
\hline$a a b$ & 3 & $a^{4} c$ & 5 & $a^{3} b^{3} c$ & 140 & 80) \\
\hline$a d c$ & 3 & $a^{3} b b$ & IO & $a^{3} b u c c$ & 210 & \\
\hline$a b b$ & 3 & $a^{3} b c$ & 20 & $a a b^{3} c c$ & $210\}$ & \\
\hline$a b c$ & 6326 & $\begin{array}{l}a^{3} c c \\
a b^{3} 3\end{array}$ & $10 / 180$ & $a^{4} b^{3} c$ & .2807 & \\
\hline $\begin{array}{c}a c c \\
b^{3}\end{array}$ & I & $a a b b c$ & $30 \%$ & $a^{4} b b c c$ & $420\}$ & 1260 \\
\hline$b b c$ & 3 & $a a b c c$ & 301 & $a^{2} b^{3} c c$ & $\{60\}$ & \\
\hline$b c c$ & 35 & $a b^{3} c$ & 20 & $a^{4} b^{3} c c$ & $1260=$ & 1260 \\
\hline & & & 10 & Summa & Permut. & 40 \\
\hline
\end{tabular}

Colligitur hine, quiòd ex tribus diverfis notis numeralibus ( non computato nullione, quo nulla earum accipitur) formari poffunt 4,024 diverfi numeri, in quorum nullo una notarum frepiùs quàm quater, altera quàm ter, \& tertia quàm bis repetatụr. Sem- per autem omnes notæ; quoties poffunt, fimul fumta, hoc eft, combinatæ fecundùm exponentium maximum tot numeros fuppeditant, quot numeros eædem exhibent combinatæ fecundùm exponentem proximè minorem; quod Theorema notatu dignum.

Hæc funt, qua de Arte combinatoria dicere in præfens fufcepimus. Potuiffemus quidem poftremis hifce capitibus, ubi in come 
Binationibus \& ordo attenditur, \& una eademque res eandem elem aionem fapius ingredi poffe concipitur, yarias iterum quaftiones nobis enodandas proponere, \& inquirere, in quot combinationibus una pluresvé res conjunctione vel divifim reperiantur, uri factum cap. $4^{\text {to }}$; aut, quot combinationes aliqua res fenel, bis, ter, quater \& $\mathrm{cc}_{\text {. }}$ pofita ingrediatur; aut, quot fint illarum combinationum, in quibus nulla rerum datarum plus unâ, duabus, tribus $\& c$. vicibus occurrit; aut in quibus defignata quæpiam res primum, fecundum, tertium \&c. locum occupat, aliisve circumftantiis veftita apparet. Sed quia quaftiones ejufmodi in infinitum multiplicari poffunt, malumus eas omnes hîc ficco pede præterire, \& fi quas earum deinceps ex ufu noftro fore videbimus, earundem applicationem $\&$ enodationem in ,reliquas partes refervare, quàm ad particularia nonnulla hîc loci defcendendo opus nunquam perficiendum aggredi. Hîc itaque fecundæe Parti limites figimus, mox tranfituri ad cæetera inftituti noftri sapita, ufumque prolixum doctrinæ hujus de Combinationibus in Arte Conjectandi per plurima varii generis Proble mata liquido oftenfuri.

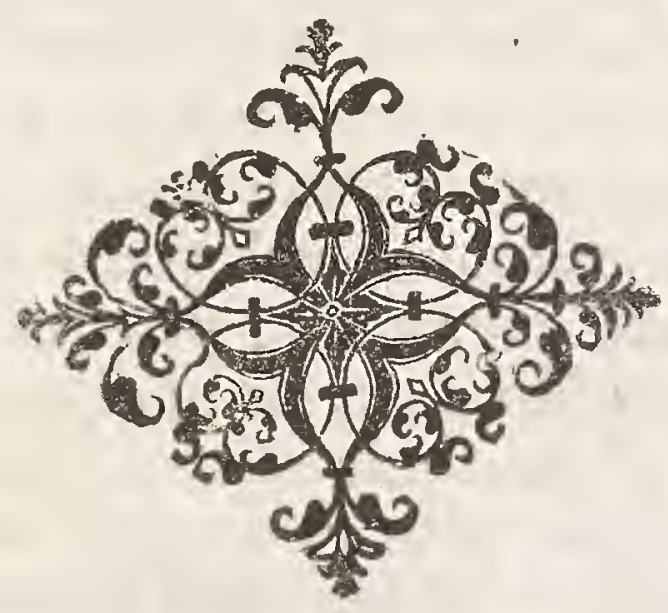




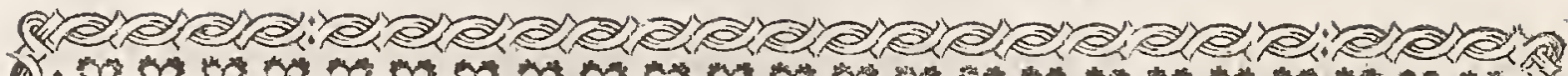

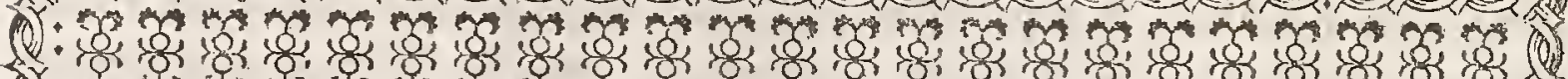

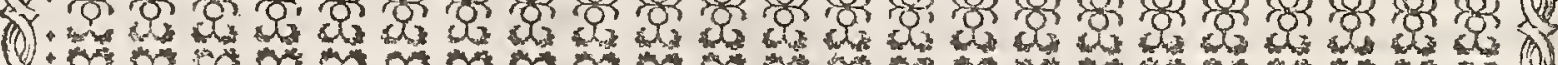

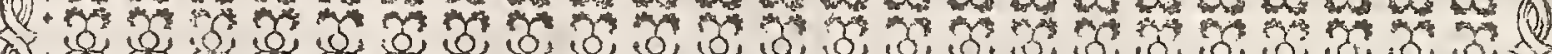

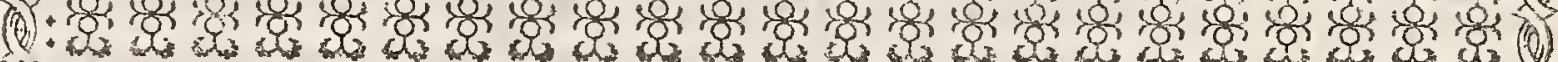

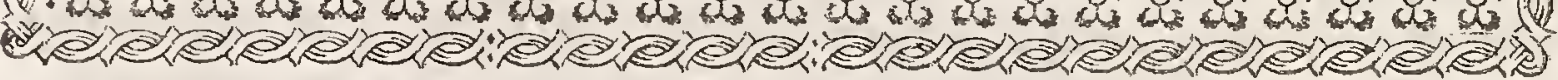

\section{ARTIS CONJECTANDI PARS TERTIA,}

explicans

\section{Ufum præcedentis Doctrinæ in variis Sortitionibus \& Ludis alex.}

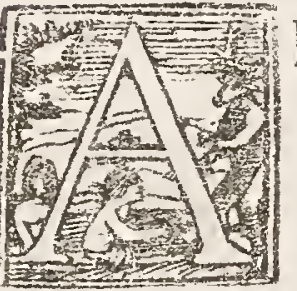

Bfolutâ in præcedente parte Operis, Permutationum \& Combinationum Doctrinâ, or. do jubet, ut ejus Ufum amplifimum in definiendis Expectationibus Aleatorum per varias Sortitiones \& Ludos alex hâc parte explicemus. Fundamentum generale hujus indaginis in eo confiftit, ut omnes permutationes vel combinationes quarum fubjecta materia capax eft, pro totidem habeantur cafibus æquè poffibilibus, \& ut diligenter attendatur, quot horum cafuum huic illive collufori faveant vel adverfentur, è quo dein cætera per doctrinam primæ partis abfolvuntur, Cùm verò fpecialis fundamenti applicatio non levem fapè induftriam requirat, \& exemplis meliùs quàm preceptis addifcatur, nolo Lectorem prolixioribus prolegomenis detinere, fed abfque morâ ad ipfam enodationem fequentium Proble- 
matum tranfeo, quæ nullo ferè habito felectu, prout in adverfariis reperi, proponam, præmiflis etiam vel interfperfis nonnullis facilioribus, \& in quibus nullus combinationum ufus apparet.

\section{PROBLEMA I.}

\section{Quidam duobus calculis albo nigrogí in urná} reconditis preminm proponit tribus $A, B, C_{3}$ eâlege, ut qui album extraxerit, pramio potiatur; $\rho$ fecus omnes faxint, premio quog careant. Primus autem extrabet ipfe $A$, Ef reponet; lecundus $B$, tertius $C$. Queruntur fingulorum fortes?

7 I Iquet, hunc cafum tantùm fpecialem effe Problematis genetaw 1. 17. lionis occafione Propor. XI. part. 1. pag. 34. foluti, quo plu2. vivm Aleatorum fortes exploravimus, qui æquali an inæquali, fortitionum à fingulis continuò inftituendarum numero aliquid praftare fufceperunt; ubi fortem cujuslibet hâc generali formulâ expreffimus: $\frac{a^{n} c^{s}-c^{n+s}}{a^{n}+s}$. Itaque cùm in praefenti exemplo lit. a (nus merus omnium cafuum) ob duos tantùm calculos valeat $2 ; c$ (ntlmerus eorun, quibus prafcriptum non impletur) ob unicum nigrum valeat $1 ; n$ ob unicam fortitionem à fingulis inftituendam itidem $I$; $s$ verò (numerus omnium fortitionum hanc precedentium ) pro primo A valeat $O$, pro fecundo. B I, pro tertio $\mathrm{C}_{2}$; fiet ( fubftitutis iftis literarum valoribus) fors primi $\mathrm{A} \frac{x}{2}$, fecuudi $\mathrm{B} \frac{\mathrm{r}}{4}$, tertii C $\frac{1}{8}$; fic ut ipfi quog; aleam proponenti relinquatur $\frac{1}{8}$ fui præmii . 
Cateris.polstis, ut prius, $f \mathrm{i}$ alex Brabeute omni jure in promium $\int e$ abdicare volens, jubeat reliquos tripartiri pramium inter $\int e_{\text {s. }}$ fi nullus corum album calculum elegerit: Queruntur tum corum fortes?

Quia fic omne jus premii in folidum tranfit in tres reliquos: perfpicuum eft, uniuscujusque expectationem meliorari $\frac{1}{24}$, hoc eft triente ejus . quod juxta præced, hypoth. foli Brabeutæ conveniffet. Quocirca addito $\frac{1}{24}$ feorfim ad $\frac{x}{2}, \frac{1}{4}, 8<\frac{1}{8}$, habetur expectatio primi $\frac{T 3}{24}$, fecundi $\frac{7}{24}, \&$ tertii $\frac{4}{24}$,

\section{PROBLEMA III.}

Sex, $A, B, C, \mathcal{D}, E, F, j u \iint u$ Principis, qui poftremis magis favet quamprimis, aleâpericlitantur: primiduo $A \in G$ feorfim fortiri incipient; uter corum vicerit, fortietur cum tertio $C$, uter horum fuperior evaferit, certabit cum D; Ef ficporrò u g gad ultimum F: pramiumǵs reportabit, qui poft ultimum congreffum victor upererit. Supponitur autem, binos quoscung, a quâ forte inter fe certare, boc eft, neutrum altero potiorem ad vincendum expectationem babere. Quaruntur ipforsm fortes?

Primus' 
Primus A præmio potiri nequit, nifi omnium reliquorum quinque victor evadat, hoc eft, nifi quinquies continuò vincat; uti $\&$ fecundus $B$ : fed nec tertius $C$ palmam reportabit, nifi alterut tum precedentium A \& B, \& omnes tres fequentes fuperet, hoc eft, nifi quater continuò vincat, nec $4^{\text {lus }} \mathrm{D}$, nifi cum uno trium præcedentium ambos fequentes, hoc eft . Inifi ter continuò vincat, \& frmiliter de reliquis . Unde conftat, Problema hoc pro cafu fpeciali habendum efle ejus, quo quæruntur expectationes colluforum, qui aliquot fortitionibus quidpiam aliquoties preftare fufcipiunt; cujus folutionem ad Propof. XII part.1. pag.38. tradidi, Tabellâ in eltm ufum fupputatâ, juxta quant primi vel fecundi fors erit $\frac{65}{a 5}$, tertii $\frac{b 4}{a^{4}}$, quarti $\frac{b 3}{a 3}$, quinti $\frac{b b}{a a}$, \& fexti $\frac{b}{a}$, hoc eft, (quia $a$ ad $b$ habet rationem duplam ob æqualem in quâvis fortitione numerum cafuum ad vincendum \& perdendum) fors primi vel fecundi $\frac{1}{3} \frac{1}{2}$, tertii $\frac{1}{1} \frac{1}{6}$, quar= ti $\frac{1}{2}$, quinti $\frac{1}{4}, \&$ exti $\frac{1}{2}$. Unde patet, exceptis duobus primis, qui æquali expectatione gaudent, quemlibet reliquorum proximè præcedenti duplo potiorem fortem nancifci; omnium verò expectatio. nes exhaurire integrum præmium.

\section{PROBLEMA IV.}

Ceteris pofitis, ut prius, Iffingamus non aquam obtinere fortem in quârvis aleâs, fed unumquem g' cum fecundo à fe congredientem duplò, cum tertio $4^{\text {plò }}$, cum quarto Splò ECc. plures ad vincendum quàm perdendum ca süs babere, exceptis tantiom duobus primis, quos aquo Marte certare ponimus: quaritur, anfic omnes fex aquale jus acquirant in $S_{3}$

pres- 
promium propofitum, compenfatis per du. plam proportionem cafunm fubduplis expectationibus pracedentis propofitionis?

Hic ob diverfitatem fortium, quæ in diverfis aleis regnat, calculus paulò intricatior: Confulatur Regula ad calcem Propor. XII part. I. pag. $44 . \&$ formula, quam fuggerit, $\frac{b e b \& c \text {. }}{a d g} \& c_{0}$ ubi literæ $b e$ h \&c. numeros cafuum ad vincendum, \& adg \&cc. numeros omnium caluum in fucceflivis aleis fignificant; exprimitur enim hâc formulâ expectatio aleatoris alicujus: qui aliquoties continuè vincere tenetur, quantumvis in diverfis aleis non idem maneat cafuum numerus, quibus vincat; uti in præced. Problemate. Patet autem, quantitatem hanc $\frac{b e b \& c \cdot}{a d g \& c .} \times \frac{b}{a} \cdot \frac{e}{d} \cdot \frac{b}{g} \& c$. hoc eft, expectationem totalem, feu fpem vincendi omnes aleas, multiplicatione conflatam effe ex fortibus pars ticularibus, quas habet ad vincendum fingulas. Conf. Coroll. $x$. Prop. 3 part . I. Quapropter ut Problematis noftri folutio methodica habeatur, inveftigandum fuccefivè, quænam juxta hanc for mulam primi $A$ fit futura fors, fi primò unum $B$, dein fi duos $B \& C$, hins, fi tres, quatuor, ac denique omnes quinque reliquos vincere furcipiat; id enim omne prærequiritur ad indagandum fortes cæeterorum. Eft verò fors ipfrus, cùm folum $B$ vincere fufcipit, $\frac{\pi}{2} ;$ cùm duos $B$ \& $C$ vincere contendit, $\frac{1.2}{2.3} \infty \frac{\pi}{3} ;$ cùm tres $B, C \& D, \frac{1.2 .4}{2.3 .5}$ $\infty \frac{4}{x}, \& c_{0}$ ut ex appofito laterculo apparet. Quod idem intelligendum de fecundo $B$. Quod (pectat tertium $C$, is cum alterutro præcedentium ( quem in laterculis lit. $P$ indigitamus ) congredi tenebitur; utrumvis autem contingat, habet $\frac{1}{3}$ expectationis ad illum vincendum: quare fi præter illum etiam fequentem $\mathrm{D}$ vincere fufcipiat, habebit $\frac{1.2}{3,3} \infty \frac{2}{3}$; fi verò $\&$ ipfunate, $\frac{1.2 .4}{1 \cdot 3 \cdot 5} \infty_{\frac{8}{4}}$. Similiter quarto $D$ cum uno præcedentium $P$ congrediendum erit: fi cum $C$ congrediatur, habet $\frac{T}{3}$ ad illum vincendum: fi cum $A$ vel $B$, habet $\frac{x}{5} ;$ fed æque facile contingit, ut cum $A$ vel $B$ vel $C$ congredi teneatur, quandoquidem omnes tres eandem habent expectationem ad 
sorsipfius .. A

ad vincen

dum

B. $\infty \frac{x}{2}$

$$
\mathrm{B}, \mathrm{C}, 0 \frac{1.2}{2.3} \infty \frac{\mathrm{x}}{3}
$$

$\mathrm{B}, \mathrm{C}, \mathrm{D} \infty \frac{1.2 .4}{2.3 .5} \infty \frac{4}{\frac{15}{5}}$

$B, C, D, E \infty \frac{1.2 \cdot 4 \cdot 8}{2.3 \cdot 5 \cdot 9} \infty \frac{32}{135}$

B

A $\infty \frac{x}{2}$

A, C $\infty \frac{I .2}{2.3} \infty \frac{I}{3}$

$A, C, D \infty \frac{\pi .2 .4}{2.3 .5} \infty \frac{4}{15}$

$A, C, D, E \infty \frac{1.2 \cdot 4 \cdot 8}{2 \cdot 3 \cdot 5 \cdot 9} \infty 0_{135}^{32}$

$B, C, D, E, F \infty \frac{1.2 \cdot 4 \cdot 8 \cdot 16}{2.3 \cdot 5 \cdot 9 \cdot 17} \infty \frac{512}{2295} \mid A, C, D, E, F \infty \frac{1.2 \cdot 4 \cdot 4 \cdot 16}{2.3 \cdot 5 \cdot 9 \cdot 17} \infty \frac{512}{2295}$

Sorsipfins .. C

ad vincen-

dum

$\mathrm{P} \infty \frac{\mathrm{I}}{3}$

P, D $\infty \frac{1.2}{3.3} \infty \frac{2}{3}$

$P, D, E \infty \frac{1.2 .4}{3.3 .5} \infty \frac{8}{4}$

$P, D, E, F \infty \frac{1.2 .4 \cdot 8}{3 \cdot 3.5 \cdot 9} \infty \frac{64}{405}$

D

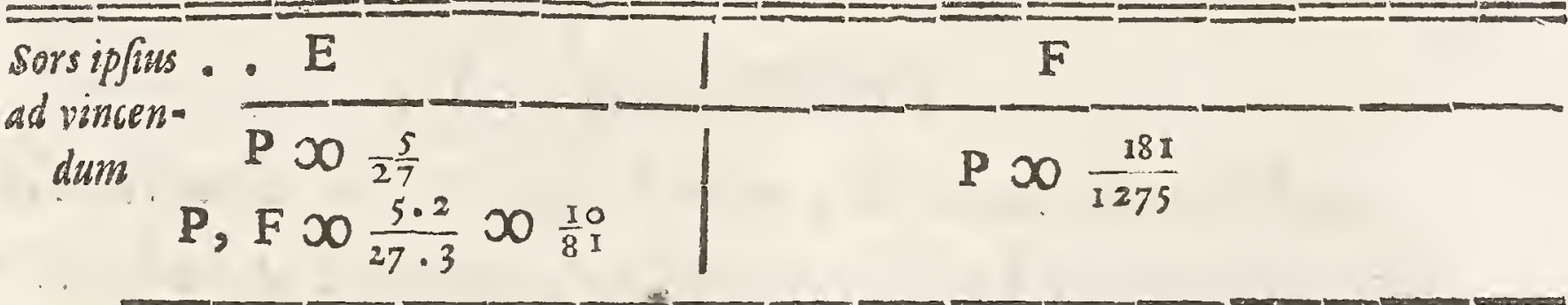

vincendum continuè, quoufque ordo certandi quartum $\mathrm{D}$ tangit ; finguli nempe ${ }_{3}^{I}$, ut ex Tabulâ liquet: quocirca ipfe D per Prop. 3 . part. 1. habet $\frac{10^{1: 3}+20^{1: 5}}{3} \infty \frac{11}{45}$ ad vincendum indefinitè unum trium præcedentium, quem ipfi fors objecerit; ideoque fi præterea \& quintum $E$ vincere conetur, habere cenfebitur $\frac{11.2}{45.3} \infty \frac{22}{135} \& c_{0}$. Non fecus quinti $\mathrm{E} \&$ fexti $\mathrm{F}$ fortes explorantur, niff quòd i pfos non æquè facilè cum unoquovis ex precedentibus congredi contingit. Nam ex. gr. primus $A$ habet $\frac{4}{15}$ ad vincendum continuè ipfos $B, C, D$, juxta 
juxta laterculum, tantundemque fecundus $B$ ad vincendum $A, C, D$, $\&$ tertius $C$ habet $\frac{2}{9}$ ad vincendum $P$ \& $D$, \& quartus $D \frac{1}{4}$ ad vincendum $\mathrm{P}$, hoc eft, redultis ad commune nomen fractionibus, $A$ $\mathrm{B}$ habent $\frac{12}{4}, \mathrm{C} \frac{12}{4}, \& \mathrm{D} \frac{1}{5}$ ad vincendum continue, quoufque ordo certandi quintum $E$ poftulat: quapropter i2 funt cafus, quibus ipfe E cum primo A, totidem quibus cum fecundo $B$, lo quibus cum tertio C, \& II quibus cum $4^{\text {to }} \mathrm{D}$ committitur; unde per Prop. 3 part. I habet $24 .^{1: 9}+10 .^{1: 5}+11 .{ }^{1: 3} 00 \frac{5}{2}$ expectationis ad 45

vincendum indefinitè adverfarium, quem ipfi fors ex precedentibus obtulerit. Et fic in cæteris: Quòd fi ubique ritè operatus fueris, deprehendes, expectationes totales aleatorum feu fpes adimplendi omnes conditiones certaminis \& reportandi præmium exprimi poAremis laterculorum fractionibus $\frac{51}{2} \frac{1}{9}, \frac{5}{2} \frac{1}{9}, \frac{64}{40}, \frac{8}{57}, \frac{10}{8},-\frac{19}{1} \frac{1}{5}$ quæ ad idem nomen 34425 reductre monitrant, illas valde diverfas elfe \& fe habere ut 7680,$7680 ; 5440,4488,4250,4887 ; \&$ quia præcisè unum integrum exhauriunt, eo iplo probitatem mo thodi \& calculi confirmant .

\section{Problema V.}

A certat cum $B$, quòd ipfe ex 40 chartis lu. foriis, id eft, 10 cujusq $q_{s}$ peciei, 4 chartas extracturus fit, ita ut ex unaquags pecie babeat unam. Quaritur ratio fortium?

Problematis hujus in Appendice Problematum Hugenianorum ordine tertii folutionem jam parte primâ exhibuimus : nunc oftendemus, quo pacto idem aliter, in auxilium vocatâ Combinationum doctrinâ confici poffit.

Hunc in finem quaratur, quoties ex 40 chartis luforiis quaternæ poffint accipi, hoc eft, quaratur numerus quaternionum in rebus 40. Inveniuntur autem per Cap.IV, part . 2. quaterniones 
nti $\frac{40.39 \cdot 38 \cdot 37}{1 \cdot 2 \cdot 3 \cdot 4}$ 9I 390 , habendi pro totidem alee cafibus, qui omnes aque facile evenire poflunt. At horum caflum funt 10000 , qui Problematis conditionem implent, faciuntque ut ex unaquaque chartarum fpecie habeatur una, quod fic oftendi poteft:

Pono pro 4 fpeciebus chartarum 4 tefferas, \& pro 10 chartis cujufque fpeciei decem facies feu hedras in quaque teffera: fic totidem erunt diverfi jactus in his tefferis, quot chartarum funt quaterniones prefcriptam conditionem adimplentes; ficut enim ad hanc implendam ex quavis fpecie neceffario una requiritur charta \& non nifi una, ita in quovis teflerarum jactu fingulæ tefferæe neceffariò unam \& mon nifi unam faciem fupernè oftentant. Sed ex iis qua Hugemius ad Prop.X. part. . præfatur, colligi potef, quòd in 4 ejufmodi tefferis reperientur jactus IO. IO. IO. 10. $\infty$ I0000; cum ergò totidem fint chartarum electiones ipfi $\mathrm{A}$ faventes, cæteræque \& 3390 contra certanti profint, fequitur fortem $A$ ad fortem B effe ut 10000 ad 8I 390 , feu ut 1000 ad 8139.

\section{PROBLEMA VI.}

CAfJumtis 12 calculis, 4 albis 6 S nigris, certat $A$ cum $B$, quid velatis oculis 7 calculos ex iis exempturus fit, inter quos tres albi erunt. Queritur ratio fortis ipfins $A$ ad fortem ipfinis $B$ ?

Problema hoc, quod in Appendice Problematum Hugenia norum eft ordine quartum, in hanc Partem rejicere coacti fuimus, propterea quòd ejus folutio aliter quàm combinationum ope, quarum Doctrina fecundâ demum Parte tradenda erat, difficulter inveRigari potuiffet.

Conftat primò, tot effe in univerfum alex propofita cafus, quoties ex 12 calculis fepteni poffunt eligi, nempe $\frac{12 \cdot 11 \cdot 10 \cdot 9 \cdot 8 \cdot 7 \cdot 6}{1 \cdot 2 \cdot 3 \cdot 4 \cdot 5 \cdot 67}$ 
\ 792, per Cap. IV . part.2. Deinde confiderandum eft, fi quis quarat, quot horum cafuum ipfi $A$ faveant vel adverfentur, hoc tantundem effe, acfi quærat, in quot feptenariis ex defignatis quatuor calculis tres qualescunque exclufo quarto reperiantur; cujus Problematis folutionem fub finem dicti capitis ante appendicem hâc generali formâ expreffimus $\frac{m \cdot m-1 \cdot m-2 \ldots m-b+1}{1 \cdot 2 \cdot 3 \cdots \cdot}$ in $\frac{n-m \cdot n-m-1 \cdot n-m-2 \ldots n-m-c+b+1}{1 \cdot 2 \cdot 3 \cdot 4 \cdot \cdots \cdot c-b}$, fignificante liters $n$ numerum rorum combinandarum, $c$ exponentem combinationis, $m$ numerum rerum defignatarum, billarum ex defignatis qux cons. binationes optatas junctim ingredi debent: quare fi interpreteris $n$ per $12, c$ per $7, m$ per $4, \& 6$ per 3 , habebis $\frac{4 \cdot 3.2}{1.2 .3}$ in $\frac{8.7 .6 .5}{1.2 .3 .4} \infty$ $4.70 x_{28}$, numerum omnium feptenariorum, quos fingulos tres albi calculi exclufo quarto ingrediuntur. Tot ergò cafibus vincet $A$, reliquis 512 ipfi $B$ profuturis, adeo ut fors illius fit ad fortem hujus, ut 280 ad 512 , five ut 35 ad 64 ; intellige fi præcisè tres albos calculos nec plures nec pauciores eximere fufceperit. Nam fi tres albi eximendi de tribus ad minimum intelligantur, ita ut fenfus Problematis fit, etiam tum lucraturum ipfum $\mathbb{A}$, fi plures tribus, h. e. omnes 4 albos elegerit, tum perfpicuum eft, numerum cafuum quibus vincit $\mathbf{A}$ augendum effe toto illo electionum numero, guas. omnes 4 albi calculi ingrediuntur; qui numerus per eandem regtlam, pofitis tantim $m \& 6$ aqualibus feu verfo valore ipfius 6 in 4 a invenitur $\frac{8.7 .6}{1.2 .3} \propto 56$, cui additus præcedens 280 efficit 336 , nus. merum electionum ipfi $A$ faventium; \& relinquuntur ipfi $B$ dunta xat 456 , fic ut eo cafu fortes ipforum fint ut $336 \& 456$, feu ut 1 o 8. 19.

\section{PROBLEMA VII.}

\section{Collus ores aliquot $A, B, C, E$ C C ex manipu- lo chartarum luforiarum, quasrum una ico.}




$$
P A R S T E M T I A \text {. }
$$

ne fignata est, reliqua iconi/mis vacuse (cartes blanches) folide ordine $E^{3}$ alternatim eximunt, eâ conditione, ut qui fignatum exemerit vincat. Tollet autem A primum, $B$ fecundum, Ctertium, of fic us $g_{3}$ ad ul timum, post quem primus A tollere perget requens folium, atg it porrò ufque ad finem ludi. Quaritur ratio /ortium?

Pater, tot effe cafus rquè faciles quot folia; cum folium iconif mo fignatum aquè facile vel primum, vel fecundum vel tertium, vel deniq; ultimum locum obtinere poffit: unde tot cafus quifque habet ad vincendum quot ipfi folia contingunt; ac per confequens

Si omnibus colluforibus æqualis foliorum numerus contingit, quod fit cum numerus colluforum eft pars aliquota numeri chartam rum, feu hic per illum exactè dividi poteft, æqualis quoque omnium fors erit: Ita fi numerus colluforum fit $a$, chartarum $m a$, unicuique obtingent $m$ chartæ, quæ fortem illi pariunt $\frac{m}{m a} \infty \frac{\mathrm{r}}{a}$, fic ut tum ordo eligendi nulli colluforum præjudicet .

Si verò non omnibus æqualis foliorum numerus obtingit, quod accidit ubi numerus chartarum per numerum colluforum exactè dividi nequit, putà fi numero colluforum exiftente $a$, chartarum numerus eft $m a x b$ (pofito $b<a$ ) neque etiam fortes omnium requales $e_{\text {. }}$ runt. Tum enim unicuique primorum $b$ colluforum cedent charta $m+i$, unicuique autem reliquorum tantum $m$ : ac proinde fors unius ex illis erit ad fortem unius ex his, ut $m+1$ ad $m$ : Ex.gr. polito colluforum numero 10 \& chartarum 64 feu 6 in io +4 ; fors unius. ex primis quatuor eft ad fortem unius ex poftremis fex, ut 7 ad 6 . 


\section{PROBLEMA VIII.}

Cateris polutis, ut prius, fi in manipulo char. tarum plures iconi/mis fignate exiftant, illeque vincere cenfendus fit, qui primain earum traxerit. Quaritur tum ratio fortium?

Híc fortes colluforum non ampliùs squales funt, fed quivis: precedentium unoquovis fequentium potiorem conditionem nancifcitur, frve eorum numerus numeri chartarum pars aliquota fie feu fes cus, ob rationem, quòd fignatarum prima, à quâ folâ vỉtoria depen det, faciliùs primum locum quàm fecundum, \& hunc faciliùs quàm: tertium \&c. occupare poteft. Etenim quò anteriorem ifta locunz occupat, eò plura exteris fignatis poft fe loca occupanda relinquit. Ut verò determinemus numerum cafuum, quibus unymquodq; fiat fumamus ex. gr . chartas 12, interque illas 4 iconibus confpicuas, nam eadem operandi methodus ubique. Tum fi prima charta icone fignata primum locum occupet, reliquis tribus undecim patent loca reliqua; unde terna horum qualiacanque occupando tot cafus diverfos efficiunt, quot continentur ternarii in rebus undecim, nempe $\frac{11.10 .9}{1.2 .3} 00$ I65. Pariter fi prime fignata charta fecundum locum teneat, reliquæe tres ex decem locis reliquis tria qualiacunque occupa. bunt; guod tot diverfos cafus prabet, quor ternarii comprohendun tur in rebus decem, vid. $\frac{10.9 .8}{1.2 .3} \infty 0$ r20. Rurfus, fignatarum primâ tertium locum occupante, reliquis tantùm patent loca novem, unde tot cafus emergunt, quor ternarii continentur in rebus . 9: \&z fic ulteriùs juxta fabjunctum laterculum, in quo prima feries ordinem col luforum fi vis, trium A, B, C alternatim trahentium; fecunda feries loca foliorum; tertia numeros cafuum . quibus primum folium fignatum in loca refpondentia incidere potef, exhibes. Hos cafus deters 
determinant ipfrfimi ternarii, quos ordine recipiunt res $I I, I 0,9$, \&c. eordem d term no rent earundem binarii, fi 3 tantìm folia fir gnata ponerentur; \& wnitates, fi duo.

ordo colluf.. | A. B. C. A. B. C. A. B. C. A.B. C. Loca folurum I. 2. 3+ 4.5. 6. 7. 8.9. IO. I I. I2. Num. cafuum $165 \cdot 120.84 \cdot 56.35 \cdot 20$. I0.4.I. 0. 0.0 .

Omnes verò hi cafus æquè facile evenire poflunt, \& fumma eorum æqualis numero quaternionum in rebus $\mathrm{I} 2 \infty \frac{12 \cdot 11 \cdot 10 \cdot 9}{\mathrm{I} \cdot 2 \cdot 3 \cdot 4} \infty$ 495: quanquam enim finguli horum cafuum ingentem numerum aliorum cafuum fecundariorum fub fe comprehendunt: (corum fcil . qui ex folâ tran(politione 4 foliorum fignatorum inter fe, \& 8 none fignatorum inter fe refultant) attamen hi cafus fecundarii magno compendio infuper haberi poffunt, quòd tum ipfr æeque funt proclives, tum idem ipforum numerus ( $o b$ conftantem foliorum 4 frgnatorum \& 8 non-fígnatorum numerum ) uni primario refpondet: cuique videl. primario $1 \cdot 2 \cdot 3 \cdot 4$ in $1.2 \cdot 3 \cdot 4 \cdot 5 \cdot 6 \cdot 7.85024$ in 4032000967680 fecundarii, per Cap. I. part. 2 . Et verò æqualis numerus cafuum fecundariorum æquè proclivium cafum æquè proclivem primarium efficir, per Cor. 2. Prop.3. part. I.

Quibus ita oftenfis, fi fortes colluforum defideres, neceffe tantùm habes addere in unam fummam numeros cafuum, locis illis refpondentes, in qua quifque collufor incidit. Atque fic reperitur numerus cafuum ipli A faventium $165+56+1002231$, ipfi B $120+35+400159$, ipfi C $84+20+100105$; unde ratio fortium fit. ut $231,159,105$, five ut $77,53,35$. Notandum hoc Problema reâpfe idem effe cum fecundo Appendicis Hugenianæ part. 3. nomine tantum calculorum in folia luforia mutato: cujus proinde folutio quo pacto aliter quàm ibi haberi, \& ex combinationum confide atione elici poffit, nunc oftendimus, Paulò intricatius eft hoc, quod fequitur.

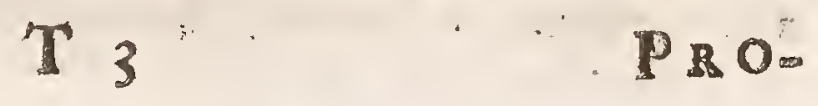


Cateris polttis, ut antea, f Collufores ita pacifcantur inter fe, ut roincat ille qui plures imagines traxerit; fl verò duo pluresve aqualem acceperint imaginum numerum, aqualiter quoque depofitum inter fe partiantur. reliquis, quibus minor carum contigit numerus, nibil babentibus. ratio fortium?

Queritur tum

Si numerus colluforum eft pars aliquota numeri chartarum; non opus eft feciâli determinatione cafuum : fed abfq; omni calculo conftare poteft, quantuscunque fit uterque \& qualiscunque etiam imaginum numerus exiftat, fortes omnium colluforum inter fe $a$ quales effe debere; cùm enim iis omnibus æquè multa folia in partem cadanit, \& fignatorum quodlibet ad quemlibet locum indifferenter fe habeat, nulla ratio eft, cur in æquali foliorum numero hic potiùs quàm ille majorem minoremve lignatorum numerum expectet.

At fi numerus chartarum numeri colluforum non fit exacte multiplex, aut etiam aliàs non æquè multa folia omnibus extrahenda concedantur, (quæ five alternatim five continuò extra hanc, perinde, cum circumftantia ordinis in extrahendo hîc nihil muter) tum fortes eorum itidem funt inæquales, eoq; difficiliùs reperiuntur, quo major tum colluforum tum fignatorum foliorum numerus exiftit. Obfervo tamen, quòd fi duo tantùm fignata adfint, colllufores verò quotcunque, fortes ifæe femper funt futuræ ut ipfi numeri foliorum; qua quifq; extrahet; prorfus ut fupra Probl. VII. in hypothefi unius folii fign. Ponatur enim numerus chartarum $a$, è quibus uni colluforum cedant $b$, alii $c$, tertio d chartæ, \& confideretur, quòd in chartis $b$, quas

primus 


$$
P A R S T E R T Y A \text {. }
$$

primus obtinet, fignatarum vel altera, vel utraque, vel neutra reperiri poffit. Sialtera tantim adfit, illa vel primum vel fecundum vel tertium \& $c$. locum in iftis $b$ chartis occupabit, intereà dum altera quoque promifcuè unumquemvis reliquorum $a-b$ locorum occupare poteft; quod proin $b \cdot a-b \infty 0 a b-b b$ diverfos cafus fuppeditat. Sin ambr fignatæ chartas primi ingrediantur, ea vel primum $\&$ fecundum, primum $\&$ tertium $\alpha c$. item $2^{\text {dum }} \& 3^{\text {tium }}$ $\& c$. locum obtinebunt; unde tot cafuum varietates emergunt, quot biniones in rebus $b$ habentur, nempe $\frac{b .6-1}{1.2} \infty \frac{6 b-6}{2}$ : quemadmodum etiam ob eandem rationem univerfus numerus cafuum $x$ quatur numero binionum contentorum in univerfis a chartis, videl. $\frac{a \cdot a-1}{1.2} \infty \frac{a a-a}{2}$ : intellige, neglectis is cafibus fecundariis, qui ex folâ utriusque fignatæ inter $\mathrm{fe}$, \& non-fignatarum inter fe per" mutatione oriuntur, utpote quorum numerus ob conftantem fignatarum 2 non - fignatarum numerum perpetuò eonftans manet : quod mox infra quoque, ut $\&$ in fequenti Problemate \& fimilibus exemplis femper fubintelligendum eft, etiamfi exprefsè non dicatur. Jam verò dictus collufor, cùm unam fignatam obtinuerit, femiffem depofiti ex pacto confequetur; \& cùm utramque; totum depofitum : quapropter habet $a b-b b$ cafus ad $\frac{x}{2}, \frac{b b-b}{2}$ cafus ad $\mathbf{n}, \&$ cæteros, qui complent numerum $\frac{a d-a}{2}$, ad o; id quod ei per Prop. 3. part. I. fortem parit $\frac{6}{a}$. Eodem modo fors ejus, cui cedunt charte

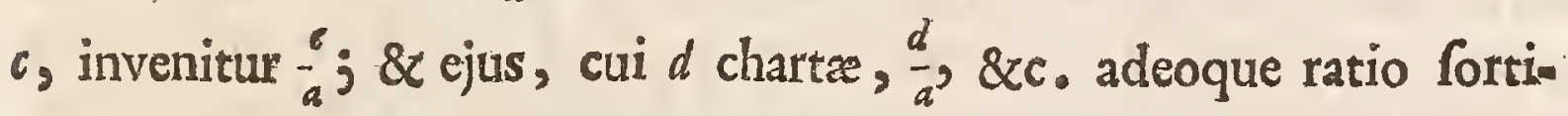
um, ut $b, c, d$, numeri fcil. chartarum, quas finguli accipiunt; quod oftendendum erat.

Exrra verò hunc cafum calculus paulò morofior evadit, \& fapè tadii pleniffimus, prafertim in hypothefi fignatarum chartarum $\&$ colluforum paulò plurium, ubi multiplex complexionuim varietas difficulter fub regulâ generali cogi poteft. Interim modus operandi femper idem, \& in eo confiftit, ut primo exploretur, quàm varie folia fignata inter collufores diftribui poffint hoc eft, quot modis poffibilibus numerus corum difpelci gueat in tot partes, quot finnt 
funt collufores, quarumque partium nulla numerum foliorum refpeEivo collufori cedentium fuperet (quod eo ferè modo efficitur, quo Irpra part. I. pag. 20. ad jactus punctorum in tefleris invefigandos ufi fuimus, nifi quod hic ipfam quoque cyphram partibus accenfeamus; cum utique fieri pofit, ut unus alterve colluforum nullum ex foliis fignatis confequarur): deinde ur fupputetur, quor cafus fingulis iftis variacionibus refpondeant; quorum numerus initur fumendo produfum continumm combinationum ex rebus tor, quot quifque chartas accipit, fecundum numerum lignatarum is permiftarum ceu exponentem; veluti fi ex churtis 40 , quarum 1o funt fignatx, unus colluforum eximere d beat I6, alius 10, tertius 8, \& quartus 6 ; quaraturque quot calibus contingere poffit, ut fimul inter chatas primi reperiantur fignatæ 4 , fecundi 3 , tertii 3 , \& quarti o; multiplico numerum quaternionum in rebus 16 , ternionum in 10 , ternionum in 8,8 nullionum in 6, in fe invicen, \& productum $\frac{16 \cdot 15 \cdot 14 \cdot 13}{1 \cdot 2 \cdot 3 \cdot 4} \mathrm{in}$

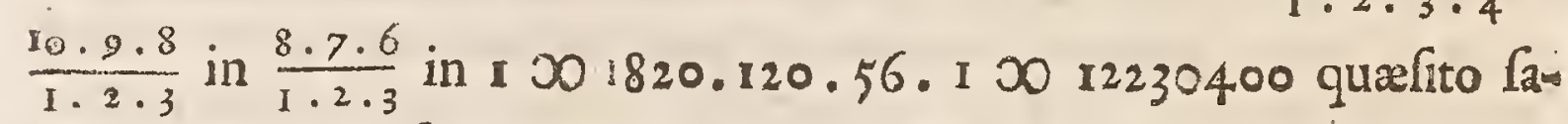
tisfaciet; uti ex fupra oftenfis colligere facile eft

Quoniam autem in integri Problematis enodatione calculo nonnunquam contraktiore uti licet, non abs re erit rem totam fpeciali aliquo exemplo declarare: Sunto charta 20 (quarum 10 fignatæ) alternatim diftribuend $x$ inter collufores tres A, B, C, fic ut primus confequatur chartas 7 , alter 7 , \& tertius tantùm 6; quæranturque eorum expectationes. Liquet primò, fieri pofle, ut in 7 chartis primi colluforis vel nulla, vel una, vel duæ, $3,4,5,6$, vel denique 7 fignace reperiantur; \& fi tantùm una vel 2 vel 3 fignatæ adfint, eum infallibiliter perditurum; quandoquidem reliquorum alteruter necef fariò plures tribus acquiret, \& fic ex padto vincet: quare numerum horum cafuum inire fuperfedeo, \& ftatim fuppono, ipfi $\mathrm{A}_{4}$ fignatas obtingere; quo pacto uni reliquorum cedere poffunt vel fex fignata reliquae, vel 5 , vel pauciores: fed quoniam quatenus ei 5 vel 6 cedunt, eatenus perdere facient colluforem A; idcirco \& hòs calus ceu inutiles prætereo, \& mox tranfeo ad fignatas $4 \& 3$, tribuendo iph $\mathrm{B}_{4} \& \mathrm{C}_{2}$, vel $\mathrm{B}_{2} \& \mathrm{C}_{4}$, vel denique utrique 3. (quarum hy pothefium duæ priores colluforém A ex femiffe, tertia ex affe depo- 


$$
P A R S T E R T I A \text {. }
$$

fiti poffefforem reddunt) atque per doctinam præced, roperio, cam fus efle 18375 qui colluforibus $\mathrm{A}, \mathrm{B}, \mathrm{C}$, fignatas $4,4,2$ : cafus 11025 . qui iis $4,2,48$ cafus 24500 , qui $4,3,3$, fignatas advehunt. "Deinde fingo collufori A obtingere fignatas 5 , fic reliquas 5 vel folus B vel folus $C$ habebit; vel partem earum hic, partem ille accipiet: atg; idcircò 21 numerum quinionum in rebus 7 , duco tum in 21 numerum totidem quinionum in aliis rebus 7, tum in 6 numerum quinionum in rebus 6 , ad habendum cafus $441+126 \times 567$, qui finguli collufor A 5 fignatas \& alterutri reliquorum 5 reliquas afferunt, adeoque ipfif A femiffem depofiti lucrantur. Haud fecis etiam fupputantur cafus, quibus fieri potef, ut dum A 5 fignatas obrinet, reliquorum uni obtingant 4 \& alteri 5 , vel uni 3 \& 2 alteri 2 ; fed non opus eft ifthuc defcendere; poffum enim collufores B \& C fumere pro uno eodemque, \& quæfitum abfque diftinctione cafuum breviùs obtinere, fi à 287 numero quinionum in chartis 13 , quas fimul ambo reliqui confequuntur, fubducantur præcedentes $21+60027$ cafus, quibus omnes 5 fignatæ eorum alterutri obtingunt; ac refrduum 260 ducatur in 21 numerum quinionum in 7 chartis primi : fic enim prodeunt cafus 264,60 , qui finguli collufori $\mathrm{A}$ integrum depofitum acquirunt. Tandem etiam pono collufori A evenire fignatas 6 vel 7, \& quia nunc ultrà fignatarum femiffem habet, video illum neceffariò victorem evafurum, quomodocunque cæteræ 4 aut 3 fignatæ inter collufores B \& C diftribuantur; quare neglecta \& hîc fpecialiore partitione, ipfisque $B \& C$ pro uno eodemque collufore habitis, fumo ex 13 eorum foliis omnes promifcuè quaterniones \& terniones, conumque numerum per numerum fenariorum \& feptenariorum in 7 chartis primi comprehenforum frgillatim multiplico, ut fiant 5005 +28600 529i novi calus, qui colluforem $\mathrm{A}$ totius depofiti dominum faciunt, prout ex appofito laterculo apparet: 
15 $\triangle R T I S$ CONGECTANDI Charta univerfa $\left|\begin{array}{ccc}\text { A } & \text { B } & \text { C } \\ 7 & 7 & 6\end{array}\right|$ Cafus $\mid$ ad $\mid \begin{array}{r}\text { His peractis numeros } \\ \text { cafuum, quibus collufor }\end{array}$ fignata $\left|\begin{array}{rrr|r|r|r|}4 & 4 & 2 & 18375 & \frac{x}{2} \\ 4 & 2 & 4 & 11025 & \frac{2}{2} \\ 4 & 3 & 3 & 24500 & 1 \\ 5 & 5 & - & 441 & \frac{x}{2} \\ 5 & -5 & 5 & 126 & \frac{2}{2} \\ 5 & 5 & 26460 & 1 \\ 6 & 4 & 5005 & 1 \\ 7 & 3 & 286 & 1\end{array}\right|$ A integro depofito potitur, in unam fummam conjicio; nec non illos, quibus dimidium depofiti acquirit, in aliam fummam addo; tandemque etiam numerum omnium abfolutè cafurm, quos io fignata in chartis 20 for. mare poffunt, inquiro, qui eft $184756:$ \& fic reperio, illum habere 5625 I cafus ad I, 29967 ad $\frac{x}{2}$, \& reliquos ad 0 ; quod expectationem ipfi parit $\frac{1424559}{36} 55$; Et quia fecundus $B$ ex manipulo chartarum totidem, quot primus $\mathrm{A}$ nancifcitur, habe-

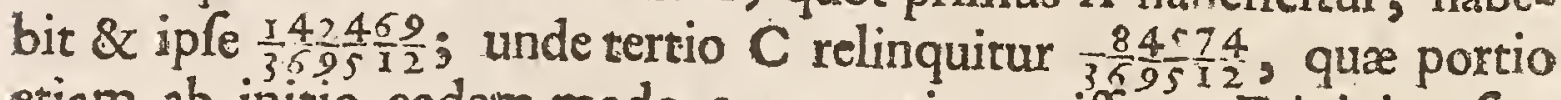
etiam $\mathrm{ab}$ initio eodem modo computari potuiffet. Erit igitur fors alterutrius ex duobus primis ad fortem tertii, ut I42469 ad 84574 , major multò quàm 7 ad 6 , qui funt numeri foliorum quæe fingulis ex manipulo debentur.

\section{PROB LEMA X.}

Quatuor Collufores $A, B, C, D$, codem pacto quo in preced. inter fe inito, ludunt 36 foliis, quorum 16 iconifmis Jgnata Junt, atque ingulis fingula folia ordine atque alternation diftribuunt. Accidit autem, ut diftributis jam 23 folitis, ip/ $A$ infor sem cefferint 4 imagines, ip $\left\{B_{3}, C_{2} \in S D_{1}\right.$, sic ut refidua fint 13 folia, interque illa 6 fignata. Quartus D Squem nunc ordo tangeret proximum acci- 
pirndifolium) videns fibi omnem ferè vin. cendipemervanuife, altericuidam jus/unm vendere vult. Queritur, quanti? of qua fingulorum expectationes?

Problema non differt à præcedenti, niff quòd collufores jama aliquioufque lufum profecuti fupponuntur . Quoniam refidua ponis mus $\mathrm{I} 3$ chartarum folia; quorum primum ipfi $\mathrm{D}$ deftinatum, fequens ipfi $A$, tertium ipfi $B$, atque ita ordine ad ultimum ufque, quod rurfus ipfi $\mathrm{D}$ continget, fequitur, ipfum $\mathrm{D}_{4}$ folia ex illis 13 accepturum, fingulos verò reliquorum tria; adeoque $D$ non plura fignata quàm 4 , nec fingulos reliquorum plura quàm 3 (ultra illa que jam habere fupponun ur) confequi poffe. Quo obfervato difpiciendum, quot diverfis modis re dua 6 folia fignata inter collufores diffribui poffint, fic ut ipfi $D$ nunquam plura quàm 4 , nec fingulis reliqorum plura quàm tria obtingant: ac deinde fupputandum, quot rurfum cafibus fingulæ hæ mutationes fint obnoxiæ; prout hæc omnia in col, I fubjunctæ tabellæ exhibentur. Fit autem operatio prorfus ut in preced. Probl. ut non opus fat ejus explicationi fufùs inherere. Solum hoc attendendum, quòd fupputatis cafibus, priufquam conftare poflit, quinam huic illive collufori faveant, numeri fignatarum chartarum augendi fint illis fignatis, quas finguli collufores (antequam D fortem fuam vendidiflet) habuerant; (quandoquidem ab utrifque conjunctim victoria dependet; ) numerus fcil. fignatarum ipfius $D$ augendus unitate, ipfius A quaternario, B ternario, \& C binario; uti videre eft in col.z tabellæe loco prioris furrogandâ. Tum verò colligendi funt in us nam fummam omnes cafus, quibus finguli collufores vel totum dea pofitum, vel dimidiam, aut 3 aut $4^{\text {tam }}$ partem depofiti auferunt, vel quibus omnino nihil impetrant: quo pacto invenietur $A$ habere 1035 cafus ad obtinendum 1,399 cafus ad $\frac{x}{2} \&$ c. (ut feorfim in adjuncto tabella laterculo notatum cernis, ) qui omnes collecti fam ciunt 1716, (quantus quoque præcisè eft fenariorum numerus in chartis 13.) Quocirca fet fors ipfius $A$ D 
$\frac{10350^{1}+390^{1: 2}+90^{1: 3}+360^{1: 4}+1380^{\circ}}{1716}$ $x \frac{2423}{34}:$ \& fimiliter ipfus:

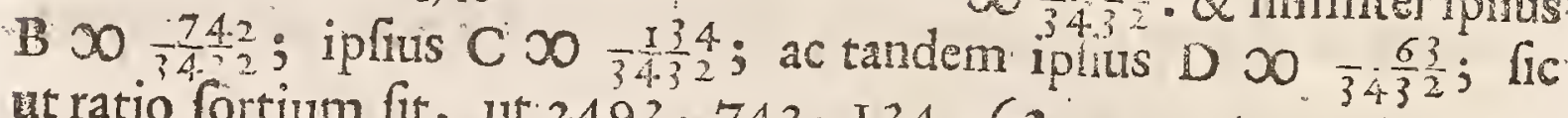
ut ratio fortium fit, ut $2493,742,134,63$.

Notandum, quòd fi chartae refidua non fuifent tam paucæ neqüe numeri cafuum inventu adeò faciles, operæ pretium fuiffet, eodem quo in preced. Probl. compendio uti; prafertim si unius. tantùm colluforis $D$ quærenda expectatio fuiffet: tum enim licuiffet præterire omnes partitionum modos, qui ipsi non plures quàm duas, h.e. (cum eâ quam jam habere fupponitur) quàm tres fignatas attribuunt; \& ex reliquis dintaxat illos paucos confiderare qui nulli cæterorum colluforum plures quàm huic fignatas addicunt. quique in tabula lit. $\mathrm{N}$ notati confpiciuntur; cùm in cæteris fignatarum partitionibus omnibus eum vi pacti toto deposito privari sit confpicuum. Nota denique idem fore genus Problematis, si loco chartarum luforiarum alternatim accipiendarum calculi sive fcheduslix aliæve res fimiles, quarum aliquæ Gnt fignate, in: loculo vel urna recondantur, atque ex iis collufores aliquot alii pauciores alii: plures, sive fimul \& femel feu fucceffivè, eximant, eâ conditione, ut ille vincere cenfendus fit, qui plures fignatas exemerit. Sup putandi enim ratio ubique eadem, neque (quod iterato hic mo neo.) circumftantia hre de eximendis continuò vel aly ternatim calculis quicquiam ad rem.

facito. 
Colum. I. D. A. B.C. Cafus

$3 \cdot 3 \cdot-$ $\cdot 3 \cdot-2.3$

-.-. 3.3

-.3. 2. I

- 3.3 .1 .2

$-.2 .3 .1$

-.I. 3.2

-.2 . I. 3

-.I. 2. 3

$-.2 .2 .2$

I. $3 \cdot 2 .-$

I. $3+-2$

I. 2. 3.-

I. - $3 \cdot 2$

(ㄷ. 2. - 3

I. -. 2. 3

I. 3. I. I

I. I. $3 . \mathrm{I}$

I. I. I. 3

I. 2.2 . I

I. 2. I. 2

I. I. 2. 2

2. 3. 1.-

2. $3 .-$ - I

2. $1.3 .-$

2. - - 3. I

$2.1 .-13$

2.-. I. 3

$2.2 .2 .0-$

$2 \cdot 2 .-2$

2.0. - 2. 2

2. 2. I. I

2. I. 2. I

2.0. I. I... 2 .

9

9

9.

9

9

27

12

I: 2

12

I. 2 .

I. 2

12.

36

36

3.6

108

108

108

I 8

I8

I 8

18

18

I8

54

54

54

662

62
Colum.2. Colum. I.

D.A.B.C D. A. B. C carfus

I. $1.7 \cdot 6.2$

I I. 7.3 .5

I I. 4.6 .5

9 I. 7.5. 3

I. $7 \cdot 4 \cdot 4$

I. $6+6.3$

I. 5. 6. 4

I. $6.4 \cdot 5$

I. 5.5.5

I. 6. 5. 4

2. $7 \cdot 3 \cdot 4$

$2.6 \cdot 6 \cdot 2$

$2 \cdot 4 \cdot 6.4$

2.. $6 \cdot 3 \cdot 5$

$2.4 \cdot 5 \cdot 5$

2.7. $4 \cdot 4 \cdot 3$

$2.5 \cdot 6 \cdot 3$

$2 \cdot 5 \cdot 4 \cdot 5$

$2 \cdot 6 \cdot 5 \cdot 3$

2.6. $6 \cdot 4 \cdot 4$

$2 \cdot 5 \cdot 5 \cdot 4$

$3 \cdot 7 \cdot 4 \cdot 2$

$3 \cdot 7 \cdot 3 \cdot 3$

$3 \cdot 5 \cdot 6 \cdot 2$

$3 \cdot 4 \cdot 6 \cdot 3$

$3 \cdot 5 \cdot 3 \cdot 5$

$3 \cdot 4 \cdot 4 \cdot 5$

$3 \cdot 6 \cdot 5 \cdot 2$

$3 \cdot 6 \cdot 3 \cdot 4$

$3 \cdot 3 \cdot-\cdot-$

$3 \cdot-3 \cdot-3$

$3 \cdot-\cdot-3$

3. 2. I. -

3. $2 .-$. I

3. I. 2. -

3.-. 2. I

3. $1 .-.2$

3.-. I. 2

3. I. I. I

4. 2. -..

$4 \cdot-2 .-$

$4 \cdot-\ldots . . .2$

4. I. I. -

4. I. - I I

4... -. I. I.

36

36

36

36
2.7.5.2

$44 \cdot 7 \cdot 3 \cdot 2$

$4.4 \cdot 4 \cdot 6 \cdot 2$

$4.4 \cdot 4 \cdot 3 \cdot 5$

3.6. $4 \cdot 6 \cdot 4 \cdot 2$

$36.4 \cdot 6 \cdot 3 \cdot 3$

$4 \cdot 5+5 \cdot 2$

$4 \cdot 4 \cdot 5 \cdot 3$

$4 \cdot 5 \cdot 3 \cdot 4$

$4 \cdot 4 \cdot 4 \cdot 4 \sqrt{N}$

$4 \cdot 5 \cdot 4 \cdot 3$

$35.6 \cdot 3 \cdot 2$

$35 \cdot 4 \cdot 5 \cdot 2 \mathrm{TH}$

$35 \cdot 4 \cdot 3 \cdot 4 \mathrm{~N}$.

$95 \cdot 5 \cdot 4 \cdot 2 \mathrm{~N}$

$95 \cdot 5 \cdot 3 \cdot 3 \mathrm{~N}$

$95 \cdot 4 \cdot 4 \cdot 3 \mid \mathbf{N}$

Summa, I7 I 6 cajus .

\begin{tabular}{|c|c|c|c|c|}
\hline \multirow{2}{*}{ Collufores } & \multicolumn{4}{|c|}{ Cafus, quibus obtinent } \\
\hline & $A$ & $\mathrm{~B}$ & I C & | D: \\
\hline$I$ & 1035 & I88 & 2,2 & 12 \\
\hline$\frac{I}{2}$ & 3.99 & 342 & 66 & $2 I$ \\
\hline$\frac{1}{3}$ & 9 & 9 & 9 & - \\
\hline$\frac{1}{4}$ & 3.6 & 36 & 36 & 36 \\
\hline 0 & 237 & I 4 II & 1583 & 1647 \\
\hline $\begin{array}{l}\text { Summa } \\
\text { Caftitum }\end{array}$ & 17 I6 & 7161 & 1716 & 1756 \\
\hline
\end{tabular}




\section{PROBLEMA XI.}

Propofitum fit, fex teffer.e jactibus fex ejus bedras jacere, fingulas fingulis, fic ut nulla bedrarum bis redeat. ad boc efficiendum?

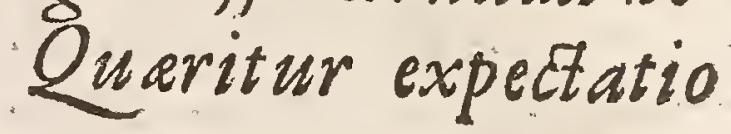

Patet, fingulos teffere jactus fex cafibus fubeffe pro numero he drarum. Harum nulla aleatori primo jactu contraria eft; fecundo jactu hedra primi jactûs ei eft adverfa, cæeteris tantùm quinque faventibus. Tertio jåtu hedræ duorum præcedentium jąuum ipfi nocent, faventque tantùm 4 reliquæ. Ita quarto jaclu duntaxat ipsi profunt hedræ 3, quinto tantùm duæ, \& fexto unica. Poblema igitur huc redit, ut inveniatur expectatio ejus, qui fucceffivè fexies præftare debet aliquid, fumma omnium cafuum in fingulis aleis exifiente $\sigma$, numero verò cafuum ipsi faventium in primâ aleâ 6 , in fecundâ $\xi$, in tertiâ 4 , \& fic porrd. Hæec ad Prop. XII. pr.part. generaliter inventa eft $\frac{b e b \& c .}{a d g \& c}$. ubi $b, e, b \& c$. feorlim valent $6,5,4 \& c$.

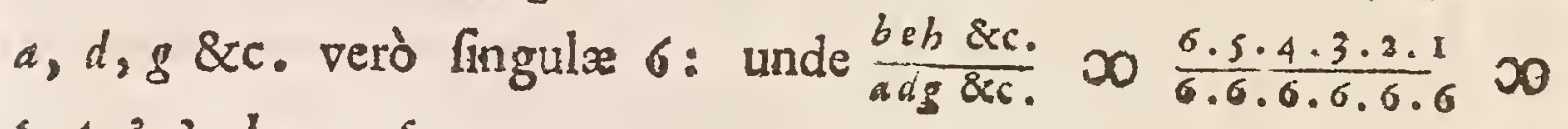
$\frac{5 \cdot 4 \cdot 3 \cdot 2 \cdot 1}{6 \cdot 6 \cdot 6.6 .6} \infty \frac{5}{324}$.

\section{PROBLEMA XII.}

Propofitum fit, fex teffers jactibus fex bedras ordine jacere, primo jactu unum punctum, jecundo duo puncta, tertio tria EGc. Queritur expectatio ad hoc praftandum?

Quia $\mathrm{fCx}$ hedræ ordine jaciendæ funt, aleator in fingulis jacibus non nifi unum cafum habet, qui fibi prodefle poffit: unde cum hîc fingulæ literarum $b, c, b \& c$. valeant $x$, erit expectatio quxfita

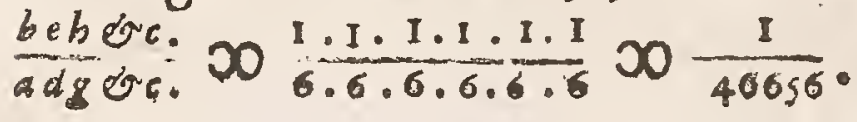




\section{- problema xill.}

Tres collufores $A ; B, C$, quorum fingulifcripias ante le babent fex primas notas numerales, alternationtefferâludunt bâc conditione, ut quem quisque punctorum numerumjecerit, exfuis notis deleat; aut, fi non babeat amplius, /equens ludere pergat, donec quis primus omnes fex notas deleverit. Contingit autem, Indo aliquandiu continuato, wtip/s $A$ reffent adbuc nota 2, ip $f_{1} B, E C_{3}$; ordoque jaciendi tangat ipfum $A$. Querun. tur ipforum fortes?

Problema hocce plus laboris \& patientiæ quàm ingenii requirit: ob magnam enim cafuum varietatem numeri protinus in immenfum excrefcunt; nec novi malo medelam, nifi putemus operationem aliquantulum contrahi poffe, fi ex fortibus aleatorum, qua in fingulos jactus mutantur, illas tantum inveftigemus, quas poft ternos quofque jactus acquirunt, cùm vices ludendi ad ipfum $A$ redierint. Hunc in finem confidero, quòd, dum collufores fucceffivè tres jątus inftituunt, fieri pofit, ut vel nullus colluforum, vel unus, vel duo, vel omnes tres aliquam ex fuis notis fupernicibus jaciant: quor cafibus autem unumquodque horum fiat, ex Reg. Pr. XII part. I. fubnexa perfpicuum eft, juxta quam (si numerum notarum fuperfitum pro ordine colluforum vocemus $b, e, b$, numerum deletarum $c, f, i$; fumm atriufque $b+c$ vel $e+f$ vel $h+i \infty$ a $\infty 0$ numero hedrarum unius tefferæ) numerus cafuum, qui nulli colluforum delejdam notam fignificant, eosque adeo in priftino ftatu relinquunt, invenitur of $i$; corum qui foli $A, b f i$; qui foli $B$, efi, \&xc. ut exs appo: 
56 URTIS CONJECTANDI

appofito laterculo apparet; numerus verò omnium cafurty $a^{3} \infty$ 6.6.6 0 276, rejefisque per Cor.4. Prop. 3. part. r. iis, quibus colluforum fortes invariata manept, numerus caterorum $x^{3}-c f i$.

\begin{tabular}{c|c|c|c|c|c|c|c} 
Null. & $\mathrm{A}$ & $\mathrm{B}$ & $\mathrm{C}$ & $\mathrm{A} \& \mathrm{~B}$ & $\mathrm{~A} \& \mathrm{C}$ & $\mathrm{B} \& \mathrm{C}$ & $\mathrm{A}, \mathrm{B} \& \mathrm{C}$. \\
efi & $b f i$ & $e 6 i$ & $b c f$ & $b e i$ & $b b f$ & $e b 6$ & $b c h$.
\end{tabular}

Quibus pramifis fortes colluforum fupputo ad omnes ftatus, in quos ludum continuando pervenire poffunt, incipiendo à fimplicifimo, \& pergendo ad omnes fequentes ufque ad fatum propofitum; ordine quem hîc fubjungo; quandoquidem nullius fequencium fors haberi poteft, quin fortes omnium precedentium compera habeantur:

$$
\begin{array}{l|l|l|l|l|l|l|l|l|}
\text { A } & \text { I.I.I } & \text { I.I. I } & \text { I.I.I } & \text { I.I.I } & 2.2 .2 & 2.2 .2 & 2.2 .2 & 2.2 .2 \\
\text { B } & \text { I.I.I } & 2.2 .2 & 3.3 .3 & 4.4 .4 & \text { I.I.I } & 2.2 .2 & 3.3 .3 & 4.4 .4 \\
\text { C } & \text { I.2.3 } & \text { I.2.3 } & \text { I.2.3 } & \text { I.2.3 } & \text { I.2.3 } & \text { I.2.3 } & \text { I.2.3 } & \text { I.2.3 }
\end{array}
$$

Primò pono, fingulis colluforum unicam fuperefle notam, quo cafu literæ $b, e, b$, fingula valebunt $\mathbf{x}, \&$ fingulæe $c, f, i, 5$; conf deroque quod primus A victoriâ potiatur, five ipfe folus, fivé una cum alterutro vel utroque reliquorum, proximis tribus jactibus notam fuam fuperfitem jecerit: fed guòd fecundus $B$ tum demùm vincere pofit, cùm vel folus vel cum tertio $C$ id præftiterit: tertius verò $C$ non nifr cum folus id effecerit; unde fortes ipforum hæ fient: rors A $00 \frac{b f i+b e i+b b f+b e b}{a 3-c f i} \infty \frac{a a b}{a 3-c f i} \infty \frac{3 \sigma}{91}$ : fors B $\infty 0 \frac{e c i+e b c}{a 3-c f i}$ $\infty \frac{a c c}{a 3-c f i} \infty \frac{30}{91}:$ fors C $\infty \frac{h c f}{a 3-c f i} \infty \frac{25}{91}$.

Fingo deinde, fingulis priorum duoram reftare unam; \& tertio C duas notas; quo pacto valor lit . beft $2, \& i_{2} 4$ : perpendoq; quòd in proximo jactuum ternario omnia eodem modo eveniant, ficut in praced. hypoth. excepto tantum, cum folus $C$ notam fuam fuperfitem jecerit: tum enim nemo adhuc vincit, fed omnes in eum fawù⿴囗 perveniunt, qui in dictâ hyp. præced. fuppofitus fuit. Unde. 


$$
P A R S T E R T I A \text {. }
$$

Gent fortes, A $\infty 0 \frac{a b b^{1}+b c f^{36: 41}}{a^{3}-c f i} \infty 0 \frac{360^{1}+50.36: 91}{116} \infty 0 \frac{2538}{5278}$ : $\mathrm{B} \infty 0 \frac{a e c 0^{\mathrm{I}}+b c f^{30: 01}}{a^{3}-c f i} \infty \frac{30 .^{1}+50.30: 91}{116} \infty \frac{2119}{5278}: \mathrm{C} \infty 0$

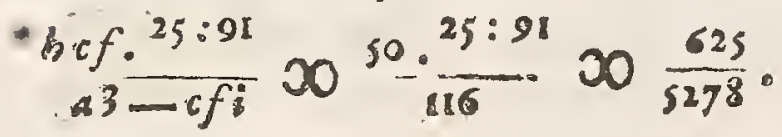

Atque ita religuorum etiam ftatuum fortes perquiri poffunt. Sed calculus integer eft hominis otio abundantis: nos occupatiore ad alia tranfimus.

\section{Problema XIV.}

Duo Collufores $A G B$, teffera in alveum projecta, conveniunt inter fe, ut quot ejus puncta ceciderint, totjactusuterque inftituat, illeg. depofitum auferat, qui plura fummatim puncta jecerit; fin autem aqualis punctorum numerus ambobus contingat, aqualiter etiam depofitum inter (epartiantur. Mox verò colluforum alter $B$ ludi pertafus loco incerte alea certum punctorum numerum affumere, ES punctis 12 pro rata fua acquiefcere mavult. Annuit A. Quaritur uter altero, Equanto potiorem vincendi Jpem habeat?

Determinandum ante omnia, an primus tefferæ jactus accenferi debeat jactibus colluforis $A$, necne. Ponamus primo non accenfo$\mathrm{ri}$ : idcirco 
Si primo jactu unum punctum cadit, collufor A unum duntaxat jactum infituet, qui ad fummum ipsi fenarium adducere poteft; unde cum B ex pacto fumferit puncta 12, A neceffariò perdet, nihilque depoliti habebit.

Si primo jactu duo cadant puncta, A duos tefferæ jactus infti- * tuet, feu (quod per Annot. Prop. 12 pr. part . tantundem valet) duabus tefferis unum jactum: fed in duabus tefferis funt cafus 36 , quorum unicus tantùm eft punctorum 12, qui ipsi A ex pacto femif fem depoliti lucratur; cateri omnes funt pauciorum punctorum, quibus ille nihil acquirit; unde tum fors ejus eft $\frac{r^{1: 2}+35^{\circ}}{36} \infty \frac{1}{72}^{\circ}$

Si primo jactu cadat ternarius, collufori A tres tefferæ jactus concedendi, feu quod perinde) tribus tefferis jactus unus. Reperiuntur autem in tribus tefferis cafus 216 , quorum 25 funt duodecim, 135 pauciorum, \& cæteri 56 plurium punctorum: unde habebit ex pacto 25 cafus ad femiffem depofiti, 135 ad nihil, \& 56 ad totum depofitum; quod ipfi tunc valet $\frac{250^{1: 2}+1350^{\circ}+56.1}{216} \infty \frac{137}{432}$.

Eodem pacto, si primo jactu quaternarius obtingat, fors collu-

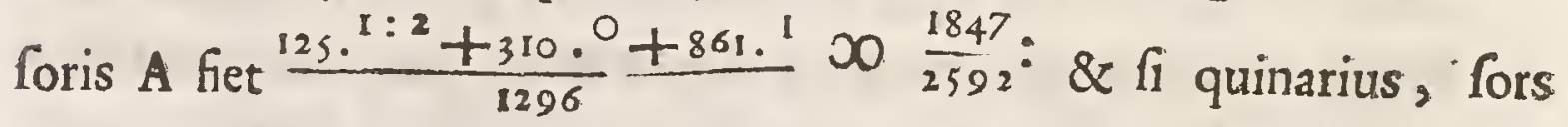
erit $\frac{305 .^{1: 2}+457 .^{\circ}+7014 .^{1}}{7776} \infty \frac{14333}{1555^{\circ}}:$ Gi denique fenarius, fors: ejus prodibit $\frac{456 .^{1: 2}+462 .^{\circ}+45738 .}{46656} \infty_{7776^{\circ}}^{7661}$.

Jam verò æquè facilè contingere poteft, ut primo tefferæ jactut unum, duo, tria, 4,5 vel 6 puncta cadant; idcirco fors colluforis A, quam ab initio ludi habet, per Prop. 2 . pr. part. eft fexta pars aggregati omnium fortium particularium $0, \frac{1}{7} \frac{1}{4}, \frac{13}{2}, \frac{1}{2} \frac{8}{5} \frac{4}{5}, \frac{14}{1} \frac{33}{5} \frac{3}{2}$, $\frac{7}{7} \div \frac{1}{6} ;$ videlicet $\frac{1}{3}, \frac{2}{15} \frac{5}{4} ;$ \& relinquitur pro forte colluforis $B, \frac{1}{3} \frac{5}{1} \frac{8}{1} \frac{9}{4}$.

Ponamus deinde, primum tefferæ jactum, qui numerum jaAuum Colluforis A determinare debet, \& ipfum his jactibus accenfendum effe: quo posito, si prima vice unum punctum cadit, liquet A perditurum. Idem intellige, si duo punda ceciderint; tum enim 
ipsi A unicus jactus reftat, quo fex ad fummum puncta jacere poteft, qua addita primi jactus binario non nifi 8 puncta efficiunt, cùm alteri $\mathrm{B} 12$ concefferit.

Si prima vice tria jaciantur punca, duo fuperfunt peragendi jam atus à collufore $\mathrm{A}$, quibus 36 cafus refpondent. Hos inter funt 4 , qui ipsi afferunt puncta g (h.e. connumerato primi jactus ternario, puncta 12) 26 cafus, qui pauciora; $\& 6$ gui plura. Habet ergo tum 4 cafus ad $\frac{x}{2}, 26$ ad $0, \& 6$ ad 5 i parit $\frac{2}{9}$.

Si primo jactu collufori A quaternarius obtingat, tres ipsi jaatus infuper inftituendi funt, in quibus 216 cafus reperiuntur. Horum funt $2 \mathrm{I}$, qui ipsi adducunt puncta 8 (id eft, si 4 primi jactus puncta accenfeas, puncta 12 ) 35 cafus, qui puncta pauciora, \& 160 qui

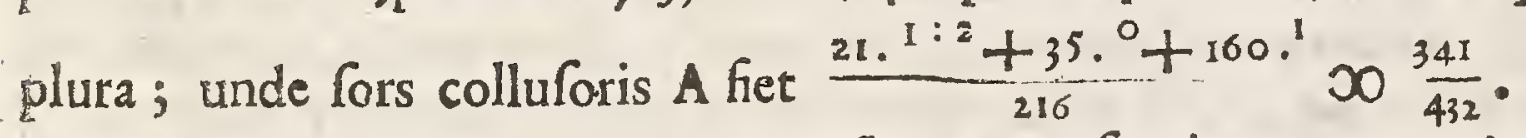

Ad eunden modum reperitur fors ejus, fi primo jactu quinafius evenerit, $\frac{127 \mathrm{I}}{1296} ; \&$ ubi fenarius, $\frac{15545}{15552}$.

Ergo, cùm primo jactu omnes fex hedræ unius tefferæ æquè finr in proclivi, fequitur, fortem colluforis $A$, quam ab initio ludi obtinet, fore fextam partem aggregati omnium fortium particulari-

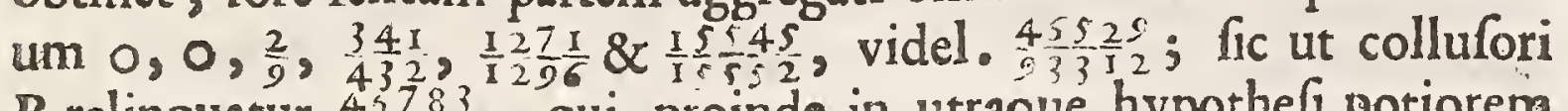
B relinquatur $\frac{4}{3} \frac{7}{3} \frac{8}{3} \frac{3}{2}$, qui proinde in utraque hypothefi potiorem vincendi fpem habet

Ut Lectores noftri exemplo difcant, quàm cautè in his ratiociniis sit verfandum, ne quis nubem pro Junone captet; non abs re me facturum fpero, fi hîc fubnectam fpecimen folution is alicujus fpurix atque fallacis ejufdem Problematis, quâ quærere quis poffet valorena. expectationis in ipfis punctis, \& quam, priore folutione non cognitâ, legitimam \& genuinam effe facilè juraret. Nimirum in $\mathrm{I}$. hyporh. si contingit, ut collufor A unicum jactum inftituere debeat, illo jactu vel 1 , vel $2,3,4,5$, vel deniq; 6 puncta impetrabit, quorum unumquodque eum pari facilitate accidere poffit, valebit hoc ipsi per Prop. 2. part.I. $\frac{\mathrm{I}+2+3+4+5+6}{6}+\frac{3 \frac{x}{2} \text { punctas medium arithme- }}{x_{2}}$ 
ticum inter 1 \& 6.' Sin ipfo contingunt duo jactus inftituendi, illis. jactibus vel 2, 3, 4 \&c. vel denique 12 puncta confequetur; \& quia unus cafus eft, quo 2 puncta, \& unus quo 12: duo vero cafus quibus $3 \&$ duo quibus II: nec non tres cafus quibus $4, \&$ totidem quibus, 10 puncta acquirit, \& fic porrò ; cenfebitur ejus expectatio, per Prop. 3. part. 1. punctorum $\frac{1 .^{2}+1 . .^{12}+2.0^{3}+2.11+3.4+3.0^{10}+4.5+4 .^{9}}{36}$

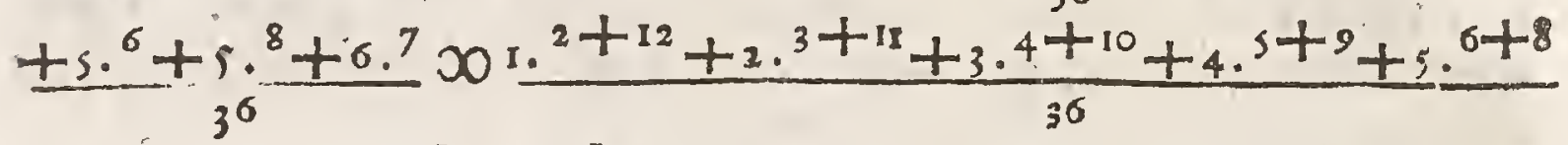
$\frac{+6 . .^{7}}{3^{6}} \infty \frac{1^{14}+2 . .^{14}+3 . .^{14}+4 .^{14}+5 .^{14}+6.7}{36} \infty \frac{15 . .^{14}+6.7}{36} \infty 0$ $\frac{18 .^{14}}{36} \mathrm{x} 7$, quod medium quoq; arithmeticum eft inter extrema punata $2 \& 12$. Quòd fi ipfum tres jactus inftituere contingit, poterit illis jactibus impetrare 3,4,5 \&zc. ufq; ad I 8 puncta, quorum qua ab extremis 3 \& 18 æquè funt remota, æquali femper cafuum numero fubjacent; unde eodem modo oftendetur, quòd ejus expectatio tum valeat puncta $10 \frac{\pi}{2}$, medium itidem arithmeticum inter extrema 38 18. Pariter etiam, fi 4, 5 aut 6 jactus ipsi peragendi funt, ejus expectatio inter $4 \& 24$, inter $5 \& 30$, inter $6 \& 36$, qui funt extremi numeri punctorum qux $4,5 \& 6$ tefferis evenire poffunt, media erit, adeoque punctorum $14,17 \frac{x}{2} \& 21$. Quare cùm æquè facilè contingere poffit, ut collufor A vel $I$, vel $2.3,4,5$ aut 6 jactibus defungi teneatur, æquam etiam habebit expectationem ad puncta $3 \frac{\pi}{2}, 7,10 \frac{\pi}{2}$, $14,17 \frac{r}{2} \& 21$; qui numeri cum \& ipsi fint in arithmetica progref. fione, interque extremos medius exiftat $12 \frac{1}{4}$, indicant expectation nem hanc reftimandam effe $12 \frac{1}{4}$ punctorum .

Haud abfimili ratione in 2 dâ bypoth. procedere licet: nam fi collufor A prima vice unum jaciat punctum, habebit tunum. Siduo jecerit puncta, habebit puncta 2, \& præterea adhuc unum jactum, qui ipsi per ante dicta valet $3 \frac{1}{2}$ puncta ; adeoq; cum duobus illis habebic puncta $5 \frac{\pi}{2}$. Si tria ipsi puncta ceciderint, habebit præter hæc 3 puncta duos jactus, quos ipsi valere diximus 7 punsts; proinde in totum habebit puncta 10. Non fecus fi 4,5 aut 6 puncta primo jactu evenerint, oftendetur habere $14 \frac{\mathrm{J}}{2}$, 19 aut $23 \frac{\mathrm{T}}{2}$ puncta. Unde cùm initio pari facilitate $1,2,3,4,5$ aut 6 puncta jacere poltit, equám itidem 


\section{$P A R S T E R T I A$}

$\&$ ( propter arirhmeticam progreffionem) mediam inter $I, 5 \frac{T}{2}, 10$ $14 \frac{1}{2}, 19 \& 23 \frac{1}{2}$ puncta expectationem obtinebit; quæ quidem rurfus eft ut antea punctorum $12 \frac{1}{4}$.

Itaq; cùm in utraq; hy pothesi collufor $A$ habere cenfeatur punota $12 \frac{1}{4}$, quorum alteri B tantum 12 conceffa funt, colligendum videtur, expectationem ipfius $\mathrm{A}$ potiorem effe quàm $\mathrm{B}$. Hujus autem contrarium ex priore folutione, qua fua luce radiat, apparet; quanquam profectò difficile dictu eft, cur ille plura quàm hic puncta, mihorem autem depofiti partem expectet, cùm tamen acquifitio depofirivi pacti pendeat à punctorum pluralitate.

\section{PROBLEMA XV.}

Cateris pofutis, ut ante, Collufor $B$ pro rata. fua quadratum numeri punctorum primi jactus concedi fibi poftulat. Quseritur nunc ratio fortium?

Diftinguantur rurfus hypothefes:

I. Hypotb. Intelligatur jactus primus non accenferi jactibus colluforis A: Igitur fi primo jactu unum punctum cadit, Collufori B ex pacto quoque tantùm unum tribuitur, dum alter $A$ inftituet unum ja\&tum, è cujus 6 cafibus unus eft, qui unicum; \& 5 qui plura ei puneta advehunt: adeoque I cafus qui ipfum ex femiffe, \& 5 qui ipfum ex affe victorem reddunt; id quod fortem ei parit $\frac{1 \cdot{ }^{1: 2}+5.1}{6} \infty \frac{11}{12}$.

Si primo jactu cadit binarius, ip $\mathcal{E}$ B ex pacto habebic bis duo feu 4 puncta, dum collufori $A$ duo jactus concedendi: funt autem in 2 jactibus 36 cafus, interque illos tres punctorum tot quot habet B, nempe punctorum 4 ; ut $\&$ tres pauciorum punctorum, \& 30 plurium: unde fors ipfius A fit $\frac{3 \cdot{ }^{1: 2}+3 .^{\circ}+30 . .^{1}}{36} \infty \frac{7}{8}$.

Si primo jactu ternarius evenit, acquiruntur ipsi B ter tria feu 2 punat, ipfique $A_{3}$ jactus, qui cafus prebent 216 . Hos inter fun $t$ 
25 punftorum novem ( plurium puntorum; quod fortem efficit $25 \cdot 1: 2+560^{\circ}+135$. I $\infty \frac{2}{4} \frac{25}{2}$.

Simili difcurfu reperitur, fi primo jactu quaternarius, quinam rius vel fenarius prodierit, fortem colluforis A fore $\frac{7}{2} \frac{4}{5} \frac{5}{2}, \frac{7}{2} \frac{7}{9}$, aut $5 \frac{1}{3} \overline{1}$. Cùm igitur omnes 6 cafus primi jactus fint æque procli ves, fexta pars aggregati harum fractionum $\frac{1}{2} \frac{1}{2}, \frac{7}{8}, \frac{25}{43}, \frac{7}{2} \frac{74}{5}, \frac{5}{2}, \frac{7}{2} .8 \mathrm{C}$

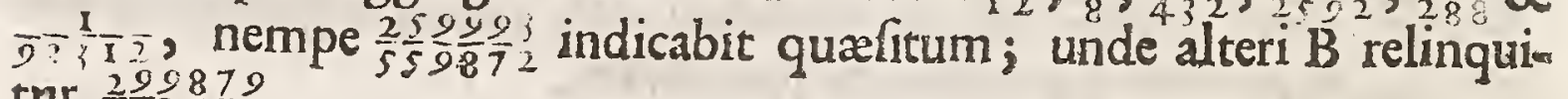
tar $\frac{2}{5} 5 \frac{9}{8} 872$.

2. Hyp oth. Sit nunc primus jactus \& ipfe computandus cum jactibus colluforis A : quo polito

Si unum prodeat punctum, liquet utrumque colluforum habere punctum, adeoque depoliti femiffem.

Si duo emergant puncta, habebit B ex pacto puncta 4 , alterq; A prater jactum quo jam functus eft adhuc alium inftituet, è cujus 6 cafibus unus eft, qui 2 puncta (i.e. fi primi jactus binarium unà computes, 4 puncta, tot fil. quot $\mathrm{B}$ habet) unus itidem cafus qui pauciora, \& 4 qui plura ipsi afferunt: unde fốs ejus tunc erit $\frac{1.1: 2+10^{0}+4 \cdot 1}{6} \times \frac{3}{4}$.

Si tria jaciantur puncta, B puncta 9 habebit, A verò præcedenti jactui duos adhuc fuperaddet, qui 36 cafibus funt fubjecti. Ex horam numero funt 5 qui fex ipsi puncta producunt (h.e. comprehenfo primi jactus ternario totidem, quot $B$ habet) Io cafus qui pamciora, \& 21 qui plura; id quod collufori A fortem progenerat $\frac{5 \cdot 1: 2+100^{\circ}+21.1}{36} \infty 0 \frac{47}{72}$.

Simili ratiocinio colliges, fi primâ vice 4,5 vel 6 puncta cam dant, fortem colluforis A futuram $\frac{13}{43}, \frac{35}{2}, \frac{5}{64}$ vel $\overline{1} \frac{1}{5} \div \frac{1}{2}$. Ob fex igitur cafus primi jactus aquè proclives, fexta pars aggregari omnium fractionum $\frac{1}{2}, \frac{3}{4}, \frac{47}{7}, \frac{1}{4} \frac{3}{3}, \frac{35}{854} \& \frac{1}{5} \frac{1}{552}$, nempe $\frac{3}{9} \frac{5}{3} \frac{5}{1} \frac{5}{2}$ oftendet quafitam; ita ut collufori $B$ relinquatur $\frac{58}{9} \frac{1}{3} \frac{57}{2}$, cui fic rurfus in utraque hypothefi potior expectatio contingit : 


\section{$P A R S$ TERIIA. \\ PROBLEMA XVI. \\ Iftimatio fortis in ludo, dicto \\ Cinq \& neuf.}

In Gallia, Dania, Suecia, Belgio, inferiore Germania \& locis finitimis alea quoddam genus in ufu eft, quod vocant cinq 6 nenf, quodque inter duos collufores A \& B duabus tefferis inftituitur, ludendi vices perpetwas in fe recipiente altero eorum A. ConSitiones ludi funt tales: Si A prima vice jaciat 3 vel 11 , aut puncta duplicata quxcunque (un doublet, cin $\mathfrak{W} a / d$ ) putà duas unitates, duos binarios, ternarios \&c. vincit ipfe A: fi jaciat 5 vel 9, vincit alter $\mathrm{B}$, fi alium quemvis punctorum jecerit numerum, putà $4,67,8$, vel 10 neuter eorum adhuc vicit, fed ludum profequi tenentur, donec aut 5 vel 9 puneta ceciderint, quo cafu ipfe femper B victor erit; aut donec idem præcisè punctorum numerus, qui primo jactu prodiit, redierit; qui cafus ipfum A victorem reddit: conditio enim de jaciendis punctis 3 vel II, aut duplicatis quibufvis ipsi non nifi in prımo jactu prodeft. Quibus politis quæritur ratio fortium?

Quoniam collufor $A$, quatenus prima vice $4,6,7,8$ aut ro puncta jacers poteft, ad fortes pervenit etiamnum incognitas \& inexploratas, hæ ante omnia veniunt inveltigandæ.

Ponamus itaque prima vice jeciffe quaternarium, \& nunc in procinctu effe alterum inftituendi jactum. Quare cùm in duabus tefferis tres fint cafus, qui eundem quaternarium revehunt, ipfumque A victorem ludi reddunt; \& octo alii qui 5 vel 9 puncta afferunt, eique depofiti jacturam caufantur; dum cæeter omnes ipfum ad reperitionem jactus obligant, eoque non plus efficiunt per Cor 4 . Prop. 3 . part . I. quàm si prorfus abeffent; idcirco fiet ejus expecta-

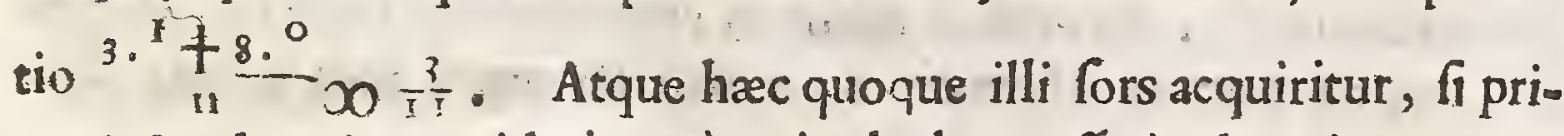
mo jactu dęnarius ceciderit, cùm in duabus tefferis denario \& quaternario æqualis cafuum numerus refpondeat . 
Ponamus deinde, primo jactu prodiiffe fenarium. Itaque cüm 5 cafus fint, quibus altero jactu idem redire poteft fenarius, dum rurfus 8 aliis 5 vel 9 puncta obtingere poffunt; fequitur nunc collum forem A 5 habere cafus pro fe, sc 8 contra fe, (neglectis, ut antea, reliquis, qui ipfum in eodem ftatu relinquunt) quod fortem ei parit $\frac{5.1^{1}+8.0}{13}$

$\infty \frac{s}{1}$. Quanta quoque illius expectatio eft, fi primo ja ctu oftonarius evenerit; cùm fenarius \& oftonarius eidem cafuum numero fint obnoxii.

Ponamus denique, primo jactu cecidiffe feptenarium . Unde cùm idem feptenarius fequenti jactu fex cafibus redire poffit, erunt nunc 6 cafus, pro collufore $A$, dum 8 ut antea funt pro adverfario; quod fortem ipfius A efficit $\frac{6 .{ }^{\mathrm{I}}+80^{\circ}}{14} \infty \frac{3}{7}$.

His ita inventis pergo in Problemate, confiderando ftatum colluforis A ante primum jactum, \& examinando quot ille cafibus per jactum hunc ad unamquamque præcedentium fortium pervenire poffit: Primo conftat, in tefferis duabus fex effe cafus punctorum duplicatorum quorumque, ut \& quatuor alios punetorum trium vell undecim, adeoque 10 in univerfum cafus, qui colluforem $A$ ex ludi præfcripto totius depofiti dominum reddunt. Deinde etiam liquet, ut jam infinuatum eft, 8 effe cafus punetorum quinque vel novem, quibus ille contra toto depofito excidit . Præeterea numeraritur 6 cafus quatuor fimul \& decem punctorum, fed comprehenfi in iis ambo cafus duplicati binarii \& quinarii, quibus collufor $\mathrm{A}$ toto depofito potitur, quorumque ratio jam habita eft; his igitur fubtractis remanent tantìn 4 , qui ipfum ad fortem fupra inventam $\frac{3}{1} \overline{1}$ perducunt. Porrò habentur cafus to pro fex $\&$ oato punctis, unde demtis iterum duobus pro duplicato ternario \& quaternario, relinquintur 8 , qui illum ad fortem fupra repertam $\frac{5}{1}$ promovent. Tandem reliqui funt 6 cafus ad puncta feptem, quibus fupra oftendimus ipsi fortem acquiri . Omnibus igitur in compendium redactis, clarum $\mathrm{ef}$, expectationem Aleatoris $\mathrm{A}$, quam $\mathrm{ab}$ initio ludi habet, fore

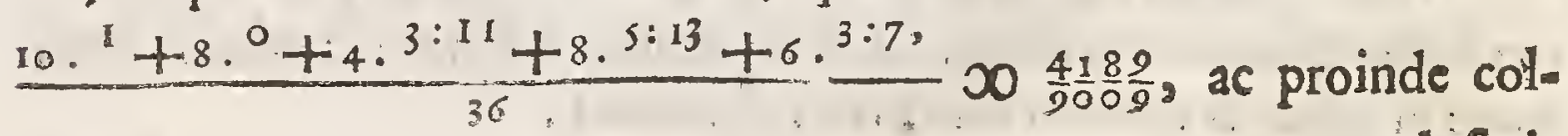
luforis 
Iuforis B $\frac{48}{9} 0 \frac{2}{2}$, fic ut ratio fortium fit, ut 4189 ad 4820 . Unde perfpicuum fit, potiorem hujus quàm illius conditionem effe, ut maximè fint qui fecus exiftiment. inque partes ipfrus $A$ tranfire max lint。

\section{PROBLEMA XVII. \\ Eftimatio fortis in alio quodam Alex genere.}

Memini me olim tempore nundinarum quendam hîc vidiffe Circulatorem, qui. fequens aleæ genus in foro exponebat, eoque prætereuntes alliciebat. Difcus erat orbicularis ad libellam compofitus, versùs medium parumper acclivis; Limbum circumcingebant 32 low culi feu foraminula contigua $\&$ æqualia, quæ in quatuor diftinata claffes vel feries numeris ordine ab I ufque ad VIII quater adfcriptis fignabantur; Medio difci perpendiculariter imminebat fritillus. Fortunam periclitaturus per cavitatem fritilli quatuor demittebat globulos excipiendos in circumferentia difci à totidem loculis, auferebatque præmium quod numeris horum loculorum in fummam collectis dicatum confpiciebat, majoris minorisve pretii pro aggregati diverfitate, ut ex fubjuncto laterculo apparet. Singuli autem globulorum jactus ipsi quaternis nummis redimendi erant. Quæritur ipfius expectatio?

Conftat primò, quòd unoquovis globulorum jątu ad minimum 4, ad fummum 32 puncta obtineri poffunt, quorum utrumvis uno duntaxat cafu contingit, illud, fi globuli finguli fingulorum ordinum prima foramina fubintrant, iftud fi ultima. Deinde obfervo, quòd cafus multiplicentur pro intermediis punctorum numeris, prout $\mathrm{ab}$ utrovis extremo 4 aut 32 magis recedunt, \& quòd maximocafuum numero fit expofitus numerus 18 , medius arithmeticus inter $4, \& 32$; bini autem numeri à medio 18 fupra infraque æqualiter remoti æquali quoque cafuum numero fubfint. Tertiò confidero, quòd foraminula, quæ quovis jactu globulos excipiunt, vel omnia quatuor figna ta effe poffint eodem determinato numero; vel tria codem, quar- 
tum diverfo: vel duo eodem; \& reliqua duo alio eodem numero: vel duo eodem, \& cretera duo diverfis: vel denique omnia quatuor differentibus determinatis numeris; quo rum quidem primum unico, alterum 16 , tertium 36 , quartum $9^{6}$, ultimum 256 cafibus: ascidere poteft. Etenim cim quaterni fint loculi homologi, five eodem determinato numero putì I notati, ff globulorum nonnulli putà tres ab iftis loculis funt excipiendi, liquet hoc tot cafibus contingere poffe, quot terniones in re: bus 4 continentur, nempe quatuor; adeò ut si quartus infuper glo. bulus in aliquem loculum alio rumero, ex . gr. II . fignacum fe reci= pere debeat (quod ob quatuor uniones in rebus 4 rurfum quatuor cafibus evenit) concludi poffit, quater quatuor feu $t 6$ in univerfum cafus exiftere, qui efficiant, ut tres globuli tres loculos $n .{ }^{\circ}$ fignatos \& fimul quartus unum loculorum n. II notatorum fubintret. Quernadmodum etiam colligere promtum eft, ob fex biniones rerum quatuor, fexies fex feu $36 \mathrm{cafus} \mathrm{haberi,} \mathrm{quibus} \mathrm{contingat,} \mathrm{ut} \mathrm{duo} \mathrm{loculi}$ n. I confpicui à duobns, \& duo $n$. II notati ab aliis duobus globura lis occupentur: nec non fexies quater quatuor, h. e. 96 cafus, qui.. bus duo loculi num. I à duobus, unus loculorum n. II a tertio, \& unus $n^{\circ}$ III à $4^{10}$ globulo occupetur: ac denique $4 \cdot 4 \cdot 4 \cdot 4 \mathrm{~h}$. 256 cafus, quibus unus globulorum in loculum n. ${ }^{\circ}$, alius in lockm Ium $n_{\text {. II }}$, tertius in loculum III, \& quartus in IV fe recipiat. Ubi tandem notandum, quod ad variationes illas 24 , qua ex folâ. 4 globulorum permutatiore mutuâ oriuntur, non attendamus, quippe qua infuper haberi poffunt ceu toridem cafus fecundarii, ex quiew bus unusguifque primariorum conflatur. 
His ita præmiffis \& intellectis inquirendum eft in numerum cafuum cuivis punctorum numero convenientem, eo ferè modo quo fupra poft Prop.9. part. 1 . ad numeros jactuum in tefferis inveftigandos uff fuimus; refolvendo vid, propofitum punctorum numeram ob 4 globulos in 4 partes, quarum nulla octonarium fuperet (quòd loculis majores numeri non fint adfcripti) idque omnibus modis porfibilibus, ac deinde fingulis modis juxta fupra obfervata fuos tribuendo cafuum numeros; horum enim fumma quæfitum exhibebit. At quoniam eâ ratione numerus cafuum duntaxat pro dato punctorum numero inveniretur, nobis verò cafuum notitia pro univerfis punctis neceffaria eft, poterimus aliam compendiofiorem inire viam, \&c onnia una operatione confequi, hoc modo:

In fupremo fequentis Tabulæ margine fcribantur ordine numeri punctorum à IV ufque ad XVIII; fufficit enim horum determinaffe cafus, cùm finguli fupra XVIII cum fingulis infra in cafuum mulcitudine, uti dictum, conveniant.

Ponamus, globulos omnes excipi 4 loculis homologis, erunt eorum numeri vel 4 unitates, vel 4 binarii, ternarii, quaternarii \&c. quorum fummæ funt, $4,8,12,16,8 \mathrm{cc}$. quare fignetur in margine finiftro I. I. I. I (cæeteris 2.2.2.2 \& c. ufq; ad 8.8.8.8 mente fubintellectis) \& è regione fub fingulis punctorum numeris IV. VIII. XII. XVI. \&c. notentur fingulæ unitates.

Ponamus tres globulos excipi loculis homologis, quartum diverfo: erunt homologorum numeri vel tres unitates, vel totidem binarii, ternarii \&cc. Si tres unitates, quartus numerus erit vel binarius, vel ternarius, quaternarius \&c. qui finguli juncti unitatibus. fummas efficiunt V. VI. VII. VIII.... XI; quocirca in margine fignetur I+ I. I. 2 (reliquis I. I. I. 3 \& c . ufque ad I. I. I. 8 mente fuppletis ) \& è regione fub punatis V.VI. VII ... XI. fcribatur 16. Si homologorum numeri fint tres binarii, quartus erit vell, vel 3 g vel 4 \&cc. qui juneti binariis fummas exhibent VII. IX.X... XIV: quare in margine ponatur 2.2.2. I (cæteris 2.2.2.3 \&C. fubintellętis) \& è regione fub fingulis punctorum VII. IX . X . . . XIV. rurfus fcribatur 16. Similiter etiam procedendum, ubi homologorum numeri funt tres ternarii, exiftente quarto I. 2.4 aut $58 \mathrm{co}$. aut $\mathrm{Y}$ 展 


\section{LRTIS CONFECIANDI}

tres quaternarii, exiftente quarto 1.2 .3 . aut $; \&$. aut tres quinarii \&xc. exiftente femper quarto uno reliquorum, fribendo nempe I6 fub fingulis punctorum fummis, quas additi 4 loculorum numeri efficiunt.

Ponamus porrò loculos globulorum duos homologos, \& alios duos rurfus homologos, fed à prioribus diverfos: etunt numeri loculorum vel duæ unitates cum duobus binariis, ternariis, quaternariis \&c. qui unitatibus juncti faciunt VI. VIII. X.... XVIII: vel duo binarii cum 2 ternariis, quaternariis $\& c_{\text {a }}$ qu addit binariis conftituunt X. XII. XIV. \& c c vel duo ternarii cum totidem quaternariis \&c. vel duo quaternarii cum totidem quinariis $\& c_{0}$, \& $c_{0}$, id circo notentur in margine Tabulæ I. I. $2.2,2.2 .3 .3,3.3 .4 .4$. \&c. (cæteris I. I. 3.3 , I. I. 4.4 \&c. nec non 2.2.4. 4 \&c. 3 . $3.5 \cdot 5 \& c$. compendii gratiâ omiffis) è regione verò fub fingulis: numerorum tam exprefforum quàm mente retentorum fummis fcribantur 36 .

Pergamus deinde ponere loculos globulorum diuos homologos reliquos ab his \& inter fe diverfos: erunt homologorum numeri rurfus vel duæ unitates, vel duo binarii, ternarii $\& c_{0}$ \& \& fi unitates, tertius erit vel binarius cum quarto ternario, quaternario, quinario \& $c_{0}$ vel ternarius cum quarto quaternario, quinario $\& c_{0}$ \& $\&$ it confem quenter: fi duo binarii, tertius effe poteft vell I cum quarto $3,4,5$,

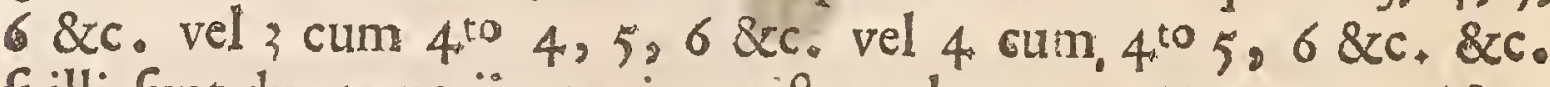
fi illi funt duo ternarii, tertius exifter vel I cum $4^{\text {to }} 2,4,5,6 \& \mathrm{cc}$. vel 2 cum $4^{\text {to }} 4,5,68 \mathrm{c}$. vel 4 cum $40^{\circ} 5,6 \& \mathrm{c}$. \& $8 \mathrm{c}$. fi illi funt quaternarii, $3^{\text {tius }}$ poterit effe vel I cum $4^{\text {to }} 2,3,5 \& \mathrm{c}$. vel $2 \mathrm{cum} 4^{\text {to }}$ 3. 5 \&c. \&c. \& ita pariter in reliquis omnibus, quamobrem primis harum combinationum I. I. 2. 3, I. 1.3 .4 , \& c c nee non 2.2. I. 3 \&c. 3.3.I. 2 \& 2 . in margine notatis \&x cæeteris mente fuppletis, fribantur fub fingulis punctorum fummis, quas finguli numerorum quaternarii efficiunt, 96.

Tandem etiam ponamus, loculos globulorum omnes differentibus numeris affectos effe; erunt ipforum combinationes tales: 1.2 .3

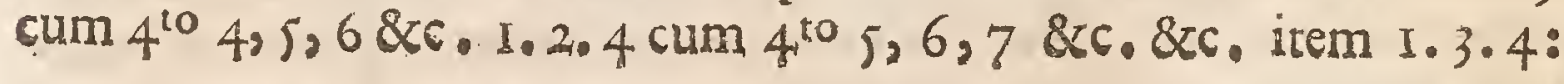




\begin{tabular}{|c|c|c|c|}
\hline \multicolumn{2}{|c|}{ Combinat. $\| I V$. } & \multicolumn{2}{|c|}{$\mathrm{V} .1 \mathrm{VI.1 \textrm {V }}$} \\
\hline$I \cdot I \cdot I \cdot I \cdot \mid$ & I & + & - \\
\hline$I \cdot I \cdot I \cdot 2$ & + & I 6 & 16 \\
\hline 2.2 .2 .1 & $\rightarrow$ & 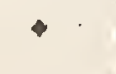 & + \\
\hline $3 \cdot 3 \cdot 3 \cdot 1$ & + & • & + \\
\hline $4 \cdot 4 \cdot 4 \cdot I$ & + & • & * \\
\hline $5 \cdot 5 \cdot 5 \cdot I$ & + & 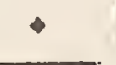 & 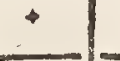 \\
\hline
\end{tabular}



| combinat.||IV. | V. | VI.|VII.|VIII.| IX.| X. | XI. | XII. | XII. | XIV. | XV. |XVI. XVII. |XVII.

\begin{tabular}{|c|c|c|c|c|c|c|c|c|c|c|c|c|c|c|c|}
\hline I.I.I.I. & I & + & - & + & I & - & + & +4 & $I$ & . & + & + & $I$ & + & . \\
\hline $\begin{array}{l}I . I \cdot I \cdot 2 \\
2.2 \cdot 2 \cdot I \\
3 \cdot 3 \cdot 3 \cdot I \\
4 \cdot 4 \cdot 4 \cdot I \\
5 \cdot 5 \cdot 5 \cdot I\end{array}$ & $\begin{array}{l}+ \\
+ \\
+ \\
+ \\
+ \\
\end{array}$ & $\begin{array}{l}16 \\
. \\
. \\
+\end{array}$ & $\begin{array}{l}16 \\
+ \\
+ \\
+ \\
+\end{array}$ & $\begin{array}{r}16 \\
16 \\
+ \\
+ \\
+\end{array}$ & $\begin{array}{l}16 \\
+ \\
+ \\
+ \\
+\end{array}$ & $\begin{array}{l}16 \\
16 \\
+ \\
+ \\
+\end{array}$ & $\begin{array}{l}16 \\
16 \\
16 \\
+ \\
+\end{array}$ & $\begin{array}{l}16 \\
16 \\
16 \\
+ \\
+\end{array}$ & $\begin{array}{r}16 \\
+ \\
+ \\
+\end{array}$ & $\begin{array}{l}16 \\
16 \\
16\end{array}$ & $\begin{array}{l}16 \\
16 \\
16\end{array}$ & $\begin{array}{l}16 \\
16 \\
+\end{array}$ & $\begin{array}{l}16 \\
+ \\
16\end{array}$ & $\begin{array}{l}16 \\
16 \\
16\end{array}$ & $\begin{array}{l}+ \\
16 \\
16\end{array}$ \\
\hline $\begin{array}{l}\text { I.I.2.2 } \\
2.2 \cdot 3 \cdot 3 \\
3 \cdot 3 \cdot 4 \cdot 4 \\
4 \cdot 4 \cdot 5 \cdot 5\end{array}$ & $\begin{array}{l}+ \\
+ \\
+ \\
+ \\
\end{array}$ & $\begin{array}{l}+ \\
+ \\
+ \\
+ \\
\end{array}$ & $\begin{array}{l}36 \\
+ \\
+ \\
+\end{array}$ & $\begin{array}{l}+ \\
+ \\
+ \\
+\end{array}$ & $\begin{array}{c}36 \\
+ \\
+ \\
\end{array}$ & $\begin{array}{l}+ \\
+ \\
+ \\
+\end{array}$ & $\begin{array}{l}36 \\
36 \\
+ \\
+\end{array}$ & $\begin{array}{l}+ \\
+ \\
+ \\
+\end{array}$ & $\begin{array}{l}36 \\
36 \\
+ \\
\end{array}$ & $\begin{array}{l}+ \\
+ \\
+ \\
+\end{array}$ & $\begin{array}{r}36 \\
36 \\
36 \\
+\end{array}$ & $\begin{array}{l}+ \\
+ \\
+ \\
+\end{array}$ & $\begin{array}{l}36 \\
36 \\
36 \\
+\end{array}$ & $\begin{array}{l}+ \\
+ \\
+ \\
+\end{array}$ & $\begin{array}{l}36 \\
36 \\
36 \\
36\end{array}$ \\
\hline $\begin{array}{l}\text { I.I.2.3 } \\
\text { I.I.3.4 } \\
\text { I.I. } 4.5 \\
\text { I.I.5.6 } \\
\text { I.I. } 6.7 \\
\text { I.I. } 7.8\end{array}$ & $\begin{array}{l}. \\
+ \\
+ \\
+ \\
+ \\
+ \\
+\end{array}$ & $\begin{array}{l}+ \\
+ \\
+ \\
+ \\
+ \\
+\end{array}$ & $\begin{array}{l}+ \\
+ \\
+ \\
+ \\
+ \\
+\end{array}$ & \begin{tabular}{l|}
96 \\
+ \\
+ \\
$+\cdots$ \\
+ \\
+
\end{tabular} & $\begin{array}{l}96 \\
+ \\
+ \\
+ \\
+ \\
+\end{array}$ & $\begin{array}{c}96 \\
96 \\
+ \\
+ \\
+\end{array}$ & $\begin{array}{l}96 \\
96 \\
+ \\
+ \\
+ \\
+\end{array}$ & $\begin{array}{c}96 \\
96 \\
96 \\
+ \\
+ \\
+\end{array}$ & $\begin{array}{l}96 \\
96 \\
96 \\
+ \\
+ \\
+\end{array}$ & $\begin{array}{l}+ \\
96 \\
96 \\
96 \\
+ \\
+ \\
\end{array}$ & $\begin{array}{l}+ \\
96 \\
96 \\
+ \\
+\end{array}$ & $\begin{array}{l}+ \\
+ \\
+ \\
96 \\
96 \\
+\end{array}$ & $\begin{array}{l}+ \\
+ \\
+ \\
+ \\
96 \\
+\end{array}$ & $\begin{array}{l}+ \\
+ \\
+ \\
+ \\
+ \\
96\end{array}$ & $\begin{array}{l}+ \\
+ \\
+ \\
+ \\
+ \\
+\end{array}$ \\
\hline $\begin{array}{l}2.2 .1 .3 \\
2.2 .3 \cdot 4 \\
2.2 .4 .5 \\
2.2 .5 .6 \\
2.2 .6 .7\end{array}$ & $\begin{array}{l}. \\
. \\
+ \\
+ \\
+\end{array}$ & i & $\begin{array}{l}+ \\
+ \\
+ \\
+ \\
+\end{array}$ & $\begin{array}{l}+ \\
+ \\
+ \\
+ \\
+\end{array}$ & $\begin{array}{c}96 \\
+ \\
+ \\
+ \\
\end{array}$ & $\begin{array}{c}96 \\
+ \\
+ \\
+ \\
+\end{array}$ & $\begin{array}{l}96 \\
+ \\
+ \\
+ \\
+\end{array}$ & $\begin{array}{l}96 \\
96 \\
+ \\
+ \\
+ \\
\end{array}$ & $\begin{array}{l}96 \\
96 \\
+ \\
+ \\
+\end{array}$ & $\begin{array}{l}96 \\
96 \\
96 \\
+ \\
+\end{array}$ & $\begin{array}{l}+ \\
96 \\
96 \\
+ \\
+\end{array}$ & $\begin{array}{l}+ \\
96 \\
96 \\
96 \\
+\end{array}$ & $\begin{array}{l}+ \\
+ \\
96 \\
96 \\
+ \\
\end{array}$ & $\begin{array}{l}+ \\
+ \\
+ \\
96 \\
96\end{array}$ & $\begin{array}{l}+ \\
+ \\
+ \\
+ \\
96\end{array}$ \\
\hline $\begin{array}{l}3 \cdot 3 \cdot 1.2 \\
3 \cdot 3 \cdot 2 \cdot 4 \\
3 \cdot 3 \cdot 4 \cdot 5 \\
3 \cdot 3 \cdot 5 \cdot 6\end{array}$ & $\begin{array}{l}+ \\
+ \\
+ \\
+\end{array}$ & $\begin{array}{l}+ \\
+ \\
+ \\
+ \\
\end{array}$ & $\begin{array}{l}+ \\
+ \\
+ \\
+\end{array}$ & $\begin{array}{l}+ \\
+ \\
+ \\
+\end{array}$ & $\begin{array}{l}+ \\
+ \\
+ \\
\end{array}$ & $\begin{array}{r}96 \\
+ \\
+ \\
+\end{array}$ & $\begin{array}{l}+ \\
+ \\
+ \\
+\end{array}$ & $\begin{array}{l}96 \\
+ \\
+ \\
+\end{array}$ & $\begin{array}{l}96 \\
96 \\
+ \\
+\end{array}$ & $\begin{array}{l}96 \\
96 \\
+ \\
+ \\
\end{array}$ & $\begin{array}{l}96 \\
96 \\
+ \\
+ \\
\end{array}$ & $\begin{array}{l}96 \\
96 \\
96 \\
+\end{array}$ & $\begin{array}{l}96 \\
96 \\
\end{array}$ & $\begin{array}{l}+ \\
+ \\
96 \\
96\end{array}$ & $\begin{array}{l}+ \\
+ \\
96 \\
96\end{array}$ \\
\hline $\begin{array}{l}4 \cdot 4 \cdot 1 \cdot 2 \\
4 \cdot 4 \cdot 2 \cdot 3 \\
4 \cdot 4 \cdot 3 \cdot 5 \\
\end{array}$ & $\begin{array}{l}+ \\
+ \\
+ \\
\end{array}$ & $\begin{array}{l}+ \\
+ \\
+ \\
\end{array}$ & $\begin{array}{l}+ \\
+ \\
+ \\
\end{array}$ & . & $\begin{array}{l}+ \\
+ \\
+ \\
\end{array}$ & $\begin{array}{l}+ \\
+ \\
+\end{array}$ & $\begin{array}{l}+ \\
+ \\
+ \\
\end{array}$ & $\begin{array}{l}96 \\
+ \\
+ \\
\end{array}$ & $\begin{array}{r}96 \\
+ \\
+ \\
\end{array}$ & $\begin{array}{r}+ \\
96 \\
\end{array}$ & $\begin{array}{l}96 \\
+ \\
\end{array}$ & $\begin{array}{l}96 \\
96 \\
+ \\
\end{array}$ & $\begin{array}{l}96 \\
96 \\
96\end{array}$ & $\begin{array}{l}96 \\
96 \\
96\end{array}$ & $\begin{array}{l}+ \\
96 \\
96\end{array}$ \\
\hline $\begin{array}{l}5 \cdot 5 \cdot 1 \cdot 2 \\
5 \cdot 5 \cdot 2 \cdot 3 \\
5 \cdot 5 \cdot 3 \cdot 4\end{array}$ & $\begin{array}{l}+ \\
+ \\
+ \\
\end{array}$ & $\begin{array}{l}+ \\
+ \\
+\end{array}$ & $\begin{array}{l}+ \\
+ \\
+\end{array}$ & $\begin{array}{l}+ \\
+ \\
+ \\
\end{array}$ & $\begin{array}{l}+ \\
+ \\
+ \\
\end{array}$ & + & + & $\begin{array}{l}+ \\
+ \\
+\end{array}$ & $\begin{array}{l}+ \\
+ \\
+\end{array}$ & $\begin{array}{r}96 \\
+ \\
+ \\
\end{array}$ & $\begin{array}{l}96 \\
+ \\
+\end{array}$ & $\begin{array}{l}96 \\
96 \\
\end{array}$ & 96 & $\begin{array}{l}96 \\
+ \\
96\end{array}$ & $\begin{array}{l}96 \\
96 \\
\end{array}$ \\
\hline $\begin{array}{l}6.6 .1 .2 \\
6.6 .2 .3\end{array}$ & + & + & + & + & + & + & + & - & + & + & + & $\begin{array}{l}96 \\
+\end{array}$ & $\begin{array}{l}96 \\
+ \\
\end{array}$ & $\begin{array}{l}96 \\
96\end{array}$ & $\begin{array}{l}96 \\
96\end{array}$ \\
\hline $7 \cdot 7 \cdot 1.2$ & + & + & + & + & + & + & + & + & + & + & + & + & + & 96 & 96 \\
\hline $\begin{array}{l}I .2 .3 .4 \\
I .2 .4 .5 \\
I .2 .5 .6 \\
I .2 .6 .7 \\
I .2 .7 .8\end{array}$ & $\begin{array}{l}+ \\
+ \\
+ \\
+ \\
+\end{array}$ & $\begin{array}{l}. \\
+ \\
+ \\
+ \\
+\end{array}$ & $\begin{array}{l}+ \\
+ \\
+ \\
+ \\
+\end{array}$ & $\begin{array}{l}+ \\
+ \\
+ \\
+ \\
+\end{array}$ & $\begin{array}{l}+ \\
+ \\
+ \\
+ \\
+\end{array}$ & $\begin{array}{l}+ \\
+ \\
+ \\
+ \\
+\end{array}$ & $\begin{array}{c}256 \\
+ \\
+ \\
+ \\
+ \\
\end{array}$ & $\begin{array}{c}256 \\
+ \\
+ \\
+ \\
\end{array}$ & $\begin{array}{l}256 \\
256 \\
+ \\
+ \\
+ \\
\end{array}$ & $\begin{array}{c}256 \\
256 \\
+ \\
+ \\
+ \\
\end{array}$ & $\begin{array}{l}256 \\
256 \\
256 \\
+ \\
+\end{array}$ & $\begin{array}{c}256 \\
256 \\
+ \\
+ \\
\end{array}$ & $\begin{array}{l}+ \\
256 \\
256\end{array}$ & $\mid \begin{array}{l}+ \\
+ \\
256 \\
+\end{array}$ & $\begin{array}{c}+ \\
\vdots \\
+ \\
256\end{array}$ \\
\hline $\begin{array}{l}I .3 \cdot 4 \cdot 5 \\
I \cdot 3 \cdot 5 \cdot 6 \\
I \cdot 3 \cdot 6.7\end{array}$ & . & $\begin{array}{r}+ \\
+ \\
+ \\
\end{array}$ & + & + & $\begin{array}{l}+ \\
+ \\
+\end{array}$ & $\begin{array}{l}+ \\
+ \\
+ \\
\end{array}$ & $\begin{array}{r}+ \\
+ \\
+ \\
+\end{array}$ & $\begin{array}{r}+ \\
+ \\
+\end{array}$ & + & $\begin{array}{c}256 \\
+ \\
+ \\
\end{array}$ & $\begin{array}{l}256 \\
+\end{array}$ & $\begin{array}{r}256 \\
256 \\
+ \\
\end{array}$ & $\begin{array}{c}256 \\
256 \\
+\end{array}$ & $\begin{array}{c}4 \\
256 \\
256\end{array}$ & $\frac{+}{256}$ \\
\hline $\begin{array}{l}I .4 \cdot 5.6 \\
I .4 \cdot 6.7\end{array}$ & + & + & + & + & + & + & + & + & + & 4 & + & + & $\begin{array}{c}256 \\
+ \\
\end{array}$ & $\begin{array}{c}256 \\
+\end{array}$ & $\begin{array}{l}256 \\
256\end{array}$ \\
\hline $\begin{array}{l}2 \cdot 3 \cdot 4 \cdot 5 \\
2 \cdot 3 \cdot 5 \cdot 6 \\
2.3 \cdot 6.7\end{array}$ & + & $\begin{array}{l}+ \\
+ \\
\end{array}$ & $\begin{array}{l}+ \\
+ \\
\end{array}$ & $\begin{array}{l}+ \\
+ \\
+ \\
\end{array}$ & $\begin{array}{l}+ \\
+ \\
+ \\
\end{array}$ & + & $\begin{array}{l}+ \\
+ \\
+\end{array}$ & 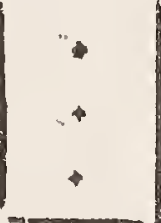 & $\begin{array}{l}+ \\
+ \\
+\end{array}$ & $\begin{array}{l}+ \\
+ \\
+\end{array}$ & $\begin{array}{l}256 \\
+\end{array}$ & $\begin{array}{c}256 \\
+ \\
+ \\
\end{array}$ & $\begin{array}{r}256 \\
256 \\
+ \\
\end{array}$ & $\begin{array}{l}256 \\
256 \\
\end{array}$ & $\begin{array}{c}+ \\
256 \\
256\end{array}$ \\
\hline $2 \cdot 4 \cdot 5 \cdot 6$ & + & + & + & + & + & + & + & + & + & + & + & + & + & 256 & 256 \\
\hline $3 \cdot 4 \cdot 5.6$ & + & + & + & + & + & + & +1 & 1. & + & + & + & + & + & $1+$ & 256 \\
\hline
\end{tabular}

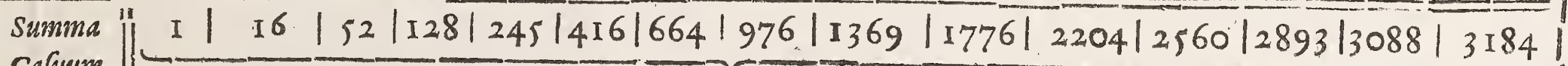





$$
P A R S T E R T I A \text {. }
$$

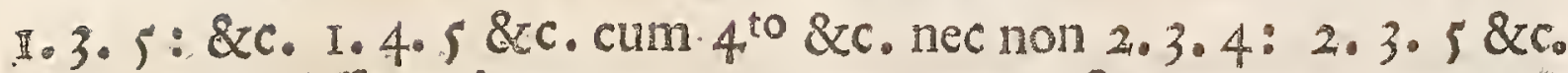
cum quarto differenti numero \&xc. \& . \& $8 x$. ufque ad $3.4 \cdot 5.6$ quầ cum omnes poflibiles combinationes funt completæ: quocirca primis harum combinationum in margine expreffis \& prætermiffis reliquis, notentur è regione fub fingulis quaternorum numerorum fummis, 256; prout hæc omnia in adjunctâ Tábulâ præêtita cernun tur.

Additis igitur in unam fummam, qui in eâdem ferie perpendio culari fibi refpondent, numeris, habebuntur omnes punctorum in vertice friptorum cafus, videl. I cafus pro punctis IV, I6 cafus pro punais $V, 52$ pro punctis $V I$; \& ita deinceps ufque ad puncta XVIII, qui numerus bis 16 , quater 36 , decies 96 \& octies 256 , id eft, in univerfum 3 I 84 cafibus expofitus eft. Et quoniam numeri punatorum fupra XVIII cum reliquis infra, finguli cum fingulis, purà $\mathrm{XIX}$ cum XVII, XX cum XVI \&zc. in numero cafuum conveniunt, ut initio monuimus \& oftenfu facile eft, fequitur, fi collecti punctis IV ad XVII cafuum numeri duplentur, duploque 32776 addantur 3184 cafus punctorum XVIII, aggregatum 35960 exhibiturum fummam omnium omnino cafuum. Quòd autem enumeratio ritè facta fit, nullaque combinationum prætermiffa, vel inde pater, quòd numerus quaternionum in rebus (putà loculis) 32, præcisè idem reperitur; eft enim ille, per Cap. 4. part.2,

$\frac{32.31 \cdot 30.29}{1.2 .3 .4}$ Do 35960 。

Inventis fic numeris cafuum pro quovis punctorum numero: cetera oppidò levia funt, \& expediuntur per Prop. 3. part. I. multiplicando videl. fingulos cafuum numeros per fingula præemias quæ iftis cafibus acquiruntur: nempe (cùm punatis IV in fup. laterculo tribuantur nummi $\mathrm{I} 20$, punctis XXXII nummi I 80, punctis $\mathrm{V}$ nummi 100 , punctis XXXI nummi 32, punctis VI 30 , punctis XXX 2, \&c.) multiplicando I cafum per 120 ; rưfusque per 180 ; 16 calus per 100 , ite umque per 3 ; 52 cafus per 30 , nec non per $25 \& \mathrm{\& c}$. five brevius, I per 30000 I $20+180,16$ per $132,00100+32,12$ per $553030+25$, atque ita deinreps ufque ad 3184 per 2 : ac tandem dividendo omnium produY 3

etorung 
Aorum fummam per fummam omnium cafuum 35960. Sic enina exibunt in quotiente pro expectatione aleatoris nummi $4 . \frac{3}{3} \frac{42}{5}:$ un de cum ipfe ex hypoth. folis 4. nummis jactum redemerit, appare potiorem illius quàm circulatoris fortem effe, iftumque proin hoc aleæ genere, ni præmia minuat, non multum lucrari poffe.

\section{Problema ẌVIII.}

\section{De Ludo chartarum, vulgò Trijaques?}

Ufitatifimum eft inter Germanos ludi genus, quod Trijaques appellatur, \& affinitatem quandam habet cum Gallorum Brelaw: Sumuntur ex Ludo chartarum folia 24 (rejectis cæteris) ex unaquaque fcil. fpecie fex; nimirum Novenarii, Denarii, Famuli, Heras, Rem ges \& Monades, quæ fuis pofthac literis initialibus N.D.F.H.R. $M$ denotabuntur, \& hunc dignitatis ordinem inter fe fervant: Primas tenet Monas, fequitur Rex, inde Hera, Famulus, Denarius; fedomnibus fupereminent Novenarii unà cum Famulotrifolii (quem proin etiam Novenariis accenfemus, fic ut 5 habeamus Novenarios, at 3 tantùm Famnlos ). Novenariorum præftantia, fimilis ferè horum, quos in ludo Hifpanico feu de l'Hombre dicto Matadors, latrones, homicidas five ficarios appellant, in eo confiftit, ut cujusvis dignitatis \& fpeciei chartis accenfeantur: fic duo Novenarii cum Monade, aut unus cum duabus juncti tres Monadas, feu Trigam (un Tricon) Monadum efficiunt: unus, duo vel tres Novenarii itipati tribus, duobus tnove Regibus Quadrigam Regum conftituunt: unus duove Novenarii in confortio crium duorumve ejufden fpeciei foliorum, quaterna illius fpeciei exhibent, ex.gr. qtaterna corda, fpicula, trifolia \& cujumodi chartarum complexio Fluvius, ein $\mathfrak{F l u p /} /$ dici confuevit, qui præterea numero punctorum æftimatur; numerantur autem pro Novenario aut Monade puncta II, pro cæterarum dignitatum char" wis fingulis puncta Io. Modus ludendi talis:

Singulis colludentium ordine bina diftribuuntur folia, quibus clam infpectis liberum eft primo arbitrariam pecunize fummam Geponere, quocum. fi congredi velit alter, tantundem deponet, aut 


\section{$P A R S I E R T I A$.}

etiam, ubi vifum fuerit, infuper adjiciet aliquid; quod pariter prior fuperaddere tenetur, fi depofiti fui jacturam facere nolit. Quo facto fingulis, qui ludum ingreffi funt, bina rurfum folia exhibentur, fed omnium palàm oculis in mensâ expofita; fic ut cujufque colluforis ludus cæeteris ex parte detectus, ex parte occultus fit: tum verò de novo pecuniâ certare incipiunt, außto, ut antea, alternis depofito, provocatoque pluris femper licitandi poteftate concefsâ. Tandem aperit unusquifque ludum fuum colluforibus, \& qui cæte-. ris potiorem habere deprehenditur, univerfo depofito potitur. Potior autem eft Quadriga Fluvio, \& Fluvius Triga, quibus omnibus præfertur Quadriga Novenariorum. In Trigis \& Quadrigis cæteris dignitatis ordo, in Fluviis punctorum numerus attenditur; fic Triga vel Quadriga Monadum prævalet Trigæ vel Quadrigæ Regum, \& Fluvius 4.3 punctorum alium 42 antecellit. Si nemo colluforum. Triga, Quadriga Fluviove fie inftructus, is qui plura ejufdem fpeciei puncta numerare poteft, depofito potitur. In cafu verò omnimodæ paritatis ludorum, ut cùm duo ejufdem dignitatis Trigam aut Quadrigam, vel totidem punctorum Fluvium numerant, is alteri victoriam præripit, qui ordine prior eft, feu qui primus chartas accepit.

Quibus fuppoftis \& intellectis poterit quilibet colluforum vifis primis fuis duobus foliis calculo fubducere, qua fibi fit expectatio ad vincendum, indeque colligere, quis in certando modus fit tenendus: quanquam enim licitationem non femper qualitati ludi proportionare debeat, ne colluforibus ludum fuum prodat (quaridoquidem anima hujus ludi eft fimulatio, \& hîc precipue in ufum vertendum, quod Galli vocant, faire lonne mine à mauvais jeu, ut alii, quibus melior fortaffe ludus contigit, fictâ hujus confidentiầ decepti ab ultrà-certando abferreantur) negari tamen non poteft, quin previa expectationis cognitio ad ipfam hanc fimulationem moderandam \& gubernandam adjumentum haud leve conferre polfit. Nos calculi fpecimen in unico tantùm exemplo exhibebimus;

Quoniam obfervatum olim mihi multoties recordor, hunc cui ab initio duo Novenarii obtigerant, non obftante hâc ludi bonitate perdidife, cupidus fum fciendi, quianto majorem talis vincendi quàm perdendi 


\section{I76 UARIS CONGECTANDI}

perdendi fpem habeat. Atque ut quaftionem plene determinem pono me ordine priorem effe collufore, mihi primis duabus chartis duos obtigiffe Novenarios, alterique unum (five quod hoc ex provo cationis meæ acceptatione præfumam, five quod aliunde mihicone ftet ) \& quærendam effe utriufque expectationem.

Primò confidero omnes poffibiles ftatus, in quos ludum profequendo pervenire poffum. Fieri autem potef, ut relique duæ, quas expecto, pagellæafferant mihi (prout in fubjuncta Tabula ordine fub lit. A videre eft, vel duos alios Novenarios, vel Novenarium cum Monade, Rege, Hera, Famulo, Denariove: vel duas Monadas, duos Reges, H. F. Denariosve: vel Monadem cum Rege, H. F. D-riove: Regem cum H. F. D-riove: Heram cum Famulo Denariove: Famulum denique cum Denario; easque dignitates vel ambas ejufdem fpeciei; vel diverfarum fpecierum, easque rurfum tales, ut vel alterutra fit ex fpecie trifoliorum, vel neutra: ob famulum enim trifolii, qui Novenariis accenfetur, difparitas hac fortes aliquantulum variat.

Deinde examino, quot cafibus fingula horum evenire poffint, confiderando, quòd poft acceptos à me duos Novenarios \& unum à Collufore, fuperfuns folia $2 \mathrm{I}$, interque illa duo adhuc Novenarii, 4 Monades, totidem Reges, Heræ, Denarii, ac 3.Famuli, (nam etiamfi collufor duo quoque folia acceperit, eoque propriè non nisi reftent 20 ; quoniam tamen alterum illorum mihi ignotum eft, tantundem hoc valet refpectu nefcientia mex, acsi non accepiffet, egoque ad duo qualiacunque ex 21 foliis æqualem expectationem habe rem. ) Quibus perpenfis facillimum eft enumerare cafus: cafus enim tot funt, quot foliorum refiduorum combinationes. Poffunt autem Novenarii refidui ambo fimul non nisi femel accipi: Novenarius cum Monade aut Rege \&c. bis quater feu octies, cum Famulo tantum bis ter feu fexies combinari poteft: Binarum autem Monadum aut binorum Regum \&c. funt fex, binorum Famulorum tres electiones: Porrò monas cum Rege, aut Hera \&c. ejusdem f́peciei, pronumero fpecierum quater; Monas aut Rex \& $\&$ cum Famulo tertantim fumi poteft. Rurfum Monadis \& Regis \&c. diverfarum fpesierum, quarum tamen altera fit trifoliorum, fex funt acceptiones; 
quandoquidem Monas trifolii cum fingulis Regibus, \& Rex trifolii cum fingulis Monadibus trium reliquarum fpecierum conjungi potef: quẻmadmodum etiam Monas trifolii cum Famulo alterius fpeciei ter conjungitur. Monas denique cum Rege, Herầ, Famulo \&c. aut alia duo folia datarum differentium dignitatum \& diverfarum fpecierum ( fed exclufo trifolio) fexies combinantur; cùm fingulæ ex. gr. trium Monadum cum fingulis reliquarum duarum fpecierum Regibus femel compingi polfint. Et fic facili negotio combinationum feu cafuum numeri finguli "determinabuntur, quemadmodum in media columna fub lit. B notaci funt. Eorum omnium fumma vel aggregatum reperitur $2100 \frac{21.20}{1.2}$ quantus etiam eft $\mathrm{ku}$ merus binionum in chartis $2 \mathrm{I}$.

Tertiò calculo perquiro, quæ meæ vel colluforis fint expectatio: nes in fingulis recenfitis ftatibus; quem in finem confidero ante 0 mnia, quod exhibitis mihi duobus aliis foliis refidua funt folia 19, quorum tria collufori debentur; fic ut ejus ludus tot variationibus obnoxius fit, quot terniones in rebus 19 habentur, nempe $\frac{19.18 .17}{1.2 .3}$ x 969, è quibus quot ipsi faveant, quot adverfentur, in quavis ludi mei conftitutione porrò explorandum eft; Patet autem, quòd five duobus meis Novenariis accedant duo alii Novenarii, feu Novenarius unus cum Monade, neceffario perdere debet collufor; tunc enim habebo Quadrigam Novenariorum aut Monadum, \& ego fum ex hy= poth.ordine prior collufore, qui Monadum tantùm Quadrigam ad fummum confequi poteft. Sin Novenariis meis accedat Novenarius cum Rege, habebo Quadrigam Regum, \&z vinci poflum à collufore, fi hic Quadrigam Monadum obtineat; unde cim in refiduis is foliis lateant 5 (unus videl. Novenarius \& 4.Monades) quorum terna qualiacunque addita Novenario, quem habere præfumitur collufor, Monadum Quadrigam efficiunt; atque in rebus 5 contineantur terniones 10, fequitur colluforem meum in variationibus 969 habere $10 \mathrm{ad}$ vincendum \& creteros ad perdendum; id quod ipsi fortem parit $\frac{1}{25} \overline{9}^{\circ}$ Si cum Novenario Hera mihi contingat, habebo Quadrigam Herarum, \& vincere poteft collufor, five Monadum five Regum Quadrigam confequatur; quare prater 10 cafus priores nunc alios $10, h, e .20$ ad 


\section{ARTIS CONJECTANDI}

vincendum habet, id quod ipsi valet $\frac{2}{55} \overline{2}$. Similiter si cum Novenario Famulum obtineam, præter 20 cafus memoratos vincere potelt collufor ro aliis, quibus quadrigam Herarum confequitur; unde. jam ejus fors exiftit $\frac{3}{5} \overline{9}$. Sed fi Novenarius meus Denario ftipetur, fic ut: infuper Quadriga Famulorum colluforem viktorem reddere poffit, accedentibus ad priores 30 cafus duntaxat 4 aliis, fors ejus fiet $\frac{34}{56}$; quippe cum in foliis 4 (quæ ipfius Novenario Trigam Famulorum addere poflunt) tribus fcil. Famulis \& uno refiduo Novenario non nifi terniones 4 habentur.

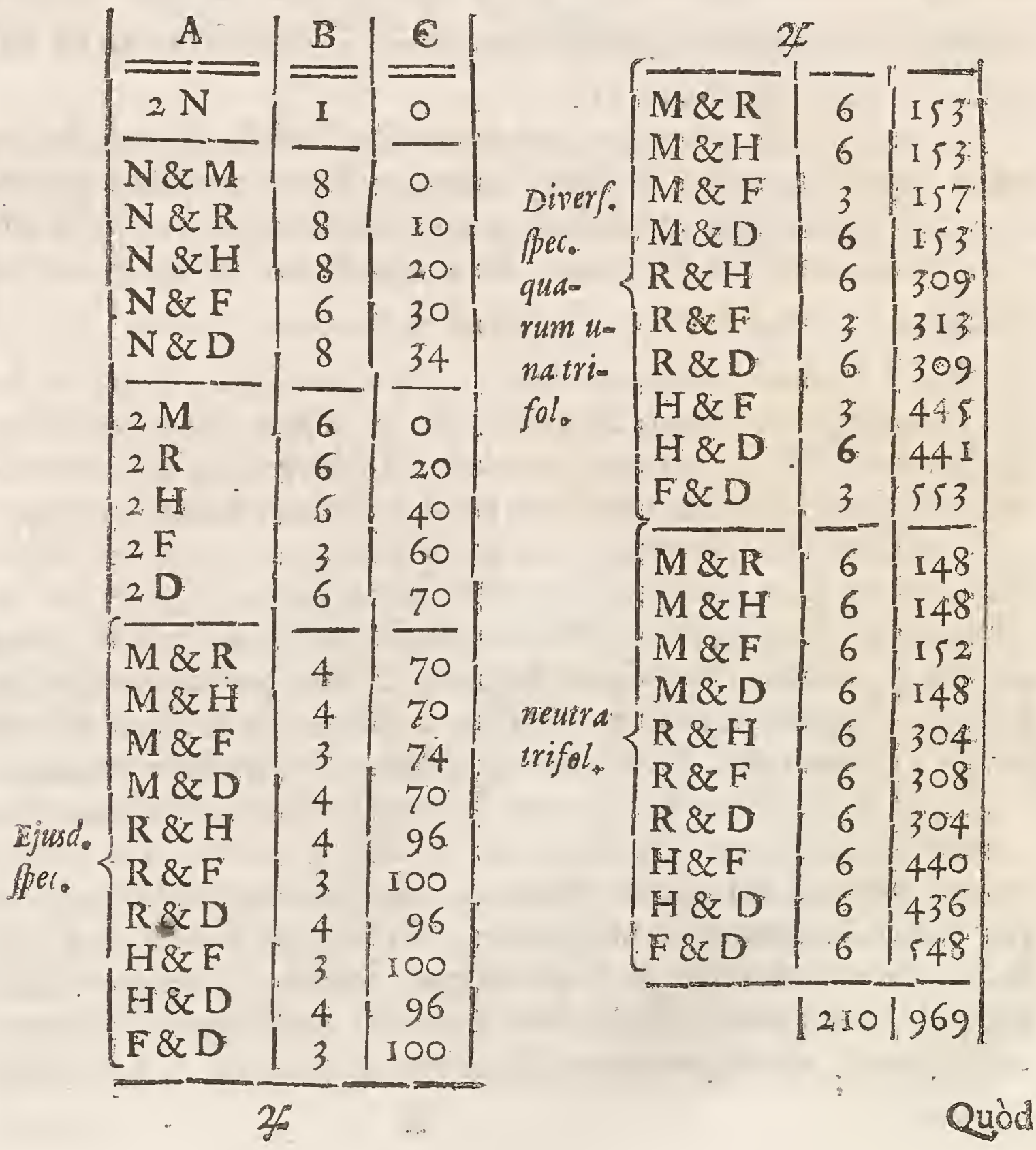




\section{- A R S TETIA.}

Quòd si Novenariis meis duæ Monades accefferint. rurfus in allibiliter perdet collufor: fi duo Reges, ipfe vincere cum Monadum Qu driga poteft; fed propter 4 Monadas \& duos nunc refiduos Novenmios, i. e eb fex folia, quorum terniones omnes Novenario colWhoris junei Quadrigam hanc confituere pofunt, viginti tunc ad sincendum cafus habet. Quibus ob fimilem rationem accedunt alio 20, $f$ loco Regum duas Heras: \& rurfus 20, fi duos Famulos adeptus fuero. Sed fi duos Denarios accepero, precedentibus tantum fuperaddendi cafus to; propterea quia funt folia folum 5 ( Famuli fil. tres \& duo refidui Novenarii) quorum temiones Famulorum Quadrigam col'ufori advehere poftunt. Unde expectationes illius ordinc habentur $\frac{20}{969}$. $\frac{47}{59}, \frac{60}{06 \%} \& \frac{70}{259}$.

Porro, fi No naris meis jungatur Monas cum Rege, Hera, Farulo, Denario homogeneo, habebo Fluvium 43 punctorum, \& vincet collufor cum Quadriga qualicunque, ron aliter: fin iis accedat Rex cum Hera, Famulo, Denariove homogeneo; aut Hera cum Famulo \&xc. habebo duntax?t Fluvium 4.2 punetorum; \& vinset collufor cum qualicunque Quadriga, atque infuper cum Fluvio 43 puntrorum. Si vero mihi cadat Monas cum Rege heterogeneo \& $c_{0}$ habebo folummodo Trigam Monadum, \& vincere poteft alter cum Quadriga pariter ac Fluvio qualicunque; cujus proinde expectationes pro fingulis his ftatibus pari modo feorfim inveftigantur, fed eo majori fubinde labore, quo major collufori vincendi fpes allucefsit. Unde cùm omnia minutatim profequi nimis prolixum foret, operationem apponam pro ultima tantùm hypothefi, quâ pono mihi cecidiffe Famulum cum Denario alterius fpeciei (putà Famulum cordium cum Denario fpiculorum ) adeoque nonnifi Famulorum T'riga me inftructum effe. Colluforem itaque victorem reddet Quadriga quæcunque \& Fluvius quilibet, nec non Triga Monadum, Regum atque Herarum: Quadrigarum cafus determino, confiderando, refidua 19 folia confiftere præter $2 \mathrm{~N}$ in $4 \mathrm{M}, 4 \mathrm{R}, 4 \mathrm{H}, 2 \mathrm{~F} \&$ $3 \mathrm{D}, \mathrm{h}$.e. (Novenariis ad fingulas dignitates adjunctis) in $6 \mathrm{M}, 6$ $\mathrm{R}, 6 \mathrm{H}, 4 \mathrm{~F} \& 5 \mathrm{D}$ : horum namque terniones oftendunt, obtingere ipsi poffe Quadrigam Monadum cafibus 20, Regum \& Heraruni tom tidem, Famulorum cafibus 4 \& Denariorum ro, quorum omnium fumma dat cafus 74. Fluviorum porrò multitudinem ita crplon: z. Atterdo, 
Attendo, quod in reliquis 19 foliis præter $2 \mathrm{~N}$ reperiuntur 4 fpicula, 5. lateres, 4 corda \& 4 trifolia; \& quòd ad Fluvium confituendum ultra Novenarium, quo colluforem jam compotem effe præfumo, requiruntur vel teina ejusdem fpeciei folia, vel faltem bina, affumto una Novenariorum refiduorum alterutro: indeque concludo, Fluviorum numerum æquari numero ternionum in omnibus fpeciebus, unà cum numero binionum bis fumto; quare cùm terniones omnes fint $4+$ $10+4+40022$, \& biniones omnns $6+10+6+6028$, fequitur, fummam cafuum ad Fluvios fore $22+28+28 \times 78$. Ad Trigas denique quod attinet, earum numerum inire pofium, fi perpendam, quòd ad Trigam Monadum (Regum five Herarum) conftituendam, Novenario quo jam pollet collufor jungendæ vel binæe. Monades (Reges aut Heræ) vel fingulæ unà cum aflumto. Novena riorum refiduorum alterutro: fi binæ junguntur, quartum folium po terit effe quodlibet ex reliquis 13; adeo ut, cùm 4 Monades (Reges Heræ) fexies poffint bina accipi, fexies quoque $3, i$. e. 78 hinc variationes oriantur: fi una fola Monas (Rex aut Hera) ei jungitur cum Novenariorum reliquorum alterutro, pro quarto folio accipi poterit. unumquodvis ex reliquis fpeciebus, quod fit inferioris dignitatis; nimirum cum Monade laterum figillatim poffunt accipi 9 folia, \& cum fingulis reliquis ro; cum Rege laterum 6, \& cum fingulis reliquis 7; cum Hera laterum 3 , \& cum fingulis reliquis $4 ;$ inde Monadum cafus emergunt 39,2 Regum 27 , Herarum 15 , qui numeri ob duos refiduos Novenarios bis fumpti \& poftmodum feorfim additi fupra. inventis 78 aliis variationibus producunt Trigas Monadum 156, Regum 132, \& Herarum 108, qua rurfus collectæ faciunt 396. Quoniam igitur repertum nobis eft, omnes Quadrigarum cafus effe 74 . Fluviorum $78, \&$ Trigarum, quæ quidem colluforem victorem reddere poffunt, 396 , fequitur quòd conflatis in unam fummam his nut meris aggregatum 548 defignet omnes in univerfum cafus, quibus: ille victoria potiri poffit; adeò ut ejus fors exiftat $\frac{58}{95}$, quemadmodum etiam fupra in laterculo fub lit. C. videre eft, ubi ordine notaqi habentur numeratores fractionum, quæ exprimunt expectationes: colluforis in quovis ludi mei ftatu, quarumque omnium communis: denominator exiftit 269 .

His: 


\section{PARS TERTIA.}

His verò inventis, ut exploretur fors, de qua principaliter quæftio mota fuit, quam nimirum habemus priusquam ego poftrema duo folia accipiam, nil fupereft aliud, quàm ut numeros cafuum $\mathrm{co-}$ lumnæ $B$ ducamus in numeratores répondentes columnæ $C, \& x$ fummam productorum dividamus per productum numeri ormnium cafuum 210 in communem denominatorem 969 : vel, quod brevius, ut numeratores omnes col. C, quibus æqualis cafuum numerus in col. B refpondet, prius addantur, ac tum fumma per illum cafuum numerum multiplicetur; tandemque productorum omnium aggre-gatum dividatur, ut antea. Et fic quidem reperio, collufor is mer fortem effe $\frac{3 .{ }^{1902}+4.498+6.4614+8.64}{210 \text { in } 969} \infty \frac{35894}{203490} \infty 0 \frac{17947}{101745} ; \mathrm{un}$ de mëa fiet $\frac{83798}{101745}$, paulo minùs quàm $\xi^{\text {ies }}$ potior altera .

Cæeterum examinanti Tabellam primo obtutu multa alia Theoremata ultro fe offerunt, qualia funt hæc: Quod ad æquam perveniam expectationem per Novenarium cum Hera, atque per duos Reges; item, per duos Denarios, 'atque per Monadem cum Rege, Hera, Denariove homogeneo: Quòd optabilior mihi fit Novenarius: cum Famulo Denariove, quàm dure Heræ: Quòd duo differentium dignitatum \& fpecierum folia femper tantillo praftabiliora fint, fi neutrum, quàm si alterutrum trifolium foret: Quòd Hera cum Denario alterius fpeciei meam, Famulus cum Denario colluforis conditionem paulo potiorem reddat \& $c$.

Et hrec quidem omnia ita fe habent in hypothefi, qua fupponit duos mihi ab initio Novenarios, unum collufori obtigiffe; nam si de neutro colluforis folio mihi conftare fupponatur, aliæ prodibunt expectationes \& alia Tabula, quam induftrius Lector mutatis mutandis fimili modo concinnabit. Inveniet autem. si calculum ritè fubduxerit, fortem meam hoc cafu ad colluforis fortem fe habere, ut 346988 ad 26077, adeoque nunc plus quam tredecies hâc meliorem effe.

Animus præterea fuerat, quasdam alias quæftiones, de quibus: frequens inter collufores fermo mifcetur, folutas hîc tradere; ex. gr. An preftabilior fit ab initio ludi Novenarius cum Famulo Dena- 
82 LATIS CONJECTANDI

riove, an vero duæ Monades? Aut uter duorum, quarum alter ab initio duas obtinuir Monadas, alter Novenarium cum Famulo Denariove, potiorem vincendi fpem habeat? \& frmiles. Sed quia futilibus nimiam jam impendiffe eperam videri poffum, hæc \& alia rerum harum curiofo Lectori indaganda \& calculo definienda relinquo.

\section{PROBLEMA XIX.}

In quolibet Alea genere, fi ludi Oeconomus fen Dispenfator (le Banquier du Jeu) nonpibil babeat prerogative in eo confiftentis, ut paulo major fit cafunm numerus quibus vin. cit quàm quibus perdit; EG major fimul cafunm numerns, quibus in offcio Oeconomi pro ludo fequenti confirmatur, quam quibus ceconomia in colluforem transfertur. Queritur, quanti privilegium boc Oeconomi lit afimandum?

Sit in quolibet aleæ jactu numerus cafuum quibus vincit œeconomus, ad numerum cafuum quibus perdit, in ratione $p$ ad $q$, majoris ad minus: item numerus eorum quibus ipsi ceconomia pro jaEtu fequenti confirmatur, ad numerum horum quibus illa in colluforem transfertur, in ratione $m$ ad $n$, rurfum majoris ad minus. E. videns eft, fi folius præfentis, nulla fequentis ludi haberetur ratio, fore (propter $p$ calus ad depofitum I, \& $q$ ad 0 ) fortem œconomi $\frac{p}{p+q}$, colluforis $\frac{q}{p+q}, \&$ ambas in ratione $p$ ad $q$. Sed si. ad futuros quoque ludos refpiciatur, res plus obfcuritatis habet, nee obvium ftatim eft, quomodo prerogativa præfentis ludi \& fpes ad 
prarogativam fequentis conjunctim fint eftimanda; ac proinde fa. cilis in paralogifmos prolapfus eft, nisi probè advertatur. Memini me aliquando fic argumentatum fuiffe: Si idem perpetuò maneret œconomus, femper eandem haberet prærogativam feu fortem, quan ratio $p$ ad $q$ definit; igitur quando periculum eft amittenda oeco nomiæ, hactenus pejor ejus conditio cenfenda videtur. Sit hæc $x_{2}$ $\&$ colluforis $y$; fiet ( ob $p$ cafus ad $\mathrm{I}, q$ ad $o, m$ cafus ad permanendum in ftatu oconomi, \& $n$ cafus ad acquirendum ftatum colluforis ) $x \infty \frac{p+m x+n y}{p+q+m+n}, \&$ fimili modo fors colluforis $y \infty$ $\frac{q+m y+n x}{p+q+m+n}$; quibus æquationibus debite inter fe collatis habetur $x_{0} y:: p+n \cdot q+n$ minor, uti collegeram, quàm $p$ ad $q$. Alia vice fic arguebam: Si cconomo debeatur $\frac{p}{p+q}$, collufori $\frac{q}{p+q}$ depoliti, fintque $m$ cafus quibus ille in Ratu economi confirmatur, \& $n$ cafus quibus in ftatum alterius tranfit, erit fors ejus $\frac{m \cdot p: p+q+n . q: p+q}{m+n} \infty \frac{m p+n q}{m+n \cdot p+q}$, relinquiturque alteri $\frac{m q+n p}{m+n \cdot p+q}$; fic ut atio fortium fiat, ut $m p+n q$ ad $m q+n p$ rurfum minor quàm $p$ ad $q$, etsi diverfa $\mathrm{ab}$ alterấ $p+n \mathrm{ad} q+n$. Vix autem ita collegeram, cùm utrumque hoc ratiocinium rurfus ceus præpofterum \& fallax rejeci, quippe cui fummè videbatur \&̌rsто", ut major probabilitas retinendi quàm amittendi munus œconomi mi nuere potiùs quàm augere dicatur prærogativam ceconomiæ annexam: quare aliquandiu eo propendebam, ut crederem prærogativam hane compolitam effe debere ex utraq; ratione $p$ ad $q, \& n$ ad $n$; adeoq; fortem oconomi ad colluforis fortem effe in ratione $p m$ ad $q n$, ma ore quàm $p$ ad $q$, vel $m$ ad $n$ feorfim. Verùm necifud affertum evidentix quicquam habere fenfi, quin \& reapfe à vero abludere deprehendi, poftquàm genuinum folvendi modum reperifern. Nolo autem often. dere, in quo laborent allata ratiocinia . ad veriorem potiùs fine morâ folutionem tranfiturus, præ cujus jubare fpurium illorum lumen mox wltrò difpariturum puto.

Hane qui legirimè inveftigare cupit, ad duo advertere debet. graxm, ut per Coroll.5. Propof.3. part. I. detenminet, quantum becono- 


\section{4}

ceconomo non ex toto depofito, fed ex folâ colluforis pecunia debeztur: alterum, ut hanc illi debitam portionem pro fingulis fubfequentibus jactibus five ludis feorfim exploret, quo omnium additione totalis expectatio patefcat. Pofito itaque Aleatores ita inter fe convenif$f e$, ut poft quemlibet jactum vidus victori tradere teneatur $a$, liquet, habere œconomum in primo jåtu $p$ cafus ad lucrandum $a, \& q$ cafus ad perdendum $a, h . e$. ad acquirendum $-a$; adeoque partem ipfi debitam ex colluforis pecunia effe $\frac{p \cdot a+q \cdot-a}{p+q} \infty \frac{p a-q a}{p+q}$ reu (factis $p-q \infty r, \& p+q \infty s) \frac{a r}{s}:$ quemadmodum contra collufor, ob $q$ cafus ad lucrandum $a, \& p$ ad perdendum, habere cenfetur $=a r$. Et quoniam præterea oconomus in primo jastu habet $m$ cafus, quibus privil egium œconomix retinet, h. e. quibus acquirit pro jactu fecundo $\frac{a r}{s} ; \& n$ calus quibus illud amittit, h.e. quibus acquirit $\frac{-a r}{s} ;$ debebitur etiam ipsi ex pecunia colluforis a fecundi jactus $\frac{m \cdot{ }^{a r: s}+n . \text {-ar:s }}{m+n} \infty \frac{m a r-n a r}{m+n . s} \infty$ (verlis $m-n$ in $t, \& m+n$ in $\left.\gamma\right)$ $\frac{a r t}{s r}:$ \& collufori vicifim ex pecunia œconomi $\frac{-a r t}{s v}$, id eft, propter fignum - debebit ille huic tantundem. Similiter ob eofdem m \& $n$ cafus primi jactus, quibus œconomia pro jactu fequenti vel confirmatur œconomo, vel ab ipfo aufertur, fiet per modo oftenfa ipfius jus in pecuniam a tertii jactus, ceu à fecundo fecundi,

$$
\frac{m .^{a r t i s b}+n-a r t: s v}{m+n} \infty \frac{m-n \cdot a r t}{m+n \cdot s v} \infty \frac{a r t t}{s p b} ; \text { \& colluforis vicif }
$$

fim $\frac{-a r t t}{s y b}$. Atque fic porrò eadem ratione invenitur deberi œconomo de pecunia jactus $4^{\mathrm{ti}}$, ceu à fecundo tertii,

$\frac{m a^{a r t i s \nu v}+n-a r t t: s \nu v}{m+n} \infty \frac{a r t 3}{s{ }^{3}} ;$ \& de pecunia jactus $5^{\text {ti }}$

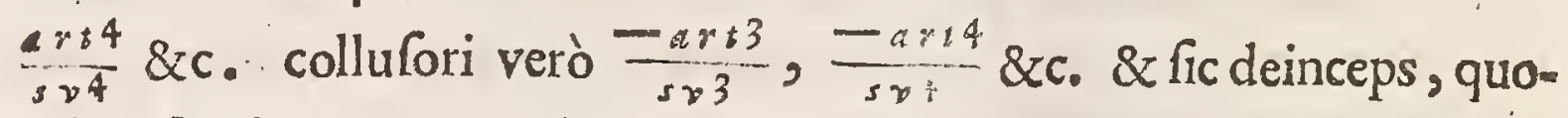
ufque fuerit opus. Collectis igitur in unam fummam portionibus; quæ œconomo pro fingulis fucceflivè jactibus debentur, fiet ejus expectatio 
peratio totalis $\frac{a r}{s}+\frac{a r t}{s v}+\frac{a r t}{s v^{2}}+\frac{a r t z}{s v^{3}}+\frac{a r t}{s v^{4}} \& c$. expreffa vid. per feriem quantitatum geometrice progredientium in ratione $v$ ad $t$, eo uqque continuandam, donec numerus terminorum æquetur numero jactuum feu lufionum, de quo initio inter Aleatores convenit, aut quem alias ante difceffum eorum abfolvi poffe præfumitur. Hunc

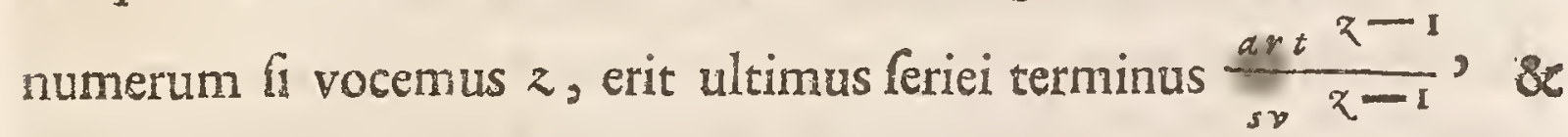

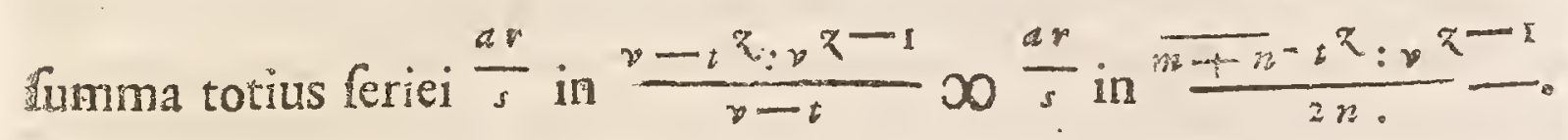

coroll. I . Si differentia inter $m \& n$, adeoque ratio $\frac{t}{v}$ minufe cula fit, aut faltem numerus lufionum $z$ majufculus, pro fumma ina venta poterit fribi $\frac{a r}{s}$ in $\frac{m+n}{2 n}$ abfque fenfibili exceflu, evanefcente vid. quantitate $\frac{t_{0} z}{v z^{-1}}$, quippe ad $v \& t$ eo ordine proportionali, quem indicat numerus lufionum $z$ unitate auctus . Quare tum valor totius prærogativæ œconomi, ad $\frac{a r}{s}$, id quod ipfi pro folo primo ludo deberetur, ferè fe habet, ut $m+n$ ad $2 n$.

Cor . 2. Si tempore exiguo magnus lufionum numerus poffit abfolvi, ceconomus autem à ludendo defiftere, alterique cuidam fuam prærogativam vendere velit, accipiet ab ipfo $\frac{a r}{s}$ in $\frac{m+n}{2 n}:$ if verò in lufu pergere, \& ceconomiam tantùm cum ftatu colluforis permutare cupiat, dabit ipsi collufor, qui in ceconomi munus fuccedit, duplum, nempe $\frac{a r}{s}$ in $\frac{m+n}{n} ;$ fimplum enim ipsi deberet, fi nunc à ludo omninò ceffare vellent; ac deinde rurfus tantundem, si̊ ludum redaufpicari, alterque fibi oconomiam fponte cedere cupe ret.

Car. 30. Si fit $m \infty p, \& n \infty q$, valor $\frac{a r}{s}$ in $\frac{m+n}{2 n}$ cond

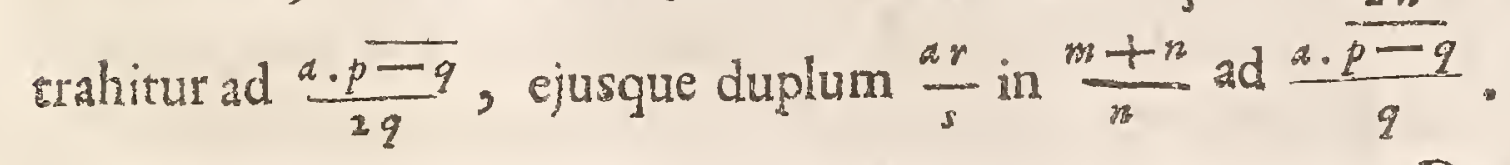




\section{Affrmatio fortis in ludo chartarum, vulgo Capriludium, sas Bocefpicl, dicto.}

Ufus hujus ludi frequens inter noftrates. Inftituitur chartis luforiis inter duos pluresve collufores, quorum unus, qui contra cæreros decertat, \& ceconomi fungitur munere ( Der Den $\mathfrak{J e c k}$ bat/) poftquam folia mifcuit, eorum fyftema in tot manipulos difpefcir, quot una fecum collufores adfunt; tum finguli horum fingulos fibi manipulos ad.moto pretio mercantur, poftremum oconomo relinquentes, qui tandem inverfis manipulis ima eorum folia, præter qua alia nulla confiderantur, retegit: Quo facto his, quorum folia dignitate fuperant folium aconomi, pendere tenetur œconomus tantum, quantum quisque aleæe expofuit; fed quibus folia cecidêre humilioris vel etiam paris dignitatis cum follo coconomi, illi depofiti fui jacturam patiuntur, cedente hoc contra in emolumentum victoris ceconomi, qui fuo præterea munere fungi pergit, quamdiu vel unicum colluforum devicerit, nec officio ceconomi exuitur, niff ab omnibus omninò colluforibus fuerit fuperatus .

His pofitis \& intellectis, fi valor expectationis aconomi fit inveftigandus, determinandæe tantùm reftant rationes $p: q, m: n$, hoc eft, definiendum quot cafibus vincere $\&$ quot perdere queat $\mathfrak{c}_{-}$ conomus in quavis lufione; item quot cafibus ille jus œconomi fervare, quot amittere poffit: cætera enim ex præced. Problemate repetuntur. Sit itaque numerus fpecierum, in quas divifum eft chartarum fyftema, $f ; \&$ numerus dignitatum in quavis fpecie, $g ;$ adeoque univ erfus foliorum numerus $f g$. Unde

I. Si duo tantim funt manipuli; patet, ambo eorum folia ima toties variari poffe, quot biniones in univerfis foliis $f g$ continentur, nempe $\frac{f_{g} \cdot \overline{f g}-1}{2}$. Horum binionum nonnulli ejusdem, alii differentium dignitatum chartis conftant, quorum numerus feorfin fic initur: Quoniam uniuscujusque dignitatis folia / biniones recipiunt $\frac{f-1}{2}$, \& dignitatum numerus eft $g$; idcirco numerus omnium bir 


\section{PARS TERTIA.}

nionum, qui folia exhibent ifodynama five ejusdem dignitatis, eft $\frac{\overrightarrow{f g} \cdot \vec{f}-1}{2}$, quo fubducto ab univerfis $\frac{f g \cdot \overrightarrow{f_{g}-1}}{2}$, relinquitur $\frac{f g f_{g}-f}{2}$ $\infty \frac{f g \cdot g-1}{2}$ numerus binionum, qui differentium dignitatum folis conftant. Atqui cùm ambo folia ima funt ifodynama, utrumvis fibi eligat collufor, ceconomus ex ludi præfcripto non poteft non vince$r e$, id quod ipsi valet I; fin verò diverfis pollent dignitatibus, uterque æqualem habet ad vincendum \& perdendum expectationem, quandoquidem collufor æque facile humilioris ac altioris dignitatis folium eligere poteft, id quod utrivis valet $\frac{x}{2}$. Sunt igitur ceconomo $\frac{f g \cdot f-1}{2}$ cafus ad I, \& $\frac{f g \cdot g-1}{2}$ ad $\frac{x}{2}$, quod facit $\frac{f g+f-2}{2 f g-2}$, \& relinquitur ejus collufori $\frac{f g-f}{2 f_{g}-2}$ : hoc verò per Annot . ad lit. I. Prop. XI. part. I. tantundem eft, acfi haberet ceconomus $f_{g}+f-2$ cafus ad lucrancium, $\& f g-f$ cafus ad perdendum; quare conftat effe $p \cdot q:: f g+f-2 . f g-f$. Et quoniam is præterea retinet pro ludo fequenti jus ceconomi, quoties vincit; eoque excidit quoties perdit, patet etiam hîc effe $m \propto p, \& n \infty q$.

Nota, fi fit numerus epecierum $f x 4$, fit $p \cdot q(:: m: n)$ $\therefore 2 g+1.2 g-2$; quxe rurfus pofito numero dignitatum $g \times 09$ reducitur ad $\rho . q:: 19.16$. Hinc fumto, quòd collufor pro fingulis lufionibus deponere foleat $a$, debebitur œconomo per præced. Probl. ejusque Coroll. 3 . pro primo ludo $\frac{a r}{s} \infty \frac{a \cdot p-q}{p+q} \infty \frac{3}{35} a_{2}$ pro omnibus ludis $\frac{a \cdot \overline{p-q}}{2 q} \infty \frac{3}{3} a$, exceffu non fuperante unam centies millionefimam partem ipfius a in ludis tantùm 7 . Si igitur œconomus à ludo ceffare velit, tertio cuidam prærogativam fuam vendere poterit pretio $\frac{3}{3} a_{j}$ at si ludum continuare, \& jus tantùm. fuum in colluforem transmittere malit, accipiet ab ipfo duplum, rempe $\frac{3}{1} \bar{\sigma} d$.

2. Si tres funt manipuli, totidemque unà cum œconomo funt collufores, liquet, duorum quorumvis manipulorum folia infima to: rurfum variationibus obnoxia fore, quot biniones in univerfo chartarum numero continentur, chm tertius manipulus confiderari poffic 
acsi abeffet, ejusque folia omnia cateris manipulis adhuc effent permis fta : quare ceono no tor erunt calus, quibus utrumvis fuorum colluforum feorfim fuperet, aut fuperetur ab iplo, quot eranr in hypothef duorum vantùm manipulorum; hoc eft, mancbit, ut antea, $p \cdot q:: f g$ $+f-2 \cdot f g-f::($ in cafu $f x 04) 2 g+\mathbf{I} \cdot 2 p-2$. Sed variat ratio m ad $n$, pro numero colluforum feu manipulorum, quorum quo plu res funt, hoc diffic liùs ceconomum munere fus excidere permittunt. Pro tribus manipulis confidero, eorum folia ima tor variationes fub. ire poffe, quot terniones recipiunt omnia folia 48 (fic pono pro $f_{3}$. concifroris calculi ergò, \& quòd prater quaternarium non alius fpecierum numerus fit in ufu) nempe $\frac{4 g \cdot 4 g-1 \cdot 4 g-2}{1 \cdot 2 \cdot 3} \infty \frac{32 g^{3}-24 g g+4 g}{3}$. Horum ternionum nonnulli ex tribus foliis ejusdem dignitatis, alii ex duobus ejusdem cum tertio diverfa dignitatis, alii denique ex trium differentium dignitatum folis confant: nimirum, cùm cuiusq; dignitatis folia 4 , terniones admittant 4 , biniones 6 , 8 dignitatum numerus fitg, erit numerus omnium ternionum ejusdem dignitatis $4.8, \&$ binionum $G g$, quorum rurfus binionum quilibet fecum aflumere potef: quodliber es reliquarum $g$ - I dignitatum foliis 48 - 4 ; quod efficit terniones $24 \mathrm{gg}-2.4 \mathrm{~g}$, quorum una medietas $12 \mathrm{~g} g-12 \mathrm{~g}$ duobus folis ifow dynamis tertium altioris, alcera medietas rentum inferioris dignitatis folium adjunctum habet; unde fubductis $4882248 g-24 \mathrm{~g}$ ex uni verfo ternionum numero $\frac{32 g^{3}-24 g g+4 g}{3}$ remanent terniones. $\frac{3^{2} g^{3}-963 g+64 g}{3}$, qui omnes trium differentium digniratum folia exhibent.

Jam autem si tribus manipulorum folis infimis ejuddem dignita tis effe contig rit, œconomus ex ludi præf fripto ceconomi r excidere nequit, utrumq; fors tulerit: neq; etiam, cum duobus ejusdem, tersium $\mathrm{e}_{-}$ Icvationis dignitatis fuerit adjundti at si tertium hoc humilionisuerit gradus, wel etiam omnia tria folia dignitutis gradu dife epent, coconomus uno calu jus fum amitere (fi nempe infini gradus folium fibi cem ciderit, duobus fervare poteft, quodipsi valet ${ }_{3}^{2}$. Sunt igitur ipsi $4.8 \mathrm{ca}=$ fus ad I, \& rurfus $12 \mathrm{gg}-12 \mathrm{~g}$ callus ad $\mathrm{s}$, nec non $12 \mathrm{gg}$ - I $2 \mathrm{~g}$ ad $\frac{2}{3}$, iserum 


$$
\text { PRSTERTLA. }
$$

$\frac{32 g 3-96 g g+64 g}{3}$ ad $\frac{2}{3} ;$ id quod facit $\frac{16 g g-3 g-4}{24 g g-18 g+3}$, \& relinqumntwr ad complendam unitatem $\frac{8 g g-15 g+7}{24 g g-18 g+3}$; quod tantundem eft, acsi diceretur habere $16 g g-3 g-4$ cafus ad fervandam, $8 x$ $8.8 g-15 g+7$ cafus ad amittendam oeconomiam; aded ut inventa sit ratio $m_{0} n:: 16 g g-3 g-4.8 g g-15 g+7:$

Nota, fig determinetur ad 9 , erit $p: q: 019: 16, \& m: n \infty$ $253:$ I 04 . Unde polito, quòd alter colluforum depofuerit $a, \&$ alter $b$, debebitur ceconomo per præced. Probl. ejusque Coroll. $\frac{a \cdot p-q \cdot m+n}{p+q \cdot 2 n} \infty \frac{153}{1040}$ refpectu prioris, \& $\frac{b \cdot p-q \cdot m+n}{p+q \cdot 2 n} \infty \frac{153}{1040} b$ refpectu pofterioris colluforis; adeoque refpecu utriufq; $\frac{153}{1040} \overline{a+b}$ non excedente una centies millefrmâ parte ipfrus $a+b$ in ludis undecim. Quapropter ceconomus gquarto cuidam, qui in locum futum fuccedere cupiet, privilegium fuum vendet pretio $\frac{193}{10+0} \overline{a+b}$; alterutri verò colluforum, quicum vices fuas pirmutare volet, putà illi qui depofuit $a$, pretio $\frac{193}{1040} \overline{2 a+b}$; nam deberettur ipsi primo per modo dicta $\frac{I_{53}}{1040} \overline{a+b}$, filudus nunc abrumperetur; ac deinde, fi reaffumeretur, adhuc $\frac{153}{1040}$ a, quandoquidem cedendo alteri csconomiam ludi, fe debitorem ejus pro hac fumma conftituit.

3. Si quatuor confitutuntur manipuli, totidemgue cum oconomo habentur collufores, tot rurfum cafus præfto funt, quibus ille unumquemque fuorum colluforum feorfim vincat aus vincatur ab ipfo, quot erant in duabus precedd. hypoth. quod idem etiam intellige de quovis manipulorum numero, cum certè bini ipforum quivis confiderari remper poffint, acfi præter iplos nulli adeffent; unde. eadem perpetuo manebit ratio $p: q 002 g+1: 2,-2$. Sed alteram rationem $m: "$, quam numerus manipulorum auget, fic exploro: Confidero, quòd quatuor manipulorum folia ima, $l$. vel omnia poffint effe ifodynama five ejusdem dignitatis: $\mu$. vel tria ejusdem cum quarto aut altioris, $H$. aut humilioris dignitatis: $I V$, vel duo ejus dem, \& relsqu duo p riter ejusdem, fed diverfe ab altera dignitasis: $V$, vel duo ejusdem cum reliquis duobus diverfarum dignica- 
tum, quarum rurfus vel utraque poffit effe eminentioris: VI. vel uे. traque ignobilioris: VII. vel una eminentioris, altera inferioris gra dus: VII. vel omni a deniq; quatuor folia differentium dignitatum.

Horum fi Primum, Secundum, Quartum aut Quintum conti. gerit, ceconomus ex ludi præfripto muneris fui jacturam facere nequit: fi Tertium, VI, VII, vel VIIIvum acciderit, uno tantùm illud cafu amittere ( $f 1$ vid. infimæ dignitatis folium fibi relinguatur) tribus cafibus retinere poteft; quod ipsi proin dat $\frac{3}{4}$. Sed primum horum evenire deprehendo cafibus $g$; Secundum cafibus $8 g g-8 g$ : Tertium totidem: Quartum I $8 \mathrm{gg}$ - I $8 \mathrm{~g}$ : Quintum cafibus $16 \mathrm{~g}^{3}$ $-48 g g+32 g:$ Sextum \& Septimum totidem: Ultimum deniq; cafibus $\frac{32}{3} g^{4}-64 g^{3}+\frac{352}{3} g g-64 g$, exiftente numero omnium cafuum, ceu fumma quaternionum in foliis univerlis, $\frac{32}{3} g^{4}-16 g^{3}$ $+\frac{22}{3} g g-g ;$ quæ omnia, ut verbis parcam, induftrio Lectori probanda relinquo. Quocirca habebit ceconomus, $g$ plus $8 g g-8 g$ plus $18 g g-18 g$ plus $16 g^{3}-48 g g+32 g$ cafus ad I, $\& 8 g g-8 g$ plus $16 g^{3}-48 g g+32 g$ plus iterum $16 g^{3}-48 g g+32 g$ plus $\frac{32}{3} g^{4}-64 g^{3}+\frac{352}{3} g g-64 g$ cafus ad $\frac{3}{4} ;$ id quod ipsi parit $24 g^{3}-24 g g+3$
$32 g^{3}-48 g g+22 g-3$ expectationis ad retinendum munus œconomi ; \& deeft ad complendam unitatem $\frac{8 g 3-24 g g+22}{32 g-6-6}$ pro metu mittendi muneris; fic ut cenfenda fit ratio $m \cdot n:: 24 g^{3}-24 g g$ t $3.8 g^{3}-24 g g+22 g-6$.

Nota, quod fi g determinetur ad 9. fiet $p . q:: 19.16,8 x$ m. n:: I5555.4080::6I.I6. Sumto itaque, quod unus cols luforum depofuerit $a$, alter $b \&$ terrius $c$, debebitur ceconomo per prac. Probl. ejusque Coroll. $\frac{p-q \cdot \overline{m+n}}{p+q \cdot 2 n} a+b+c \infty \frac{33}{160} \overline{a+b+c_{2}}$ non una decies millefrma parte ipfius $a+b+c$ minus in folis is ludis. Quocirca si quinto cuidam locum fuum cedere velit oeconomus, ipfe à luảo cellaturus, venundabit illi privilegium ceconomi pretio $33 \overline{\frac{1}{t} b+c}$; at si, continuaturus ludum, cum colluforum 
quodam fortem fuam commutare cupiat, accipiet ab ipfo vel $\frac{33}{160}$ $\overline{2 a+b+c}$, vel $\frac{33}{160} \overline{a+2 b+c}$, vell $\frac{33}{160} \overline{a+b+2} c$, prout is depoluerit vel $a$, vel $b$, vel $c$.

Atque haud abfimiliter determinari poterit valor prærogativa economi, si plures ponantur manipuli \& collufores.

\section{PROBLEMA XXI. \\ De Ludo Baffete (de la Baffette.)}

Celebratifimus eft hic ludus ob innumeras turbas $\& z$ tragoedias, quas hinc inde, in Italia prefertim \& Gallia, olim excitavit, ob quas etiam ex inis regionibus non multo pol profcriptus \& fub gravi pœna prohibitus fuit. Eo tempore, quo exercitium illius in aula Regis Galliarum maximè florebat, D. Salvator (Sauveur) Mathematicus Gallus \& Seren. tum Delphini Præceptor expectationes lüdentium calculo fubjecit, brevique Tabularum quarundam fynopsi comprehenfas in Parifienfi Erudit. Diario m. Febr. 1679 in lucem edidit; è quo Diario nos de natura $2 x$ conftitutione hujus ludi ea recenfebimus, quæ ad examinandas Tabulas \& eruendum quem Augtor fuppreflit calculum fitu neceffaria videbuntur.

Poftquam is, qui ceconomi fungitur munere, completum chattarum luforiarum fyftema prehendit \& mifcuit, finguli colluforum ante $f e$ in menfa exponunt folium cujuslibet dignitatis aliunde depromtum unà cum arbitraria pecuniæ fumma. Tum verò aconomus fyftemate fuo, 'ut imum ejus folium pateat, inverfo, factog; ab eodem initio bina fubinde folia fucceffivè \& ordine ad finem ufque fytematis tollit; quod dum exequitur, cujusvis foliorum paris feu bige folium anterius five pracedens in coconomi, polterius \& fe. quens in colluforis commodum cedere cenfetur, ita nimirum, ut si anterius Regis verbi gratia imaginem habeat, ceconomus auferat guicquid Regibus appofirum eft; si vero pofterius, colluforibus viciffim pendere tantundem teneatur, quantum illi Regibus appofuế-

re. $\mathrm{Er}$ 
re. Et hactenus quidem nullus præ altero quicquam prarogativas habet: fed fequentes praterea leges notanda:

I Si ambo folia funt ifodynama \& ejusdem cum expofito dis gnitatis (quod doublets appellant, nos gemella vocabimus) quo cafu lucri \& damni deberet feri compenfatio, folus tamen lucratur œco. nomus, aufertque quod dignitatis illius foliis appofitum eft.

2. Cuilibet colluforum etiam in medio ludi integrum ef, de novo quodlibet folium pretio mercari; quo pacto fieri potef, ut in chartis refiduis vel unum tantum, vel 2, 3, aut omnia 4 illius dignitatis folia fuperfint; quod fortem ipfius notabiliter variat. Sed obfervandum, quod biga illa, cujus alterutrum confpexerit folium, nullius cenfetur valoris ratione dignitatis quam mercatus eft; \& quidem, si pofterius folium bigæ ejusmodi hâc dignitate veftitum comparet, non tantum ceu pracox (trop jeune) nihil acquirit collufori, fed \& ludo finem imponit alterius folii optione redaufpicando: fin autem dignitas illa prodeat in proximo folio bigæ fequentis, valoris fal tem eft imminuti ( c'eft une face) ceconomoque non nifi bellem feu duos trientes depofiti lucratur.

3. Anterius quoque folium primæ bigæ, cùm fufpicio effe poffic illud vifum osconomo, valoris femper eft imminuti, eumque non nifi ex befle victorem reddere potelt.

4. Cìm unico folio ejus dignitatis, pro qua decertatur, fú pertite, foliis gemellis, in quibus prærogativa ceconomi confiftit, non poffit effe locus, fatutum eft in favorem ceconomi, ut poftrema omnium charta, qua alias collufori prodefie deberet, pro nulla haberetur.

Quibus ita pramiflis, pergo exponere methodum, qua expectam tiones aconomi quàm promtiffimè determinantur: Polfto numero bigarum refiduarum $n$, adeog; numero foliorum $2 n$, \& colluforis de pofito $x$, ante omnia confidero, quòd in unaquaq; biga vel neutrum, velalterutrum, vel urrumg; folium pofit effe expofitx dignitatis: fi neutrum, hiquet per hanc bigam nihil nec acquiri nec perdi œcono= mo: si alterutrum, confat, eadem facilitate utrumvis efle poffe (cim excipiendis religuo aut reliquis illius dignitatis folis eadem in 
bigis fequentibus loca pateant:) ac totidem proinde cafus effe, quibus vineat oconomus five acquirat $+\mathrm{I}$, \& quibus perdat five obtineat - I: qui propterea quia fe mutuò deftruunt, magno quoque compendio infuper haberi poffunt. Soli ergo reftant expendendi cafus, quibus contingere poteft, ut folia alicujus biga fint gemella, id eft, ut ambo fint illius dignitatis.

I. Equidem fi unicum ejus dignitatis folium fuperfit, quo cafu folia gemella effe non poffunt, liquido patet, ratione cujusvis bi:gæ feorfim, si ultimam excipias, nullam effe poffe prærogativam $œ-$ conomi ( vid. $T a b .5$. ). Quoniam tamen poftrema charta, quæ collufori prodeffe poffet, per leg. 4 . pro nulla habetur, fit ut ratione omnium femper uno cafu amplius lucrari, quàm perdere poffit $\propto-$ conomus; quod propter numerum foliorum 2 n ceu totidem cafuum, quibus expofitæ dignitatis folium fubeft, prærogativam œconomi in bigis univerfis facit $\frac{1}{2 n}\left(T a b . I_{0}\right)$. Rurfus autem, si proxima biga fit valoris imminuti pro œconomo, ex univerfis $2 n$ cafibus unus eft, qui ipfum triente depofiti privat, per leg.3. quod decrementum prærogativæ ejus efficit $\frac{1 .{ }^{1: 3}}{2 n} \infty \frac{1}{6 n}\left(T_{a b} ._{2}.\right)$. Hoc igitur ablato tum ex $\frac{1}{2 n}$, tum ex 0 , relinquitur $\frac{1}{3 n} \&-\frac{1}{6 n}$, pro refiduo lucro $œ$ conomi ratione universi ludi, aut damno ejus ratione folius big quæ imminuti eft valoris. ( $T a b \cdot 3 \& 6$.$) .$

II. Si duo expofitæ dignitatis folia reftent, tot illa variationibus ceu cafibus obnoxia funt, quot biniones in foliis $2 n$ continentur, nempe $\frac{2 n \cdot 2 n-1}{2}$. Horum in fingulis bigis unus, adeoque in univerfis $n$ bigis, $n$ cafus exifunt, qui foliis gemellis œconomo victoriam procurare poffunt; unde in fingulis lucrum illius efficitur $\frac{1}{2 n \cdot 2 n-1: 2} \infty \frac{1}{2 n n-n}\left(T_{a b}, 5_{\cdot}\right)$, in univetfis $\frac{n}{2 n \cdot 2 n \cdot-1: 2} \infty$ $\frac{I}{2 n-I}\left(T a b_{.} I_{\bullet}\right)$. Quòd si alterutrum dignitatis illius folium primo titim loco primæ bigæe prodeat, adeoque valoris fit imminuti per leg 3 . alterum folium ad unumquemque ex reliquis $2 n-\mathbb{I}$ $\mathrm{Bb}$ locis 
locis indifferenter fe habendo, totidem cafus praber, quibus lucrum cconomi triente minuitur, cujus proinde decrementum aftimatur $\frac{2 n-1.1: 3}{2 n \cdot 2 n-1: 2} \infty \frac{1}{3 n}(T a b, 2$.$) . Hoc ergo detracto tum ex \frac{1}{2 n-1}$, tum ex $\frac{I}{2 n n-n}$, remanet pro lucro refiduo in ludo univerfo $\frac{n+1}{6 n n-3 n}(\operatorname{Tab} 3$.$) \& pro damno in fola prima biga \frac{-2 n+4}{6 n n-3 n}$ $(T a b, 6$.$) .$

1II. Si tria optatæe dignitatis folia fuperfint, tot cafuum vas rietates inducunt, quot terniones in foliis $2 n$ locum habent, videl.' $\frac{2 n .2 n-1.2 n-2}{1.2 .3} \infty \frac{2 n .2 n-1.2 n-2}{6}$ Ex horum numero foliorum gemellorum cafus elicio, confiderando quod, pofitis alicu= jus bigæ foliis ambobus laudatre dignitatis, tertium iis fuppar folium unumquemque ex reliquis $2 n-2$ locis occupare poffit, eoqs tot cafus pro illa biga fuppeditet: unde, cùm fumtis fucceffivè pro a numero bigarum, $\mathrm{I}, 2,3,4$ \&c. numeri horum cafum fiant 0,2 , 4, 6 \&c. erunt foliorum gemellorum cafus in omnibus $n$ bigis , $0+2+4+6+8 c$. ufque ad $2 n-200$ (propter progreff. 2 rithm.) $n . n-\mathrm{I}$. Quare lucrum œconomi in qualibet biga feparatim valet $\frac{2 n-2}{2 n .2 n-1.2 n-2: 6} \infty \frac{3}{2 n n-n}($ Tab.5.) $)$, in omnibus conjunctim $\frac{n \cdot n-1}{2 n \cdot 2 n-1 \cdot 2 n-2: G} \infty \frac{3}{4 n-2}$ (Tab. I. ). Quòd si unum horum trium foliorum primo ftatim loco exeat, eoque fit valoris imminuti per leg . 3. reliqua duo toties locari poffunt diverfimodè , quot biniones cæter $2 n-$ I folia recipiunt, adeoque $\frac{2 n-1.2 n-2}{2}$ cafus fuppeditant, quibus lucrum ceconomi triente muldatur; cujus proin detrimentum fit $\frac{2 n-1.2 n-2.1: 6}{2 n .2 n-1.2 n-2: 6} \infty \frac{1}{2 n}(T a b, 2.0)$. Hoc igitur ablato partim ex $\frac{3}{4 n-2}$, partim ex $\frac{3}{2 n n-n}$, relinquitur if lic $\frac{n+1}{4 n-2 n}(T a b \cdot 3 \cdot)$ pro lucro refiduo in bigis univerlis: ifthic $\frac{-2 n+7}{4 n-2 n}(T a b .6$.$) pro damno in prima feparatim.$ 


$$
P A R S T E R T I A \text {. }
$$

IV. Si omnia 4 expofitæ dignitatis folia chartis refiduis adhuc immerfa lateant, tot cafus in univerfum fuggerunt, quot quz-

\section{Tabella:}

Numerus foliorum expofite dignitat is in chartis refidus:
1.
II.
III.
IV.

I. Lucrum aconomi in bigis refuluis, cum omnes funt valoris integri:

$$
\frac{1}{2 n} \quad \frac{1}{2 n-1} \quad \frac{3}{4 n-2} \quad \frac{4 n-5}{4 n n-8 n+3}
$$

2. Siprima eft valoris imminuti, fit decrementum lucri:

$$
\frac{1}{6 n} \quad \frac{1}{3 n} \quad \frac{1}{2 n} \quad \frac{2}{3 n}
$$

3. Refiduum lucri in bigis, quarum prima eft valoris imminuti:

$$
\frac{1}{3 n} \quad \frac{n+1}{6 n n-3 n} \quad \frac{n+1}{4 n n-2 n} \quad \frac{4 n n+n-6}{12 n 3-24 n n+9 n}
$$

4. Lucrum aconomi in bigis refficuis, initio facto ab illa quanulla eft:

$$
\frac{2}{6 n-3} \frac{n}{6 n n-9 n+3} \frac{n n-2 n}{4 n 3-12 n n+11 n-3} \frac{4 n n-7 n-3}{12 n 3-36 n n+33 n-3}
$$

5. Lucrum cconomi in qualibet biga valoris integri, citra refpeclum ad bigas fequentes:

$$
\text { - } \frac{1}{2 n n-n} \quad \frac{3}{2 n n-n} \quad \frac{6}{2 n n-n}
$$

6. Dannum ceconomi in biga valoris imminuti, citra refpectum ad lits crum, quod babet in fequsntibus:

$$
-\frac{1}{6 n} \quad \frac{-2 n+4}{6 n n-3 n} \quad \frac{-2 n+7}{4 n n-2 n} \cdot \frac{-4 n+20}{6 n n-3 n} \text {. }
$$

terniones in chartis $2 n$ continentur, nempe $\frac{2 n .2 n-1.2 n-2.2 n-3}{1 \cdot 2 \cdot 3 \cdot 4}$ $\infty \frac{2 n .2 n-1.2 n-2.2 n-3}{24}$. Et si duo illorum in eadem biga fe fe gemello amplexu excipiunt, reliqua duo toties ordinem variare poffunt in cæteris $2 n-2$ chartis, quot hæ biniones admittunt; un$\mathrm{Bb} 2$ de pro 
YQ6 LRTIS CONGECTANDI

de pro illa biga foliorum gemellorum cafus $\frac{2 n-2.2 n-3}{2}$ emergunt. Et quoniam fumtis fuccelfivè pro $n$ numero bigarum $1,2,3$, 4,5 , \&c. numeri cafuum evadunt $0,1,6,15,28$ \&cc. hinc gernellorum cafus in omnibus $n$ bigis collective accepti erunt $0+1+6+$ I) $+28+\& c$. ufque ad $\frac{2 n-2 \cdot 2 n-3}{2}$, de cujus feriei fummanune difpiciendum. Video autem, hanc variis modis elici poffe:

I. Mod. Quia termini feriei fecundas fuas differentias æquales habent, erunt figuratorum analogi, quorum fumma quo pácto inveniri poffit, fupra part.2. in fin. cap.3 oftenfum.

2. Mod. Quoniam iidem etiam ex ipfa Trigonalium ferie per faltum funt excerpti, refolvatur Trigonalium feries A à gemina cyphra incipiens in duas alias B \& $C$, quarum illa noftra fit, \& im-

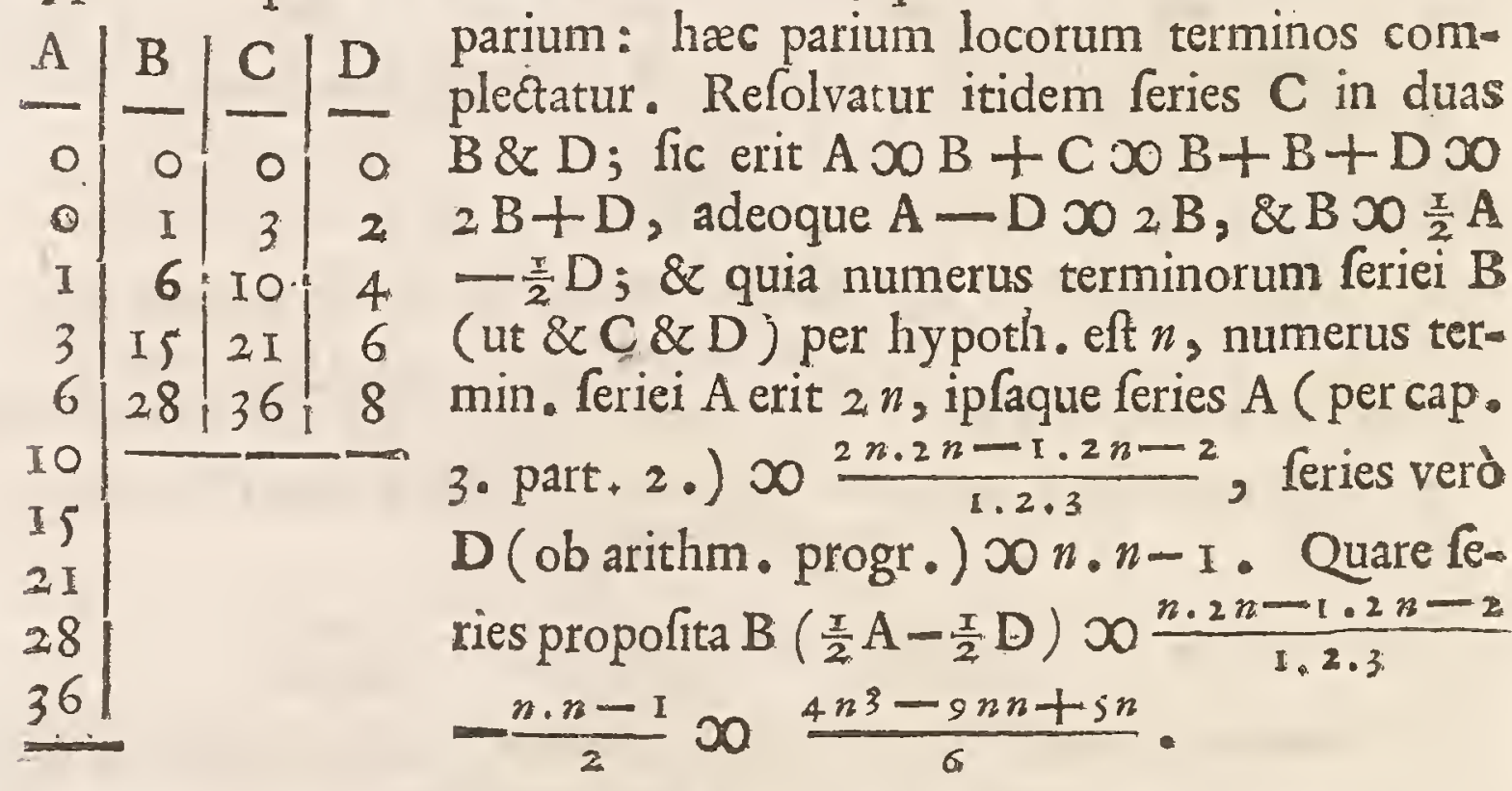

3. Mod. Terminus feriei $B$ indefinite fumtus per hypoth . eft $\frac{2 n-2 \cdot 2 n-3}{2} \infty \frac{4 n n-4 n}{2}-3 n+3 \infty \frac{n \cdot n-1}{2} 4-\frac{n-1}{I} 3$; tota ergo feries B æquatur quadruplo omnium $\frac{n \cdot n-1}{2}$, minùs tric plo omnium $n-$ I: fed novimus ex cap.3.part.2. $\frac{n \cdot n-I}{2}$ effe numerum trigonalem, \& $n$ - I lateralem; atque omn. $\frac{n \cdot n-1}{2} \infty$ $\frac{n+1}{1.2}$. 


$$
P A R S \text { TERTIA. }
$$

$\frac{n+1 \cdot n \cdot n \cdot r}{I \cdot 2 \cdot 3}, \&$ omn. $n-I$ I $\infty \frac{n \cdot n-I}{2}$; quare fit feries B $\infty$ $\frac{4 \cdot n+1 \cdot n \cdot n-1}{1 \cdot 2 \cdot 3}-\frac{3 \cdot n \cdot n-1}{2} \infty \frac{4 n 3-9 n n+5 n}{6}$, ut antea.

Cùm itaque oftenfum fit, foliorum gemellorum cafus in fingulis bigis effe $\frac{2 n-2.2 n-3}{2}$, in univerfis $\frac{4 n 3-9 n n+5 n}{6}$; concludimus, lucrum oconomi fpectatum in qualibet biga feorfim valere $\frac{2 n-2.2 n-3: 2}{2 n \cdot 2 n-1.2 n-2.2 n-3: 24} \infty \frac{6}{2 n n-n}($ Tab.5.): in omnibus conjunctim $\frac{4 n 3-3 n n+5 n: 6}{2 n .2 n-1.2 n-2.2 n-3: 24} \infty$ (divid. per $n . n-I: 6$ feu $\left.\frac{n n-n}{6}\right) \frac{4 n-5}{2 n-1.2 n-3} \infty \frac{4 n-5}{4 n n-8 n+3}$ (Tab. I.). Porrò si unum 4 foliorum expofita dignitatis in prina ftatim biga primo loco prodierit, valoris adeò exiftens imminuti per $\operatorname{leg} \cdot 3$. reliqua tria toties ordinem variare poffunt, quot terniones refidua $2 n \rightarrow$ I folia admittunt; unde nafcuntur $\frac{2 n-1.2 n-2.2 n-3}{1.2 .3}$ cafus, quibus lucrum œconomi triente mulktandum eft; cujus propterea decrementum cenfetur $\frac{2 n-1.2 n-2.2 n-3.1: 18}{2 n .2 n-1.2 n-2.2 n-3: 24} \infty \frac{2}{3 n}($ Tab.2.). Hoc igitur detracto ex inventis tum $\frac{4 n-5^{4}}{4 n n-8 n+3}, \operatorname{tum}_{a} \frac{6}{2 n n-n}$, remanet ex una parte $\frac{4 n n+n-6}{12 n^{3}-24 n n+9 n}(T a b .3$.$) pro lucro refiduo in bigis$ univerlis, ex altera $\frac{-4 n+20}{6 n n-3 n}\left(T_{a b} .6.\right)$ pro damno ejus in prima feparatim.

Atque ita fex Tabularum, quas dedit Auctor Gallus, quinque jam complevimus; fupereft unica reftituenda, nempe $4^{\text {ta }}$, qua lucrum œconomi continet in bigis refiduis, quando prima earum ob confpectum anterius ejus folium nulla eft. Hæc verò ex iis, quæe IV. præcedd. articulis jam præmontrata funt, facillimè concinnabitur; modò ad hæc duo attendatur:

I. Quòd bigæe, cujus anterius folium confpectum fuerit, pofterius aut erit expofitæ dignitatis, aut non erit: fi erit, nihil ceconomo vel nocet vel prodeft, fed velut præcox ludo prorfus finem $\mathrm{Bb} 3$ impo- 
imponit per leg. 2, fi non erit, idem pracisè cafuum numerus fupereft œconomo ad obtinendum depofitum, feu ex affe feu exbefle, qui preftò effer, fi biga illa quæ nulla eft planè abeffet; hac fola cum differentia, quòd numerus bigarum refiduarum, qui alias diceretur $n$, ob alteram quæ nulla eft una computatam nunc eft tantìm $n$ - I.

2. Quòd vifo primo folio primæ bigæ, fuperfunt tantùn $2 n$ - I folia non vifa, adeò ut numerus omnium omninò cafuum ex multitudine combinationum non omnium $2 n$, fed tantùm $2 n-1$ foliorum æfimari debeat. His enim perpenlis facilè perfpicitur ratio fequentis operacionis:

Exfcribantur ex pracedd. IV. I. fractiones Tabulæ primæ \& $2^{d x}$, fed quales erant ante reductionem, ita:

I. Lurum aconomi in bigis refaduis, cum omnes funt valoris integri:

$\frac{1}{2 n} \cdot \frac{n}{2 n \cdot 2 n-1: 2} \cdot \frac{n \cdot n-1}{2 n \cdot 2 n-1 \cdot 2 n \cdot-2: 6} \cdot \frac{4 n 3-9 n+5 n: 6}{2 n \cdot 2 n-1.2 n-2 \cdot 2 n-3: 24} \cdot$

2. Decrementum lucri, cum prima eft valoris imminuti:

$\frac{1: 3}{2 n} \cdot \frac{2 n-1: 3}{2 n .2 n-1: 2} \cdot \frac{2 n-1.2 n-2: 6}{2 n \cdot 2 n-1.2 n-2: 6} \cdot \frac{2 n-1.2 n-2.2 n-3+18}{2 n \cdot 2 n-1.2 n-2: 2 n-3: 24} \cdot$

Jam fingulæ hæ fractiones mutentur in alias, furrogando tantùm ubique loco $n$ in numeratoribus $n-$ I \& loco $2 n$ in denominatoribus $2 n-1$; ut fiat

I. Lucram aconomi drc:

$\frac{1}{2 n-1} \cdot \frac{n-1}{2 n-1.2 n-2: 2} \cdot \frac{n-1 \cdot n-2}{2 n-1 \cdot 2 n-2 \cdot 2 n-3: 6} \cdot \frac{4 n 3-21 n+35 n-18: 6}{2 n-1 \cdot 2 n-2 \cdot 2 n-3 \cdot 2 n-4}: \frac{24}{0}$

2. Decrementum tucri \&c.

$\frac{1: 3}{2 n-1} \cdot \frac{2 n-3: 3}{2 n-1.2 n-2: 2} \cdot \frac{2 n-3.2 n-4: 6}{2 n-1.2 n-2.2 n-3: 6} \cdot \frac{2 n-3.2 n-4.2 n-5: 18}{2 n-1.2 n-2.2 n-3.2 n-4: 24^{\circ}}$.

Decrementis enim his refpectivè ex lucro detraktis, relinquuntur pro Tabula $4^{\text {ta }}$ fractiones:

$\frac{2: 3}{2 n-1} \cdot \frac{n: 3}{2 n-1.2 n-2: 2} \cdot \frac{n . n-1,2 n-2.2 n-3: 6}{2 n-2 n-1.2 n-2.2 n-3 \cdot 2 n-4: 24} \cdot \frac{4 n 3-15 n n+11 n+6: 18}{2 n-2 n-2 n}$.

feu facta reductione: 
$\frac{2}{6 n-3} \cdot \frac{n}{6 n n-9 n+3} \cdot \frac{n n-2 n}{4 n^{3}-12 n n+11 n-3} \cdot \frac{4 n n-7 n-3}{12 n 3-36 n n+33 n-9} \cdot$

Et fic quartam quoque Tabulam adornavimus. Quòd si quis D. ni Salvatoris Tabellas cum hifce noftris contulerit, deprehendet illas in quibusdam locis, præfertim ulcimis, nonnihil emendationis indigere. Quæ vero ibidem obfervata adjiciuntur de proportione augmenti vel decrementi prærogativæ œconomi, prout numerus foliorum augetur minuiturve, de his $\&$ aliis dicere nil attinet, cùm ex infpectione Tabularum cuivis ultrò manifefta fint .

\section{PROBLEMA XXI.}

Eft Ales quoddam genis, in qua numerus omnium cafuum eft a, numerus quorundam ex iis b, ceterorum a-b o c. Titius fmgulos alee jactus jingulis nummis redimit $C a$. jo perfolvendis; tum quoties unum b ca- fuum jecerit, à Cajo vicißim accipiet $\mathrm{m}$ nummos, at quoties jecerit unum ex $\mathrm{c}$ cafibus, nibil babebit: tamen fi unum c cafunm jecerit continuis n vicibus, Cajus ip $/ \mathscr{b}$ omnes fuos n nummos reddere obfrictus eft. Queruniur fortes Titii ES Caji?

Problema hoc in fpeciem fatis impeditum nihil admodum difficile habet, si dextrè tractetur. Incipio à fine, ponendo Titium jam decoxiffe $n$ - I nummos, hoceft, jam $n$ - I vicibus jeciffe unum $c$ cafuum, \&x nunc in procinctu effe inftituendi $n$ jactum. Itaque vel unus $b$ cafuum ipsi eveniet, vel rurfus unus $c$ cafuum: si prius, à Cajo accipier $m$ nummos, qualium iple jam Cajo $n$ perfolvis 
folvit; fic ut ipsi remaneat lucrum m - n nummorum: si poferius, recuperabit ex pacto omnes fuos $n$ nummos, nihilque adeò vel lucri vel damni faciet; unde lucrum ejus cenfebitur $\frac{b . m-n+c^{0}}{a}$ $\infty \frac{m-n \cdot b}{a}$.

Pono deinde, ipfum lufiffe $n-2$ vicibus, totiesque jeciffe un num $c$ cafuum, \& nunc aggredi $n-1$ jactum: confequetur à Cajo ( $s i$ unum $b$ cafuum jecerit) $m$ nummos, qualium illi jam $n-1$ erogavit; adeoque pro lucro fuo retinebit $m-n+\mathrm{r}$ : fin denuò jecerit: unum $c$ cafrum, perveniet in eum ftatum, qui in præced. hypoth. obtinebat, habebitque $\frac{\overline{m-n} \cdot b}{a}$ joquare jam fors ejus fit,

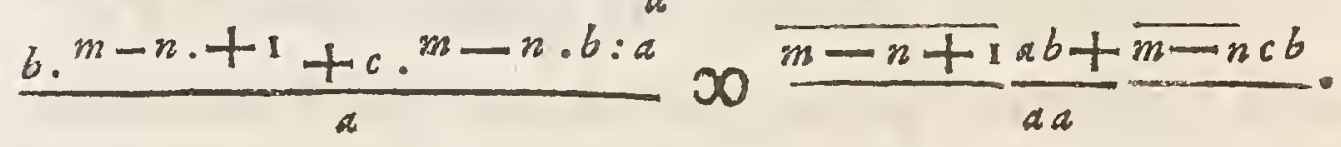

Fingo porrò, jeciffe $n-3$ vicibus unum $c$ cafuum, \& nunc fe accingere ad jasum $n-2$; fiet, ut vel lucrum acquirat $m-n+2$ nummorum, qui fibi, detractis quos Cajo fucceffive numeravit $n-2$ nummis, remanent; fi nempe unum $b$ cafuum jecerit: vel ut pertingat in ftatum præcedentis hypoth. si pergat jacere unum $c$ cafu= um; unde jam fors ejus refultat $\frac{b^{m-n+2}+c^{m} \text { præc }}{a} \infty$ $\overline{m-n+2} a a b+\overline{m-n+1} a c b+\overline{m-n} c c b$.

Suppono rurfus, jeciffe $n-4$ vicibus unum $c$ cafuum, $\&$ jamjam defuncturum $n-3$ jactu: perinde liquet, ac antea, eum habere $b$ cafus ad obtinendum lucrum $m-n+3$ nummorum, qui fibi, ablatis quos Cajo jam pendit $n-3$ nummis, relinguuntur; \& $c$ cafus ad perveniendum in fatum præced. id quod fortem ipsi nunc parit $\frac{b^{m}-n+3+c \cdot \text { prac }^{m}}{a} \infty$

$\frac{\overline{m-n+} 3 a 3 b+\overline{m-n+2} a a c b+\overline{m-n}-1+1 c c b+\overline{m-n} c 3 b}{a 4}$.

Atque fic porrò retrogredi conveniret, ponendo Titium $x=5$, $n-6 \& x$. jactus infituiffe, fl opus effet pergere ulterius; id verò non fuecelle, cum ex allatis ratio progrenionis jam fatis patefat: 
colligimus enim facilè, quòd fors quám ab initio ludi habet, priusquam jacere inchoat, fucura fit:

$$
\begin{aligned}
& \frac{\overline{m-1 a^{n-1}} b+\overline{m-2} a^{n-2} e b+\overline{m-3} a^{n-3} c c b+\overline{m-4} a^{n-4} c^{3} b+}{a^{n}} \\
& m-5 a a^{n-5} c 46 \ldots+\sqrt{4-n} c^{n-1} 6
\end{aligned}
$$

(factâ feparatione terminorum diverfis fignis affectcrum)

$$
+m b \text { in } \frac{1}{a}+\frac{c}{a b}+\frac{c c}{a^{3}}+\frac{c^{3}}{a^{4}}+\frac{c 4}{a^{4}} \cdots+\frac{c^{3-1}}{a^{n}}
$$

$$
-b \text { in } \frac{1}{a}+\frac{2 c}{a b}+\frac{3 c c}{a^{3}}+\frac{4 c^{3}}{a^{4}}+\frac{5 c^{4}}{a^{5}} \cdots \cdots+\frac{n c-1}{a^{n}}
$$

quam quantitatem liquet duabus conftare partibus, priore affirmata, pofteriore negata, quarumque illa in ferie gtometrice progreffionslium, hac in ferie ex geometrice \& arithmeticè progreffionalibus mixta conitit: Utriufue fumma per notas regulas habetur: illius $\frac{3 n \cdot a^{n}-c^{n}}{a^{n}}$, hujus $\frac{a^{n}-c^{n}}{a^{n-1} b}-\frac{n c^{n}}{a^{n}}$ quarum proinde differentia quxfitum exprimit, lucrum vid. refpectu Titii, \& damnum refpectu $\mathrm{Ca}$ ji, si pars affi mata præpolleat negatæ; damnum verò ex parte Titii \& lucrum ex parte Caji, si hæc pravaleat 1 lli.

Unde jam rorrò fequitur quòd si ponatur æequalitas inter utramque, determinari pollit, quis valor fatui debeat literæ $m$ vel $n$, ut fores Caji \& Titii aquentur : Facta enim aquatione $\frac{m^{n} \cdot a^{n}-c^{3}}{a^{n}} \infty$ $\frac{a^{n}-c^{n}}{a^{n-1} b}-\frac{n c^{n}}{a^{n}}$, infituatur divifio per $\frac{a^{n}-c^{n}}{a^{n}}$, \& prodibic $m \infty$ $\frac{a}{b}-\frac{n c^{n}}{a^{n}-c^{n}}$. Si verò data $m$, quæratur $m$ ordinetur equatio ita

$$
\mathrm{C} \text { c }
$$

$$
\frac{c^{3 x}}{x^{n} c^{n g}}
$$


$\frac{n c^{n}}{a^{n}-c^{n}} \infty \frac{a}{b}-m$, ac fiat $a^{n}-c^{n} \cdot c^{n}:: n \cdot \frac{a}{b}-m:: b n \cdot a-b m, \&$ componendo $a^{n} \cdot a^{n}:: a-b m+b n \cdot a-6 m$; eruntque aggregata ex logarithmis extremorum \& mediorum æqualia, nimirum $n l a+$ $\overline{b a-b m} \infty n l c+l \overline{-b m+b n}$, h. e. $n l a-n l c x l a-b m+b n=$ $\overline{a-b m}$, \& $\cdots \frac{l a-b m+b n-l \overline{a-b m}}{l a-l c}$, feu (polito $b \infty$ I) $n$ $\infty \frac{l \overline{a-m+n-l a-m}}{l a-l c} ;$ quod per Logarithmicam ita facilè confruo:

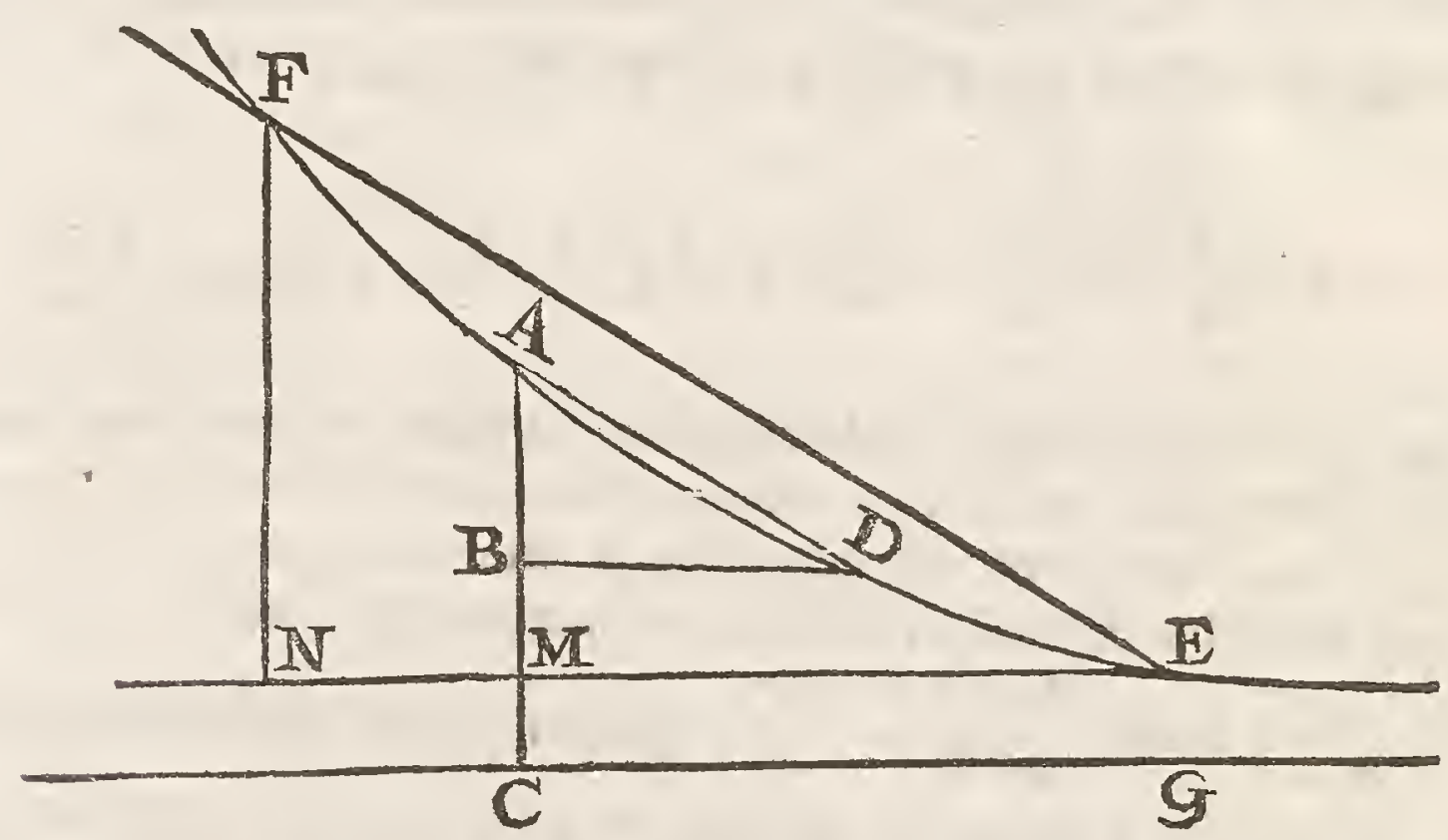

In quacunque Logarithmica F A D E fecetur applicata quælibet A C in $B$, ut $A B$ fit ad $B C$ in ratione $b$ ad $c$, fumtaque $A B$ loco unitatis, in eadem $\mathrm{AC}$ abfindatur $\mathrm{A} M \mathfrak{M}$ m, per $\mathrm{B} \& \mathrm{M}$ agantur recta $B D, M E$, parallelæe axi $C G, \&$ occurrentes curvæ in $D \& E$; junctæque $A D$ ducatur parallela $E F$ fecans curvam in $F$, ac denique ex F demittatur applicata $F$ Noccurrens productr $E M$ in $N$; erit $F \mathbf{N}$ valor optati numeri $n$.

Proponatur in exemplum hæe Alea: Titius duabus tefferis duos fenarios jacere contendit, nummoque in jactum perfoluto poftulat à Cajo, ut fibi viciTim fex nummi numerentur, fi id pratiterit; fi fecus faxit, nihil; attamen fivicies continuo fcopo aberrarit, ut fibi omnes fui 20 nummi reftituantur. Hic propter 36 cafus duarum tefferarum, interque hos unicum qui duos fenarios advehat, litera- 
rum valor eft, $2 \infty 36,6 \times 1$, adeoque $c \infty 035$; nee non $m x^{2}$, $\& \approx x_{20}$. Nunc autem per logarithmos compendiosè invenitur vicefima poteftas ipfius $\frac{c}{a}$, feu $\frac{c^{n}}{a^{n}}$ Do $\frac{5693}{10000}$; proinde $\frac{m \cdot a^{n}-\varepsilon^{n}}{a^{n}}$ $\infty m_{+} \mathrm{I}-\frac{c^{n}}{a^{n}} \infty 6 \cdot \frac{4307}{10000} \infty \frac{25842}{10000} ; \&$ pari modo altera pars $\frac{a^{n}-c^{n}}{a^{n-16}}$ $-\frac{n c^{n}}{a^{n}} \infty \frac{a}{b}-\frac{a}{b}-n \frac{c^{n}}{a^{n}} \infty 36-\frac{56.5603}{10000} \infty 36-\frac{318808}{10000} \infty 0 \frac{41192}{10000} ;$ quæ cùm priorem excedat tota quantitate $\frac{\mathrm{I} 5350}{10000} \infty 0 \frac{307}{200}$, paulò adm huc majore quàm $\frac{3}{2}$, innuit, Titium non fine detrimento hanc aleam fubire poffe, \& fatius facturum fi exemptionem ftatim à ludendi neceffitate vel fesquinummo redimat. Quòd fi tamen vel m augeretur, vel minueretur $n$, poffet alea fic attemperari, ut neuter præa altero quicquam prærogativæ haberet; nam si retento $n \infty 20$ fiat $m \infty 9 \frac{2429}{4307}$, aut manente $m \infty 6$ ftatuatur $n \infty$ I I aut I 2 , utriusque fors propemodùm ad æqualitatem redacta erit.

Obfervo generaliter in hujusmodi alea fequentia:

I. Quòd fi datis $a, b, c \& m$, litera $n$ fucceffivè induit valores numerorum I , 2, 3, 4 \&c. lucrum Titii (utpote cujus fors in cafu n $\infty$ I femper eft potior forte Caji) aliquousque fubinde crefcit .

2. Quòd ejus conditio optima fit, cùm ponitur $n: \infty \mathrm{m}-\mathrm{I}$ vel $m$; \& quidem perpetuò eadem in utraque hypothefi.

3. Quòd crefcente $n$ ulterius, dẹcrefcat illa porrò continuò in infinitum, ufque è ut \& lucrum fæpe in damnum abeat, prævalente deinceps forte Caji.

4. Quòd lucrum vel damnum obtinens in hypothesi numeri $n$ valdè magni $\&$ velut infiniti, ad illud quod obtinet refpeetu unici jactus ( rejeeta illa poftrema conditione de reftituendis Titio fuis nummis, fi continuis $n$ jactibus nullus $b$ cafum evenerit), rationem femper habet, ut $a$ ad $b$, majoris ad minus; nimirum cum iftud per Cor. 6. Prop. III. parto I. fiat $\frac{b^{m}{ }^{m . I}+c_{0}^{-1}}{b} \infty \frac{b m-b-c}{a} \infty \frac{b_{m} m-a}{a}$, $\mathrm{C}_{\mathrm{c}} 2$ erit 
erit illud $\frac{b m-a}{b} ;$ \& quidem utrumque frmul vel lucrum ratione To tii \& damnum ratione Caji, vel vicifim, prout $6 \mathrm{~m}$ majus minusve ponitur ipfo $a$.

\section{Problema XXIII. \\ De eAlea Tefferarum cxcarum (blinde 20uinft.)}

Sic vocant fex illas Tefferas, circulatoribus plerunque noftris: folennes, quæ cum fint cubiformes ut ordinariæ, exoculatæ tamen velut apparent, \& fingulæe in una duntaxat hedra punctis notatæ, una fcil. unico, alia duobus, terria tribus, ufque ad fexram, quæ unam hedrarum fex punctis fignatam habet; fic ut univerfis non niff $I+2+3+4+5+602$ I punda inveniantur. EjusmodiTefferas impoftores emuncturi plebiculam in foro exponunt una cum præmiis fecundùm omnes puictorum numeros $a b$ I ufque ad 2 I, quanta circiter fubjunctæ Tabula inferta videntur. Tum qui fortunam fuam periclitari voluerit, nummo circulatori perfoluto tefferas iftas in alveum projicit, \& si quem pundtorum jecerit numerum, huic affignatum præmium aufert; fi verò nullum fibi punctum cecio derit, nummi fui jacturam facit.

His pofitis, qui fortem horum Aleatorum inveftigare cupit, notare debet fequentia:

1. Quòd numerus omnium cafuum in fex ejusmodi tefferis, non fecus atque in tefferis ordinariis, per ea quæ part. I . poft Prom pof. IX. oftenfa funt, fit 46656 , quanta nim. eft fexta poteftas fenarii.

2. Quòd numerus eorum cafuum, qui nullum omnino punQum advehunt, determinetur per fext $m$ poteftatem quinarii, qua eft $1562 ;$; quoniam in quavis teffera quinque funt hedræ punctis orbatæ, quarum quxliber cum qualibet quinque hedrarum alterius tefferæ combinari, \& harum combinationum quælibet rurfus cuilibet 5 


\section{$P A R S T E R T I A$.}

bet $\rho$ hedrarum tertix adjungi poteft; ita ut precedentium cafuum numerus acceffione novæ tefleræ femper quintuplicetur.

3. Quòd quivis punctorum numerus vel ab una, vel à duăbus pluribusve tefferis efficiatur: fi ab una efficitur, in cæeteris quinm que tefferis nallum comparebit punctum; quare cùm fingularum etiam quinque fint hedræ punatis deftitutæ, numerus cafuum, quibus id accidit, defignabitur per 3 I 25 quintam poteftatem quinarii: si numerus punctorum à duabus producitur tefferis, in cæteris qquatuor nulla eminebunt punda; unde nunc propter eandem rationem numerus cafuum, quibus id fit, erit 625 quarta poteltas quinarii. Et pariter, fi à tribus, 4 aut 5 tefferis conftituitur, in cæeteris tribus, duabus aut una tefferis puncta deficient; unde tum numeri cafuum erunt 125,25, aut 5 , id eft $, 3^{\text {tia }}, 2^{\text {da }}$ aut pirma poteftas quinarii

4. Quòd idem punctorum numerus non tantùm à pluribus \& paucioribus plerunque tefferis, fed $\&$ ab eodem tefferarum numero pluribus quandoque modis produci poteft: fic puncta XII tribus modis produci poffunt à tribus, \& duobus modis à 4 tefleris; nam trium tefferarum puncta poterunt effe vel I, 5,6 ; vel $2,4,6$; vel $3,4,5 ; \&$ quatuor tefferarum puncta vel $I, 2,3,6 ;$, vel I, $2,4,5$.

Ut verò nulli modorum prætereantur, quibus componi poflune pinctorum numeri, eadem ferè, quam fupra in Probl. XVII, adhibuimus, methodo utemur. Scriptis ordine punctorum numeris ab I ufque ad XXI, fumo omnes combinationes fex primarum notarum numeralium tum fingularum $1,2,3,4,5,6$; tum binarum $I+2, I+3, I+4,8$ c. item $2+3,2+4, \& c_{0} 3+4, \& c_{0} \& c_{0}$. tum ternarum $1+2+3, I+2+4, \& c$. quaternarum, quinarum, \& tandem fenarum I $+2+3+4+5+6$, ponendo confeftim fingulas ad latus ejus numeri, quem fumma combinatarum notarum efficit: fic quia biniones I $+2, I+3, I+48 x c$. efficiunt $3,4,5 \& c$. Fcribo illos ad latus punctorum III, IV, $V$ \& $x$ : atque ita in cæteris omnibus. Hoc peracto cafuum numeros, qui fingulis punctorum numeris refpondent, facillime determino, numerando folummodo pro unoquoque modorum, quo illi producuntur ab una teflera 3 I 25 ; pro unoquoq; quo producuntur à tefferis duabus, 625 ; 


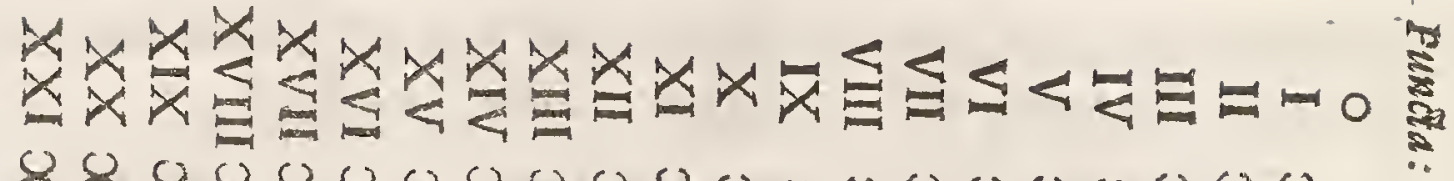
888888888888888888888

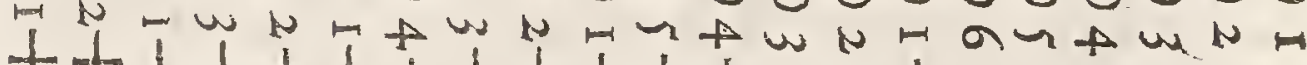

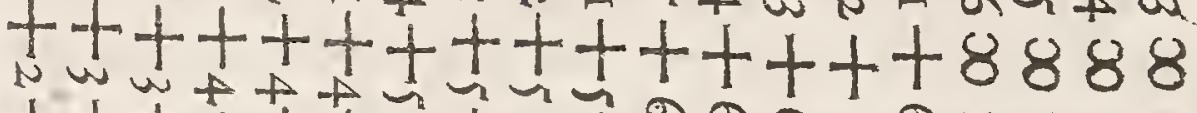
$++1+1+1+1+1+1$ a a

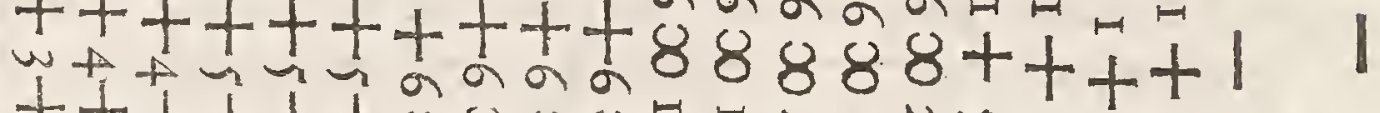

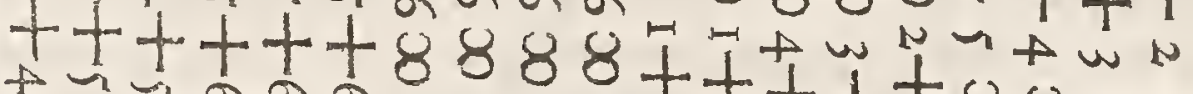
+7 a

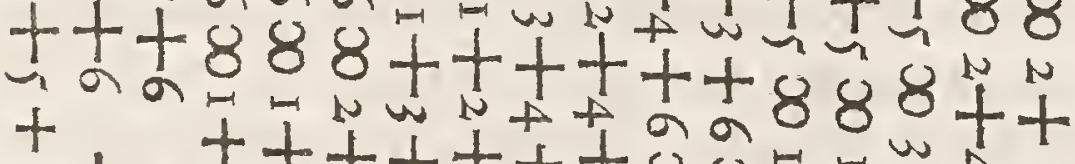

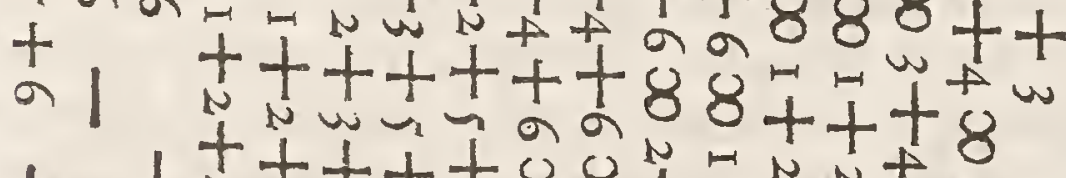

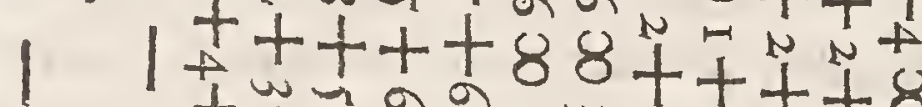

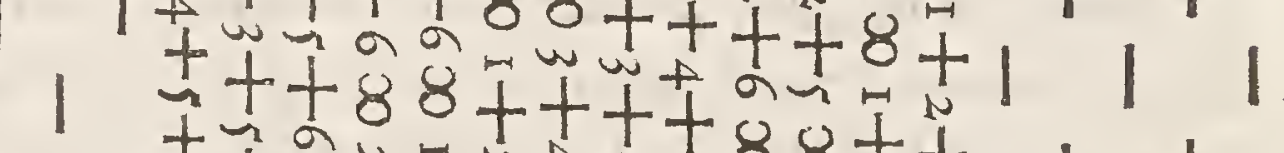

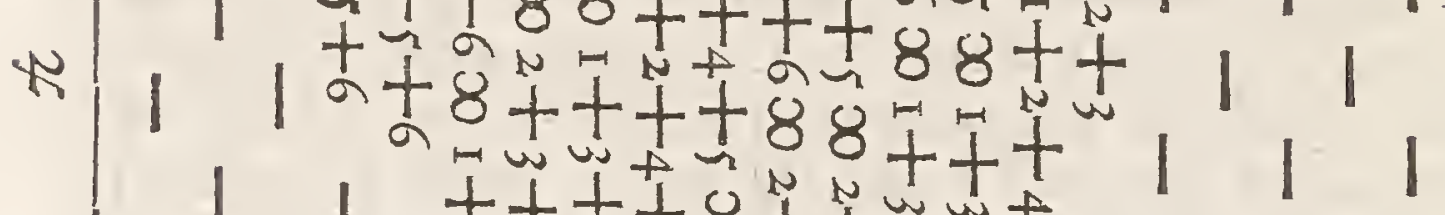

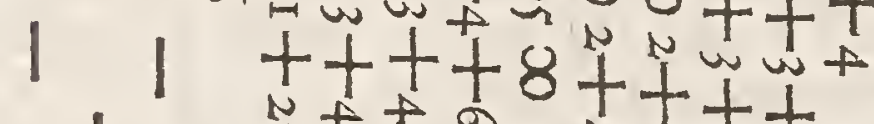

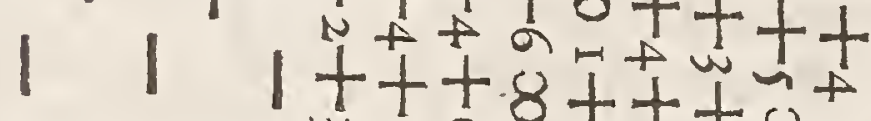

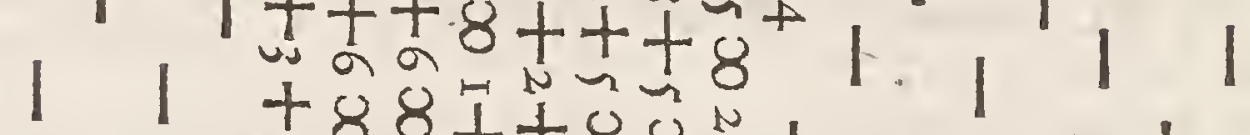

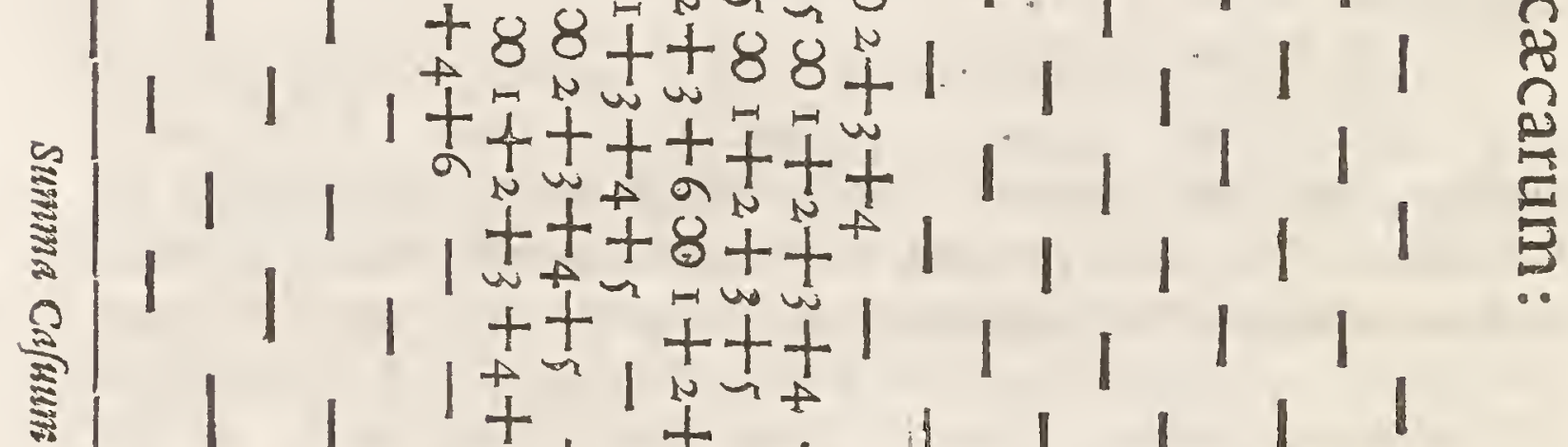

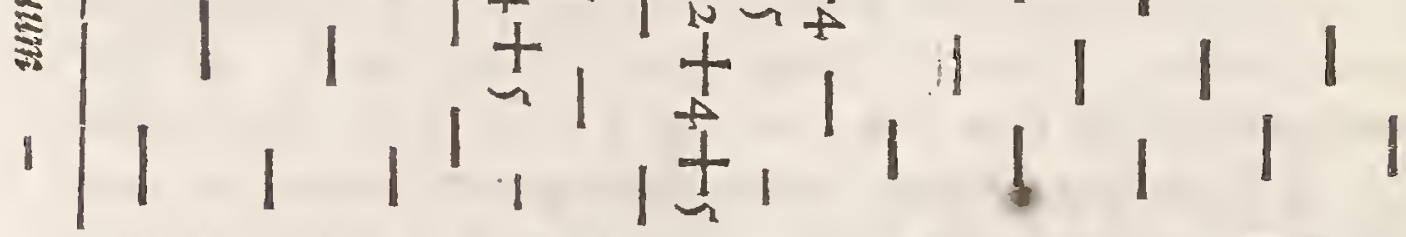

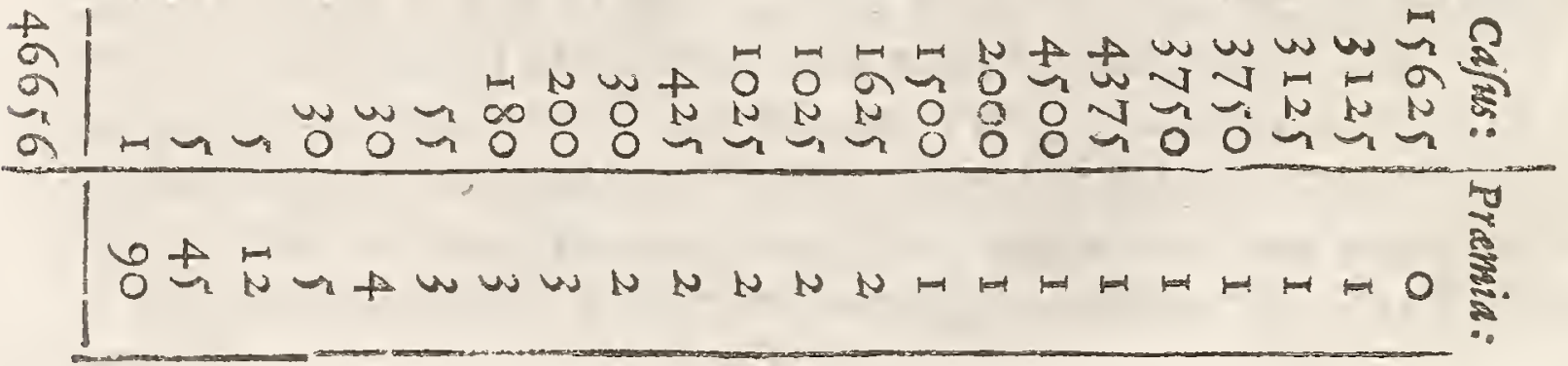




\section{$P A R S T$
$\mathscr{F}$}

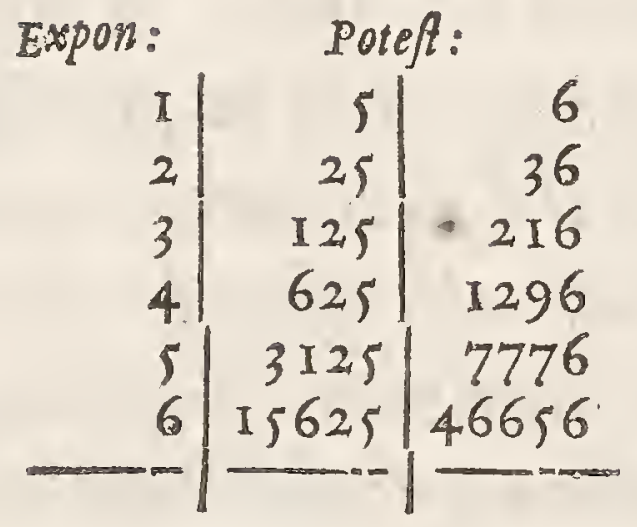

\& quo à tribus, 4 aut 5 tefferis, I25, 25 aut 5 ; ut fupra in obfervat. 3. dictum: fic quia puncta XII tribus modis à tribus, \& 2 modis à 4 . tefferis componi oftenfum eft, numerus cafuum, quibus XII puncta eveniunt, erit ter 125 + bis 2500425 , quem in adjuncta Tabula adfcribo. Quòd fi ubique fimiliter operatus fuero, \& numeri omnium cafuum in fummam collecti conftituant 46656 fextam poteftatem fenarii, certus ero me nullum modorum præteriifle.

Abfoluta autem hacce Tabula fumma rei perasta eft, nec fupereft aliud, quam ut finguli cafuum numeri in fua refpectivè præmia ducantur, \& productorum aggregatum per 46656 dividatur ad obtinendam optatam Aleatoris fortem, quæ hac ratione fer $\frac{156250^{\circ}+26125.1+4400.2+435.3+30.4+30.5+5 . x^{2}+5.45+1.90}{46656}$ $x_{46656}^{36875}$; ita ut tantùm ipsi deponendum fuiffet $\frac{36875}{46656}$ unius nummi, si æqua forte ludere voluiffet; quare cùm circulatori pe日derit integrum; reliquum nummi $\frac{9781}{46656}$ in ejus damnum \& contra deceptoris lucrum computatur. 


\section{PROBLEMA XXIV.}

Pofitis 65 repetitis, qua in precedenti, fLDOminus Alex it a pacilcatur cum collufore, wi ille obfrictus velit effe adreftituendum buic omnes fuos nummos, fi quingue continuis jactibus nullum ip/ipunctum ceciderit Qubriiur nunc utriusque fors?

Vidi quondam Circulatorem, qui adftantes ut inefcaret, hanc infuper condirionem is offerebat, eoque tum anfam mihi dedit co. girandi primùm de Problemate fupra propof to XXII. Hujus itaq; folutio cùm ibid. generaliter exhibita fit, nihil nobis hic pensi reftat, quam ut ill $m$ literis ad numeros revocatis huc applicemus: Conftat. ex præced. numerum omnium cafuum in fex cæcis tefferis effe $466 ; 6$, numerum eorum quibus nullum emicat punctum I 5625 , cætero 31031 ; unde valores literarum in re prælenti funt, a $x_{4} 46656$, $65031031,6 x$ I 5625 ; nec non per hypoth. $n \infty 5$; \& valor ipfrus $m$, qui varius eft, per Cor . 3. Prop. III. part. I. ad medium reductustit $x_{31031}^{36875}$, quandoquidem 3 I0 3 I cafus ad $\frac{36875}{31031}$, \& 15625 cafus ad $\circ$, eandem co'lufori expectationem $\frac{36875}{40656}$ pariunt, quam habere deprehenfus eft in pracedenti. En tibi jam calculum: 


$$
P A R S T E R I A
$$

$$
\begin{aligned}
& \$ 5046656 \text {.... } 14504.6689075 \\
& \text { i } 50 \text { I5625 . . . . } 16004.1938200 \\
& \frac{a}{b} \infty \frac{46696}{31031} \quad l \frac{0}{3} \infty \text { lc-la } 00-0.4750875 \\
& m \infty \frac{36875}{31031}
\end{aligned}
$$

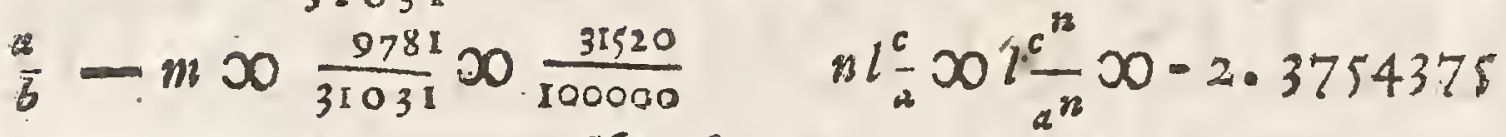

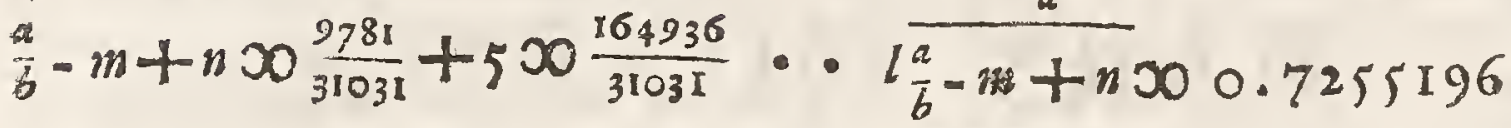

$$
\begin{aligned}
& \frac{a}{-6}=m+n, \frac{c^{n}}{a^{n}} \infty \frac{2239}{100000} \cdot l_{\frac{a}{b}-m+n+l} \frac{c^{n}}{a^{n}} \infty \cdot 1 \cdot 6499179 \\
& \text { Quare, } \frac{m \cdot a^{n}-c^{n}}{a^{n}}-\frac{a^{n}+c^{n}}{a^{n-1} b}+\frac{n c^{n}}{a^{n}}\left(\infty m-m c^{n}-\frac{a}{a^{n}}+\frac{a c^{n}}{b a^{n}}+\frac{n c^{n}}{a^{n}} \infty\right. \\
& \left.m-\frac{a}{b}+\overline{\frac{a}{b}-m+n}, \frac{e^{n}}{a^{n}}\right) \infty \frac{-31520}{200000}+\frac{2239}{100000} \infty 0-\frac{2928 \pi}{100000} .
\end{aligned}
$$

Oftenfum autem eft in Probl. XXII, hac quantitate exprimi damnum colluforis, quod quidem in præced. Probl. tantùm erat $\frac{9781}{46656} \infty \frac{20964}{100000}$, fesquialtero ferè minus: unde conditionem hane de reddendis collufori fuis nummis, quam veterator in ejus favorem adjeciffe videtur, in majus potius illius damnum vergere conftat . De cætero \& hoc obfervo, quòd etiamsi circulator poft duos ftatim continuos inanes jactus ad reftituendum fe obftringere vellet, illud cum aliquali adhuc lucro pro fe facere poffes. 


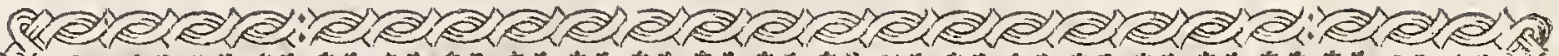

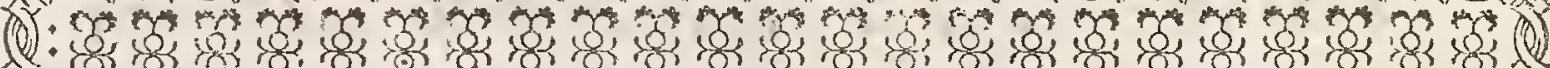
(1): : 1.

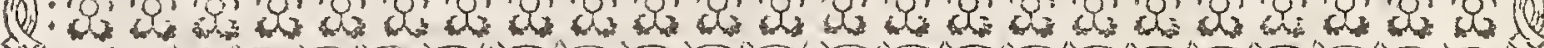

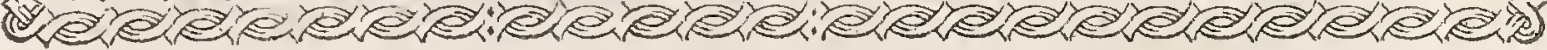

\section{ARTIS CONJECTANDI PARS QUARTA,} tradens

Ufum \& applicationem precedentis Doctrina in Civilibus, Moralibus \& Oeconomicis.

\section{A P U T I.}

Praliminaria quadam de Certitudine, Pro. babilitate, Neceßitate 6 Contingentia Rerums.

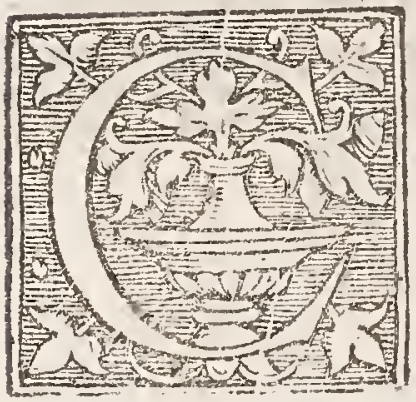

Ertitudo rei cujusvis fpectatur vel objectivè \& in fe; nec aliud fignificat, quàm ipfam veritatem exiftentio aut futuritionis illius rei : vel jabjectuve $\&$ in ordine ad nos; \& confiftit in menfura cognitıonis noftre circa hanc veritatem.

Omnia, qua fub Sole funt vel funt, praterita, prafentia five futura, in fe \& objectivè fummam femper certitum dinem habent. De præfentibus \& prateritis conit:t; quoniam eo ipfo, quo funt vel fuerunt, non poffunt norf effe vel furffe: Nec de futuis ambigendum, qux pariter etsi non fati ali.ujus inevitabili ne- 
ceffitate, tamen ratione tum prafcientiæ tum prædeterminationis divinæ non poffunt non fore; nisi enim certò eveniant quacunque fütura funt, non apparer, quio pacto fummo Creatori omnifcientiæ \& omnipotentia laus illibata conftare quear . Quomodo autem hac futuritionis certitudo cum contingentia aut libertate caufarum fecundarum confiftere polfit, de hoc difputent alii; nos à fcopo noftro aliena nolumus tangere.

Certitudo rerum, fpectata in ordine ad nos, non omnium eadem eft, fed multipliciter variat fecundirm magis \& minus. Illa de quibus revelatione, ratione, $\mathrm{Cenfu}$, experientia, ảvo \&ia aut aliter ita conftat, ut de eorum exiftentia vel futuritione nullo modo dubitare poffimus, fumma \& abfoluta certitudine gaudent. Cætera omnia imperfectiorem ejus menfuram in mentibus noftris obtinent, majorem minoremve, prout plures vel pauciores funt probabilitates qua fuadent rem aliquam effe, fore aut fuiffe.

Probabilitas enim eft gradus certitudinis, \& ab hac differt uit pars à toto. Nimirum fi certitudo integra $\&$ abfoluta, quam litera $a$ vel unitate I defignamus, quinque verb. gr. probabilitatibus ceu pariibus conftare fupponatur, quai um tres militent pro exiftentia aut futuritione alicujus eventus, reliquæ contra: eventus ille dicetur habew re $\frac{3}{5} a$, feu $\frac{3}{5}$ certitudinis.

Illud igitur altero probabilins vocatur, quod majorem certitudio nis partem habet; etsi in pofitivo probabule ex ufu loquendi tantùm dicatur id, cujus probabilitas femiffem certitudinis notabiliter fuperat. Dico, notabiliter; nam quod femiffem certitudinis circiter æquat, dum bium vel anceps vocatur. Ita probabilius eft, quod $\frac{1}{5}$ ccrtitudinis habet, quàm quod $\frac{\mathrm{r}}{\mathrm{I} j}$; etsi neutrum in pofitivo fit probabile.

Poßsibile eft, quod vel tantillam certitudinis partem obtinet: Imporfibile, quod nullam aut infinitè exiguam. Ita poflibile eft, quod habet $\frac{1}{20}$ aut $\frac{1}{30}$ certitudinis.

Moraliter certum eft, cujus probabilitas ferè æquatur integræ certitudini, fic ut defectus fentiri non poffit: Moralizer muposibile contra, quod tantum duntaxat probabilitatis habet, quantum moraw liter certo ad omnimodam certitudinem deeft. Ita si pro moraliter 
certo habeatur, quod 9390 certitudinis poffidet, erit moraliter imporribile, quod ejus tantùm habet $\frac{3}{3} \overline{0}$.

Neceffarium eft, quod non poteft non efle, fore aut fuife; idque meceßitate vel phyfica: quo pado neceffum ef ignem urere, trianguIum habere tres angulos xquales duobus reetis, plenilunium, guod Luna exiftente in nodis ingruit, effe eclipticum: vel bypotbtica, qua unumquodq; dum eft aut fuit, vel effe aut fuiffe fupponitur, non potef non effe aut fuiffe; quo fenfu neceflum eft Petrum fcribere, quem f́io ponog; fribere: vel denique neceßitate pacti feu inftituti, quo pacto aleator, qui teffera fenarium jecerit, neceffario vincere dicitur, fi prus inter lufores ita conventum fucrit, ut jafu fenarii victoria conlet.

Contingens (tam literum, quod ab arbitrio creatura rationalis: quàm fortuitum \& casuale, quod à cafu vel fortuna dependet ) eft id, quod poffet non efle, fore aut fuifle; intellige potentia remota, non proxima: nec enim contingentia femper omnem neceffitatem, etiam quoad caufas fecundas, excludit; quod exemplis declaro. Certifrmum eft, quòd data.tefferz politione, velocitate $\&$ difiantia ab alveo, eo momento quo manum piojicientis deferit, tellera non poteft aliter cadere, quàm uti revera cadit: item, quod data aëris confitutione prafente, datisque ventorum, vaporum, nubium mole, fitu, motu, directione, velocitate \& mechanifmi legibus, quibus hæc omnia in fe invicem agunt, tempeftas craftina diei non polfit alia fore, quàm qualis reapfe futura ent; adeo ut hi effectus ex fuis cauls. proximis non minus neceffario, atque Eclipfium phænomena ex luminarium motu fequantur: \& tamen ufus obtinuit, ut folæe Ecliples neceffariis, cafus vero tefferæ \& tempeftatis futuritio contingentibus annumerentur; cujus rei non alia ratio eft, quàm quòd ea, quae ad determinandos pofteriores effectus ut data fupponuntur, atque eriam in natura talia funt, non fatis tamen nobis fint cognita; nec fi effent, fatis excultum Geometrix \& Phylicæ ftudium, ut ex datis effectus hi calculo fubduci poffint; quemadmodum ex perfpectis $A=$ fronomiz principiis fupputari \& prædici poffunt Ecliples: quæ propterea \& ipfa, ante Afronomiam eo perfectionis promotam, non minus ac cætera duo inter futura contingentia referri opus habebant. Seguitur hin, uni \& uno tempore videri polfe contingens, quod alii 
(imò \& eidem) alio tempore poft cognitas ejus caufas fir neceffarium; adeo ut contingentia pracipue etiam refpiciat cognitionem noftram, in quantum nos nullam videmus repugnantiam in objecto ad non ef fe vel fore, etiamsi hic \& nunc vi caufæ proximæ fed nobis ignotæ neceffario fit vel fiat.

Fortuna propera, un Bonbeur, cin (Sinick / \& Fortuna adverfa, un Malbeur, ein lunglite dicitur, cum nobis bonum vel malum obtingit non quodvis, fed quod probabilius, aut faltem æquè probabiliter, poterat non obtigiffe; eoque proinde melior vel pejor fortuna, quo minus probabile erat, bonum vel malum hoc eventurum. Sic infigniter fortunatus eft ille, qui terram fodiendo thefaurum invenit; quoniam millies fodiendo ne fernel hoc accidit. Si viginti defertom res, quorum unus cæteris in exemplum fufpendio necandus, alea de vita contenderint: propriè non fortunati dicuntur illi novendecim, qui benigniore forte funt uf, fed infortunatifimus ille vicefimus, cui fors atra cecidit. Ita nec fortunatus prædicandus amicus tuus, qui è prælio falvus evafit, in quo exigua præliantium pars occubuit; nifi fortaffis ob excellentiam boni, quod in vitæ confervatione confifit a ita vocandum exiftimes.

\section{A P. II.}

De Scientia Es Conjectura. De Arte Conjectandi. 'De Argumentis Conjecturarum. Axiomata quedam generalia bucpertinentia.

Ea quiæ certa funt $8 x$ indubia, dicimur fire vel intelligere: $\mathfrak{c x}_{-}$ tera omnia cenjicere tantìm vel opinari.

Conjicere rem aliquam eft metiri illius probabilitatem: ideoque Ars Conjectanui five Stochaftice nobis definitur ars metiendi quàm fieri poteft exactifime probabilitates rerum, eo fine, ut in judiciis $\&$ actionibus nofris femper eligere vel fequi poffimus id, quod melius, fatius, tutius aut confultius fuerit deprehenfum ; in quo folo omnis Philofophi fapientia \& Politici prudentia verfatur.

$$
\text { Dd } 3
$$

Prow 
Probabilitates æftimantur ex numero fimul \& pondere argumentom rim, qua quoquo modo probant vel indicant, rem aliquam effe, fore aut fuife. Per pondus autem intelligo vim probandi.

Argumenta ipfa funt vel intrinfeca, vulgò artificialia, defumta ex locis topicis caufr, effectus, fubjecti, adjuncti, figni aut alterius cujusvis cir-w cumfantiæ, quæ qualemcunque nexum cum re probanda habere videtur: vel extrimfeca \& inartificialia, petita ab authoritate \& teftimonio. hominum. Exemplum efto: Titius occifus reperitur in viâ, Mævius commiffi homicidii accufatur; Argumenta accufationis funt, I . quòd conftet illum odio habuiffe Titium (en argumentum à caufa, potuit enim odium hoc ipfum impuliffé ad occidendum ). 2 . quòd examinatus palluerit timideque refponderit (en argumentum $a b$ effutu; poteft enim pallor \& metus ifte ex confcientia patrati criminis profluxife) . $3 \cdot$ quòd in adibus Mrvii repertus mucro fanguine tincus (en frgnm). 4. quòd quo die occifus in via Titius, eodem illac tranfierit Mavius (en cirsumftantiam loci \& temporis). 5 . quòd denique Cajus deponat, pridie commifli homicidi Titio cum Mævio lites interceffife (en tefimonium).

Priusquam autem propius ad infitutum accedamus, oftendendo, quomodo his argumentis conjecturarum in probabilitatibus metiendis uti conveniat, premittere lubet generales quasdam Regulas feu Axiomata, quæ unicuique fanæ mentis homini fimplex ratio diEtare folet, \& quæ in vitæ civilis ufu à prudentioribus etiam perpetuò obfervantur.

1. Conjecturis locus non effe debet in rebus, in quibus omnimodam certitudinem affequi licet. Fruftra proin effer Aftronomus, qui ex co quòd quotannis duas vel tres contingere novit Eclipfes, de Plenilunio quodam augurari vellet, num fit eclipticum, necne; cùm veritatem rei certo calculo confequi poffit. Ira fi fur interrogatus refponderit, fe rem ablatam vendidiffe Sempronio, ineptè ageret Judex, qui ex vulEx tonoque loquentis, aut ex qualitate rei furto ablatæ aliisve furti circumftantis de probabilitate aflerti conjicere vellet, quando præftò êt Sempronius, è quo rem omnem certò \& facilè experiri licebir.

2. Non fufficit expendere unum alterumve argumentum, fed congrivenda 
quirenda funt omria, que in cognitionem noftram venire poffint, at's ulllo modo ad probation m rei facere videntur. Tres naves ex. gr. folvunt è portu, poft aliquod tempus nunciatur, unam illarum naufragio periiffe; conjicitur quænam? fi folum numerum naviun fpectarem, infortunium fingulis æquè accidere potuife colligerem; fed quia memini, unam earum præ cæereris carie \& vetuftate fuiffe exefam, velis \&x antennis malè armatam, nauclero quoque novitio \& inexperto inftructam, hanc utique probabilius quàm cæteras interiiffe judico.

3. Nec tantuma illa funt attendenda, que rei probande conduccurt; fed \& ommia illa, qua in contrarium adduti poffunt, ut trutinatis probè utriscriscine feet utra praponderent. De amico diutifimè à patria abfente quaritur, an pro mortuo declarari poffit? Pro affirmativa militant hæc argumenta: Quòd omni licet adhibita cura toto vicennio nihil de illo innotuit: quòd peregrinantes plurimis vita periculis expofiti funt, quibus exempti hi gui domi manent; fortè igitur in undis finiit vitam, fortè occifus in via, fortè in prælio, fortè morbo aut cafu aliquo obiit in loco, ubi nemini fuit notus: guodd si in vivis effet, ejus jam ætatis effe deberet, quam pauci vel domi attingunt: quod fcripturus fuiffet, etiamsi in extremis Indiæ oris verfaretur, quia fcivit fe hæreditatem expectare domi: \& quæ funt alia. Quibus tamen argumentis non eft acquiefcendum, fed opponenda quoque fequentia, quæ negativam tuentur. Conftat, hominem fuiffe focordem, æegrè arripuiffe calamum, amicos contempliffe; fortè à Barbaris captivus ductus, ut fribere non potuerit; forte etiam fripfit ex India aliquoties, fed litere vel incuria latorum vel naufragio periêre; conftat denique, multos diutius emanfife, \& tamen tandem rediife incolumes.

4. Ad judicandum de univerfalibus fufficint argumenta remota \& univerfalia; fed ad conjecturas formandas de individuis, propiora quág \& $\&$ p.o cialia adjungenda funt, fo modo baberi poffunt. Ita cum quaritur in abfradto, quantò fit probabilius, juvenem viginti annorum feni fexam genario fore fupertitem, quàm verò hunc illi, preter difcrimen ætatis $\&$ annorum nihil eft, quod confiderare pofis ; fed ubi fpecialiter fermo eft de individuis Petri juvenis \& Pauli fenis, attendere infuper oportet ad fpecialem eorum complexionem \& ftudium, quo uterque 
valetudinem fuam curat; nam fi Petrus fit valetudinarius, fi affect bus indulgeat, fi intemperanter vivat, fieri poteft, utPaulus, etsi ætate provectior, optima tamen ratione longioris fpem vita concipere valeat.

5. In rebus incertis of dubiis adiones nofire fupendenda funt, donec major lux affulferit; fed fi occafio agendi nullarn patiatur moram, inter duo fomper eligendum id, quod convenientius, iutius, confultius aut probabilius videtur, etfin neutrum in pitivo tale fit. Sic in oborto incendio, è quo aliter elabinon polfis, nisi vel ex fummo tecto vel ex inferiore quadam contignatione te præcipitem des, præftabit pofterius eligere, quia tutius; etsi neutrum fimpliciter tutum fit, aut fine lafionis periculo fieri pont.

6. Quod aliquo cafu prodeffe, nullo nocere poteft, preferendum oft illi, quod nullo vel prodeft vel nocet; quorfum collimat illud, quiod vornacu-

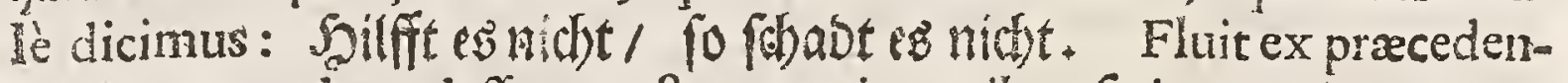
ti nam quod prodeffe poteft, cæereris paribus fatius, tutius, optabilius eft illo, quod non poteft.

7. De Adtionum humanarum pretio non fatuendum ex eventu; cim tolidifimæactiones quandoque optimo, prudentifimæ contra peffimo fucceffu fruantur; hinc Poëta: Careat fucceßibus, opto, quisquis ab evenu facta notanda outat. Ita fi quis tribus tefleris prima vice tres fenarios jacere fufcipit, etiamsi fortaffe vincat, ftolidè tamen egiffe cenretur - Notandum contra perverfa vulgi judicia, cui præftantior habetur, quò quifque eft fortunatior; imò cui profperum ac felix fcelus plerunque virtus vocatur, de quo rurfum eleganter Ovvenus:

Epigr. lib. Jing . \$. 216 .

Quòd malè confultum cecidit feliciter, Ancus

Arguitur fapiens, qui modo ftultus erat;

Quod prudenter erat provifum, fi malè vortar,

Ip fe Cato populo judice ftultus erit.

8. In judiciis noftris cavendum, ne rebus plus tribuamus quàm par efts seque quod probabilius ef ceteris, pro ablolutè serto babeamus ipfi aut obtrudamus aliis. Oportet enim, ut fides, quam rebus tribuimus, proportionata 
tionata fit gradui certitudinis, quam unaquæque res obtinet atque adeo in eadem ratione minor, qua minor eft ipfa rei probabilitas; qucd vernacule fic enunciamus; 2 2an mup ein jeoes in feinem giserth uno Unmerth beruben lafen.

9. Quia tamen rarò admodum omnimodam certitudinem affequi licee, secefsitas \&o ufus volunt, ut quod moraliter tantiem certum eft, pro abfolutè serro babeatur. Utile pro in effet fi Magiftratus autoritate morali cerxitudini determinati limites confituerentur; putà si definiretur, num ad illam efficiendam fufficiant $\frac{29}{10}$, an requirantu $\frac{929}{1000}$ certitudinis; ne partium ftudio aliquid dare foffic Judex, fed cynofuram 好abeat, quam in ferenda fententia conftanter obfervet.

Plura ejusmodi Axiomata alia unusquifque quotidiano rerum ufu edoctus proprio marte fibi cudere poterit, quorum omniums nos extra datam occafionem difficulter meminiffe poffemus.

\section{Ca PuT III.}

De variis argumentorum generibus, 6 quomodo corum pondera eftimentur ad Jupputandas rerum probabilitates.

Qui varia argumenta examinat, quibus opinio vel conjectura generatur, triplex in iis difcrimen animadvertet: nam quædam corum neceffario exiffunt é contingenter indicant: alia contingenter exifunt on neceffario indicant: alia denique contingenter exifunt fimul o indicant . Difcrimen declaro exemplis: Frater meus diu nihil ad me literarum dedit; dubito, an ejus fegnities aut negotia in culpa fint; vereor etiam ne planè fato concellerit. Hîc intermiffe fcriptionis argu. menta funt tria: Segnities, Mors \& Negotia; quorum primum exiftit neceffario, ( neceffitate hypothetica, quia fratrem fcio ponoq; fegnem effe) red indicat contingenter; potuiffet enim fegnities hiec ipfum non cohibere à fcribendo: fecundum contingenter exiftit, (poteft enim frater adhuc in vivis effe) at neceffario indicat, cum mortuus Ee Cribere 
Cribere non poffit: tertium \& contingenter exiftit \& contingenter in dicat; poffet enim ille habere $\&$ non habere negotia, \& fi qua ha: bet, poffunt tanta non effe, quæ ipfum de fcriptione detineant. Aliud exemplum: Pono aleatorem, cui ex ludi præf cripto præmium debeatur, fi tefferis duabus feptem puncta jecerit, voloque conjicere, quam talis vincendi fpem habeat. Hic argumentum victoria eft jactus feptenarii, qui illam indicat neceffario, (neceffitate nimirum pacti inter collufores initi), fed tantùm exiftit contingenter; cum preter feptenarium \& alii punctorum numeri cadere poffint:

Prater hanc argumentorum difinctionem aliud quoque in is difcrimen obfervare licety dum quadam eorum funt pura, alia:mixta . Pura voco, quæ in quibusdam calbus ita rem probant, ut in aliis nihil pofitive probent: Mixta, quæ ita rem sant in cafibus nonnullis, ut in cateris probent, contrarium rei. Exemplum efto: Si in turba tumultuantium qu dam gladio fuerit confolfus, \& teftimonio hominum fide dignorum eminus adfpectantıum conftet, huic nigram fuife chlamydem qui facinus commifit, reperiaturque inter tumultuantes Gracchus cum tribus a lis ejus coloris tunicâ indutus ; erit hac tunica argumentum aliquod commifla à Graccho cædis; fed mixtum; quoniam uno cafu ejus culpam, tribus cafbus ejusinnocentiam probat, prout videl . vel ab ipfo vel ab uno reliquorum trium cades patrata fuerit; nec enimab iftis patrari potuit, quin eo ipfo Gracchus ponatur innocens. Quòd fi verò in fubfecuto examine Gracchus palluerit, pallor hic faciei eft argumentum purum: probut enim Gracchi culpam, fià lafa confcientia proficifatur; fed non vicifim probat ejus innocentiam, fi aliunde proveniat; poteft enim fieri, utalia de caufa pallefcar Gracchus, \& tamen ipfe fir auctor cæedis.

Ex is, quar hactenus dicta funt, perfpicuum eft, vim probandi; qua pollet quodl bet argumentum, pendere à multitudine cafuum, quibus illud exiftere vel non exiftere, indicare vel non indicare, aut etiam contwarium rei indicare potef; adeoque gadum certitudinis feu probabilitatem, quam generat hoc argumentum, excalibus iftis per Dofrinam primæ Partis non aliter elici poffe quim fortes aleato rum in ludis aleæ inveftigari folent. Ad quod ofendendum fumamus numerum cafuum, quibus contingere poteft ut argumentum a 
Tivquod exiftat, effe $b$; entum, quibus fieri poteftut hon exiftar, $c$; amborum a $D b+c$; item numerum cafutum, quitus contingere poteffut indicet, $\beta$; ut non indicet, aut contrarium rei indicet $; z ;$ amborum \& $\gg \beta+2$. Pono autem, omnes $c$. fus æque poffibiles efle, feu pari facilitate evenire pofle; 'alias enim moderatio eft adhibenda, \& pro quovis cafu faciliori tot alii cafus numerandi funt, quoties is cæeteris fâcilius evenit: ex. gr. pro cafu triplo faciliorinumero tres cafus, qui pari cum ceteris facilitate concingere poffint .

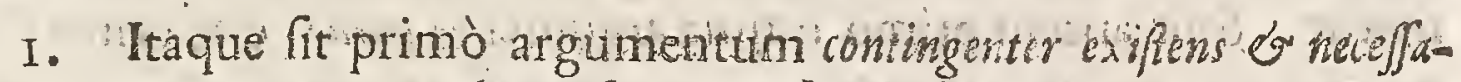
yòindicans: erunt ex modo pơfitis 6 cafus, quibus exiftere adeoque 2 indicare rem ( (eu I) poteft; \& $c$ cafus, quibus poteft non exifte$r e$, adeoque nec quicquam indicare; id quod per Coroll. I .Prop.

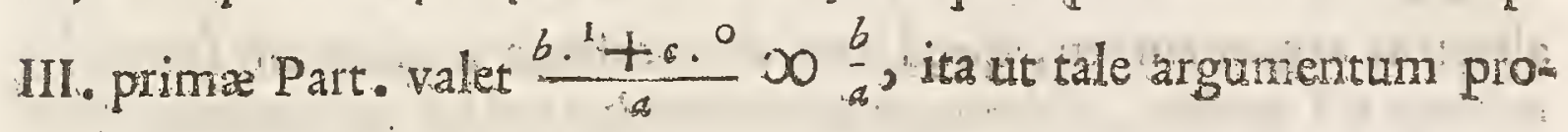
bet $\frac{b}{a}$ rei feu certitudinis rei.

2. Sit deinde argumentum neceffario exiftens of contingenter in dicans: erunt exhyp. $\beta$ cafus, quibus fieri poteft ut indicet rem, \& * cafus ut non indicet, feu ut contrarium indicet; quod vim arguinenti ad rem probandam nunc efficit $\frac{\beta{ }^{1}+{ }^{\gamma}{ }^{0}}{\alpha} \infty \frac{\beta}{\alpha}$ : probat ergò hujusmodi argumentum $\frac{\beta}{\alpha}$ certitudinis rei, atque infuper fi fit mixtum (quod eodem modo pater) $\frac{x^{x}+\beta 0^{0}}{\alpha} \infty \frac{\gamma}{\alpha}$ certitudinis contxarii.

3. Si quod argumentum contingenter exifit on contingenter indicat, pono ftatim exiftere, quo cafu per modo oftenfa probare cenfetur ${ }^{\beta}$ rei, $\&$ infuper fi fit mixtum, $\frac{\gamma}{a}$ contrarii : unde cum fint $b c a$ t fus, quibus exifere; \& c cafus, quibus non exiftere, adeoque \& nil probare pofit ; valebit hoc argumentum ad rem probandam $\frac{b . \beta: \alpha+c .0}{a} \infty \frac{b \beta}{a \alpha}: \&$, si fit mixtum, ad probandum contrarium $\frac{6 \cdot 2 \cdot \alpha+c 0^{\circ}}{\sigma} \infty \frac{b \gamma}{x \alpha} \quad \mathrm{Ee}_{2}$ 4. Porío 
4. Porrò si plura concurrant argunenta ad ejusdem rei pro. bationem, vocenturque

mumeri cafuum, argumenti pr. fer. qert. quart. quint. \&c. omnitsm

probaintium

mon-probantium

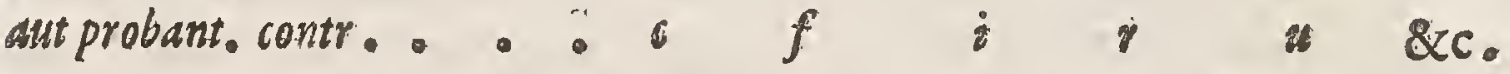

vis probandi ex omnium argumentorum concurfu refultans fic æfti matur. Sint autem primò omnia argumenta pura; erit primi feorfin fpectati pondus $\frac{b}{a} \infty \frac{\alpha-c}{a}$ (vocando fic $\frac{\beta}{\alpha}$, fir contingenter indicet aut $\frac{b \beta}{a \cdot \alpha}$, fi fimul contingenter exiftat) ut vidimus . Accedat nunc alterum argumentnm, quod e vel $d-f$ cafibus probar rem feu I, \& $f$ calibus nil probat, folumque adeò poindus primi argumenti, quod oftenfum eft effe $\frac{a-c}{a}$, efficax relinquit: valebit pondus ex utroq; rgumento conflatum $\frac{\overline{d-f} \mathbf{r}+f_{0}^{\overline{a-c}: a}}{d} \infty \frac{a d-c f}{a d} \infty \mathrm{I}-\frac{e f}{a d}$ re Jungatur \& tertium; erunt $b$ feu $g-i$ cafus, qui probant rem, $\&$ icafus, quibus nullum eft argumentan, folaque duo priora vim fuam probandi $\frac{a d-c f}{a d}$ retinent: unde vis omnium trium cenfetur

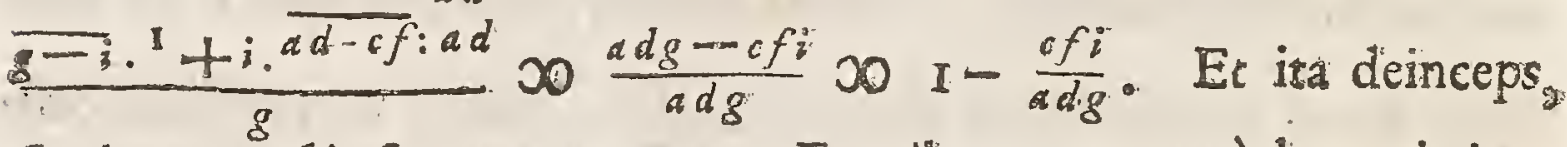
fi plura præftò fint argumenta. E quibus patet, quòd omnia jun stim funta probabilitatem inducunt, quæ ab abfoluta rei cercitudi: ne feu unitate deficiat parte unitatis, orta ex divifione producti cafuum non probantium per productum cafuum omnium in univerfis argumentis.

5. Sint deinde omnia argumenta: mixta: Quoniam numerus: cafuum probantium primi argumenti eft $b$, fecundi, tertii $b$, \&cc $\&$ probantium contrarium $c, f, i, \& c$. probabilitas rei ad probabili tatem contrarii, vi folius primi argumenti, fe habet ut $b$ ad $c$; \& vi folius fecundi, ut $e$ ad $f ; \&$ vi folius tertii, ut $b$ ad $i, \& c$. unde fac evidens eft, quod vis probandi totalis ex omnium argumentorum concurfu refultans componatur ex yiribus omnium argumentorum 


$$
P A R S \text { QUIARA. }
$$

particularium, i. e. quod probabilitas rei ad probabilitatem contrarii fe habeat in ratione $b \bullet b \& c$, ad $i f i \& c$. adeò ut probabilitas abfoluta rei fit $\frac{b e b}{b e b+c f i}, \&$ probabilitas abfoluta contrarii $\frac{c f i}{b e b+c f i}$.

6. Sint rurfus quzedam argumenta pura (velut tria priora) \& quadam mixta (ut duo reliqua). Confidero primò fola pura, qua per $\mathfrak{I} .4$. probant $\frac{a d g-c f i}{a d g}$ ertitudinis rei, defectu ad unitatem exiItente $\frac{e f i}{a d g}$; funt ergò velut $a d g-c f i$ cafus, quibus tria hæc argumenta junctim fumta probant rem feu $\mathrm{I}$; \& c f $i$ cafus, quibus nil probant, folisque proin argumentis mixtis locum probandi concedunt: probant autem hæc duo per præced. S. $5, \frac{q t}{q t+r u}$ rei, \& $\frac{r s}{q t+r u s}$ contrarii. Quare probabilitas rei ex omnibus argumentis refultans

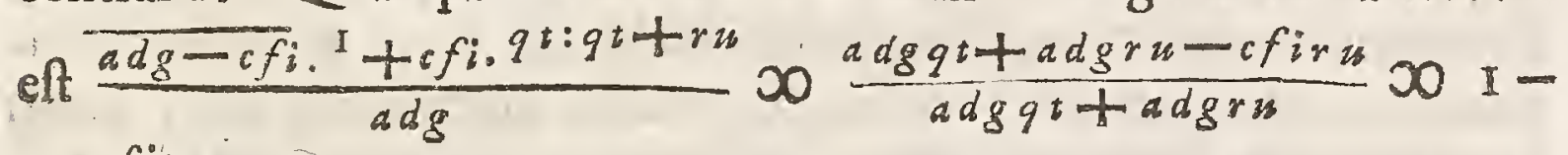
$\frac{\text { ofir } u}{a d g \cdot \overline{q t+r u}}$, quæ ab omnimoda certitudine ceu unitate deficit prom ducto partis $\frac{e f i}{a d g}$ (qua ab eadem deficit probabilitas rei per $\mathcal{I}$. 4. ex fo= lis argumentis puris refultans) per $\frac{r v_{b}}{q^{t}+r u}$ probabilitatem abfolutam contrarii per præced. $\mathfrak{I} .5$. exargumentis mixtis elicitam.

7. Quòd fi præter argumenta quæ rei probandæe conducunt, alia fe offerunt argumenta pura, quibus contrarium fuadetur, utriufque generis argumenta per præced. regulas feorfim ponderanda funt, ut inde conftare poffit ratio, qua inter probabilitatem rei $\&$ probabilitatem contrarii intercedit. Ubi notandum, fi argumenta, quæ in utramque partem afferuntur funt fatis fortia, fieri poffe, ut $a b$ foluta probabilitas utriusque partis femiffem certitudinis notabilite fuperet, h.e ut utramque contrariorum reddatur probabile, etfi relative loquendo unum fit minus probabile altero; fic fieri poteft, ut quidpiam habeat $\frac{2}{3}$ certitudinis, dum ejus contrarium poffidet $\frac{1}{4}:$ quo pacto utrumque contrarior um erit probabil, \& tamen prius minus probabile fuo contrario, idque in ratione $\frac{2}{3}$ ad $\frac{3}{4}$, five 8 ad 9 .

Diflimulare hic non poflun, quòd in fpeciali applicatione haw $\mathrm{Ee} 3$

rums 
scum regularum multa occurfura prævideo, quæ in caufa effe queunt. ut turpiter fape quis hallacinetur, nifi in difcernendis argumcntis caute procedat: quandoque enim diftincta videri poffunt argumenta, qua reaple unum idemque argumentum cónfituunt; aut vice verfa unum videntur, qux diftinda funt; nonnunquam ponuntur in argume to talia, quæe argumentum contrarii planè evertunt $; 8 \mathrm{c}$. In cujus rei illuftrationem unum tantùm alterumve exemplum adduco: Pono in fupra allato exemplo Gracchi, homines hos fide dignos, qui tumultuantes viderunt, in Auctore cadis rufos infuper capillos obfervaffe, talique capillitio Gracchum cum duobus aliis notari, fed quorum neuter nigra toga fit veftitus. Hic, fl quis ex iftis'indiciis, quòd præter Gracchum tres fint atro colore veltiti, \& præter eundem duo rufis capillis infignes, colligere vellet probabilitatem culpa ad probabilitatem innocentia in penfona Grachi per $\int . ? 5$. fe habere in ratione compofita ex fubtripla \& fubdapla, h.e. in ratione fubCextupla, illumque adeo verifimitius multo innocentem effe; quàn reum facinoris, is utique ineptè colligeret; cùm hîc propriènon adfint duo argumenta, "fed unum tantùm idemque à duâbus fimul circumftantris coloris veftum \&xapilorum petitum, quæ duæ circumfrantia cùm in fola perfona Gracchi jundim conveniant, arguun certò non alium quàm ipfum auctorén cædis effe potuifle. Aliud exemplum efto : De.Contractu quodam foripto dubium move tur, an dies inftrumento appofitus fraudulenter fit anticipatus? Ar= gumentum pro negativa hoc effe poteft, quòd infrumentum figna tum fit manu Notarii, i.e. perfora publica $8 x$ jurata, quem non verifmile eft quicquan comminfe fradis, cum id fine fummo ho noris ac fortuna fux periculo facere non potuiffer, ac propterea $e_{-}$ siam inter 50 vix unus reperiatur, qui ifthuc nequitia procedere audeat. Argumenta vero pro affirmativa poffunt efle, quòd Notarii hujus fama peffmè audiat, guò ex fraude maximum expectare potuit lucrum, \& prefertim guod talia atteftetur, cuæ nihil probabilitats habent, veluti fr fripfifet, quesdam altei mutuo locafe rocoo aureos, eo tempore, quo ex omnium æltimaticne vix centum in univerfis bonis habere poterat. Hîc llargumentum à charadere ejus qui fubfriphr petitum feorfim confideres, cenfere poteris pro- babio 


\section{DRS $2 U A R T A$}

babilitatem authentize inftrumenti velut $\frac{49}{50}$ certitudinis valere. Sin argumenta in contrarium expendas, agnofcere teneris fieri vix pof$\mathrm{fe}$, quin inftrumento falfum infit, adeoque fraudem in illo commif fam moralem plane certitudinem, $h, e$. velut $\overline{1} \frac{2}{0} 20$ certitudinis habere: Inde verò concludi non debet, probabilitatem authentia ad probabilitatem fraudis per $\mathbb{J}: 7$. effe in ratione $\frac{42}{50}$ ad $\frac{2}{1}=2$, hoceft in ratione pene rqualitatis: dưm enim Notarium pono diffámata fidei, hoc ipfo pono, eum non comprehendi in cafu horum 49 proborum Notariorum, qui fraudes deteftantur; fed effe ipfum illum quinquagefinum, qui fibii religioni non dúcit; perfide in officio fuo verfari: id quod vim omnem illius argumenti, quod alias authersiam inftumenci probare poffet proffus tollit ac deftruit.

\section{CA P T T T.}

De diplici Modo inveftigandi numeros calu um. Quid'fentiondumide illo, qui infituitur per experimesta. Problema fingulare: cam in rem propofitum E?c.

Oftenfum eft in Capite præced "quonodo ex numeris cafuum, quibus rerum quarumvis argumenta exiftere vel non exiftére, indicare vel hon indicare, aut etram contrarium indicare poflünt, ipforum vires probandi iisque proportionatæ rerum probabilitates calculo fubduci \& æftimari queant. Eò itaque deventum eft; ut ad. conjęuras de requalibet rite formandas aliud nil requiratur, quàm ut tum numeri horum cafuum accuratè determinentur, tum \& definiaturi quanto facilius alii aliis accidere poffint. At hîc tandem nobis aqua harare, videtur, cum vix in paracinmis præftare hoc.liceat, nec alibi ferè fuccedat. quàm in alea ludis, quos primi inventores ad æequitatem ipfis: conciliandam data opera fic inftituerunt, ut. certi notique eff nt numer cafuum, ad quos fequi deber lucrum aut damnum \& ut cafus hi, omnes pari facilitate obringere poffent. In cateris enim plerisque vel à naturæ operatione vel ab hominum axbitrio pendentibus effectis id neutiquam locum habes. Ira ex. gr . 
noti funt numeri cafuum in tefferis; in fingulis enim tot manifefte funt quot hedræ, iique omnes æquè proclives; cùm propter fimilitudinem hedrarum \& conforme tefferre pondus nulla fit ratio, cur una hedrarum pronior effet ad cadendum quàm altera, quemadimodum fieret, si hedræ diffimilis forent figuræ, aut teffera una in pate ex ponderofiore materia conftaret quàm in a'tera. Sic itidem noti funt numeri cafuum ad educendam ex urna fchedulam albam nigramve, \& notum eft omnes æquè polfibiles effe; quia nimirum determinati notique funt numeri fchedarum utriusque generis, nullaque perfpicitur ratio, cur hæc vel illa potius exire deb at quàn quælibet alia. At quis cedo mortalium unqu m definiet nume rum ex. gr. morbo um, veluti totidem cafuum, qui innumeras corporis humani partes quavis atate invadere, mortemque nobis inferre valent; \& quantò facilius hic quàn ille, peftis quàm hydrops, hydrops quàm febris, hominem perimat, ut inde de futuro vitæ necisque ftatu conjectura formari polfit? Quis item recenfebit cafus innumeros nutationum, quibus aër quotidie obnoxius eft, ut inde conjicere poffit, quænam polt menfem, nedum poft annum, ejus futura fit conftitutio? Rurfus, quis mentis humanæ naturam, aut admirabilem corporis noftri fabricam fatis perfpetam habuerit, ut in ludis. qui ab illius acumine aut hujus agilitate in totum vel ex parte dependent, determinare audeat cafus, quibus hic vel ille ludentium victoria potiri vel excidere poffit? Hæc enim \& talia cùm dependeant à caufis omnino latentibus, atque infuper innumerabili complexionum varietate induftriam noftram xternum lufuris, infas: nientis planè foret, quicquam hoc pacto cognofere velle.

Verum enimverò alia hîc nobis via fupperit, quâ quæfitum obtineamus; \& quod à priori elicere non datur, faltem à pofteriuri, hoc eft, ex eventu in fimilibus exemplis multoties obfervato eruere licebit; quandoquidem prafumi debet, tot cafibus unumquodque pofthac contingere $\&$ non contingere poffe, quoties id antehac in fimili rerum ftatu contigiffe $\&$ non contigiffe fuerit deprehenfum. Nam fi ex. gr . facto olim experimento in tercentis hominibus ejusdem, cujus nunc Titius eft, ætatis \& complexionis, obfervaveris ducentos eorum ante exactum decennium mortem oppetiiffe, reliquos ultra vi- 
tam protraxiffe, fatis tuto colligere poteris, duplo plures cafus effe, quibus \& Titio intra decennium proximum naturæ debitum folvendum fit, quàm quibus terminum hunc transgredi poflit. It fi quis plurimis retrò annis ad coeli tempeltatem attenderit, notaveritque, quoties ea ferena aut pluvia extiterit: aut si quis duobus ludentibus fepiffrmè adftiterit, videritque quoties hic aut ille ludi victor evafe. rit, co ipfo rationem detexerit, quam probabiliter habent inter fe numeri cafuum, quibus iidem eventus præviis fimilibus circumftantiiis \&c polthac contingere ac non contingere poffunt .

Atque hic modus empiricus determinandi numeros cafuum per experimenta neque novus eft neque infolitus; nam \& Celeb. Audar Artis cogitandi magni acuminis \& ingenii Vir Cap. 12. \& feqq. poAtremæ Partis haud diffimilem præcribit, \& omnes in quotidian̊ praxi eundem confanter obfervant. Deinde nec illud quenquam lacere potelt, quòd ad judicandum hoc modo de quopiam eventu non fufficiat fumfiffe unum alterumque experimentum, fed quòd magna experimentorum requiratur copia; quar do \& Rtupidifimus quifque nefcio quo naturæ inftinctu per fe \& nulla prævia inftitutione (quod (anè mirabile eft) compertum habet, quo plures ejusmodi captz fuerint obfervationes, è minus à fcopo aberrandi periculum fore. Quanquam autem hoc naturaliter omnibus notum fit, demonftratio, qua id ex artis principiis evincitur, minimè vulgaris eft, $\&$ proin nobis hic loci tradenda incumbit: ubi tamen parum me praftiturum exiftimarem, fi in hoc uno, quod nemo ignorat, demonftrando fubfifterem. Ulterius aliquid hic contemplandum fupereft, quod nemini fortafis vel cogitando adhucdum incidit. Inquirendum nimirum reftat, an aucto fic obfervationum numero ita continud augeatur probabilitas affequendæ genuinæe rationis inter numeros caflum, quibus eventus aliquis contingere \& quibus non contingere poteft, ut probabilitas hæc tandem datum quemvis certitudinis gradum fuperet: an verò Problema, ut fic dicam, fuam habear Afymptoton, h. e. an detur quidam certitudinis gradus quem nunquam excedere liceat, utcunque multiplicentur obfervationes, putà, ut nunquam ultra femiffem, aut $\frac{2}{3}$, aut $\frac{3}{4}$ certitudinis partes certi fieri poffimus, nos veram cafuum rationem detexiffe, Ut exemplo conftes quid velion, pos 
no in urna quadam te infcio reconditos effe ter mille calculos albos \& bis mille nigros, teque eorum numerum experimentis exploraturum educere calculum unum poft alterum (reponendo tamen fingulis vicibus illum quem eduxift, priusquam fequentem eligas, ne numerus calculorum in urna minuatur) \& obfervare, quoties albus \& quoties ater exeat. Quæritur, ucrum toties hoc facere poffis, ut decuplo, centuplo, millecuplo \& c . probabilius fiat (h.e . ut moraliter tandem certum evadat) numeros vicium, quibus album \& quibus nigrum eligis, eandem rationem féfuialteram, qua ipñ calculorum ceu cafuum numeri gaudent, inter fe habituros, quàm aliam quamlibet rationem abifta diverfam? Nisi enim hoc fiat, fateor actum fore de noltro con itu explorandi numeros cafuun per experimenta. At fi id obtineat, acquiraturque tandem hoc pacto moralis certitudo (quemadmodum hoc etiam reapfe fieri fequenti Capite oftendam) æquè propermodum exploratos habebimus à pofteriori cafuum numeros, acfi nobis à priori cogniti effent; quod fane in ufu vitæ civilis, ubi moraliter certum pro abfolute certo habetur, per Ax . 9. Cap. II abunde fufficit ad conjecturas noftras in quavis materia contingente non minus fcientifice dirigendas, atque in ludis aleæ: etenim fi lo:o urnæ fubftituamus aërem, ex.gr. five corpus humanum, quæ f. nn item variarum mutationum atque morborum intra $f e$, velut urna calculos, continent, poterimus utique eodem modo per obfervationes determinare, quanto facilius in iftis fubjectis hic vel ille eventus accidere polfit.

Ne autem hæc fecus intelligantur quàm oportet, probè notandum eft, quòd rationem inter numeros cafuum, quam experimentis determinare aggredimur, non præcise $\&$ in indivifibili acceptam ve$\lim$ (fic enim contrarium prorfus eveniret, eoque minus probabile fieret, veram rationiem inventam effe, quo plures caperentur obfervationes ) verum rationem in aliqua latitudine fumtam, i.e. binis limitibus conclufam, fed qui tam arcti conftitui poffunt, quàm quis voluerit. Nimirum, fi i exemplo calculorum modo allato duas ratio-

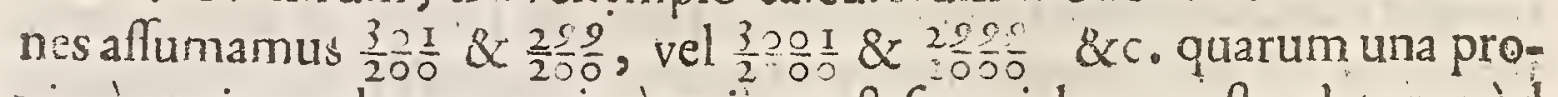
ximè major, altera proximè minor eft fesquialtera, oftendetur quòd data quavis probabilitate probabilius fieri polfit, rationem per expe.

rimenta 
rimer ta crebro repetita inventam intra hos limites $x$ tionis fesquialteræ, quàm extra cafuram effe.

Hoc igitur eft illud Problema, quod evulgandum hoc loco propofui, poftquam jum per vicennium preffi, \& cujus tum novitas, tum fumma utilitas cum pari conjuncta difficultate omnibus reliquis hujus doctrinæ capitibus pondus \& pretium fuperaddere poteft. Ejus autem folutionem priufquam tradam, paucis objectiones diluam, quas Viri quidam doeti contra hæc placita moverunt.

I. Objiciunt primò, aliam effe rationem calculorum, aliam morborum aut mutationum aëris; illortm numerum determinatum effe, horum indeterminatum \& vagum. Ad quod refpondeo, utrumque refpectu cognitionis nofræ æquè poni incertum \& indeterminarum; fed quicquam in fe \& fua natura tale effe, non magis à nobis poffe concipi, quàm concipi poteft, idem fimul ab Auctore naturæ creatum efle \& non creatum: quacungue cnim Deus fecit, eo ipfo dum fecit, etiam determinavit .

2. Objiciunt fecundò, calculorum numerum finitum effe, mor borum $\& c$. infinitum. Resp. fupendè vaftum potius effe, quàm infinitum; fed demus actu infinitum effe: notum elt, quòd etiam inter duo infinita determinata poffit intercedere ratio, eaque numeris finitis vel accuratè, vel faltem quàm proximè quis voluerit, explicabilis. Sic utique circumferentiæ circuli ad diametrum determinata cft ratio, quæ licet accuratè non exprimatur nifi per numeros cycli$\cos$ Ludolphi in infinitum continuatos, ab Archimede tamen, Metio "\& ipfo Ludolpho limitibus ad ufum fufficientiffimè confrictis defim nitur: unde nil impedit, quo minus ratio inter duo infinita, fed numeris finitis quàm proximè expreffa, finitis quoque experimentis determinetur.

3. Ajunt tertiò, numerum morborum non manere confanter eundem, fed quotidie novos pullulare. Reff. quin traku temporis mosbi multiplicari quernt, inficiari non poffur us; \& certum eft, eum qui vellet ex obfervationibus hodiennis concludere ad tempora Patrum antediluvianolum, à veritate enormiter aberraturum effe. Inde verò nil aliud fequitur, quàm quòd interdum novæ capienda funt

$$
\text { Ff 2 }
$$
obfers 
obfervationes; quemadmodum capienda forent cum calculis, fintamerus corum in urna mutari fupponeretur.

\section{A P U T V. \\ Solutio Problematis precedentis.}

Ut prolixæ rem demonftrationis quâ licet brevitate \& perfpí cuitate expediam, conabor omnia reducere ad abftractam Mathefin, depromendo ex illa fequentia Lemmata, quibus oftenfis cæetera in nuda applicatione confiftent.

Lemms 1. Pofita ferie quootlibet numerortm $0,1,2,3,4, \& \mathrm{c}$. à nulla feu cifra naturali fe confequentium ordine, quorum extremus \& maximus dicatur $r+s$, intermediorum quispiam $r$, \& qui huic ex utraque parte proximè latus cingunt, $r+I \& r-I$ : fi continuetur porrò hac feries, donec extimus terminus utcunque multiplex fiat numeri $r+s$, putà donec fit $n r+n s$, atque in eadem ratione augeantur intermedius $r$, \& ejus laterales $r+\mathrm{I} \& r$ - I ; fic ut eorum loco prodean $n r, n r+n \& n r-n$, iplaque feries initio pofita

$$
0,1,2,3,4, \ldots . r-I_{2}, r, r+I_{2} \ldots \ldots+s_{a}
$$

mutetur in hane

$$
0, \mathrm{I}, 2,3,4, \ldots \ldots n r-n \ldots n r \ldots n r+n \ldots \ldots \ldots n r+n s_{0}
$$

multiplicabuntur quidem hoc pacto termini feriei, tam illi qui medio $n r \&$ alterutri limitum $n r+n$ aut $n r-n$ interjacent, quàm illi quis inde à limitibus ad extimos ufque $n x+n s$ aut o porro protenduntur: nunquam tamen (quantumvis magnus affumatur numerus $n$ ), numerus terminorum ultra limitem majoren $n r+n$ plusquam $s-I$; nec numerus terminorum ultra minorem $n r-n$ plufquam $r-1$ vicibus. fuperabit numerum horum, qui intermedio $n r \&$ alterutro limitum $n r+n$ vel $n r-n$ funt conclufi. Nam facta fubtractione patet, limite majore ad terminum extremum $n r+n s$ effe intervallum terminorum $n s-n$; à limite minore ad alterum extremum 0 intervallum $n r-n ; \&$ ab intermedio numero ad alterutrum limitem intervallum $n$ terminorum. Eft verò femper $n s-n$. n:: s-I. I \& \& $n x-n_{0}$ $n:: x-I . I . \quad$ Quare conftat \& $\&$. 
Lemm. 2. Omnis poteftas integra alicujus biromii $r+s$ terminis exprimitur uno pluribus, quàm eft unitatum numerus in poteftatis indice. Nam Quadratum conftat terminis tribus, Cubus 4 o Biquadratum $\zeta_{2} \&$ ita porrd, ut notum.

temm. 3. In qualibet poteftate hujus binomii (faltem cujus index requalis binomio $r+s 0 t$, aut ejus multiplex, purà $n r+n s$ Do $\mathrm{nt}$ ) fi terminum quempiam $M$ nonnulli precedant, alii fequantur, \& fit numerus omnium precedentium ad numerum omnium fequentium reciprocè, ut $s$ ad $r$, feu quod eodem redit, fi in illo termino numeri dimenfionum literarum $r \& s$ directe fint, ut ipfæ quantita-

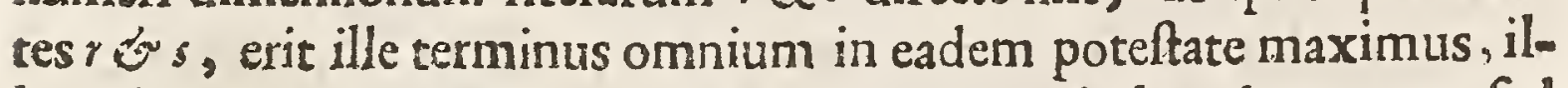
li vero propior $a b$ utravis parte major remotiori $a b$ eadem parte: fed idem terminus $M$ ad propiorem minorem habebit rationem, quàm (in pari terminorum intervallo) propior ad remotiorem.

Dem. I. Nota res eft inter Geometras, quòd poteltas nt binomii $r+s$, hoc êt, $\overline{r+s^{n t}}$ hâc lerie exprimitur:

$r^{n t}+\frac{n z}{1} r^{n t-1} s+\frac{n t \cdot n t-1}{1 \cdot 2} r^{n t-2} s s+\frac{n t \cdot n t-1 \cdot n t-2}{1 \cdot 2 \cdot 3} r^{n t-3} s^{3}+\& c$.

ufque ad $+\frac{n z}{1} r s^{n s-1}+s^{n t} ;$ in cujus progreflu pars una binomii gimenfionibus fuis gradatim minuitur, pars altera $s$ augetur, exiftentibus interea coëffricientibus fecundi \& penultimi termini $\frac{n t}{I}, 3^{\text {ti }}$ \& antepenultimi $\frac{n t \cdot n t-1}{1.2}, 4^{t i} \&$ proantepenultimi $\frac{n t \cdot n t-1 . n t-2}{1.2 \cdot 3}$, \& fic deinceps. Et quia numerus omnium præter $M$ terminorum per Lemm. 2. eft $n t 00 \mathrm{nr}+n s_{2}$ ex hypoth. autem numerus ipfum præcedentium ad numerum fequentium fe habet, ut $s$ ad $r$, erit numerus eorum, qui terminum $M$ pracedunt, $n s ; \&$ qui ipfum fo. guuntur, $n r$. Unde ex lege progreffionis terminus $M$ fet

$$
\begin{aligned}
& \frac{n t \cdot n t-1 \cdot n t-2 \ldots n t-n s+1(n r+1)}{n \cdot 2 \cdot 3 \cdot 4 \cdots n s} r^{n v} s^{n s} \text {, vell } \\
& \frac{n t \cdot n t-1 \cdot n t-2 \ldots n t-n r+1(n s+1)}{1 \cdot 2 \cdot 3 \cdot 4 \cdots \cdots n r} y^{n r} s^{n s} \text {; }
\end{aligned}
$$

2. fimiliter serminus huic proximus ad 
finiftram:

dextram:

$\frac{n t \cdot n t-1 \cdot n t-2 \ldots \ldots n r+2}{1 \cdot 2 \cdot 3 \cdot 4 \cdots n s-1} r^{n r+1} s^{n s-1} \frac{n t \cdot n t-1 \cdot n s-2 \ldots n s+2}{1.2 \cdot 3 \cdot 4 \ldots n r-1} r^{n r-s} s^{n s+r}$

nec non fequens verfus finiftram:

dextram:

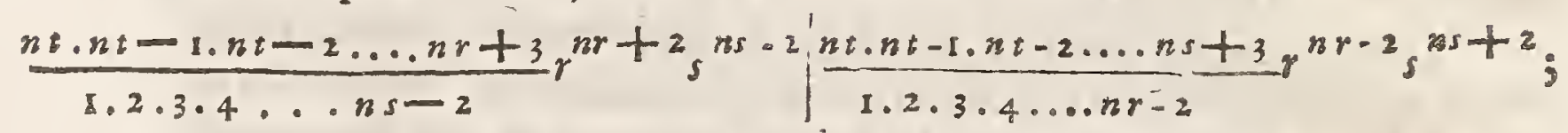

è quibus, præmiffa ubique convenienti reductione tam coëfficientium quàm terminorum purorum per divifores communes, patebit, quòd terminus $M$ ad proximum verfus finiftram fe habet, ut $\overline{n r+I_{\text {. }} s}$ ad $n s . r$, hic ad fequentem, ut $\overline{n r} \bar{T} . s$ ad $\overline{n s-1} . r \& c_{0}$ nec non terminus $M$ ad proximum verfus dextram, ut $\overline{n s+I_{+} r}$ ad $n r_{\text {. }} s$; \& hic ad fequentem, ut $\overline{n s+2}, r$ ad $\overline{n r-1}$.s. \&zc. Eft veró $\overline{n r+1} \cdot s$ $(n r s+s)>n s . r(n r s), \& n r+2 . s(n r s+2 s)>n s-1 . r$

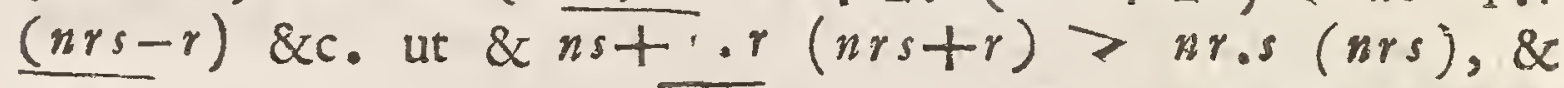
$n s+2 . r(n r s+2 r)>\overline{n r-1} \cdot s(n r s-s) \& c$. ut apparet. Ergò terminus $M$ major proximo ab utravis parte, hic major remotiori ab eadem parte, \&c. Q.E.D.

2. Ratio $\frac{n r+1}{n s}$ minor eft ratione $\frac{n r+2}{n s-1}$, ut patet: ergò \& addita communi ratione $\frac{s}{r}$, ratio $\frac{\overline{n r+1 . s}}{n s, r}<\frac{\overline{n r+2 . s}}{n s-1, r}$. Similiter ratio $\frac{n s+1}{n r}<\frac{n s+2}{n r-1}$, ut liquet: igitur addita ratione communi $\frac{r}{s}$, ratio quoque $\frac{\overline{n s+1} \cdot r}{n r . s}<\frac{\overline{n s+2} \cdot r}{\overline{n r-1} \cdot s}$. Sed ratio $\frac{\overline{n r+1} \cdot s}{n s, r}$ eft illa quam tetminus $M$ habet ad proximum verfus finiftram; \& $\frac{n \overline{r+2 . s}}{n s-\mathrm{r} . r}$ illa, quam habet hic ad fequentem: item ratio $\frac{\overline{n s+r} \cdot r}{n r . s}$ eft ea, quam terminus $M$ habet ad proximun verfus dextram; $\frac{\overline{n s+2} \cdot r}{n r-1 . s}$, quam habet hic ad fequentem; uti modò oftenfum eft, $\&$ ad cæteros omnes ex æquo concludi potef. Quare maximus terminorum $M$ ad propiorem ex utravis parte minorem rationem haber, quàm (in pari terminorum intervallo) prepior ad remotiorem ex eadem parte. Q.E.D. 
Iemm. 4. In poteftate binomii, cujus index $n t$, tantus poteft concipi numerus $n$, ut maximus terminorum $M$ ad alios duos $L \& \Lambda$, intervallo $n$ terminorum finiftrorfum $\&$ dextrorfum à fe diftantes, rationem acquirat qualibet data majorem .

Dem. Cùm enim in Lemm, praced. terminus $M$ fit inventus $\frac{n t \cdot n t-I \cdot n t-2 \ldots \cdots n r+I}{I \cdot 2 \cdot 3 \cdot 4 \cdot \cdots \cdot n s} r^{n s}$, vel $\frac{n t \cdot n t-1 \cdot n t-2 \ldots \ldots n s+1}{1 \cdot 2 \cdot 3 \cdot 4 \cdots n} r^{n} s^{n}$,

erit ex lege progreffionis ( addito $n$ ad ultimum factorem coëficientis in numeratore, \& ablato ab ultimo in denominatore; nec non alterius literarum $r \& s$ dimenfionibus eodem $n$ auctis, alterius diminutis ) terminus

\section{$L$ ad finifram:}

$\Lambda$ ad dextram.

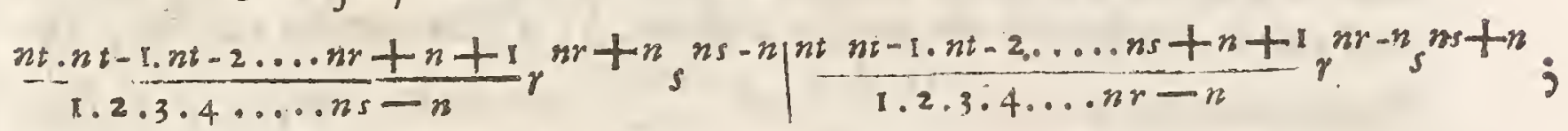

unde facta convenienti reductione per divifores communes, refultat

$\frac{M}{L} \infty \frac{n r+n \cdot n r+n-1 \cdot n r+n-2 \ldots n r+1 \times s^{n}}{n s-n+1 . n s-n+2 . n s-n+3 \ldots n s \times r^{n}}$

$$
\mid \frac{M}{\Lambda} \infty \frac{n s+n \cdot n s+n-1 \cdot n s+n-2 \ldots n s+1 \times r^{n}}{n r-n+1 . n r-n+2 . n r-n+3 \ldots . . n r \times s^{n}},
$$

five (dimenfionibus quantitatum $r^{n} \& s^{n}$ in fingulos factores, ob æqualem amborum numerum, æqualiter difributis )

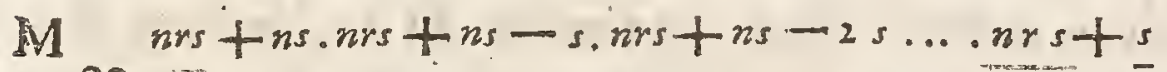

L $D_{n r s-n r+r . n r s-n r+2 r . n r s-m r+3 r \ldots . . n r s}$

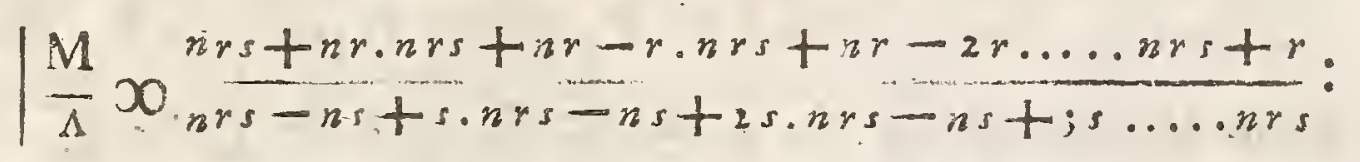

fed ha ration's funt infinite magnæ, cùm numerus $n$ ponitur infinitus; tunc enim evanefcunt numeri $1,2,3,8 \mathrm{c}$. præx $n$, ipłeque nr $n 8 \mathrm{I}, 2,3,8 \mathrm{c}$. \& 258 \& $8 \mathrm{I}, 2,3,8 \mathrm{c}$. tantun tem valent, ac mer 8 \& $n s \quad 8 n$, fic ut divifione inftitu: per $n$, prodeat 


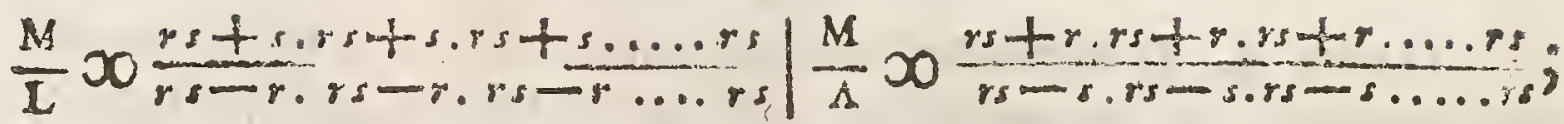

qua quantitates componuntur, ut patet, ex tot rationibus $\frac{r+s}{r s}$ at $\frac{r s+r}{r s-s}$, quor funt factores: at horum numerus eft $n, h . e_{\text {. infinitus ; cun }}$ inter primum $n+n$, aut $n s+n, \&$ ultimum $n+I$ aut $n s+r$ differentia fit $n-I$. Idcircò raciones ifta funt infinituplicata rationum $\frac{r s+s}{1 s-r} \&$ $\frac{r+r}{r s-s}$, ae proinde fimpliciter infiniti: qua de fequela si dubites, concipe infinitos continue proportionales in ratione $r s+s$ ad $r s-r_{\text {, }}$ vel $r s+r$ ad $r s-s$; erit primi ad tertium ratio duplicata, primi ad $4^{\text {tum }}$ triplicata, ad $5^{\text {tum }}$ quadruplicata, \& $x$. ad ultimum infinituplicata rationis $\frac{r s+s}{r s-r}$ vel $\frac{r s}{r s-s}$ : conftat autem, rationem primi ad ultimum infinitè magnam effe, ob ultimum $\infty \circ$. (Vid, ceroll. Pofit . noftre 6tx de Sericbus Infrisiis.) Quare etiam confat, inEnituplicatam rationis $\frac{r_{s}+s}{r s-r}$ vel $\frac{r s+r}{r s}$ infinitam effe. Oftenfum itaque eft, quòd in poteftate infinitè alta binomii terminus maximus $M$ ad duos $L$ \& $\wedge$ rationem habeat omni anignabili ratione majo rem. Q. E. D.

Lemm . 5. Pofitis, qua in praced. tantus intelligi poteft numerus $n$, ut fumma omnium termmorum ab intermedio \& maximo $M$ ad ambos ufque $L \& \Lambda$ inclufive fumtorum, ad fummam 0 mnium reliquorum extra hos limites $\mathrm{L} \& \wedge$ utrinque protenforum rationem habeat omni data ratione majorem .

Dem. Vocentur termini intra maximum. M \& limitem fini-

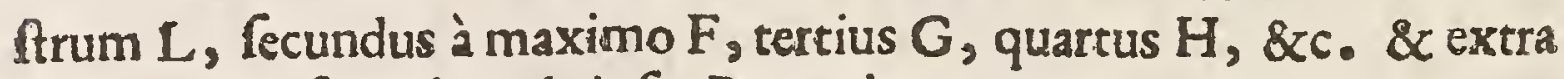
$\operatorname{limitem} \mathrm{L}$, fecundus ab iplo $\mathrm{P}$, tertius $\mathrm{Q}$. quartus $\mathrm{R}$, \&c. Quoniam igitur ratio $\frac{M}{F}<\frac{L}{P} \& \frac{F}{G}<\frac{P}{Q}, \& \frac{G}{H}<\frac{Q}{R} \& c$. per part. 2. Lem. 3. erit quoque vicilim $\frac{M}{L}<\frac{F}{P}<\frac{G}{Q}<\frac{H}{R} \& x$. Quare cùm politio numero infrito, ratio $\frac{M}{I_{0}}$ fit infinitè magna, per 


$$
\text { TARS } 2 U A R T A .
$$

Lem. 4. fortius etiam cateræ rationes $\frac{F}{P}, \frac{G^{*}}{C}, \frac{H}{R}, \& c$. erunt in-

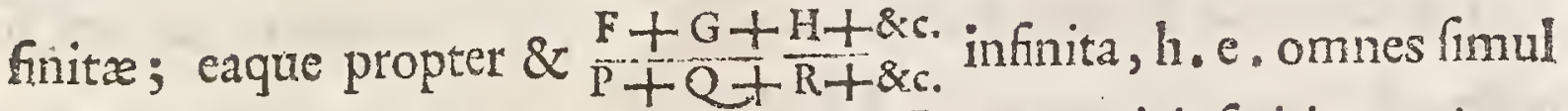
termini intra maximum $M \&$ limitem $L$ contenti infinities majores erunt totidem frmul terminis extra $\mathrm{L}$ porrectis ipsi $\mathrm{L}$ proximis. Et quoniam numerus omnium terminorum extra limitem $\mathrm{L}$ numerum omnium intra eundem \& maximum $M$ non nisi $s-I$ (h.e. non nisi fnitis ) vicibus fuperat, per 1 . Lem. ipfrque infuper termini en minores evadunt, quo funt à limite remotiores, per $\mathbb{1}$. part. 3 . Lem̃ , idcirco termini fimul omnes intra $M \& L$ (etiam non computato $M$ ) omnes fimul terminos extra $L$ adhuc infinities fuperabunt. Similiter autem oftend tur ab altera parte, quodd omnes intra $M$ \& $A$ conclusi termini onnes extra $\Lambda$ porrectos (quorum numerus priorum numerum per Lém. $I$, non nifi $r-I$ vicibus excedit) infinities fuperant. Quare denique omnes termini inter utrumque limitem $L \& \Lambda$ comprehensi (demto licet maximo $M$ ) omnes omninò terminos extra pofitos itidem infinities fuperabunt . Ergo multo magis unà cum maximo. Q. E, D.

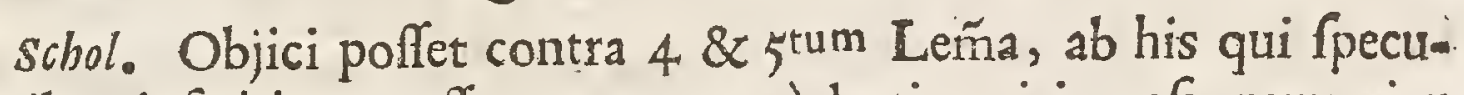
lationibus infiniti non affueverunt, quòd etiamsi in cafu numeri $n$ infiniti factores quantitatum, qua rationes $\frac{M}{L} \& \frac{M}{\Lambda}$ exprimunt; nr $8 n 8 \mathrm{I}, 2,3,8 \mathrm{c}$. \& $n s 8 n 8 \mathrm{I}, 2,3$, \&c. tantundem. valent ac $n r \& n \& n s \quad 8 n$, evanefcentibus ratione fingulorum factorum numeris $\mathrm{I}, 2,3,8 \mathrm{c}$ 。 fieri tamen poffit, ut omnes collecti vel in fe ducti (propter infinitum factorum numerum ) in infinitum excrefcant, adeoque rationem infinituplicatam rationis $\frac{r s+s}{r s-r}$ aut $\frac{r s+r}{r s-s}$ infinite diminuant, h. e. find tam reddant. Cui fcrupulo melius fatisfacere non poffum, quàm fi nunc porro modum oftendam affignandi, reapfe finitum numerum $n$, five finitam poteftatem binomii, in qua fumma terminorum intra limites $L \& \Lambda$ ad fummam terminorum extra, rationem habeat data ratione quantumvis magna, quam litera $c$ defigno, majorem: utpote quo oftenfo objectionem ultro corruere neceffe $\mathrm{e}$.

$$
\text { og Hunc }
$$


Hunc in finem aflumo rationem quamlibet majoris inæqualitatisi, qux tamen fit minor ratione $\frac{r s t s}{r s-r}$ (pro terminis ad partem fio. miftam ) puta rationem $\frac{r s+s}{r s}$ feu $\frac{r+1}{r}$, eamque toties ( $m$ vicibus ) multiplico, quoad æquet vel fuperet rationem $c_{0} \overline{s-\mathrm{I}}$ ad $\mathrm{I}_{\mathrm{g}}$ hoc eft, ut fit $\frac{\overline{r+1}}{r^{m}} \infty$ vel $>c_{0} \overline{s-1}$. Quoties autem id fieri des. beat, compendiesè inveftigatur per logarithmos; nam fumtis quantitatum logarithmis fit $m L r+I-m L r \infty$ vel $>L \bar{c} \cdot \overline{s-I}$, \& divi frone peracta ftatim habetur $m \frac{\infty}{\gtrless} \frac{\overline{L s-1}}{L+1-L r}$; quo invento fic pergo: In ferie illa fractionum five factorum, $\frac{n r s+n s}{n r s-n r+r}$. $\frac{n r s+n s-s}{n n s-n r+2 r} \cdot \frac{n r s+n s-2 s}{n r s-n r+3 r} \ldots . . \frac{n r s+s}{n s s}$, è quorum duktu per Lem̌. 4. refultat ratio $\frac{M}{\mathrm{~L}}$, obfervare licet, quòd fingula fractiones fint. minores quàm $\frac{r s+s}{r s-r}$, ita tamen ut ad hanc continuè propius accedant, quo major fumitur $n$ : itaque qualibet earum aliquando fiet: aqualis: ipfi $\frac{r s+s}{r s} \infty \frac{r+\mathrm{r}}{r}$; Quare videndum, guantus fit accipiendus valor $n$, ut fractio (cujus numerus ordinis eft $m$ ) requetur. ipfi $\frac{r+1}{r}$. Eft verò ( ut ex progreflionis lege perfpicuum fit) fraEio ordine $n$ hæc: $\frac{n r s+n s-m s+s}{n r s-n r+m r}$, quæ adæquata fractioni $\frac{r+1}{r}$, dat $n \infty m+\frac{m s-s}{r+1}$, \& inde $n t \infty m t+\frac{m s t-s t}{r+1}$. Dico, hunc effe indicem poteftatis, ad quam si elevetur binomium $r+s$, futuxum ut terminus maximus $M$ fuperet limitem $L$ plus quàm $c_{0} \overline{s-r}$ vicibus. Nam quia fractio ordine $m$ per hanc afumtionem numeri $n$ fit $\frac{r+r}{r}$, per hypoth. \& verò $\frac{r+1}{r}$ fractio fecum ipfa $m$ vicibus

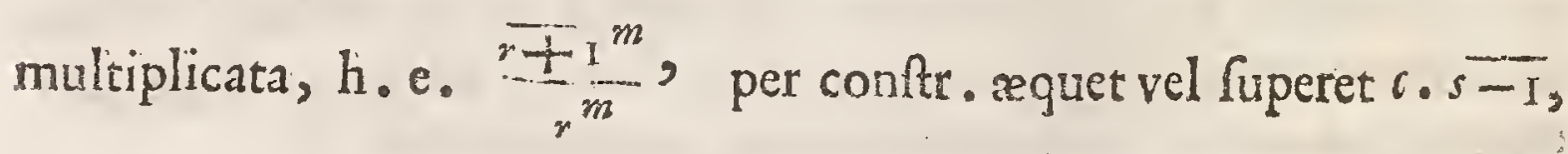


fit ut hæc fractio in omnes præcedentes fractiones ducta multo magis excedat $6 . \overline{s-I}$; cùm fingulæ præcedentiun majores fint quàm. $\frac{r+1}{r}$. Ergo magis adhuc fuperabit $c . s-I$, quando ducitur una cum precedentibus in omnes etiam confequentes, utpote quarum fingula faltem rqualitatis rationem excedunt. Sed productum omnium harum fractionum rationem exhiber termini $M$ ad $L$; igitur omnino conftat, terminum $M$ fuperare limitem $L$ plus guàm $c_{0} s-\mathbb{I}$ vicibus. Jam autem $\frac{M}{L}<\frac{F}{P}<\frac{G}{Q}<\frac{H}{R}$ \& c . ut oftenfum. Hinc multo magis fecundus à maximo $M$ fecundum à limite $L$ plus quàm. c. $s$ - I vicibus fuperabit, \& magis adhuc tertius tertium, \&cc. Itaque tandem omnes termini intra maximum $M \&$ limitem $L$ fupe-

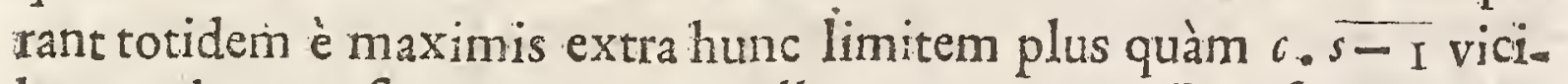
bus; adeoque fuperant totidem illorum $s$ - I vicibus fumtos plus quàm c vicibus. Ergo multo evidentius fuperant omnes ex tra limitem $\mathrm{L}$, quorum non nisi $s$ - I vicibus plures funt, plus quàm $c$ vicibus.

Pro terminis dextimis pari modo procedo: Affumo rationern $\frac{s+1}{s}<\frac{r+r}{r s-r}$, \& facio $\frac{\overline{s+1}}{s^{m}} \geqslant$ c. $\overline{r-I}$, inveniog; $m \frac{\infty}{2} \frac{L \overline{c . r-1}}{L s+1-L s}$. Deinde, in ferie fractionum $\frac{n r s+n r}{n r s-n s+s} \cdot \frac{n r s+n r-r}{n r s-n s+2 s}$. $\frac{n r s+n r-2 r}{m r s-n s+3 s} \ldots \frac{n r s+r}{n r s}$, qua rationem $\frac{M}{\Lambda}$ innuir, pono fractionem, qux ordine eft $m$, nempe $\frac{n r s+n r-m r+r}{n r s-n s+m s} \infty \frac{s+r}{s}$, indeque elicio $n \infty 0 m+\frac{m r-r}{s+r}$, ac proin $n t \infty m t+\frac{m r t-r t}{s+1}$. Quo facto fimiliter oftendetur, ut antea, quòd binomio $r+s$ ad hanc pote. ftatem fublato, terminus ejus maximus $M$ fuperabir limitem $\Lambda$ plus quàm $c_{0} r-I$ vicibus \& per confequens etiam, quòd ommes maximo $M \&$ limite $\Lambda$ concluff fuperabunt omnes extra hunclimitem, quorum non nifi $r$ - I vicibus plures funr, plus quam $c$ vicibus. Itaque finaliter tandem concludimus, quòd elevato binomio $r+s$ ad poter tem, cujus index æquetur majori harum duarum quantitatam $m t$

$$
\mathrm{Gg} 2 \frac{m-54}{m+1}
$$


$\frac{m s t-s t}{r+1} \& m t+\frac{m r t-r t}{s+1}$, omnes fimul termini inter utrumque limio: tem $\mathrm{L} \&$ \& comprehensi multo pluribus quàm 6 vicibus fuperabunt omnes fimul terminos extra limites ab utraque parte protenfos. Reperta igitur eft finita poteftas, qua optatam habeat proprictatem. Q.E.F.

Propof. Princip. Sequitur tandem Propofitio ipfa, ctjus gratia hæc omnia dicta funt, fed cujus nunc demonfrationem fola Lemmatum præmifforum applicatio ad præfens inftitutum abfolvet. U't circumlocutionis tædium vitem, vocabo cafus illos, quibus eventus quidam contingere poten, faundos feu fertiles; \& feriles illos, quibus idem eventus poteft non contingere: nec non experimenta facunda five fertilia illa, quibus'aliquis cafum fertilium evenire deprehenditur; \& infocunda frve ferilia, quibus ferilium aliquis contingere obfervatur. Sit igitur numerus cafuum fertiliam ad nume= rum fterilium vel pracisè vel proximè in ratione $\frac{r}{s}$, adeoque ad liumerum omnium in ratione $\frac{r}{r+s}$ feu $\frac{r}{t}$, quam rationem terminent limites $\frac{x+1}{t} \& \frac{r-1}{t}$. Oftendendum eft, tot poffe capi experimen: ta, ut datis quotlibet (puta c) vicibus verifimilius evadat, numerum fertilim obfervationum intra hos limites quàm extra cafurum effe, h. e. numerum fertilium ad numerum omnium obfervationum rationem habiturum nec majorem quàm $\frac{r+1}{t}$, nec minorem quàm $\frac{x-r}{t}$.

Dem. Ponatar numerus capiendarum obfervationum $n t$, \& quxeratur, quanta lit expectatio, feu quanta probabilitas, ut omnes exiftant focunda, exceptis primo nulla, dein una, duabus, $3,4 \& c_{*}$ fterilibus. Quandoquidem autem in qualibet obfervatione prafo funt ex hyp. $t$ cafus, eorumque $\gamma$ foecundi \& $s$ feilis, \& Inguli cafus unius obfervationis cum fingulis alterius combinari, combinatique rurfus cum fingulis tertize, $4^{\text {tx }}$ \&c. conjungi poffunt, fasile patet, huic negotio quadrare Regulam Annotationibus Prop. 
Xill. primæ Part, in fine fubnexam, \& ejus Corollarium fecundum quod univerfalem formulam continet, cajus ope cognolictur, quod expectatio ad nullam obfervationem fterilem fit $r^{n t}: t n t$, ad unam $\frac{n t}{x} r^{n t-1} s: t^{n t}$, ad duas fteriles $\frac{n t \cdot n t-1}{1.2} \gamma^{n t-z_{s s}: t^{n t}}$, ad tres $\frac{n_{1} n t-1 \cdot n t-2}{1 \cdot 2 \cdot 3} r^{n t-s} s^{3}: t^{n t}, \&$ fic deinceps; adeoque (rejecto communi nomine $t^{n t}$ ) quod gradus probabilitatum feu numeri cafuum, quibus contingere poteft, ut omnia experimenta fint foecun$d a$, vel omnia prater unum fterile, vel omnia præter duo, $3,4 \& c^{\delta}$ fterilia, ordine exprimantur per $r^{n t}, \frac{n t}{\mathrm{I}} \gamma^{n n-1} s_{2} \frac{n t \cdot n t-1}{4 \cdot 2} \gamma^{n t-2} s s_{3}$ $\frac{n t \cdot n-1 \cdot n t-2}{1 \cdot 2 \cdot 3} \gamma^{n t-3} s^{3}, \&$. ipfifimos nempe terminos poteftatis $n$ binomii $x+s$, in Lemmatis modo noftris excuffe: unde jam cretera omnia oppido manifefta funt. Patet enim ex progrefionis natura, quòd numerus cafuum, qui cum ns fterilibus experimentis $\mathrm{wr}$ foecunda adducunt, fit ipfe terminus maximus poteftatis $M$, utpote quem $n s$ termini præcedunt, \& $n r$ fequuntur, per Lem. 3 . item, quòd numeri illorum cafum, quibus aut $n r+n$ aut $n r-n$ experim mencis focundis cæeterisque fterilibus effe contingit, exhibeantur per terminos poteftatis $\downarrow \& \%$, quippe intervallo $n$ terminorum à maxì mo $M$ utrinque diftantes; \&x per confequens etiam, quòd fumma cafuum, quibus non pluribus experimentis quàm $n r+n$; nec paucioribus quàm $n x-n$ fuecundis effe contingit, exprimatur per fummam terminorum poteftatis intra limites $L \& \Lambda$ comprehenforum; fumma reliquorum cafuum, quibus aue plura aut pauciora experimenta foccunda redduntur, per cæterorum terminorunt limites hos L \& $\&$ excedentium fummam expreffa. Quare cùm tanta fumi poffit poteftas binomii, ut fumma terminorum utroque limite $L \& A$ incluforum pluribus quàm $c$ vicibus furperet fummam cæterorum limites hos excedentium, per Lern. 4. \& 5. fequitur etiam, capi poffe tot obfervationes, ut fumma cafuum, quibus numero fertilium obfervationum ad numerum omnium xationem habere contingit, non excedentem limites $\frac{n r+n}{n t} \&$ 
$\frac{n r-n}{n t}$, feu $\frac{r+1}{t} \& \frac{r-1}{t}$, pluribus quàm $c$ vicibus fuperet fuñam cafuum reliquorum; h.e. ut pluribus quàm $c$ vicibus probabilitus reddatur, rationem numeri obfervationum ferilium ad numerum omnium intra hos limites $\frac{r+1}{t} \& \frac{r-1}{t}$, quàm extracafuram efle. Quod demonitrandum erat.

In fpeciali autem horum applicatione ad numeros ratis per fe pazet, quod quo majores in eadem ratione affumuntur numeri $r, s \& t_{s}$ eo arktius quoque conftringi poffunt limites $\frac{r+1}{t} \& \frac{r-1}{t}$ rationis *. Idcirco si ratio inter numeros cafuum ${ }_{s}^{r}$, per experimenta deter minanda, fit ex.gr. fefquialtera, pro $r \& s$ non pono $3 . \& 2$, fed $30 \& 20$, vel $300 \& 200 \& c$. fufficiat pofuiffer $x 30, s \infty 020, \&$ $t \infty r+s \infty 50$, ut limites fiant ${ }^{r+1}+\infty, \frac{31}{50}, \& \frac{r-1}{i} \infty \frac{29}{50} ; \&$ Patuatur infuper $c \infty 01000$ : sic fiet ex Scholii prefcripto, pro ter: minis ad

$$
\begin{aligned}
& \text { finiftram: } \\
& m>\frac{\overline{L \cdot \bar{c}-I}}{L \overline{L+1-L^{r}}} \infty \frac{4.2787536}{142405}<301 \\
& m t 50 m t+\frac{m s t-s t}{r+t}<24728
\end{aligned}
$$

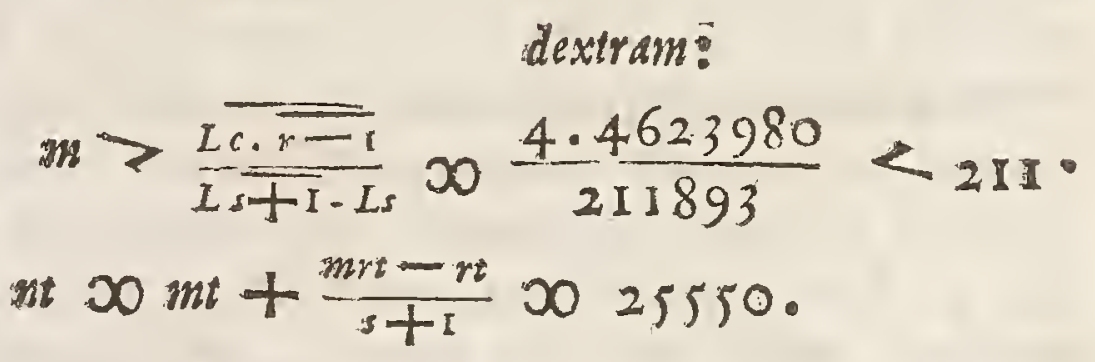

Unde per ibi demonftrata infertur, quòd inftitutis 25550 experimentis multo plus millies verifimilius fit, rationem quam numerus fertilium obfervationum obtinebit ad numerum omnium, intra hos limites $\frac{3}{5} \frac{1}{0} \& \frac{2}{5} 0$ cafuram, quàm extra. Atque eodem pacto, pofita

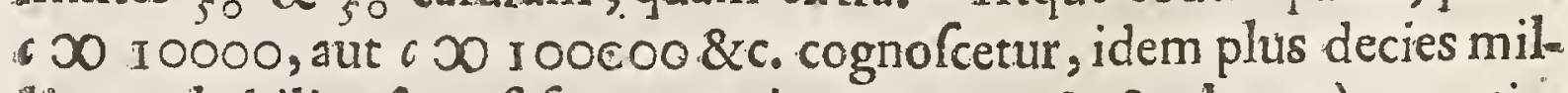
lies probabilius fore, fi fiant experimenta $31258 ; 2$ plus quatm centies millies, 
millies, fi capiantur 36966 , \& c . \& fic porrò in infinitum, add tis nempe continuo ad 25550 aliis. 5708 experimentis. Unde tandem hoc fingulare fegur videtur, quòd si eventuum onnium obfervationes per totam eternitatem continuarentur, (probabilitate ultrimo in perfectam certirudinem abeunte): omnia in mundo certis rationibus \& conftanti vicifitudinis lege contingere deprehender entur; adeo ut etiam in maxime cafualibus atque fortuitis quandam quafr neceffio tatem, \&, ut fic dicam, fatalitatem agnofcere teneamur; quam neficio annon ipfe jam Plato intendere voluerit, fuo de univerfali resum apocataftafi dogmate, fecundum quod omnia poft in numerabilium feculorum decurfum in priftinum.

geverfura ftatum prædixit。

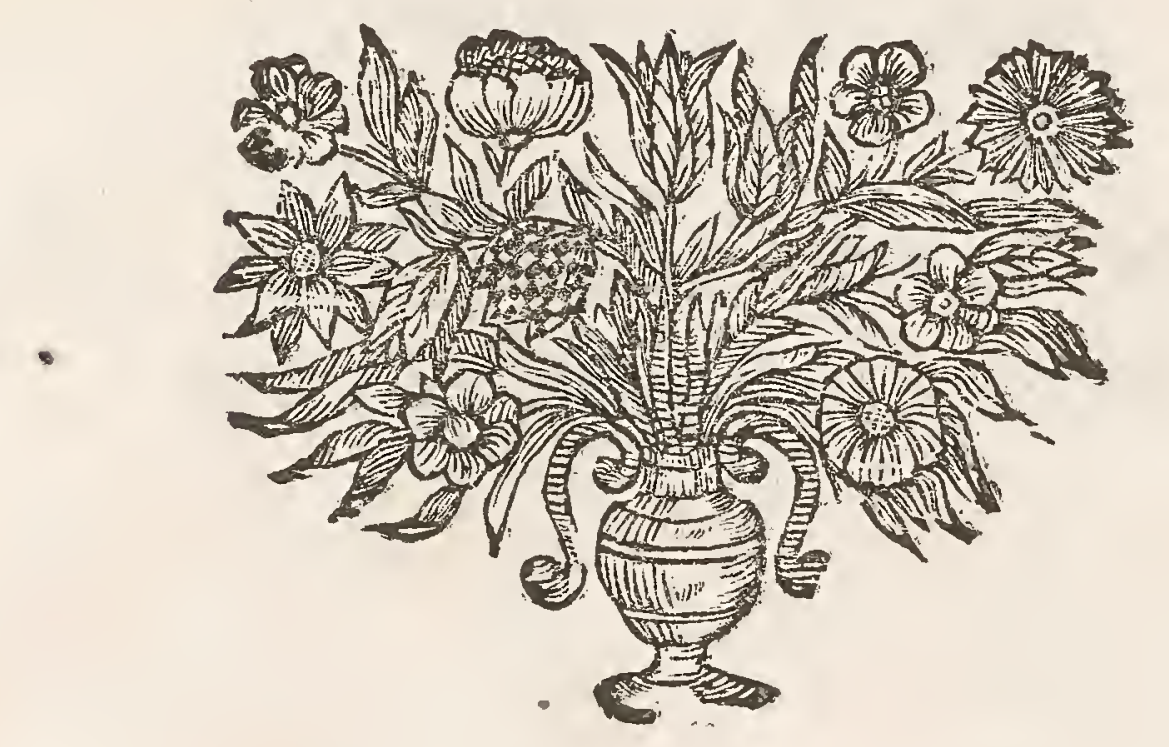





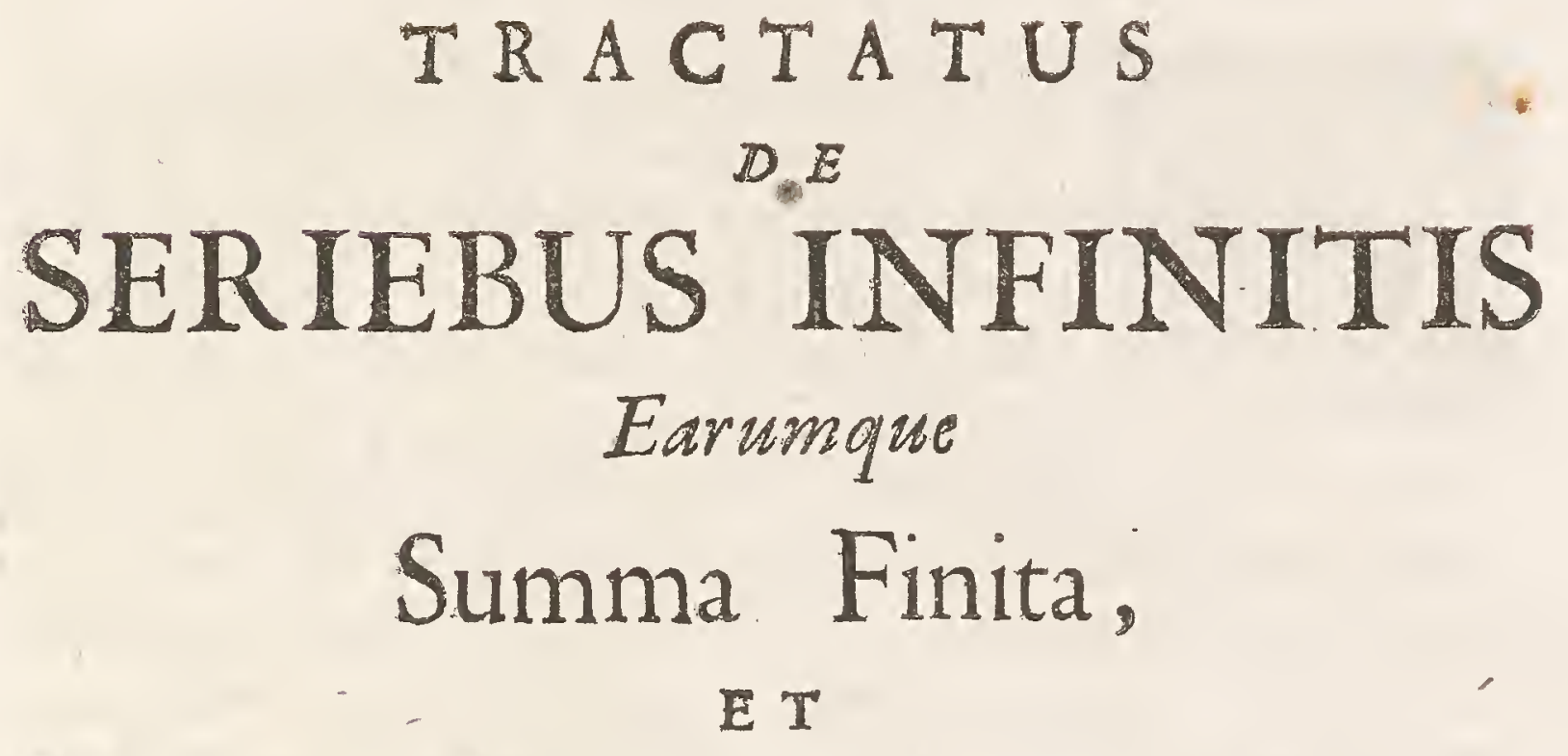

\section{Ufu in Quadraturis Spatiorum \& Rectificationibus Curvarum.}




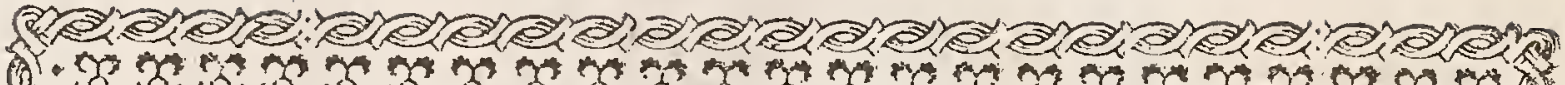

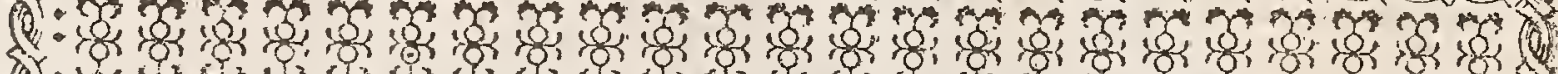

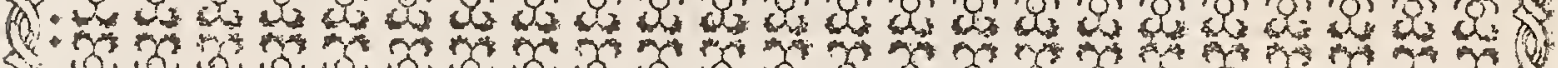
र.

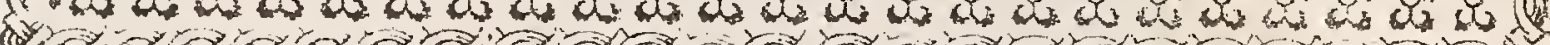

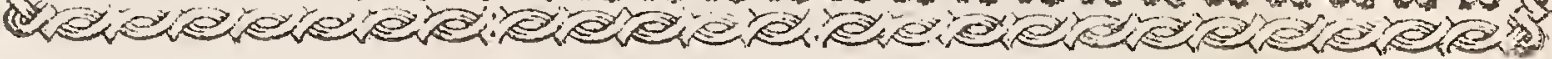

\section{T R AEF A TIO.}

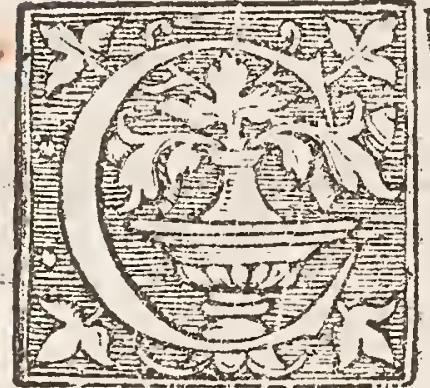

Um non ita pridem in Serierum Infinitarum fpeculationem incidifem, prima, cujus fumina polt Geometricam Progreffionem ab aliis jam tractatam mihi lefe offerebat, erat feries fractionum, quarum denominatores Geometrica, numeratores Arithmetica progreffione crefcunt: quod cum Fratri indicaffem, non tantum mox idem adinvenit ille, fed \& præterea novæ cujusdam fractionum feriei, cujus denominatores Trigonalium, ut vocantur, numerorum dupli erant, fummam perveftigavit; quam vero \& ipfe, cum frgnificafret, poitridie detexi, propofitis ei vicifim aliis nonnullis, qux interea, ut clavus clavum trudere folet, occafione hac repereram. Quibus inventis certatim alter alterum fic exercuimus, ut paucorum dierum fpatio non tantum ferierum illarum, quas Celeb. Leibnitius in Actis Erud. Lipf. Anno 1682. M.Febr. \& 1683. M. Octob. recenfet, nosque paulo antea mirati fuimus, fummas dare poffemus, fed \& plura alia eaque non contemnenda ex gemino duntaxat fundamento invenerimus, quorum unum confiftit in refolutione feriei in alias infinitas feries, alterum in fubductione feriei uno alterove termino mutilatæà feipfa integra. Horum vero pracipua (cum eorum nihil apud hos quos legi hactenus, publicatum viderim) enucleanda. 
anda proponam, premiflis nonnullis, qux paffim apud alios quoque vulgatæ proftant, Propofitionibus, ne ilas aliunde petere opus effet. Caterum quantæ fit neceffitatis pariter \& utilitatis hæc ferierum contemplatio, ei fane ignotum effe non poterit, qui perfpectum habuerit, ejusmodi feries facram quafi efle anchoram, ad quam in maxime arduis \& defperatz folutionis Problematibus, ubi omnes alias humani ingenii vires naufragium panx, velut ultimi remedii loco confugiendum ent.

得能

\section{exiomata feu Pofulata.}

I. Mne quantum eft divifibile in partes fe minores.

2. Omni quantitate finita poteft accipi major.

3. Si quantitas quæpiam multata parte fui aliqua fubtrahitur à Seipfa integra, relinquitur illa pars.

\section{PROPOSITIONES:}

1. Ouod data quavis quantitate minus eft, illud eft non-quantum fell nibil. Dem. Nam fi quantum effet, dividi poffet in partes fe ma: nores, per Axiom. I. non igitur effet data quavis quantitate minus, contra hyp.

II. Quod data quavis quantitate majus eft, infinitum eft.

Nam fi finitum effet, illo polfet accipi quantitas major, per $A x, 2$. non igitur quavis data quantitate foret majus, contra hyp.

III. Omnis Progreffio Geometrica continuari potefl per terminos infinitos.

Semper enim fieri poteft: Ut primus terminus ad fecundum, fic poftremus ad fequentem, \& fequens ad alium \& alium fine fine in infinitum; quorum quidem terminorum nullus æquari poteft vel nihilo vel infinito, cum fecus ad illum pracedens eam rationem thabere non poffet, quam habet primus ad fecundum, contr. defin. progr.

IV. Si fit Progrefsio Geonsetrica quacunque $\mathrm{A}, \mathrm{B}, \mathrm{C}, \mathrm{D}, \mathrm{E}$; \& alia Arith mietica totidem terminorum $A, B, F, G, H$, incipiens ab isdem terminis $A$ Hh 2 s 
bo $\mathrm{B}$, ertnt reliquorm finguli in Geometrice fongulis ordine fibi refpondent silus in sritbmetica majores, tertius rertio, quartus quarto, ultimus ultimo. adeogu. omnes onnibus.

Quia enim $A, B:: B, C:: C, D:: D, E$. erit per 25.5. Eucl. tum $A+C>2 B X$ (ex nat. Progr.Arith.) $A+F$; unde $\rightarrow F:$ tum $A+D>$ $B+C>B+F D A+G ;$ unde $D>G: \operatorname{tum} A+E>B+D>B+G$ $\infty \mathrm{A}+\mathrm{H}$; unde $E>H$. Quæ erane demonftr.

$\mathrm{V}$. In progreffone Geometrica crefent $\mathrm{A}, \mathrm{B}, \mathrm{C}, \mathrm{D}, \mathrm{E}$ perveniri tats dem poief ad terminum $\mathrm{E}$ quoris dato $Z$ ins jorem.

Incipiat $a b$ isdem terminis Progreno Arithm. $A, B, F, G, H_{g}$ continuata quoufque ultimus $H$ fupe er $Z$ (d enim fieri paffe claret.) tum vero continuetur Geometrica per terminos totidem, eritque per praced. polremus $E>H>Z$. Q. E. D.

coroll. Hinc in Progr. Geom. crefiente infinitorum terminorum pofremus terminus eft $\infty$, per Prop. II. ( $\infty$ eft Nota Infiniti.)

VI. In Progreff. Geometr. deciefunte $\mathrm{A}, \mathrm{B}, \mathrm{C}, \mathrm{D}, \mathrm{E}$ pervenitur tandem ad vermivam $\mathrm{E}$ quovis daro $Z$ minorem.

Conftituatur Progreffio afcendens: $Z, X, X, V, T$, in ratione $B$ a $A$, quouque ultimus terminus fup ret $A_{2}$ ( quod fieri poffe per præced. confat;) tum continuetur altera defcendendo per totidem terminos $A, B, C, D, E$; eritque ultimus $E<$ dato 2 . Quia enim Pro grefiones $A, B, C, D, E, \&, T, V, X, Y, Z$, por eandem rationem a ad $B$ progrediuntur, \& terminos numero $x$, ulles habent, erit ex aquo A.E::T.Z. fed $A<T$, per conftr. Ergo \& $t<Z$. Q.E. D.

coroll. Hinc in Progr. Geomet. decrefente in infonitum conte nuata ulcimus terminus elt or per Prop. I.

VII. In ommi Pregr. Geom. $A, B, C, D, E$, primus terminus eft ad fecume dum, ficut fumm omnism excepto ulnano ad lummam onnium excepto primo. ( $\mathrm{A} \cdot \mathrm{B}:: \mathrm{A}+\mathrm{B}+\mathrm{C}+\mathrm{D} \cdot \mathrm{B}+\mathrm{C}+\mathrm{D}+\mathrm{E}$. )

Quia enim $A . B:: B, C:: C, D:: D, E$, erit per 12,5, Eucl, $A . B:$ : $A+B+C+D . B+C+D+E . \quad$ Q.E.D.

VIII. Propreffonis Geom, cajuscunque $A, B, C, D, E$, fumman Sinvenite.

Per prac, eft $A, B:: S-E . S-A ;$ quare convertendo $A \cdot A=B:: S-E_{0}$. $A=E ;$ unde $S-E X \frac{A \text { in } A=E}{A=B}, \& S X \frac{A \text { in } A=E}{A=B}+E \cdot(=$ denotat differen- 
đifferentiam duarum quantitatum, quibus interferitur, cum non de finirur, penes ut am fit exceffus.)

coroll. Si Progreffio Geometr. defcendendo continuetur in inffnitum, adeoque ulrinus terminus per Coroll. VI. evanefcat, erit fumma omnium $\frac{A q}{A-B}$ : unde liquet, quo pacto infiniti etiam termimi finitam fummam conftikuere poffunt.

1X. Si scries infinita continuè proportionalium $\mathrm{A}, \mathrm{B}, \mathrm{C}, \mathrm{D}, \mathrm{E}, \mathrm{B} \epsilon_{\mathrm{a}}$ decrefat in rationt $\mathbb{A}: d \mathbb{B}$, erunt fumme omnitum termonorum, omniuns dente prino, onnium demtis duobus prim is, oc. etiam continsule proportiowales, or quidem in eadem ratione $A$ ad $B$.

Quoniam $A, B:: B . C:: C . D$, erit tum $A q . B 7:: B q . C q$ : tum etiam $A . B:: A-B, B-C:: B-C, C-D$, quare dividendo rationes æquales per æquales, $\frac{A q}{A-B}: \frac{B q}{B-C}:{ }_{B}^{B}-\bar{C} \cdot C_{C}-D$, hoc eft per Cor. præced. Summa omnium ad omnes fequentes primum, ut hi ad omnes fequentes fecundum. Q.E. D. Et proinde per 19.5. Eucl. fumma omniurti ad omnes fequentes primum, ut primus ad fecundum, Q. E. D.

X. Seriei infinite fractionum, $\frac{a}{b}, \frac{a+c}{b+a}, \frac{a+2 c}{b+2 d}, \frac{a+3 c}{b+3 b}$, doc quarum numeratores \&o denominatores crefount Progreflone A titlimeto ultinus termi-

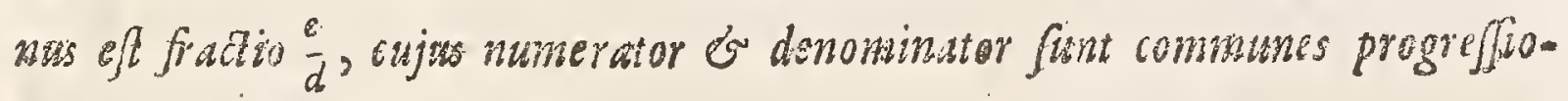
num differentia.

Ad hoc analytice inveftigandum confideretur quifitus terminus ut cognitus, \& vocetur $t$; numierus vero termini ut quæfitus, \& dicatur $n$; eritque ex generatione progreflonis terminus optatis $t \infty \begin{gathered}a+n c-b \\ b+n-d\end{gathered}$ $\&$ quia numerator hujus fractionis eft finitus ( nam infinitus efie non poteft, aliàs $t$ deberet effe $\infty 0 \infty$; ideoque effer $c<d t$, ipfaque adeo fractio negativa quintitss, quod abfurdum,) oportet ut denoninasor fit equalis nihilo, ac proinde $c x d t, \& t \infty \frac{c}{d} \cdot$ Q.E.D.

Brevius ita: Ex feriei genefi patet, terminum infinitefimum efe $\frac{t+\infty c}{b+\infty d} \infty \frac{\infty c}{\infty} \infty \frac{c}{d} \cdot$ Q.E.D.

Coroll. Summa omnium terminorum, five ultimus primo major H. . 3 
fit minorve, neceffario infinita eft; infiniti enim termini minori horum duorum rquales infinitam dant fummam: Unde à fortiori, \& $\mathrm{c}_{0}$

$X I$. Fraclionis ad aliam ratio compofita eff ex ratione directa numuratotum of reciproca denominatorum.

$$
\operatorname{Nam} \frac{A}{B} \cdot \frac{C}{D}:: \frac{A D}{B D} \cdot \frac{B C}{B D}:: A D \cdot B C:: A, C+D, B \cdot Q \cdot E, B_{\theta}
$$

XII. In ferie fiactionum, quarum numeratores cref cunt Progreflone Arith. denominatores Geometria, aut vice verfa, st $\frac{\mathcal{A}}{F} \cdot \frac{\mathcal{A}+C}{G} \cdot \frac{A+2 C}{H} \cdot \frac{A+3 C}{I}$, aut $\frac{F}{A} \cdot \frac{G}{A+C} \cdot \frac{H}{A+2 C} \cdot \frac{I}{A+3 C}$ : si $\mathrm{N}$ nomen ordinis ultimi termini ad unitatem. majorem rationem babeat, quam $G$ ad $G-F$, erit ille terminus ibi fequenti major, bic miner.

I. Hyp. Quia $N$, I. $>G_{0} G-F$, erit convertendo $N . N-1<G$. F \& $C N . C N-C<G . F$. Ergo $C N-C$ : in $G>C N$ in $F$, ergo fortius ( $a b$ $A G>A F$ ) $A+N C-C:$ in $G>A+C N$ : in $F$, hoc eft, Numerator termini $N$ in $G>$ Numeratore termini fequentis in $F$ : Sed ita fe habet terminus $N$ ad terminum fequentem, per preced. Quare terminus $N$ major fequenti, \& ita deinceps ab illo omnes. Q.E. D.

2. Hyp. Inverfis invertendis eodem modo demonftratur.

XIII. Si infinite fint fractiones $\frac{A}{B} \cdot \frac{C}{D} \cdot \frac{E}{F} \cdot \frac{G}{H} \cdot \frac{I}{L} \cdot \frac{M}{N} \cdot \frac{D}{P} \cdot$ Gc $c$ qua= gum numeratores crefcant progr. Arithm. \& denominatores Geom. erit ultimus terminus 0 ; fin illi crefcant Geometr. bi Arithmo evit ultimus $\infty$.

r. Hyp. Si primus terminus fecundo non fit major, continuari, faltem poterit Progreflio, quoufque pracedens fuperet fequentem, per præced. Efto $\frac{G}{H}>\frac{I}{L}$, \& fint infiniti continuè proportionales $G, I$, $Q, R, \& C$ ande propter $H, L, N, P \div$ erunt \& iplæ fractiones $\frac{G}{H} \cdot \frac{I}{L} \cdot \frac{Q}{N} \cdot \frac{R}{T^{\prime}} \& c_{\bullet} \div$ quæ $\circ \frac{G}{H}>\frac{I}{L}$. in nihilum tandem abeunt per Cor. VI. Quare cum $Q>M^{*}, R>0, \&$ c. per IV. multo magis $\frac{G}{H} \cdot \frac{I}{L} \cdot \frac{M}{N} \cdot \frac{O}{P}, \& c_{+}$in nihilum abibunt. Q.E. D.

2. Hyp. Nifi primus fecundo minor fit, continuetur progreffio, groufque præcedens fequenti minor fiat, per præced. Efto $\frac{G}{H}<\frac{I}{L}$, 
\& fint infiniti $H, L, S, T, \& c_{0} \div$ unde propter $G, I, M, O, \& c_{0} \div$. $\&$ ip $æ$ fractiones $\frac{G}{K}, \frac{T}{L}, \frac{M}{S}, \frac{O}{T}, \& c_{\text {. }}$ proportionales erunt, qua ab $\frac{G}{H}<\frac{I}{L}$ in infinitum definunt per Cor. V. Quare cùm $S>N$, $T>P$, \& $c_{*}$ per IV. multo magis $\frac{G}{H}, \frac{T}{L}, \frac{M}{N}, \frac{O}{P}, \& c_{0}$ in infinitum excrefcent. Q.E.D.

XIV. Invenire fummam feriei infinite fractionum, quarum denominatores crefiunt progreffione Geometrica quacunque, numeratores verò progres diuntur vel juxta numeros naturales $1,2,3,4$, boc. vel trigonales $1,3,6$, $10, \sigma c_{0}$ vel pyramidales $1,4,10,20,6 c_{0}$ aut juxta quadratos $1,4,9 \%$ $16,6 c$. aut cubos I, 8, 27, 64, bc. corumve equemultiplices.

I. Si Numeratores progrediuntur juxta numeros naturales:

Summa invenitur, refolvendo feriem propofitam $A$ in alias infinitas feries $B, C, D, E, \& c_{0}$ quæ fingulæ geometricè progrediuntur, qुuarumque fummæ (fi primam hîc excipias) novam Geometricam progreffionem $F$ conftituunt per IX. cujus quidem, uti cæterartum, fumma per Coroll. VIII. reperitur. En operationem:
$\mathrm{A} \infty \frac{a}{b}+\frac{a+c}{b d}+\frac{a+2 c}{b d d}+\frac{a+b c}{b d} \& x c . \infty \mathrm{B}+\mathrm{C}+\mathrm{D}+\mathrm{E}+\& \times \mathrm{c}_{0}$
B $\infty \frac{a}{b}+\frac{a}{b d}+\frac{a}{b d d}+\frac{a}{b d_{3}} \& c_{3} \infty \frac{a d}{b d-b}$
$\mathrm{C} \infty \cdot+\frac{c}{b d}+\frac{c}{b d d}+\frac{c}{b d z} \& c_{0} \infty \frac{c}{b d-b}$

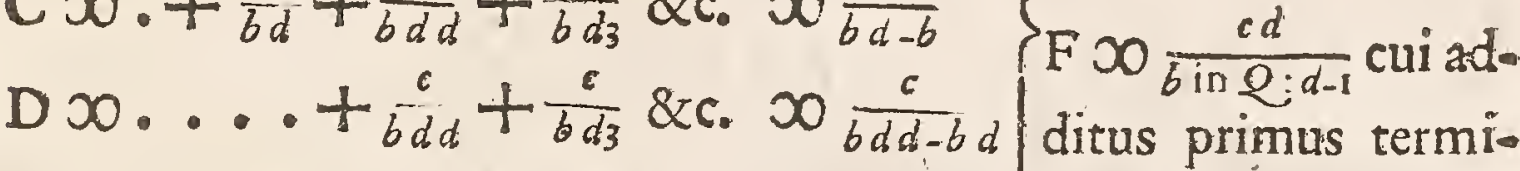
E $\infty \ldots \ldots+\frac{c}{b d_{3}} \& c_{0} \infty \frac{c}{b d d_{3}-b d d}$ nus $\frac{a d}{b d-b}$ producit to-

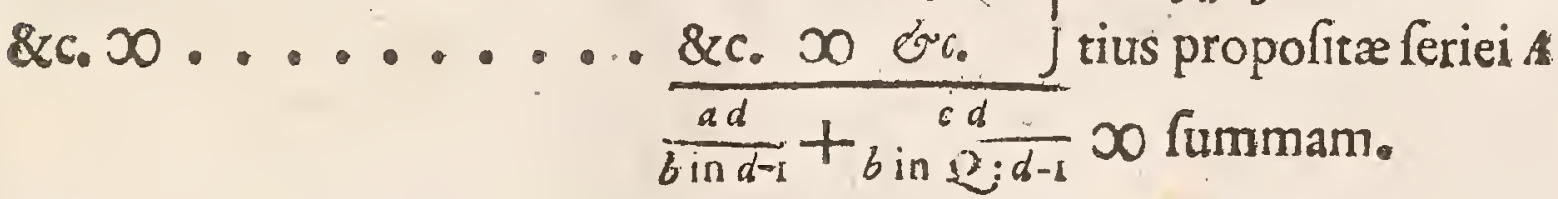

2. Si Numeratores funt juxta Trigonales:

Series propofita $G$ refolvenda eft in aliam $H$, cujus numeratores fint juxta pracedentem hypothefin, hoe modo: 


$$
\begin{aligned}
& \cos \frac{c}{b}+\frac{3 c}{b d}+\frac{6 c}{b d d}+\frac{10 c}{b d_{3}} 8<c \text {. } \\
& \frac{c}{b}+\frac{c}{b d}+\frac{c}{b d d}+\frac{c}{b d 3} \& c . \infty \frac{c d}{b d-b} \\
& +\frac{2 c}{b d}+\frac{2 c}{b d d}+\frac{2 c}{b d_{3}} \& c_{0} \infty_{\frac{2 c}{b d-b}} \quad \text { H } \infty \frac{c d_{3}}{b \text { in } c: d-1} \text { quando- } \\
& +\frac{3 c}{b d d}+\frac{3 c}{b d 3} \& c \cdot \infty_{b} \frac{3 c}{d d d-b d} \text { proidem hæc feries ad }
\end{aligned}
$$

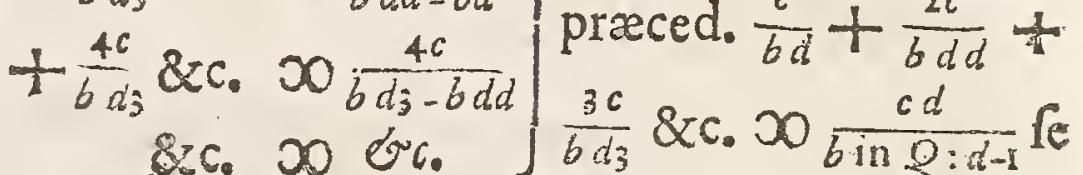

$$
\begin{aligned}
& \text { habeat ut } d d \text { ad } d-I_{0}
\end{aligned}
$$

3. Si Numeratores funt juxta Pyramidales:

Series refolvitur in aliam, cujus numeratores progrediuntur juxta Trigonales, quæque ad præecedentem feriem fe habet, ut $d$ ad $d-I$; ande fumma ejus invenitur $\infty \frac{c d_{4}}{\sin Q Q ; d-1}$. Generaliter, fi propofitre feriei numeratores fint juxta figuratos cujuslibet gradus, ejus funma fe habebit ad fummam fimilis feriei gradus præcedentis, ut $d$ ad $d-1$ : unde reliquarum omnium fummam invenire proclive admodum eft.

4. Si Numeratores fant juxta Quadratos:

Series $L$ refolvitur in aliam $M$, cujus numeratores funt Arithme zicè progreffionales, adeoque juxta priman hypothefin.:

$$
\begin{aligned}
& \mathbb{L} \infty \frac{c}{b}+\frac{4 c}{b d}+\frac{9 c}{b d d}+\frac{16 c}{b d_{3}} \& c \text {. } \\
& \frac{c}{b}+\frac{c}{b d}+\frac{c}{b d d}+\frac{c}{b \cdot d} \& \text { c. } 00 \frac{c d}{b d-b}
\end{aligned}
$$

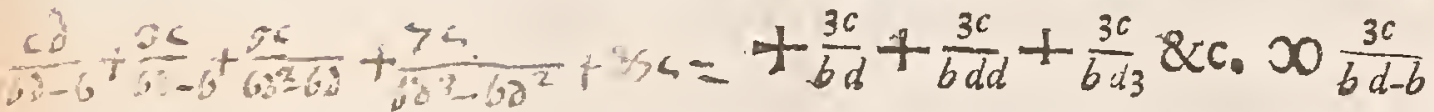

P. Si Numeratores funt juxta cubos:

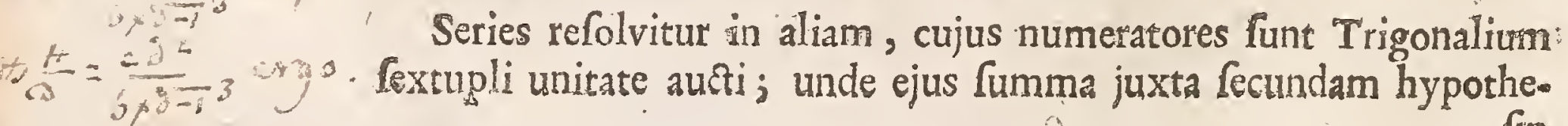

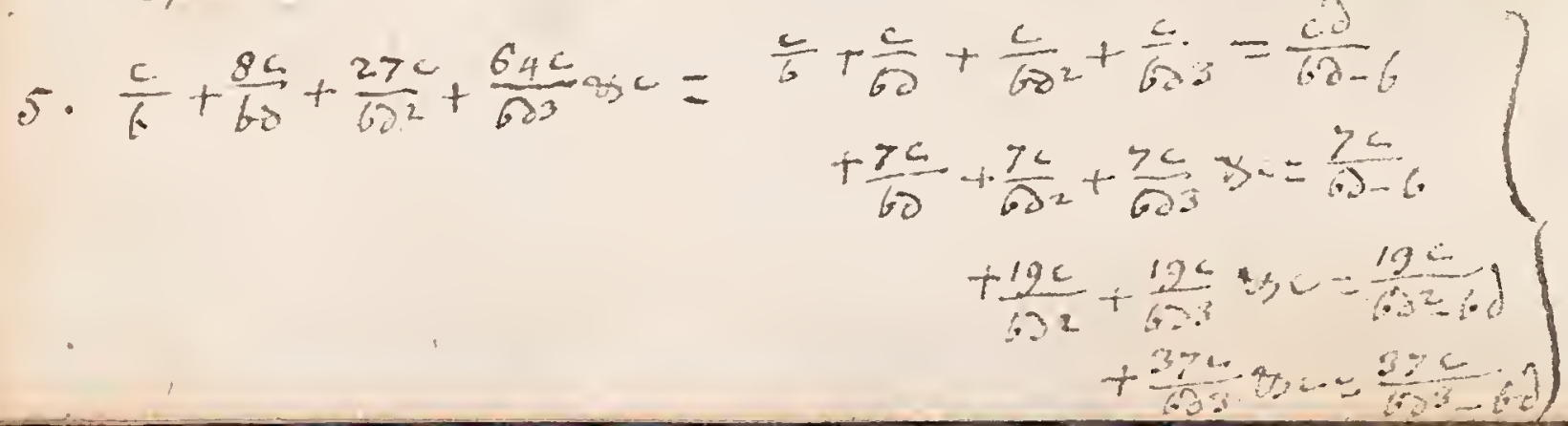
fin 
$\frac{c d}{60-6}+\frac{7 c}{6-1-6}+\frac{19 c}{6 \partial^{2}-6 d}+\frac{33 c}{6 \partial^{9}-6 \partial^{2}}$

$$
\text { INFINITIS. }
$$

249

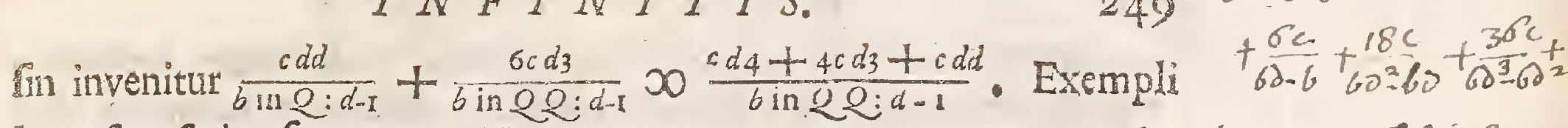
loco fint feries fequentes, Numeratorum

Naturalium,$\frac{x}{2}+\frac{2}{4}+\frac{3}{8}+\frac{4}{16}+\frac{5}{32} \& c_{0} \cdot \infty 2$

Trigonalium $\frac{x}{2}+\frac{3}{4}+\frac{6}{8}+\frac{10}{16}+\frac{15}{3} \& \& c_{0} \infty 4$

Pyramidalium $\frac{x}{2}+\frac{4}{4}+\frac{10}{8}+\frac{20}{16}+\frac{35}{32} \& c_{0}, \infty 8$

Quadratorum $\frac{x}{2}+\frac{4}{4}+\frac{9}{8}+\frac{16}{1} \frac{6}{6}+\frac{25}{3} \frac{5}{2} 8 c_{0} . \infty 6$

$$
\begin{aligned}
& \text { sed. prior pass }=r \times x^{3}[n-1]= \\
& \frac{\partial^{2}}{6 \times \partial-1} \text {; s posterión } \\
& =\frac{64}{\partial-1}(n .2)=\frac{6 c \partial 3}{6 \times 2-1} 4^{j}
\end{aligned}
$$

Cuborum . . $\frac{x}{2}+\frac{8}{4}+\frac{27}{8}+\frac{64}{15}+\frac{125}{32} \& c_{0} 0026$

coroll. Patet, in omnibus hujusmodi feriebus poftremos terminos in nihilum definere, \& evanefcere debere (quod ipfum jam praced. Propof. de earum una ex abundanti oftendimus;) cim alias illarum rumma finite effe non poffent.

$\mathrm{XV}$. Invenire fummam feriei infinite fractionum $\mathrm{R}$, quarum numeratores conffitulint feriem aqualium, denominatores yero Trigonalium, corumve aquestuliplicium.

Si à ferie harmonicè proportionalium $N$, eademmet multata primo termino $P$ fubtrahatur, exoritur nova feries $Q$, cujus denominatores. Trigonalium dupli funt, cujusque adeo fumma æqualis erit ipfi primo termino feriei Harmonicæ $N$, per $\mathrm{Ax} .3$.

Operatio talis: A ferie $\mathrm{N} \infty \frac{a}{c}+\frac{a}{2 c}+\frac{a}{3 c}+\frac{a}{4 c}+\frac{a}{3 c} \& \mathrm{c}$.

fubtracta feries $\quad \mathrm{P} \infty \frac{a}{2 c}+\frac{a}{3 c}+\frac{a}{4 c}+\frac{a}{5 c}+\frac{a}{6 c} \& c . \infty N-\frac{a}{c}$

relinquit feriem $\bar{Q} \infty \frac{a}{2 c}+\frac{a}{6 c}+\frac{a}{12 c}+\frac{a}{20 c}+\frac{a}{30 c} \& c . \infty \frac{a}{c}$

cujus duplum $\quad$ R $\infty \frac{a}{c}+\frac{a}{3 c}+\frac{a}{6 c}+\frac{a}{10 c}+\frac{a}{15 c} \& c . \infty \frac{2 a}{c}$

feries fcil. fractionum propofita, quarum denominatores funt numeri Trigonales, eorumve æque-multiplices.

Obfervandum tamen, non fine cautela hac utendum effe methodo: Nam fi à fequente ferie $s$ eadem demto primo termino $T$ fubtrahaturi , prodibit feries $Q$, quie antea; nec tamen inde fea guitur, fumnam feriei $Q$, æqualem effe primo termino feriei $\$ \infty \frac{2 a}{9}$. Cujus rei ratio eft, quòd, frà ferie s fubtrahitur feries ter-

minorum 
minorum totidem $T$, in qua finguli termini poftremum præceden tes fingulos primum confequentes in altera deftruunt, refiduum, hoc: eft refultans feries $Q$, evidenter debet adæequari primo termino feriei $s$ minus ultimo ipflus $T$; adeoque ipfr primo feriei $S$ abfoluté aqualis effe nequit, nifi tum cùm ultimus ipfius $T$ in nibilum defrenit, uti quidem definere perfpicuum eft in ferie $P$ vel $N$ : at non evas mefcit pariter in ferie $T$ vel $s$, verum eft $\infty \frac{a}{c}$, per $X$. Quin itaque po tius fumma ferier $Q \infty \frac{2 a t}{c}-\frac{a}{c} \infty \frac{i}{c}$, ut fuprà.

$$
\begin{aligned}
& S \infty \frac{2 a}{c}+\frac{3 a}{2 c}+\frac{4 a}{3 c}+\frac{5 a}{4 c}+\frac{6 a}{5 c} \& c_{0} \\
& T \infty \frac{3 a}{2 c}+\frac{4 a}{3 c}+\frac{5 a}{4 c}+\frac{6 a}{s c}+\frac{7 a}{6 c} \& c_{0} \\
& Q \infty \frac{a}{2 c}+\frac{a}{6 c}+\frac{a}{12 b}+\frac{a}{20 c}+\frac{a}{30 c} \& c_{0} \cdot \infty \frac{2 a}{c}-\frac{a}{c} \infty
\end{aligned}
$$

XVI. Summa ferici infinite harmonicè progrejfgonalium, $\frac{x}{1}+\frac{x}{2}+$ $\frac{1}{3}+\frac{1}{4}+\frac{1}{5}$ orce eft infinitas

Id primus deprehiendit Frater : inventa namque per præced。 fumma feriei $\frac{x}{2}+\frac{1}{6}+1 \frac{\pi}{2}+\frac{1}{20}+\frac{\mathrm{r}}{30}, \& c_{\text {. }}$ vifurus porro, quid emer geret ex ifta ferie, $\frac{x}{2}+\frac{2}{6}+\frac{3}{2}+\frac{4}{2}+\frac{5}{30}, \&$ c. fir refolveretur methodo Prop. XIV. collegit propofitionis veritatem ex abfurditate: manifefta, quæ fequeretur, fi fumma feriei harmonicæ finita ftatue zetur. Animadiertit enim,

Seriem $A, \frac{T}{2}+\frac{1}{3}+\frac{T}{4}+\frac{r}{5}+\frac{T}{6}+\frac{T}{7}, \& c_{0}, \infty$ (fractionibus fingulis: ina alias, quarum numeratores funt $\mathrm{r}, 2,3,4, \& \mathrm{c}_{0}$ transmutatis)

feriei $B, \frac{x}{2}+\frac{1}{6}+\frac{3}{1}+{ }_{20}+\frac{5}{30}+\frac{6}{42} 28 c_{0} 00 \mathrm{C}+\mathrm{D}+\mathrm{E}+\mathrm{F}, 8 \mathrm{cc}_{0}$.

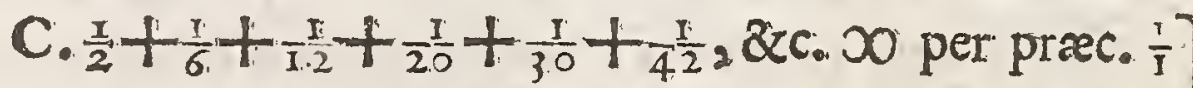
D... $+\frac{1}{6}+\frac{T}{12}+\frac{1}{20}+\frac{T}{30}+\frac{T}{4}, \& c_{0} \infty C-\frac{x}{2} \infty \frac{I}{2}$ E.... $\left.+\frac{1}{12}+\frac{1}{2} \frac{1}{0}+\frac{1}{3}+\frac{1}{4}, \& c_{0} \infty D-\frac{1}{6} \infty \frac{1}{3}\right\}$ unde.

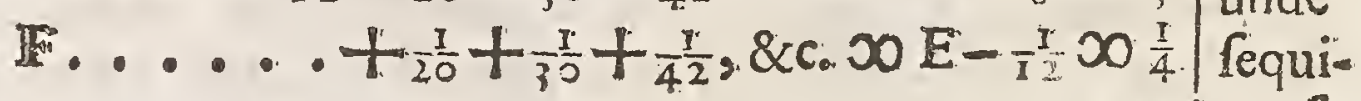
$\left.\& c_{0} \cdot x \quad \& c_{0}\right]$ tur, fe (riem $6 x^{\circ} \mathrm{A}$, totum parti, fi fumma finita effet. 
Ego poltmodum, cum indicaffer, idem oftenfive hunc in modum: Summa feriei infinitæ harmonicæ $\frac{1}{1}+\frac{x}{2}+\frac{1}{3}+\frac{1}{4}$, \&c. fupea rat datum quemvis numerum. Ergo infinita eft, per II. Efto datus numerus $N$ quantumcunque magnus: Abfcinde à principio feriei aliquor terminos, quorum fumma axuet vel fuperet unam unitatem numeri $N$, \& à ferie reliqua iterum aliquos ab cinde, quorum fumma aliam unitatem numeri $N$ fuperet, idque fi fieri poffit repete toties, quot in numero $N$ funt unitates; fic termini abfciff omnes fuperabunt totum numerum, multo magis igitur tota feries eundem fuperabit. Si neges, abicifis aliquor reliquos unitatem fuperare poffe, efto primus reliquorum, qui poft abfirfionem ultimam remanferunt, $\frac{1}{a}, \&$ fequentes $\frac{1}{a+1}, \frac{1}{a+2}, \frac{1}{a+3}, \& x$. Confituatur. ad duos primos terminos $\frac{1}{a} \& \frac{1}{a+1}$ Progrelfio Geometrica, cujus ideo finguli polt fecundum termini fingulis refpondentibus in Progreffione Harmonica minores funt ob denominatores majores, per IV. \& continuetur hæe ufque ad $\frac{\mathrm{I}}{a}$ ( quod quidem fiet in terminis numero finitis propter a numerum finitum) eritque hæc feries Geome- . trica finita $\infty \mathrm{I}$, per VIII. Harmonica itaque terminorum totidem fuperabit unitatem. Q.E.D.

coroll. I. In propofita ferie initio fumto à quolibet termino, erunt $a b$ illo deinceps omnes, ufque ad illum, cujus locus defignatur per quadratum numeri ordinis primi termini, fimul fumti unitate majores: fic termini à $2^{\text {do }}$ ad $4^{\text {rum }}$ ufque unitatem fuperant, hinc à $5^{\text {to }}$ ad $25^{\text {tum }}$, hinc à 26 ad $676(0: 26)$ hinc à 677 ad 458329 $(Q: 677) \& c_{0}$. Nam in Geometrica progreflione termini his limitibus intercepti unitatem æequant; ergo in Harmonica fuperant, ubi \& plures intercipiuntur \& majores; majores quidem uti vidimus; plures, quia denominatores terminorum, cùm fint minores quàm in Geometrica per IV. tardiùs illos limites affequuntur.

2. Patet, omnem aliam feriem harmonicam infinitam, fummam quoque exhibere infinitam; ut ex. gr. fi loco $\frac{1}{3}+\frac{x}{2}+\frac{1}{3}+\frac{1}{4} \& c_{0}$ proponatur $\frac{\mathrm{I}}{1000}+\frac{\mathrm{l}}{2000}+\frac{1}{3000}+\frac{\mathrm{I}}{4000}$ \&c. ubi.finguli termini fia Ii 2 gulorurge 
gulorum fibi refpondentium in altera, adeoque $\&$ onnes omning funt fubmillecupli : nam infnici pars millefma \& ipra infinita eft.

3. Summa feriei infinitæ, cujus pofremus terminus evanefcit quandoque finita eft, quandoque infinita.

4. Sequitur etiam, fi modo in Geonetriam faltum facere per

voceher insenip hum inpertote Pai abelozram mum o, Als - i/so infinife pana qua om aquales surt et on inala esite $1=x$ (n. Go. L'trospitale $\frac{1}{x}=y$; esponalur fow $x$ per $3,2,3$

Quadratis vel Trigonalibus.

miffum eft, fpatium Curva Hyperbolica \& Afymptotis comprehenfum infinitum effe: Secta intelligatur Afymptotos linea à centro $A$ in partes æquales infinitas in punßtis $B, C, D, E, \& C$. è quibus ad. curvam educantur recta totidem alteri Afymptotôn parallelæe $B M_{2}$ $C N, D O, E P, \& C$. \& compleantur parallelogramma $A M, B N$, $C O, D P$, \&c. qua ob bafrum æqualit tem inter fe erunt, ut altitudines, feu ut rectr $B M, C N, D O, \angle P$, \& c. hoc eft, ut $\frac{I}{1}, \frac{x}{2}, \frac{1}{2}, \frac{I}{4}, \& c_{0}$ ex natura Hyperbola ; cum igitur funma $\frac{1}{1}+\frac{x}{2}+\frac{1}{3}+\frac{1}{4} \& c$. infinita oftenfa fit, erit \& fumma Parallelogrammorum $A M, B N, C O$, $D P$, \& $R c_{0}$ infinita, multoque magis fpatium Hyperbolicum, guod Parallelogrammis illis circumícriptum eft.

X V II. Invenire fummaim ferierum Leibnitzianarum, D. H. I. aliarumn Gue gr:artum denominato es fuvt numeri Quadrati aut Trigonales, mimuti alis

Cel. Leibnitius occafione mirabilis fuxe Quadratura Circuli in principio Actorum Lipf. publicate, mentionem injicit furmme quarundam ferierum infinitarum, quarum denominatores conftituunt feriem quadratorum unitate mińutorum, diffimulato quo eam repererat artificio. En breviter totum myfterium:

A. ferie. ...A $00 \frac{1}{2}+\frac{2}{2}+\frac{2}{3}+\frac{2}{4}+\frac{1}{5}$ \& c. fubtrahatur iplamet demtis duobus

primis terminis, $B D 0 \frac{1}{3}+\frac{1}{4}+\frac{1}{5}+\frac{1}{6}+\frac{1}{7} \&$.c. $00 A-\frac{7}{7}-\frac{\pi}{2}$

relinquitur $\quad C D 0 \frac{2}{3}+\frac{2}{8}+\frac{2}{15}+\frac{2}{24}+\frac{2}{35} \&$ CC. $00 A-B D 0 \frac{2}{1}+\frac{7}{2} \cdot 0 \frac{3}{2}$ \& proptereà $\quad D 00 \frac{7}{3}+\frac{2}{8}+\frac{7}{15}+\frac{1}{24}+\frac{1}{35} \& c_{0} 00 \frac{\pi}{2} C 00 \frac{3}{4}$

A ferie ... E $E 0 \frac{1}{1}+\frac{1}{3}+\frac{1}{5}+\frac{1}{7}+\frac{1}{9} \&$ \& fubtrahatur eadem demto primo

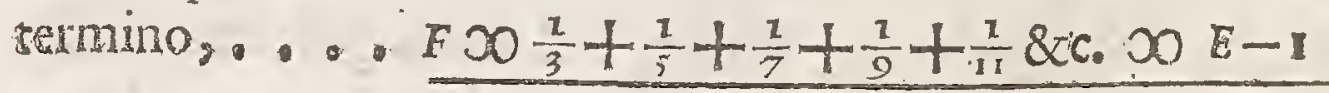

relines 


$$
\text { INFINITIS. }
$$

relinquitur $G \infty 0 \frac{2}{3}+\frac{2}{15}+\frac{2}{38}+\frac{2}{63}+\frac{2}{59} \& C_{0} \infty O E-F D O$ 8 proprerea. . H D $0 \frac{1}{3}+\frac{1}{15}+\frac{1}{35}+\frac{1}{6}+\frac{1}{99} 8 c_{0} \times 0 \cdot \frac{\pi}{2} G 00 \frac{1}{2} 9$

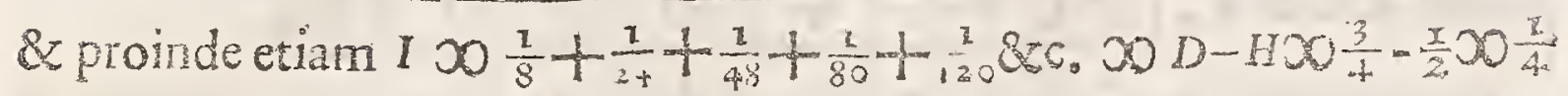
Quod ipfum quogue fic oftenditur:

A ferie... $x>0 \frac{x}{2}+\frac{z}{4}+\frac{z}{\sigma}+\frac{z}{5}+\frac{1}{10}$ \& $x_{0}$ fubtrahatur eadem demto primo

termino,...M Mn $\frac{1}{4}+\frac{1}{5}+\frac{1}{8}+\frac{1}{10}+\frac{\pi}{12} \& c_{0} .00 t-\frac{2}{2}$

relinquitur, $N 00 \frac{2}{8}+\frac{2}{24}+\frac{2}{48}+\frac{2}{80}+\frac{2}{120} 8 x c_{0} 00 \mathrm{~L}-3100 \frac{\pi}{2}$

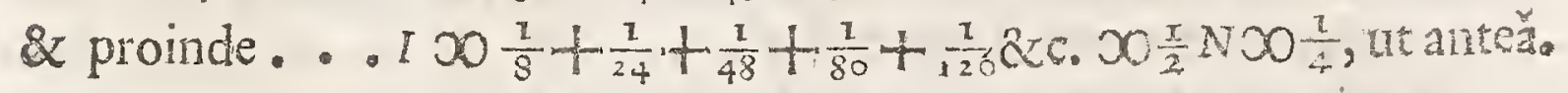

Memorabile autem prorfus eft, quod fumma feriei $D, \frac{1}{3}+\frac{1}{4}+$ $\frac{1}{15}+\frac{1}{24}+\frac{1}{35}+\frac{1}{48}+\frac{1}{63} 8 z c$. (cujus denominatores funt numeri quadrati $4,9,16,25,36,82 c$. unitate minuti) invenitur. $\frac{3}{4}$, quin \& excerptis per faltum alternis terminis, fumma feriei $H, \frac{2}{3}+\frac{4}{15}+\frac{7}{35}+\frac{7}{65} 8 \mathrm{rc}$. $\infty \frac{x}{2}$; at fi ex hâc iterum fimplici faltu terminos loco pari poftos exsexpas, ut relinquatur $\frac{1}{3}+\frac{1}{35}+\frac{3}{99} \&$ c. ejus feriei infinite fumma eft vera magnitudo circuli nullo numero exprimibilis, furto vid. quadrato diametri $\infty \frac{x}{2}$.

Cæterum generaliter invenire poffumus fummam cujus libet $f_{\text {- }}$ riei, cujus numeratores conftiruunt feriem æqualium, \& denominatores feriem quadratorum minutorum com muni aliquo quadrato Q. aur etiam feriem Trigonalium minutorum commeni aliquo numero Trigonali $T$ : fi obfervemus, ejusmodi feries nafci per fub. ductionem feriei harmonicæ truncatæe ab initio tot terminis (quot indicat ibi duplum radicis quadrate communis quadrati $Q$, hic duplum unitate audum radicis-trigonalis numeri trigonalis $T$ ) à feipfa integra:

Ex.gr, ad inveniendam fummam feriei $D, \frac{1}{7}+\frac{1}{16}+\frac{2}{27}+\frac{1}{40}+\frac{1}{19} \& C_{0}$. cujus denominatores funt quadrati, $16,25,36,49,64,8 \mathrm{r}, \&<$. minuti communi Quadrato $Q \ldots .2,9,9,9,9,9$. (cuius Radix Q.3, \& duplum 6.) $7,16,27,40,55,72$, \&c. Ii 3 A rerie v. Cor. 45 Props. pag. 279 
A ferie ....A $50 \frac{1}{3}+\frac{x}{2}+\frac{1}{3}+\frac{1}{4}+\frac{x}{5}+\frac{x}{5} \& c_{0}$ fubtrahatur eadem multata fex prinis terminis... $B x x \frac{1}{7}+\frac{x}{8}+\frac{x}{9}+\frac{1}{10}+\frac{1}{11}+\frac{1}{12} 8 c c$. relinquitur. ... C $\infty \frac{\sigma}{7}+\frac{\sigma}{16}+\frac{\sigma}{27}+\frac{\sigma}{40}+\frac{\sigma}{15}+\frac{\sigma}{7^{2}} 8<c . \infty 0 A-B>0$ $\frac{x}{3}+\frac{x}{2}+\frac{1}{3}+\frac{\pi}{4}+\frac{1}{5}+\frac{1}{6} 502 \frac{2}{20}$

adeoque...DD D $\frac{1}{7}+\frac{1}{16}+\frac{1}{27}+\frac{2}{40}+\frac{1}{15}+\frac{1}{72} \& c_{0} 20 \frac{1}{6} C 0_{120}^{49}$ Rurfus pro invenienda fumma feriei $E, \frac{1}{4}+\frac{1}{9}+\frac{1}{18}+\frac{1}{22}+\frac{1}{30}+\frac{1}{39} \& c_{0}$ cujus denominatores funt Trigonales $10,15,21,28,36,45, \& \mathrm{c}$. minuti communi Trigonali $T \ldots .6,6,6,6,6,6,8 c$. (cujus Radix Trigon. 3. \& duplum $4,9,15,22,30,39,8 r_{0}$ unitate auctum 7)

A ferie ... A $>0 \frac{x}{2}+\frac{x}{2}+\frac{1}{3}+\frac{x}{4}+\frac{1}{5}+\frac{1}{6}+\frac{1}{7} \&$ c fubtrahatur ea. dem truncata feptem primis terminis

$$
F \geq 0 \frac{1}{8}+\frac{1}{9}+\frac{1}{10}+\frac{1}{11}+\frac{1}{12}+\frac{2}{13}+\frac{1}{14} \& c_{0}
$$

relinquitur $G x 0 \frac{7}{8}+\frac{7}{18}+\frac{7}{30}+\frac{7}{44}+\frac{7}{60}+\frac{7}{78}+\frac{7}{98} 8 \mathrm{CC} . \infty 0 A-F x$ $\frac{1}{1}+\frac{x}{2}+\frac{1}{3}+\frac{1}{4}+\frac{1}{5}+\frac{1}{6}+\frac{1}{7} \infty \frac{36}{14} \frac{3}{3}$ adeoque .. E $00 \frac{1}{4}+\frac{1}{9}+\frac{1}{15}+\frac{1}{22}+\frac{1}{30}+\frac{1}{39}+\frac{1}{49} \& c_{0} 00 \frac{2}{7} G 00 \frac{26}{4} \frac{5}{0}$

Atque ita per hanc Propolitionem inveniri poffunt fummæ ferierum, cum denominatores funt vel numeri Trigonales minuti alio Trigonali, vel Quadrati minuti alio Quadrato; ut \& per XV. quando funt puri Trigonales, ut in ferie $\frac{1}{1}+\frac{1}{3}+\frac{1}{6}+\frac{\pi}{10}+\frac{1}{15} \&$ \&c. at, quod notatu dignum, quando funt puri Quadrati, ut in ferie

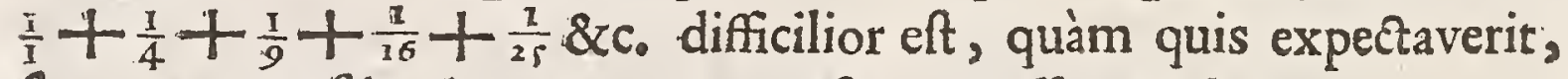
fummæ perveltigatio, quam tamen finitam effe, ex altera, qua manifefto minor eft; colligimus: Si quis inveniat nobisque communicet, quod induftriam noftram elulit hactenus, magnas de nobis gratias feret.

Hoc faltem monere adhuc liceat, quod fpatium Hyperboloide Cubicali (cujus natura exprimitur per æequationem $x x y$ yo a ab, hoc eff, in qua Quadrata abfiffarum ex Afymptotis funt in applicatarum 


\section{INFINITIS.}

watione reciproca, ) \& Afymptotis fuis comprehenfum, eodem mo dio ex firita hujus feriei fumma finitum effe demonftrari poffit, quio frmile fpatium in ipf Hyperbola ex infinita feriei Harmonicæ funmat infinitum oftenfum eft

XVIII, Invenire fummam feriei infinite reciproce numerorum Trigons" Laum, Pyramidalium, Trianguli-Pyramidalium, Pyramidi-Pyramidalium, ét figuratorum altioris cujusvis gradus in infinitum: atque infinitarums simmoF:um flimandw.

1. Quemadimodum fi à ferie fractionum harmonicè progreffio malium, hoc eft, ferie reciproca numerorum naturalium $A$, eadem multata primo termino fubtrahatur, nafcitur feries fractionum, quarum numeratores funt unitates, denominatores trigonalium duplt; ut: patet ex demonftr. XV. Ita fi à ferie reciproca trigonalium $B$, eadem truncata primo termino fubducatur, exoritur feries fractionum quarum numeratores progrediuntur juxta numeros naturales 2.3 . 4.5.\&c. fed quæ reducuntur ad fractiones, quarum omnium numeratores funt brinarii, denominatores vero pyramidalium tripli; unde ipfa feries ad feriem reciprocam pyramidalium C, ut $\frac{2}{3}$ ad $\mathbf{I}_{0}$. Pariter fi a ferie hac reciproca pyramidalium, ipfamet nutilata primo termino fubducatur, relinquitur feries fractionum, quarum numeratores progrediuntur juxta numeros trigonales $3 \cdot 6.10 \cdot 15 \cdot 8 \mathrm{rc}$. fed quæ reduci poffunt ad alias, quarum numeratores omnes. funt ternarii, denominatores vero trianguliopyrarisidalium quadrupli, unde ipfa feries ad feriem reciprocam trianguli-pyramidalium $D_{2}$ ut $\frac{3}{4}$ ad I: Et fic deinceps in infinitum. Quocirca cum fingulæ hæe per fubductionem genita feries, quarum numeratores funt unitatum, denow minatores figuratorum multipli, 2 per $\mathrm{Ax}$. 3 \% æquipolleant unitati, ipfæe figuratorum feries reciprocæ ordine dabunt fummas, ut fequitur:
A. Natur. $\frac{x}{2}+\frac{\pi}{2}+\frac{x}{3}+\frac{x}{4}+\frac{y}{5}+\frac{x}{6} \& c_{0} \infty \frac{x}{0} \infty 0 \times \frac{x}{0}$, per XVI。

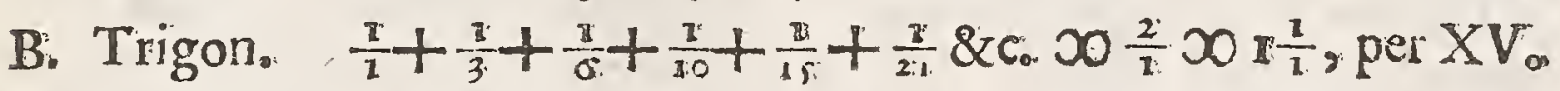

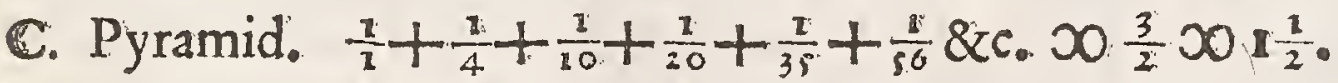
D. Triang.Pyr. $\frac{1}{1}+\frac{1}{5}+\frac{1}{15}+\frac{3}{35}+\frac{1}{70}+\frac{1}{126} 8 \mathrm{c}_{0}, \infty \frac{4}{3} \infty \mathrm{1} \frac{1}{3}$.

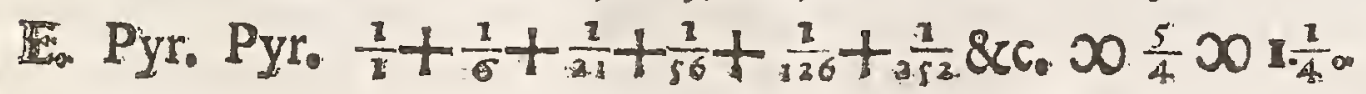




\section{DE SERIEBUS}

2. Summæ hæ à fecunda ferie ordine collectre funt $1 \frac{\pi}{3}, \mathrm{I} \frac{\mathrm{T}}{2}, \mathrm{R} \frac{\mathrm{T}}{3} \mathrm{~s}$ $1 \frac{7}{4}, 8 x c$. unde furma fummarum eft $1 \frac{1}{2}+1 \frac{x}{2}+1 \frac{3}{3}+1 \frac{1}{4}+8 x c$. que infinita eft: quin \& demtis fingularum ferierum primis terminis feu unitatibus, fumma fit $\frac{1}{2}+\frac{x}{2}+\frac{1}{3}+\frac{1}{4}+8 x c$. quæe itiden infuita exifitit, per XVI. ${ }^{x}$ at demtis infuper fecundis terminis $\frac{1}{3}+$ $\frac{2}{4}+\frac{1}{5}+\frac{2}{6} \& x_{0}$. fumma evadit finita $\&$ aqualis $1+\frac{2}{2} \infty \frac{3}{2}$ per
Axion. 3 . hur summa 3 ine $\mathrm{XIX}$. Invenire fummam feriei finite reciproce Trigonalium, pyramidd $B=\frac{2}{3}, C=\frac{2}{2}, x=$ tioris cujus is gradus in infiritum.

$\frac{2}{15}, \varepsilon=\frac{2}{24}$, sed

Pofito in qualibet ferie numero terminorum $n$, poftremi ter $\frac{2}{3}+\frac{2}{2}+\frac{2}{15}+\frac{2}{3}+\operatorname{mini}$ in feriebus directis numerorum naturalium, trigon. pyramid. $2 \gamma\left(p .25^{2}\right)=\frac{3}{2}$. (denotantibus hîc $\&$ ubique punculis continuam multiplicationem * D. Wull $\ddot{y}$ in ithquantitatum, quibus interferuntur.)

metica $g_{n+i}{ }_{0}, \frac{n \cdot n+1}{1 \cdot 2}, \frac{n \cdot n+1 \cdot n+2}{1 \cdot 2 \cdot 3}, \frac{n \cdot n+1 \cdot n+2 \cdot n+3}{1 \cdot 2 \cdot 3 \cdot 4}, \& c_{0}$ prop. 19\$. \& $C$. \& qui hos immediatè excipiunt, funt ift:

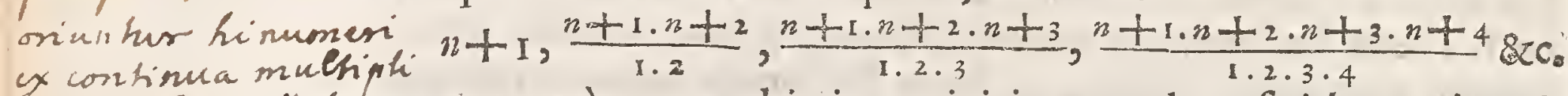
catione 2 mantitatuonac proptereà erunt ultimi termini in eorundem feriebus reciprocis $\frac{n}{3} \times \frac{n+1}{2} \times \frac{n+2}{3} \times \frac{n+3}{4} \times 4 x$ ilti:

$$
\frac{I}{n}, \frac{1 \cdot 2}{n \cdot n+1}, \frac{1 \cdot 2 \cdot 3}{n \cdot n+1 \cdot n+2}, \frac{1 \cdot 2 \cdot 3 \cdot 4}{n \cdot n+1 \cdot n+2 \cdot n+3}, \& c_{0}
$$

\& qui hos immediatè fequuntur,

$$
\frac{8}{n+1}, \frac{1 \cdot 2}{n+1 \cdot n+2}, \frac{1 \cdot 2 \cdot 3}{n+1 \cdot n+2 \cdot n+3}, \frac{1 \cdot 2 \cdot 3 \cdot 4}{n+1 \cdot n+2 \cdot n+3 \cdot n+4}, 8 c_{0}
$$

Jam fi à qualibet ferie reciproca eadem ipfa truncata $a b$ initio \& aucta in fine uno termino methodo Prop. XV. fubtrahatur, fub. duk̂ figillatim fecundo termino à primo, tertio à fecundo, fequente ultimum ab ultimo, nafcitur feries terminorum totidem, que per ea quæ in præced. Propor, dieta funt, feriei reciprocæ figuratorum gradus fequentis aut fubdupla eft, aut fubfefquialtera, aut fubferquitertia, \&zc. atque infuper per obfervata Propof. XV. æqualis primo termino minus fequente ultimum ejus feriei, per cujus fubductionem nata fuit: unde ipfa fumma feriei finitie reciprocæ figuratorum quom romcungue obtinetur facile, ut fequitur:

B. Tri- 


\section{IINFTNITIS}

B. Trigon, $\frac{x}{3}+\frac{1}{3}+\frac{1}{6}+\frac{1}{10} 8 x$. ufquie ad $\frac{1 \cdot 2}{n \cdot n+1} \infty \frac{2}{2}-\frac{2}{1}$ in thempe $\frac{1}{1}-\frac{1}{n+1} \times 2$

$$
\frac{1}{n+i} \quad \infty \frac{2}{n}-\frac{2}{n+1}
$$

C. Pyram: $\frac{1}{3}+\frac{2}{4}+\frac{1}{10}+\frac{1}{20} 8 c_{0}-\cdots \frac{1 \cdot 2 \cdot 3}{n \cdot n+1 \cdot n+2} \infty 0 \frac{3}{2}-\frac{3}{2}$ ia ol rationem sution plasn; $\frac{1}{1-\frac{1 \times 2}{n+1 \times n+2} \times \frac{3}{2}}$

$$
\frac{1 \cdot 2 .}{n+1 . n+2} \infty \frac{3}{2}-\frac{1 \cdot 3}{n+1 \cdot n+2}
$$
of rationem sub:

D. $\Delta$. Pyr. $_{0} \frac{x}{3}+\frac{1}{5}+\frac{x}{15}+\frac{\pi}{35} 8 \mathrm{rco}_{0} \frac{1 \cdot 2 \cdot 3 \cdot 4}{n \cdot n+1 \cdot n+2 \cdot n+3} \infty \frac{4}{3}-\frac{4}{3}$ in 28$) \mathrm{C}$.

$$
\frac{1 \cdot 2 \cdot 3}{n+1 \cdot n+2 \cdot n+3} \infty \frac{4}{3}-\frac{1 \cdot 2 \cdot 4}{n+1 . n+2 \cdot n+3}
$$

E. Py. Pyr. $\frac{2}{3}+\frac{1}{6}+\frac{1}{21}+\frac{1}{56} \&$ c. $\frac{1 \cdot 2 \cdot 3 \cdot 4 \cdot 5}{n \cdot n+1 \cdot \cdot-n+4} \infty 0 \frac{5}{4}-\frac{5}{4}$ in

$$
\frac{1 \cdot 2 \cdot 3 \cdot 4}{n+1 \cdot \cdots+n+4} \infty \frac{5}{4}-\frac{1 \cdot 2 \cdot 3 \cdot 5}{n+1 \cdot \cdots \cdot-n+4}
$$

$\mathrm{XX}$. Invenire fermman feriei infinite reciproce Trigonalium, Pyramidalium, Triang. Pyranidalitum, $\$ \%$ multate terminis initialibus quotibet: of infinitarum fummarum funmam.

т. Summa feriei infinitæ integræ Trigonalium, Pyramidalium, Triang. Pyramidalium, \&c. eft $\frac{2}{2}, \frac{3}{2}, \frac{4}{3}, \frac{5}{4}, \& c_{0}$ per XVIII. fi ex unaquaque feric $a b$ initio abfindantur $n$ termini, fumma abfififorum ent $\frac{2}{I}-\frac{2}{n+1}, \frac{3}{2}-\frac{1 \cdot 3}{n+1 \cdot n+2}, \frac{4}{3}-\frac{1 \cdot 2 \cdot 4}{n+1 \cdot n+2 \cdot n+3}, \frac{5}{4}-$ $n \frac{1 \cdot 2 \cdot 3 \cdot 5}{n+1 \cdot n+2 \cdot n+3 \cdot n+4}, 8 x c$. per XIX. fubtracta ergo hac à fumma omnium, erit fumma reliquorum $\frac{2}{n+1}, \frac{1 \cdot 3}{n+1 \cdot n+2}, \frac{1 \cdot 2 \cdot 4}{n+1 \cdot n+2 \cdot n+3}$, $\frac{1.02 .3 .5}{n+1 . n+2 . n+3 . n+4}, 8 c_{0}$

2. Summa ferierum omnium mutilatarum feu nullo feu uno termino eft infinita, duobus terminis eft $\frac{3}{2}$ per XVIII. Hinc fi demas tertios terminos (qui confituunt feriem trigonalium $B$ truncatam duobus terminis, cujus fumma per eandem eft $\frac{2}{3}$ ) erit reliquorum omnitum fumma $\frac{3}{2}-\frac{2}{3} \infty \frac{5}{6} \infty \frac{5}{2 \cdot 3}$. Hinc denuo fi quartos terminos auferas (qui formant feriem pyramidalium $\mathrm{C}$ itidem truncatam duobus terminis, fummamque proin per praced, efficiunt $\frac{2}{3}$ ) IKk relin- 
relinquetur caterorum omnium fumma $\frac{5}{6}-\frac{2}{8} \infty \frac{7}{12} \infty \frac{7}{3 \cdot 4}$. Hine iterum fi quintos terminos refeces, exibit cæterorum fumma $\frac{9}{4.5} \mathrm{~g}$ fi fextos, $\frac{\mathrm{II}}{5.6} ;$ feptimos, $\frac{\mathrm{I}}{6.7} ;$ \&c. adeoque univerfaliter fi ex unaquaque ferie tollantur $n$ termini, erit murilatarum ita feriexum omnium fumma reliqua $\frac{2 n-1}{n-1 \cdot n}$.

coroll. Series $\frac{2}{n+1}+\frac{1 \cdot 3}{n+1 \cdot n+2}+\frac{1 \cdot 2 \cdot 4}{n+1 \cdot n+2 \cdot n+3}+$ $\frac{1 \cdot 2 \cdot 3 \cdot 5}{n+1 \cdot n+2 \cdot n+3 \cdot n+4}+8$ re. five, $\frac{2}{1}$ in $\frac{1}{n+1}+\frac{3}{2}$ in $\frac{1 \cdot 2^{4}}{n+1 \cdot n+2}+$ $\frac{4}{3}$ in $\frac{1 \cdot 2 \cdot 3}{n+1 . n+2 \cdot n+3}+5$ in $\frac{1 \cdot 2 \cdot 3 \cdot 4}{n+1.0 . n+4}+8 c_{0}, \infty \frac{2 n-1}{n-1 . n}$ : fingula enim feriei hujus membra fingulas figuratarum ferierum mutilatarum fummas exprimunt, per $\mathbf{x}_{0}$ part, hujus; adeoque \& om nia omnium.

$X X I_{6}$ seriei bujus, $\frac{1 a}{1.2}+\frac{2 a}{1.2 .3}+\frac{3 a}{1.2 .3 .4}+\frac{4 a}{1.2 .3 .4 .5}+\&$ G: bo6 $e f_{2} \frac{a}{2}+\frac{a}{1.3}+\frac{a}{1.2 .4}+\frac{a}{8.2 .3 .5}+8 x c$ : fummann invenire.

Series hæc nafcitur fubduatione fequentis feriei, $\frac{a}{1}+\frac{\alpha}{1.2}+\frac{a}{1.2 .3}+$ $\frac{a}{1.2 .3 \cdot 4}+\& c$ : multatæ primo termino à feipfa integra, methodo Propo $\mathrm{XV}$. quare ejus fumma $x$ a, primo (c. termino hujus, per Axioma 3 . Coroll. Hinc $\frac{1}{1.2}+\frac{4}{1.2 \cdot 3}+\frac{9}{1.2 \cdot 3 \cdot 4}+\frac{16}{1.2 \cdot 3 \cdot 4 \cdot 5}+8 c_{0}(x F+G+$ $\left.H+1+\& c_{,}\right) \infty \frac{1}{1}+\frac{1}{i .2}+\frac{1}{1.2 .3}+\frac{1}{1.2 .3 .4}+\& c_{0}$

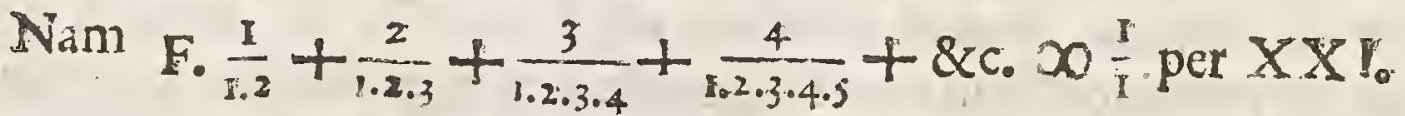
$\mathrm{G}_{0}=-\frac{2}{1.2 .3}+\frac{3}{1.2 \cdot 3 \cdot 4}+\frac{4}{1.2 \cdot 3 \cdot 4 \cdot 5}+8 \mathrm{cc}_{0} \infty \mathrm{F}-\frac{1}{1.2} \infty 0 \frac{1}{1.2}$

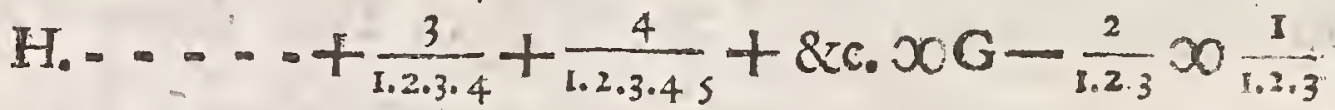

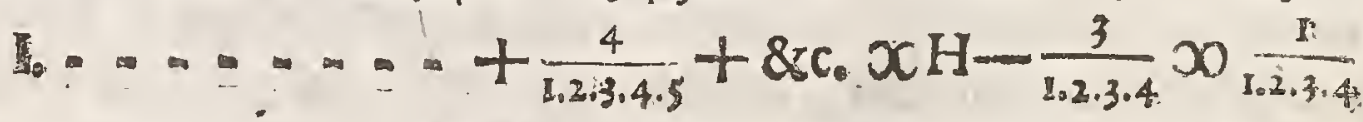


- XXII. Inrenire fummas ferierum $\mathrm{K}, L, M, N$, quarum sumeratores funt aritbmetice progreffionales, denominatores Trigonalium integrooum aut Quadratorum unitate minutorum quadrat a.
$K \infty \frac{3}{\square^{1}}+\frac{5}{\square 3}+\frac{7}{\square \cdot}+\frac{9}{\square 10}+\frac{Y I}{\square 15}+\frac{13}{\square 2 I}+2 \mathrm{C}_{0}$
$\mathrm{L} \infty \frac{2}{\square_{3}}+\frac{3}{\square 8}+\frac{4}{\square 15}+\frac{5}{\square 24}+\frac{6}{\square 35}+\frac{7}{\square 4^{8}}+8 \mathrm{rc}_{0}$

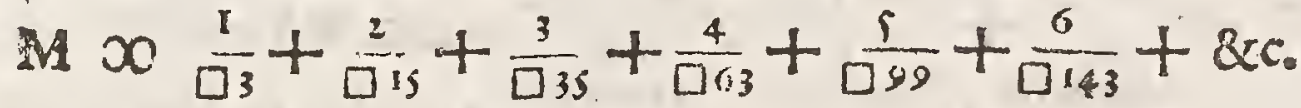
$\mathrm{N} \infty 0 \frac{3}{\square 8}+\frac{5}{\square 24}+\frac{7}{\square+8}+\frac{9}{\square 80}+\frac{11}{\square 120}+\frac{13}{\square 168}+8 \mathrm{c}$.

Per fubductionem feriei $\frac{1}{a_{1}}+\frac{1}{a^{2}}+\frac{1}{a_{3}}+\frac{1}{D_{4}}+\frac{1}{a_{5}}+\frac{1}{D_{6}}+8 c_{0}$ mutilatæ primo termino à feipfa integra nafcitur feries aliqua, cujus termini funt fubquadrupli terminorum refpondentium feriei $\mathrm{K}$; unde per $\mathrm{Ax}, 3$. feries $\mathrm{K} \infty_{4}$ in $\frac{1}{\square} \infty_{4}$

Per fubductionem vero ejusdem feriei mutilatre duobus primis terminis à feipfa integra oritur feries, qua quadrupla eft feriei $L$; unde per id. Ax. feries $L \infty \frac{1}{4} i n: \frac{1}{\square}+\frac{1}{\square 2} \infty \frac{5}{86}$.

Denique per fubductionem feriei $\frac{1}{\sigma_{1}}+\frac{1}{D_{3}}+\frac{1}{\square 5}+\frac{1}{\sigma_{7}}+\frac{1}{D^{2}}+$ \&c. multatæ primo termino à feipfa integra emergit alia, qua octupla eft feriei $M$, quare per 3. Ax. feries $M \infty \frac{1}{8}$ in $\frac{1}{\square} \infty \frac{1}{8}: \&$ propterea duplum feriei $M$, hoc eft, omnes termini locorum imparium feriei $\mathrm{L}>\frac{1}{4}$; adeoque reliqui termini ejusdem feriei, hoc eft, ipfa feries $N$ D $\frac{5}{16}-\frac{1}{4} \infty \frac{1}{16}$.

$X X I I I$. Invenire fummas ferierum $Q \& R$, item $V \& X, \& c$ quarum denominatores funt termini integri progreffionis quadrup le, Honcuple, or $c_{+}$numeratores vero termini progreffionis dupla, triple, \&o $G_{+}$unitate tum minuti, tum aucli, Operatio talis :

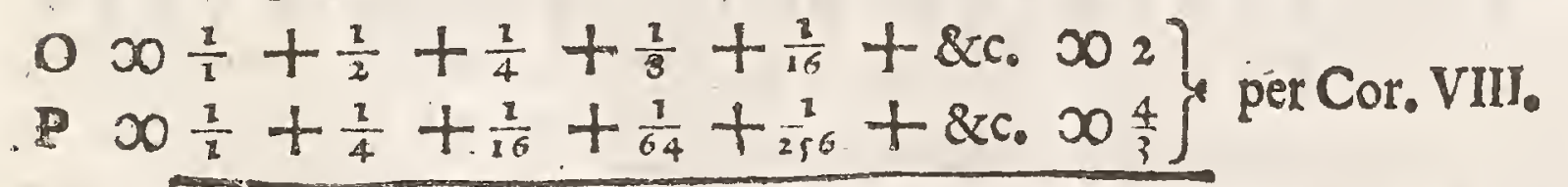


$260 D E S E R I E B$ I $S$

$200 \frac{1-1000}{1}+\frac{2-1001}{4}+\frac{4-1003}{16}+\frac{8-1007}{64}+\frac{16-10015}{256}+820.000-\mathrm{P} 002-\frac{4}{3} 50 \frac{2}{3}$ $\mathrm{R} 00 \frac{1+1002}{1}+\frac{2+1003}{4}+\frac{4+1005}{16}+\frac{8+1009}{64}+\frac{16+10017}{256}+8 C_{0} 000+\mathrm{P} 002+\frac{4}{3} \times \frac{10}{3}$ $S 00 \frac{1}{2}+\frac{1}{3}+\frac{1}{2}+\frac{1}{27}+\frac{8}{8 x}+8 x \cdot 00 \frac{3}{2}$

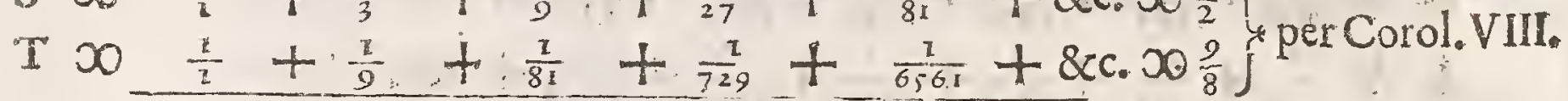

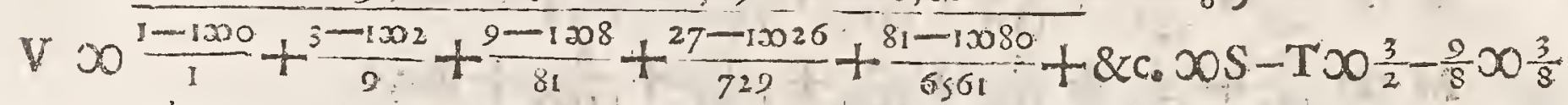

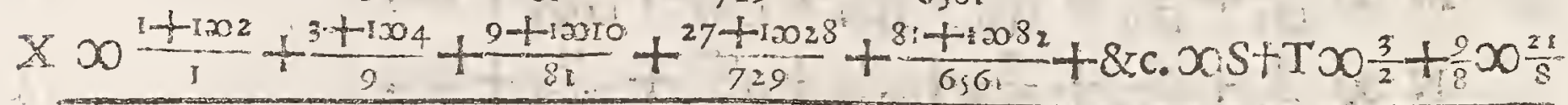

Idem inveniri potef, refolvendo feries propofitas $\mathrm{Q}, \mathrm{R} ; \mathrm{V} \& \mathrm{X}$ me thodo Prop. XIV. Exempli loco efto feries

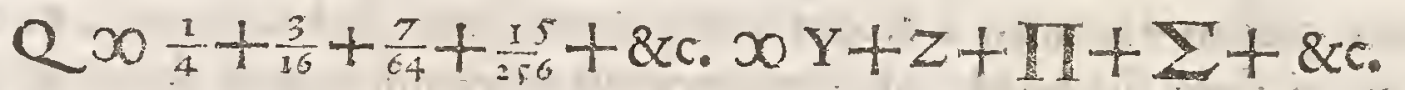

Y $\infty \frac{1}{4}+\frac{x}{16}+\frac{1}{64}+\frac{1}{256}+8 x c_{0} \infty$ per Coroll. VIII. $\left.\frac{1}{3}\right]$

$Z \infty 0-\cdot+\frac{2}{16}+\frac{2}{64}+\frac{2}{256}+$ \&C. $02 Y-\frac{2}{4} \infty \frac{2}{3}-\frac{2}{4} \infty \frac{1}{0}$

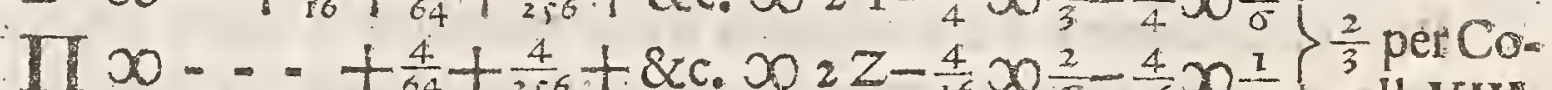

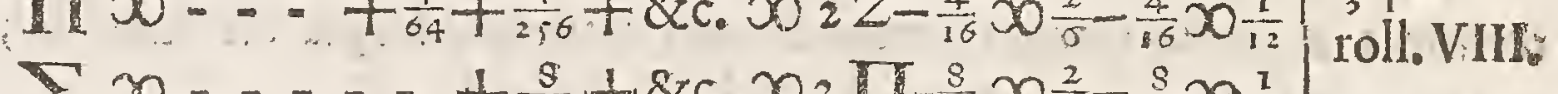

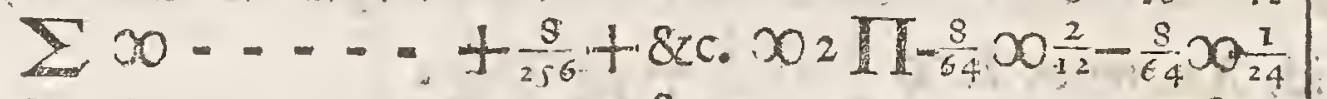

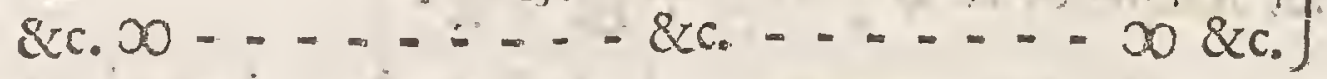

XXIV. In feric quavis infinita; cujus numeratores onnes, funt dequales, denominatores vel mureri naturales, vel corufdem quadrata, cubi, aut alia que curque potelias, fumma terminorum ovtrium in loi is imparibus efl ad fuminam. omium in paribus, ut fimilis poteftas binarit witate muitats ad unitatsm.

Puta in numeris naturalibus, ut I ad $\mathrm{I}$; in quadratis ut $3 \mathrm{ad} \mathrm{I}$; in cubis ut 7 ad $\mathrm{I}$; in biquadratis ut 15 ad $1 ; \& c_{0}$ :

Modus invefigandi talis:

In Numeris Naturalitus:

Series ina $\frac{1}{7}+\frac{1}{2}+\frac{1}{3}+\frac{1}{4}+\frac{1}{5}+\frac{1}{13}+\frac{1}{7}+\frac{1}{5}+\&$ \&c. æquatur fuis: partibus, videl. feriebus $A+B+C+D+\& C$.

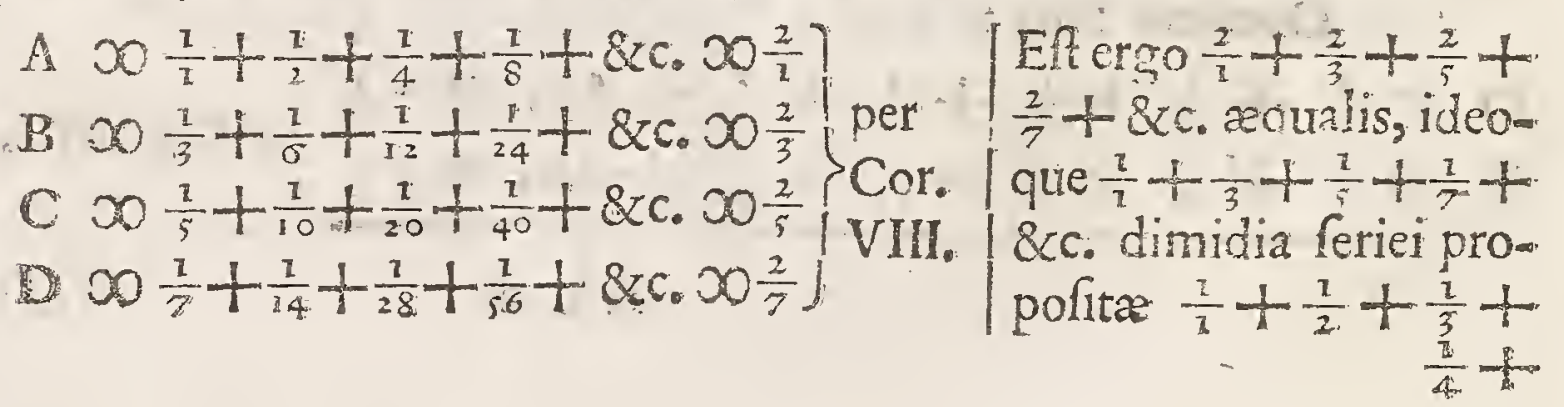


$\frac{5}{4}+\& c_{0}$ hoc eft, fumma terminorum in locis imparibus dimidia feriel totius, \& proinde æqualis fumma reliquorum $\frac{x}{2}+\frac{1}{4}+\frac{1}{6}+$ $\frac{2}{8}+3 x$.

Pare hinc rufun veritas Prop. XVI. cum enim $\frac{1}{2}>\frac{1}{2}, \frac{1}{3}>\frac{1}{4}$,

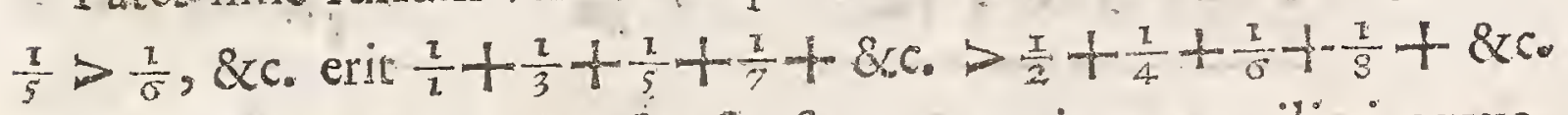
cui tamen requalis modo oftenfa eft; qua utique conciliari nequeunt, niff fumma urriusque ferie ftatuatur infinita, hos eft, tanta ut qux inter illas intercedit differentia, rationem xqualitatis deffusre non poffit.

\section{In Numeris Quadratis:}

Series $\frac{2}{1}+\frac{1}{4}+\frac{1}{9}+\frac{\pi}{16}+\frac{1}{25}+\frac{1}{36}+\frac{\pi}{49}+\frac{1}{64}+8 c_{0} . \infty E+F+G+$ $\mathrm{H}+\& \mathrm{c}$.
$E \infty \frac{1}{1}+\frac{1}{4}+\frac{1}{16}+\frac{1}{64}+8 c_{0} \infty \frac{4}{3 \cdot 1}$
$F \infty \frac{1}{9}+\frac{1}{36}+\frac{1}{144}+\frac{1}{576}+2 x c_{0} \infty \frac{4}{3.9}$
$G>0 \frac{1}{25}+\frac{1}{100}+\frac{1}{400}+\frac{1}{1600}+8 c_{0} \cdot 00 \frac{4}{3.25}$ per Cor. VIII.
$\left.H \propto 0 \frac{1}{49}+\frac{1}{196}+\frac{1}{784}+\frac{1}{3136}+8 C_{0} .00 \frac{4}{3.4 y}\right)$

Eftergo $\frac{4}{3.1}+\frac{4}{3.9}+\frac{4}{3.25}+\frac{4}{3.49}+8 c_{0} 00 \frac{1}{1}+\frac{1}{4}+\frac{1}{9}+\frac{\pi}{16}+\frac{\pi}{25}+8 \mathrm{cc}_{5}$ adeoque prioris fubfefquitertia, hoc eft, $\frac{1}{1}+\frac{1}{9}+\frac{1}{25}+\frac{1}{49}+8 x c_{0}$ xqualis $\frac{3}{4}$ pofterioris, hoc eft, termini omnes locorum imparium in ferie propofita confituunt tres quartas partes totius feriei, \& reliqui unam: quare fumma terminorum, illorum ad fummam horum, ut 3 ad 1 .

Eadem invefigandi methodus obfervetur in reliquis poteftatibus. Arrer 8 univer- $\times \infty$
Cliter ita:

$$
\text { y } \infty \frac{1}{1^{m}}+\frac{1}{3^{m}}+\frac{1}{5^{m}} \quad \& c_{0}
$$

$\mathrm{Kk} 3$

$x-y$ 


$$
\begin{aligned}
& D E S E R I E B L S \\
& x-y \infty x+\frac{1}{2^{m}}\left(\frac{1}{2^{m} 1^{m}}\right)+\frac{1}{4^{m}}\left(\frac{1}{2^{m} 2^{m}}\right)+\frac{1}{6^{m}}\left(\frac{1}{2^{m} 3^{m}}\right) \& c_{0} \\
& 2^{m x-2^{m}} \text { y } x+\frac{1}{1^{m}}+\frac{1}{2^{m}}+\frac{1}{3^{m}} \& c_{0} \infty x
\end{aligned}
$$
$\mathrm{x}-\mathrm{y}:: \mathrm{x}-\frac{\mathrm{x}}{2^{m}} \cdot \frac{\mathrm{x}}{2^{m}}:: 1-\frac{1}{2^{m}} \cdot \frac{1}{2^{m}}:: 2^{m}-I_{0} I_{0}$

Scbol. Liquet hine, quod fummæ duarum ferierum (etiamfi. incognitæ) polfint ad fe invicem habere rationem cognitam. vid. Prop. X VII. fub fin. Extendit fe autem demontratio ad poteftatum radices five ad poteftates fractas non minus ac integras: fic ex. gr. colligimus, in ferie $\frac{1}{\sqrt{1}}+\frac{1}{\sqrt{8}}+\frac{1}{\sqrt{27}}+\frac{1}{\sqrt{64}}+\frac{1}{\sqrt{125}}+\& c_{\text {. }}$ (ubi denominatores funt cuborum radices quadratæ) omnes terminos locorum imparium ad omnes parium effe, ut $\sqrt{8}-1$ ad I. Mirabile verò eft, quod in ferie $\frac{1}{\sqrt{1}}+\frac{1}{\sqrt{2}}+\frac{1}{\sqrt{3}}+\frac{1}{\sqrt{4}}+8 x c$. (cujus fumma

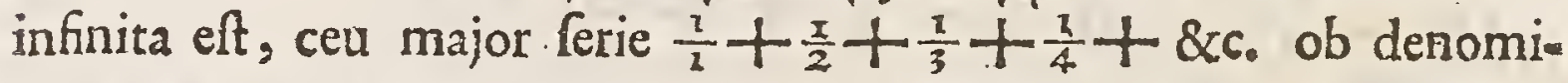
natores minores) termini locotum imparium ad terminos parium juxta regulam inveniuntur habere rationem $\sqrt{ } 2-1$ ad 1 . minoris fc. ad majus, cùm tamen illi cum his figillatim collati iisdem manifelto fint majores: cujus śry?opovéres racionem, etfl ex infiniti natura finito intellectui comprehendi non poffe videatur, nos tamen fatis perfpectam habemus. Idem vero de fimilibus feriebus aliis, qux infinitam fummam habent, intelligendum.

$\mathrm{XXV}$. Series Thefos $X, \frac{a}{b}-\frac{a+c}{b+d}+\frac{a+2 c}{b+2 d}-\frac{a+3 c}{b+3 d} ;$ \& alie How monica terminorum totidem of denominatorsm eorssndem, $\frac{f}{b}-\frac{f}{b+d}+$ $\frac{f}{b+2 d}-\frac{f}{b+3 d} ;$ fignis $+\mathcal{F}$ - alternatim fe expipientibus, funtoque $f 00 a-\frac{b c}{d}$, equalios fummes babento. 
Etenim fubtrahendo terminos locorum parium à terminis in parium, provenit eadem utrobique feries, $\frac{a d-b c}{b b+b d}+\frac{a d-b c}{b 6+5 b d+6 a d s}$ five $\frac{d f}{b b+b d}+\frac{d f}{b b+5 b d+6 d d}$, \& c.

ERto ex.gr.feries th.X. feries harmonica, $\frac{2}{1}-\frac{2}{2}+\frac{3}{3}-\frac{7}{4}+\frac{7}{5}-\frac{3}{6}$, erit

fumma urriusque $\frac{x}{2}+\frac{1}{12}+\frac{3}{30}$, pex faltum excerpta ex Ferie Q. th, $X V$.

$\mathrm{XXVI}$. Seriei infinite fractionum $\mathrm{K}$ (quaram denominatares crefounz progreffione Geometrica, boc efl, fequentes pracedentium fint aque-mulltiplices exaldè, numeratores però pracedentivan aque-multiplices auchi vel minuti commusi quodam numero, funsmam ultimumve terminum reperire.

( 8 denotat vel ubique + vel ubique - )

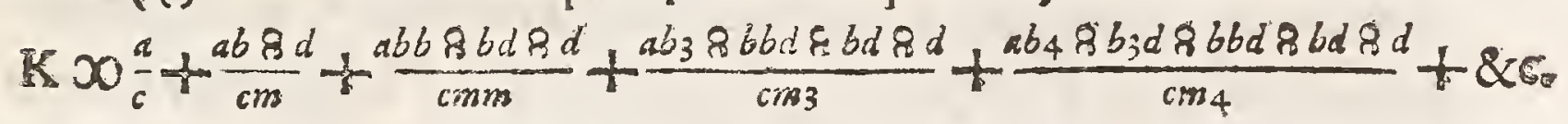

I. Summa feriei invenitus, refolvendo illam methodo Prop.XIV. in feries fractionum purè proportionalium $\mathrm{L}+\mathrm{M}+\mathrm{N}+\mathrm{O}+\mathrm{P}+2 \mathrm{C}_{0}$ $\mathbf{L} \infty \frac{a}{6}+\frac{a b}{c m}+\frac{a b b}{c m m}+\frac{a b 3}{c m_{3}}+\frac{a b 4}{c m_{4}}+\& c_{0} \infty+\frac{a m s}{b s-b: 1 n c}$

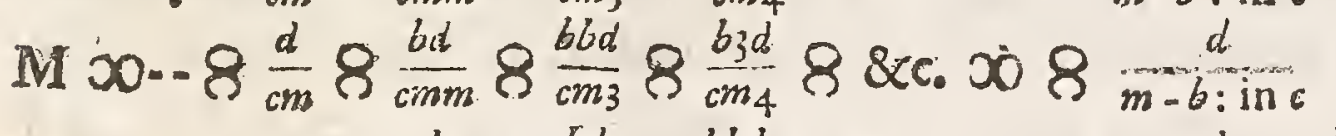

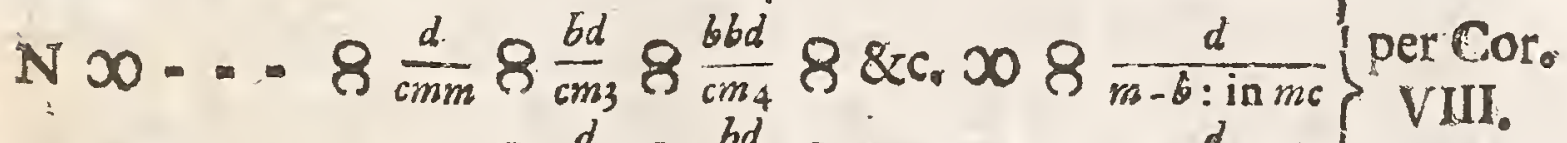

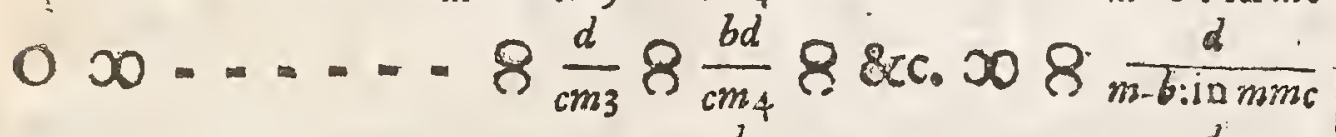
P $\infty \ldots \ldots . . . .8 \frac{d}{c m_{4}} 8 \& \varepsilon_{0} \infty 8_{m-b: i}^{d}$ $\& c_{0} \infty 0 \ldots \ldots . . .8 \& c_{0} \infty \& \& c_{0}$

Summe ferierum $M, N, O, P_{s} \& c_{0}$, novam progreffionem Geometricam conftituunt, cujus fomma per Coroll. VIII. eft $\frac{m d}{m-1: \text { in } m-b: \ln c}$, quxe fummi feriei $\boldsymbol{L} \frac{a m}{m-b: \text { inc }}$ addita vel fubtra* Eta efficit $\frac{a m m-a m s m d}{m-1: m-b: \text { in } c}$ fummam onnium ferierum $L_{2} M, N, \& c_{0}$ hoc eft g ipfius feriei propofita $\mathrm{K}_{\text {. }}$ 
2. Obfervandum, fi $m>b$, fummam effe finitam, adeoque ultimum feriei terminum evanefcere, vid. Cor. XIV.

$\operatorname{Sin} m<b, \&$ fumma infinita eft, \& ultimus quoque terminus eft infinitus; tum enim fingulæ progrefliones Geomietricæ L., $M_{2}^{3}$ $N$, \&c. funt crefcentes: confer Prop. V.

At exiftente $m x b$, fumma guidem infinita eft, fed poftremus terminus finitus: tum enim furrogato $m$ in $\operatorname{locum}_{b} b$, fecundus terminus fit $\frac{a m g d}{c m}$, hoc eft, $\frac{a}{c} 8 \frac{d}{c m}$ : tertius $\frac{\text { amm } 8 \mathrm{md} 8 d}{\mathrm{~cm}}$, hoc eft,

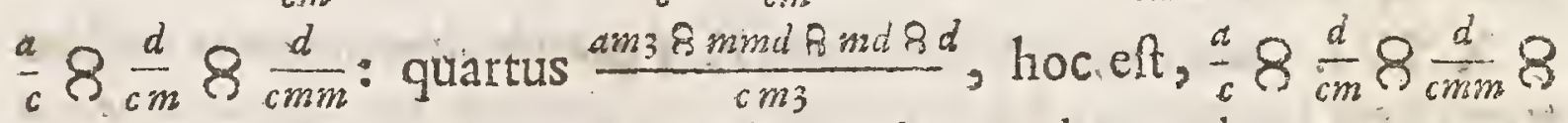
$\frac{d}{\mathrm{~cm}_{3}}$ : atque ita poltremus $\frac{a}{c} 8 \frac{d}{\mathrm{~cm}} 8 \frac{d}{\mathrm{cmm}} 8 \frac{d}{\mathrm{~cm} 3} 8 \frac{d}{\mathrm{~cm} 4} 8 \mathrm{\& c}$. in infinitum: unde patet, terminum infinitefinum refolvi in $\frac{a}{c} 8$ ferie infinitorum Geometricè progreffionalium in ratione $m$ ad $\mathrm{I}$, quorum fumma per Cor. VIII, eft $\frac{d}{m=\text { : in } c}$, quxe ipfi $\frac{a}{c}$ addita vel fubtracta efficit terminum infinitefimum $\frac{a m-a \& d}{m-1: 1 n c}$, cujus numerator differentiam numeratorum primi \& fecundi termini, uti \& denominator denominatorum eorundem differentiam exprimit: quare cùm ex Prop. X. manifeftum fit, terminum ultimum hujus progreffionis

$$
\begin{aligned}
& \text { Q } 0 \frac{a}{c}, \frac{a m 8 d}{c m}, \frac{2 a m-a 82 d}{2 c m-c}, \frac{3 a m-2 a 83 d}{3 c m-2 c}, \frac{4 a m-3 a 84 d}{4 c m-3 c}, \& x c_{0} \\
& \text { five } \frac{a}{c}, \frac{a}{c} 8 \frac{d}{c m}, \frac{a}{c} 8 \frac{2 d}{2 c m-c}, \frac{a}{c} 8 \frac{3 d}{3 m c-2 c}, \frac{a}{c} 8 \frac{4 d}{4 c m-3 c}, \& c_{0}
\end{aligned}
$$
itidem effe $\frac{a m-a 8 d}{m-1: \ln c}$ five $\frac{a}{c} 8 \frac{d}{m-1: \text { in } c} ;$ fequitur in utraque progreffione $\mathrm{K} \& \mathrm{Q}$, primis duobus terminis exiftentibus iisdem ultimos quoque effe pares, quamvis incrementa vel decrementa prioris magis fubitanea fint, quandoquidem ejus termini non' nifi per faltum $\mathrm{EX}$ poftriore funt excerpti: Invenio enim, quod memorabile eft, tertium terminum feriei $\mathrm{K}$ convenire cum termino $m+2$, quartum cum $m m+m+2$, quintum cum $m 3+m+m+2$, fextum cum $m_{4}+m_{3}+m n+m+2$ feriei $Q$, \& fic deinceps; uti patere poterit ex fubjundis feriebus, ubi a valet $2, c_{3}, b$ vel $m$ \& d I. 
整 $00 \frac{2}{3}, \frac{7}{9}, \frac{22}{27}, \frac{57}{8}, \frac{202}{24}, \& c_{0}$. ultimus $\frac{5}{6}$. .

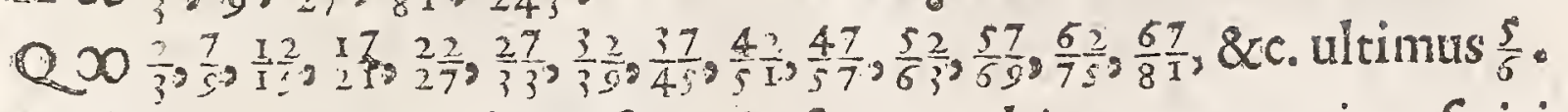
Intellige vero, qux dicta funt de fumma ultimoque termino feriei $\mathrm{K}$, fi numeratores præcedentium funt æque - multiplices aucti communi numero $d$; vel diminuti quidem eodem numero, at infuper $a b>a+d$. . Nam fi fit $a b \infty 0 a+d$, æquivalebunt finguli numeratores ipfi $a$, fummaque feriei fiet finita, nempe $\frac{a m}{m-1: 1 n c}$, \& ultimus kerminus evanefcet, five $m$ exiftat $<$ vel $\infty$ ipfi $b$.

XXVII. si dati cujusliber mumeri radix quadrata ducatur in ipfum mumerum, of prodsicti radix quadrata deino ducatur in eundews, \&o producti bujus radix iterum iterumque; idque fut continuo in infinitum: erit radix prow ducti ultimi aqualis ipfi dato numero: (puta, fi datus numerus vocetur $a$, erit $\left.\sqrt{a} \sqrt{a} \sqrt{a} \sqrt{a} \sqrt{a} \& c_{0} \infty a_{0}\right)$

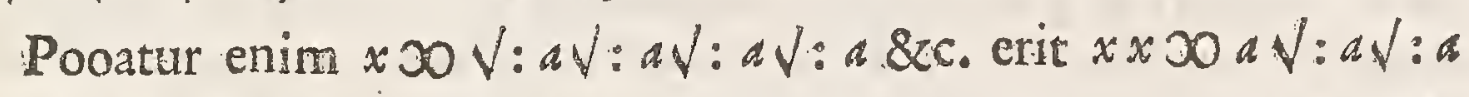

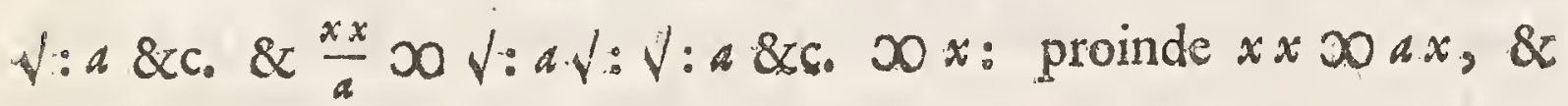
$x . \infty$ a. Q. E. D.

$\mathrm{XXVIII.} \mathrm{si} \mathrm{dati} \mathrm{numeri} \mathrm{wiuslibet} \mathrm{radix} \mathrm{quadrata} \mathrm{addatur} \mathrm{ip} f i$ dato animero, \& aggregati radix quadrata denuo addatur eidem, \& aggregati bujus radix iterum iterumque; idque frat continuo in infinitum: radix aggregati ultimi radicem dati numeri quarsa parte unitatis aucti dimidia unitate fuperabit. (putà $\sqrt{ }: a+\sqrt{ }: a+\sqrt{ }: a+\sqrt{ }: a+\& c_{0} \infty \frac{1}{2}+\sqrt{\frac{1}{4}+a_{0} \text { ) }}$

Pofito enim $x>1: a+\sqrt{ }: a+\sqrt{ }: a+\& c_{\text {. erit }} x x \infty a+$ $4: a+\sqrt{ }: a+\& c_{\text {. }} \& x x-a 30 \sqrt{ }: a+\sqrt{ }: a+\sqrt{ }: a+\& c, \infty x:$ proinde $x \times x x+a, \& x>\frac{1}{2}+\sqrt{\frac{1}{4}+a_{0}}$ Q. E. D.

$\mathrm{XXIX}$. Datis duobus numeris quibusvis, $\sqrt{2}$ radix quadrata units ducatur in alterum, \& producti radix quadrata in primum, of bujus producti radix in alterum; atque ita Semper productorum radices ducantur alternatim in datorum alterum; idque continuetur in infnitum: erit radix producti ultimi equalis alteratri duorum mediorum proportionalium inter duos datos numeros (pucà fi dati numeri dicantur $a \& b$, erit $\sqrt{ }: a \sqrt{ }: b \sqrt{ }: a \sqrt{ }: b \sqrt{ }: a \sqrt{ }: b . \& c_{0}$ 30 ( $\left.C_{0} a b_{0}\right)$ 
Efto namque $x, \infty \sqrt{ }: a \sqrt{ }: b, \sqrt{ }: a \sqrt{ }: b, \& c_{0}$ erit $x x \infty a \sqrt{ }: b$ $\sqrt{ }: a \sqrt{ }: b \& c_{0} \& \frac{x x}{a} \infty \mathrm{V}: l \sqrt{ }: a \sqrt{ }: l_{0} . \& c_{0} \& \frac{x_{4}}{a a} \infty 0 b \sqrt{ }: a V_{0}: b_{0} \& c_{0} \&$

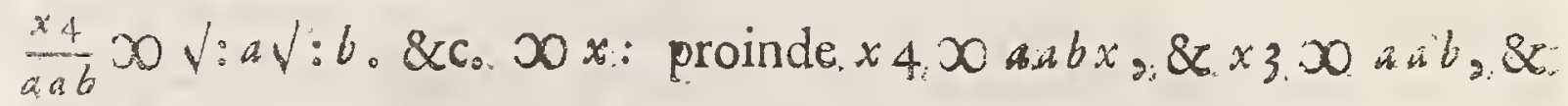

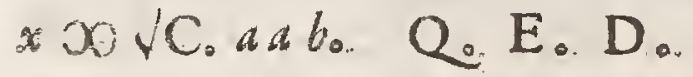

$\mathrm{XXX}$. Datis duobus numeris quibuspis, fi radix cubica producti ex utro. gue ducatur in corum prinium, \& prodicti. radix quadrata ducatur in predictum

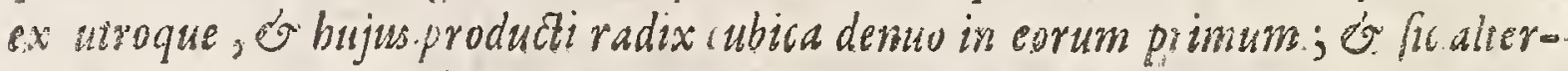
nation radices cubice or quadrate ducantwr in corum primum os productim ex sitroque, erit radix product ultimi aqualis primo vel fecundo quatuor medio um proporionalium inter duos datos (putà $\sqrt{ }: a \sqrt{ } C: a b \sqrt{ }: a \sqrt{ } C: a b$, \& $c_{0}$.

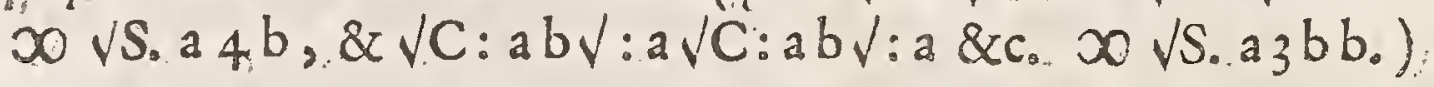

XXX I. Datis duobus momeris quibusvis, $\sqrt{3}$ radix quadrata fecunai duca wr in promum, of producti radix quadrata iterus in primum, producti vero. Lujus radix in fecundum, of hujus productiradix denuo in prinum, of fic alternatim productorum radices multiplicentur; bis in primum, femel in feuvadum, erit radix producti ultimi 0 primo, fecundo vel quarto fex proporticnalinus:

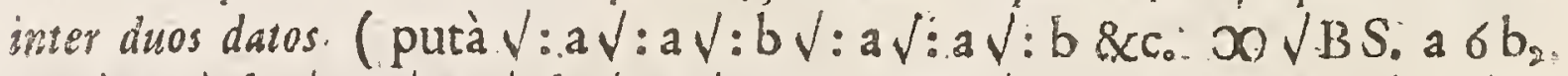

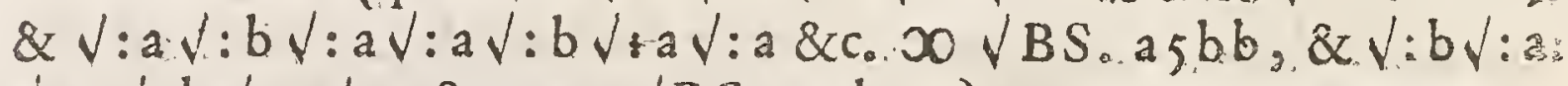

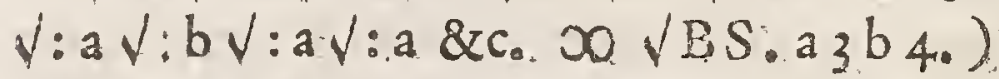

XXXII: Datis duobus numeris quibusvis per $q$, fi tertius quicunque ductu. in $\mathrm{q}$, addatur ipf $\mathrm{p} \mathrm{p}$, \& ex radice fumme fubtrabatur $\mathrm{p}$; of refidui radix in $\mathrm{q}$ : ducta addutur ipfi $\mathrm{pp}$, \&o ex radice jummo denuo fubtrabatur $\mathrm{p}$, \&o fic deinceps. jn infinitı $p+\sqrt{ }: p p+q \sqrt{ }: p+\& c_{0}$ radix equationis cubice $\times 3 x-2 p$ $x+q$

XXXI11., lisdem pofitis, que in precedente, fifubtradtio ipfius $\mathrm{p}$ vertatur in additionem, erit radix aggregati ultimi, puta $\sqrt{ }: p+\sqrt{ }: p p+q$.

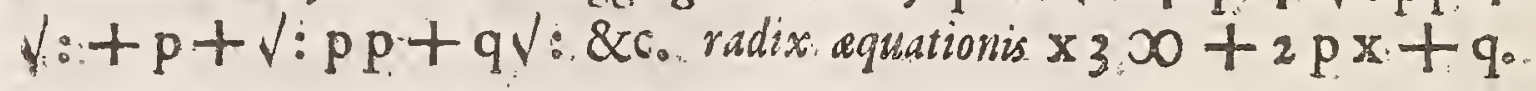

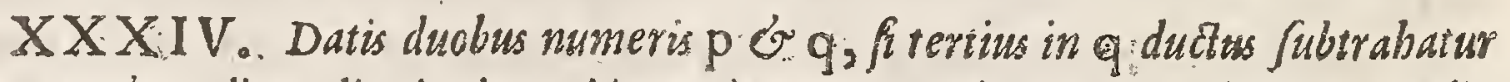

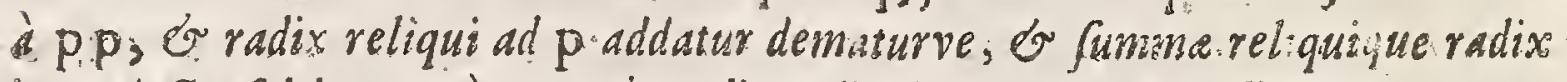
in $\mathrm{q}$ ducta fubducatur à $\mathrm{p} p$; of radix reliqui, \&cc. erunt radices fumme refiduique ultimi, putà $\sqrt{ }: p 8 \sqrt{ }: p \mathrm{p}-\mathrm{q} \sqrt{ }: \mathrm{p} 8 \sqrt{ }: \mathrm{p} p-\mathrm{q} \sqrt{ }: \& \mathrm{c}_{0}$ vadices equationis $\mathrm{x}, 30+2 \mathrm{px}-\mathrm{q}$. 


$$
\text { TNFTATTIS. } 267
$$

XXXV. Non fecus datis tribus numeris $p, q, r$, erit $\sqrt{ }:-p+\sqrt{ }:$

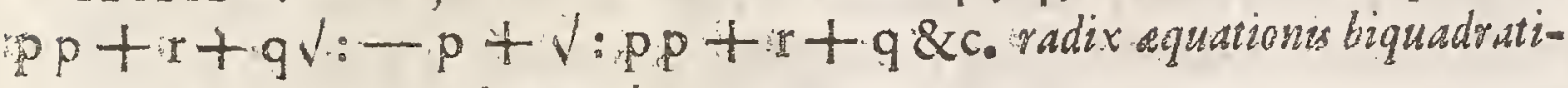
a $\mathrm{x} 4 \mathrm{x}-2 \mathrm{pxx}+\mathrm{q} \mathrm{x}+\mathrm{r}$.

Omnès hæe Propp. ad eundem modum demonftrantur, quo Propp. XXVII. XXVIII. \& XXIX. quorfum itaque roxкí\}

sibol. Patet hinc aditus ad inventionem 2. med. proport. \& v. Zef frospital in genere radicum Problematum folidorum \& hyperfolidorum per De 2 a Cons huchion folas rectas lineas \& circulos, quam praftantirrmi omnium feculo-bes Eqa lite's prop. rum Geometræ à bis mille retro annis anxiè fed fruftrà quáfivere. 12 . hag. 35 o oc. Hanc ego, quoad feri potuit, per feriem confruktonis in infinitum continuanda, prinus omnium exhibui in Adis Lipf. menf. Sepremb. 1689. cum nemo fimile quicquam fripto publicaflet, fortè nec animo concepillet ufpiam.

\section{De Ufu Serierum Infinitarum in Quadraturis Spatiorum \& Rectificationibus}

\section{Curvarum.}

Tostquam prima parte laboris noftri defuncti funus, variarumque quoad 1 fieri potuit, ferierum fummas exhibuimus, fupereft, ut ad alteram inftiauti partem tranfediwus, oftendindo modum eas applicandi ad dimenfiones quantitatum Geometricarum, preertim illarum, quas tranfcendentes num cupant, licet feriebus, que bic ufui venient, 'raro contingat effe ex numero earum, quas proxime contemplati fumus, quarumque fuminas in poteftate habemus. Obfervarunt enim Geometra, plutimas dari quantitates, cujusmodi funt plereque Line Curve, \& pleraque ab iis comprebenfa patia, qua nullis numeris vel rationalibus vel furdis quantumvis compofitis exprimi, $b$. $e$. quarum relationes ad alias datas fub nulla aquatione algebraica definiti gradus cogi poffent, fed qua umnes aquationum gradus quajt tranjcenderent; ac idcirco attentandum duxexunt, num quas uno aliquo numero effari non poterant, per feriem faltem infinitorum, maximè rationalium, exprimere liceret, quibus ita continuò ad quefitum accederetur, ut error tandem data quavis guantitate minor fieret, totaque feries èxactum quafiti valorem exhiberet. Anvenium, quod, quantsm conflat, vergente demus boc feculo à Mercatore, 
$268^{\circ} D E S E R I E B U S$

Gregorio, Newtono, Leibnitio, in lucem produclum fuit. Quid prina tres de bis memoria prodiderint, etiamnum ignorawns. Summus Geometr bo - Leibnitizus, qui rem basd dubie longiffinè provexit, inter alias feries, quas. - obis in Acitis Lipf. impertivit, unam initio ACior um 1682. pro Circuli magnituline dedit fed methodum, qua illuc pervenit, nersquam expofuit. Quantwres: conjicio, nồ differt jlla à nofra; nam of in easdem cum info feries incadio. mus os ipfius fubinde calculo differentiali ufi fumus, uti pofthac patebit. Prinsipis bujus calculi exponere nimis longum \& alienum forte. Ea Vir per. ills:firis D. Marcbio Hofpitalius in Libro de Analyf infinitè parvorum nuper.

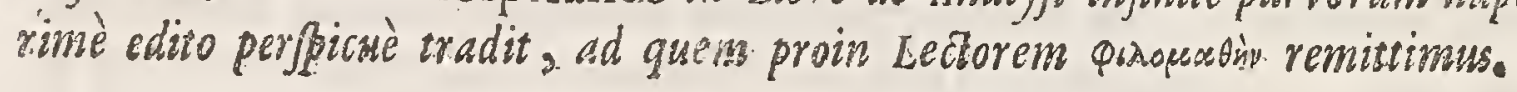

\section{Definitio :}

Ixtam Seriem voco, cujus termini multiplicatione funt conto 1 flati ex terminis ejusdem ordinis aliarum ferierum. fint feries $a, b, c, d, e, \& c_{0}$. \& $f, g, b, i, k, \& c_{0}$. mixta ex utraque erit af $, \lg _{2}, c h, d i, e k, \& c_{0}$.

\section{$\mathrm{XXXVI。}$}

Fractionem $\frac{1}{m-B}$ convertere in feriem infinitan quantitatum geometrice: proportionalium.

Fit hoc per divifionem continuam numeratoris per denominato. rem, hoc pacto: $m$ in $l$ habeo $\frac{l}{m}$, quod multiplicatum per divifo. rem $m-n$, \& fubtractum ex dividendo $I$ relinquit $\frac{i n}{m}$; hoc rurfus divifum per $m$ facit $\frac{l n}{m m}$, quod ductum in $m-n$ \& fubtractum ex: dividendi reliquo efficit refiduum $\frac{l n n}{m}$; hoc denuo divifum per $m$, facit $\frac{\ln n}{m^{3}}$, quo ducto in $m-n$ \& fubtracto remanet $\frac{\ln 3}{m^{3}}$, atque ita. deinceps fine fre in infinitum: femper enim aliquid dividendum fupereft, cum unius membri dividendus à divifore bimembri nunquam fine tefidio exhauriri poffit. At hoc refiduum, continuata operatione pofitnque $m>n$, perpetuo decrefcit, \& tandem data quนavis quantitate minus fit, ut patet. Eft ergo fractio propolita 
$\frac{l}{m-n} \infty \frac{l}{m}+\frac{l n}{m m}+\frac{\ln n}{m^{3}}+\frac{l n 3}{m^{4}}+\frac{\ln 4}{m^{5}} \& c_{\text {c. quæ fories eft quantita }}$ tum geometricè progredientium in ratione $m a d n$; quandoquidem quilibet ejus terminus ex conftructione in $n$ ductus $\&$ per $m$ divifus proximè fequentem exhibet.

Idem brevius fic evincitur: Summa Progrefionis Geometricæe $\frac{l}{m}+\frac{l n}{m m}+\frac{\ln n}{m 3}+\frac{\ln 3}{m 4}+\frac{\ln 4}{m 5} \& \varepsilon_{\text {e }}$ eft $\frac{l}{m-n}$, per Corollar. VIII. Ergo reciprocè valorem fractionis $\frac{l}{m-n}$ per talem feriem exprimere licet:

XXXVII. Fractionem $\frac{1}{\mathrm{~m}+\mathrm{n}}$ wejolvere in feriem infinitam geometricè proportionalium.

Facta divifione continua numeratoris per denominatorem, equ dem refultat feries, quæ anteà, nifị quod termini ejus alterna tim fiant politivi \& negativi. Eft igitur quartitas $\frac{l}{m+n} \infty$ $\frac{l}{m}-\frac{l n}{m m}+\frac{l n n}{m 3}-\frac{l n_{3}}{m 4}+\frac{\ln 4}{m_{2}} \& c_{\text {. }}$. faltem fi ponatur $m>n$ : tum enim quod poft fingulas divifiones reliquum manet, continuo minuitur, donec continuata in infinitum operatione prorfus evanefcat.

Idem quoque fic elucefcit: Quoniam in ferie quantitatum $\frac{l}{m}, \frac{\ln }{m m}, \frac{\ln n}{m^{3}}, \frac{\ln 3}{m_{4}}, \frac{\ln 4}{m_{5}} \& c_{\text {. }}$ ex hyp. primus terminus eft ad fecundum, ut tertius ad quartum, \& quintus ad fextum \& $\mathrm{c}$. nec non fecundus ad tertium, ut quartus ad quintum, \& fextus ad feptimum \&c. erit etiam ex æquo, primus ad tertium, ut tertius ad quintum, \& quintǔs ad feptimum \&c. quod docet, primum, ter-

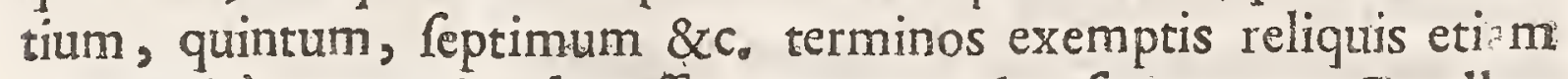
geometricè proportionales effe, quorum adeo fumma per Corollar.

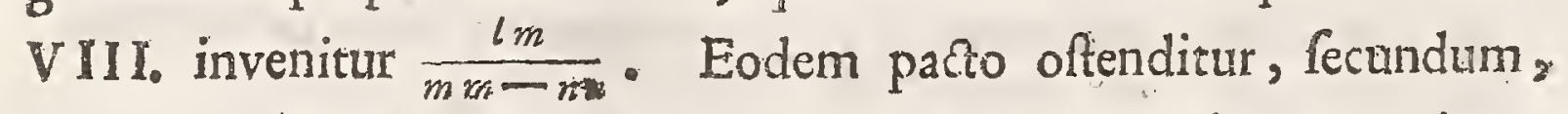
guartum, fextum \& $c_{0}$. terminos feriem geometrice proportionalium efficere, cujus fumma $\frac{l n}{m-n n}$. Igitur differentia harum 
duarum ferierum, feu $\frac{l}{m}-\frac{\ln }{m m}+\frac{\ln n}{m_{3}}-\frac{\ln 3}{m_{4}}+\frac{\ln 4}{m_{5}} \& c_{0} 30$ $\frac{l m-\ln }{m m-n n} \infty \frac{l}{m+n}$, ac propterea quantitas $\frac{l}{m+n}$ in iftam feriem vicifim converti potef.

Coroll. I. In omni Progreffione Geometrica defcendente (primo termino exiftente determinato, fignisque $+8 x$ - alternatim (e excipiencibus) fumma feriei limites habet, quos nequit attingere, nedum egredi, qualiscunque ftatuatur ratio progreffionis. Cum enim per hyp. $n>0, \&<m$, erit $\frac{l}{m+n}<\frac{l}{m+o}=\frac{l}{m} ; \&>\frac{l}{m+m}$ $=\frac{l}{2 m}$, hoc eft, valor feriei perpetuo minor eft ipfo primo termino, \& major ejus femiffe.

Coroll.2, Si tamen $m \infty n$, fiet $\frac{\ell}{m+n} \infty \frac{\ell}{2 m}, \&$ feries $\frac{l}{m}-$ $\frac{l n}{m m}+\frac{\ln n}{m_{3}}-\frac{\ln 3}{m \cdot 4} \& c_{0} \infty \frac{l}{m}-\frac{l}{m}+\frac{l}{m}-\frac{l}{m}$ \&rc. unde paradoxum. fluit non inelegans, quod $\frac{l}{m}-\frac{l}{m}+\frac{l}{m}-\frac{l}{m} \&$ rc. $\infty \frac{l}{2 m}$. Etenim fi ultimus feriei terminus figno - affectus concipiatur, termini omnes fe mutuò deftruere apparebunt, \& fi figno + , rquari videbnntur ipfi $\frac{l}{m}$, non $\frac{l}{2 m}$. Ratio autem paradoxi eft, quod con= tinuata divifione ipfius $l$ per $m+m$, refiduum divifionis non minuitur, fed perpetuo ipfl $l$ xquale manet; unde quociens divifionis propriè non eft fola feries $\frac{l}{m}-\frac{l}{m}+\frac{l}{m}-\frac{l}{m}$ \& c . fed $\frac{l}{m}-\frac{l}{m}+$ $\frac{t}{m}-\frac{l}{m} \& c_{\infty}+v e l-\frac{l}{2 m}$, faciendo fcil. fractionem ex refiduo \& divifore, illamque figno + vel - afficiendo, prout ultimus feriei serminus vicifim - vel + habere fingitur.

$\mathrm{XXXVIII.} \mathrm{Fractionem} \frac{1}{\square: \mathrm{m}-\mathrm{n}}$ transmutare in feriem infinitam. Quoniam quantitas $\frac{l}{m-n} \infty \frac{l}{m}+\frac{\ln }{m m}+\frac{\ln n}{m_{3}}+\frac{\ln 3}{m_{4}} \&$ c. per XXXVI. facta utrinque multiplicatione per $\frac{1}{m-n}$, habebitur $\frac{l}{\square: m-n} \infty$ feriei 


$$
I N I I N I I S_{0}
$$

feriei $A$, cujus termini finguli de novo in rotidem alias feries $B$, $C, D, E, F, Z c_{0}$. per eandem XXXVI, Prop. convertantur. Quo: faco. ferierum iftarum termini homologi in unam fummam

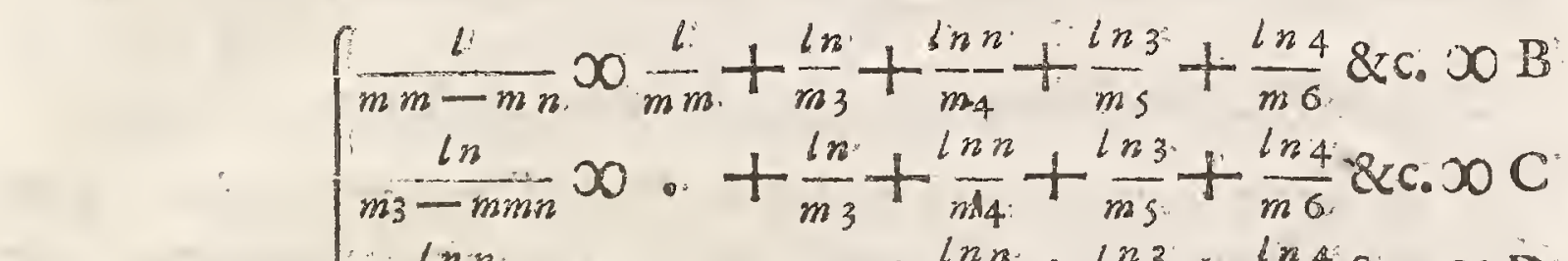

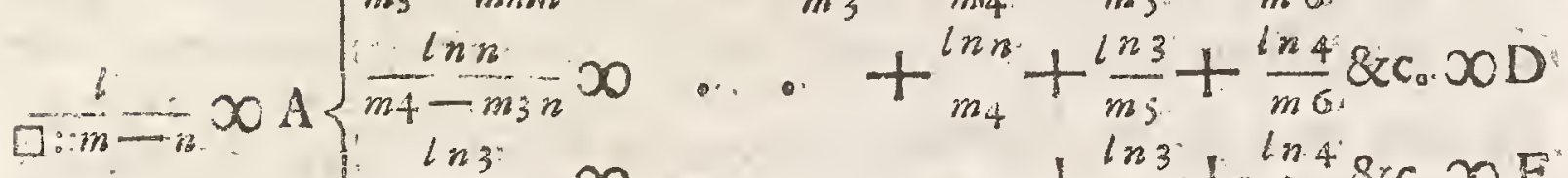

$$
\begin{aligned}
& \frac{\ln 3}{m 5-m_{4} n} \infty \ldots+\frac{\ln 3}{m_{5}}+\frac{\ln 4}{m 6} 8 x c_{0} \infty \mathrm{E}^{\prime} \\
& \frac{\ln 4}{m 6-m 5 n} \infty \ldots+\frac{\ln 4}{m 6} \& c_{0} \cdot x \mathrm{~F}
\end{aligned}
$$

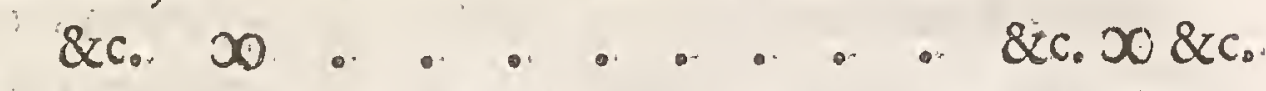

$$
\begin{aligned}
& z \quad \infty \frac{b}{m m}+\frac{2 \ln }{m_{3}}+\frac{\ln m}{m_{4}}+\frac{4 \ln 3}{m_{s}}+\frac{\sin 4}{m 6} \& c_{0} \infty 0 \frac{l}{0: m-n}
\end{aligned}
$$

conflati novam feriem $\mathcal{Z}$ conftituent, æqualem proptereă quantitati propofita $\frac{l}{\square: m-n}$, mixtamque ex ferie numerorum naturalium $\mathrm{I}_{\cdot} \cdot 2 \cdot 3 \cdot 4 \cdot 8 \mathrm{cc}_{0 .}$ \& quantitałum geometricé progrefionalium. $\frac{l}{m_{m}}, \frac{\ln }{m_{3}}, \frac{\ln n_{3}}{m_{4}}, \frac{\ln 3}{m_{5}} \& c_{0}$

Eadem feries $Z$ elici quoque poteft divifione continua nume. ratoris $l$ per denominatorem $m m-2 n n+n n$, dicendo: $m m$ in $l$, habeo $\frac{b}{m m}$, quod ductum in diviforem \& fubtractum ex dividendo relin quit $+\frac{2 l n}{m}-\frac{l n n}{m m} ;$ tum porrò $m m$ in $+\frac{2 l n}{m}$, reperio $+\frac{2 l n}{m}$, guod multiplicatum \& fubtractum, ut decet, refiduum efficit + $\frac{3 \ln n}{m m}-\frac{2 \ln 3}{m_{3}}$, atque ita ulterius pergendo in infinitum: quo pacto. obfervabitur, poft fingulas operationes duo membra reliqua mane-.. re, fed illa ufque \& ufque minora, tandemque dáta quavis quantitate propius ad nihilum vergentia.

Idem etiam oftenditur ex lege reciprocorum, refolvendo feriem: Z methodo Prop. XI V: in infinitas feries geometricas $B, C, D, E_{D}$. F \&c. harum enim: fumm cum novam progreffionem A conftituant; 


\section{2 \\ $D E S E R I E B U L S$}

tuant, quæ ipfa fummam efficit $\frac{1}{m m-2 m n+m n}$, fequitur reciprocê, $\&$ hanc quantitatem $\frac{1}{\square: m-n}$ per feriem $z$ legitimè efferri poffe. XXXIX. Fradionem $\frac{1}{\square: m+n}$ compertere in feriem.

Si operatio inftituatur methodo Propor. præced. eadem, qua ibi, obtinebitur feries, nifi quod termini locorum parium acquirant fignum -, fic ut habeatur: $\frac{l}{0: m+n} \infty \frac{l}{m m}-\frac{2 \ln }{m_{3}}+\frac{3 \ln n}{m_{4}}-$ $\frac{4 \ln 3}{m 5}+\frac{s \ln 4}{m 6}-\frac{6 \ln 5}{m_{7}} \& \mathrm{cc}$.

$\mathrm{XL}$. Fractionem $\frac{1}{\mathrm{c}: \mathrm{m}-\mathrm{n}}$, aut $\frac{1}{\mathrm{c}: \mathrm{m}+\mathrm{n}}$, exprimere per feriems

Ex analogia operationum præcedentium liquet modus hoc efficiendi; quorfum igitur plura? En operationem :

$\frac{l}{0: m-n} \infty \frac{l}{m m}+\frac{2 \ln }{m 3}+\frac{3 \ln n}{m 4}+\frac{4 \ln 3}{m s}+\frac{\sin 4}{m 6} \& c_{0}$ per XXXVIII, factaque hinc inde multiplicatione per $\frac{\mathrm{I}}{m-n}$,

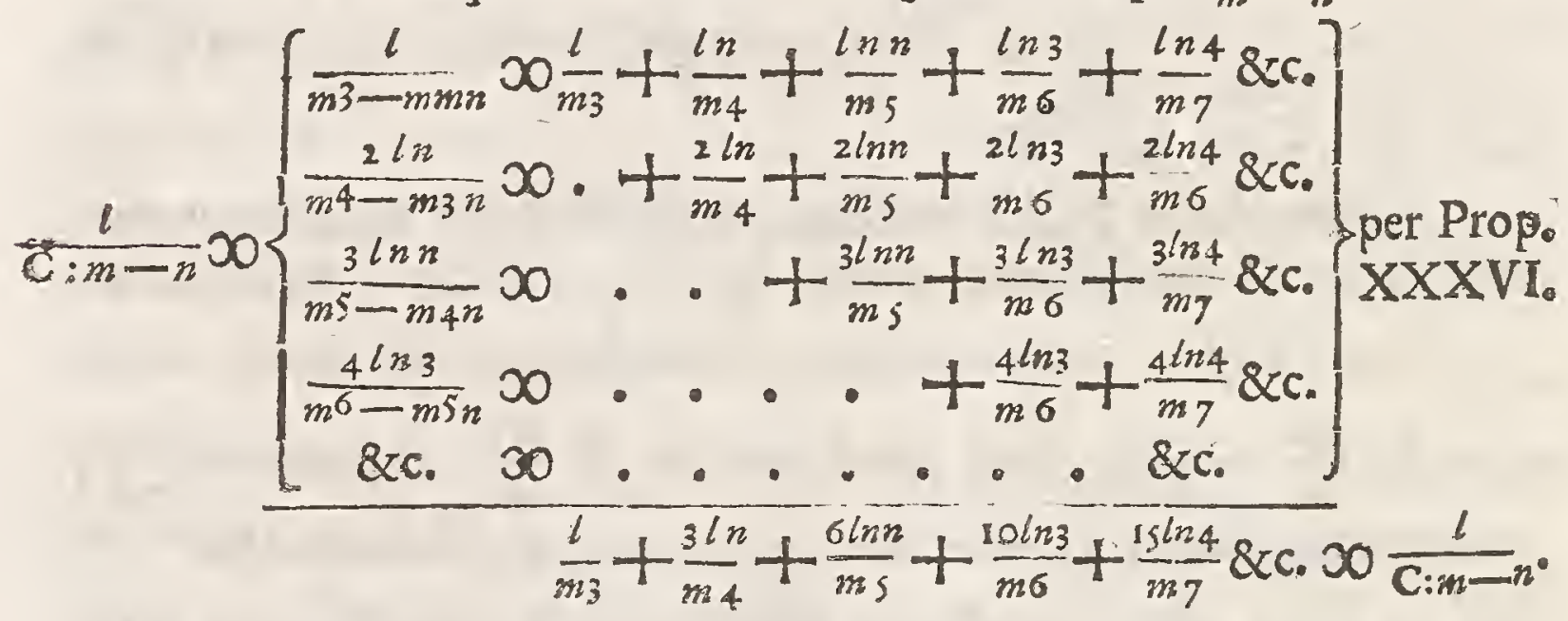

Eodem pacto habetur $\frac{1}{\mathrm{c}: m+n} \infty \frac{1}{m_{3}}-\frac{3 \ln n}{m_{4}}+\frac{6 \ln n}{m_{5}}-\frac{10 \ln n}{m 6}+$ $\frac{{ }_{3} \ln 4}{m 7} \& \mathrm{c}$.

Conflantur autem termini harum ferierum ex ductu terminorum

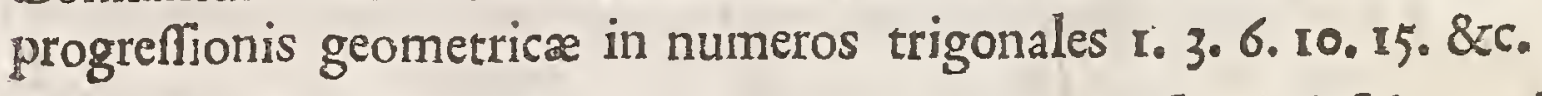

Si quis idem per divifionem continuam confequi defideret, is obfers 
obfervabit, poft fingulas operationes tria fupereffe membra, fed ea fubinde minora, ultimoque prorfus evanefcentia.

Idem etiam regrediendo à ferie inventâ patebit, fi illa methodo Prop.XIV. in alias refolvatur, \&re.

Scbol. Hacid difimili operatione teperitur $\frac{1}{\mathrm{C}: m_{8}} \infty \frac{l}{m_{4}} 8$

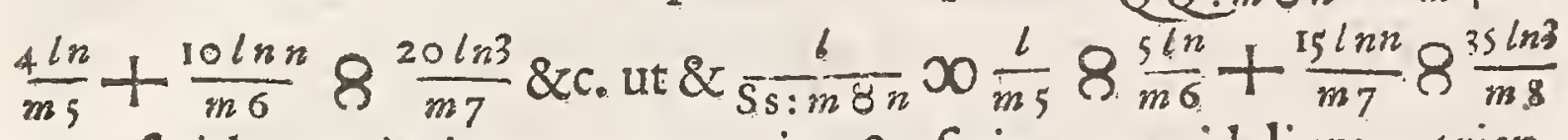
\&c. feriebus mixtis ex geometrica \& ferie pyramidalium, trianguli-pyramidalium, \& ita confequenter in omnibus altioribus, fervatâ femper eadem analogiæ ratione, ut non opus fit his diutius immorari。

XL I. si proponatur feries differentialitu, qua mixta fit ex ferie geometrica quantitatum indeterminatarum, \&o alia quavis ferie quantitatum conftantium feu coëfficientium, integralis corum abjaluta ferient confituent mixtam ex eadem ferie coëflicientium, finili geometrica indeterminataruin, on alia quadam harmonica.

Patet ex princ, calc, diff, vel fummatorii, juxta qua quantitatis differentialis $n x^{2} d x$ integrale abfolutum reperitur $\frac{n \cdot x+1}{m+1}$; hine enim fi coëfficientes $n$ fint progreflionis cujusvis, \& exponentes $n$ progreflionis arithmeticæ, $h_{0} e_{0}$ ipfa $x^{m}$ progr, geometrica, erunt quoque $m+1$ arithm, adeoque $x+r$ geometr. $\& \frac{1}{m+1}$ harmonice progreffionis. Ut fi proponatur feries differentialium $a x d x$, $b x^{3} d x, c x^{5} d x, f x^{7} d x$ \&c. mixta ex ferie quavis $a, b, c, f \& c$. \& geometrica $x d x, x^{3} d x, x^{5} d x, x^{7} d x$ \& . erunt eorum integralia $\frac{a \times x}{2}, \frac{b x_{4}}{4}, \frac{c \times 6}{6}, \frac{f \times 8}{8} \& x$. mixta ex eadem ferie $a, b, c, f \& c$. geometrica fimili $x x, x 4, x 6, x 8 \&$ cco $_{\text {, \& harmonica }} \frac{x}{2}, \frac{7}{4}, \frac{1}{6}, \frac{1}{8} \& \mathrm{cc}_{\text {. }}$ XLII. Exbibere aream Hyperbola inter Afymptotes per Seriens infinitam. Fig. I.

Mod. 1. Per Arithm. Infin. Wyall. Efto Hyperbola PCQ, cujus centrum A, afymptotæ AD, AS, applicata BC, IO (10), quærendumque fit fpatium C B IO (CB:0). Sumto autem A B 20 I 00 M m 
$\left.\mathrm{BD}, \mathrm{B} C x b, \mathrm{BI}\left(\mathrm{B}^{\prime}\right)\right) x$, qux non fit $>\mathrm{AB}$ vel $\mathrm{BD}, \mathrm{h}_{e} e_{0}$ unitate. Dividatur $B I\left(\mathrm{~B}^{\prime}\right)$ in partes aliquot æquales $B E, E F$, $F \mathrm{G}, \mathrm{GR}, \mathrm{R} I(\mathrm{~B} \varepsilon, \varepsilon \phi, \phi \gamma, \gamma \rho, \rho)$ quarum numerus fit $n, \&$ fingulæ dicantur $d$, fic ut $n d$ fit $\bigcirc \times \times \mathrm{BI}\left(\mathrm{B}^{6}\right)$. Tum circumfor bantur (infcribantur) hyperbolæ parallelogramma $B K, E L, F M$ 。 $\mathrm{GN}, \mathrm{RO}(\mathrm{B} x, \varepsilon \lambda, \phi \mu, \gamma v, \gamma)$ duktis applicatis $\mathrm{EK}, \mathrm{FL}, \mathrm{GM}$, $\mathrm{RN}, \mathrm{HO}\left(s x, \varphi \lambda, \gamma \mu, \xi^{y}, b\right)$ quæ ex natura hyperb. ordine repe-

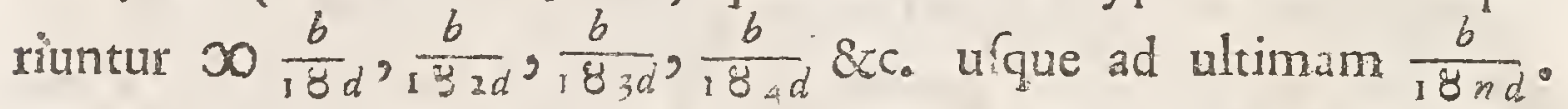
Singulis igitur in $d$ duktis, habentur arex parallelogrammorum, quxe porro in feries convertendæ funt per XXXVI。 \& XXXVII, ut le.. quitur:

$\mathrm{BK}(\mathrm{B} *) \approx \frac{b d}{38 d} \infty 0 b d 8 b d d+b d_{3} 8 \quad b d_{4}+b d s 8 \quad 6 d 6 \& c_{0}$ $\operatorname{EL}(\varepsilon \lambda) \infty \frac{b d}{182 d} \infty b d 82 b d d+4 b d 38 \quad 8 b d_{4}+16 b d 58 \quad 32 b d 68 x c_{0}$ $\operatorname{FM}(\varphi \mu) \infty \frac{b d}{188_{3}} \infty 0 b d 83 i d d+9 b d 3827 b d 4+81 b d 58243 b d 6 \& c_{0}$ $\mathrm{GN}\left(\mu_{\nu}\right) \infty \frac{6 d}{184 d} \infty 0 b d 84 b d d+16 b d 3864 b d 4+256 b d 581024 d d 6 \& c_{0}$

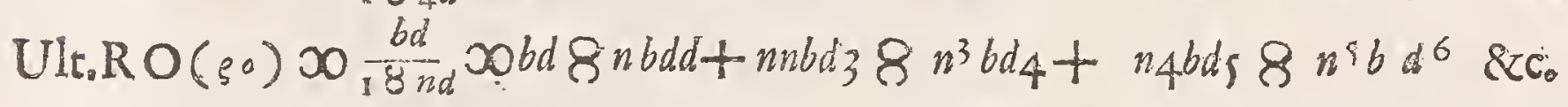

Harum ferierum primi termini æquantur, fecundi progrediuntur ut numeri naturales, tertii ut corundem quadrata, quarti ut cubi, \&xc. hine pofito numero ferierum feu parallelogrammorum $n$ infinito (quo quidem cafu fumma parall-orum feu infcript. feu circumfcriptorum ab iplo curvilineo $C B I O$ vel $C B$ : o non differt ) fum ma terminorum primæ feriei perpendicularis erit æaualis, terminorum fecundre dimidia, tertiæ fubtripla \&c. fummæ totidem, hoc eft, $n$ terminorum ultimo æqualium, per ea, quæ docet Wallifius in Arithm. Infinit. nosque demontrabinus alibi : ac propterè fumma omnium ferierum perpendicularium, i. e. omnium pas rallelogrammorum, feu area fpatii hyperbolici $\mathrm{CBIO}(\mathrm{CB} \bullet \mathrm{o})$ hac Terie expimetur:

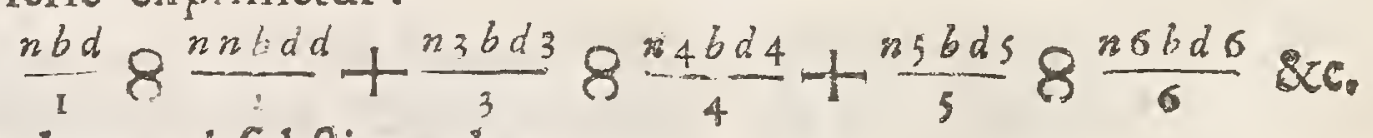

five, loco $n d$ fubftituendo $x$, 


$$
\begin{gathered}
\text { INFINITIS } \\
\frac{8 x}{8}+\frac{b \times x^{2}}{3} 8 \frac{b \times 3}{4}+\frac{b \times 4}{5} 8 \frac{b \times 6}{6} \& x
\end{gathered}
$$

Mod. 2. Per calc diff. Leibn. Poficis, ut prius, A B 0 I 00 BD, $B C \infty b, \& B I(B b) \rightsquigarrow x$, ejusque elemento $\mathrm{R} I(\rho) \infty 0 d x$, erit ex natura hyperbole $\mathbb{I O}(6) \infty \frac{b}{18 x^{2}}$ \& elementum fpatii hyperbolici RO ( $\left.\rho^{\circ}\right) \infty \frac{b d x}{18 x} x$ feriei geometric $b d x 8 b \approx i x+b x x$ $d x 86 x^{3} d x+6 x^{4} d x$ \&ce. per XXXVI. \& XXXVII ; adeoque fumma elemcntorum $S \frac{b d x}{18 x}$, five fparium CBIO (CB.0) $006 x 8$

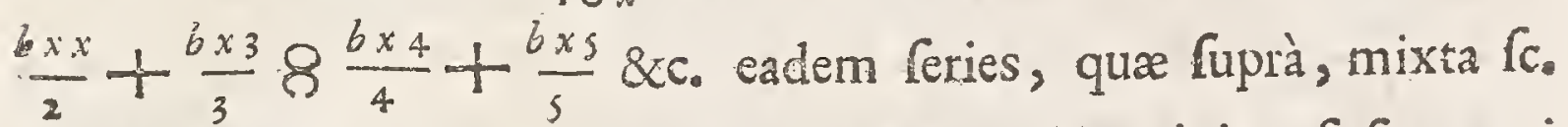
${ }^{2}{ }^{2}$ geometrica $\&$ harmonica, per præed. Hæc igitur fi fummari poffet, daretur Hyperbola quadratura.

coroll. 1. Si BI $\bigcirc$ B', dabitur: tum fummatum differentia fpatiorum $\mathrm{CB}$ B \& $\mathrm{CB}$ ، p per Leriem ex geom. \& harm. mixtam: cum enim fit ofenfum

$\mathrm{CBIO} 006 x+\frac{b \times x}{2}+\frac{b \times 3}{3}+\frac{b x_{4}}{4}+\frac{b \times 5}{5}+\frac{b \times 6}{6} \& c_{0}^{\prime}$ fiet facta ferierum $\mathrm{CB} \cdot 0 x b x-\frac{b x x}{2}+\frac{b \times 3}{3}-\frac{b \times 4}{4}+\frac{b x 5}{5}-\frac{b \times 6}{6} 8 x_{0}$ additione

$\mathrm{CBIO}+\mathrm{CB} \cdot 0 \mathrm{OO} \frac{26 x}{1}+\frac{2 b \times 3}{3}+\frac{2 b \times 5}{5} \& \mathrm{C}$ $\mathrm{CBIO}-\mathrm{CB} \cdot 0 \times \frac{26 \times x}{2}+\frac{26 \times 4}{4}+\frac{26 \times 6}{6} \& \mathrm{C}_{0}$

Coroll 2 . Pofita BI, $x x^{-} \mathrm{BA}$, I, fit fpatium interminatum hyperbolicum PCBAS $x \frac{6}{1}+\frac{6}{2}+\frac{6}{3}+\frac{b}{4}+\frac{b}{5}+\frac{6}{6} 8 x c$. fimplici feriei harmonice, qua cum infinita fit per XVI, arguit \& aream hujus fpatii talem effe. Conf. Cor. 4. ejusd. Prop.

cor.3. Sin $8 \mathrm{~B}^{6}, x, \infty \mathrm{BD}, \mathrm{I} \infty \mathrm{BC}, 6$, refultat pro fpatio CBDQ feries harmonica $\frac{x}{1}-\frac{1}{2}+\frac{1}{3}-\frac{1}{4}+\frac{1}{5}-\frac{x}{\sigma} \& c$. hoc eft, fubducendo unumquemque terminum figno - affectum à præcedenti, feries $\frac{\pi}{2}+\frac{1}{12}+\frac{1}{30}+\frac{1}{56}$ \&c. cujus termini per faltum excerpti funt ex Erie reciproca trigonalium Q Prop. $X V, \frac{x}{2}+\frac{1}{6}+\frac{1}{12}+\frac{1}{20}+\frac{3}{30} \& c$. Mm 2

Quòd 
Quòd fi ftatuatur $\square \mathrm{AB}, \mathrm{BC}$ vel $\mathrm{BD}$ quadruplo minus, np. $\frac{\bar{z}}{4}$, exhibebitur etiam fpatium CBDQ per feriem prioris fubquadru plam $\frac{\pi}{8}+\frac{i}{48}+\frac{1}{120}$ \&c. quæ per faltum formatur ex ferie I Propol. XVII. Conf. Aa. Lipr. 1682. p. 46.

XLIII. Invenire aream .jpatii A BEFS ( $B D \phi)$ comprebenf Afymptotr. byperbole $A D$, Curva $B E F(\approx \phi)$, que talis, ut $\square$ fub ejus applicat a IE ( $\varepsilon$ ) o recta conjlante $A B, B C$ vel $B D$ (qua fit I) equetur patio by: perbolico $C B Y O\left(C B 60^{\circ}\right)$. Fig. 2 .

Quoniam, pofitá BI $00 x$, fpatium hyperbolicum C BIO $x x$ + $\frac{x x}{2}+\frac{x 3}{3}+\frac{x 4}{4}+\frac{x 5}{5} \&$ c. per præced. eadem quoque feries denotabir (ob A B vel BC $\infty$ I) longitudinem applicatæ IE, quæ propte. reà ducta in IR feu $d x$ producit $x d x+\frac{x_{x d} d x}{2}+\frac{x_{3} d x}{3}+\frac{x_{4} d x}{4}+\frac{x_{5} d x}{3}$ \&c. $\infty \mathrm{RE}$, elem. fpatii BIE. Hujus feriei terminos fummando fit fpatium BIE $\infty \frac{x x}{2}+\frac{x_{3}}{6}+\frac{x_{4}}{12}+\frac{x_{5}}{20}+\frac{x^{6}}{30} \&$ c. feriei mixtæ ex geometrica \& reciproca trigonalium, que pofito infuper $\mathrm{B} I, x>0$ $B A, I$, mutatur in fimplicem trigonalium reciprocam $\frac{x}{2}+\frac{x}{\sigma}+$. $\frac{1}{12}+\frac{i}{20}+\frac{7}{30} \& c_{0}$ c cujus fumma 50 , per $X V_{0}$. Ef igirur totum fpatium ABEFS abfolute quadrabile, æiquale quippe $\square^{\text {to }} \mathrm{AB}$. Nota hîc exemplüm Curvæ mechanicæ; ubi quadratura Ipecialis fuccedit absque generali; fimplicis enim feriei fummam dedimus, mixtæ non item.

Eadem ratione oftendetur ex altero latere fpatium $\mathrm{B}$ is $\infty \frac{x x}{2}-$

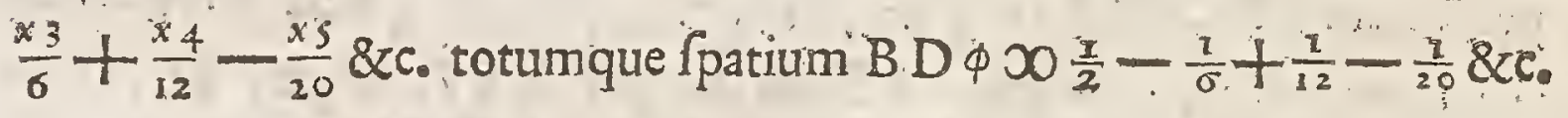

Coroll. Completis rectangulis $C D \& B Q$, ajo fore curvilineum mechanicum $\mathrm{BD} \varphi$ Do duplo curvilineo hyperbolico $\mathrm{CQL}$, differentiam curvilineorum $A B E F S \& B D Q \infty$ duplo fpatio $C Q H$, \& fummam eorundem $\mathrm{x}_{2} \mathrm{CBDQ}$; quæ fic palàm funt: Si a ferie $\frac{1}{x}-\frac{x}{2}+\frac{7}{3}-\frac{1}{4}+\frac{1}{5}-\frac{1}{5} \&$ c. fubducatur $\frac{x}{2}-\frac{1}{3}+\frac{1}{4}-\frac{1}{5}+$ $\frac{1}{3}-\frac{1}{7} \& \mathrm{c}$. auferendo figillatim primum terminum à primo, $\mathrm{re}$ cundum à fecundo, tertium a tertio, \&ce relinquetur $\frac{x}{2}-\frac{1}{1}+$ 


$$
\text { INFINITIS. }
$$

$\frac{\pi}{12}-\frac{1}{20}+\frac{1}{30}-\frac{l}{42} \& c$. $\infty$ fpatio $\mathrm{BD} \varphi$, ut oftenfum. Si vero eaw dem feries ex altera fic tollatur, ut primus ejus terminus dematur ex fecundo alterius, fecundus ex tertio, tertius ex quarto \& $\mathrm{cc}_{\text {. orie- }}$ tur $\frac{1}{1}-\frac{2}{2}+\frac{2}{3}-\frac{2}{4}+\frac{2}{5}-\frac{2}{5} \&$ c. $\infty \frac{2}{3}-\frac{2}{2}+\frac{2}{3}-\frac{2}{4} \&$ c c. $-1 \infty 0$ (per preced.) duplo. fpat. hyperb. $\mathrm{CBDQ}-\mathrm{BH} \mathrm{X}_{2} \mathrm{CBDO}$ $-2 \mathrm{DL} \mathrm{O}_{2} \mathrm{CLQ}$. Ergo $\mathrm{BD} \phi \mathrm{O}_{2} \mathrm{CLQ}$. Igitur cum oftenfum etiam fit $\mathrm{ABEFS} \infty \mathrm{O}_{1} \infty \mathrm{BH} \mathrm{O}_{2} \mathrm{DL} \mathrm{O}_{2} \mathrm{LH}$, erit $\mathrm{ABEFS}$ $\mathrm{BD} \varphi \mathrm{O}_{2} \mathrm{LH}-2 \mathrm{CLQ} \mathrm{O}_{2} \mathrm{CQH}$; nec non $\mathrm{ABEFS}+\mathrm{BD} \bar{\phi}$ $5 \mathrm{O}_{2} \mathrm{DL}+2 \mathrm{CLQ} \mathrm{O}_{2} \mathrm{CBDQ}$ Quæerant demonitr.

XLIV. Invenire aream 3 pativ $A B K G M T(B D N \gamma \mathrm{K})$ comprehenfi afymptota hyperbole $A D$ \& \& Curva K $G M \cdot(K y N)$, que talis, ut $\square B I G$ $(B, y)$ fub ejus applicata I $G(b y)$ \&o indeterminata $B I(B b)$, squetur $: p a=$ tio byperbolico $C B \leq O$ (CB:8). Fig. 20

Quia pofitis omnibus, ut prius, fpatium hyperb. CB IO $\infty x+$ $\frac{x x}{2}+\frac{x_{3}}{3}+\frac{x_{4}}{4}+\frac{x 5}{5} \&$ c. per XLII, erit per hyp. facta divifione per B I feu $x$, recta IG $\infty$ I $+\frac{x}{2}+\frac{x x}{3}+\frac{x-3}{4}+\frac{x 4}{5} \& x$. adeoque $\mathrm{R} \mathrm{G}$ elem. fpat. BIGK $D d x+\frac{x d x}{2}+\frac{x x d x}{3}+\frac{x 3 d x}{4} \& x$. omniaq; R G feu fpatium BIGKDO $\frac{x}{1}+\frac{x x}{4}+\frac{x 3}{9}+\frac{x 4}{16}+\frac{x 5}{25} \& c_{0} \&$ polita $x 90 \mathrm{r}$, fpatium totale A B K GMT $00 \frac{7}{7}+\frac{1}{4}+\frac{i}{9}+\frac{7}{16}+\frac{2}{25}$ \&c. feriei rom ciprocæ quadratorum, cujus fummam etiamnum defideramus. Conf. Prop. XVII. fub fin.

Haud diffimili modo reperitur ex altera parte fpatium $\mathrm{B}, 2 \mathrm{~K} \infty$ $\frac{x}{1}-\frac{x x}{4}+\frac{x_{3}}{9}-\frac{x 4}{16}+\frac{x 5}{25} \& c$. fumtaque $x x_{1}$, totale fpatium BD Ny, \& \& $\frac{7}{1}-\frac{x}{4}+\frac{7}{9}-\frac{7}{16}+\frac{7}{25} \& x$.

Corol. Spatium ABKGMT duplum eft Patii BDN2K; cum enim fumma utriusque fit $\frac{2}{1}+\frac{2}{9}+\frac{2}{25} 8 \mathrm{cc}$. 8 differentia $\frac{2}{4}+\frac{2}{16}+\frac{2}{36}$

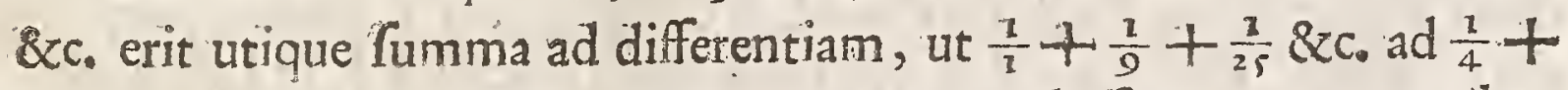
$\frac{1}{36}+\frac{\tau}{36}$ \&c. ho e. ut 3 ad I, per XXIV; unde fpatium unum alterius duplum effe neceffe eft, ut maximè neutrius abfolutam magnistuditiem exploratam habeamus. Vid. Schol, ibid.

$\mathrm{Mm} 3$

XLW 
$\mathrm{XLV}$. Exbibere Quadraturam circuli aut Reclificationem Linea Circu laris per feriem. Fig. 3 .

In peripheria femicirculi $B C D$, fumto indefinitè puncto $H$, demittatur ex illo in radium $A B$ perpendicularis $\mathrm{HE}$; \& fit $\mathrm{AB}$ $\infty \mathrm{I}, \& \mathrm{BE} \infty \infty x$, adeoque ex nat. circ. $\mathrm{EH} \infty \sqrt{2 x-x x}$ : quo pofito, cum ob fimil. Triangul. characteriftici L GH \& Triangul. $H E A$, $H E$ fit ad $H A$, ficut $L G$ vel $E F$ elem. abfciff $B E$, ad $\mathrm{L} H$ elem, arcus circ. $\mathrm{BH}$, reperitur $\mathrm{LH} ⿻ \frac{d x}{\sqrt{2 x-x x}}$, factaque multiplicatione per $\frac{x}{2}$, femiffem radii $\mathrm{AH}$, fector $\mathrm{HAL}$ feu elem. fectoris HAB $\infty \frac{d x}{2 \sqrt{2 x-x x}}$. Hæc igitur quantitas, cum abfolutè fummari nequeat, in feriem convertenda eft, fed prius tollenda irrationalitas, quiod eo ferè modo fit, quo in Problematis Diophanteis uti vulgo fueverunt. In hunc finem pono $\sqrt{2 x-x x}$ $\infty \frac{x}{t}$, feu $2 x-x x \infty \frac{x x}{t t}$, ubi quia divifio feri poteft per $x$, ipfaque non nifi unius dimenfionis in æquatione relinquitur, ejus valor in rationalibus prodibit, unde $\& d x, \&$ per hypoth. $\sqrt{2 x-x x}$ feu $\frac{x}{t}$, iplaque adeo fractio $\frac{d x}{2 \sqrt{2 x-x_{x}}}$, rationales fient; nempe $x>0$ $\frac{2 t t}{1+t t}, d x \infty \frac{4 t d t}{\square: 1+t t}, \sqrt{2 x-x x} \infty \frac{x}{t} \infty \frac{2 t}{1+t t}, \&$ denig; $\frac{d x}{2 \sqrt{2 x-x x}}$ $\infty \frac{d t}{1+t t}$; hinc fractio in feriem geometricam per XXXVII converfa exhibet $d t-t t d t+t^{4} d t-t^{6} d t+t^{8} d t \& 2$. Summa igitur elementorum $\mathrm{HAL}$, feu totus fector $\mathrm{HAB} \infty \mathrm{t}-\frac{13}{3}+\frac{t 5}{5}-$ $\frac{t 7}{7}+\frac{t 9}{9} \& c_{0}$ e eoque per femifem radii $\frac{x}{2}$ divifo, arcus $\mathrm{BH} \infty$ $\frac{2 t}{3}-\frac{2 t 3}{3}+\frac{2 t 5}{5}-\frac{2 t 7}{7}+\frac{2 t 9}{9}-\frac{2 t \pi}{11} \& c_{0}$ quxe feries mixtæ funt ex geometrica \& harmonica, per XLI, à quarum proin fummatione decantatum illud de Circuli Tetragonismo Problema dependet. Nota, ductis ex B \& $\mathrm{H}$ tangentibus circuli B I, HI, fibi mutwo occurrentibus in 1 , junctaque $H D$, qua radium $A C$ fecet in $K$, fore $B I$ vel $I H \infty D A$, utramlibet autem $\infty$ t. Nam 2. ang. $B A I \infty \mathrm{BAH} \infty \mathrm{AHD}+\mathrm{ADH} \infty 2 \mathrm{ADH}$. Ergo BAI $\infty$ ADH 
$A \mathrm{DH}$; cumque \& ABI \& DAK anguli, nec non latera $\mathrm{A} \mid \mathrm{B} \&$ $\mathrm{AD}$ æquentur, erit quoque $\mathrm{BI} \nsim \mathrm{AK}$. Deinde cum fit per hypoth. I ad $t$, ut $\sqrt{2 x-x} x$ ad $x$; itemque, ob fim. $\triangle D A K$ \& $D E H, A D$ feu $I$ ad $A K$, ficut $D E$ ad $E H$, hoc eft, ex nat. circul. $H E$ ad $E B$, feu $\sqrt{2 x-x x}$ ad $x$; erit utique 1 . $t:: 1$ 。 $A K$, ac proinde AK feu BI $\infty 0 t$.

Coroll. $I_{+}$Sumta $t \infty 0 \mathrm{I}$, quo cafu $\& \mathrm{~B} \mathrm{E}, x \mathrm{feu}_{1+t t}^{2 t t}$, xquatur B A, $I$, fiet quadrans B A C $x$ fimplici feriei harmonica $1-\frac{1}{3}+\frac{1}{5}-$ $\frac{1}{7}+\frac{1}{9}-\frac{1}{11} \&$ c. $x$ (fubducto reapfe unoguoque termino figno - affecto à precedente) $\frac{2}{3}+\frac{2}{3.5}+\frac{2}{99} \& c$. Hinc quia quadra tum radii eft ad quadrantem circuli, ficut quadratum diametri ad totum circulum, fequitur fi quadratum diametri, h. e. quadratum circulo circumfcriptum fit $I$, ac proin eidem infcriptum $\frac{x}{2}$, totius circuli aream per modo memoratam feriem expreffum iri; adeoque fi quadratum circulo infcriptum fit $\frac{1}{4}$, circuli aream fore $\frac{1}{3}+$ $\frac{7}{39}+\frac{1}{93} \&$ c. cujus feriei termini per faltum excerpti funt ex ferie H Prop. XVII. Conf. Att. Lipf, 1682. p. 45.

Coroll. 2, Pofita Tangente BI $x t$, erit arcus, cujus tangens eft; $\infty \frac{t}{\mathrm{~T}}-\frac{t_{3}}{3}+\frac{t_{5}}{5}-\frac{t_{7}}{7} \& \mathrm{x}$. utpote femifis arcus BH. Confer Ad? Lipf, 1691. pag. 179.

X L V I. Exhibere generaliter Sectorem cuinsvis Sectionis Conice ex centro per feriem. Fig. 4. \& 5 .

Efto Coni Sectio quxcunque, Hyperbola five Ellipfis, $B \mathrm{CD}$, cujus centrum $A$, vertex $B$, femi-latus transverfum $A B \infty 0$ a, femiaxis conjugatus $\mathrm{AL} \infty \mathrm{I}$, adeoque femi-1 tus rectum $\infty \frac{1}{a}, \&$ ratio laterum, ut $a A$ ad 1 . Ponanturque porrò, abfeiffa indeterminata B G $x$ x , A G 00 < 00 a $8 \times$ ( 8 fignificat + in Hyperbol. $\&$ - in Ellip. uti $\prec$ viciflim - in Hyp. \& + in Ell. )ejusque elementum FG vel CH $x d x>8 d z$, ordinata $G D x y$, ejus elementum DH $\infty d y, \&$ jungens $D$ cum centro recta $A D x u \infty$ $\sqrt{z z+y y}$. Duata etiam intelligatur HCI parallela axi, fecans- 
que curvam in $C$ \& rectam $A D$ in $I$, atque ex $C$ demiffa concipida tur in AD perpendicularis CE. Quibus pofitis, erit primo ex nat. Curv. $a a_{0}$ I $:: 8 z z 8 a a(2 a x 8 x x), y y$; unde fit a ayy $\infty$ \& zz 8 a $(2 a x 8 x x)_{2}$ \& differentiando a aydy $\infty 8 z d z_{2}$ $\&$ denique $d y$ $\infty \frac{8 z d z}{a a y} \infty \frac{z d x}{a a y}$. Deinde quoniam, ob fim. $\triangle$ $D G A \& D H I, D G$, $y$ eft ad $G A, z$, ficut $D H, d y$, ad $\mathrm{HI}_{z}$ invenitur H I $>\frac{z d y}{y}$, ac proinde CI ( H I \& HC) $x_{\frac{z d y}{y}}^{z d y}-d z \infty$ a dy $-y d z$. Quare denuò propter $\triangle$ fim. AGD \&IEC, ut $A D_{2}$ $u$, ad $\mathrm{DG}, y$, fic IC, $\frac{z d y-y d z}{y}$, ad $\mathrm{CE}$; unde reperitur CE $\infty$ $\frac{z d y-y d z}{z}$, qux ducta in femiffem $\mathrm{AD}$, feu $\frac{\pi}{2} u_{2}$ dat aream triangus li elementaris $A C D \infty \frac{z d y-y d z}{2} \infty$ (pofito loco $d y$ valore ejus) $\frac{8 z z d z}{2 a a y}-\frac{y d z}{2} \infty \frac{8 z z d z-\alpha a y y d z}{2 a a y} \infty$ (fubltituendo $8 z z 8 a$ loco a a yy) $\frac{8 z z d z 8 z z d z 8 a a d z}{2 a a y} \infty \frac{8 a d x}{2 a y} \infty \frac{a d x}{2 a y} \infty$ (loco ay) furrogando $\sqrt{2 a x 8 \times x)} \frac{a d x}{2 \sqrt{2 a x 8 \times x}}$, de qua in feriem conver= tenda \& fummanda agitur. Primò autem irrationalitas ex illa tollenda, mediante alia indeterminata, quæ loco $x$ furrogari de-

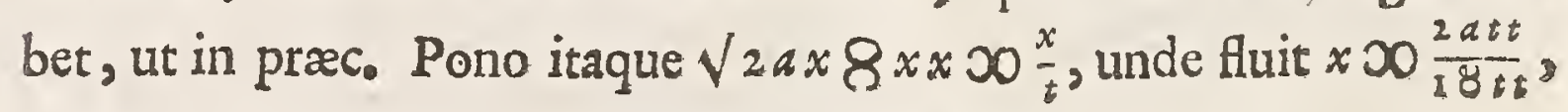
$\& d x \infty_{\square: 18 t}^{4 a t d t}, \& \sqrt{2 a x 8 x x} \infty \frac{x}{t} \infty \frac{2 a t}{18 t}, \&$ denique $\frac{a d x}{2 \sqrt{2 a x 8 x x}}$ $\infty \frac{a d t}{18 t t} \infty$ feriei geom. adt $8 \cdot a t t d t+a t^{4} d t 8 a t^{6} d t+a t^{8} d t$ \&c. per XXXVI \& XXXVII. Summa igitur omnium fectorum elementarium ACD, i. e. area totius Sectoris ABCD so at 8 $\frac{a t 3}{3}+\frac{a t s}{5} 8 \frac{a t 7}{7}+\frac{a t 9}{9} \& c_{0} \square$ fil. comprehenfo fub a femi-latere transverfo \& recta, cujus longitudo eft $t 8 \frac{t 3}{3}+\frac{t 5}{5} 8 \frac{t 7}{7}+\frac{t 9}{9}$ \&xc. Unde patet, quo pakto generaliter quadraturæ fectionum Conicarum ad fummas. ferierum ex geomet, \& harmon. mixtarum reducantur. 
Nota, ductis per verticem $B$ \& punctum Curvæ $D$ tangentibus $B M, D T$, fibi mutuo occurrentibus in $M$, dico fore $B M \infty 0$. Quoniam enim A G. AB : : A B. A T, per 37. lib. 1. Apoll. ac idcircò convertendo $A B . T B:: A G, z, G B, x$; nec non (ob fim. $\triangle \mathrm{TBM} \& \mathrm{CHD}) \mathrm{TB}, \mathrm{BM}:: \mathrm{CH}, d x . \mathrm{HD}, d y::$ (ex æquat. Curvæ different, ) a ay. $z$; erit ex sequo perturbatè $\mathrm{AB}, a . \mathrm{BM}:$ : a a $y . x$; unde obtinetur $\mathrm{B} M \infty \frac{x}{a y} \infty \frac{x}{\sqrt{2 a x x_{i} x}}$; adeoque $\sqrt{2 a x 8 x x} \cdot x:$ I,$B M$ : verum per conftrutionem. $\sqrt{2 a x 8 x x} \cdot x::$ 1 $t$. Ergò omnino $B M 50 t$. Confo Aat. Lip?. 1691. p. 179.

XLVII. Dato Numero invenire Logarithmum per Jeriem. Fig.6.

Intelligatur fuper axe $S \mathrm{~A} \sigma$ Curva quadam $\mathrm{CB}$, ejus nature ræ, ut abfciffæ AR, AS ( $A \rho, A \sigma$ ) crefcant arithmetice, dum applicatæ RE, SC $(\rho \varepsilon, \sigma x)$ crefcunt vel decrefcunt geometricè, h. $e_{\text {. }}$ ut iftæ fint ut Numeri, dum illæ funt ut Logarithmi. Vocabitur hæc Curva Logaritbmica, cujus hæc eft propriecas, oftendente Acut. Leibnitio in Act. Lipf. 1684. p. 473."ut Subtangentes ejus omnes $A K, R N$, $\varrho$, fint æquales. Applicetur in $A$ reeta $A B, \&$ fumto quovis in curva puncto $\mathrm{E}\left({ }^{\varepsilon}\right)$ ducatur recta $\mathrm{EI}\left(\varepsilon_{\imath}\right)$ parallela axi $S A$; voceturque $A B I, B I\left(B^{\circ}\right) x$; adeoque $A I$ ( $A^{\circ}$ ) feu $R E$ $(\rho \varepsilon) 18 x ;$ nec non $A R(A \rho) y$, \& conftans curva fubtangens b. Dato itaque numero RE $(\rho \varepsilon)$ ejus Logarithmus A R (A $\rho)$ fic invenitur. Quoniam ex nat. gen. curvarum, elementum applicatæ EF $(s \phi) d x$, eft ad elementum abfciffre FG $(\phi \gamma) d y$, ficut applicata $\operatorname{RE}\left(\rho^{\varepsilon}\right)$ I $8 x$, ad curvæ fubtaugentem $\mathrm{RN}\left(\rho^{\nu}\right) b$, habebitur $d y \infty \frac{6 d x}{18 x} \infty$ fractione in feriem refoluta per XXXVI \& XXXVII ) $b d x 8 b x d x+b x x d x 8 b x^{3} d x+b x^{4} d x 8 b x^{5} d x$ \&c. ideoque facta fummatione, $y$, hoc eft, $\mathrm{AR}(\mathrm{A} \rho) \infty 06 \times 8$ $\frac{3 \times x}{2}+\frac{6 \times 3}{3} 8 \frac{b \times 4}{4}+\frac{b \times 5}{5} 8 \frac{b \times 6}{6} \& c_{\text {. }}$ quæ infuper in cafu fpeciali $\mathrm{BI}$ ( B. ) $\infty \mathrm{BA} \infty \mathrm{BD}$, fer $x \infty \mathrm{I}$, fit $68 \frac{6}{2}+\frac{6}{3} 8 \frac{6}{4}+\frac{6}{8} 8$ $\stackrel{b}{-} \& c_{0}$ 
Coroll. I. Identitas hujus feriei cum illa, quam fupra Prop. XLII. pro Ppatio Hyperbolico quadrando reperiimus, de mutua depen-s dentia \& affinitate inter Hyperbolam \& Logarithmos nos admonet, perfpicuumque facit, quod fumtis in utraque Fig. r. \& 6. ipfis $\mathrm{BI}\left(\mathrm{B}^{6}\right)$ requalibus fpatium hyperbolicum CBIO ( $\mathrm{C}$ B 60) aquetur $S^{\text {lo }}$ fub unitate $A B$ \& Logarithmo AR $(A \rho)$. Unde porrò infertur, quòd fumtis utrobique $A B, A s, A D$, hoc eft, $A B, \rho \varepsilon$, * $x$ continué proportionalibus, quo cafu ex natura Logarithmicæ $A$. dupla fiet ipfius $A_{\rho}$, fpatium hyperbolicum $C B D Q$ duplum quoque fit ipfius: $C B 60$, indeque $C B 10,06 \mathrm{DQ}$ fpatia futura fint æ. qualia.

Coroll. 2. Quoniam evidens eft, exiftente BI $\infty \mathrm{AB}, \mathrm{h}$. e. eva nefcente $A I$ feu $R E$, Logarithmum $A R$ reddi infinitum, fequitur \& feriem harmonicam Logarithmum hunc exprimentem, $b+$ $\frac{b}{2}+\frac{b}{3}+\frac{b}{4}+\frac{b}{5} \& c_{0}$ talem effe; unde denuo veritas Prop. XVI。 conftat.

Coroll. 3. Dato quovis Logarithmo putà binarii, determinari po: teft ex 1 lllo curva fubtangens $b$; cum enim pofita $B D \infty$ I $D A B_{8}$ adeoque $A D \infty a * \infty 2$, oftenfum fit $A \sigma$ Log-um binarii effe $\infty$ b$\frac{b}{2}+\frac{b}{3}-\frac{b}{4} \& c_{0}, \infty 6$ in $1-\frac{x}{2}+\frac{\pi}{3}-\frac{1}{4} \& c$. erit vicifina $b x$ Iog. 2 .

$I-\frac{\pi}{2}+\frac{1}{3}-\frac{I}{4} \& c_{0}$

XLVIII. Dato sinu complementi reperive Logarithmum sinus rect per feriem. Fig. 6 .

In eadem fig. centro A per $B$ defcriptus efto circuli quadrans $\mathrm{BH} \sigma$, quem producta $E I$ fecet in $H$, erit $A I$ feu $R E$ finus arcus H $\sigma$, \& A R ejus Logarithmus, exiftente vid. radii A B ceu unitatis Logarithmo o. Ponatur finus complementi-I H. $\infty x$, ut fiat finus rectus $A I$ feu $R E \infty \sqrt{1-x x}$, ejusque elementum $E F \infty$ $\frac{-x d x}{\sqrt{1-x x}}$, erit ex nat. gen. curv. EF $\frac{-x d x}{\sqrt{1-x x}}$ ad $F$, elementum Log-i AR; ut RE, $\sqrt{I-x} x$ ad fubtangentem Logarithmice RN qua fit I; adeoque F G $\infty \frac{-x d x}{1-x x} \infty$ (per XXXVI) $-x d x$ 


$$
I N F I N I T I S
$$

283

$-x^{3} d x-x^{4} d x-x^{7} d x \& c_{0}$. Quare fummando fient omnia FG, feu $\log -$ us A R $x-\frac{x x}{2}-\frac{x 4}{4}-\frac{x 6}{6}-\frac{x 8}{8}-\frac{x 10}{10} \& c$. negativus fil. quia numerus ejus $R E$ minor ef unitate $A B$; at fi frat politivus $\frac{x x}{2}+\frac{x 4}{4}+\frac{x \sigma}{6}+\frac{x 8}{8} \& c_{\text {. }}$ hoc eft, fi $\mathrm{AR}$ transferatur ex altera parte in $A \rho$, erit is proprie Logarithmus reetæ $\rho \varepsilon$, id ef (ex natura Log-orum) tertiæ proportionalis ad ipfum finum $\mathrm{RE}$ $\&$ radium $A B$; qui tamen $\log$ - us immediate quoque reperiri potuiffer ex valore numeri fui $\xi \varepsilon D D_{\sqrt[3]{1-x x}}^{3}$.

Idem etiam D. Leibnitius Act. Lipf. 169r. p. I80. eleganter hoc modo:

$\left.\begin{array}{l}\log \cdot \overline{1-x} x-y x-x-\frac{x x}{2}-\frac{x 3}{3}-\frac{x 4}{4}-\frac{x 5}{5}-\frac{x 6}{6} \& c_{0} . \\ \log \cdot \overline{1+x} x+y \infty x+x-\frac{x x}{2}+\frac{x 3}{3}-\frac{x 4}{4}+\frac{x 5}{5}-\frac{x 6}{6} \& c_{0}\end{array}\right\}$ prxc.

$\log \cdot 1-x \times x($ ex nat. $\log$. $)$

$\log _{0} \overline{I-x}+\log _{0} \overline{I+x} \infty-x x \quad-\frac{x 4}{2} \quad-\frac{x 6}{3} \& c_{0}$

$\log \cdot \sqrt{1-x \times \infty} x_{2} \log \sqrt{1-x x} \infty-\frac{x x}{2} \quad-\frac{x 4}{4} \quad-\frac{x 6}{6} \& c_{0}$

Coroll. Polito inu complementi $\mathrm{H} I$ hujus fig. $\infty \mathrm{B}$ I vel B' fig. I. xequabitur $\square^{\text {lum }}$ fub Logarithmo finus recti AR \& radio AB dimidio exceffui, quo fpatium hyperbolicum CBI O fuperat alterum $\mathrm{CB}$ \%. Patet ex Cor, I. XLII, ubi CBIO-CB 0 ferie præefentis dupla expreffum legitur. Cæterùm moneri potuiffet ibi, quod fumta $z$ tertia proportionali ad I \& $x$, feu pofita $z \infty 0 x x$, feries illa convertatur in aliam $z+\frac{z z}{2}+\frac{z^{3}}{3}+\frac{z 4}{4} \& c$. qua quoque fpatium hyperbolicum, pută $\mathrm{CBGM}$, exiftente $\mathrm{BG} \infty \mathrm{B}$ vel $x x$, innuitur. Hinc enim patet, quòd $\mathrm{CBIO}-\mathrm{CB} \cdot 00 \mathrm{CBGM}$; \& $\mathrm{CBIO}-$ CBGM feu MGIO $\infty \mathrm{CB}$ ، ; adeoque (cum his pofitis AI, $1-x$ fit ad $A G, 1-x x$, ficut $A B, 1$ ad $A, I+x)$ quòd fumtis $\mathrm{A} I, A \mathrm{~A}, \mathrm{AB}, \mathrm{A}$ ' utcunque proportionalibus fpatia fegmentis $\| G, B$ infiftentia femper futura fune æqualia. 


\section{7 \\ $D E S E R I E B U S$}

XLIX. Applicatam Curve Catenare exhibere per feriem, Fig. 6 .

Efto Curva $\mu \mathbf{B} \lambda$, quam Catena ab extremitatibus fuis libere fufpenfa proprio pondere format, dicta Catenaria; cujus centrum $A_{2}$ vertex $B$, axis $A B D$, paramerer $A B D 0$, ablciffa $A^{\prime} \infty z_{2} \&$ ap.

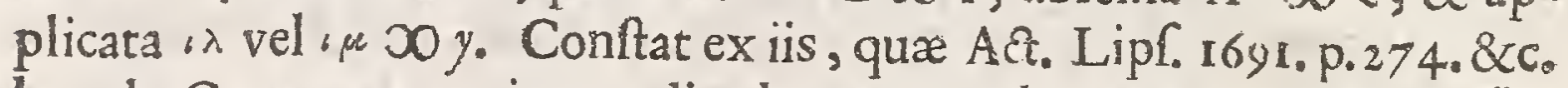
sit $A B=a=s, B_{1}=$ hac de Curva memoria prodita leguntur, elementum applicatæe"dy $x=z-1$; exit effe $x \frac{d z}{\sqrt{z z-1}}$. Hinc ad tollendam furditatem pono $\sqrt{z z-1} \infty$ Iluxio ordinahe $y$ $=\frac{a x}{\sqrt{x a x+x} x}(+$ grey.

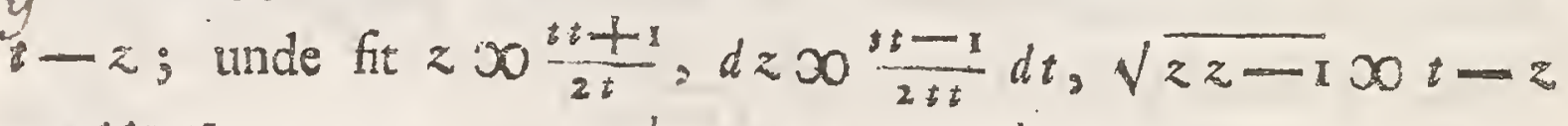
Demons. in phiffir. $\infty \frac{t t-I}{2 t}$, ac denique $\frac{d z}{\sqrt{z z-1}}(d y) \infty \frac{d t}{t}$. Quam porrò fras $p \cdot 40)=$ (swbiticendionem ut in feriem convertam, facio denominatorem bimemDo $z-1$ prox $\frac{\dot{z}}{\sqrt{z^{2}-1}} \cdot$ brem, fubltituendo $I+x$ loco $t, \& d x$ loco $d t$; eritque $\frac{d t}{t}$ feu $d y$ $\infty \frac{d x}{1+x} \infty$ (per XXXVII) $d x-x d x+x x d x-x^{3} d x+x^{4}$ $d x$ \&c. unde omnia $d y$ feu $y \infty x-\frac{x x}{2}+\frac{x^{3}}{3}-\frac{x 4}{4}+\frac{x 5}{5} \& c_{0}$ Quoniam autem $z \infty \frac{t t+1}{2 t}$, hoc eft, it $\infty 2 z t-\mathrm{I}, \& t$ feu $\mathbb{I}+x \infty z+\sqrt{z z-1}$, prodibit $x \infty x-1+\sqrt{z z-1} \infty$ (faw cta $\cdot D \infty \sqrt{z z-I}) B^{\prime}+$ 'D $\infty$ BD; igitur data $A^{\prime \prime}, z$ dabi. tur $\mathrm{BD}, x$, indeque $، \lambda$ feu $y$ per feriem.

Coroll. Ex ferie inventa collata cum Prop. XLVII. liquee, $y$ effe Logarithmum numeri $x$; unde data Logarithmica $* \mathrm{~B} \mathrm{C}$, cujus fubtangens $\infty$ A B $\infty \mathrm{I}$, puncta Catenarize reperire proclive. Cùm

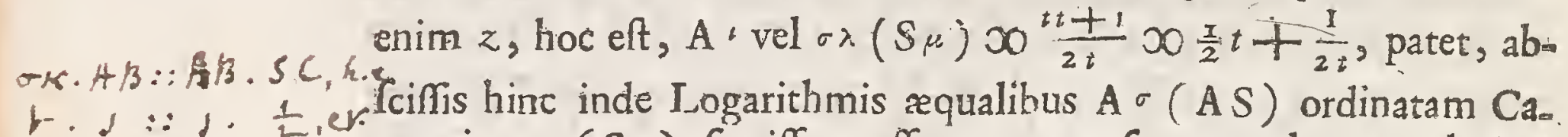

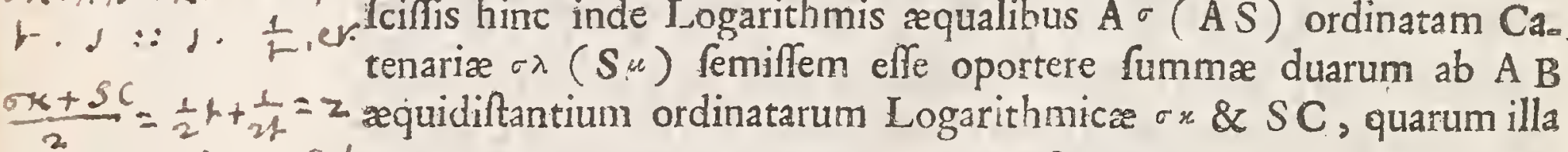
$=\sigma \lambda=$ Orjin. Cut. $\infty$ AD $\infty$ t, hæc ex natura Log. $\infty \frac{1}{t}$. Atque in hoc ipfo con. v. phil. Irans.p.4fittit elegantiflima hujus Curvæ confructio Leibnitiana, quam viProp. 7 . defis in Act. Lipl, 1691. p. 277. Eeqq. 
L. Datis latitudine loci alicuins in Curva Loxodromica on anglo Rumbi 然u meridiano, exbibere longitudinem loci per feriem. Fig. 3.

Lineam Rumbicam feu Loxodromicam vocant Nautæ, quam navis fecundùn eundem venti Rumbum conftanter incedens in fum perficie globi terr-aquei defcribit; adeoque curva eft, quæ omnes meridianos exdem angulo obliquo interfecat. Incipit hac in Equa tore, indeque verfus alterutrum polorum oblique recedendo, tan dem in ipfum polum, quem infinitis gyris ambit, definit. Sumto in fig. 3. finus totus, idemque \& radius Equatoris, A C 0 r, B C D meridianus, B \& D poli, tangens anguli Rumbici $x 0 t, \mathrm{H}$ pun tum in Loxodromica, ejus latitudo $\mathrm{HC}$; finus latitudinis $\mathrm{AE}, \&$ finus complementi $\mathrm{HE}$ qui vocetur 2 , longitudo verò feu arcus æquatoris inter meridianum loci $\mathrm{H}$ \& principium Loxodromice interceptus dicatur $x$. His pofrtis, per illa qua in AR. Lipf. 169r. p.284. oftenfa funt, invenitur elementum longitudinis $d x \infty$. $\frac{-t d z}{z \sqrt{1-z z}}$ ad cujus tentandam reduationem pono primò $z \infty \frac{1}{p}$; ande fit $d z \infty \frac{-d p}{p p}, \frac{d z}{z} \infty \frac{-d p}{p}, \sqrt{1-z z} \infty \frac{\sqrt{p p-1}}{p}, \&$ denique $\frac{-z d z}{z \sqrt{1-z z}}(d x) \infty \frac{t d p}{\sqrt{p p-1}}$; porrò quidem memini, ejusdem formæ fuiffe elementum Catenariæ in præc. pergo ponere ficut ibi, $\sqrt{p p-1} \infty p-q$, indeque elicio $\frac{t d p}{\sqrt{p p}-1}(d x) \infty$ $-i d q$, ac rurfum fatuendo $q x \mathbf{x}-r$ tandem obtineo $\frac{-t d q}{q}(d x)$ $\infty \frac{t d r}{1-r} ;$ quæ quidem quantitas etiam immediatè elici potuiffet ex quantitate $\frac{-1 d z}{z \sqrt{1-z z}}$ f f fatim feciffem $z \infty \frac{2-2 r}{2-2 r+r r}$ : at in ta les hypothefes incidere fepenumerò difficile ef, nifr jam ufu com pertum habeatur, quæ formulæe in quas transformari pofint. Nota, r $0 \mathrm{AC}-\mathrm{BI}$, exceflui nempe radii fuprà tangentem femifis complementi laticudinis puncti $H$; etenim fuppoitta $B$ I $\infty \mathrm{I}-r$, ductaque recta $\mathrm{BH}$, cum fimilia fint triangula $\mathrm{HEB}$, $A B I$, erit $H E, z, a d E B, I-\sqrt{1-z z}$, ut $A B, I$, ad $B I, 1-r$, unde 
286 DE SERIER IIS

refultat $\approx \infty \frac{2-2 r}{2-2 r+r r}$, ut oportet. Converfa autem per XXXVI. inventa quantitate $\frac{t d r}{1-r}$ in feriem, habetur $d x \infty t d r+t r d r+$ $2 r r d r+t r^{3} d r$ \&c. \& facta Cummatione $x$. $00 t r+\frac{t r r}{2}+\frac{t r 3}{3}+$ $\frac{\operatorname{tr} 4}{4} \& \mathrm{c}$. Patet igitur, quomodo ex data tangente femifris complementi latitudinis inveniatur longitudo.

Sciendum autem, elementum longitudinis $\frac{-t d z}{z \sqrt{1-z z}}$ adhuc ali: ter poffe reduci, fratuendo nempe $\sqrt{1-2 z} \infty$ y ; hinc enim fit $z \infty$ $\sqrt{1-y y}, d z \infty \frac{-y d y}{\sqrt{1-y y}}, \& \frac{-t d z}{z \sqrt{1-z z}}(d x) \infty \frac{t d y}{1-y y} \infty$ (per $\mathrm{XXXVI}) t d y+t y y d y+t y^{4} d y+t y^{6} d y \& c$. ac deniq; omnia $d x$ feu $x x^{2} t y+\frac{t y_{3}}{3}+\frac{t y 5}{5}+\frac{t y 7}{7} \& c_{0}$ ubi perficum eft, $y$ feu $\sqrt{ } 1-z z \infty 0$ $\mathrm{AE}$ finui recto arcus $\mathrm{HC}$; unde conftat ratio definiendi etiam quafitum ex finu recto latitudinis, quemadmodum fecit Dn. Leibnitius Ad. Lipr. 1691. p. 181. Et patet, fi in calculo, per quem ad initio memoratam æquationem $d x x \frac{-t d z}{z \sqrt{1-z z}}$ perveni, loco quantitatis indeterminatæ ipfum fium rectum $A E$ præ finu complementi $H E$ felegiffem, me ftatim ad alteram æquationem immediate in feriem convertibilem $d x \infty \frac{t d y}{1-y y}$ perventurum fuiffe. Creterum ex eo, quod duæ inventæ feries eandem quantitatem $x$ denotant, obiter concludimus, quòd fi in circulo finus cujuslibet arcus $\mathrm{AE}$ dicatur $y, \& \mathrm{AC}-\mathrm{B} I$ exceffus radii fuprà tangentem femiffis complementi vocetur $r$, perpetuò futurum fit $y+\frac{y 3}{3}+\frac{y s}{5} \& c_{0} \infty x+\frac{r r}{2}+\frac{r_{3}}{3} \&$ \&. Notamus etiam, fi locus $\mathrm{H}$ fit in ipfo polo, quo cafu $r \infty$ r $\infty 0 y$, fore $x \infty t+\frac{t}{2}+\frac{t}{3}+\frac{t}{4} \&$ c. vel $\infty t+\frac{t}{3}+\frac{t}{5}$ \&.c. quarum ferierum fummæ cum fint infinitæ per XVI, docent longitudinem loci $\mathrm{H}$ quoque infinitam effe, adeoque, quod dixi, curvam loxodromicam. infinitis polum gyris ambire, priusquam in ipfum incidat。 


$$
\text { INFINITIS. }
$$

Coroll. 1. Si in eadem Loxodromica præter locum $\mathrm{H}$ alius fit locus note laticudinis, cujus fnus re\&us $00 v, \&$ exceflus radii fuprà tangentem femifis complementi $x \mathrm{~s}$, erit fimiliter ejus longitudo $\infty t$ in $v+\frac{v 3}{3}+\frac{p s}{5} \& c$, vel $D o t$ in $s+\frac{s s}{2}+\frac{s 3}{3} \& c$. adeoque differentia longitudinum utriusque loci erit utriusque feriei differentia, $n p$. $t$ in $\frac{y \equiv x}{r}+\frac{y_{3}=y_{3}}{3}+\frac{y_{5} \equiv y_{5}}{5}$ \&c. vel, $t$ in $\frac{r=s}{1}+\frac{r^{2}=s^{2}}{2}+$ $\frac{r^{3}=s^{3}}{3} \& c$. Hinc fi in alia quadam Loxodromica duo concipiantur loca latitudine cum prioribus convenientia, erunt, manentibus $y$ $\& v$, vel $r \& s$ iisdem, differentix longitudinum ut tangentes angulorum, quos Rumbi faciunt ad meridianos. Vid. Act. Lipf. 169r. p. 182. \& 285.

Coroll, 2. Ex collatione harum ferierum cum feriebus Propp. XLII. XLVI. \& XLVII. liquet Problematis convenientia cum quadratura Hyperbolæ \& Logarithmis. Speciatim notamus, quòd exiftente fubtangente Logarithmic $\infty t$, quæefita longitudo puncti $\mathrm{H}$ fit ipfe Logarithmus rectæ $\mathrm{I}-r$ feu BI, ut patet ex XLVII; vel etiam (cum $D_{0}$ Leibnitio $\operatorname{loc}_{0}$ cito) femiffs $\log -i$ quantitatis $\frac{1+y}{I-y}$ feu $\frac{D E}{E B}$, guod fic oftenditur:

$$
\left.\begin{array}{l}
\log \overline{x+y} x+t y-\frac{t y y}{2}+\frac{t y s}{3}-\frac{t y 4}{4}+\frac{t y s}{5}-\frac{t y \sigma}{6} \& c_{0} \\
\log \overline{x-y} x-t y-\frac{t y y}{2}-\frac{t y 3}{3}-\frac{t y 4}{4}-\frac{t y 5}{5}-\frac{t y 5}{6} \& c_{0}
\end{array}\right\} \begin{gathered}
\text { per } \\
X V V I .
\end{gathered}
$$

$\log \frac{\overline{r+y}}{1-y} \infty$

$\log _{1} \overline{1+y}-\log _{0} \overline{1-y} x z_{t y}+\frac{2 t y z}{3}+\frac{2 t y 5}{5} \& c_{0}$

Coroll. 3. Data longitudine \& latitudine loci, dabitur angulus. Rumbi cum meridiano; cum enim $x x$ in $r+\frac{r r}{2}+\frac{r 3}{3} \& c_{0} \infty t$ in

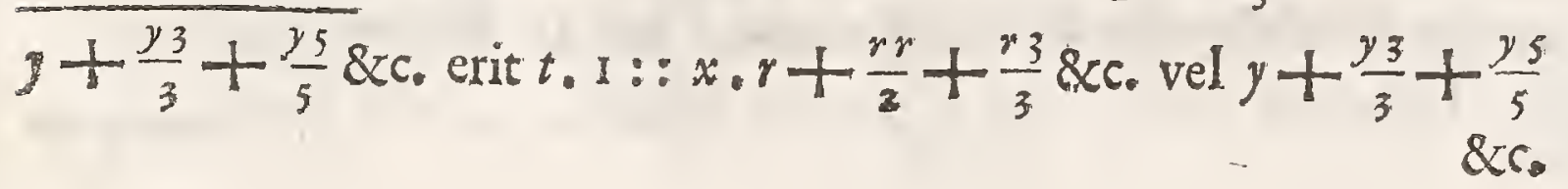


\&c. id eft, tangens anguli quæefiti ad finum torum, ut âtreus lorit gitudinis ad $\log$-um $B I$, vel femiflem $\log -i \frac{D E}{E B}$; adeoque pere Coroll. I. hujus, ut differentia duarum longitudinum ad differentism duorum $\log$-orum $B I$, vel femi-differentiam duorum $\underset{E B}{D}$. Intellige hic Logarithmos acceptos in Curva, cujus fubtangens $\infty 0$ radio $\infty$ I. Nota, fi defideretur angulus Loxodromicæ, qua non nifi poft unam pluresve integras revolutiones in darum locum perducat, augendus eft arcus differentix longitudinum integra peripheria æquatoris ejusve multiplo.

Schol. Ex hactenus didis expeditus habetur modus conftruen di Scalam quandam Laxodromicam: Efto in Fig. 6. B M $\sigma$ circumferentia æquatoris in gradus fuos \& graduum minutias divifa; hæc extendatur in reetam A $S$ axem Logarithmicæ $C B *$, ejufque divifionibus ordine $\mathrm{ab} A$ adfcribantur gradus longitudinum: tum fum to indefinitè in circumfirentia hac puncto $M$, bifectoque arcu $M \sigma$ per rectam A $T^{*}$ occurrentem tangenti $\sigma x$ in $\mathbf{T}$, ducatur ex $\mathbf{T}^{*}$ recta $T E$ axi A $S$ parallela, fecans Logarithmicam in $E$; ac denique ex $\mathbf{E}$ demittatur in axem perpendicularis $E R$; punctoque $\mathbf{R}$ adfcribatur numerus graduum in arcu $B M$ : fic habebuntur etiam gradus latitudinum; parataque erit Scala Loxodromica, quæ primario inferviet Rumbo, cujus anguli tangens æquatur fub tangenti Logarithmicæ. Numeri enim graduum cujusvis datæ latitudinis in fcala ftatim à latere afpectui offerant refpondentes longitudinis gradus. Eadem tamen etiam cuilibet Rumbo prodeffe poterit, fit fiat per Coroll. r. hujus, ut fubtangens Logarithmicæe, è qua fcala confructa eft, ad anguli Rumbici tangentem, fic longitudo vel differentia longitudinum per $\mathrm{K}$ alam inventa ad longitudinem vel differentiam longitudinum qua fitam: adeo ut fcala ejusmodi in ufum nautarum circino proportionis infculpta, \& lineæe partium æqua lium, qua longitudinum gradus repræfentarent, juxta pofita infrumentum foret omnium forfan, quæ Natura hachenus tractarunt compendiofifimum \& utilifimum, sed de his fatis。 
Antequam pergatmus, Leclor advertere poteft, qudd bucurgue in differenthalium Jummatione pro quovis elemento femper ejus integrale purwm feu abo folutum fubfituimus, velut $\mathrm{x}$ pro $\mathrm{d} \mathrm{x}, \frac{\mathrm{xx}}{2}$ pro $\mathrm{x} \mathrm{d} \times \mathrm{d}$. At fore ipfurm volumus, boc minimè effe perpetuum; quanquam enim una eademque quars" titas $\mathrm{x}$ non nifi unum habeat differentiale $\mathrm{d} \mathrm{x}$, idem tamen differentiale $\mathrm{d} \mathrm{x}$ infinita babet integralia, unum quidem purum $\mathrm{x}$, reliqua admifions quantitatum conftantium affecta $\mathrm{x}+\mathrm{a}, \mathrm{x}-\mathrm{b} \& \mathrm{c}$. quorum in furmation his negotio pro re nata nunc boc nunc illud feligendum eft, neque adeo fine prafenti ballucinationis periculo indifcriminatim femper purum adfumi potef. Refat itaque, ut ad vitandum fropulum, quen communem ferè effe video oms. sibus iis, qui calculum bunc incautinus tractant, fubjiciamus adbuc ejus rei exemplum in uno alterove Problemate, ì cujus enodatione Lectori confare poffit, undenam \&o quibus criteriis dignofcatur, quid pro quovis femper eleanento fummando fubfitui conveniat.

L I. Exbibere longitudinem Curve Parabolice per feriem. Fig. 4.

Fingamus BCD Curvam effe Parabolam, cujus vertex $\mathrm{B}$, axis BG, latus rectum $\infty$, abfiffa B G $\infty x$, applicata GD $\infty y$, ipfa $B C D$ curva $\infty$; proinde elem. FG vel $\mathrm{CH} \infty d x, \mathrm{DH} \infty$ $d y, \& \operatorname{CD}\left(\sqrt{d x^{2}+d y^{2}}\right) \infty d s$. Erit ex natura Curva $a x \infty y y$; hinc differentiando $a d x D_{0} 2 y d y$, quadrandoque $a a d x^{2}\left(a a d s^{2}-\right.$ a a d $\left.y^{2}\right) \infty 0.4 y d y^{2}$, \& facta transpofitione a ad ${ }^{2} \infty 0 a a d y^{2}+4 y y$ $d y^{2}$, extractaque tandem radice ads $\infty d y \sqrt{a a+4 y y}$, qux quantitas eft, de qua fummanda agitur. Ad furditatem primò eliminandam pono $\sqrt{a a+4 y y} \infty z-2 y$, fiet a a $\infty z z-4 z y$, \& y $\infty \frac{z z-a a}{4 z}$; hine $d y \infty \frac{z z+a a}{4 z z} d z$, nec non $\sqrt{a a+4 y y}(z-$ 2.y) $\infty \frac{z z+a z}{z z}$, adeoque $d y \sqrt{a a+4 y y}(a d s) \infty \frac{z 4+2 a z z+a_{4}}{8 z 3}$ $d z \infty$ (membris feparatim politis) $\frac{z d z}{8}+\frac{a d d z}{4 z}+\frac{d 4 d z}{8 z^{3}}$, de quo= rum nunc fummis difpiciendum. Hunc in finem confidero relationem, quam habet affumta litera indeterminata $z$ ad ordinatas Curvæ noftre, eamque ex facta hyp. $\sqrt{a a+4 y} y \infty z-2 y \operatorname{cog}-$ nolco talen efle, ut exiftente $y \infty 0, z$ non pariter evanefcat, fed 
Iit $20 \%, \&$ quod crefcente $y$ eò fortius crefcere debeat $z$ quaprope ter extenfa concipiatur ipfa $z$ in reda $D$ B fig. 3 a à puncto $D, \& C$ Iit prima $D A$, quæ nafenti y refponder, $\infty \mathrm{a}$, ultimaque $z$, qua refpondet ultima y feu applicatæ GD fig. 4. efto DE. Tum flue re intelligatur $a b A$ ad $E$ indefinita recta $A K$ vel $E H$, xqualis ubique $\frac{z z}{16}$ (integrali fcil. puro primi membri $\frac{z d z}{8}$ ) minimaque adeo in $A$ \& $\infty \frac{a a}{16}$; fic ipfum fluentis lineæ incrementum fiet $\frac{z d z}{8}$, \& o m nia incrementa quæ capit linea, dum ex A movetur in $\mathrm{E}$, repraCentabunt omnia $\frac{x d}{8}$, qua ordinatis $y$ à minima $(0)$ ad ultimam (GD) ordine refpondent, $h_{0}$ e. quæe pertinent ad Curva Paraba: licæ portionem reetificandam BD (fig. 4.) Conftituiunt autem omnia illa incrementa, ut liquet, non integram $E H\left(\frac{2 \pi}{16}\right)$ fed exceffum tantum ejus fuprà rectam $\mathrm{AK}\left(\frac{a a}{16}\right)$ hoc eft, $\mathrm{EH}-\mathbb{A K}$ feu $\frac{z z-d a}{16}$. Integrale igitur primi membri $\frac{z d z}{8}$, quod hue quas drat, eft $\frac{z z-a d}{16}$. Similiter pro integrando tertio membro $\frac{a d x}{8 z^{3}}$, fingo $z$ extendi in recta $A D$ fig. ro à puncto $A$, primamque quia nafcenti $y$ refpondet effe $\mathrm{AB} \times a$, \& quæ refpondet uiltimæ, $\mathrm{AD}$ : hinc fluere concipio à $B$ verfus $D$ quantitatem $\frac{\alpha_{4}}{16 \% 2}$, ceu integrale purum ipfius $\frac{a 4 d z}{8 \chi_{3}}$, putà reetam $B C$ vel $D Q$, quæ proin maxio

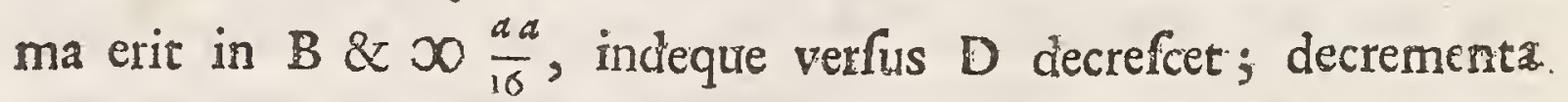
itaque, qux patitur linea $B C$ quoulque pervenit in $D Q$, denota bunt omnia elementa $\frac{a 4 d z}{8 z z}$, quæ portioni Curvæ Parabolicæ BD (fig. 4.) refpondent: fed omnia illa decrementa, ut apparer, non efficiunt rectam DQ feu $\frac{a 4}{162 \pi}$, verum potius BC-DQ feu $\frac{a d}{16}-$ $\frac{a 4}{36 z^{2}} ;$ qutrapropter integrále tertiz membri $\frac{a 4 d}{8 z^{3}}$ huc pertinens 
$\infty 0 \frac{a a}{16}-\frac{a 4}{16 z z}$, fummaque adeo primi \& tertii $\left(S \frac{z d z}{8}+S \frac{a+4 d z}{8 z^{3}}\right)$ $\infty \frac{z z-a z}{16}+\frac{a z}{16}-\frac{a 4}{16 z z} \infty \frac{z 4-a 4}{16 z z}$.

Reftat intermedium adhuc membrum expediendum $\frac{a d z}{4 z}$. Hoc cum abfolutè fummari nequeat, in feriem converto, ponendo porius $z \infty a+t$, ut denominator fiat bimembris; hinc enim fit $\frac{a d d z}{4 \pi}$ $\infty \frac{a a d t}{4 a+4 t} \infty$ (per XXXVII) $\frac{a d t}{4}-\frac{t a t}{4}+\frac{t d t}{4 a}-\frac{t 3 d t}{4 a d} \&$ rc. \& facta fummatione, $S \frac{a d z}{4 z}>\frac{a t}{4 \cdot 1}-\frac{t b t}{4.2}+\frac{t 3}{4.3 a}-\frac{t 4}{4.4 a d}+{ }_{4.5 a}^{t 5}$ \&cc. Nota, quod hîc pro quolibet feriei termino fubttituam ejus integrale purum, quoniam ex aquatione $z \supset 0 a+t$ colliga, quod exiftente $z \infty 0$ a (hoc eft $y \infty 0$ ) ipfa $t$, ut \& quantitates fluentes omnes, $\frac{a t}{4.1}, \frac{t t}{4.2}, \frac{t 3}{4.3 a} \& c_{0}$. quoque fint $\infty 0$, id eft, quod hæ à o fluere feu incrementa fumere occipiant; hinc enim manifefte liquet, omnia ipfarum crementa, nempe omnia $\frac{a d t}{4}, \frac{t d t}{4} \&$ c. ipfis quantitatibus ultimis $\frac{a t}{4}, \frac{t t}{4.2} \& c_{\text {. }}$ æqualia fore. Quod idem quoque, fi quis exa= minet, in omnibus præcedentium Propp. exemplis contingere obCervabit, indeque concludet, rectè à nobis factum, quod ibidem inter "fummandum pura femper integralia affumferimus, tametî ejus rei rationem diferte non adjecerimus. Sed revertamur ad propofitum: Inventa fumma medii membri $\frac{a d z}{4 z}$, fi reliquorum fummæ fuprà repertæ adjiciantur, emergit fumma omnium $S \frac{z d z}{8}+S \frac{a d d z}{4 z}+S \frac{4 d d z}{8 z 3}$, hoc eft, $a s \infty \frac{z-4-a 4}{16 z z}+\frac{a t}{4 \cdot 1}-\frac{t}{4 \cdot 2}$ $+\frac{t 3}{4 \cdot 3 a}-\frac{44}{4 \cdot 4 a a} \& c$. \& facta divifione per $a$, longitudo Curvas feu B D $\infty \frac{z 4-a t}{16 a_{2} z}+\frac{t}{4 \cdot 1}-\frac{t t}{4 \cdot 2 a}+\frac{t_{3}}{4 \cdot 3 a a}-\frac{t_{4}}{4 \cdot 4 \cdot a_{3}} \& c_{\text {. qu de }}$ nique pofita a $\infty 0004,2 z z \infty a+t \infty 08$, fit $\frac{15}{1} \frac{5}{6}+1-\frac{x}{2}+$ $\frac{2}{3}-\frac{z}{4}+\frac{2}{5} \& c_{1}$ unde cum fit hoc cafu y $\infty \frac{2 z-a d}{4 \pi} \infty \frac{3}{2}, \& x$ $\mathrm{OO} 2$ 
$x_{0} \frac{y y}{a} \infty \frac{9}{16}$, fequitur, quod exiftente latere recto Parabola $4, \&$. ablififa $\mathrm{BC} \frac{9}{16}$, aut applicata $\mathrm{GD} \frac{3}{2}$, longitudo Curve Parabolica: $\mathrm{BD}$ xquetur $\frac{x}{3} \frac{5}{6}+\frac{1}{1}-\frac{x}{2}+\frac{1}{3}-\frac{1}{4}+\frac{1}{5} \& \mathrm{C}_{0}$

coroll. Ex ferie collata cum XLiI. Curvam Parabolicam cum Spatio Hyperbolico inter Afymptotas comparandi modus innotefit. Sufficit monuife.

LII. IRecificare curvam Logaritionicam per feriem oliter. Fig. 6.

Infiftat axi $S A \sigma$ Curva Logarithmica $C B$ *, cajus ordinata $A B$ $\infty \mathbf{1}$, fubtangens $A K: b$, alia quavis applicata $R E\left(\rho^{\varepsilon}\right) \infty z$, ejusque elementum EF $(\varepsilon \varphi) \infty d z$; quaritur rectificatio portionis. Curvæ $B E(B \varepsilon)$. Quoniam per XLVII. elementum abfeiffæe $A R(A \rho)$ nempe $F G\left(\varphi_{\gamma}\right) \infty \frac{b d z}{2}$, erit $E G^{2}\left(E F^{2}+F G^{2}\right)$ $\infty d z^{2}+\frac{b b d z=}{2 z} \infty \frac{\overline{z z+}-6 b}{2 z} d z^{2}$, indeque elementum curvæ $E \mathrm{G}$ ( $\varepsilon \dot{y}) \infty \frac{d z \sqrt{z z+b b}}{z} \infty$ (terminis fractionis per $\sqrt{z z+b b}$ aque - multiplicatis ) $\frac{z z d z+b b d z}{z \sqrt{z z+b 6}} \infty \frac{z d z}{\sqrt{z+b 6}}+\frac{b b d z}{z \sqrt{z z+6 b}}$ de quorum fummatione hic quæritur. Prioris membri integrale: purum eft $\sqrt{z z+b b}$, quod ( ob primam $z \infty A A B \infty 1$ ) inde a: $\sqrt{I+b b}$ decrefcere (crefcere) intelligitur ad ufque $\sqrt{z z+b b}$; adeo ut omnia ejus decrementa (incrementa) huc quadrantia, feu

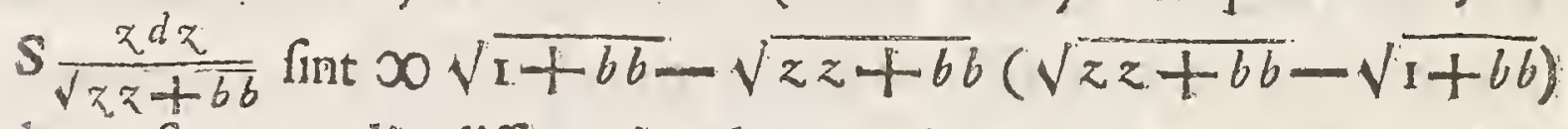
hoc eft, æqualia differentiæ duarum in $B \& E(\varepsilon)$, tangentium rectarum $\mathrm{BK} \& \mathrm{EN}(\varepsilon \nu)$. Pofterioris membri $\frac{b .6 d z}{z \sqrt{z z+b b}}$ integrale, quoniam ita planum non eft, previa reductione inveftigare conor, eaque fimili huic, qua fuprà Prop. L, pro Curva Loxodromica fui ufus, cum in elementis analogiam quandam obfervem. Pom no itaque primo $z \infty \frac{b b}{p}$, eoque mediante transformo $\frac{b b d z}{z \sqrt{z z+b b}}$ in $\frac{-b d p}{\sqrt{b b+p p}}$, deinde facio $\sqrt{b b+p p} \infty p+q$, five $p \infty \frac{b b-q q}{2 q}$; inder 


$$
\text { INFINITIS. }
$$

Indeque elicio $\frac{-b d p}{\sqrt{b b+p p}}\left(\frac{b b d z}{z \sqrt{z \alpha+b b}}\right) \infty \frac{b d q}{q}$, quod per XLVII. elementum effe cognofco abfcifle cujusdam in Logarithmica, quam tandem ita determino: Quoniam $p \infty \frac{b b-q q}{2 q}, \& z \infty \frac{b b}{p}$, fiet $z \infty$ $\frac{2 b b q}{b b-q q}$, ficut vicifim $q \infty \frac{-b 6+b \sqrt{z z+b b}}{z} ; \&$ quia prima $z \infty$ $A B \times O I$, erit qua huic refpondet prima $q \infty 0-b 6+6 \sqrt{\mathrm{I}+6 b}$. Pro conftruatione, abfcindo in tangente $\mathrm{BK}$ partem $\mathrm{K} \propto ⿻ \mathrm{KA}$, in ordinata $A B$ partem $B V \infty B^{\infty}$, \& in V ftatuo $V X$ paralleIam ipfi $\mathrm{AK}$; pari modo in tangente $\nu \varepsilon$ (idem imaginatione fupple in NE) fumo ${ }^{\nu} \mathrm{r} \infty \mathrm{\nu}_{\mathrm{\nu}}$, hinc ${ }^{\varepsilon} \vee D^{\varepsilon} \mathrm{r}, \&$ duco $\vee \times$ parallelam $\nu_{\xi}$; quo pacto conftat fore $V X \infty 0$ primæ $q 00-b b+$ $b \sqrt{I+b b}, \& \vee \times \infty$ ultime $q \infty \frac{-b b+b \sqrt{2 z+b b}}{2}$. Quocirca fi amba VX \& vX, vel etiam loco harum fola quarta proportionalis ad $\mathrm{VX}, \mathrm{VX} \& \mathrm{AB}$ (quæ fit $\mathrm{SC}$ vel $\sigma x$ ) applicetur Logarithmicæ, erit intercepta applicatis $\mathrm{VX} \& \mathrm{VX}$ axis portio, vel etiam ipfis $A B, S C(\sigma *)$ interjecta portio A S (A, $\sigma)$ [ex natura enim curvæ æqualis utrisque intercipietur] $\infty \mathrm{s}_{\frac{b}{q} q}$, id eft, omnibus $\frac{b d q}{q}$, feu omnibus $\frac{b b d z}{2 \sqrt{2 z+b b}}$ pro portione curvæ $\mathrm{BE}(\mathrm{B} \varepsilon)$ rectificanda infervientibus. Et quoniam pofita differentia inter A B \& SC $(\sigma x) \infty x$, refegmentum axis $\mathrm{A} S\left(\mathrm{~A}^{\sigma}\right) \infty 6 \times 8 \frac{6 \times x}{2}+\frac{6 \times 3}{3} 8$ $\frac{b b d z}{z \sqrt{z z+b b}}$ fumma etiam per feriem reperta. Addicis itaque amborum fummis fient omnia $\mathrm{EG}(\varepsilon x)$ feu longitudo curve $\mathrm{BE}(\mathrm{B} \varepsilon)$ $\infty \sqrt{1+b 6}=\sqrt{z z+6 b}+b \times 8 \frac{b \times x}{2}+\frac{b \times 3}{3} 8 \frac{b \times 4}{4} \&$ xco $_{0} \infty$ diffe rentix tangentium $\mathrm{BK} \& \mathrm{EN}(\varepsilon y)$ unà cum refegmento axis A. $S(\mathrm{~A} \sigma)$.

Cuim non omnes quantitates furde, nedum tranfsendentes, differentialszies converi pofint, ad alis fubinde nobis artificia recurrendum oft ad obtisendum propofitum, inter que of whiverfalitatein fuam eminent Interpola$\mathrm{O} 0-3$ tiones 
riones Wallifiane, vel Exaltatio binomii ad poteftatem indefnicam, vel Affumtio feriei ficte inftar quæfita, ast confimilia fubfidia alia, quorum pro re nata nuns unw nunc plus in ufum verti queunt. Nos pauca corum pecimina pof generalia nownulda in uno alterove exemplo fuligungentus.

LIII. Quanitatem quanumane furdam vel irrationalem in feriem in finitam rationalium convertere per interpolationes Wallifanas.

Reducatur quantitas rationalis, cujus poteftas fracta five radix aut latus quæritur, ad fractionem hujus formæ $\frac{l}{m-n}$ (ponendo $m<n)$. Hujus fractionis poteftates integræ, prima, fecunda, tertia, \&c. convertantur ope divifionis continure in totidem feries, per XXXVI. ufque ad XL. Propp. hoc pacto:

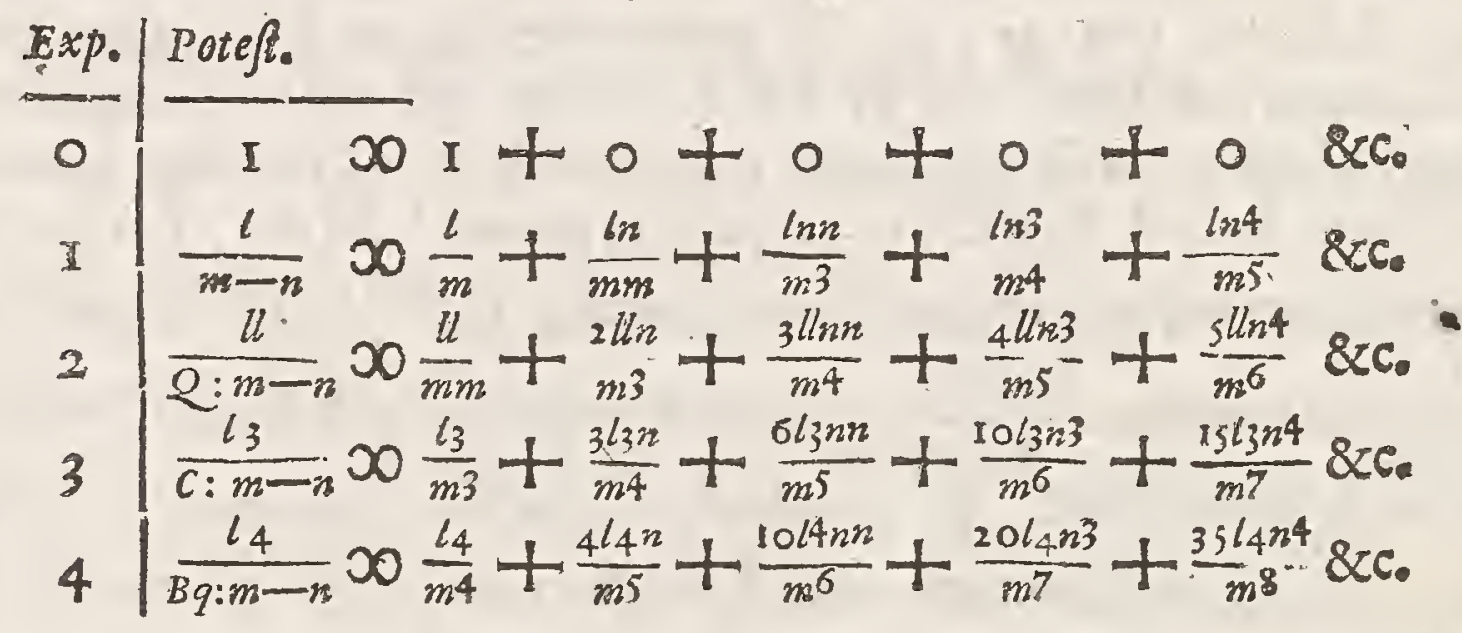

In his feriebus obfervabis, coëfficientes primorum terminorun conftituere unitates, coëfficientes fecundorum numeros laterales, tertiorum trigonales, quartorum pyramidales, \& fic porrò; terminos verò puros ordine oriri ex důtu fractionis $\frac{l}{m}$ (ad poteftatem elevatæ fimilem ei ad quam elevanda fractio $\frac{l}{m-n}$ ) in $1, \frac{n}{m}, \frac{n n}{m}$, $\frac{23}{m 3}$, \&c. Hinc ad inveniendas poteftates intermedias five radices (ceu media quædan geometrica, quorum exponentes funt arithmeticè medii inter exponentes integrorum ) numeri terminozum figurati tantum funt interpolandi juxta dotrinam Wallifii 
Prop. 172. feqq. Arithm. Infin. Eft vero, pofito exponente vel indice poteftatis. $p$, generalis character lateralium quoque $p$, trigonain lium $\frac{p \cdot p+1}{1 \cdot 2}$, pyramidalium $\frac{p \cdot p+1 \cdot p+2}{1 \cdot 2 \cdot 3}$, \& c . ut ibid. docetur Prop. 182. Quare fi $p$ interpreteris per $\frac{x}{2}$, invenies poteftatem dimidian quantitatis $\frac{l}{m-n}$, nempe $\sqrt{ } \frac{l}{m-n} \infty \sqrt{ } \frac{l}{m}$ in $1+\frac{1 n}{2 m}+\frac{r .3 m n}{2.4 m m}+\frac{1.3 .5 n}{2.4 .6 m s}$ $+\frac{1 \cdot 3 \cdot 5 \cdot 7 n 4}{2 \cdot 4 \cdot 6.3 m 4}+8 x c$. fi $p$ explices per $\frac{\pi}{3}$, habebis trientem poteftatis

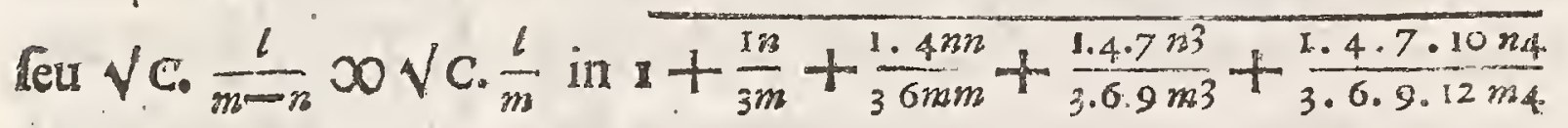
+\&rc. fi per $\frac{3}{2}$, obtinebis fefquialteram poteftatem feu $\frac{1}{m-n} \sqrt{ } \frac{1}{m-n}$ $\infty \frac{6}{m} \sqrt{\frac{l}{m}}$ in $+\frac{3 m}{2 m}+\frac{3.5 m m}{2.4 m m}+\frac{3.5 \cdot 7 m 3}{2.46 m_{3}}+\frac{3.5 .7 .9 n 4}{2.4 .6 .8 m_{4}}+\& c_{0} \& c_{0}$

Coroll. Quoniam pofitis $l, m \& n$ equalibus inter fe, fit quantitas $\frac{l}{m-n} \infty \frac{l}{0} \infty \infty 0$, feries autem pradicta abeunt in feries parorum coëfficientium $x+\frac{x}{2}+\frac{1.3}{2.4}+\frac{1.3 .5}{2.4 .6} \& c_{0} I+\frac{x}{3}+\frac{1.4}{3.6}+\frac{1.4 .7}{3.6 .9} \& c_{0}$ $+\frac{3}{2}+\frac{3.5}{2.4}+\frac{3.5 .7}{2.4 \cdot 6} \& x c_{0}$ colligimus, feries ejusmodi natas ex ductu continuo fractionum, quarum numeratores \& denominatores in progreff. arithm. per differentias primo denominatori æquales infurgunt, fummas fundere infinitas; quod apertius ita conftabit: Minue numeratores, eosque æequales conftitue denominatoribus fingulos fingulis, nempe fecundum numeratorem primo denominatori, tertium fecundo, $4^{\text {tum }} 3^{\text {tio }}$ \& $\&$ ita deinceps; fic enim ex. gro loco primæ feriei habebis I $+\frac{\pi}{2}+\frac{1.2}{2.4}+\frac{1.2 .4}{2.4 .6}+\frac{1.2 .4 \cdot 6}{2.4 \cdot 6.8} 8 x c_{0} \infty$ (perimentibus fe mutuo diatis numeris) I $+\frac{x}{2}+\frac{1}{4}+\frac{1}{\sigma}+\frac{1}{8} \& c_{0}$. $\infty \propto \infty$, per Cor.2. XVI, unde fortius altera $\mathrm{I}+\frac{\mathrm{x}}{2}+\frac{\mathrm{r} .3}{2.4}+\frac{\mathrm{k} .3 .5}{2.4 .6} 8 \mathrm{r} \mathrm{c}_{0}$ ob numeratores majores infinita erit. Caterùm poffremus terminus cujusque feriei nunc nullus eft nunc infinitus, prout exponens: poteltatis p. yel prima feriei fractio, unitate minor eft majorve: Sic 


\section{DE SERIEB LES}

ultimus terminus primæ feriei $\frac{1 \cdot 3 \cdot 5 \cdot 7}{2 \cdot 4 \cdot 6.3} \& \mathrm{c}$. nullus eft; nam fi quantus effet, etiam hic foret quantus $\frac{2.4 \cdot 6.8}{3 \cdot 5 \cdot 7.9} \&$ c. utpote cujus finguli faktores fingulis factoribus præcedentis termini ordine funtis funt majores;

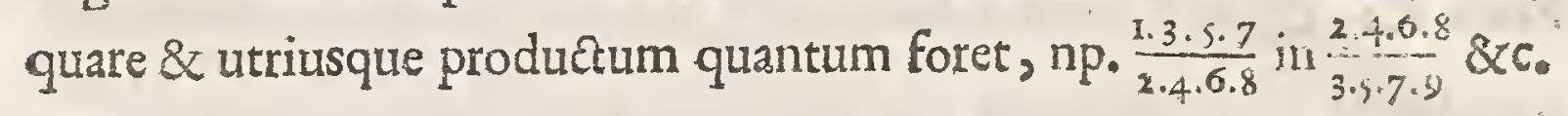
$j 0$ ( permiftis alternatim utriusque factoribus) $\frac{1.2 \cdot 3 \cdot 4 \cdot 5 \cdots \cdots \infty}{2 \cdot 3 \cdot 4 \cdot 5 \cdot 6 \ldots \ldots \infty} t$ $\infty$ (ob numeratores omnes primum fequentes, \& denominatores

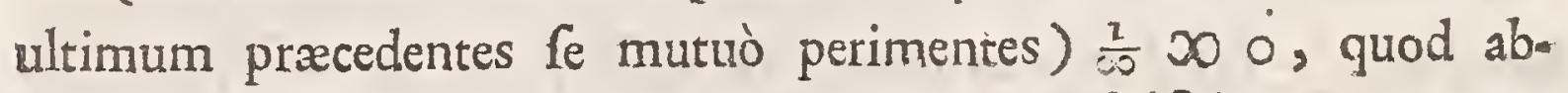
furdum, Ultimus contra terminus tertix feriei $\frac{3 \cdot 5.7 .9}{2 \cdot 4.6 .8}$ \& $x$. infinitus eft; nam fi finitus effer, etiam hic foret finitus $\frac{4 \cdot 6.8 .10}{3 \cdot 5 \cdot 7.2}$ \&c. utpote cujus finguli factores fingulis illius funt minores; quocirca $\&$ utriusque productum finitum foret, nempe $\frac{3.5 .7}{2.4 .6} \& c_{0}$ in $\frac{4 \cdot 6.8}{3.5 .7} \& c_{\text {. }}$ $\infty \frac{3 \cdot 4 \cdot 5 \cdot 6 \ldots \infty}{2 \cdot 3 \cdot 4 \cdot 5 \ldots \infty-1} \infty$ (deftruentibus fe mutuo numeratoribus qui ultimum præcedunt, \& denominatoribus qui primum (equuntur) $\frac{\infty}{2} \infty \infty$, quod pariter abfurdum.

LIV. Idem praftare per exaltationem binomii ad potefatem indefinitam.

Quantitas rationalis, cujus poteftas per feriem defideratur, fit exprefla per binomium $\mathbf{I}+n($ ponendo $\mathbf{}>n)$. Hujus binomii potefas indefinita $p$, ut jam paffim inter Geometras notum, per feriem exprimitur $\mathrm{I}+\frac{p}{\mathrm{I}} n+\frac{p \cdot p-1}{1.2} n n+\frac{p \cdot p-\mathrm{I} \cdot \mathrm{p}-2}{1.2 .3} n^{3}+\frac{p \cdot p-\mathrm{I} \cdot \mathrm{p}-2 \cdot \mathrm{p}^{3}{ }^{3}}{\mathrm{I}_{0} 2.3 .4} n^{4}$ $+2 x$ c ubi perfpicuum eft, quod quotiescunque exponens poteftatis $p$ eft numerus integer \& pofitivus, feries neceffariò aliquando abrumpetur; quandoquidem in continuatione ulteriori coëfficientium $p . p-1 . p-2$. \& c . neceffariò tandem devenietur ad $p-p \infty 0$; quod proin illum terminum $\&$ ab illo deinceps omnes evanefcere facit. Sed quoties $p$ numerus fractus eft aut negativus, coëfficientes nunquam in nihilum abibunt, ac ideò feries in infinitum excurret: qua ratione habetur ex. gr, $\sqrt{I+13}$ (ubi $p$ valot $\frac{x}{2}$ ) $\infty$ 
$1+\frac{x}{2} n-\frac{1}{2.4} n n+\frac{1.3}{2.4 .6} n^{3}-\frac{1.3 \cdot 5}{2.4 .0 .8} n^{4}+8 c_{0} \& \sqrt{C_{0.1}+n}$ (ubi $p$ valet $\left.\frac{1}{3}\right) x 01+\frac{x}{3} n-\frac{2}{306} n n+\frac{2.5}{3.6 .9} n^{3}-\frac{2 \cdot 5 \cdot 8}{3.509 .12} n^{4} \& c_{0} \& \frac{1}{\sqrt{1+1} n}$ $\left(\right.$ abi p notat $\left.-\frac{x}{2}\right): 001-\frac{x}{2} n+\frac{1.3}{2.4} n n-\frac{1.3 .5}{2.4 .6} n^{3}+\frac{1.3 .5 .7}{2.4 \cdot 6.8} n^{4}-\& c$. \& pariter in cæteris.

Nota, quòd exaltatio binomii ad potefatem indefinitam \& interpolationis negotium reepfe in idem recidunt, unoque \& eodem nituntur fundamento, quod confiftit in proprietate quadam numerorum figuratorum fupra jam pralibata Propof XIX. fed cujus demonftrationem, ne hîc nimii fimus, in aliam occafionem refervamus. $x$

L V. Duarum quantitatum indeterminatarum relationem unius ad altesam per feriem exprimere, ope affumta feriei ficte inflar quafite.

Ponatur alterutra indeterminatarum $x$ of $y$, quarum relatio ad Le invicem quæritur, putà $y$, æquari feriei $a+b x+c x x+c x^{3}$ $+f x^{4}, 8 x$. aut $a+b x x+c x^{4}+e x^{6}, \& c$. aut $a+b x^{4}+c x^{8}$ $+e x^{12}, \& c_{0}$ aut fimili, prout opus videbitur; atque tum in quan. titate vel æquatione propofita locn y fubftituatur hæc feries, nec non loco $d y \& d d y$, \&x. feriei differentiale aut differentio-differentiale, \&cc. quo facto ex comparatione homologorum terminokum determinari poterunt affumti coëfficientes $a, b, c, \& c$. Sequuntur Exempla:

\section{Invenire relationem coordinatarum Curva Elafice per feriem.} Fig. $\%$

Flectatur Elater in curvaturam $A Q R$ à potentia applicata in $A$, \& trahente juxta directionem $A Z$; fitque $A B$ vel $R Z D O A, A E$ vel $P Q D 0 x, A P$ vel EQDO y, \& $A Q D 0 z$; oftenfum eft in Act.Lip..1694. p. 272. \& 1695. p. 538. naturam hujus curvæ exprimi equatione d $y \infty \frac{x x d x}{\sqrt{a^{4}-x^{4}}}$, è qua qui methodo Diophanti, qua in præced. part. ufi fuimus, irrationalitatem tollere vellet, ætatem confumeret; cum deprehenfum fit à Geometris, fummam vel differentiam duorum bigxuadratorum, qualis eft $a^{4}-x^{4}$, nunquam poffe confituere qua- 
298

dratum: Quare nobis confugiendum eft vel ad Interpolationes, vel ad indefinitam Potentiam binomii, hoc pacto:

I. Mod. Interpretemur $x^{4}$ tam per $l$, quàm per $n, \& a^{4}$ per $m$; erit $\frac{x_{4}}{a 4-x_{4}} \infty \frac{1}{m_{-1}}$; unde per LIII habetur $\sqrt{\frac{1}{m-n}}$, id eft, $\sqrt{\frac{x_{4}}{a_{4}-x_{4}}}$

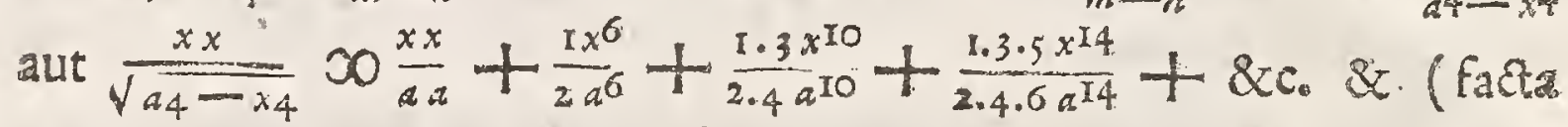
multiplicatione per $d x) \frac{x x d x}{\sqrt{a_{4}-x_{4}}}$ feu $d y$ y $\frac{x x d x}{a \cdot a}+\frac{1 x^{6} d x}{2 a^{6}}+\frac{1.3 x^{10} d x}{2.4 a^{10}}$ $+\frac{\mathrm{r} \cdot 3.5 \times 14 d x}{2.4 .6 a^{14}}$ \&r. \& denique fummando, $A P$ feu $y \infty 0 \frac{x_{3}}{3 a_{a}}+\frac{1 \times 7}{2.7 a^{5}}$ $+\frac{1.3 x^{11}}{2.4 .11 a^{10}}+\frac{1.3 .5 x^{15}}{2.4 .6 .15 a^{14}}+\& c_{0}$

2. Mod. Explicemus nuns a per $\mathbb{8}, \mathbb{E}-x^{4}$ per $n$; erit $a^{4}-x^{4}$ $\infty_{1}+n_{2} \& \frac{1}{\sqrt{a_{4}-x_{4}}} \infty \frac{1}{\sqrt{x+n}}:$ unde per LIV. fit $\frac{1}{\sqrt{1+n}}$ feu $\frac{1}{\sqrt{a+-x_{4}}}$ $201+\frac{x}{2} x^{4}+\frac{1.3}{2.4} x^{8}+\frac{x .3 .5}{2.4 .6} x^{12}+\& x c . \&$ (multiplicand. per $x x d x) \frac{x x d x}{\sqrt{a+x_{4}}} \infty x x d x+\frac{x}{2} x^{6} d x+\frac{1.3}{2.4} x^{10} d x+\frac{1.3 .5}{2.4 .6} x^{14} d x$ $+\& c_{0} \&$ integrando, $\frac{\pi}{3} x^{3}+\frac{I}{2.7} x^{7}+\frac{1.3}{2.4 .11} x^{m}+\frac{1.3 .5}{2.4 .6 .15} x^{15}$

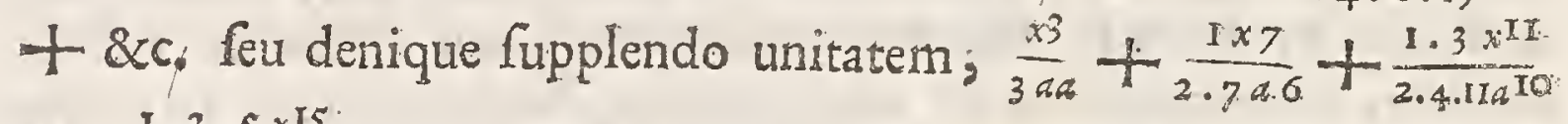
$+\frac{1 \cdot 3 \cdot 5 \times 15}{2 \cdot 4 \cdot 6 \cdot 15 a^{14}}+\& c_{0}$. ut anteà.

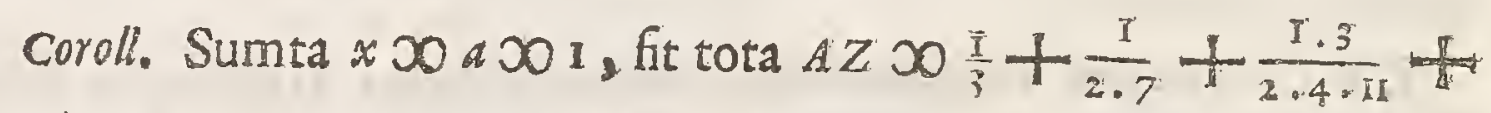
$\frac{1.3 \cdot 5}{2.4 \cdot 6.15}+\& c_{3}$ Conf. Ad. Lipf.1694. p. 274. \& 369.

LVII. Reclificare eandem Curvam Jeriem. Fig. 7.

Quia æquatio curva, ut diktum, eft $d y \infty \frac{x \times d x}{\sqrt{a_{4}-x_{4}}}$, fiet qua đrando $d y^{2} \infty \frac{x 4 d x^{2}}{64-x_{4}} \& x d z^{2} \infty d y^{2}+d x^{2} \infty \frac{x 4 d x^{2}}{d 4-x^{4}}+d x^{2}$ Do $\frac{a 4 d x^{2}}{a 4-x_{4}}$, adeoque $d z \infty \frac{a d d x}{\sqrt{a 4-x_{4}}}$. Exponamss a nune per

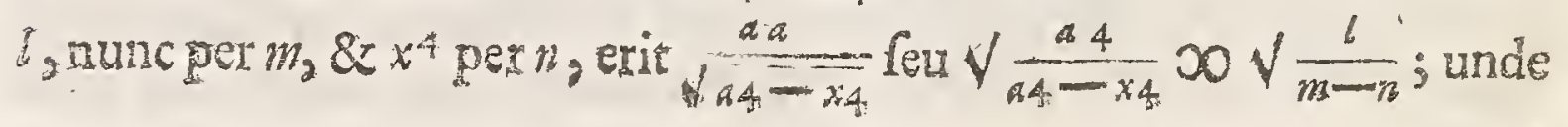


per LIII. fit $\sqrt{\frac{1}{m-n}}$ five $\sqrt{ } \frac{a 4}{a_{4}-x_{4}} \infty \mathrm{I}+\frac{1 \times 4}{2 a_{4}}+\frac{1 \cdot 3 x^{8}}{2 \cdot 4 a^{8}}+\frac{1 \cdot 3 \cdot 5 x^{\mathrm{I} 2}}{2 \cdot 4 \cdot 6 a^{\mathrm{I} a}}$ $+\& c_{0} 8$ (multiplic. per $d x$ ) $\frac{a d d x}{\sqrt{a 4_{4}-x_{4}}}$ feu $d z \infty 0 d x+\frac{1 \times 4 d x}{2 a 4}$ $7 \frac{1.3 x^{8} d x}{2.42^{8}}+\frac{5 \cdot 3 \cdot 5 x^{12} d x}{2.4 .5 d^{12}}+\& c_{0}$ tandemque fummando, $z$ five

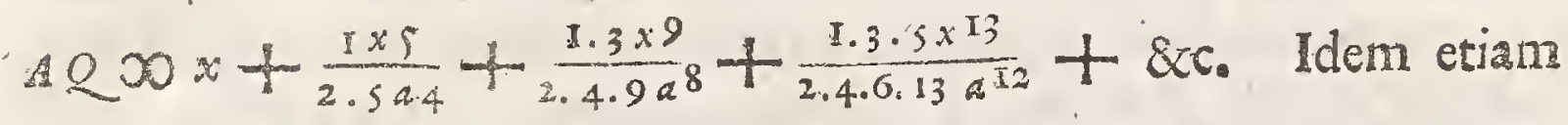
per LIV. fimili modo oftendetur.

Coroll. Facta $x \infty$ a $\infty \mathrm{I}_{\mathrm{I}}$, habetur tota $A Q R \times \mathrm{I}+\frac{\mathrm{I}}{2.5}+\frac{1.3}{2.409}$ + $\frac{1 \cdot 3 \cdot 5}{2 \cdot 4 \cdot 6 \cdot 13}+8 \varepsilon_{\text {. }}$ vid. Act. Lipf. 1694. p.274.

LVIII. Definire limites precedentium Jerierum. Fig. $\%$

Quoniam feries his methodis reperta nimis lentè convergunt, non abs re erit, fi modum oftendam, quo levi labore fummis earum, quantum ad ufum fufficit, approximare \& limites confituere poffimus. In exemplum propofite frnt proxima duæ feries, quibus exprimitur applicata Elaftica $B R$ vel $A Z$, \& longitudo ipfius curve $A R$, nempe: $\frac{1}{3}+\frac{1}{2.7}+\frac{1.3}{2.4 .11}+\frac{1 \cdot 3 \cdot 5}{2 \cdot 4 \cdot 6 \cdot 15}+8 \mathrm{XC}_{0}$ \&, $I+\frac{I}{2.5}+\frac{1.3}{2 \cdot 4 \cdot 9}+\frac{1 \cdot 3 \cdot 5}{2 \cdot 4 \cdot 6 \cdot 13}+2$ c. Sumo quantitatem, cujus integrale haberi polfit, datis $\frac{x x d x}{\sqrt{a 4-x_{4}}} \& \frac{d a d x}{\sqrt{a_{4}-x_{4}}}$, è quibus feries propolitæ fluxerunt, affinem, putà $\frac{x 3 d x}{\sqrt{a 4}-x_{4}}$, cujus integrale eft $\frac{a a-\sqrt{a^{4}-x^{4}}}{2}$, eamque pari methodo in feriem refolvo, $\&$ feriei terminis fummatis pro $x$ \& a unitatem pono; quo pacto re. ries emerget: $\frac{1}{4}+\frac{1}{2.8}+\frac{1.3}{2.4 .12}+\frac{1.3 .5}{2.4 .6 .16}+\& c_{\text {. }}$ xqualis proinde $\frac{a a-\sqrt{a^{4}-x^{4}}}{2} \infty \frac{x}{2}$ feü 0.5000000 . Colligo jam fingularum ferierum terminos aliquot $\mathrm{ab}$ initio in unam fummam (quod expedite fit per Logarithmos) ex. gr. decem primos terminos, qui. collecti efficiunt in prima ferie 0.5102560: in fecunda ferie I. 2207187 : in tertia 0.4 I I90I4. Hujus igitur reliqui polt $\mathrm{p} \mathrm{p}_{2}$ decimum, 
decimum termini (ad complendum $\frac{x}{2}$ feu 0.5000000 ) confti. tuent 0.0880986 , qui numerus additus fumma 10 primorum terminorum in pr. \& fec. Cerie exhibet $0.5983546 \& 1.3088173$, fummis totarum ferierum jufto minores, ob fingulos tertia ferie? terminos minores homologis terminis reliquarum.

Deinde, quia undecimi termini in tribus iftis feriebus funt

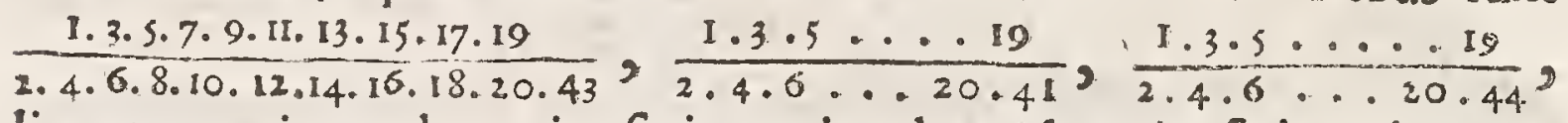
liquet terminum hunc in ferie tertia ad eundem in ferie prima reciprocè effe ut 43 ad 44,8 ad eundem in fecunda ut $4 \mathrm{I}$ ad 44 ; terminorum veró fequenti m fingulos in tertia ferie ad ejusdem ordinis terminos in reliquis feriebus habere rationem majorem. quàm 43 ad $44, \&$ quàm $4 \mathrm{I}$ ad 44 : unde \& fumma omnium fequentium decimum in tertia ferie ad fummam omnium polt decimum in reliquis feriebus majorem rationem habebit. Idcirco fi fiat, ut 43 ad 44 , nec non ut $4 \mathrm{I}$ ad 44 , ita fumma terminorum. poft decimum in tertia ferie, nimirum 0.0880986 , ad 0.0901474 . $\&$ ad 0.0945448 ; erunt hi numeri majores fummis terminorum decimum fequentium in prima \& fecunda ferie: quapropter fi addantur fummis Io priorum, quæ funt $0.5102560 \& 1.2207187$. erunt quoque numeri provenientes 0.6004034 \& I. 3I5.2635 majores fummis totarum ferierum.

Reperti ergo funt limites, quibus fummæ primæ \& fecundæ feriei defniuntur: limites illius funt $0.5983546 \& 0.6004034$; hujus I. 3088I73 \& I. 3152635: unde applicata $B R$ vel $A Z$. major eft quàm $0.598,8 x$ minor quàm 0.601 ; ipfa verò curva $A B>1.308, \&<1.316$, fic ut tres if proxime te habeant ut I0, 6, I3. Conf. Act. Lipfo 1694. p. 274.

$5 \% \%$ Q Qoniam ex natura defenfus gravium demonftratury cuod rempus dercenfus penduli alicujus per quadrantem circuli ad cemptis defenfus perpendicularis per ejus radium eam rationem habet, gum habet Curva Elaftica $A R$ ad ejus axem $R Z, h_{0}$ e. majorem, untendimus, quàm 1308 ad 1000 , \& minorern quàm 1316 ad 1000 : tempus autem defcenfus perpendicularis per circuli radium at surnous per femiradium fe habet, ut $\sqrt{ } 2$ ad I: 8 tempus per femiradium 
miradium ad tempus per arcum minimum (confentiente Hugenio in Horol. Ofcillat. p. 155.) ut diameter circuli ad ejus femiperipheriam, h. e. ut 226 ad 355 : inferri poteft ex aquo, quod tempus defcenfus penduli per quadrantem integrum ad tempus defcenfus ejus per arcum minimum fe habet in ratione majore quàm 3400 ad 2888,8 in minore quàm 3400 ad 2869 ; unde rationem 3400 ad 2900, five 34 ad 29, quam prefatus Auctor ibid. pag. 90 temporibus horum defcenfuum affignat, extra hos limites cadere liquet.

LIX. Dati Eogarithmi Numerum invenire per feriem. Fig. I.

Intelligatur Curva Logarithmica $P C Q$, cujus axis $A D$, fubtangens conftans $x_{t}$, applicata $B C D_{1}$, Logarithmus datus $B_{1}\left(B_{6}\right)$ $\infty 0 x$, ejusque Numerus $I O(\circ 0) D^{\prime}$; erit ex generali curvarum natura $8 d y, d x:: y, t$, adeoque $y \infty 0 \frac{t d y}{d x}$. Fiat juxta præfcriptum Prop.LV. $y x 1+b x+c x x+e x^{3}+f x^{4} \& z$. \& differentiando, $\frac{d y}{d x} \infty b+2 c x+3 e x x+4 f x^{3} \& c$. eritque $1+b x+c x x+e x^{3}$

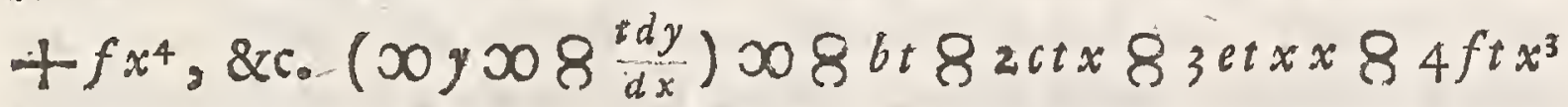
$85 g^{t} x^{4}, \& x$. \& facta comparatione homologorum terminorum elicietur, $608 \frac{1}{t}, c\left(\infty 08 \frac{b}{2 t}\right) \infty \frac{1}{1.2 .2 t}, e\left(\infty 8 \frac{c}{3 t}\right) \infty 8 \frac{1}{1.2 .363}$,

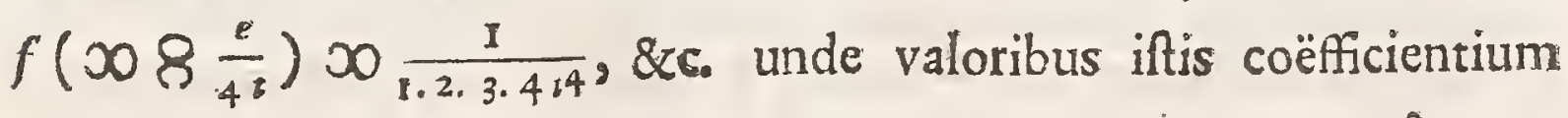

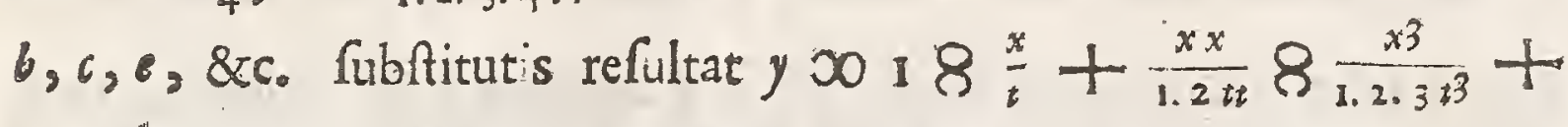

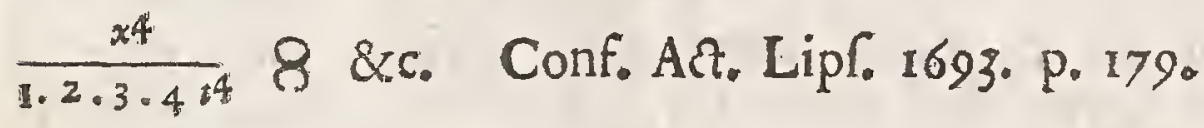

Aliter idem absque differentialium adminiculo: Concipiatur Log-us $B I\left(B^{\circ}\right)$ divifus in partes quotlibet æquales $B E, E F, F G, \& C_{0}(B \varepsilon, \varepsilon \phi$, $\left.\phi 2, \& c_{0}\right)$ quarum numerus fit $n$, \& fingule dicantur $d$, fic ut $n d$ fit $\supset B I(B-\infty x$. Tum applicatis curvæ rectis totidem $E K, F L$, $G M, \& c_{0}\left(\varepsilon x, \varphi \lambda, y \mu, \& c_{0}\right)$ jungantur extremitates $C \& K(x)$ duarum $B C, E K(\varepsilon x)$ per rectam $C K\left(C^{*}\right)$, fitque axis portio inter productam $C K\left(C_{x}\right)$ \& applicatam $B C$ intercepta $x$ t; quo pacto proper triangula fimilia fiet $t .1(B C):: t 8 d .18 \frac{d}{-} \infty \mathrm{EK}(\varepsilon x)$. Et

$$
\text { P p } 3
$$

quoniam 
quonian ob æquales $B E, E F, E G, 8<c_{.}\left(B \varepsilon, \varepsilon \phi, \phi r, \& c_{0}\right)$ ipla $B C, E K_{3}$ $F L, \& C .\left(B C, \varepsilon x, \varphi \lambda, \& C C_{*}\right)$ in continua funt proportione, earumque prima $B C D O$, idcirco defignabit $F L(\varphi \lambda)$ fecundam poteftatem, $G M$ ( $(\mu)$ tertiam, $R N(s y)$ quartam, $8 x c$, tandemque ultima $I O(60)$ feu y ipfarn $n$ poteftatem applicata $E K(\varepsilon x)$ feu $18 \frac{d}{i}$ (pro numero vid. particularum, in quas divifa eft $B I\left(B^{b}\right)$; quæ quidem poteftas per LIV。 reperitur $\infty \times 8 \frac{n d}{t}+\frac{n \cdot n-1 . d d}{1.2 t t} 8 \frac{n \cdot n-1 . n-2 d 3}{1.2 .3 t 3}+\frac{n . n-1 . n-2 . n-3 . d 4}{1.2 .3 .4 .14}$

8 \&c. Quòd fi jam numerus particularum "ponatur infinitas ; producta $C K(C x)$ abibit in tangentem, \& ip $\{t$ in fubtangentem

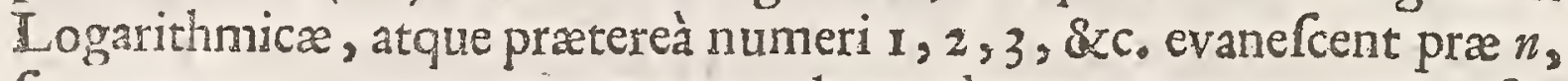
fic ut $n-1, n-2, n-3$, tantundem valeant ac $n$ : quare tum fiet $y 3018 \frac{n d}{t}+\frac{n n d d}{1.2 t} 8 \frac{n 3 d 3}{1.2 .3 t 3}+\frac{n 4 d 4}{1.2 .3 .444} 8$ \&rc. $\infty$ (propter $n d$

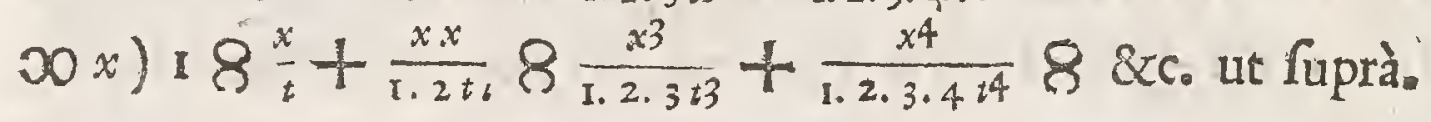

Nota , quòd exiftente $x>t$, termini quidem feriei aliquousque crefcunt, tandem tamen decrefcere pedetentim occipiunt, ultimeque vergunt in nihilum. Nam fumtis $a b$ initio m terminis, erit ex lege progreflionis fumtorum ultimus $\frac{x^{m-1}}{1.2 \cdot 3 \ldots m^{m-1} \cdot t m-1}$ $\&$ fequens ultimum $\frac{x^{m}}{1.2 .3 \ldots m t^{m}} ;$ adeoque ratio illius ad hune; ut $m t$ ad $x$ : unde cum ratio $t$ ad $x$ determinata fit, numerus vero rerminorum $m$ ufque $\&$ ufgue major poffit accipi, ratio quoque $m t$ ad $x$ tandem quavis data major fiet. Exiftente autem $x>0$ vel $<t$, feries ifta, $\&$ aliz hujus generis, fatim ab initio celerrimè convergunt, eoque celeriùs quò minor $x$ : unde difcimus quod multo commodius \& minori cum labore Logarithmorum Canon adornari poffit, fi per hanc Propof. ex Log-is datis Nunveri, quàm fi viciffim per XL VII. ex Numeris datis Log-i quarantur. Quanquam \& illic compendium fefe nobis offerat non contemnendum, quod quia in dica Propof. intactum præeteriit, breviter hîc indicandum reftat: Quoniam polutis in Logarithmica (Fig. 6.) $A B$ 


$$
I N F I N I T I S .
$$

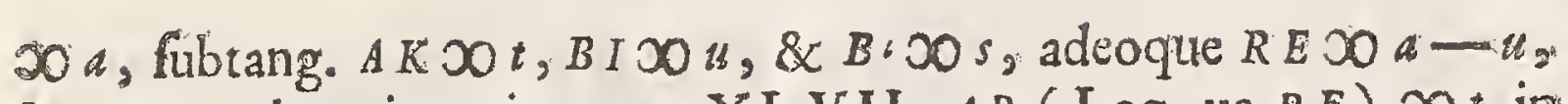
$\& \rho_{\varepsilon} \infty{ }_{a}+s$, invenitur per XLVII, $A R(\log -u S R E) \infty t$ in $\overline{\frac{w}{a}+\frac{w u}{2 a b}+\frac{w^{3}}{3 a^{3}}+\frac{w^{4}}{4 a^{4}}+\& c_{0}} \& A_{e}\left(\log -u s \rho_{\rho} s\right) \infty t$ in $\frac{s}{a}-\frac{s s}{2 a a}+\frac{s 3}{3 \cdot a^{3}}-\frac{s a}{4 a^{4}}+8 x c_{0}$ fequitur ex natura $\log \rightarrow$ micæa has duas feries inter fe æquari, fi tres applicatæ $R E, A B, \rho_{g}$, feur $a-u_{2}$ $a \& a+s$ continue proportionentux, h. e. fi ftatuatur u $\infty \frac{a s}{a+s} ;$ led quia per hanc hypothefin perpetuo fit $u<s$, \& nominatim hac fumta $¥ 0, a, \frac{x}{2} a, \frac{1}{3} a, \& c_{0}$ illa fic $\infty \frac{x}{2} a, \frac{1}{3} a, \frac{1}{4} a, \& c_{\text {e multò }}$ femper celerius prior feries converget pofteriore : unde plurimum: laboris in practica effectione $\log$-orum refcindi poterit, fi loco hiujus illa furrogetur, ex, gr. fi (facta $s x_{\text {a }}$ ) loco feriei $1-\frac{x}{2}$ $\frac{1}{3}-\frac{1}{4}+\frac{1}{5}-8 \mathrm{Cc}_{0}$ hoc elt, loco $\frac{1}{\mathrm{I} .2}+\frac{1}{3.4}+\frac{1}{5.6}+\frac{1}{7.8}$ $+\& c_{0}$ fubftituatur $\frac{1}{3.2}+\frac{1}{2 \cdot 0}+\frac{1}{3.8}+\frac{1}{4 \cdot 16}+\frac{1}{5 \cdot 32}+\& c_{0}$ quippe per cujus primos 18. terminos tantundem approximatur: quantum per mille terminos alterius; quod ipfum etiam ad Coroll. 3. XLVII. in fubtangente Log * micæ definienda obfervabi tur. Sed rei utilifima uberiorem explicationem anguftia paginæe non permittit.

schol. Si fumma quædam pecunix fonori elocata fit, ea lege ut fingulis momentis pars proportionalis ufuræ annuæ in fortem: computetur; exponatur autem ipfa fors per $b C$ few $\mathbf{I}$, tempus annuum per $B I$ feu $x$ divifum in punctis $E, F, G, \&<$, in momenta innumera xqualia, atque ufura annua per $\frac{x}{t}$; inventa feries $\mathbb{I}+\frac{x}{t}$ $+\frac{x x}{1.2 t t}+\frac{x 3}{1 \cdot 2 \cdot 3 t^{3}}+8 x c_{0}$ hoc eft, (explicata forte I per $a_{2} \&$ urura $\left.\frac{x}{t} \operatorname{per} b\right) a+b+\frac{b 6}{2 a}+\frac{b 3}{2 \cdot 3 \cdot a}+\frac{b \cdot 4}{2 \cdot 3 \cdot 4 a^{3}}+8 x c_{0}$ indicabic valoren ejus, quod finito anno debebitur. Cum enim, ut tempus: annuum $B I$ ad primum ejus momentum $B E$, feu ut $x$ ad $d$, ira fe. habeat ufura annua $\frac{x}{t}$ ad partem proportionalem u.furæ, erit hæc $\frac{d}{t}$, Cignif 


\section{$304 D E S E R I E B U S$}

fignificabitque $\mathrm{I}+\frac{d}{t}$ feu applicata $E \mathrm{~K}$ fortem diata parte proportio nali ufuræ auctam : unde fors aucta $E K$ fecundo momento pariet $F L, \&$ hac pariter tertio momento pariet $(A M, \&$ fic porrò, propter $B C, E K, F L, G M, \& c_{0} \ddot{\circ}$. Quare poftrema applicata $1 O$, quam feries inventa exprimit, denotabit valorem ejus, quod credi= tori elapfo toto anno debetur. Confe Act. Lipr. 1690. p. 222.

LX. Inrenire aream jatii comprebenfi à Curva genitrice Elafice, feu que evolutione fui Elaficam defcribit. Fig. 7 .

Defribatur Elaftica $A Q R$ ex evolutione Curvæ $M N T$, \& fit filum evolvens $Q N(D G)$, quod productum fecet axem in $V$; ponaturque, ut fupra, $R Z D O$ a $, P Q D O x, A P D O y$. Quoniam ex Act. Lipf. 1694. p. 273. manifeftum eft, quòd $Q N \infty \frac{x}{2} Q V$, erit \& $N H \infty \frac{x}{2} P Q$ $\infty 0 \frac{\pi}{2} x$, \& N $N \infty \frac{x}{2} F Q \infty \infty \frac{x}{2} d x$; ac proinde ob ang. reet, $D Q N^{2}$ $D F . F Q\left(:: d y \cdot d x::[\right.$ ex natura Elaftica $\left.] x x, \sqrt{a^{4}-x^{4}}\right)::$ $\frac{x_{2}}{2} d x(N S) \cdot \frac{d x \sqrt{a^{4}-x^{4}}}{2 x x} x S G$ vel $H I$. Quare HI in NH feu $\square N I$

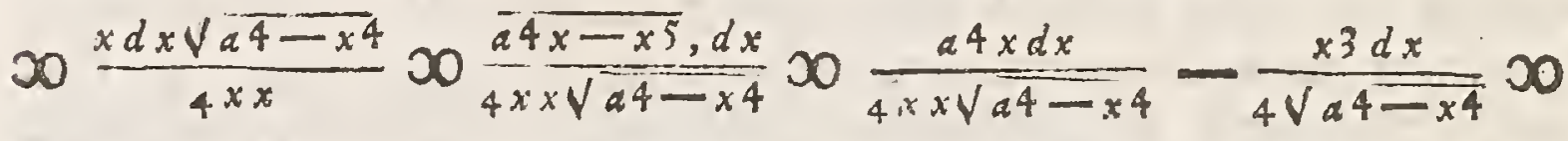
Elemento fpatii $M N H Z$, de cujus fummatione jam agitur. Pofterioris membri $\frac{x 3 d x}{4 \sqrt{a 4-x^{4}}}$ integrale pertinens ad partem curvx $R Q$ vel $M N$ eft $\frac{1}{8} \sqrt{a^{4}-x^{4}}$. Prius autem $\frac{a 4 x d x}{4 x \times \sqrt{a^{4}-x^{4}}}$ cum abfo= lute fummari nequeat, fublata irrationalitate in feriem convertetur. ut fequitur.

Ponatur $\sqrt{a^{4}-x^{4}} x^{t x x} \frac{a}{a}-a$, fiet $x \times x \frac{2 a 3 i}{a+b i b}, 2$ differentiando $-x d x \infty \frac{\overline{a 3 t t-a^{5}, d t}}{Q^{2} a d+t t} ;$ nee non $\frac{t x x}{a}-a a\left(\sqrt{a^{4}-x^{4}}\right)$ $\infty \frac{a a t-a 4}{a a+t t}, \&$ denique $\frac{-a 4 x d x}{4 \times x \sqrt{a 4-x^{4}}} \infty \frac{a a d t}{8 t}$. Jam quia exiftente maxima $x \infty a_{8}$ ipfa quoque $t \infty a_{8} \&$ illa decrefcente crefcit hae, 


$$
\text { INFINITIS. }
$$

ftatuatur $t \infty 0 a+s$, ut fit $\frac{a d d t}{8 t} \infty \frac{a a d s}{3 a+{ }^{\prime} s} \infty \frac{a d}{8}$ in $\frac{d s}{a+s} \infty \frac{a d}{8}$ in

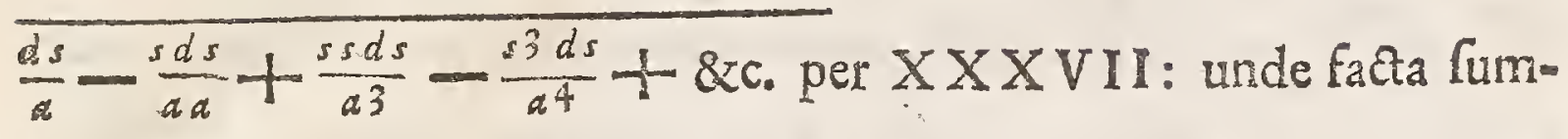
matione habetur $S \frac{d a d t}{8 t}(\infty) \frac{a 4 x d x}{4 x x \sqrt{a t-x^{4}}}$, diffimulato nempe figno - , quod híc nota tantum eft refpectivi decrementi ipfarum $x$ ) $\infty \frac{a a}{8}$ in $\frac{s}{a}-\frac{s s}{2 a d}+\frac{s 3}{3 a^{3}}-\frac{s 4}{4 a 4}+\& a^{4}$. demtoque $S \frac{x 3 d x}{4 \sqrt{a 4}-x^{4}}$ $\infty \frac{1}{8} \sqrt{a^{4}-x^{4}}$, refultat $S \frac{a 4 x d x}{4 x x \sqrt{4}-x^{4}}-S \frac{x 3 d x}{4 \sqrt{a^{4}-x^{4}}} \infty \frac{a d}{8}$ in $\frac{s}{a}-\frac{s s}{2 a d}+\frac{s 3}{3 a^{3}}-\frac{s^{4}}{4 a^{4}}+8 c_{0}-\frac{1}{8} \sqrt{a^{4}-x^{4}}$ fpatio nempe quafito $M N H Z$, Et quia, fumta $u \infty 0 \cdot \frac{a s}{a+s}$, feries $\frac{s}{a}-\frac{s s}{2 a a_{b}}+\frac{s^{3}}{3 a^{3}}-$

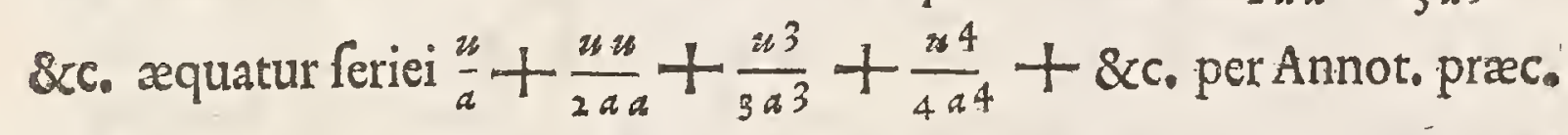
Propol. idcirco diaum fpatium $M N H Z$ quoque fic exprimetur, $\frac{a}{8}$

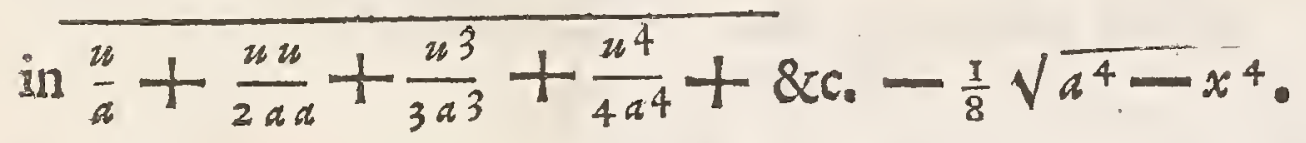

Nota, fi ftatuantur $a a x 8$, \& s $\infty$ a, adeoque $t(a+s) \infty 2 a$ $\& \times\left(\sqrt{\frac{2 a 3 t}{a d+t t}}\right) \infty 2 a \sqrt{\frac{1}{s}}, \& 4\left(\frac{d s}{a+s}\right) \infty \frac{x}{2} a:$ hoc eft, fi conftructo fuper $M Z$, femiffe ipfius $R Z$, femicirculo infribatur Triangulum Ifofceles $M C Z$, cujus crus $M C$ unitatem defignet, atque Curvæ $M N T$ applicetur $N H\left(\frac{x}{2} x\right) \infty \sqrt{\frac{8}{5}}$, predictum fpatium $M N H Z$ fiet $\infty 1-\frac{x}{2}+\frac{1}{3}-\frac{1}{4}+\frac{1}{5}-E x c_{0}-\frac{3}{5}$. vel etiam $\infty \frac{I}{1.2}+\frac{I}{2.4}+\frac{z}{3.8}+\frac{I}{4.36}+\frac{1}{5.32}+\& c_{0}-\frac{3}{5}$. Conf. A $\varepsilon_{0}$ Lipf. 1694. p. 273 .

Corol. I. Quoniam ex is, qua loc. modo cit. Actorum doculMnus, colligi poteft, quod $Q V \infty \frac{a a}{x}, \& Q N \infty \frac{x}{2} Q V \infty \frac{a d}{2 x}, \&$
Qg
I) $Q$ feus 
D.2 feu $d z \infty \frac{a a d x}{\sqrt{a 4-x t}}$; fequitur, triangulum $Q G D$ ( $Q D$ in $\frac{x}{2} Q N$ ) $\infty \frac{a^{4} a x}{4 \times \sqrt{a}-x 4}, \&$ per confequens omnia triangula $Q G D$ feu fpatium RMNOR $⿻ S \frac{a 4 d x}{4 x \sqrt{a^{4}-x^{4}}} \infty$ (ut oftenfum) fpatio MNHZ $+S \frac{x 3 d x}{4 \sqrt{a^{4}-x 4^{\circ}}}$ unde cum $S \frac{x^{3} d x}{4 \sqrt{4-x^{4}}}$ feu $\frac{1}{8} \sqrt{a^{4}-x^{4}}$ exprimat quadrantem fpa tii Elaftici $P Q R Z$ (ut per fe liquet), concludimus, fpatium $R M N Q R$ excedere aream $M N H Z$ quarta parte ipfius $P Q R Z$.

Coroll.2, Quia differentiale $\frac{a d t}{8 t}$, ad quod reduximus elemen: tum fpatii $M N H Z$ vel $R M N Q R$, elementum quoque denotat fpatii hyperbolici inter afymptotas, cujus abfcifla à centro eft $\infty \mathrm{t} t$, ipfa vero $t$ in aflumta hypothefr $\sqrt{a^{4}-x^{4}} \infty \frac{t x x}{a}-a a$ propter $x$ decrefcentem ad nihilum excrefcat in infinitum, \& fpatium hyperboliow cum in infinitum protenfum fit infinitum; idcirco \& fpatium. totum interminatum genitricis Elafticæ MNTXZ feu NTXH infinitum erit. Vid,Act, Lipfo loc $_{\text {p. }}$ cit $_{\text {. }}$

UT non-finitam Seriem finita coërcet, Summula, \& in nullo limite limes adeft:

Sic modico immenfi veftigia Numinis hærent Corpore, \& angufto limite limes abeft. Cernere in immenfo parvum, dic, quanta voluptas: In parvo immenfum cernere, quanta, Deum!. 


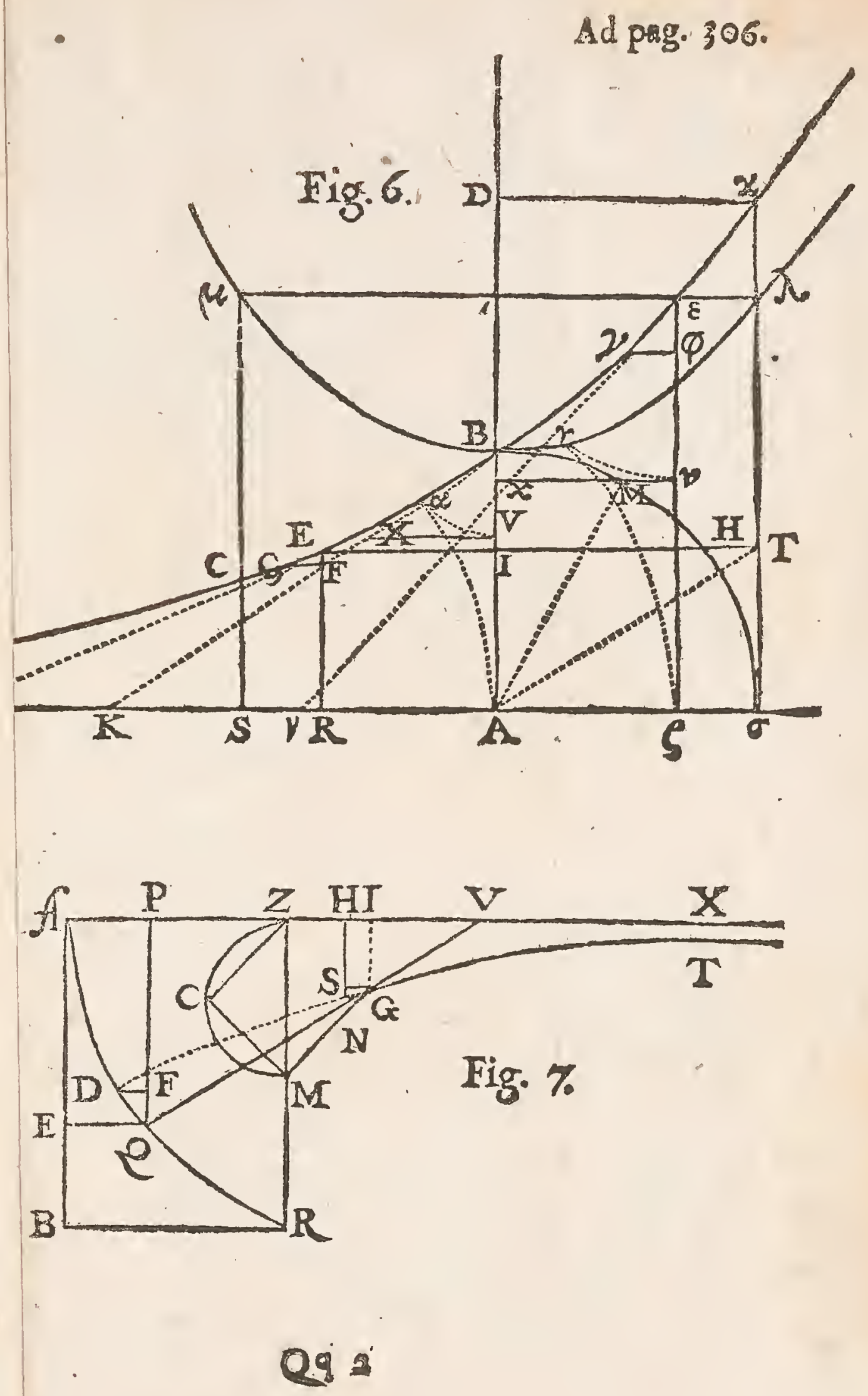




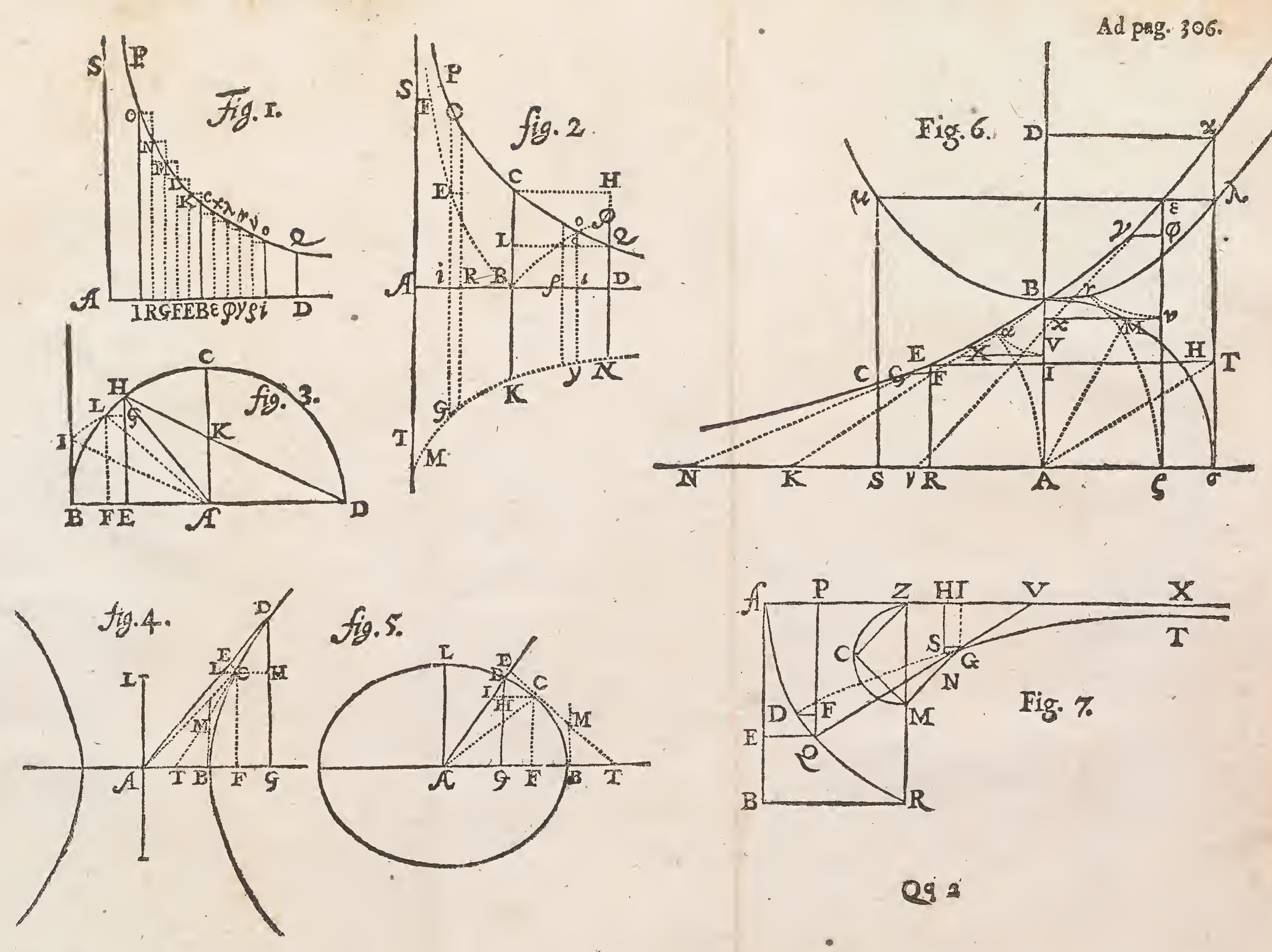

QS: 


1 



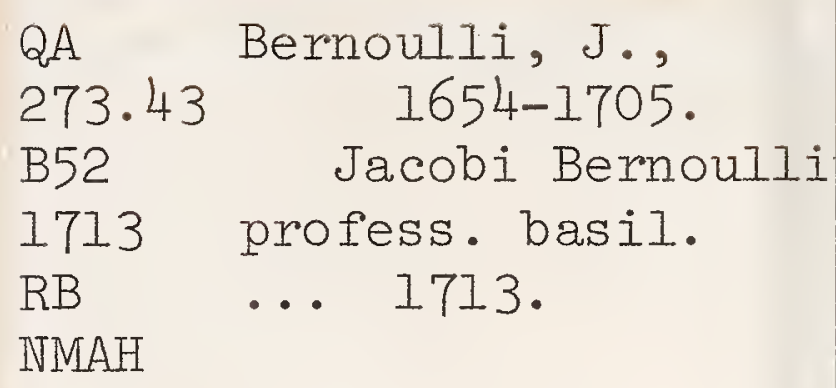







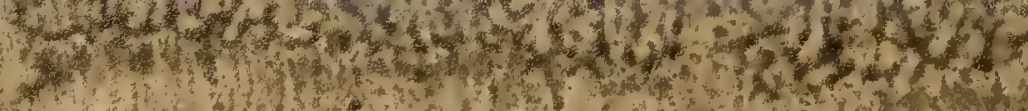

